



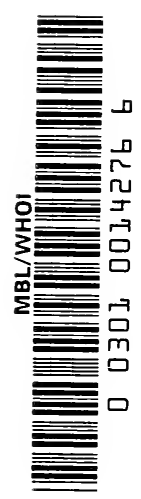







\section{Pflanzenphysiologie}

Versuche und Beobachtungen an höheren und niederen Pflanzen einschließlich Bakteriologie und Hydrobiologie mit Planktonkunde.

\section{R. Kolkwitz}

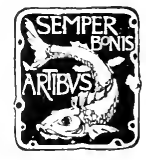

Jena

Verlag von Gustav Fischer 
Alle Rechte vorbehalten. 


\section{Vorwort.}

Die vorliegende Veröfentliehung hat sich ans meinen ,Pflanzenphysiologischen Versuchen zu C̈bungen im Winter" 1899(1) entwickelt. Diese Übungen bezweckten seinerzeit, die Studierenden an der Berliner Universität und Landwirtschaftliehen Hochschnle dureh selbständige Kursusibungen, nicht durch blobe Demonstrationen, in die physiologische Botanik einzufïhren. l)er Stoff hatte speziell die Ernährungsphysiologie zum Gegenstand.

Die Versuche fangen mit der Verarbeitung der Kohlensäure, ihrer Synthese zn organischen Verbindungen. an, zeigen die Bedentung der aufgebauten Produkte im Pflanzenkörper, besonders ihren Wert als kapitalisierbare Nahrungsstoffe, und behandehn dann wiederum den Abbau bis zur Kohlensäure. Diese Reihenfolge entspricht in der Hauptsache auch dem von Emil Fischer (1) innegehaltenen Gedankengang in der Darstellung der Entwicklung moderner chemischer l'robleme anf genanntem Gebiet.

Bei der Auswahl der Versuche wurde besonderer Wert darauf gelegt, aus der groben Fülle des zur Veffiigmng stehenden Materials dasjenige herauszufinden, dessen Ihurcharbsitung im Vergleich zur aufgewendeten Zeit die beste Belehrung bot und tabei doch den als Richtschnur gewählten Zusammenhang wahrte. Auberdem sollten die Versuche den Experimentator fortwährend beschäftigen und ihm das Resultat nach Möglichkeit sogleich oder in kiirzester Zeit vor Augen fiihren.

Alle diese Gesichtspunkte sind auch in der vorliegenden erweiterten Bearbeitung meiner früheren Veröffentlichung geltend geblieben. Auch die Auswahl des Stoffes hat sich nich mehr als 25maligem Durcharbeiten des Kursusmaterials während einer Zeit von 14 Jahren dauernd bewährt.

Der Hauptanteil dieser Kurse entfiel anf Übungen, welche ieh mit Oberlehrern und Kandidaten des höheren Lehramtes, atso Herren, welche das akademische studium bereits absolviert hatten, in amtlichem Auftrage ausführte, doch wurden sie, wie eingangs hervorgehoben, auch für studierende und mit Auswahl auberelem auch fïr Praktikanten am Institut fiir Zuckerindustrie abgehalten.

Der Begründer dieser praktischen Oberlehrerkurse, Provinzialschulrat Geheimrat Dr. (). Vogel, den uns der Tod leider vor kurzem entrissen 
hat, wollte den biologischen Interricht in den höheren Klassen heben nnd gleichzeitig besonders denjenigen Herren, welche während ihrer akademischen Studien ihre Hauptkraft der Mathematik und Physik gewidmet hatten, Gelegenheit geben, sich nach $A b s c h l u B$ ihrer auf die Hauptfächer gerichteten Studien durch eigene Versuche auch in den , beschreibenden" Naturwissenschaften weiter zu bilden, was zur Begründung einer besonderen staatlichen Fortbildungsanstalt in Berlin fuihrte, in der außer Botanik auch Zoologie, Chemie, Physik und praktische Arbeiten in einer merhanischen Werkstätte getrieben werden. Die physiologischen Übungen sind auf den Winter gelegt, um im Sommer, gleichsam in Ergänzung des Winterpraktikums, für wöchentliche floristische Ausfliige - mit meist denselben Teilnehmern wie im Winter - Zeit zu haben.

Da in den Räumen dieses Institutes seit Jahren im Oktober auch Kurse für Obertehrer aus allen Teilen I'reußens stattfanden, so hatte ich die beste Gelegenheit, meine Versuche mit erprobten Lehrkräften durchzuarbeiten und ausgedehnte Erfahrungen zu sammeln.

Bei diesen Studien wurden anch die niederen Pflanzen von Anfang an berïcksichtigt, doch waren die Planktonorganismen und die Hydrobiologie dabei zunächst nur schwach vertreten.

Meine Tätigkeit als wissenschaftliches Mitglied der Königlichen Landesanstalt für Wasserhygiene in Dahlem gab mir reiche Gelegenheit, das Gebiet der Hydrobiologie zu pflegen, wodurch es sich von selbst ergab, die Wasserorganismen mehr und mehr in meine Übungen mit einzubeziehen. Anch durch enge Fïhlung mit dem Fischereiverein fiir die Provinz Brandenburg hatte ich gute Gelegenheit, mich ïber cinige gröBere Aufgaben in der Hydrobiologie zu orientieren.

Ich konnte mich zur Zeit nicht entschlieBen, vielfachen Anregungen zu entsprechen und eine Veröffentlichung ïber Planktologie und allgemeine Hydrobiologie herauszugeben, weil dieses Gebiet dadurch gegenwärtig zn sehr als Spezialwissenschaft hervorgetreten wäre, was es eigentlich in den Hauptziigen gar nicht ist. Ich benutze deshalb die erweiterte Veröffentlichung meiner friiheren pflanzenphysiologischen Versuche, um dieses anregende und an wissenschaftlichen Aufgaben reiche Gebiet in die allgemeinc Physiologie, wenn auch nur in engem Rahmen, so doch in einem neuen Gewand, mit einzubeziehen und mit den friiher veröffentliehten Versuchen zu verschmelzen. Die Darstellung bezweckt indessen nur, cin bestimmtes allgemeines, nicht spezielles Wissen zu ïbermitteln und dabei nach VIöglichkeit Können auszulösen.

Das Gebiet der hier behandelten Hydrobiologie ist außer in den eben besprochenen liursen jahrelang durchgearbeitet worden durch Untersuchungen an den versehiedensten Gewässern Deutschlands, durch Vorlesungen, Demenstrationen und Übungen vor Baubeamten, Chemikern, Medizinabeamten, Studierenden u. a. m. Cherall in diesen verschiedenem Kreisen begegnete mir ein tiefes und lobhaftes Intresse fiir 
physiologisehe und rerwandte Fragen. . Wir wollen wissen", hieb es oft, ,was die Pflanze kann, und nieht blob, wie sie heibt." I)amit soll aber" der Blick nicht von der Bedeutung der namengebenden siystematik abgelenkt werden, im Gegenteil habe ich diese bei den kryptogamen ganz besonders in den Vordergrund gedrängt, weil sich hier die Physiologie gerade dadurch besonders lehrreich gestaltet, daß man die ganze Gruppe ïberbliekt. Es ist auth Bedatht darauf genommen worken, keine der großen systematischen Gruppen zn vernachässigen. Fast wäre eine dureh Phỵsiologie belebte Systematik der niefleren Pflanzen entstanden.

Beziiglich der Nomenklatur bin ith aus praktischen Grinden der Regel in der Zoologie gefolgt, wonach alle Gattungsmamen groß, alle Artennamen klein geschrieben werden.

Inie Auswahl der zu behandelnden objekte ist unter tunlichster Beschränkung so getroffen, daß nach Möglichkeit das geeignetste und dabei leicht zu beschaffende Objekt an der richtigen stelle behandelt wird. Nur keine Miberfolge beim Experiment, die im Objekt selbst liegen! Im Cegenteil, geschickt gewähltes Kursusmaterial soll bei gründlicher Untersuchung sogar neue wissenschaftliehe Ergebnisse zeitigen können.

Manche etwas umständlichen und zeitraubenden Versuche sollten besser bei experimental-physiologisehen Vorlesungen demonstriert als in Kursen behandelt werken.

Ein Teil der im vorliegenden Buch veröfentlichten Versuche und Beobathtungsstudien ist seit längerer ofler kïrzerer Zeit in der hier gesehilderten Form bereits Allgemeingut beim Unterrieht geworden. Das Mitgeteilte wird hoffentlich noch eine weitere Zahl von Experimenten dazu geeignet erscheinen lassen und vielleicht der großen Schar derjenigen, welche den Wunsch nach wissenschaftlicher Betätigung in freien Stunden hegen, wie er nach meinen Erfahrungen beispielsweise in der gesamten Lehrerschaft rege ist, Stoff zur Inangriffnahme einiger neuen Aufgaben bieten.

Den Herren Obertehrer H. Bethge und Direktor Hr. O. Pliimecke sage ich an dieser SteHe meinen verbindlichsten Dank für die freundlichen Ratschläge, durch welehe sie mich bei der Abfassung der Arbeit nnterstuitzt, und fiir das lebhafte Interesse, das sie den behandelten Aufgaben entgegengebracht haben. Den gleichen Dank möchte ich dem Verleger, Herrn Mr. Fischer, hiermit abstaten.

Herrn Lithographen B. Grefrath, \%eiehner an eler Königlichen Landesanstalt für Wasserhygiene, rerelanke ieh die mit lebhaftem Eifer erledigte Ausfïhrung eines großen Teiles der nach ter Natur und nach Vorlagen angefertigten Zeichnungen, bei denen es oft galt, nach Möglichkeit in wenigen Striehen das Charakteristisehe heransznheben. 



\section{TEIL.}

Phanerogamen. 



\section{Gruppe. Das Chlorophyll und seine Funktion.}

\section{Versuch. Assimilation von Elodea. Sauerstoffnachweis mittels der Indigomethode.}

Bei der Kohlenstoffassimilation scheiden die grïnen Pflanzen bekanntlich bei gleichzeitiger Einwirkung des Lichtes Sanerstoff aus. Es handelt sieh darum, diese Sanerstoffansscheidung nachzuweisen.

Man stelle von der unter dem Namen Indigokarmin, auch Jndigotin, in den Apotheken käuflichen blanen haltbaren, im auffallenden Licht etwas rötlichen Paste*) eine wässerige, kliimpchenfreie, in etwa 1 dm dicker Schicht tief himmelblane Lösung her und fïlle von dieser in eine mehrere hundert Kubikzentimeter faßende Glasflasche mit Glasstöpsel und engem Hals ab. Sehr geeignet für den Versuch sind die von L. Kny konstruierten flachen Flaschen, deren Form und Größe ans der Abbildung anf Taf. I hervorgeht, doch können anch runde Flaschen von ca. $250 \mathrm{ccm}$ Inhalt verwendet werden.

Gesondert hiervon stelle man eine nicht zu konzentrierte Lösung des stark reduzierenden hydroschwefligsauren Natriums, Natriumbydrosulfit $\left(\mathrm{NaHSO}_{2}\right)$, her. Dieses Salz ist seit einigen Jahren als weißes trockenes, recht beständiges Pulver in den Handel gekommen (100 $\mathrm{g}=0,65$ M.). Es wird im Großen als Bleichmittel in der Färberei verwendet. Früher mußte man sich diese Substanz aus Natriumbisnlfit (Natrium bisulfurosum siceum, $\mathrm{NaHSO}_{3} ; 100 \mathrm{~g}=$ ca. 0,25 M.) unter Schiitteln mit Zinkstaub selbst herstellen; vgl. R. Kolkwitz (1). Zum Abstumpfen einer etwaigen deutlich sauren Reaktion kann Zusatz von Kalkmilch empfehlenswert sein. Die triibenden Kalkmilchbestandteile werden vor dem Versuch abfiltriert.

Diese Lösung von hydroschwefligsaurem Natrium benutzt man zur Reduktion der blauen Lösung von Indigokarmin (Indigoschwefelsäure). Man fiigt soviele Tropfen mittels Glasstal, oder Pipette unter Unrïhren zu, bis die blaue Fliissigkeit entfärbt (schwach gelblich) ist, was ganz plötzlich einzutreten pflegt. Diese entfärbte Fliissigkeit kann bisweilen eine ganz schwache bläuliche Fluoreszenz zeigen.

Geschah die Entfärbung sehr vorsichtig, so wird in der Nähe der Flaschenöffnung sofort immer wieder eine Bläunng eintreten, weil der Sauerstoff der Luft in die empfindlich gestimmte Indigoweißlösung ein-

*) Nach W. Palladin (1) kann auch Nigrosin verwendet werden. 
dringt und stets wieder die Indigofarbe herstellt. Verstöpselt man dagegen die bis oben gefiillte Flasehe sogleich, so bleibt sie nubegrenzt lange Zeit farblos, weil kein Sauerstoff zutreten kann. Sollte aber, was öfter geschieht, demnoch wieder Blänung eintreten. da vielleicht schwach gebundener sanerstoff noch frei geworden ist. so muB man durch weitere Zugahe einiger Tropfen der reduzierenden Lösung dir. Entfärbung noch einmal vornehmen. dann aber bleibt die Fliissigkeit (das sogenannte Schiitzenbergersche Reageus) sicher hell. Man tut gut, nach Verschwinden der ersten Bläunng die Flasche noch often zu lassen, um zu sehen, ob die Flïssigkeit noch Neigung zeigt, in ihrer Gesamtheit schnell wieder blan zu werden. Hat man vorher auf den Boden der Flasche ein mit einem Stiuckehen Bleidraht beschwertes Endstiick von Elodea gebracht (es kömnen auch mehrere ziemlich lange stengel in die Flasche gegeben werden, auch Fontinalis, Cladophora u. a. m. ebenfalls verwendet werden), wobei zu beachten ist, dab keine Luftblasen hängen bleiben, so steigen, wie die Abbildung auf Taf. I zeigt, beim Belichten (auch Petroleumlicht ist ausreichend), von den griinen Pflanzenteilen blaue schlieren in der entfärbten Fliissigkeit empor, weil sauerstoff ausgeschieden wird. Während des Versuches soll das GofäB. unter welches man zweckmäBig einen weißen Bogen l’apier legt, nicht beriihrt werden. Beläßt man die Flasche dagegen im Dunkeln, so unterbleibt die Blaufärbung, da in Finstern keine Assimilation möglich ist. Der Versuch eignet sich in flachen Flaschen gut zur Projektion, besonders wenn die Indigoweiblösung sehr hell ist. Vorheriger Zusatz von etwas Selterwasser kann manchmal die Reaktion beschleunigen. Nach Verlauf von etwa einer Stunde ist der Versuch nicht mehr anschaulich, da sich dann meist die ganze Fliissigkeit gebläut hat. I) Assimilation verläuft nach der formel

$$
\left.6 \mathrm{CO}_{2}+6 \mathrm{H}_{2} \mathrm{O}\right)=\underset{6}{\mathrm{C}_{6} \mathrm{H}_{12}()_{6}+6()_{2}}
$$

Bei dieser Photosynthese des Zuckers tritt als Zwischenprodukt möglicherweise Formalin $\left(\mathrm{CH}_{2} \mathrm{O}\right)$ auf, das polymerisiert wird (Hypothese ron A. v. Baeyer); man könnte dam diesen Prozeß durch die Formel andeuten:

$$
\begin{aligned}
& 6 \mathrm{CH}_{2} \mathrm{O}=\underset{6}{\mathrm{C}_{6} \mathrm{H}_{12}()_{6}} . \\
& \text { Formalin Tranbenzucker. }
\end{aligned}
$$

In welcher speziellen Weise die Kohlensänre in Formaldehyd umgewandelt wird, ist noch strittig. Curtins u. Franzen haben Formaldehyd in griinen Blättern nachgewiesen. Nach netueren Versuchen scheint Assimilation bei grïnen Pflanzen auch dann möglich zu seiu, wenn man die Kohlensäure vorsichtig durch Formaldehỵdgase essetzt; Formaldehyd soll anch rein chemisch bei geeigneter Belichtung eines (iemisches von Kohlensäure nud Wisserstoff herstellbar sein.

()hure den grimen ('hlorophyllarbstoff findet in der Pflanze keine Kohlenstolfassimilation statt: eine Ausnahme bilden mur einige Bakterien, 
z. B. der Nitratbihdner Bacterium nitrobacter. Man hat deshall, dem Studium dieses Farbstoffes die größto Aufmerksamkeit zugewendet, wenngleich norh nicht sicher bekannt ist, ob or boi diesem wichtigen Prozeb eine in erster Linie tonangebende Rolle spielt odter nur als Sensibilisator wirkt [rgl. W. Pfeffer (1), Bd. I, s. 334 und 340)]. Nach E. Stahl (1) kommt den Grin als solchem eine biologische Beclentung zı, nämlich die, das Himmelslicht am besten ausnutzen zu können.

(x. A. Nadson hat eine auf Siehlamm im Wasser lebende kleine Alge namens Chlorobium limicola beschrieben. welche merkwiirdigerweise

Schattcublatt

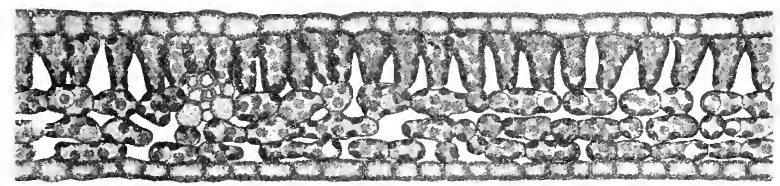

Sonnenblatt

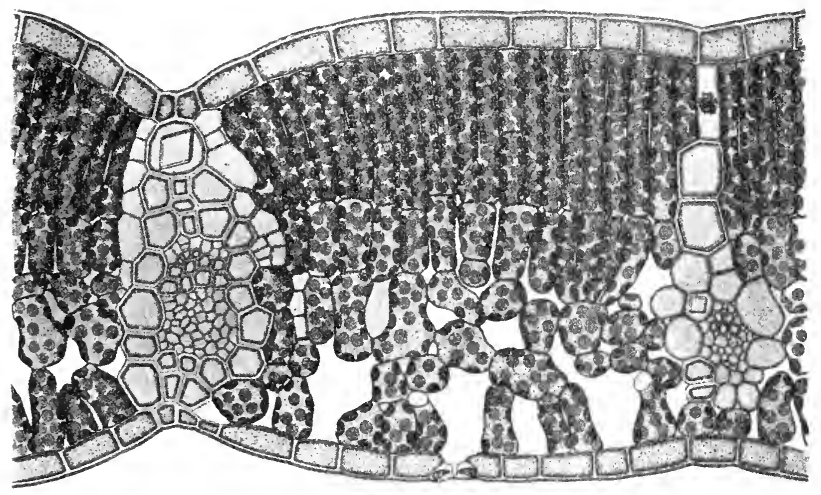

Abb. 1. Querschnitte durch das Blatt der Buche (Fagus silzatica). Im Schatten entwickeln sich Yalisadenzellen und schwammgewele viel schwicher als in der Sonne. Vergr. mittelstark. (Nach L. K n y.)

in der lebenden Zelle inaktives (d. h. nicht assimilierendes) Chlorophy] enthält, wenigstens lieb sich kein Tntersehied zwischen diesem Algengriin und Blattgriin feststellen.

In der Dunketheit nehmen die meisten grinen Pflanzen gelbe liabe an (Etiolement), z. B. die Sprosse im Dnnkeln keimender Kartuffen, einige dagegen, besonders manche Algen, bleiben griin. 
Der Nachweis der Sauerstoffausscheidung chlorophyllführender Zellen im Licht kann natürlich auch durch Verwendung von Luftgewächsen an Stelle von Wasserpflanzen geführt werden.

Zur Veranschaulichung des anatomischen Baucs der hauptsächlich assimilatorisch wirkenden Gewebe und zur Demonstration der Einwirkung des Lichtes auf die Blattstruktur ist mebenstehend je ein Querschnitt durch ein Schatten- und Somnenblatt der Buche (Fagus siliatica) nach L. Kny*) abgebildet.

\section{Versuch. Nachweis abgeschiedenen Sauerstoffs durch die Bakterienmethode von Th. W. Engelmann.}

Zu diesem Versuch bedient man sich sauerstoffempfindlicher Bakterien [z. B. Psendomonas (Bacterium) fluorescens], welche aus faulendem Fleischoder Erbsenwasser nach den ïblichen Methoden der Reinkultur gewonnen werden können. Diese sind lebhaft beweglich, wenn Sauerstoff zutreten kamn, kommen dagegen zur Ruhe, wenn er fehlt.

Übergießt man ein höchstens fingergliedgroßes, geschabtes, mageres Stück rohen Fleisches mit otwa 100 ccm Leitungswasser, so entwickeh sich sauerstoffempfindliche Bakterien aus vorhandenen Keimen in wenigen Tagen in dem Wasser, vorwiegend an der Oberfläche. Bringt man einen Tropfen davon auf den Objektträger und legt ein Elodea-Blattstïck oder ainen Faden von Spirogyra dazu, so wird man, wenn das Deckgläschen so aufgelegt wird, daß keine Luftblasen entstehen, schon bei ciner 250 fachen Vergrößenung leicht wahrnchmen, daß die meisten Bakterien dieses Gemisches sich nur in unmittelbarer Nähe des assimilierenden Objektes bewegen, ein Beweis dafïr, daß tatsächlich im Licht durch die grïne Alge Sauerstoff produziert wird. Im Bedarfsfalle kamn man das Deckgläsehen mit einem Vaselimring umgeben. Stiilpt man eine Papp-oder Blechkappe zwecks Verdunkelung über das Mikroskop, so kommen nach kurzer Zeit die Bakterien zur Ruhe, um bei erneuter Belichtung durch Abheben der Kappe die Bewegung sofort wieder zu beginnen. Öfters wird man aneh in großer Entfermung vom Blatt noch vereinzelte Bakterien herumschwimmen sehen: diese gehören einer anderen Gruppe an und sind für den Versuch nicht geeignet, da sie nämlich anaerob sind und demmach ihre Beweglichkeit auch bei Mangel an Sauerstoff beibehalten.

Wendet man zu diesem Versuche rein geziichtetes Bakterienmaterial an, so fallen solche dic Exaktheit des Versuehes etwas störenden Nebenerscheinungen natïlich fort.

Um während längerer Zeit brauchbare Reinkulturen zur Verfiigung

*) Znr Demonstration des Assimilationsgewebes sind Schnitte durch das leicht zu handhabende Blatt des Gummibaumes (Ficus elastica), quer zn den Nerien ansgefïhrt, besonders beliebt. Die Schnitte können gut bei mittlerer Vergrößerung betrachtet und znm honservieren in Glyzerin (s. später) eingelegt werden. 
zu haben, mïssen die Bakterien alle 2-3 Tage in neue Kulturröhrchen übergeimpft werden (vgl. den Abschnitt Bakteriologie).

Will man zeigen, daß es gerade die grïnen Chromatophoren sind, welche den sauerstoff ausscheiden, so wähle man Spirogyra mit sehr lang ansgezogenen Spiralbändern. Dann ist die Bewegnng der Bakterien nur iiber den Spiralbändern zu beobarhten.

Man kann aber auch das Elodea-Blatt zerzupfen und das Wimmeln der Bakterien an den herausgetretenen Chromatophoren beobachten. Dann muß man aber die Vorsicht gebrauchen, die Zellen unter dem Deckgläschen in eine etwa $10 \%$ ige Rohrzuckerlösmng zul legen, weil reines Wasser anf die Chromatophoren tödlich zu wirken pflegt. Reines Wasser ist ja auch nicht das Medium, in welchem die Chlorophyllträger in der intakten Zelle leben, denn gerade durch die Kohlenstoffassimilation wird fortwährend Zucker in dem Innern der Zellen abgeschieden.

Sehr geeignete Objekte für vorliegende Versuche sind auch einzellig und in Verbänden lebende Diatomeen, Oscillatorien und viele andere mehr, doch gohört deren Besprechung in den zweiten Teil dieses Buches.

\section{Versuch. Assimilationsnachweis von Elodea canadensis mittels der Bläschenmethode.}

In einfachster Weise kann man den Versuch so gestalten, daß mar: ein gewöhnliches Trinkglas mit Wasser fiillt und einen etwa 1 dm langen Stengel von Elodea mit unverletzter spitze und - mittels Schere oder Messer — frisch emeuter Schnittfläche hineinwirft. Mittels eines Glasstabes kann man den Stengel leicht verhindern an die Oborfläche anfzusteigen. Schon bei Belenchtung mittels Petrolemmlampe wird man, wemn das Material gut ist, deutlich Sauerstoffbläschen in schnellem Tempo und regelmäßigen Abständen ans der Schnittfläche der lakunösen Stengel infolge eines immeren Überdrnckes hervortreten sehen. Es soll in der Regel etwa jede Sekunde ein Bläschen anfsteigen. Gelingt der Versuch nicht sogleich, so erneuert man die Schmittfläche (im Bedarfsfalle mehrfach); bleiben auch dann die Bläschen ans, so verwerfe man das Exemplar und wähle ein neues. Durch Zusatz von etwas Selterwasser wird das Tempo des Bläschenaufsteigens in der Regel sehr beschleunigt. Bei Verwendung: flacher Gefäße läßt sich das Ganze leicht projizieren.

Man könnte den Versuch auch so anstellen, daß man die ElodcaPflanze noch besonders in ein mit Wasser gefiilltes (ev. gradniertes) Reagensglas oder einen Trichter schiebt; damn ließe sich aber eine etwa nötige Erneuerung der Schnittfläche weniger leicht durchfïhren.

Wenn das Elodea-Material nicht krankhaft ist, gelingt der geschilderte Versuch ohne Ausnahme.

Will man einen Massenversuch anstellen und den ausgeschiedenen Sauerstoff in größerer Menge in einem geeigneten Trichter auffangen, 
so empfiehlt es sich, mindestens einen halben Eimer voll Elodca zum Versuch zu verwenden, die Schnittflärhe wenigstens bei einer größeren Anzahl von Stengeln zu erneuern und zur Bestrahlung nach Möglichkeit direktes Somnenlielnt zu verwenden. Hat man zu diesem Versuch kein kohlensäurehaltiges Brumnenwasser zur Verfïgung, so setze man Selterwasser hinzu oder leite vor dem Versuch einige Zeit lang Kohlensäure hindurch.

Auch im Freien kamn man an zufällig verletzten Exemplaren von Elodca, Potamogcton nsw. Perlenketten von Bläschen aufsteigen sehen.

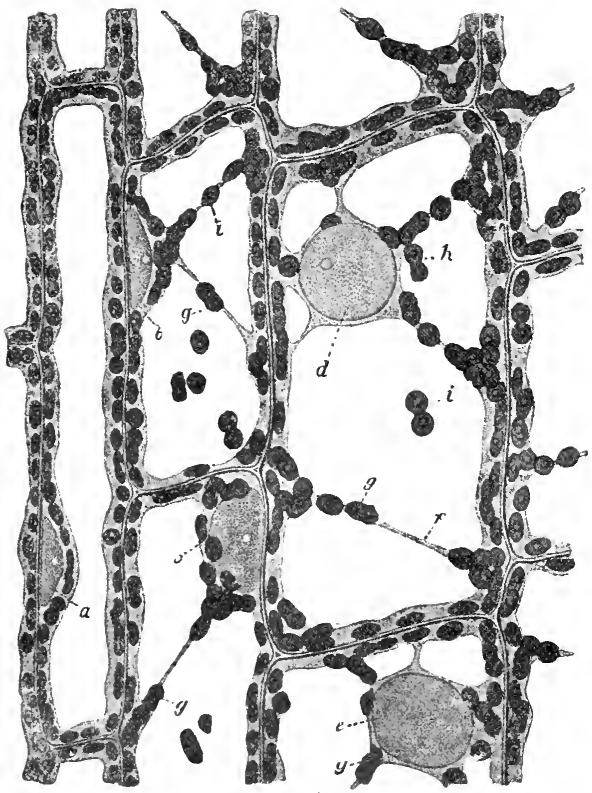

Abb. 2. Zellen der Blattoberseite ron Elodéa canatensis. ca. 600 mal rergr. Die lange schmale Zelle zur Linken hefindet sich iiler der Mittelriplue. $a--e$ Kerne in Seiten- mol l lïhenansicht; f llasmastrang; g-i Chlorophyllkörner in Teilung. (Nach L. li ny, liot. Wandtafelu.)

Im spektroskopisch zerlegten Licht wirken die roten und blanen strahlen am stärksten auf den Assimilationsprozeb ein: vgl. Kniep 11. Minder (1).

Die Blätter von Elodea kömnen dazu verwendet werden, die $\mathrm{Ro-}$ tationsbewegung des Protoplasmas zu demonstrieren. Tha es sich dabei um einen Verletzungsreiz handelt, wird die sitrömung erst nach etwa lo Minuten deutlich. sichwathes Erwärmen iiber des Lampe kamn don Prozeb etwas beschleunigen. Die Internodien von Nitclla, auch Chara, eignen sich ebenfalls zul diesen Beobachtungent.

Die lebhafteste Plasmastrimmng zeigen die Zellen an der Mittelrippe auf der Lntuseite der Blätter. Han vergleiche die nebenstehende Abbildung und L. Kuy, Erlauterungen zu den Wandtafeln. .

Zipkulationsbewegung des Protoplasmas beobachtet man gut in den Staubfadenharen von Tradescantia virginica.

\section{Versucl. Bewegung chlorophyllführender Körper.}

lu den Lallen der Intergetanchten Wasserlinse (Lomna trisulca) bewirkt starke Beliehtung. dab die Chromatopheren von den parallel zur 
Oberfläche gerichteten Wänden anf die Seiten ibbergehen. Wie ans der Abbildung erschen werden kinn. Man nimmt an. dab dadurch das ('hlorophyll vor einer gewissen Zersetzung durch das Licht geschiitzt wirl. Eine entgegengesetzte Gruppirrung der Chlorophỵllkörner beobarhtet man an Exemplaren, welche $1-2$ stunden im Innkeln gehalten worden sind.
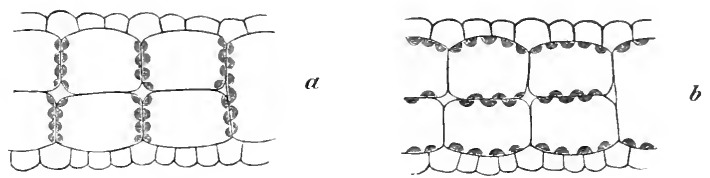

Abb. 3. Lagerung der Chlorophyllkörner a) bei starker Belichtung, b) im Schatten hzw. im Dunkeln. Die Figuren stellen (uuerschnitte durch die hattartigen Partien der untergetauchten Wasserlinse (Lemna trisulca) dar. (Nach E. Stahl.)

Zur Beobachtung können Stiucke der Lema trisulca direkt auf den Objektträger gebracht werden.

Weitere geeignete Untersuchungsobjekte hierfür sind nach E. Sitahl die im Schatten entwickelten Blätter vom Hollunder (Sambucus nigra), von Funaria hygrometrica und von grimen Prothallion der Farne.

Bei dem grïnen Flagellatan Euglena viridis, der in Dorfteichen, Jauchetümpeln usw. in großen Massen auftreton kann, vernag man bei nicht zu starker Beleurhtung positiv heliotaktische Bewegung sohr leicht zu beobarhten. V'gl. den Abschnitt Algen.

\section{Versuch. Extraktion und Zerlegung des Chlorophylls.}

Man stellt sich eine Lösung dieses Farbstoffes dadurch her. lab man geeignete griine Blätter, z. B. Grasblätter. mit Alkohol (gegen $98 \%$ oder etwas verdiunter) iibergie ht, mit sand in einer Porzellansehale zerreibt nnd die Flïssigkeit dann abfiltriert. Man kann die Blätter aurh rinige Tage vorher mit Alkohol ibbergioßen und in einem versehlossenen Greäb) dunkel aufbewahren. l)ann läBt sich das ('hlorophyll ohne Zerreiben der Pflanzenteile extrahieren. Willstätter u. Stoll (1) empfehleu als besonders kṛätiges Extraktionsmittel Azeton.

Die so gewonnene Chlorophylläsung ist in diumnen schichten grïn und flnoresziert blutrot, besonders im Licht, welches reich an ultravioletten Strahlen ist (Somnenlicht und elektrisches Bogenlicht). Wirft man mittels einer nicht zu starken Lupe einen konzentrierten Lichtkegel in eine verdiinnte Chlorophyllösung, so tritt die rote Farbe besonders deutlich hervor.

In dicken schichten ist die Chlorophyllösung dagegen auch bei durchfallendem Licht rot. Man kann sich davon leicht iiberzeugen. wenn man ein mit Chlorophyllextrakt gefülltes Reagensöhrchen in einen leeren Mikroskoptubus stellt und mittels spiegel von unten beleuchtet. Daher erklärt es sich auch, dab bei vielen Pflanzen im wesentlichen nur noch 
rotes Licht passiert, wenn man 5-8 Blätter ïbereinander legt und in geeigneter Weise gegen die Sonne hält; vgl. Sac hs(1) unter Di a phanoskop. Diese Erscheinung wird ohne weiteres verständlich, wenn man bedenkt. daß nur der äuBerste rote Teil des Chlorophyllspektrums ganz frei von Absorptionen ist. Beziiglich des Absorptionsspektrums der Chlorophyllösungen vgl. man W. Detmer (1). W. Pfeffer (1) und R. Willstätter (1).

Das spektrum des Chlorophylls zeigt einen besonders charakteristischen Absorptionsstreifen im Rot bei der Frannhoferschen Linie C; hierauf folgen nach dem Violett zu mit abnehmender Stärke drei Absorptionsbänder und unter vollständiger Auslöschung der blauen bis violetten Region ein zweites Absorptionsmaximum.

Im Licht tritt allmählich Zersetzung des Chlorophylls unter Bräunung ein.

Zur Zerlegung der Chlorophyllösmng in Dunkelgriin und Gelb fïgt man in einem Reagensröhrchen zu dem Chlorophyllextrakt etwas Benzin und, falls die Lösung nicht schon ein wenig verwässert ist, ein bis einige Kubikzentimeter Wasser. Es tritt dann, wie die Abbildung auf der Tafel I zeigt, eine sonderung der Emulsion in zwei scharf getrennte Schichten ein, eine obere blaugrïne Benzinschicht und eine untere gelbe Alkoholschicht. Die obere fluoresziert blutrot, der unteren fehlt diese Eigenschaft, wenn die Trennung eine vollkommene war. Die Spektren beider Teile (vgl. Willstätter) sind ganz verschieden; nur die dunkelgrüne obere Schicht (Cyanophyll) enthält noch den charakteristischen Absorptionsstreifen im Rot; die untere Schicht (mit Xanthophyll) verdankt ihre gelbe Farbe den Karotinoiden. Die Trennung beider Farbstoffe kamn man nun auch, wie die Tafelabbildung zeigt, dadurch erreichen, daß man in die chlorophyllösung einen freiverdunstenden streifen FlieBpapier hängt. Sehon nach kurzer Zeit kann nuan beobachten, daß der gelbe Farbstoff kapillar höher hinaufgesaugt wird als der grime. (Goppelsroeders Kapillaranalyse.) Beziiglich weiterer Literaturs. W. Pfeffer (1).

\section{Versuch. Kristallisiertes Chlorophyll.}

('hlorophyllkristalle wurden zum erstenmal 1881 von J. Borodin (1) in st. Petersburg an mit Alkohol behandelten mikroskopischen Präparaten beobachtet. Unter 776 daraufhin gepriften Pflanzenarten lieferten 190 Arten (also 24\% solche Kristalle. 1893 gelang es N. A. Monteverde (1) ebenda die Natur dieser Körper durch eingehende Untersuchung des spektrums an makroskopischen Proben als Chlorophyll näher zu kennzeichnen.

Von 1907 ab veröffentlichte dann R. Willstätter (1) mit seinen Mitarbeitern Benz und Stoll ansfïhrliche chemische Untersuchumgen an groben Mengen von Material, welehe uns mit der chemischen Natur dieser Kristalle ausgezeichnet bekannt gemacht haben. Eine Abbildung 
aus seinen Arbeiten findet sich nebenstehend. Um die kiristalle zu gewinnen, bringt man eine Anzahl mikroskopischer Blattschnitte, am besten von der Bärklane (Heracléum sphondylium) oder vom Hohlzahn (Galeopsis tetrahit), unter Zusatz von etwa $90 \%$ igem Alkohol auf den Objektträger und legt ein Deckgläschen auf. Das so hergeriehtete Präparat läßt man neben einem Schälchen mit Alkohol unter einer kleincn Gilasglocke bis zum Eintrocknen stehen, am besten einen halben bis ganzen Tag oder länger. 1)ann zeigen sich die schönen drei- und sechseckigen Blättchen des ,kristallisierten Chlorophylls".

In der lebenden Pflanze findet sich dasChlorophyll in kolloidalem Zustand als eine, chemisch gesprochen, wachsähnliche Substanz, ohne Fluoreszenzerseheinungen. Nach Zusatz vou Alkohol spaltet

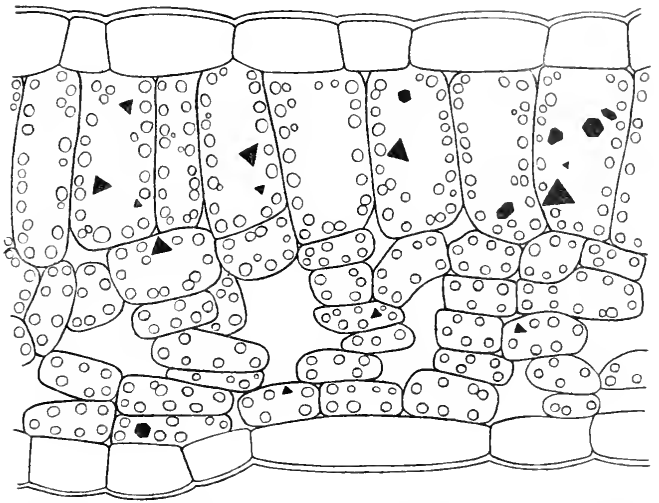

Abb. 4. "Kristallisiertes Chloroplyyl" im Blatt von Heracleum, nach der Borodinschen Nethode gewonnen. (Nach R. Willstätter n. A. Stoll.) sich aus diesem Chlorophyll unter Mitwirkung des Fermentes Chlorophyllase ein höherer Alkohol von glyzerinartiger Beschaffenheit, das Phytol $\left(\mathrm{C}_{20} \mathrm{H}_{40} \mathrm{O}\right)$, ab

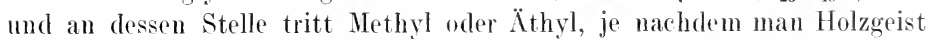
oder Äthylalkohol zur Extraktion angewendet hat. Das Produkt der Kristallisation ist dann ein (phytolfreies) Methyl- oder Äthylchlorophyllid.

Die genaue chemische Analyse hat das Vorhandensein von vier kristallisierenden Pigmenten in den (hloroplasten ergeben, zwei grünen und zwei gelben, von folgender Natur:

1. $\mathrm{C}_{55} \mathrm{H}_{72} \mathrm{O}_{5} \mathrm{~N} \mathrm{~N}_{4} \mathrm{Mg}$ (Chlorophyllkomponente a, in Lösung griinblan),

2. $\mathrm{C}_{55} \mathrm{H}_{70} \mathrm{O}_{6} \mathrm{~N}_{4} \mathrm{Hg}$ (Chlorophyllkomponente $\mathrm{b}$, in Lösung reingriin),

3. $\mathrm{C}_{40} \mathrm{H}_{56}$ (Karotin, Kristalle orangerot),

4. $\mathrm{C}_{40} \mathrm{H}_{56} \mathrm{O}_{2}$ (Xanthophyll, Kristalle gelb).

Das Chlorophyll verkohlt ohne zu schmelzen und hinterläßt beim Glïhen eine Asche von reiner Magnesia ( $\mathrm{MgO}$ ), ohne Phosphor oder Eisen, obwohl die letztgenannte Substanz zur Bildung des Chlorophylls in der lebenden Pflanze nötig ist. 


\section{Versuch. Verbreitung und Nachweis des Karotins.}

Der gelbrute Farbstoff der IHohrriibe (Daucus carota) wird Karotin genannt. Er findet sich, nicht direkt an Plasma gebunden. in Furm ron stäbchen und Plättchen in den Zellen (vgl. C'ourchet, Anmales des sciences naturelles. 1888).

Dieser Farbstoff ist identisch oder nahe verwand mit zahlreichen unter anderen Namen im Pflanzen- und Tierkörper allgemein bekannten gelben oder roten Farbstoffen. Nach R. Willstätter ist das Karotin der Mohruibe ein ungesättigter Kohlenwasserstoff ron der Formel $\mathrm{C}_{40} \mathrm{H}_{56}$, mithin stickstoffrei, ebenso wie der eine gelbe Bestandteil in den grïnen Chloroplasten, während der andere bei sonst gleicher Zusammensetzung noch etwas sauerstoff enthält.

Zu den Karotinoiden (so benannt von M. Tswett) rechnen auch: das (ielb) herbstlich verfärbter Blätter (das Rot der Herbstblätter des wilden Weins, der roten Weinbeere und anderer ist gelöstes Anthocyan).

das Etiolin (z. B. bei im Punkeln erzogenen Gerstenkeimlingen und bei den sehr hellen sprossen des spargets).

das Gelb vieler Bliitenfarbstoffe.

das Rot des sugenannten Veilchenmoss: :Trentepohlia iolithus).

das Cielbrot der Credo-. Telento- und Ä.idiosporen.

das Bakteriopurpurin des Chromatium okenii.

die Augenflecke vieler Flagellaten und schwärmer.

das Rot der Goldfische.

das (rello des Eidotters.

Die Haut der lebenten Krebse enthält vor allem rote und bläulichgriine Farbstoffe: ans ihrem Gemisch entstehen die allgemeinen Farbentöne des Krebspanzers. Durch Kochen werden die letztgenannten Farbstoffe zerstört. si daß Rot iibrig bleibt.

Die Bedentung der Karotinnide ist wenig bekannt. Sie sind in ihrer Bildnng von der Anwesenheit reichlicher Ilengen son Reservestoffen. wie stärle und Fett. abhängig. sind selbst aber fettfrei. Sie sind möglieherweise ein speichermaterial und gleichzeitig wahrseheinlich sanerstoffiiberträger.

Um das Karotin zu extrahieren und nathzuweisen. verfährt man in folgender Weise:

Mohrriben werden auf einem Reibeisen zerrieben. dinn getrocknet und in einer Porzellansehale gepulvert. Beim Übergießon mit schwefelkohlenstoff. einem guten Lösungsmittel für Karotin, färbt sich dieser sogleich tief galbrot. Wer schwefelkohlenstoff wird num abfiltriert (wobej das Filter nicht mit Wasser angefenchtet werden darf) und spektroskopisch exepriift. Es zeigt sith dabei, daß im wesentliehen der blane und violette Teil des spelitrums absubiert wird. 

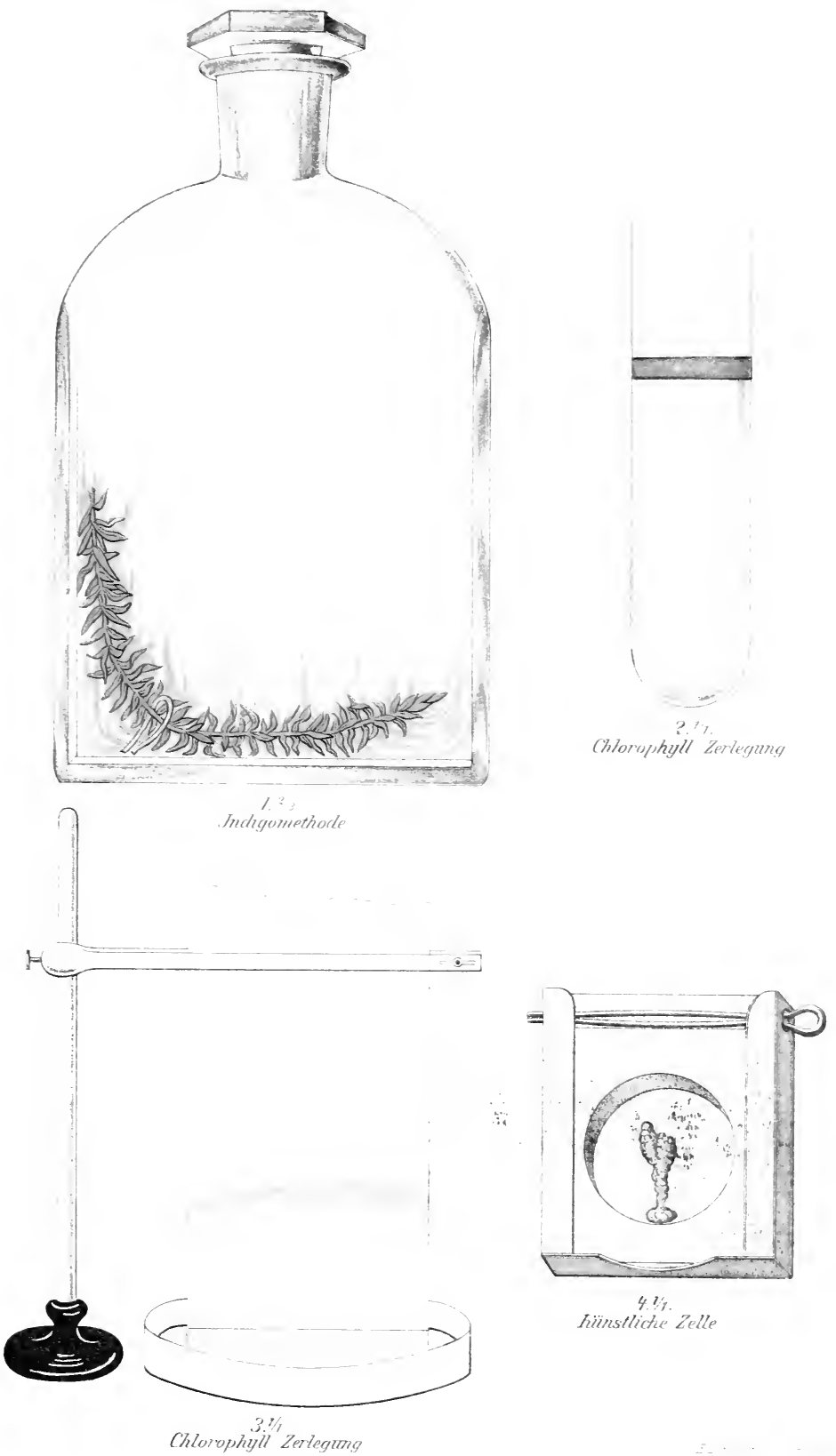

Verlag von Gustav Fischer in Jena 

Gießt man von der Flïssigkeit eine Probe auf ein Uhrschälchen und läßt den Schwefelkohlenstoff verdunsten, so bleibt als Riickstand fast reines Karotin. Dieses färbt sich nach Zusatz von konzentrierter Schwefelsäure schön blau, ähnlich wie manche rote Käferfligel im trockenen Zustande, die zum Teil Karotinkristalle enthalten [vgl. Paul Schulze (1)]; nach Zusatz von Jodlösung tritt Girinfärbung ein. Besitzt der Karotinbeschlag eine zu große Dicke, so kann es vorkommen, daß die Reaktionen versagen.

In gleicher Weise kann man mit herbstlich verfärbten Laubblättern, im Finstern erzogenen Gersten- oder Weizenpflanzen usw. verfahren. Übergießt man getrocknete, zerriebene grïne Pflanzen mit Schwefelkohlenstoff, so wird nur der gelbe Bestandteil des Chlorophylls extrahiert.

Sehr schöne Resultate erhält man beim Studium der roten Schwefelbakterien Chromatium okenii, Lamprocystis rosco-persicina u. a. m., die hier kurz erwähnt seien (Abbild. s. später). Nach Zusatz von konzentrierter Schwefelsäure gewahrt man, daß die einzelnen Zellen eine schöne, himmelblaue Färbung annehmen; die Grünfärbung durch Jod ist dagegen weniger ausgesprochen. Es empfiehlt sich, bei diesen Beobachtungen die lrisblende ziemlich weit zul öffnen.

Der gelbe Farbstoff der Chromatophoren bei Diat o meen, welcher den griinen Farbstoff verdeckt, ist ebenfalls wasserunlöslich; seine chemische Natur ist zurzeit noch nicht geniigend bekannt: wahrschein-

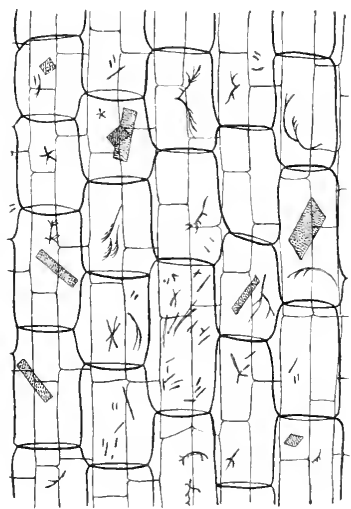

Abb. 5. Karotinkristalle aus dem Blatt von Elodea canadensis, durch die "Kalimethode" gewomnen. Vergr. mittelstark. (Nach H. Moliseh.) lich handelt es sich $11 \mathrm{~m}$ ein Karotinoid.

Legt man nach den Angaben von Molisch (1) mehrere Tage lang ein Blattstïck, z. B. von Clivia nobilis, in 40\% igen Alkohol, welchem $20 \%$ Kalilauge zugefügt ist, so treten durch Veränderung der Chlorophyllkörner des Blattes deutliclse Kristalle von Karotin auf, wie die Abbildung zeigt.

Die Bildung von Chlorophyll aus Karotin ist auch in der lebenden Pflanze nicht sicher beobachtet worden. Wenn etiolierte Blätter ergrünen, wird vielleicht nur der dunkelgriine Bestandteil hinzugefügt.

Über die Entwicklungsgeschichte des Chlorophylls in der lebenden Pflanze ist noch wenig bekannt. Der Embryo in den Samen von Pinus und anderen Coniferen enthält kein Chlorophyll und ist farblos. Läßt man solche Samen im Dunkelschrank auskeimen, so entwickeln sich normale, chlorophyllgriine Keimlinge, während andere Pflanzen gelb werden [vgl. 
W. Pfeffer (1), S. 318]. Es bleibt noch näher zu erforschen, welche Umstände in diesen Beispielen die Entstehung des Chlorophylls im Dunkeln gestatten. Bezüglich Karotin vgl. auch A. Zimmermann (1).

\section{Gruppe. Turgor und Osmose.}

Der durch den Assimilationsproze $B$ entstandene Zucker kann in der Pflanze leicht nachgewiesen werden, zum Teil schon durch den Geschmack. Er spiclt als wichtiger Nährstoff im Pflanzenkörper eine bedeutsame Rolle, doch kommt ihm auch in physikalischer Beziehung eine besondere Bedeutung zu, da seine Lösungen im Verein mit den Eigentümlichkeiten im Bau der lebenden Zellen starke Spannkräfte hervorbringen, welche in diesem Abschnitt behandelt werden sollen.

\section{Versuch. Mohrrübenversuch.}

Man höhle einige etwa $12 \mathrm{~cm}$ lange und $4-5 \mathrm{~cm}$ dicke Rüben oben einige Zentimeter tief aus und stelle sie frei auf $(z$. B. durch nicht zu weites Abschneiden des spitzen Endes) oder stecke sie in ein mit Sand gefülltes Gefäß. Hierauf fülle man mittels eines Messers, Löffels, trockenen Reagensglases oder gefalteten Papierstreifens gewöhnlichen Zucker trocken in die vorher nötigenfalls mit einem Tuch ausgewischte Höhlung; weitere Exemplare beschicke man mit Stärkemehl. Schon nach Verlauf einer viertel bis einer Stunde fangen die der Wand der Grube anliegenden Teile des Zuckers an stark feucht zu werden. Im Laufe weiterer Stunden wird dem oberen Teil der Rübe, auch den mehr peripherisch gelegenen Zellen, dauernd Wasser osmotisch entzogen, so daß der Zucker sich löst und die entstehende Flüssigkeit, unter gelindem Schrumpfen der Rübe, fortwährend an Volumen zunehmend, schließlich nach ein bis einigen Tagen iiberlaufen kann. Die mit der osmotisch unwirksamen Stärke gefüllte Riibe bleibt einige Tage lang im wesentlichen unverändert.

Die durch Wasserentzug entspannten oberen Teile der Rübe werden allmählich schlaff und beginnen stärker zu schrumpfen, während der untere kompakte Teil der Riibe lange Zeit noch ganz prall und hart ist. Der Wasserentzug durch die starke Zuckerlösung war in den oberen Partien der Rübe so stark, daß auf osmotischem Wege aus den unteren Teilen nicht genug Wasser zum Ersatz nachströmen konnte. Legt man aber die Ruibe nach Abspiilen des Zuckers in reines Leitungswasser, so nehmen ihre an Wasser arm gewordenen Zellen dieses von außen auf, wodurch der obere Teil der Rübe wieder seine ursprüngliche Größe und Festigkeit annimmt.

Man erkennt aus dem Versuch, daß der Rohrzucker, den man übrigens auch durch Kochsalz, Kalisalpeter usw. ersetzen könnte, wie eine hỵgroskopische Substanz wirkt und das Welken der Riibe herbeifiilnt. Der Wasserentzug hält solange an, bis das in der Aushöhlung zurïckbleibende 
Zuckerwasser dieselbe Konzentration angenommen hat, wie der saft im oberen Teil der Mohrrübe. Man sagt dann, der Rübensaft und das Zuckerwasser sind isotonische Lösungen, $d$. h. beide Fluissigkeiten besitzen dieselbe osmotische Saugkraft. Bei dem Hineinlegen der wetken (plasmolysierten) Rübe in reines Wasser kommt natïrlich die wasseranziehende Kraft des Rübensaftes wieder zur Geltung und stellt durch Wasseraufnahme die alte Festigkeit von neuem her.

Überzuekert man frische, unverletzte, pralle und nicht entstielte Kirsehen mit gewöhnlichem Kochzucker, so wird man keine starke Wasserentziehung erwarten kömen, weil die Kirschen mit einer wenig wasserdurchlässigen Haut überzogen sind.

Zum Schluß mag noch erwähnt werden, daß die wasserentziehende Kiraft des Zuckers auch vom Publikum mehrfach benutzt wird. Nan höhlt z. B. einen Rettig aus, durchsticht seinen Boden mittels eines Stiftes und füllt Zucker ein. Der Zuckersaft, weleher bald unten ans dem Loch herausfließt, schmeckt nach Rettig und wird als Hustenmittel verwendet. Ersetzt man den schmelzenden Zucker reehtzeitig wieder dureh festen, so wird schließlich dem schrumpfenden Rettig fast alles Wasser entzogen, weil die osmotische Saugkraft des Zuckers in der Höhlung die des Zellsaftes überwiegt.

\section{Versuch. Die künstliche Zelle.}

In den Jahren 1864-1866 veröffentlichte M oritz Tra u be (1) ,Experimente zur Theorie der Zellenbildung und Endosmose“. Diese Versuche behandeln die Herstelhnng künstlicher Zellen, wetche das Verständnis für die osmotischen Vorgänge im Pflanzenkörper sehr gefördert haben. Es sei vorausgeschickt, daß die im Folgenden geschilderte Versuchsanstellung sich nicht in allen Punkten mit der Traubes deckt; er verwendete nämlich Kupferchlorid, während hier Kupfersulfat, das bessere Resultate liefert, angewandt wurde.

Man geht zweckmäßig von einer konzentrierten (noch Kristalle als Bodensatz enthaltenden) Kupfersulfatlösung (d. s. ('a. 30\%) in destilliertem Wasser aus, die man sich vorrätig halten kann. Nan gießt eine Probe aus dieser Flasehe ab und verdünnt sie in einem Meßzylinder oder direkt im Beobachtungsglase mit dem mindestens zweifachen und höchstens etwa siebenfachen Volumen destillierten Wassers. Man kann auch direkt die $\mathrm{CuSO}_{4}$ haltige Stammfliissigkeit der Fehlingschen Lösung (d. s. ca. $7 \%$ ) für den Versuch verwenden.

Die für das Experiment geeignete Lösung von Kupfersulfat kann man einfüllen in ein Becherglas, ein Reagenzglas, eine Medizinflasche, eine viereckige Lindnersche Flasche, eine Planktonkammer (vgl. Abbild. anf Taf. I und den zweiten Teil des Buches) usw. Mehr oder weniger geeignet ist ïbrigens jedes helle Glasgefäß, dessen Wände einigermaßen glatt sind.

Wirft man ein stark hirsekorn- bis höchstens erbsengroßes, nicht krümeliges (weil dann lufthaltiges) Stiick gelben Blutlaugensalzes in die 
blaue Fliissigkeit, so bildet sich durch die Berührung dieser beiden chemischen Substanzen kolloidales Ferrozyankupfer, das als feine, rotbraune, osmotisch wirksame Membran den am Boden liegenden Kristall von gelbem Ferrozyankalium iiberzieht, wenn man das Gefäß ruhig stehen läßt.

$$
\underset{\text { Kupfersulfat }}{2 \mathrm{CuSO}_{4}}+\underset{\text { gelb. Blutlaugensalz }}{\mathrm{K}_{4} \mathrm{Fe}(\mathrm{CN})_{6}}=\underset{\text { Ferrozyankupfer }}{\mathrm{Cu}_{2} \mathrm{Fe}(\mathrm{CN})_{6}}+\underset{\text { Kaliumsulfat }}{2 \mathrm{~K}_{2} \mathrm{SO}_{4}} \text {. }
$$

Das Kaliumsulfat kommt fiir den Versuch nicht in Betracht.

Der in die Kupfersulfatlösung geworfene Kristall umgibt sich unter der rotbraunen Hant mit einer konzentrierten Lösung seiner eigenen Substanz, durch welche der blauen Lösung schnell Wasser entzogen wird, aber nur Wasser, da es eine äuBerst wichtige Eigenschaft der semipermeablen Ferrozyankupfermembran ist, weder Kupfervitriolmolekuile zum Blutlaugensalz noch umgekehrt passieren zu lassen. Um gut beobachten zu können, lege man gleich zu Beginn des Versuches ein weißes Blatt Papier unter das Gefäß. Diese Membran zeigt also physikalisch dieselben Eigensehaften wie der lebende Protoplasmaschlanch der Zelle. Nun darf man aber nicht vergessen, daß sich der lebende Plasmaschlauch bei längerer Dauer eines Versuches für Molekiile, z. B. des Zuckers, als durchlässig erweist, denn sonst bliebe unverständlich, wie Zucker von Zelle zu Zelle wandern könnte, z. B. aus den Palisadenzellen in das Schwammparenchym der Blätter und weiter abwärts.

Läßt man das Versuchsgefäß ganz ruhig stehen, so wächst die künstliche Zelle in der blauen Flïssigkeit meist in Gestalt einer unregelmäBigen Keule oder eines Bäumchens von rotbranner Hülle und gelbem Inhalt empor (vgl. Abbild.). Das Wachstum beginnt sogleich; nach etwa einer halben Stunde pflegt der Versuch dann beendet zu sein. Die treibende Kraft fiir das Wachstum der kiinstlichen Zelle ist der besonders zu Anfang bestehende große Konzentrationsmnterschied zwischen der blanen und gelben Flüssigkeit.

I) kiunstliche Zelle kann in der Planktonkammer, auch wemn man sie in der Hand hält und etwas bewegt, sehr gut beobachtet werden, bei vertikaler Stellung makroskopisch (mit Lupe oder in Projektion), bei horizontaler Lage unter dem Mikroskop bei 20-100facher Vergrößerung. Beim Umdrehen der Kammer um $180^{\circ}$ sinkt die konzentrierte Lösung von gelbem Blutlaugensalz im Innern der kïnstlichen Zelle herab, so daß infolge der am Kopf der Zelle verstärkten Konzentration ein neues Bäumchen neben dem ersten emporwä̈hst.

Bei mikroskopischer Betrachtung kann man auch in der Weise verfahren, daß man anf einem Objektträger bei schwacher oder mittlerer Vergrößerung einen nicht zu großen Kristall von Ferrozyankalium cinstellt, nachdem man ein Deekgläschen darüher gelegt hat, und unter Vermeidung von Luftblasen mittels Saugpipette die Kupfersulfatlösung zufiggt. Man erkennt dann leicht, daß die sich bildende rotbraune Membran bei ihrer Ansdehmung platzt und sieh durch Neubildungen wieder schließt. In 
dieser Beziehung erfolgt das Madhstum rtwas anders als das des sthleimigen Plasmaschlauches.

Bei Verwendung konzentrierter Kupfersulfatlösung tritt begreillicherweise so gut wie kein Wachstum der kiinstlichen Zelle ein. da heide Läsungen ziemlich gleich starke osmotisebe Saugkraft besitzen.

Ist die kïnstliche Zelle gewachsen und wird dann die äubere Flïssigkeit durch konzentrierte Lösung ersetzt. so zicht sich die Zelle nicht zorsammen, wie es bei dem lebenden, schleimigen Protoplasmaschlauch geschicht.

Die kiinstliche Zelle kann jederzeit leicht demonstriert werden. da der Versuch niemals miBgliiclit.

Man halte sich vorrätig:

1. Flasche mit konzentrierter ('uso, in destilliertem IIasser (am Boden mogelöste Kristalle),

2. Flasche mit destilliertem Wasser,

3. Pulverflasche mit Kristallen von gelbem Blutlaugensalz,

4. Meßzylinder von 50-100 rem Inhalt.

Über kiinstliche Silikatzellen vgl. man J. Reinke, Bot. Ztg. 1875.

\section{Versuch. Permeabilität des abgetöteten Plasmaschlauches.}

Es ist bekannt, daß der lebende Plasmaschlauch für den in vielen Blättern, Blïten mol Frïchten vorkommenden, lakmusähnlichen Anthozyanfarbstoff undurchlässig ist. Legt man also Fäden von Spirogyra, welche einen deutlich sichtbaren Kern haben, in solchen roten Saft, $z$. B. der Heidelbeere, so dringt der Farbstoff nicht ein. solange die Zellen lebend sind, tötet man sie aber, z. B. durch Erwärmen, Gifte oder durch den Induktionsstrom, so färbt sich der Kern sogleich tiefrot, weil er selbst und der wandständige Plasmaschlauch für den Farbstoff durchlässig geworden sind. Die an späterer Stelle behandelten Zellen von Tradescantia discolor verlieren, wie die mikroskopische Beobachtung zeigt, ihren roten Farbstoff durch Austritt aus den Zellen, wenn man diese durch Erhitzen tötet. Bezïglich Lebendfärbung vgl. man W. Pfeffer (1), s. 103.

Auch makroskopische Versuche lassen sich zur Demonstration des oben Gesagten ausfihren, z. B. mit Blättern von Rotkohlköpfen.

Man fïlle zwei Bechergläser mit destilliertem Wasser, nicht Leitungswasser, da dieses alkalische Reaktion besitzt. Nan sehneidet nun Rotkohlblätter in Stücke und bringt diese in die beiden Bechergläser. Wird das Wasser in dem einen auf mebr als $50-60^{\circ} \mathrm{C}$ erwärmt, so tritt wegen des Abtötens der Plasmaschläuche der rote, im Zellsaft gelöste Farbstoff aus, während das Wasser des nicht erwärmten Kontrollgefäßes farblos bleibt. Blätter von etwas lockeren Kohlköpfen pflegen bei dem Versuch mehr Farbstoff zu liefern als solche sehr fester Köpfe. Man kann statt der Bechergläser auch Reagenzgläser benutzen.

Kolkwitz, Pflanzenphysiologie. 
Der gleiche Versuch gelingt auch sehr gut mit roten Kirschen, etwa in der durch nebenstehende Abbildung angegebenen Form. Im Bedarfsfalle
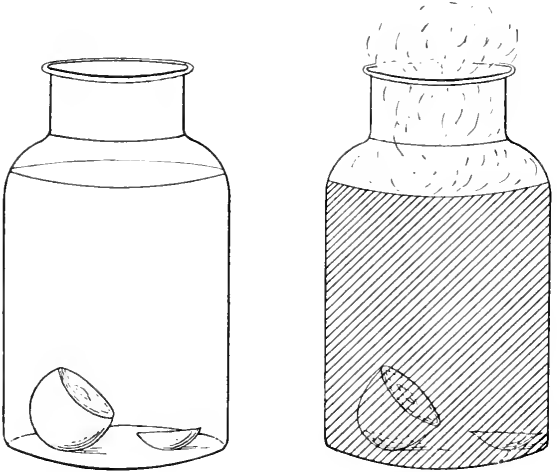

Abb. 6. Kirschenversuch zur Demonstration der Durchlässigkeit abgetöteler Plasma schläuche. Links: Wasser von Zimmertemperatur, farblos. Rechts: Heißes Wasser, rot durch Kirschsaft. (Orig.)

Anch durch Kältewirknng können saftige Zellen zum Absterben (Erfrieren) gebracht werden, wie es scheint dann, wenn im Zellstoff ein Gemisch von Eis und Salzen entsteht [Kryohydratpunkt*)]. Die versehiedenen Organe desselben Individunms können bei verschiedenen Temperaturen erfrieren, ein Apfel z. B. bei $-3^{0} \mathrm{C}$, cin Apfelbaumstamm erst unter $-20^{\circ} \mathrm{C}$.

\section{Versuch. Kïnstlicher Turgor.}

Der Turgordruck kommt dadurch zustande, dab die osmotische Sangkraft des Zellsaftes und die elastische Spannkraft der Zellhaut gegeneinander wirken. Zur Demonstration dieses Wechselspiels kann folgender Versuch dienen: Man ibberbinde ein weites Glasrobr von 10-20 c'm Länge an beiden Enden fest mit nasser, vorher stundenlang gewässerter Schweinsblase, nachdem man es mit einer hochprozentigen Zuckerlösung unter Vermeidung von Luftblasen gefïllt hat, und lege es in eine Schale mit Leitungswasser. Besonders bei höherer Temperatur (ca. 50\% C) wird die Zuckerlösmmg, welche sich im Innern der Röhre befindet, nach Verlanf mehrerer Stunden reichlich Wasser anzichen und die Schweinsmembranen vorwölben. Sind sie recht prall gespannt, so steche man in eine Membran mit riner Nadel hinein. Sogleich nach dem Herausziehen der Nadel wird rin Strahl von Znekerlösung in einem etwa 2 m langen Bogen herausschießen.

Weitere Modifikationen dieses Versuches s. bei W. Detmer (1).

*) Dieser Punkt wird erreicht, wenn der Zellsaft zn einem Gemisch von Eis und Salz erstarrt. 
Der Vergleieh dieses Morlells mit einer Zelle ist nur nnvollkommen, da in der turgeszenten Zelle z wei Häute untersehieden werden: die elastisehe Zellulosehant und die schleimige, semiperneable Protoplasmahaut, welche in der erstgenannten ihr Widerlager findet. Die Zunalime der Turgeszenz einer Zelle hört auf, wenn sich osmotische Saugkraft nnd elastische spannkraft das Gleichgewicht halten. Der Turgorelruck in den lebenden Pllanzenzellen beträgt im Mittel 7 Atmosphären, atso so viel wie die spannung in manchen Dampfkessetn. Wären dio Zellen nieht so klein, wiirde man auch hier beim Hineinstechen mit einer feinen Nadel einen Saftstrahl hervorschießen sehen.

Man kann die Saugkraft osmotiseh wirksamer Lösmgen auch in der Weise demonstrieren, daß man nach den Angaben von Dutrochet die Miindung eines mit Kugeltrichter versehenen Steigrohres mit Schweinsblase ïberbindet, das Rohr mit Zuckerlösung, alkannarot gefärbtem Alkohol oder dergleichen fiilt und in Wasser taucht. Dann steigt infolge von Endosmose des Wassers die Fluissigkeitssäule in dem Rohr nach Verlauf einiger stunten.

\section{Versuch. Natürlicher Turgor.}

Man beobachte unter dem Mikroskop bei etwa 150 facher VergröBerung einen gesunden nicht zu kurzen Faden von Spirogyra crassa. 1)ie Querwände seiner Zellen sind besonders in der Mitte des Fadens vollkommen gerade und zur Längsausdehnung des Fadens quergerichtet. Sticht man mit einer spitzen Nadel eine der mittleren Zellen an, so hört in dieser der hydrostatische Druck wegen der Verletzung des Primordialsehlauches auf. Demzufolge wölben sich in den Nachbarzellen die Querwände wegen des dort hersehenden Turgordruckes stark vor. (Ahnliche Bilder liefern Oscillatoria-Fäden mit Nekridien.) Fiigt man jetzt 4\%ige Kalisalpeterlösung hinzu, so wird wegen des Wasserverlustes in allen Zellen des Fadens der Turgor (unter Abheben der Plasmaschläuche von den Wänden) aufgehoben. Dadurch miißten sich alle vorgewölbten Querwände wieder gerade strecken, doch sind diese gerade bei Spirogyra crassa meist so duktil, daß ein Teil der Vorwölbungen dauernd bleibt.

Hätte man vorher die Trilstriche eines Okularmiklometers scharf auf die Ansatzstellen zweier benachbarter Querwände eingestellt, so wïrde man beim Aufheben des Turgors eine Kontraktion der Längswände $11 \mathrm{~m} 6-8 \%$ feststellen können.

Diese mikroskopisch sichtbare Kontraktionswirkung kann man auch makroskopisch erzielen, z. B. in der Weise, daß man ein etwa 6 cm langes Hypokotyl von Lupims albus längs aufspaltet und die beiden Hälften zum Plasmolysieren in eine 4\% ige Kalisalpeterlösmng legt. Wegen des dadurch bewirkten Turgorschwundes tritt anch hier in etwa einer halben Stunde eine Verkïrzung von $6-8 \%$ ein. Legt man die Gewebehälften nachber in reines Leitungswasser, so werden sie wiederum prall und dehnen sich min- 
destens bis auf ihre urspriingliche Länge wieder aus. Sollten sich die Objekte bei diesen Versuchen stark kriimmen, so empfiehlt es sich, sie vorher zu schälen.

Übrigens kann man die plasmolysierte Hypokotylhälfte statt durch osmotische Kräfte auch durch Anhängen von Gewichten wieder auf ihre urspriingliche Länge dehnen. I)ann entspricht die Größe der Gewichte (abgesehen von Fehlern, die durch Verzerrung des Zelhnetzes bedingt sind) dem osmotischen Druck in den Zellen.

Das Einspannen des Hypokotyls kann man durch diinne Gummischlauchstiicke mit iibergezogenen Klemmschrauben bewirken.

\section{Versuch. Gewebespannung.}

Trennt man von einem reichlich fingerlangen Stengelstiick von Begonia oder von jungen Wurzelschossen des Sambucus nigra auf eine längere Strecke Rinde und Holz durch Längschnitte ringsum ab, so gewahrt man leicht, daß das Mark, welches vorher gleichsam gestaucht war. sich verlängert.

Stehen einem leicht Schafte von Taraxacum officinale zur Verfigung, so spalte man diese durch zwei krenzwe is geführte Längsschnitte. wobci die so getremnten Stengelstiicke wegen der Ausdehmung des Markes sogle ich nach auben klaffen werden. Natürlich nimmt diese Krimmung beim Hincinlegen in Wasser noch stark zu. Inurch Plasmolyse mittels 4\% iger Kalisalpeterlösung wird sie vieder vollständig rïckgängig gemacht. Auch Hỵokotyle von Lupinus albus und Ricimus communis können verwendet werden.

Die Rinde der Bänne ist ebenfalls gegen den Holzkörper gespannt (Rindenspannung).

Die vorstehend beschriebenen, durch Gewebespannung bedingten Kriimmungen sind der Wirkung nach rergleichbar der Bewegung knochiger Körperteile durch die Muskehn. Den Knochen wïrde hier der Holzkörper, den Muskeln das turgeszente Markparenchym des Stengels vergleichbar sein.

Die meisten Bewegungen lebender Pflanzenteile kommen durch diese Wirkmngen der Parenchymzellen zustande, so z. B. das Öffnen und Schlieben vieler Bliiten, die sogenannten nyktitropischen Bewegungen der mit Gelenkpolstern versehenen Blätter der Bohne. des Klees usw. und die Reizbewrgungen der Mimosa pudica*). Man rgl. hierzn J. Sachs (2). G. Haberla d $_{\mathrm{t}}(1)$. Diese zu Bewegungen oder Krïmmungen fïhrenden Differenzen in der Turgorspannung können entweder an längeren Gewebepartien auftreten, z. B. bei der revolutiven Nutation, oder lokalisiert sein. z. B. bei Gelenkpolstern (die eime gewisse Horsiventralität zeigen können).

*) M. pudica, I'flänzchen von etwa $10 \mathrm{~cm}$ Ilöhe. sind in Töpfen bei Gärtnem für etwa 20 Pf. pro Stück käuflich. Sie sind zn Reizversuchen ganz gut verwendbar. Zum Weiterzüchten setzt man die Töpfe zweckmäßig in ein bedecktes größeres Akkumulatorenglas, das gut belichtet wird, am besten durch direkte Sonne. Auf den Boden des Gefäßes bringt man feuchten Kies und eine Schale mit Wasser. 
und bei den Bewegungen vicler Bliiten (z. B. in Verbindung mit Warhstum bei den diageotropischen der Blïten von Narcissus) und vieler Laubblatter.

Turgordifferenzen, Wachstum und Reizerscheinungen, z. B. bei Ranken, können niteinander kombiniert sein. Es handelt sich hierbei vielfach 1 m Anpassungserscheinmgen (Aufsuchen geeigneter stiitzen, Einnehmen giinstiger fixer lichtlagen, Vermeidung von Wärmeausstrahhungen, Pollensehutz usw.).

Als Beispiele seien genamnt:

Versuchsptllanzen:

Acacia lophanta (Leguminosat)

Mimosa pudica

Trifolium pratense

Amorpha fruticosa

Coronilla varia

Amicia zygomeris

Phaseolus multiflorus

(vgl. nebenstehende Abbildung.)

Oxalis acetosella (Oxalidaceae) im Thukeln:

Blättchen anfgerichtet

Blattstiele gesenlit (Pflanze reizhar)

Blättchen aufgerichtet

, herabgeschlagen

,, aufgerichtet

,. herabgeschlagen
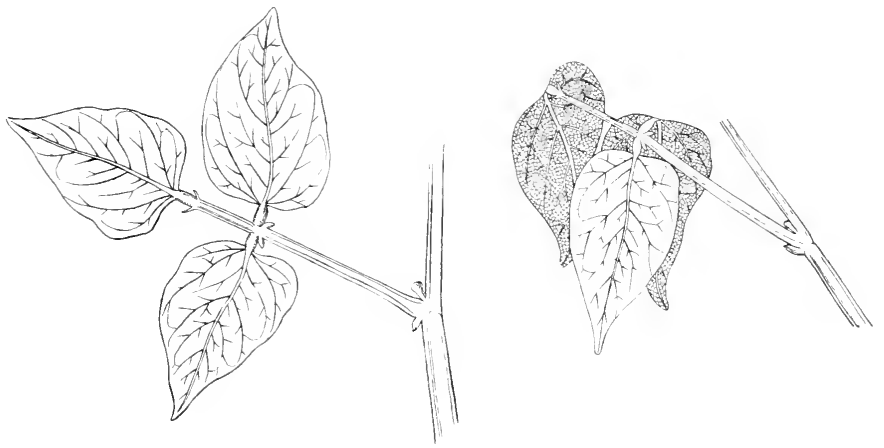

Abb. 7. B lätter der Feuerbohne:(Phascolus multiflonus), links in Tag-, rechts in Nachtstellung. Am Grunde der Blättchen erkennt man deutlich die Gelenkpolster. Zı Versuchen kömnen Pflanzen in Töpfen verwendet werden. (Orig.)

Autonome Bewegungen.

Desmodium gyrans (Leguminosae) Trifolium pratense

Phascolus multiflorus Humulus lupulus (Moraceae)

Calystegia dahurica (Convolvulaceae) Convolvulus sepium
Seitenblättchen schwingend

Blättchen sich sehr langsam auf und ab bewegend

revolutive Nutation der Sprolsspitze 
Der Hopfen windet, im Gegensatz zn den meisten anderen Schlingpflanzen, rechts, d. h. seine Stengel erscheinen rechts aufsteigend, wenn man sich selbst als sitiitze hineindenkt.

\section{Rankenpflanzen.}

Clematis vitalba (Ranunculaceae), Blattstiele reizbar

Vitis vinifera (Vitaceae)

Parthenocissus (Ampclopsis), Wickel-, Haftscheiben- und Klemmranken

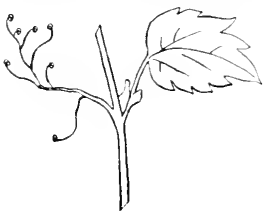

Abb. 8. Haftscheibenranken von Parthenocissus (Ampelopsis)radicantissimus. (Orig.) (vgl. nebenstehende Abbildung.)

Cobaca scandens (Polemoniaceae), Krallenranken

Bryonia alba (Cucurbitaceae)

Cucumis sativus, Gurke, (Cucurbitaceae)

Cucurbita pepo, Kürbis,

Sicyos angulatus ('ucurbitaceae)

Cyclanthera explodens ,

Öffnen und Schließen der Bläten.

Versuchspflanzen

im Dunkeln

Tulipa (Liliateae)

geschlossen

Crocus (Amaryllidaceae).

Silene mutans (Caryophyllaceae . . . . . . . geöffnet

Linum, Flachs (Linaceae). . . . . . . . . . . geschlossen

Oenothera, Nachtkerze (Onagraceae) . . . . . . geöffnet

Bellis perennis, Gänseblümchen (Compositae). . . . geschlossen

Taraxacum officinale, Löwenzahn (Compositae). . . . . .

Tragopogon pratense, Bocksbart (Compositae). . . . . .

Über die Forschungen, betreffend die physiologischen Leistmngen der Gewobe, vergleiche man G. Haberlandt (1).
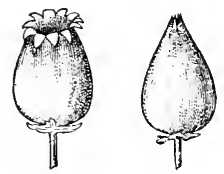

Abb. 9. Hygroskopischer Mechanismus an der Kapsel der Abendlichtnelke (Jelandrym album) Links in trockenen Zustande, rechts nach Eintanchen in Wasser. (Orig.) 
Hygroskopische und Kohäsionsmechanismen, welche sich an t 0 te $n$ Objekten abspielen, sind nebenstehend abgebildet und bei Besprechung der Farnsporangien noch näher behandelt.

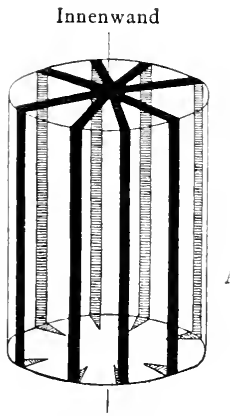

Außenwand
Innenwand

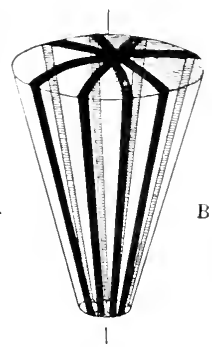

Außenwand

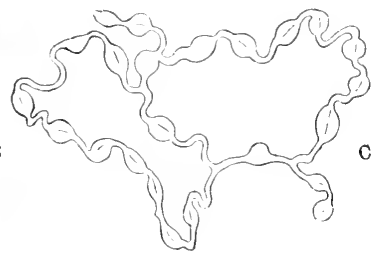

Abb. 10. Kobäsionsmechanismus in den Antherenzellen des Fingerhutes (Digitalis purpurea). A Längswände der Faserzelle ungefaltet; $B$ Längswände der Faserzelle gefaltet; $C$ Tangentialschnitt durch zwei Faserzellen, deren Radialwände wellblechartig verbogen sind. Vergr. 900. (Nach C. Steinbrinck.)

\section{Versuch. Isotonische Lösungen.}

Die Zellen der Blattunterseite von Tradescantia discolor, besonders diejenigen der Mittelrippe, besitzen annähernd den gleichen Turgor und enthalten im Zellsaft Anthocyan. Abb. s. unter Spaltöffnungen.

Man bereite eine 1,5\% ige Lösung von Kalisalpeter und eine $8 \%$ ige von Rohrzucker und gieße sie in je ein Schälchen. Legt man in beide Schälchen Oberflächenschnitte eines gut gesäuberten Blattes von Tradescantia discolor hinein, die Schnittfläche am besten nach unten, so wird man finden, daß nach Verlauf von 10-20 Minuten beide Lösungen ungefähr gleich starke Kontraktion des Plasmaschlauches verursacht haben, die zunächst als Rückzug des Plasmaschlauches aus den Ecken erkemmbar ist, wodurch sich das gerade eingetretene Aufhören des Tugordruckes mikroskopisch kenntlich macht (Plasmolyse*). Man vergleiche auch die vorher besprochenen Versuche mit Spirogyra crassa und die Ausfiihrungen in dem Kapitel iiber die Zuckerrübe. Bisweilen kann es nötig sein, $2 \%$ Kalisalpeter und 10\% Rohrzucker anzuwenden. Wollte man iibrigens ganz korrekt verfahren, so mißßte man die verwendeten substanzen vor dem Abwägen sorgfältig trocknen.

Die beiden genannten Flïssigkeiten iiben in ihren beziiglichen Konzentrationen ungefähr die gleiche wasseranziehende Kraft aus. Solche gleich

*) D. h. Loslösen des Plasmaschlauches von der Zellwand. Die Kontraktion kompakten Plasmas, z. B. bei Myxomycetes, bezeichnet Balbiani als Plasmorhyse (rhysos = Schrumpfung). 
stark wasserentziehenden (osmotisch wirksamen) Fliissigkeiten nennt man isotonisch. Genaue Zahlen für isotonische lösungen sind:

Rohrzucker 7,62\%, Kalisalpeter 1,5\%, Kochsalz 0,8615\%.

Die Werte 1,5:0,8615 verhalten sich ziemlich genau wie die Molekulargewichte (101 für Kalisalpeter und 58,5 für Kochsalz). Also

$$
\frac{1,5}{0,8615}=\frac{101}{58,5} \text {. }
$$

Isotonische Lösungen sind mithin solehe von gleicher Molekiilzahl, d. h. die Molekiile der versehiedensten Substanzen ziehen mit derselben Kraft Wasser an. Für alle Substanzen trifft diese Regel indessen nicht zu; das einzelne Rohrzuckermolekiil z. B. besitzt zwar theoretisch die gleiche wasseranziehende Kraft wie das einzelne Kalisalpetermolekiil, es dissoziiert sich dieses aber in der schwachen Lösung und erscheint dadurch stärker wasseranziehend. Man muß deshalb, damit sich die richtige Proportion ergibt, das Molekulargewicht des Rohrzuckers $(=342)$ erst mit dem empirisch ermittelten Faktor $\because 3$ multiplizieren. Dann gilt die Gleichung $\frac{342 \cdot \frac{3}{2}}{101}=\frac{7,62}{1,5}$. Dieser Faktor heiBt der isotonische Koeffizient. Vgl. H. de Vries (1).

Fiir die den verschiedenen Substanzen entsprechenden Atmosphärendrucke gelten nach W. Pfeffer (1) folgende Zahlen:

$\begin{array}{ll}1 \% \text { Rohrzucker } & =0,69 \text { Atm. } \\ 1 \% \text { Traubenzucker } & =1,25, \\ 1 \% \text { Glyzerin } & =2,54 \quad, \\ 1 \% \text { Kalisalpeter } & =3,50 \quad, \\ 1 \% \text { Kochsalz } & =6,09, \\ 1 \% \text { Gunmi arabicum } & =0,085,\end{array}$

Wie leicht einzusehen ist, kann mit Hilfe der isotonischen Lösungen in Wirkung auf geeignete Pflanzenzellen das Molekulargewicht bestimmt werden, wie es z. B. für manche Zuckerarten geschehen ist.

Statt Pflanzenzellen hat man auch rote Blutkörperchen zum Studium isosmotischer Lösungen verwendet.

Werden die Zellen von Tradescantia discolor seln stark plasmolysiert. so konzentriert sich der rote Zellsaft mehr und mehr (bis zur Fabe des Rotweins), während der farblose Plasmaschlauch infolge der Kontraktion dicker wird. Er ist dann bei stärkerer VergröBerung und kräftiger Beleuchtung gut zu sehen.

Eine kntze Erwähnung verdienen noch die Meerespllanzen und die Halophyten des Strandes. Um die Zellen dieser Gewächse zu plasmolysieren, bedarf es natirlich verhältnismäßig hoch konzentrierter Lösungen. 
Das Plankton der Fliisse wird beim Eintritt in stark salzige Meere natïrlich plasmolysiert und geht, falls sich nicht ein Teil dem Meereswasser anpaBt, zugrunde.

Umgekehrt werden die Zellen vieler Meerespflanzen, wenn man sie in Siißwasser bringt, platzen.

\section{Versuch. Beobachtungen an der Zuckerrübe.}

Die Zuckerrübe ist eine Form der zur Familie der Chenopodiaceen gehörigen Runkelriube (Beta vulgaris forma rapa), welche durch hohen Gehalt an Rohrzucker ausgezeichnet ist, dessen Verteilung nach mittleren Zahlenwerten aus nebenstehender Abbildung ersehen werden kann. Über die Wachstumsgeschichte der Zuckerriibe vergleiche man $H$. de Vries (2), ferner Knauer-Hollrung (1). Die mittlere Konzentration des Zellsaftes an Zucker beträgt ‘a. 18\% (= ca. 12,5 Atm. Druck), die höchste bisher beobachtete $25 \% \quad(=17,25 \mathrm{Atm}$. Druck). Die chemische Analyse der Zuckerribe gibt etwa folgende Werte:

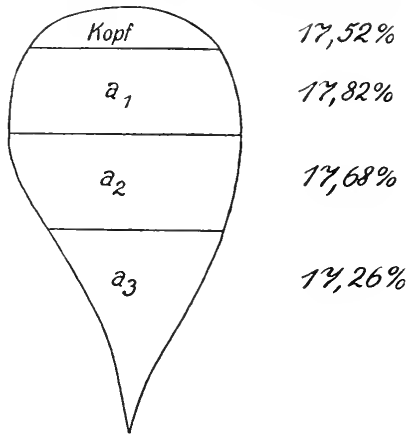

Abb. 11. Verteilung des Zuckers in der R ï be. Der Höchstgehalt findet sich unter dem Kopfteil. Zuckerrübe in der Längsansicht dargestellt. (Nach Proskowetz.)

$$
\begin{aligned}
& \text { Cellulose (u. Gummiarten) . . . . . 4-6\%, } \\
& \text { Zucker. . . . . . . . . . . . 12-18\%, } \\
& \text {, . . . . . . . . . . selten bis } 25 \% \text {, } \\
& \text { Wasser . . . . . . . . . . } 75-80 \% \text {, } \\
& \text { Nichtzuckerstoffe, mineralisch . . . } 0,5 \% \text {, } \\
& \text {, organisch . . . . } 0,5-1 \% \text {. }
\end{aligned}
$$

Die letztgenannten Stoffe*) bestehen aus:

$\begin{array}{ll}\text { Eiweiß, } & \text { Oxalsäure, } \\ \text { Betain, } & \text { Gerbsäure, } \\ \text { Glutamin, } & \text { Apfelsäure, } \\ \text { Asparagin, } & \text { Weinsäure, } \\ & \text { Zitronensäure. }\end{array}$

Die in der Zuckerriibe überhaupt vorkommenden Kohlenhydrate sind nach W. Ruhland (1):
1. Stärke,
4. Glukose,
2. Raffinose,
5. Fruktose.
3. Rohrzucker, Leptomitus.

*) Diese wirken in den Abwässern der Zuckerfabriken z. T. als Nährstoffe für 
Isotonisch mit den Zellsäften sind ca. 3,5\% NaCl bzw. ca. $5 \% \mathrm{KNO}_{3}$, da Kalisalpeter osmotisch zirka fïnfmal wirksamer ist als Rohrzucker.

Man wird also zur wirksamen Plasmolyse der Zuckerribenzellen nicht unter $5 \% \mathrm{KNO}_{3}$ anwenden. In dem Maße, wie diese Lösung unter Passieren der Zellulosehäute in tas Gewebe eindringt, zieht sie in entgegengesetzter Richtung das Wasser aus den Zellsäften heraus. Benutzt man $6 \% \mathrm{KNO}_{3}$, so zieht sich der Plasmaschlauch deutlich von der Wand zuriick, wie die beistehende Abbildung zeigt.

Fïr isosmotische Studien ergeben sich die Gleichungen:

$$
\frac{\mathrm{KNO}_{3} \%}{\mathrm{NaCl} \%}=\frac{6}{3,476}=\frac{101}{58,5}=\frac{\text { Mol. Gew. d. Salpeters }}{\text { Mol. Gew. d. Kochsalzes }}
$$

Die osmotisch Wasser entziehende Kalisalpeterlösung dringt durch die Zellulosehäute der Zellen, aber nicht durch den Plasmaschlauch und

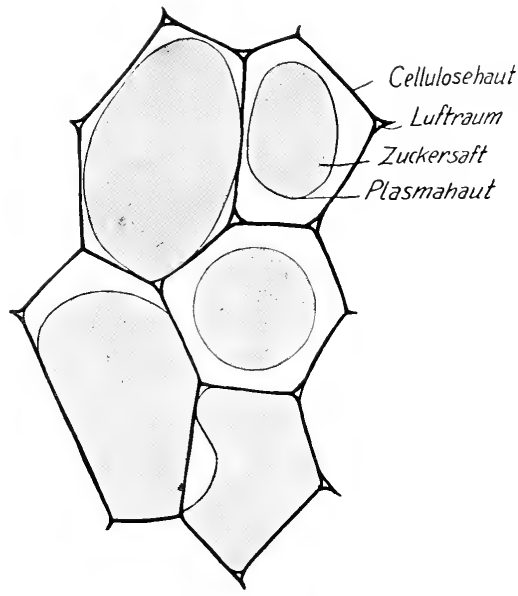

Abb. 12. Zellen aus der Zuckerrïbe, plasmolysiert. Man erkennt leicht die melır oder minder regelmäßige Zurïckziehung des den Znckersaft umschließenden Plasmaschlauches von der Zellwand. Vergr. mittelstark (Orig.) dickt den Zellsaft ein, im vorliegenden Fall bis ca. $30 \%$, da Rohrzuckerlösung in dieser Konzentration mit einer $6 \%$ igen Kalisalpeterlösung isotonisch ist, so dab mit ca. $30 \%$ Rohrzucker gefüllte Plasmaschläuche von 6\% iger Kalisalpeterlösung umspiilt werden. Die den stark konzentrierten Zellsaft umsehließenden Plasmakiigelchen zeigen unter dem Mikroskop eine etwas erhöhte Lichtbrechung. Sie erscheinen in jeder Zelle wie ein $\mathrm{Ei}$ in mehr oder weniger eckigem Karton. Vgl. die Abbildung.

Man kann anch konzentrierte Lösung vou Kalisalpeter verwenden, da diese immerhalb ter Beobachtungszeit das Plasma nicht abtötet; es ist möglich, daß dann sehon einzelne Kristalle im konzentrierten Zellsaft entstehen; ähnlich pflegen sich auch in einer durch Plasmolyse mehr und mehr konzentrierten Anthoxyanlösung Ausscheidungen zu bilden. Legt man Sticke der Zuckerrïbe längere Zeit in starken Alkohol, so kann man unter dem Mikroskop die ansgeschiedenen monoklinen Rohrzuckerkristalle wahrnehmen.

Die fiir die mikroskopische Beobatehtung bestimmten schnitte durch die Zuckerriibe dürfen nicht zu dïnn gemacht werden, da die einzelnen 
Zellen ziemlich grob sind und durch das Messer nicht verletzt werden diurfen. Für plasmolytische Beobachtungen (auf dem Objektträger) sind noch Schnitte von etwa Linsengröbe gut verwendbar, welche mit dem Taschenmesser angefertigt worden sind. Trotz einer gewissen Unregelmäßigkeit der Zuckerribenzellen liefern schnitte fïr mittlere mikroskopische Vergrößerungen ein ziemlich regelmäßiges Bild von zelliger Schaumstruktur der Zuckerribe, bei durchfallendem sowohl wie auffallendem Licht.

Dadureh, daß man nach eingetretener Plasmolyse wieder vorsichtig Wasser zusetzt, kann man den ursprïnglichen Zustand der Zellen von neuem herstellen.

In den Monaten August und September sind die Riiben auf den Feldern schon zuckerreich und doch diffundiert der Zucker bis zur Erntezeit im Oktober trotz hoher Turgorspannung der Zellen nicht in den Boden. Man kann daraus die ausgesprochene Semipermeabilität der Plasmaschlänche, welche durch die AnBenhant der Riibe noch unterstiitzt wird, ableiten.

Bei dem zur Zuckergewinnmng eingeleiteten Diffusionsprozeß werden die Plasmaschläuche durch Erhitzen der Riibenschnitzel abgetötet, worauf der Zucker leicht austreten kann.

Die Zuckerriibe enthält, wie versehiedene andere Chenopodiaceen, z. B. Chenopodium album, deutliche Mengen von Nitraten. welche mittels der Diphenylamin-Schwefelsäure-Reaktion leicht nachgewiesen werden können. Sie sind geeignet, die osmotische Saugkraft des Zellsaftes erhöhen zu helfen.

Infolge ihres spezifischen Saftgehaltes erfriert die Zuckerribe erst bei etwa $-5^{0} \mathrm{C}$, während die saftärmeren Blattstiele der Pflanze nur etwa $-3^{0}$ C ertragen.

Beziiglich der Vergärung des Zuckers sei auf die Kapitel Bakterien und Hefen verwiesen.

\section{Gruppe. Zucker, Stärke, fettes öl, Reservezellulose.}

Man kann mit gutem Girunde die Behauptung aufstellen, dab die Glukose (Traubenzucker), das Produkt der Kohlenstoffassimilation, für die Pflanzen, speziell die höheren, dieselbe Bedeutung hat, wie das Geld im menschlichen Leben. Aus Glukose verschafft sich die Pflanze mit spielender Leichtigkeit eine große Zahl wichtiger anderer Substanzen, wie Stärke, Rohrzucker, Zellulose*), Eiweiß usw. Die einzelnen Zucker, wie Glukose, Saccharose, Trehalose, Melicitose, Mannose, Xylose, Arabinose

*) Die Zellulose der Rottanne (Picea excelsa) liefert den Zellstoffabriken das wichtigste Rohmaterial zur Gewinnung der Zellulose für die Papierfabrikation; vgl. G. Sch w al be (1).

- Gute Watte ist Baumwolle, ebenso gutes Filtrierpapier. 
und andere mehr ineinander überzuführen, ist im gegebenen Falle für das Protoplasma eine Kleinigkeit.

\section{Versuch. Nachweis des Zuckers.}

Zum Nachweis des Zuckers können folgende, meist leicht zu beschaffende Objekte dienen:

1. Blätter vom Flieder (Syringa vulgaris) (getrocknet und zerkleinert). Das Material kann auch noch im Herbst gesammelt werden. Der Zucker wird zum Versuch in warmem Wasser ausgelaugt.

2. Mohrriiben (Daucus carota).

3. Küchenzwiebeln. Diese sind besonders geeignet, da man bei ihnen den Zucker nicht schon durch den Geschmack nachweisen kann. Die Zerkleinerung kann geschehen durch Schaben mit dem Messer, auf dem Reibeisen oder durch Zerkleinern durch die Zitronemreibe. Gelegentlich kommen ziemlich stark sauer reagierende Zwiebeln vor, bei denen der Zuckernachweis etwas schwieriger gelingt*).

Tulpen- und Hyazinthenzwiebeln (ungekeimt) enthalten Stärke statt Zucker.

4. Kartoffeln, in denjenigen Sorten, welehe süß sind. Sonst sind Kartoffeln hauptsächlich Stärkespeicher.

5. Äpel.

6. Birnen.

7. Pflaumen. An Backpflaumen kamn man den Zucker direkt sehen, da er die AuBenseite der Frucht als aschenartiger Überzug bedeckt.

8. Kirschen.

9. Weinbeeren und Rosinen.

10. Apfelsinen und Mandarinen. Die gleichzeitig vorhandene Säure pflegt die Reaktion nicht zu stören.

11. Kokosnüsse (Cocos mucifcra). Sie enthalten Trauben- und Rohrzucker.

12. Zuckerriben und Runkelriben. Sie enthalten vorwiegend Rohrzucker.

Der Nachweis des Traubenzuckers geschieht am einfachsten durch Feblingsche Lösung, deren blane Farbe sich durch Erhitzen über

*) Junge Oberhautzellen der Zwiebel (Allium cepa) eignen sich ausgezeichnet zum Demonstrieren des Zellkerns. Er ist so groß, daß man ihn in den Zellen abgezogener Häute im durchfallenden Licht mit einer 40 fach vergrößernden Lupe bereits gut erkennen kann. Junge Epidermiszellen der Zwielel lassen sich im mikroskopischen Gesichtsfeld besser überllicken als ältere, die wiederum leichter zu präparieren sind. Junge Zellen sind kurz und verhältnismäßig plasmareich, ältere langgestreckt und inhaltsarm. 
der Gasflamme oder Petroleumlampe mit der reduzierenden \%uckerlösung in Rot (Kupferoxydul) oder (iolb (Kupleroxydulhydrat) unwandelt.

Der Nachweis kamm auch mikroehemisch geschehrn. J)ie Fohlingsche Lösung besteht aus:

1. Kupfersulfat,

2. Kaliumnatriumtartrat (Seignettesalz),

3. Natronlauge

in bestimmten Grwichtsverhältnissen.

Sie kann in zwei stammlösungen unbegrenzt haltbar aufbewahrt werden, in den Teilen 1. und 2. +3 . Für 2. +3 . muß ein Gummistopfen auf die Flasche gesetzt werden, da rin Glasstopfen festbacken wïrde.

Beide Stammlösungen werden zu genan gleichen Teilen gemischt, wenn es sich $\mathrm{um}$ quantitative Bestimmungen handelt. $10 \mathrm{c} \times \mathrm{m}$ verbraucht Lösung entsprechen $0,05 \mathrm{~g}$ Traubenzucker. Fehlingsche Lösung ist in Apotheken vorsätig und känflich.

Ein anderes, wichtiges Verfahren, Glukose nachzuweisen, wenn sic in größeren Mengen vorhanden ist, besteht darin, daß. man möglichst dicken Saft, z. B. aus der Mohrribe, im Reagensrohr etwa 20 Minuten lang auf dem Wasserbade mit essigsaurem Phenylhydrazin erhitzt. Es bilden sich damn Kristallbiischel von gelbem, nadelförmigem Glukosazon, deren Form unter dem Mikroskop studiert werden kann.

Zur quantitativen Ermittelung des Zuckers in kleinen Fliissigkeitsmengen bei fast $0 \%-10 \%$ Konzentration (z. B. von ausgepreßten Pflanzensäften. Harn usw.) nach der Gärmethode dient das nebenstehend abgebildete Gärungssaccharometer von Theod. Lohnstein (D. R. G. M. Nr. 119945, Med. Woch. 1900, Nr. 14).

Die zu untersuchende Flüssigkeit wird unter Zusatz lebender Hefe in genau abgemessenem Quantum (z. B. $0,5(\cdot \mathrm{cm})$ an die Stelle $a$ gebracht und der kurze

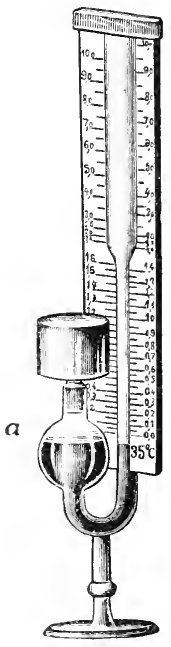

Abl). 13.

Lohnsteinsches Saccharometer zur quantitativen Bestimmung von Zucker in Fliissigkeiten. Schenkel dann verschlossen. Die bei der Vergärung des Zuckers boi $20^{\circ} \mathrm{C}$ oder $35^{\circ} \mathrm{C}$ entstehende Kohlensäure drückt das Quecksilber im Kugelschenkel herab, wodurch die Säule in dem langen, offenen Schenkel steigt; an den empirisehen Skalen, welche für die Gärungstemperaturen $20^{\circ}$ bzw. 350 C gelten. kamn damn der Prozentgehalt der Flïssigkeit an Zucker direkt abgelesen werden.

Endlich können quantitative Zuckerbestimmungen auch unter Anwendung von Polarisationsapparaten ausgeführt werden. wie es in der Zuckerindustrie geschieht. 
Ein sehr lehrreiches Objekt für Zuckernachweis ist die Cocos- NuB. (Man iiberzenge sich durch Schiitteln, daßs sie Milch enthält.) Zuerst bohre man mit Messer oder Schere den Keimporus heraus und lasse die Milch in ein Becherglas laufen. Hierauf kann man durch einige Hammerschläge die Nuß in freier Hand leicht in zwei Hälften zerlegen und das Fleisch für den Versuch entnehmen.

Man erhitze etwa 10 c'm Cocos-Milch mit ca. 1 c'm Fehlingscher Lösung bis zum Kochen (unter Vermeidung zu starken Stoßens der Fliissigkeit), wodurch sofort Rotlärbung eintreten wird. Beim ansgewässerten Fleisch der NuB gelingt diese Reaktion nicht, obgleich es ebenso wie die Milch siiß schmeekt. Das Fleiseh enthält nämlich Saccharose (Rohrzucker), die auf Fehlingsche Lösung nicht wirkt. Dieses Disaccharid muß erst in zwei reduzierend wirkende, rechts und links drehende Honosaccharide invertiert werden nach der Formel:

$$
\underset{\text { Rohrzucker }}{\mathrm{C}_{12} \mathrm{H}_{22} \mathrm{O}_{11}}+\mathrm{H}_{2} \mathrm{O}=\underset{\text { Traubenzucker }}{\mathrm{C}_{6} \mathrm{H}_{12} \mathrm{O}_{6}}+\underset{\text { Fruchtzucker }}{\mathrm{C}_{6} \mathrm{H}_{12} \mathrm{O}_{6}} \text {. }
$$

Die Inversion gesehieht in der Weise, daß mau den aus dem geschabten Fleisch der NuB. unter Zusatz von Wasser extrahierten zuckerhaltigen Saft einige Ninuten lang mit einigen Tropfen Salzsäure erhitzt und diese dann durch soda abstumpft. Hierauf tritt mit Fehlingscher Lösung cine Reaktion ein.

War die Cocos-Nuß noeh unreif, was verhältnismäßig selten vorkommt, so enthält auch das Fleisch Traubenzucker. Das gleiche ist der Fall, wenn das Fleisch stellenweise verschimmelt ist (durch Penicillium), weil Pinselschimmel an den Stellen seiner Entwicklung zur Inversion befähigt ist.

In gleicher Weise muß man invertieren, wenn man den Zuekernachweis in der Zuckerrïbe oder Runkelriibe führen will. Rohrzucker ist ïbrigens ein Körper, der im Pflanzenrelch weitverbreitet ist, da die meisten höheren Pflanzen ihn in geringerer Menge enthalten können, wenigstens in einzelnen Organen und in gewissen Vegetationsperioden. So enthält z. B. der im Frühling reichlich anftretende Birkensaft neben koagulierbaren Eiweißsubstanzen auch Rohrzucker.

Bei den Versuchen iiber den Nachweis des Zuekers hat man gute Gelegenheit, das Phänomen der sogenannten Brownschen Molekularbe wegung zu studieren. Es handelt sich dabei um die 1827 ron dem englischen Botaniker Brown gemachte Beobachtung. dab kleine, mbelebte Körperchen, welche im Wasser suspendiert sind, sich zitternd und wimmelnd hin und her bewegen, tanzenden Miickenschwärmen vergleichbar. Diese Erseheinung zeigen auch die Körnchen des roten Kupferoxyduls, die im vorliegenden Falle nicht mit kleinen lebenden Organismen durchmischt sein können, da die Fliissigkeit zuror gekocht werden mußte. 
Je kleiner die Köperchen sind, um so lebhafter ist die zitternde Bewegung, je größer sie sind, um so plumper. Die Bewegungen lassen nicht mit der Zeit nach, auBer wenn die Körnchen am Gilase festhaften. Ameh die Aufschwemmungen von chinesischer Tusche zeigen die Erscheinung bei starker Vergrößerung sehr schön, cbenso die Kriställehen in den Endvakuolen (Tanzstïbchen) von Closterinm.

Nach den Untersuchungen der Physiker, die sieh dabei zum Teil des Ultramikroskops bedienten, handelt es sich bei diesen Erseheinungen ım ganz dieselben Gesetze, welehe die molekularkinetische Theorie für die Molekiile in Lösungen annimmt. Mit steigender Temperatur scheint die Bewegung in dem Grade zuzmnehmen, wie es die kinetische Gastheorie erwarten läßt. Näheres vgl. man z. B. bei .l. Perrin (1).

Das Verhalten der lebenden, beweglichen Bakterien mnter dem Mikroskop ist ein wesentlich anderes. Während diese nämlich durch das Gesichtsfeld gehen, bleiben die der Brownsehen Bewegung unterliegenden Körper innerhalb eines engen Bezirks, wenn man Strömungen in der Flïssigkeit ausschließt.

Inulin beicompositen.

In den Knollen der Georgine (Dahlia rariabilis) und den Wurzeln vieler Compositen findet sich ein der stärke physiologisch verwandter Körper. Inulin, von der Formel $\left(\mathrm{C}_{6} \mathrm{H}_{16}\left(\mathrm{O}_{5}\right)_{x}\right.$, welcher in Alkoholmaterial in Form von farblosen Kugelkristallen ausfällt. Diese Kristalle färben sich durch Jod gelb.

\section{Versuch. Bildung von Stärke aus Zucker.}

Es ist allgemein bekannt, daß die neisten griinen Pflanzen, wenn sie einige Zeitlang im Dunkeln gestanden haben. frei von Stärke sind, auber wenn es sieh $10 m$ stärkespeichernde Organe handelt. Belichtet man sie wieder, so tritt von neuem Assimilation oin und ein Teil des dadurch produzierten Zuekers wird in Stärke umgewandelt. Benutzt man zu solchen Versuchen Spirogyra, so achte man darauf, eine solche spezies zu wählen, bei welcher das Verschwinden der Stärke im Dunkeln nicht zu lange dauert.

Die Auflösung der Stärke im Dunkeln wird begreiflich, wenn man bedenkt, daß wegen Aufhörens des Assimilationsprozesses im Dunkeln kein nener Zucker erzengt wird. Ersetzt man die Assimilation durch kïnstliche Zufuhr von Zucker, z. B. dureh Auflegen stärkefreier Blätter auf mehrprozentige Zuckerlösung (auch Glyzerin kann unter Umständen verwendet werden), so bildet sich Stärke auch im Innkeln. Bei diesen Versuchen handelt es sich um sogenannte Assimilationsstärke, deren Körner relativ klein sind. Der Nachweis kleiner Stärkemengen geschieht am besten nuter dem Mikroskop mit Hilfe von stark konzentrierter Chloralhydratlösung, die quellend wirkt, muter nachträglichem Zusatz von 
Jod-Jodkaliumlösung, wodurch Blaufärbung eintritt. Bei größeren Stärkekörnern genügt blober Zusatz von Jod-Jodkaliumlösung in nicht zu reichlicher Menge.

Die Reservestärke in den Knollen der Kartoffeln, Tulpen. Hyazinthen usw. ist natiurlich auch durch Umwandlung ans Tranbenzucker, der als Assimilationsprodukt in deu Blättern entstanden und nach den unterirdischen Organen abgeleitet ist, gebildet worden.

Unreife Weizenkörner u. a. m. schmecken noch siiß, weil der Zucker in ihren Speicherzellen noch nicht in Stärkemehl umgewandelt ist. Die

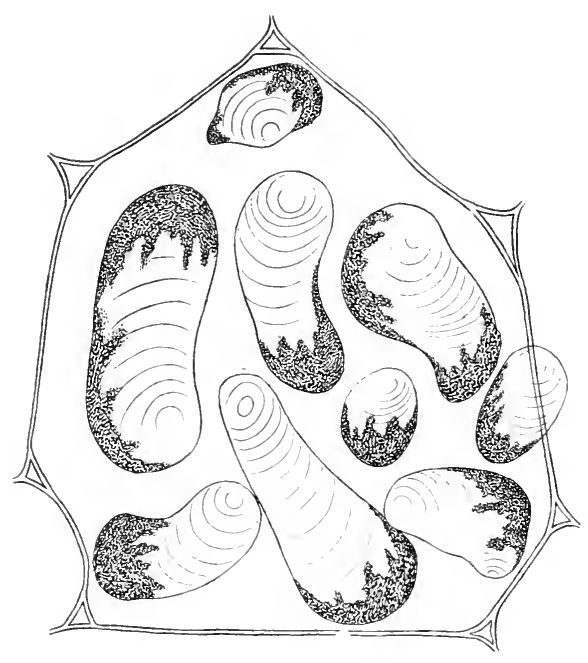

Abb. 14. Stärkekörner mit grünen Stärkebildnern, aus dem Stengel von Pellonia dazeanana. Vergr. mittelstark. (Orig., gez, nach A. Dodel.) von gequollenen Gerstenkörnern mitsamt dem Schildchen abpräparierten Embryonen enthalten anfänglich Rohrzucker, nach 3-4 Tagen kleine stärkekörner und zwar sogenannte transitorische stärke.

Jedes Stärkekorn bedarf zu seiner Entstehung rines eigenen Organs. des stärkebildners, der aber in den meisten laallen nur schwer zu sehen ist, besonders bei großkörniger Reservestärke.

Ein ausgezeichnetes ()bjekt zum Studium der Stärkebildner ist nach A. Dodel (1) die Urticacee Pellionia daveanana. Die Pflanze stammt ans Cochinchina und wird in den (iewächshäısern der botanischen Gärten gezogen, wo sie während des ganzen Jahres ohne besondere Pflege wuchert. Man fertigt Querschnitte durch die jungen Stengel an und betrachtet bei starker Vergrößerung die peripherischen Zellen. Man erkennt (hlorophyllhaltige Kuppen. welche den Stärkekörnern, die durch sie unter Bildung von schichten durch Apposition gebildet sind, aufsitzen, wie die Abbildung zeigt. Die Stärke körner werden durch Jodlösmng violett. Tgl. Florideen.

Man kann die Stengel in Wasser (nuter Zusatz von Formalin) im Dunkeln aufbewahren. Zur Herstellung mikroskopiseher Dauer- 
präparate können die Stengelquerschnitte in Glyzeringelatine*) eingelegt werden.

Sehr geeignet zum Studium der Stärkebildner sind auch die nicht zu alten Scheinknollen der Orehidee Phajus grandifolius (käuflich). Ferner werden die Rhizome von Iris germanica und I. pallida von Strasburger u. Koernieke (1) und A. Me yer (1) empfohlen.

Stärke (von zum Teil knochenförmiger Gestalt) wird anch in Milehsaftsehläuchen gebildet (neben Kautsehuk, Guttapercha, Harzen, ätherischen Ölen, Alkaloiden, Gerbstoffen usw.).

Beispiele für milehsaftführende Pflanzen finden sich in den Familien der Papaveraceae, Euphorbiaceae, Asclepiadaceac, Compositae usw.

\section{Versuch. Beobachtungen an der Kartoffel.}

Die Stärkebildner (Leukoplasten) in den Kartoffelknollen sind leider verhältnismäßig klein und deshalb sehwer sichtbar zu machen. Sie werden mit Säurefuchsin gefärbt; vgl. die Abbildung nach A. Zimmer$\operatorname{mann}(1)$.

Der chemische Nachweis der Stärkekörner durch Färbung kam makroskopisch geschehen. Nan schneidet die Kartoffel dureh oder nimmt

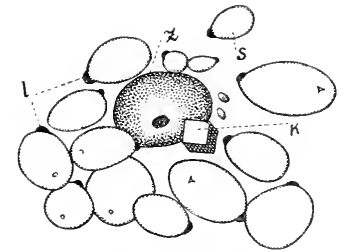

Abb. 15. Stärkebildner in der linolle der Kartoffel (Solanum tuberosum). Der abgebildete Zellinhalt stammt aus einer Parenchymzelle, welche wenige Schichten von der Korkhülle entfernt war. Fixierung mit SublimatAlkohol, Färbung mit Säurefuchsin. l Stärkebildner (Leukoplast); s Stärkekörner; $k$ Eiweißkristall: $z$ Zellkern. (Nach A. Zimmermann.)

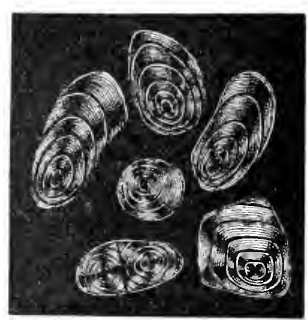

Abb. 16. Stärkekörner der Kartoffel im polarisierten Licht bei mittelstarker Vergrößerimg. (Orig.)

Stücke davon und betupft die Sehnittflächen mit wenig Jodtinktur oder Jod-Jodkahiumlösung. Diese färben die Schnittfläche roher Kartoffehn dunkel schwarzblau, diejenigen gekochter, bei denen die stärkekörner ge-

\begin{tabular}{|c|c|c|}
\hline Gelatine . & . & \\
\hline Wasser. & . & 42, \\
\hline Glyzerin . & . . & . 50 \\
\hline Karbolsäure & $\dot{.}$ & . $\quad 1$ \\
\hline
\end{tabular}

Glyzeringelatine kann käuflich bezogen werden. Mian halte sich für jedes Präparat ein Würfelchen davon bereit. Durch zu vieles Hineinstechen in eine kompakte Masse dieses Einbettungsmittels erhält man Luftblasen in den Präparaten. 
quollen sind, blau. Die gefärbten Körner auf den Schnitffächen roher Kartoffehn kann man im auffallenden Licht bei schwacher mikroskopischer Beobachtung deutlich sehen. Natiirlich kann der Nachweis auch rein mikroskopiseh' geschehen, wemn man die S'chnittflächen auf dem Objektträger unter Zusatz von wenig Wasser abtupft, wobei man die einzelnen Körner beobachten kann. Das Zellgewebe tritt nach dem Verquellen der Körner dureh Erwärmen des Objektträgers (iiber einem brennenden Streichholz oder einer Spiritusflamme) deutlich hervor.

Die achatartige, exzentrisehe Schichtung der einzehnen Stärkekörner ist nicht bei allen Kartoffelsorten*) gleich deutlich. Die Quellung der Stärkekörner mit allen Übergangsstadien beobachtet man am besten dadurch, daß man den Objektträger mit dem Präparat vor der mikroskopischen Betrachtung der Körner nur an einer Seite eshitzt. oder daturch, daß man den Vorgang des Quellens unter seinen Augen auf einem heizbaren Objekttiseh, den man auch provisorisch herstellen kann, verfolgt**).

Der physikalische Nachweis der stärke gesehieht mit Hilfe des Polarisationsmikroskops. Bei gekreuzten Nikols erscheinen die Stärkekörner, wie die Abbildung zeigt, auf schwarzem Gruncle weiß mit dunklem Kreuz. Dieses Kreuz wird bedingt durch die konzentrische Lagerung der doppelbrechenden Micellen zu den Polarisationsebenen. Für die Beobachtung unter dem Polarisationsmikroskop kömnen die Stärkekörner herausgeschabt oder in Schnitten betrachtet werden. Es kömmen Schnitte mit einem scharfen Taschenmesser geniigen, wemn man auf die Randpartien einstellt.

Säuren und Speichel wandehn die Stärke in Dextrin und bei weiterem Abbau in Zucker um.

Legt man schnitte dureh die Kartoffel zur Herstellung mikroskopischer Präparate in Glyzerin***) oder (ilyzeringelatine ein, so bleiben bei geeignetem Material die Schichten der Körner sichtbar.

\section{Versuch. Bildung von Zucker aus Stärke.}

Die Umwandlung der Stärke in Zucker bedentet eine Molekiilverkleinerung; es handelt sich aber weniger um einen Abbau- als um einen Umbildungsprozeß unter Anlagerung von Wasser (Hydrolyse).

*) Prüft man mehrere Kartoffelsorten durch, so fertige man auch durch die peripherischen Parenchymschichten Schnitte an, um in geeigneten Knollen würfelförmige EiweiBkristalloide (rgl. die obenstehende Figur und die Abbildung bei Ricinus) beobachten zu können.

**) Um trockene Stärke am Aufquellen zu verhindern, hedarf es nach Rodewald-Kiel eines Druckes von $2523 \mathrm{Atm}$.

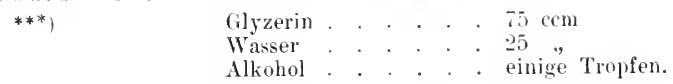

Abschließender Fand durch Goldsize, renetianisches Terpentin odes Kanadabalsam. 
1. $\left(\mathrm{C}_{6} \mathrm{H}_{10} \mathrm{O}_{5}\right)_{x}$ wirke $z u \mathrm{C}_{12} \mathrm{H}_{22} \mathrm{O}_{11}$ durchen I)iastase (intermediär können l)extrine entstehen).

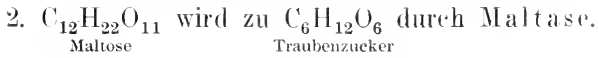

Vgl. v. Lippmann (1), O. Emmerling (1), Jos. Klein (1) ll. a. m.

Die hierbei wirksamen Fermente finden sich reichlich im Malzkorn, d. h. in Gerste, die in bestimmter Weise gekeimt hat und wieder getocknet ist. Man kann zu den Versuehen auch gequollene und eventuell wieder getrocknete Körner benutzen, ja selbst im ungequollenen Korn können sich geringe Mengen von Frrmenten finden. Der Hauptsitz der Diastase ist das Schildchen. mit welchem der Gerstenembryo dem Mehlkörper anliegt.

a) Man bereite unter Erwärmen eine sogenannte Lösung von gewöhnlicher oder käuflicher lösliches stärke und iiberzenge sich an einer kleinen Probe, daß diese Lösung, richtiger gesagt Pseudolösung. sich nach Jodzusatz dentlich blau färbt. Hierauf fiige man $10 \%$ Gelatine hinzu und gieße das Ganze in dünner schicht in ein Petrischälchen aus. (Vol. den Abschnitt über Bakteriologie.) l)ann sehneide man ein Malzkorn in einige Quer- oder Längsscheiben und lege ron diesen vier bis sechs auf die inzwischen erstarrte Gelatineschitht.

Die Schale bzw. Schalen stelle man unter eine cilasglocke und fïge ein kleines GefäB mit Chlor oform bei, dessen bämpfe sterilisierend wirken und dadurch die Entwicklung von Bakterien verhindern. während die Wirksamkeit der Diastase, welche aus den Schnitten in die Gelatine diffundiert, nicht beeinträehtigt wird. Nach Verlauf einiger Tage uiberschichte man die Gelatine mit Jodlösung. Man wird dann leicht erkennen, daß jedes Malzkornstiick von einem großen hellen Hof umgeben ist, während die ïbrigen Teile der Platte sich blan färben. In der Umgebung der Malzkornstïcke ist eben die Stärke in Zucker verwandelt worden, weshalb hier die Blaufärbung ansbleibt. Bisweilen bildet sich auBer dem hellen Hof noch ein mit Jod sich gelb färbender Ring, welcher daher riihrt. daß hier die Stärke erst bis zum Dextrin abgebaut ist (Methode nath IV. Beijerinek). Man kamn den Versuch auch unter Verwendung von keimenden Schimmelpilzsporen statt der Malzkornschnitte wiederholen.

b) Man zermahle Malzkörner in einer Kaffeemiihle und iibergieße das Pulver mit so viel Leitungswasser, daß ein nicht zu dicker Brei entsteht. Nach tiichtigem Durchschüteln wird abfiltriert und das die Diastase enthaltende Filtrat zu möglichst dümner, aber sich mit Jod noeh deutlich bläuender Stärkelösung gesetzt. Nach 5-10 Ninuten Einwirkung tritt nach Jodzusatz wegen Bildung von Erythrodextrin statt der Blau- eine Braunfärbung ein. Hier sei auch crwähnt, daß mit speichel durchfenchtetes Mehl sich nach einiger Zeit teilweise in Tranbenzucker umwandelt. 
(.) Man ziehe etwa 1-10 cm hohe Keimpflanzen vom Weizen (Triticum vulgare) oder von der Gerste (Hordeum vulgare) in Erde, Sägespänen, zwischen Watte oder zwischen Fließpapier. Die gekeimten Körner riechen wegen Bildung von Dextrin nach Gurke. Sie enthalten eine milchige Flïssigkeit, die sich leicht zwischen zwei Fingern auspressen läßt; man
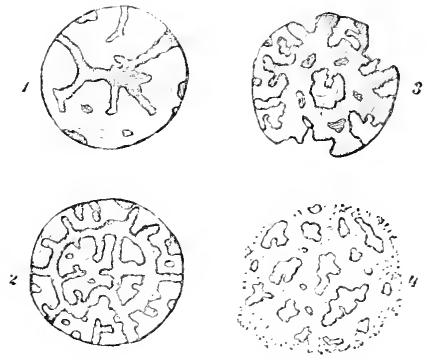

Abb. 17. Korrodierte Stärkekärner. aus dem gekeinten (ierstenkorn. I, 2, $3,+$ anfeinanderfolgende Stadien der durch Diastase erfolgenden Anflösung. wie sie sich neheneinander vorfinden. (Nach F. No 11.) kann sie auch ohne Wasserzusatz nach dem Ausdriicken direkt unter dem Mikroskop betrachten. Man sieht in ein und demselben Gesichtsfeld alle Stadien des Angriffs durch Diastase: angefressene, halbkorrodierte und fast zerfallene Stärkekörner (vgl. die Abbildung). Was durch die Fermente gelöst worden ist, ist zu Dextrin oder Zucker geworden. Die korrodierten Körner ähnehn, wie die Abbildung zeigt, Erbsen, welche durch Käfer angefressen sind. Im ungekeimten Korn findet sich natürlich keine korrodierte Stärke.

Es empfiehlt sich, nicht zu hohe Keimpflanzen zum Versuch zu wählen, weil sich allmählich Bakterien zwischen die Stärkekörner mischen und dadurch unter Umständen das Bild remer Diastasewirkung verwischen können.

Zu den Untersuchungen kann auch Alkoholmaterial verwendet werden.

d) Die Kotyledonen der Erbse sind voll von Stärke; ist dagegen erst eine etwa spamehohe Keimpflanze herangewachsen, so ist der Stärkegehalt nur noch gering oder gleich Null. Anch das spezifische Gewicht wird geringer, wovon man sich durch Hineinwerfen der Kotyledonen in Wasser iiberzeugen kamn.

Ungekeimte Zwiebeh der Hyazinthe und Tulpe enthalten Unmassen von Stärke, deren Henge mit dem Erscheinen der Blätter abnimmt, um nach dem Entfalten der Blüten ganz oder fast ganz zu verschwinden. Die Stärkekörner sind also in Zucker umgewandelt und dieser ist zum Aufbau der Pflanzen verwendet worden. Ber Umstand, daß ein Teil des Zuckers veratmet worden ist, soll hier unberiuksichtigt bleiben.

\section{Versuch. Umwandlung der Reservezellulose.}

Dir Reservezellulose wird nicht so wesentlich durch die chemische Natur als durelo die leichte Löslichkeit bei Einwirkung versehiedener Agentien gekemuzeichnet. Nan hat sie deshall, anch passend als Hemizellulose bezeichnet. 
Querschnitte durch die Kotyledonen ron Tropacolmm mains, der Kapuzinerkresse, zeigen, daß die Zellwände ziemlich dick sind und sich nach bloßem Zusatz von Jollösung blan färben. Solche Zellulose hat man anch als Amyloid bezeichnet. Derartige Quersehnitte rignen sich zn Dauerpräparaten.

Auch die Samen von Phoenix. Phytelephas (bildet Manmose), Allium, Coffea und viclen anderen besitzen heservezellulose, die sich aber durchaus nicht in allen Fällen nach Zusatz von Jodlösnng blan färht. Iie hauptsächlichste Eigenschaft dler Reservezellulose bleibt, wie gesagt, ihre leichte Löslichkeit.

Nach dem Auskeimen der Samen von Tropacolum wird man beobachten, daß die Zellen mur noch diinne Wände aufweisen, welehe sich durch Jodlösung nicht mehr blau färben; der größte Teil der Wand ist verzuckert und zum Aufbau des Keimlings verwendet worden.

\section{Versuch. Physiologie der Keimung von Ricinus.}

Was uns hier in Verfolg mnserer Disposition bei Ricinus an erster Stelle interessiert, ist das physiologische Verhalten seines Fettes bei der Keimmng. Durch den hohen Ölgehalt seines Samens $(70 \%)$ unterscheidet sich seine Keimungsgeschichte wesentlich von derjenigen der Gierste, Erbse nsw. Den Samen von Ricinus könnte man einen tierischen Samen nennen, demn er speichert Fott und Eiweiß wie die Tiere, besonders die höheren (z. B. im Hiihnorei), bei denen Zncker-oder Stärkespeicherung wohl kaum vorkommt.

Legt man einen trockenen samen von Ricinus (das Material ist in jeder Samenhandlung känflich) anf cin Drahtnetz und hält ihn solange in die Bunsenflamme, bis er brennt, so wird man leicht beobachten, dab. er nun von selbst weiter bremnt; oft schießen förmliche Flammenzungen unter starker Rubentwicklung hervor, und an manchen stellen quillt das siedende Öl heraus. Stärkehaltige Samen und reines Mehl, wenn man sie auf Platinblech oder auf einem Glimmerblättchen erhitzt, entwickeln bei gleicher Behandlung ruhig brennende, nicht rußende Flammen.

Man kann das (j) aurh mit Alkohol extrahieren, denn Rizinusöl gehört zu den wenigen in Alkohol löslichen Ölen. fettig an.

Beim Zerreiben zwischen den Fingern fühlt sich das Nährgewebe

Schnitte durch den trockenen samen oder Stïcke davon lege man auf einen Objektträger und setze konzentrierte Chloralhydratlösung hinzu; dann wird man das Öl seitlich in Nenge hervortreten sehen. Wie bereits bemerkt, löst es sich bei Zusatz von Alkohol auf.

Die Asche eines auf dem Drahtnetz verbramten Samens benutzen wir, um in ihr Phosphor nachzuweisen. Der Same wird in der Reibschale mit etwas Salpetersäme verieben, diese dann abfiltriert und nach Zusatz 
von Ammoninmmolyblat etwas erwärmt. Es lällt ein reichlicher, gelber Niederschlag rom molybdänphosphorsaurem Ammon. Phosphor ist gewöhnlicb ein Bestandteil der Reservematerial speichernden samen. läßt sich bei Ricimus dazu noch um so mehr vermuten, als die bekannten Globoide scines Endosperms (s. die Abbildung) phosphorhaltig sind. Wiirfelförmige Eiweibkristalloide sind im Kap. Kartoffel erwähnt.

Zum Keimen legt man die Samen ungequollen in fenchte lockere Sägespäne. Dieses Keimbett geniggt. da man höehstens fingerhohe Keimpflanzen für dic vorliegenden Versuche erzielen will. ( $\mathrm{rgl}$. die Abbildung). Es vergehen oft gegen 3 Wrochen, bis die Pflänzchen hervorbrechen.

Beim Keimen kommt, wie gewöhnlich. zuerst die Wurzel aus dem samen hervor. Hat sie mit dem Hypoketỵl eine Länge von 6-8cmerreicht, so treme

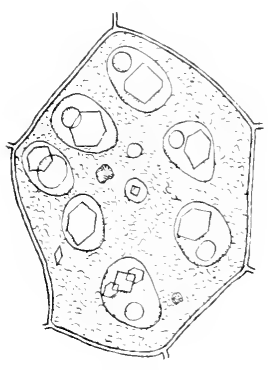

Abl. 1s. Zelle aus dem $\mathrm{N}$ ährgewebe (Endosperm) vou Ricinus communis. Die sieben großen Aleuronkörner enthalten Eiweißkristalle und phosphorhaltige Glohoide.

(Nach E. Strasburger.)

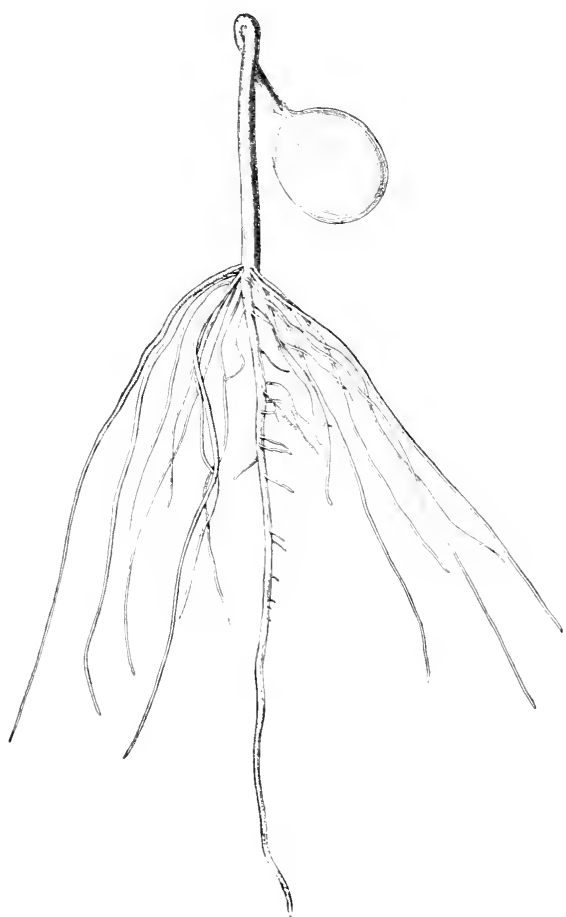

Abb. 19. Keimpflanze ron Ricinus communis. Nat. (ir. (Nach W. Detmer.)

man das Cianze an der Basis ab, zerhacke es, bringe es mit etwas Wasser in ein Reagensglas und koche es getinde aus. Lie Fohlingsehe Probe wird reichliche Mengen rom Zueker anzeigen. Ahuliches ist bei den ölhaltigen samen des Kiirhis (Cucurbita pepo) and denen der Kïchenzwiebel (Allium cepa) zu beobatehten. Wieser Zurker ist aus dem fotten Öl entstanden. Stärke ist. wio bereits betont. im mogekeinten samen 
von Ricimus niemals vorhanden, ebensowenig natiulich Zucker, deshall, bleibt anch die Fohlingsche Probe mit ungekeinten samen gesultathos.

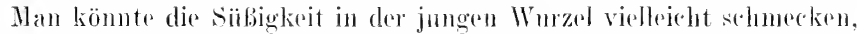
wenn nicht gleichzeitig Bitterstoffe vorhanden wären. Während die Wurzel auf etwa Fingerlänge answäehst, fällt der Ölgehalt im samen, bezogen auf Trockensubstanz, von 70\% anf $6 \%$, während der Zureliergehalt von $0 \%$ anf $32 \%$ in der Pflanze steigt [vgl. Leclere du Sablon(1)].

Jie beiden kotyledonen der gekeinten samen bleiben einstweilen noch im Endosperm stecken ( $v$ gl. die Abbildung) und nehmen aus diesem das 0 l auf. Sie besitzen noch keine Spaltöfnumgen. Die Oberhant ist, entsprechend ihrer Funktion als Aufnahmeorgan, sehr zart. Demzufolge vertrocknen die Kotyledonen in 10-15 Minnten, wenn man sie heranstrennt und frei liegen läßt.

Der ans dem (i) entstandene Zucker kann sich in der l'flanze teilweise zu transitorischer Stärke umwandeln. Wir finden solehe sehr reichlich im Hypokotyl, besonders in der sogenannten stärkescheiae, wo die Stärkeanch mit Jocllösung, am besten nach vorheriger Quellung durel Chloralhydrat, leicht nachuweisen ist.

Mit dem Öl nimmt anch das gespeicherte Eiweib, wolches in großer Menge in Form von Nonronkörnern vorhanden ist, beim Keimprozel, im Samen ab.

Das Vorhandensein von Eiweib läbt sich dureh zwei cinlache chemische Reaktionen leicht nachwrisen. Nit Millons Reagens*), das man ohne Zusat\% von Wasser cinwirken läßt, werden Schnitte durch den trockenen samen, die dick sein können, oder stiicke davon in der Kälte langsam, in der Wärme schmell ziegelrot, zerriebene Partien mit Fehlingscher oder ähnlich zusammengesetzter Lösung violett (BiuretReaktion).

Eine dritte Reaktion ist die Xanthoprotëin-Reaktion, bei der durch konzentrierte salpetersänre und nachfolgenden Zusatz von Ammoniak orangerote Färbung eintritt.

Ist die Wurzel erst etwa fingerlang, dann sind die Alenronkörner aus dem Endosperm verscliwndien, wenigstens an den Stellen, wo dieses etwas wässerig erscheint: zuletzt enthält das Endospern, da es ausgesogen wird, weder Öl noch Alenronkörner.

Durch welche Mittel diese Körner bei der Keimung der Samen von Ricimus gelöst werden, ist noch unbekannt. Man könnte an Pepsin, das Magenferment, oder an Trypsin, das Ferment der Banchspeicheldrise, denken. Beide sind im Rizinussamen bisher aber nicht nachgewiesen worden. Dabei ist zu bemerken, daß Pepsin (als Pulver käuflich) im Innern von Geweben kaum vorkommt, weil es aner zu großen Menge von Sänc"

*) Eine Lösung von Quecksilbernitrat, welche freie Salpetersäure und salpetrige Säure enthält. 
(1/3\% Salzsäure) bedarf, mm wirken zu können. (Die käufliche konzentrierte Salzsäure hat meist ein spezifisches Gewicht von 1,124, enthält also etwa $25 \% \mathrm{HCl}[\mathrm{vgl}$. W. Behrens (1)]. Wo Pepsin im Pflanzenreich beobachtet ist, wird es nach a u Ben abgeschieden, z. B. beim Somnentau (Drosera) und der Kamnenpflanze (Nepenthes). Das Trypsin (enthalten in dem in den Apotheken käuflichen Pankreatin) wirkt am besten in alkalischer Lösung $(0,5-1,5 \%$ Soda $)$. Es findet sich sehr häufig bei Hefen und Bakterien und verflüssigt, wie das Pepsin, die Gelatine; vgl. P. Lindner (1) und W. Pfeffer (1), S. 511.

Wie Diastase auf Stärke, so wirkt also Pepsin oder Trypsin auf Eiweiß.

Dir Vorgänge beim Transport des Öles in der keimenden Pflanze beanspruchen ganz besonderes Interesse. Es ist hinlänglich bekannt, daß die meisten Öle aus Glyzerin und Fettsäure bestehen. Sie könmen in diese beiden Komponenten leicht zerspalten werden; man spricht dann von Ranzigwerden des Öles. Im tierischen Körper besorgt ein Ferment des Pankreassaftes diese Spaltung, im Pflanzenreich sind solche fettspaltenden Fermente anBer bei Ricinus u. a. m. noch bei Bakterien beobachtet worden; vgl. W. Benecke (1), C. Flïgge (1), R. H. Sehmidt (1) und W. Pfeffer (1), S. 510.

Alles Öl, welches als solches wandern soll, muß vorher fein zu Tröpf(hen zerteilt (emulgiert) werden. I)ieser höchst lehrreiche Emulsionsprozeß ist ohne Fettzerspaltung und gleirhzeitige Alkaleszenz nicht möglich. Er vollzicht sich folgendermaßen: Zunächst wird durch ein Ferment oder durch die Tätigkeit des Plasmas ein Teil des Fottes in Glyzerin und Fettsäure zerspalten. Das Glyzerin ist für unsere Betrachtungen unwesentlich, die Fettsäure aber sehr wichtig, denn sie verbindet sich mit dem Alkalikörper (der sich z. B. im Plasma befinden kann) zu einem Salz (Seife). Dieses bewirkt infolge der veränderten Oberflächenspannung ein Auflösen der Fettmasse in kleine Kügelchen, der en je de von einer feine n Se if e $n$ me m br a n umgeben ist.

Um diesen Prozeß zu demonstrieren, verfahre man folgendermaßen: Man vermische Rizinusöl, 11 es ranzig zu machen, mit nicht zu wenig käuflicher, gewöhnlicher ölsäure und bringe davon einen Tropfen auf den Objektträger; daneben trage man eine kleine Menge ca. $1 / 3 \%$ iger Sodalösung anf und bringe beide Fliissigkeiten zur Beriilnung. Betrathtet man dann die Berïhrungszone unter dem Mikroskop, ohne ein Deckgläsehen aufzulegen, so wird man in günstigen Präparaten schr schön das Abschnüren der feinen Öltröpfehen wahrnehmen und somit den Enulsionsprozeb in anschanlicher Weise sich in seinen Feinheiten direkt abspielen sehen. Durch das Hinzufügen freier Ölsäure ist die Tätigkeit des ölspaltenden Fermentes ersetzt worden; mit nicht ranzig gemachtem Rizimnsöl wiirde der Versuch mißgliiclisen.

Ol, num in der Pflanze die feinen Öltröpfehen als solehe von Zelle zu Zelle wantorn oder in ihre Komponenten zerlegt und damn wieder rekon- 
struiert werden, ist mongwiß. Sicher ist aber, dab das Ö ziemlich sehmell von Zelle zu Zelle befordert wird [rgl. W. Pfeffer (1). S. 85)]. Yon den nackten Plasmodien der Nyxomyceten wird (j) leicht anfgenommen.

Um das Wandern des Gles in der l'flanze zu demonstrieren. mache man an einer an sich öfreien Krimptlanze einen Einschnitt nnd ziehe nach R. H. Schmidt einen nit Handelöl getränkten Streifen Fließpapier hindurch. Nach einigen Tagen kann man dann massenhaft (i) in den Kellen mittels Osmiumsäure, besonders beim krwärnen, nachweisen.

Glyzerin konnte beim Wandern der Fette in den Pflanzen bisher nicht nachgewiesen werden, wohl aber freic sänre. Offenbar wird das Glyzerin zur Bildung von Zucker verbraucht. Beim Fauden ölhaltiger substanzen scheinen die Verhältnisse ähnlich zu liegen.

Zum Schluß sei noch erwähnt, daß das Rizinusöl an sich für Menschen und Tiere nicht giftig ist, wohl aber das darin ruthaltene Toxalbumin Ricin, von dem schon winzige Spuren ein Meerschweinchen töten könuru.

Beziiglich spezialliteratur sei verwiesen auf: Jul. Sachs (2 1. 3), van Tieghem (1) und M. E. Mesnatd (1).

\section{Gruppe. Eiweiß.}

In den Pflanzen finden sich gelöste und ungelöste Eiweißsubstanzen. Zu den letztgenamnten gehören teils tote Zellbestandteile (z. B. Eiweißkristalloide), teils lebende (Protoplasma).

\section{Versuch. Gelöstes bzw. pseudogelöstes Eiweiß.}

Man zerreibe auf einem Reibeisen rohe Kartoffeln und filtriere den Saft klar ab. Beim Erhitzen koaguliert reichlich darin enthaltenes Eiweiß (Rotfärbung mit Nillons Reagens).

\section{Versuch. Ungelöstes Eiweiß.}

Kotyledonen ungekeimter Erbsen färben sich, hauptsächlich wegen ihres reichlichen Gehaltes an Alemonkörnern, auch ohne Erhitzen intensiv rot mit Millons Reagens. Während des Austreibens der Keimpflanzen nimmt, wie die Reaktion lehrt, der Eiweißgehalt der Kotyledonen mehr und mehr ab. Neben der Millonsehen Probe kann man auch die Xanthoprotëin-Reaktion anwendon (vgl. S. 39 ).

\section{Versuch. Reaktion des Eiweißes.}

Eiweiß an sich diurfe im allgemeinen neutral reagieren, doch sind ihm häufig gelöste Salze beigemischt, welche Alkaleszenz verursachen; auch das Plasmodium der Schleimpilze reagiert, soweit bekannt, alkalisch. In den Blüten vieler Borraginaceae steht das Protoplasma mit saurem roten oder alkalischem blauen Zellsaft in Beriihrung. 
Zu Versuchen werde das leicht zu beschaffende Hiihnereiweib verwendet. Ileses reagiert auf Lakmus alkalisch. Wird das Hiihnereiweiß in einem Pergamentpapierschlauch unter der Wasserleitung 24 Stunden lang dialysiert, so diffundieren die alkalischen Salze heraus, das zuriekbleibende Eiweib reagiert neutral und seine Koagulation tritt bei etwas niedrigerer Temperatur ein.

Trockene Samen der weiben Bohne geben schwache amphotere Reaktion, wemn man sie quer durchschneidet und auf fenchtes Lakmuspapier legt. Hiese Reaktion wird wie in der Milch offenhar durch Phosphorsalze be dingt.

\section{Versuch. Die Synthese des Eiweißes.}

Man kultiviere höhere griine Pflanzen, z. B. Mais (Zea may's) oder Buchweizen (Polygonum fagopyrmm), in K nopscher Nährlösung:

Wasser, destilliert (oder aus der Leitung). . . 1 l

Kalziumnitrat . . . . . . . . . . . . $1,0 \mathrm{~g}$

Monokalimphosphat . . . . . . . . . . $0,25 \mathrm{~g}$

Kalimmitrat. . . . . . . . . . . $0,25 \mathrm{~g}$

Kaliumcblorid . . . . . . . . . . . . . . . $0,25 \mathrm{~g}$

Magnesiumsulfat . . . . . . . . . . . . . $0,25 \mathrm{~g}$

Eisenchlorid . . . . . . . . . . . . cinige Tropfen

[vgl. auch Detmer(1).]

Bei diesen Versuchen wird als Stickstoffquelle Nitrat geboten. während der Zucker von den Pflanzen selbst durch Lnfternährung synthetisch hergestellt wird. Es wird demnach folgende Synthese vollfiihrt:

Nitrate + Glukose = Eiweib.

Ähnliche Versuche lassen sich mit Hefen und Schimmelpilzen anstellen, woriber in den einschlägigen Kapiteln nachgelesen werden mag. Synthetisicrt werden durch diese zn Eiweib:

1. Weinsaures Ammon + Glukose.

2. Doppeltphosphorsames Ammon + Glukose.

3. Salpetersaures Ammon + Rohrzucker.

4. Asparagin + Rohrzucker.

Eine Synthese des Eiweißes durch Asparagin + Zucker kann auch bei höheren Pflanzen stattfinden. z. B. bei Lupinus.

Un das Asparagin zum Auskristallisieren zu bringen, lege man etwa fingerlange Keimpflanzen von Lupinus albus in starken Alkohol. Nach längerer Zeit findet man dann die Kristalle auf der Oberfläche der hỵpokotylen Glieder in Form von niedrigen Prismen, die man in der Regel unter dem Mikroskop rollen muß, um die rhombisehen Flächen zu sehen. Bezüglich der Reaktionen auf Asparagin sei verwiesen auf $\mathrm{A}$. Zimmermann (1).

Rhombische Tafeln erhält man bisweilen. wenn man käufliches Asparagin im Reagenzrohr mit wenig Wasser löst und durelh starken Alkohol wieder fällt. l)ie Bildung der Kristalle wird dureh Roiben mit einem Gilasstabe an der Wrand hegiinstigt. 
Die Synthesen des Eiweibes sind (unmittelbar) vom Licht unahhängig.

Höchst bemerkenswert sind die EiweiBsynthesen ams $\mathrm{NH}_{3}$, ('(), und $\mathrm{H}_{2} \mathrm{O}$ durch Salpeter- und wohl anch Schwefelbakterien, von denen später noch die Rede sein wird, und die bakteriellen Prozesse, durch welche die Eiweißmolekïle wieder in ihre einfachsten, anorganischen Bestandteile zertrïmmert werden. Übrigens pflegt anch im stoffwethsel der höheren Pflanzen neben der Bildung von Eiweiß auch eine fortgesetzte weitgehende Zerstückelung der Eiweißmoleküle vorzulommen.

\section{Gruppe. Atmung.}

Die Atmung ist ein AbbauprozeB, durch welchen bei den Pflanzen sowohl wie den Tieren zur Gewinnung von Betriebskraft organische Stoffe oxydiert (verbrannt) werden. Bei manehen Bakterien ist anch eine Oxydation anorganischer Verbindungen (mineralische Atmung) an stelle der gewöhnlichen Atmung festgestellt worden.

Die normale Atmung der höheren Pflanzen ist ein der Kohlenstoffassimilation entgegengesetzter Proze . Sie verläuft nach der Formel:

$$
\underset{\text { Traubenzucker }}{\mathrm{C}_{6} \mathrm{H}_{12} \mathrm{O}_{6}}=6 \mathrm{CO}_{2}+6 \mathrm{H}_{2} \mathrm{O} \text {. }
$$

Über den Prozeb der Gärung vgl. man den zwoiten Tril des Buches.

Die Atmung findet bei Pflanzen wie bei Tieren Tag und Nacht statt, in chlorophyllführenden Organen der Pflanzen wird sie aber im Licht dureh die Assimilation, die starke Sauerstoffproduktion bedingt, verdeckt.

Fänden beide Prozesse bei chlorophyllhaltigen Gewächsen mit gleicher Intensität statt, wiirden sie sich gerade aufheben. Da aber am Tage die Assimilation meist weit iiberwiegt, was der Assimilationsversuch mit Indigo beweist, so wird Stärke und Zucker erzengt. In der Nacht wird dann der am Tage gebildete Zucker teilweise wieder abgebant.

Nur die grünen belichteten Pflanzenteile assimilieren unter Sanerstoffabscheidung, während alle lebenden pflanzlichen sowohl wie tierischen Organe atmen. Deshalb wählt man zum Nachweis der Atmung mit Vorliebe nichtassimilierende, d. h. nicht grïne Objekte, also Samen, Blüten, Wurzeln oder dergleichen.

\section{Versuch. Nachweis der Kohlensäureausscheidung.}

Ein längliches Zylinderglas mit Glasdeckel wird auf otwa ein Drittel bis ein Halb nit gequollenen Gerstenkörnern (Hordeum), Klecsamen (Trifolium), Rïbsen (Brassica), Keimpflanzen von Lupinus, Keimpflanzen der Gerste oder des Weizens, wie sie bei den Beobachtungen ïber korrodierte Stärke abfallen, Elodea-Stengeln, kräftigen Riibenblättern oder dergleichen angefüllt, versehlossen und ins Dunkle gesetzt. Nach etwa einem Tage hat sich das Gefäß infolge starker Atmung des Pflanzenmaterials reichlich mit 
Kohlensäure gefült. Nan setze 2-3 Versuchsgefäße an. Hält man ein bremnendes streichholz (Pinzette!) hinein, so erliseht dieses sogleich.

Weiter fülle man cin kleines Becherglas etwa $1 \mathrm{~cm}$ hoch mit konzentrierter Barytlauge, die man in einer Flasche von 1/2-1 1 Inhalt vorrätig halten kann. (Zur Vermeidung des Festsetzens des Stöpsels klemme man einen Streifen Flic Bpapier ein oder bestreiche den Stöpsel mit Vaseline: Kristalle am Boden!) Gießst man mun die schwere Kohlensäure in das Becherglas iiber, so tritt sogleich eine starke, weißlich-trïbe Verfärbung der Lauge infolge Bildung von Baryumkarbonat ein, wodurch die reichliche Bildung von Kohlensäure ebemisch nachgewiesen ist..

An dieser Stelle seien einige lehrreiche Experimente erwähnt, die an dem vertieften Vorraum der Dunsthöhle des Bades Pyrmont, welche Kohlensäure enthält, gezeigt werden.

1. Steigt man einige Stufen herab, so stellt sich das Gefiihl des Erstickens ein.

2. Seifenblasen bleiben längere Zeit an der Beriihrungsstelle zwischen Kohlensäure und Luft freischwebend stehen.

3. Ein glimmendes Strohbiischel crlischt, wemn man es in die Kohlensäureschicht eintaucht.

Bei ungekeimten, trockenen Samen (z. B. der Gerste) ist die Atmung äuberst gering. so claß sie kein leicht nachweisbares Quantum Kohlensäure ausscheiden; $1 \mathrm{~kg}$ lufttrockene Körner produziert in 24 Stunden 1.5 mg Kohlensäure. [Versuchsordnung s. bei R. Kolkwitz(2).] Bei Veratmung von Zucker ist das Volumen verbraurhten Sauerstoffes gleich dem der produzierten Kóhlensäure, so daß in dem Versuchsgefäß kein Überdruck entsteht.

Bei Mangel an Sanerstoff tritt keine Keimung ein, da dem Samen dann die zum Wachsen nötige Betriebskraft fehlt; er erstickt. Den Beweis hierfür rrbringt man dadurch, daß man Samen in dïnner Wasserschicht mit Paraffinöl oder dergl. ïberschichtet.

\section{Versuch. Nachweis des Sauerstoffverbrauches.}

Aus den Versuchen der ersten Gruppe hatten wir ersehen, daß eine entfärbte Lösung von Indigokarmin durch assimilierende Pflanzen infolge von Sanerstofferzengung seitens der grïnen Organe blan wird. Da die Atmung den genau umgelsehrten Prozebs der Assimilation darstellt, so wird bei Dunkelversuchen die blaue Fliissigkeit infolge des Sauerstoffrerbrauches farblos.

Man fuille in eine otwa 100 ecen fassende Flasche bis oben hin eine schwach blaue Indigokarminlösung oder Methylenblaulösung. bringe lebhaft atmende griine Pflanzenteile, Keimpflanzen oder gequollene Samen hinein, versehliebe dicht und stelle die Flasche ins Dunkle. Je nach der lntensität des Sanerstoffverbranches wird die Fliissigkejt nach kiirzerer oder längerer Zeit entfärbt. Giebt man solche entfärbte lösung in rine Porzellanschale, 
so färbt sie sich infolge des Luftzutrittes sogleich wieder blan. I)ie Farbstoffe werden in ihre Leukoverbindungen umgewandelt, sobald der im Wrasser gelöste freie Sauerstoff verbraucht ist.

Methylenblau wird auch von Chemikern zum Narhweis der Sauerstoffzehrung im Wasser bemutzt.

\section{Versuch. Intramolekulare Atmung.}

Bei Mangel an Samerstoff bleiben höhere Pflanzen auch im Dunkeln noch eine Zeitlang am Leben (keimen aber nicht) und atmen damn intramolekular, d. h. sie nehmen, theoretisch gesprochen, den zur Atmung nötigen Sauerstoff aus Verbindungen und spalten Kohlensäure ab, ähnlich als ob sie normal atmeten.

Fïllt man ein (wie für die normalen Atmungsversuche verwendetes) Gefäß fast bis oben mit gequollenen Samen, mit Bliiten, Blättern oder dergleichen und verschließt es, so intsteht bald ein Überdruck, da nach Verbrauch des noch vorhandenen sauerstoffs Kohlensäure nach wie vor produziert wird und naturlich zu einer Volumen- bzw. Druckvergrößerung fiihrt.

Bei der intramolekularen Atmung wird neben Kohlensäure auch etwas Alkohol gebildet.

Über Gärung und anaerobes Wachstum s. spätere Kapitel.

\section{Versuch. Wärmebildung bei der Atmung.}

I) die Atmung ein der Verbrennung vergleichbarer ProzeB ist, führt sie zur Wärmebildung. Experimentell verfährt man in der Weise, daß man einen großen Trichter mit reichlichen Mengen keimender Samen (z. B. Gerste oder Weizen) anfïllt und in die Masse ein Thermometer steckt. Dieses wird eine Temperaturerhöhung mm einige Grade anzeigen, welche nicht das Produktvon Quellungswärme der Stärke ist, sondern durch intensive Atmung bedingt wird. Ein geringer Teil der Temperaturerhöhung kann unter Umständen auch durch die Wirksamkeit etwa reichlich vorhandener Bakterienmengen bedingt sein. Bedentende Temperaturerhöhung entsteht in dem Blütenstand von Arum maculatum*) u. a. m., wemn bei der Blütenreife die Stärkemassen in der Keule verarbeitet werden; vgl. E. Leick (1 u. 2).

Die Blïten von Soldanella bilden so viel Wärme dab sie Eis schmelzen und dieses durchdringen kömnen, wie die umstehende Abbildung zeigt.

Ahnliches kann man beobachten, wenn man anf eine sich entfaltende Blattknospe ein Stiuckelien Eis legt. Dieses schmilzt, anch wenn die umgebende Luft eine Temperatur von $-1^{0} \mathrm{C}$ besitzt.

Abgesehen von besonderen Beispielen ist aber das thermische Verhalten des Pflanzenkörpers, verglichen mit der seitens des Körpers höherer Tiere erzengten Wärme, wenig bemerkenswert. Infolge von Verdunstung kann sich eine Pflanze sogar kiihl anfiihlen.

*) Findet sich in der Sammlung Brendelscher Modelle. 
Bezuiglich thermischer Erwägungen iiber den Atmungsprozeß sei bemerkt, daß es sich nach den Studien von W. Palladin bei der aeroben Atmung um einen kompliziert verlaufenden Oxydationsprozeß handelt, in dessen Phasen Wasserstoff und Atmungspigmente eine Rolle spielen sollen. Die anaerobe A tmung und die Gärung scheinen gleichsam nur Ausschnitte aus diesem komplizierten Prozeb zu sein.

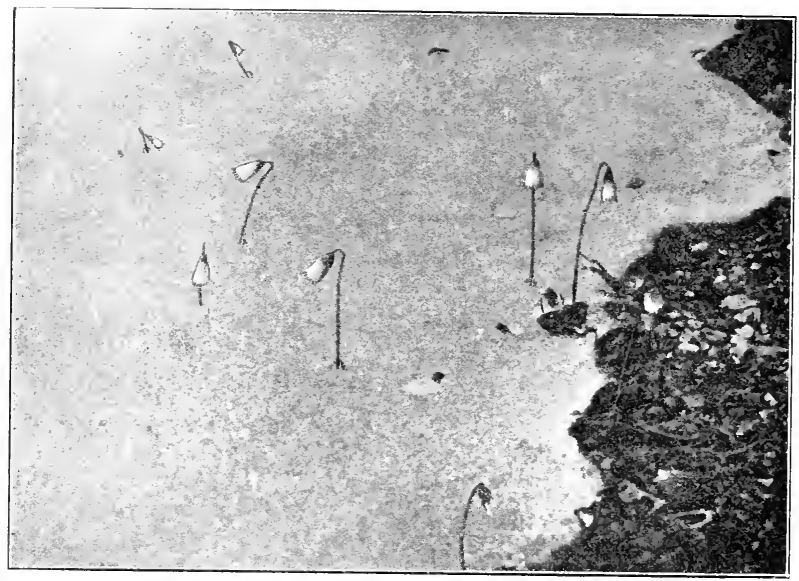

Ab. 20. Blïten der Primulacee Soldanella pusilla, welche mittels Atmungs. wärme eine Eisdecke durchschmolzen haben. Von der Pastura di Lagalb beim Berninahospiz, lei $2500 \mathrm{~m}$ am 2. August 1910 aufgenommen. Bei den Blüten an der linken Seite ist das Eis $4 \mathrm{~cm}$ dick. (Nach E. R ï bel.)

Zusammenfassme: An dieser Stelle mag noch einmal kurz darauf hinge wiesen sein, dal.s nach unseren Versuchen der in Rede stehende Stoffumsatz der Pflanzen sich in folgender Weise abspielt: Zuerst sahen wir, wie aus der Kohlensäure Zucker entsteht und wie die osmotischen Prozesse in der Pflanze wesentlich durch clas Vorhandensein von Zncker bedingt werden. Dann behandelten wir die Umwandlung des Zuckers in Stärke, (j), Zellulose usw.

Endlich erkannten wir, daß Zucker ein wesentlicher Bestandteil bei der Eiweißsynthese ist und schlossen dann mit dem Kapitel Atmung, durch welche die anfgebauten Moleküle schlieBlich wieder bis zur Kohlensäure, dem Ausgangspunkt unserer Betrachtung, zertrümmert wurden.

\section{Saprophyten und Parasiten.}

Im Anschlub an die vorstehenden Darlegungen sind im folgenden anhangsweise einige Beispiele von ernährungsphysiologiseh bemerkenswerten 
höheren Pflanzen zusammengestellt, welche ihre organischen Nälrstoffo ganz oder zum Teil von a ben beziehen, also nicht a utotroph ${ }^{1}$ ), sondern mixotroph*) oder heterotroph*) sind.

1. Ganz-Saprophyteri (sind chlorophyllfrei).

Coralliorrhiza imata (Urchidaceae),

Epipogon gmelini (Orchidaceac),

Bumania, den Orehidaceac nahestehend, meist tropiseh.

Triuris, wohl den Butomaceae nahestehend, tropisch,

Monotropa (Pirolaceae),

Sarcodes (Pirolaceae),

Voyria (cientianaceae)。

Ler saprophytismus wind in den vorliegenden Beispielen meist durch llycorrhizen erleichtert. Die mit ektotropher Mycorrhiza versehenen feinen Endfasern der Wurzen von Fagus silvatica und Pinus silvestris (vgl. Knys Wandtafehn, Nr. 116) eignen sich in toto zu mikroskopischen Daucrpräparaten. Unstehend ist die endotrophe Mycorrhiza in einer tropischen Orchidee abgebildet.

Hierher rechnen anch viele Pollenkörner der Bliitemptlanzen die freilich nur Teilsticke höherer Gewächse sind), soweit der in ihnen gespeicherte Vorrat zur Bildung der Pollenschäuche nicht ausreitht. Pollen vou Narcissus psendonarcissus oder $N$. tazetta keimt sehr gut in ca. 21,2\% iger Rohrzuckerlösung in einer Stunde. Es können Daterpräparate in Glyzerin oder Gilyzeringelatine angefertigt werden.

2. Halb-Saprophyten (enthalten ('blorophyll).

Neottia nidus avis**) (Orchidaceae), kömnte in bezug auf clen Mycorrhiza-Pilz wohl auch als Halb-Parasit bezeichnet werden, Sarracenia purpurea (Sarraceniacear),

I)arlingtonia californica (Sar raceniaceae),

Nepenthes destillatoria (Nepenthaceae),

Dionaea muscipula (Iroseraceae),

Aldrovandia vesiculosa (I) roseraceae),

Drosophyllum lusitanicm (D)oseraceae),

Urosera rotundifolia***) (s. Abbild.) (Droseraceac),

Pinguicula rulgaris (Lentibulariaceae),

Utricularia vulgaris (Lentibulariaceae) u. a. m.

*) autos = selhst, heteros $=$ anders,

mixos = gemischt, trophe $=$ Nahrung.

**) Eine Abbildung des Wurzelstockes von Neottia und der zugehörigen Mycorrhiza findet sich bei L. Kny und W, Magnus, Wandtafel Nr. 117.

***) Legt man auf Exkursionen Blätter von Drosera in eine Planktonkammer, so kann man die Schleimahscheidungen au Kopf der Tentakeln mit Lupen selır gut erkennen, mit 40 fach vergrößernden sogar die einzelnen Zellen der Tentakeln. 
Die Samen der meisten Orchidaceae keimen nur in Symbiose mit bestimmteu Fadenpilzen auf Ioos, Banmrinde, Löschpapier usw. Zur Orientierung diene die nebenstehende Abbildung nach H. Burgeff (1). Bei vielen unserer heimischen Orchideen sind Mycorrhizen beobachtet worden.

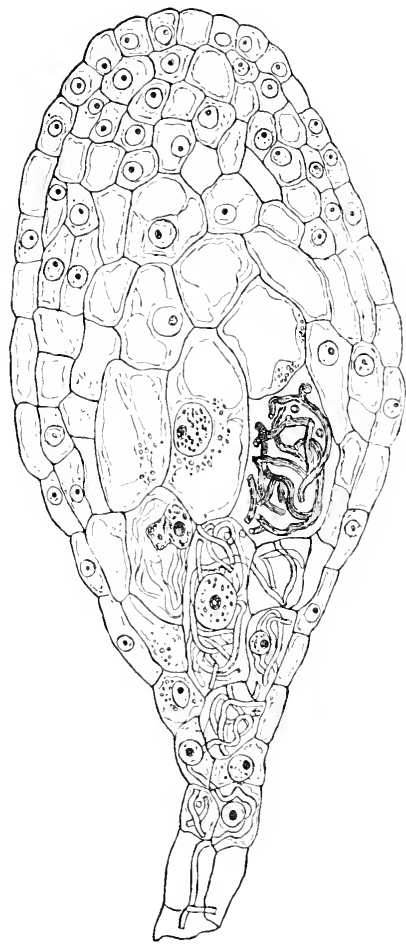

Abl. 21. Keimling eines liastardes der Orchidee Cattlera. m Innern mit symbiotischen Wurzelpilzen. (Nach II. Burgeff.)

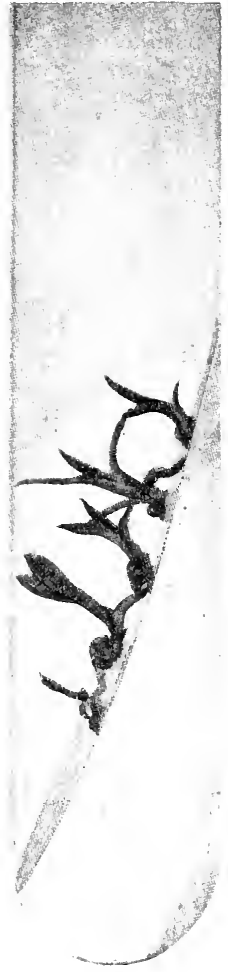

Abb. 22. Sämlinge eines Hybriden der Orchidee Odontoglossum, in den Reinkulturen eines Wurelpilzes (Mycorrhiza). Dic l'flänzchen sind bewurzelt und $6 \%$. Nonate alt; sie wrden wiederholt anl ein nenes Substrat übertragen. (Nach II. Burgeff.)

Die Aufnahme organischer, nach Stahl wesentlich anch anorganischer Nährstoffe durch die verdanende Tätigkeit der insektenfressenden Pflanzen scheint fakultativer Natur zu sein.

Zur Kultur von Drosera sei bemerkt, daß sie sich in mit Sphagmum gefüllten Schalen gut züchten läßt. Die Pflanzen müssen feucht und somnig ge- 
halten werden, im Zimmer am besten unter einer Glocke. Zum C̈berwintern hält man die Pflanzen bej +3 bis $6^{0} \mathrm{C}$, damit sie eine wirkliche Winter-

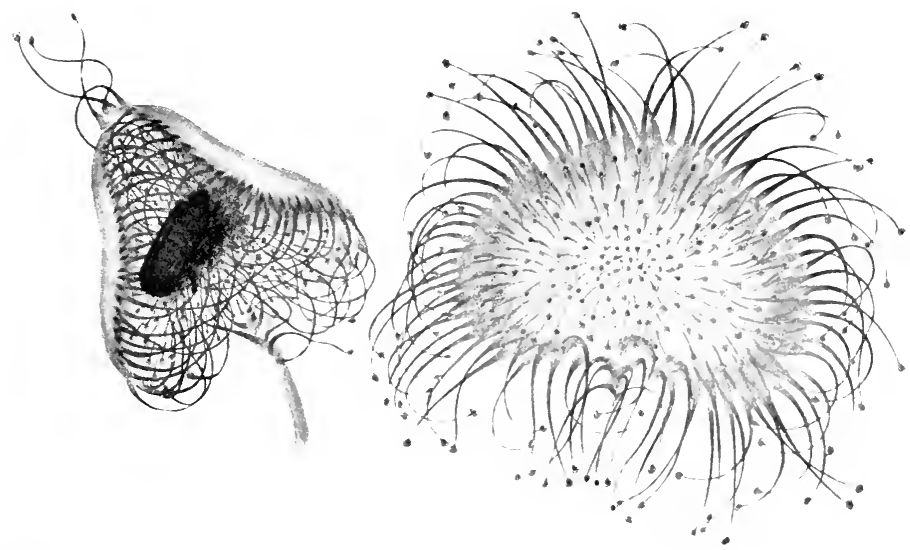

Alb. 23. Blätter des Sonnentaus (Drosera rotundifolia). Linkes Blatt mit eingefangenem Käfer. Statt lehender Ohjekte werden auch feine Fleischstïckchen verdaul. Elienfalls gute Stndienohjekte sind Drosera longifolia, anglica und Drosophyllum Etwa fünfach vergrößert. (Orig.)

ruhe durchmachen. Zum Begieben des Sonnentaus mub weiches Wasser verwendet werden.

3. Ganz-Schmarotzer (sind (hlorophyllfrei).

Balanophora dioica u. a. m. (Balanoploraceac),

Rafflesia arnoldii u. patma (Rafflesiacrae).

Pilostyles hausknechtii u. a. Sipezies (Rafflesiareae),

Cuscuta curopaca u. a. m. (Convolvulaceae).

Die samen von Cuscuta keimen leicht anf feurbtem FlieBpapier und auf Erde. Ohgleich die ansgebildete Pflanze ein Parasit ist, besitzen die Keimlinge (s. Abbild.) reichlich (hlorophyll. Mikroskopisehe Bilder der Hanstorien siehe bei L. Kuy. Wandtafel Nr. 104.

Lathraea squanaria (Scrophulariaceae),

Orobanche speciosa (Oroluanchaceae).

Samen von Orobanche wurden mit denen von Ticia faba Ende April $10 \cdot \mathrm{m}$ tief in die Erde geloracht. Anfang Juni blible die I icia, Mitte Juli die Orobanche. 


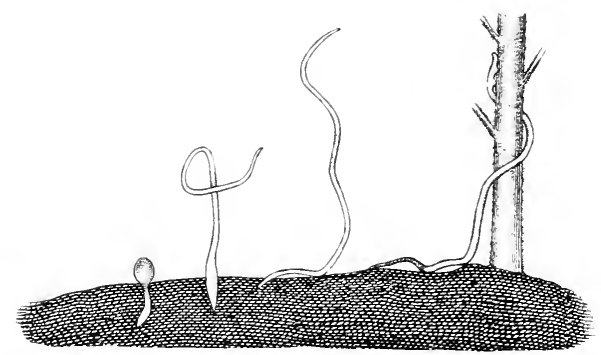

Abb. 24. Keimlinge des Schmarotzers Seide (Cuscuta europaea). Keimblätter fehlen. Die Spitze der I'flänzchen beschreibt langsam kreisende Bewegungen und kommt dadurch in Berührung mit einer Wirtspflanze (Brennessel. Hopfen, Hanf. Weide 11. a.), in welche sie Haustorien entsendet. (Nach (). Schmeil.)

4. Halb-Sclumarotzer (enthalten ('hlorophyll).

Thesim intermedimm 11. a. (Santalaceae).

Loranthus europaeus (Loranthaceae).

Tiscum album*) (Mistel) (Loranthaceac).

Euphrasia officinalis (Norophulariaceae).

Rhinanthus maior. minor (scrophulariaceae),

Melampyrum nemorosum n. a. m. (sicrophnlariaceae).

Die nächste Grmppe beschäfigt sich mit dem Träger der hisher behandelten Nährstoffe im Pflanzenkörper. dem Wasser. und mit den das Zellgewebe durchsetzenden Luftwegen.

\section{Gruppe. Wasser und Luft.}

1. Wasser.

Das Wasser ist das Medium. in welehem sich als dem Hauptbestandteil des Zellsaftes ein grober Teil der vorstehend geschilderten, anBerdem die durch anorganische Verbindungen bedingten Umsetzungen abspielen. Wir müssen das Wasser deshalh gleichfalls als eine Art Nährstoff betrachten, wodurch sich die Behandhung in einem besonderen Absehnitt rechtfertigt.

Das wichtigste Aufnahmeorgan für das Wasser und in ihm gelöste Stoffe ist die Wurzel.

) Vgl. Flughblatt Nr. 32 d. Kais. Biol. Anstalt in Dahlem. 


\section{Versuch. Lepidium sativum.}

Die Wurzeln der Keimpflanzen der Gartenkresse (Lepidium satioum)*, eignen sich vorziiglich zur Beobachtmog der IVurzelbaare, welehe - als dusstiilpungen der Epidermiszellen - wesentlich zur Vergräbermng der Wurzaloberfläche beitragen. oft $u m$ das 6 - 12 fache. Anf 1 qmm Wurzoloherläche können Hunderte von Wurzolharen kommen.

hie Versuehsanstellung geht im wesentlichen aus der beigefigeten Abbildnng hervor. Die samen. welche iiberall im Handel käuflich sind. werden trocken anf das die Giassoheibe (z.B. photographischePlatte $9 \times 12(\mathrm{~m})$ bedeckende. feuchte Flinßpapier anfgelegt. mit der Wmzelspitze. Welche durch die samensehale hindurelosehon mit der Lupe erkemmbar ist. nach unten orientiert. Sehr bald fangen die Epidermiszellen der Samensehale an. wie man aneh mikroskopiseh gut beobachten kann, gallertartig aufzuquellen. so dabs eine willkommene Klebmasse entsteht, die das Herabfallen der samen verhindert.

Giebt man in das Gefäb etwas Wasser und stellt es rerleckt fort, so begimnt bald das Hervorbrechen des Wurzehn. Innerhalb von spätestens einer Woche bietet sich ein lehrreiches Bild. (1)ie ersten Keimnngserscheinungen sind bequem in der Planktonkammer, die hier als fenchte Kammer wirkt, zu beobarhten.)

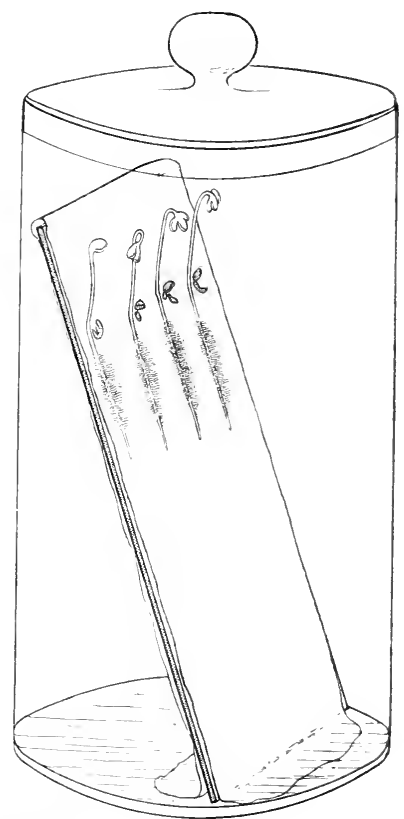

Abl. 25. Lepidium-Versuch. Dient hauptsächlich zur Demonstration der Wurzelhärchen. (orig.)

Man erkennt bei dem Wurzelversuch folgende Einzelheiten:

1. Iie Wrurzelhaare bitden ein weißes .. Höschen" um die Murzel.

2. Die Hauptwachstumszone der Wurzel ist frei ron Wurzelhadren (Spitzenwachstum der Wurzel).

3. An den heimblättern hisweilen ansgeschiedene Tröptehen zeigen den Wurzeldruckan.

*) In Giegensatz zu Nasturtium officinale, Brumnenkresse n. Tropaeolum mains, Kajuzinerkresse. 
4. Die Wurzeln (Hauptwurzeln) sind positiv geotropisch infolge des Schwerkraftreizes*).

う. Auf der Unterseite der schräg stehenden Scheibe wachsende Wurzehn zeigen positiven Hydrotropis mus, da sie bei richtigem Auflegen der Samen dem Fliebpapier angeschmiegt bleiben.

6. Die stengelartigen Teile sind negativ geotropisch**) und lassen, bei einseitiger Belenchtung, positiven Heliotropismus erkemnen.

Durch verschiedene Lagerung des Gefäßes kann man den Versuch mannigfach variieren. Die Versuche gelingen stets sehr gut.

Wie sehr Wurzeln imstande sind, den Boden zu erobern und dem Wasserbediirfnis der Pflanze zu entsprechen, beweist die Tatsache, daß das Wurzelsystem vielfach eine reiche Verzweigung besitzt. So z. B. kann eine Weizenpflanze ca. 15 Wurzeln erster Ordnmng, ca. 3000 Wurzeln zweiter, fast ebensoviele dritter und etwa 500 Wurzehn vierter Ordnung haben.

Freilich ist dabei zu beachten, daß nur die Spitzen der Wurzehn zur Aufnahme von (nicht zu kaltem) Wasser befähigt sind. während die weiter rückwärts gelegenen Teile verkorken oder sich sonst nach anßen fest abschließen.

Die Seitenwureh verbreiten sich nach allen Richtungen des Raumes, da sie gar nicht oder nur schwach positiv geotropisch sind und mehr transversal-geotropische Eigenschaften besitzen.

Wie ausgiebig die Pflanzen befähigt sein können, für Wasseraufnahmeorgane zu sorgen, beweist die schnelle Bildung von Wurzeln an Stecklingen von Weiden u. a. m., die unter Umständen selbst damu noch Tendenz zur Wurzelbildung zeigen können, wenn man sie unter Mißachtung ihrer ,Polarität" umgekehrt in die Erde steckt, in das Wasser stellt oder in wasserdampfgesättigter Luft aufhängt; vgl. H. Vöchting (1).

Zu Versuchen eignen sich kahle Weidenzweige ron etwa $15 \mathrm{~cm}$ Länge und ca. $8 \mathrm{~mm}$ Dicke. Für den ()rt der Entstehnng ron Wurzehn und bebätterten Seitenzweigen sind dabei innere und änßere Faktoren maßgebend. Nach G. Klebs (1) ist die Fähigkeit der Pflanze zu Organbildungen der verschiedensten Art und zu Reaktionen auf änßere Einfliisse viel mehr in der Hand des Experimentators, als man zurzeit denkt.

In Anpassung an den Standort wurzeln viele Wïstenpflanzen ganz besonders tief. Andererseits zeigen Wasserpflanzen (submerse Hygrophyten) vielfach eine starke Riickbildung der Wurzeln, da die Transpiration fehlt und die Blätter zur Wasseranfnahme befähigt sind. Lemna arrhiza besitzt überhaupt keine Wurzeh, obgleich sie nicht völlig im Wasser untergetancht lebt.

*) Die Schwerkraft kann durch die Zentrifugalkraft ersetzt werden. Wegen der Statolithentheorie vgl. G. Haberlandt (1).

**) Bei den Gräsern findet die Aufwärtskrümmung in den Knoten statt. 
Weitere Pflanzen mit besonders bemerkenswerter Art der Wasseraufnahme sind $z$. B.:

\section{Tillandsia usneoides*) (Bromeliaceae),}

Billbergia horrida (Bromeliaceae),

Dischidia rafflesiana (Asclepiadaceae);

vgl. G. Haberlandt (1), F. schimper (1).

\section{Versuch. Chemotropismus der Wurzeln.}

Die Wurzeln passen sich im Buden in vielen Beziehnngen den giinstigsten Lebensbedingungen an, wozu sie durch eine Reihe von Reizreaktionen befähigt sind, die sich als Nebenresultat z. T. schon beim vorstehenden Versuch ergeben haben.

Der hier zu besprechende Chemotropismus vollzicht sich in wasserhaltigem Medium im vorliegenden Falle in (3-) 5\% iger Gelatine (bergestellt ans den käuflichen Tafeln bester Qualität).

Die in destilliertem Wasser gelöste Crelatine wird in ein rundes (ilasgefäß von etwa 15 cm lichter. Weite nnd ca. 12 ‘m Höhe eingefüllt; es könn'n aber anch Bechergläser verwandt werden. Solange die Gelatine noch flïssig

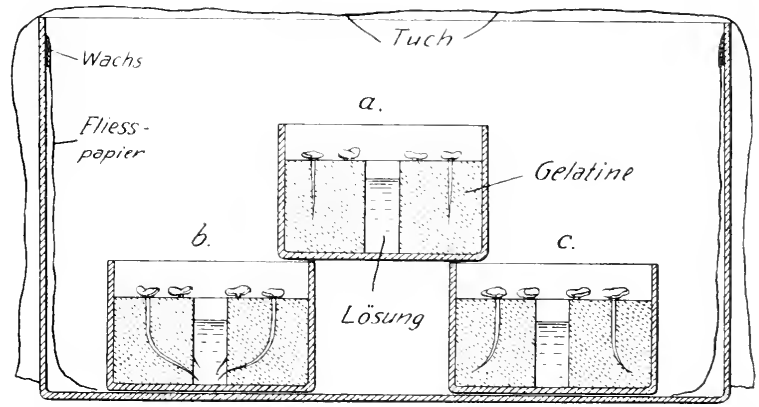

Abb. 26. Chemotropismus der Wurzeln. a Richtung der Wurzeln zu Anfang des Versuches; $b$ Zukrümmen der Wurzeln zur Ammonphosphat-Lösung; $c$ Wegkrümmen der Wurzeln von der Kochsalz-Lösung. (Orig.)

ist. wird in den mittleren Teil der Schale cin Glasrohr von etwa 3 em lichtem Durrhmesser (weites Reagensrohr, Lampenzylinder o. a. m.) eingestellt, dits später, nach Herumfahren mit einer langen Xadel zum Zwecke der Lockerung, zur Herstellung einer zentralen Höhlung herausgenommen wird. In diese Höhlung wird die chemotropisch wirkende Lösung eingefiillt. Nan bereite

*) Gedeiht, wie viele andere Bromelaceae, in Gewächshäusern in frei aufgehängten Astgabeln u. dgl. 
vier Schalen vor mud beschicke sie parweise mit einer Lösung von (1-) $2 \%$ igem Ammonimmphosphat $\left[\left(\mathrm{NH}_{4}\right)_{2} \mathrm{HPO}_{4}\right.$, alkalisch $\left.)\right]$ bzw. $(1-) 2 \%$ igem Kochsalz in destilliertem Wasser. Diese beiden substanzen eignen sich für die vorliegenden Versuche besonders gut. [Vgl. M. Lilienfeld(1) und die beistehende Abbildung.]

Als Versuchsobjekte dienen zweckmäBig Wurzehn von Lupims albus, wemn sie 1,j- 4,0 ('m lang sind. Die Samen werden am besten zuvor in ganz flacher Wasserschicht 24 Stunden lang angequollen und dann in gut durchfenchtete, durch Reiben zwischen den Händen gelockerte sägespäne*) in einer saatschale von größeren Dimensionen (rgl. Abbild.) horizontal flach eingelegt und mit einer diumnen

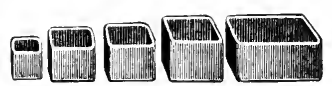

Abb. 27. Unglasierte Tonschalen fïr Pflanzenkulturen. Seitenlängen $5-20 \mathrm{~cm}$. (Preise ca. 0,20 bis $0,50 \mathrm{M}$.) scchicht von sägespänen überdeckt. Nach t-5 Tagen pflegen die Wurehn bis zu der gewiinschten Länge herangewachsen zu sein. Man legt am besten einige Dutzend samen ein und wählt später zum Versuch nur schmurgerade gewachsene Wurzeln aus. Diese werden in Wasser abgespült und zu etwa je sechs rings $11 \mathrm{~m}$ die Höhlung der Gelatine in dem ats der Zeichnung ersichtlichen Abstand in die weiche Masse senkrecht hineingesterkt. Hieranf werden die Schalen in ein größeres, mit nassem Fließpapier ansegekleidetes Gefäb gestellt und durh Überdecken eines dunklen Tuches (val. Abbild.) gegen Licht geschützt, um die Dunkelheit des Bodens nachzuahmen. was aber fiir den Ausfall des Versuches von keiner Bedeutung ist, da die Wurzehn ron Lupinus albus - im Gegensatz zu denen von Raphanus satious und Sinapis alba - nicht lichtempfindlich sind.

Nach einigen Tagen zeigt sich positiver Chemotropismus der Wurzehn nach der Ammonphosphatrösung, während sich die Wurzeln von der Kochsalzlösung fortgekriimmt haben. Die Phosphate sind gute Lockmittel, während die Chloride, Nitrate und Sulfate abstoßend wirken.

Nach etwa einer Woche pflegen Bakterienkolonien und Schimmelpilze in der Gelatine aufzutreten, womit sich das Abbrechen der Versuche von selbst ergibt.

Die Frage ïber die Beziehungen des Tranmatropismus (Krimmmug infolge von Verletzung durch Brand-, Atzwonden usw.) zum Chemotropismus ist zurzeit noch nicht genügend geklärt.

Wie besondere Versuche von Otto Gïnther gezeigt haben. befähigt der Tranmatropismus die Wurzeh nicht, spitzen und scharfkantigen Steinen im Boden geschickt auszuweichen: dazu miißten die Steine schon ätzende oder sonst giftige Substanzen ausscheiden.

*) Gerade Wurzeln von besonderer Lebensfrische erhält man nach E. Tiegs hei Verwendung von B u chen-Sägespänen; Späne von Kiefernholz sind zu harzreich, 
bie Wurzelhatre wirken ihrerseits angreifend anf feine Gesteinspartikel, hauptsächlich durch Ansscheidung von Kohlensäure, deren Menge fiir die verschiedenen Pflanzen spezifisch zu sein seheint, und sehmiegen sich dicht an die Partikel an (Korrosionsrersuche an geschliffenen und polierten Marmorplatten).

Die Wurzeln stehen den ihnen als Nahrung im Boden gebotenen mineralischen Nährstoffen nicht wahllos gegeniiber, nehmen also die im Wasser gelösten Stuffe nicht rein physikalisch anf, sondern zeigen ein solektives Verhalten.

\section{Versuch. Wurzeldruck.}

Zur Demonstration des Wurzeldruckes eignen sich gut entwickelte Topfpflanzen der Sonnenblume (Helianthus ammuss) mul der Fuchsia, nach W. Detmer auch im Winter besonders gut die Acantluace Sanchezia nobilis, ferner Lrtica macrophylla. Man setze auf die dekapitierte Pflanze so, wie es die Abbildıng zeigt. mittels Gummischlanch ein Kngelsteigrohr und beobachte den Austritt des Saftes. Seine besonders in der Wärme reichliche Ausscheidung kommt hauptsärhlich dadurch zustande, daß durch osmotische sangkraft das Wasser aufgenommen und an den stellen geringerer Filtrationskraft (Gefäße) wieder ansgepreßt wird. Der hierbei entwickelte Druck beträgt meist $3 / 4-2$ Atmosphären, also relativ wenig, bei der tropischen Leguminose Schizolobium excelsum, nach den Untersuchungen von Figdor, dagegen 8 Atmosphären. Tie Birke (Betula alba), welehe kurz vor Entfaltung der Blätter aus Schnitten oder Bohrlöchern in der Nacht und vormittags stark .,blutet", treibt den saft mit etwa 1,5 Atmosphären Druck hervor und scheidet dabci pro Tag etwa 1 l Fliissigkeit ab, wenn das Bohrloch eine Weite von knapp 1 cm besitzt.

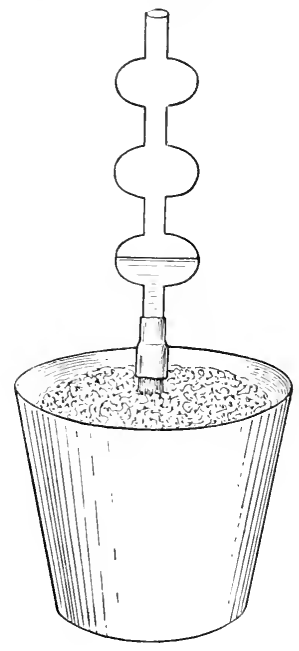

Abl. 2S. Demonstration des Wurzeldruckes an einer dekapitierten Fuchsia. Pflanze. Der ausgeschiedene Saft sammelt sich in einem aufgesetzten Kugelrohr. (Orig.)

\section{Versuch. Leitungsbahnen des Saftes.}

Sietzt man Stengel von Impatiens parviflora oder Impatiens noli tangere in Eosinlösung (rote Tinte), so gewahrt man bei der Durchsichtigkeit der Stengel, daß die rote Flüssigkeit in den Gefäßbahnen aufsteigt.

Bei weißen Bliiten, z. B. denen der Abendlichtnelke Melandryum album), werden bei solchen Versuchen dic Nerven rot. 
Bei Ringelungsversuchen an belaubten Baumzwoigen, bei welchen an einer ringförmigen Stelle die Rinde entfernt wird, sieht man, wenn die Zweige im Wasser stehen, kein Vertrocknen der Blätter, ein Beweis, daß das Wasser im Holzkörper aufsteigt.

Die Frage des saftsteigens bis in die Kronen hoher Bäume ist noch nicht einwandfrei gelöst, wie die kritischen Untersuchungen von S. Schwendener gezeigt haben. Ob die Kohäsion des Wassers eine ausschlaggebende Rolle spielt, bleibt noch näher zu untersuchen.

\section{Versuch. Transpirationsnachweis durch die Kobaltprobe.}

Nach E. Stahl (2) benutzt man Kobaltchlorid (CoCl. $+6 \mathrm{H}_{2} \mathrm{O}, 100 \mathrm{~g}=$ (a. 1,20 M.) zum Nachweis der Verdunstung von Wasser unter Benutzung des Imstandes. daB das wasserhaltige salz rot. das wasserfreie dagegen blatl ist.

Man tanche Blätter von Fließpapier von der Größe der photographischen Platten 9:12 ('m in ca. 5\% ige Lösung von Kobaltchlorid und trockne sie (z. B. iiber Exk aufgehängt und mit einem Reibnagel odler einer Stecknadel befestigt) hängend oder horizontal anf einer Enterlage licgend, dep sich das Blatt nicht fest ansehmiegt. Man kann es anch mit einer Pinzette fassen und iiber einer Lampe oder einem Bremner trocknen.

Endlich kann man auch gröBere streifen durch ein-bis zweimaliges Einlegen in die Fliissigkeit tränken, zmm Trocknen anlhängen und rorrätig halten. Man vermeide es nach Möglichkeit, mit den Fingern anf die Papierfläche zil fassen.

Das gut getrocknete Papier ist blan. Legt man das Blatt einer Pflanze zwischen zwei solche Bogen und bedeckt diese mit trocknen Glasplatten, wie es die Abbildumg zeigt, so bildet sich die Tnterseite des Blattes infolge von Verdunstung seines Wassers schon nach einigen Jinuten rot ab.

Als Versuchsobjekte eignen sich alle weichen Blätter mit nicht zu dicker Mittelrippe, z. B. Ribes, Philadelphus. Sambucus, im Winter z. B. die Acanthacer Justicia carnea.

Aus der Beobachtumg, daß in der Regel nur die Tonterseite innerhalh der Versuchszeit rötend wirkt, erkennt man, dab die kutikuläre Transpiration gegeniiber der stomatären wenig in Betracht kommut.

Wiederholt man den Versuch mit welken Blättern oder solehen, welche längere Zeit im Dunkeln verweilt haben. so wird die Rötung des Kobaltpapieres ausbleiben oder lange Zeit erfordern, weil in beiden Fällen die spaltöffumgen sich geschlossen batten.

I)er Srhutz sehr junger Blätter gegen Verdunstung geschieht vielfach durch Kinospensehuppen und Haare.

In gleicher Weise wie die Kutikula wirkt natiorlich anch Korkgawebe rerdunstungshemmend. I)ie Kartoffel ist hierfiir ein gutes Bei- 
spiel. Schneidet man sie durch, so bildet sie an der Schnittliäehe von nenem ein schiitzendes It undperiderm, wenn man die Hälften etwa cine Woche lang mnter aner fenchten Gilocke aufbewaht.

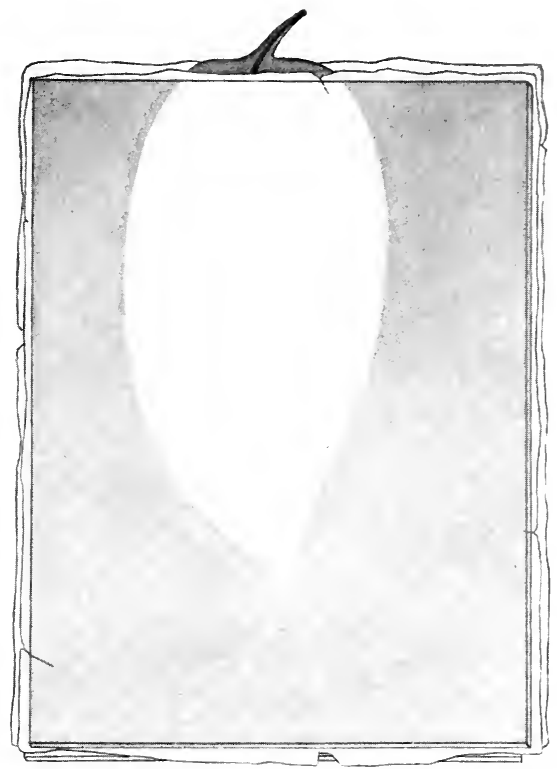

Alb. 29. Stablsche Kobaltprobe zum Nachweis der Verdmstung von Wasser an. Blättern. Die hlanen Papierflächen werden an der Stelle, wo das verdunstende Blatt liegt, rosa gefärlot. (Orig.)

Die absolute Gröbe der Verdunstmmg kamn sehr beträchtlich sein; so kann rin Banm pro Tag hunderte von Litern Wasser verdunsten.

Xerophyten (Bewohner trockner Standorte) und Halophyten (Salzpflamzen) zeigen infolge spezifischer Eimrichtmoen Beschränkmmg der Transpiration. Hydrophyten (soweit sie zarthlätterig sind) rorwelken in trockener Luft sehnell. Vol. F. Sehimper (1), E. Warming (1).

Beispiele:

Xerophytem:

Sedum acre,

Mesembrianthemum.
Helichrysum,

Rhipsalis u. a. Cactaceate. 


\section{Halophyten: \\ Salicornia herbacea. \\ Honckenya peploides, Atriplex litorale. Rhizophora mangle}

(Rhis, mit versenkten spaltöffnmugen).

Hydrophyten:

Myriophyllum.

Batrachium.

Caltha.

Elodea.
Tallisneria.

Sagittaria sagittifolia

var. vallisneriifolia.

\section{Lıft.}

Ebenso wie Wasserströme durchziehen anch Luftströme viele Pflanzen. Ihese letztgenannten Ströme werden in trockener Luft viel mehr erleichtert

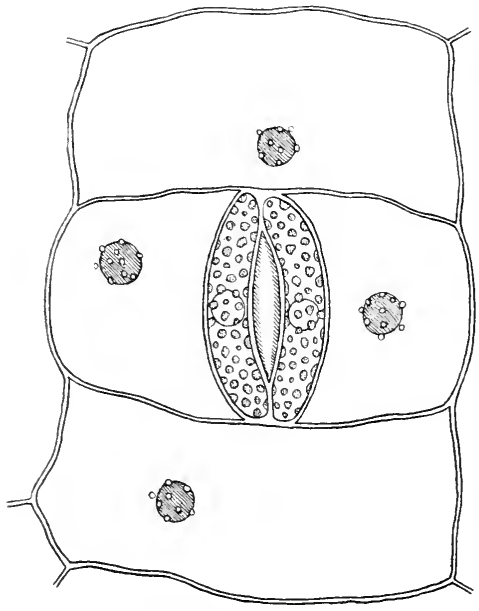

Abb. 30. Offene Spaltöffnung von Tradescantia rirginica. Epidermis der Blattunterseite. Den Kernen der die Spaltöffnung umgebenden Oberhautzellen sind rudimentäre, farblose Chromatophoren aufge-. lagert. (Orig.) als in fenchter, nebeliger; in dieser besteht eine gewisse Gefahr, daß Wasserdampf sich niederschlägt und die Interzelhularränme verstopft bzw. abspert. Bei den größeren Wasserpflanzen endlich ist sogar ein innerer Luftrorrat in Kanälen nötig. da Wasser nur den etwa 20. Teil des in einem gleich großen Volumen Luft vorhandenen Sanerst offquantums enthält.

Besontere Organe mit spezifischen Dechanismen zur Einatmung (Heppiation) nud zor Ansatmung (Exspiration) fehlen den Pflanzen: sie vollführen keine Atembewegungen. Wir finden deshalb iiber ihre Oberflärhe zahlreiche Poren in Form von sipaltöfunngen (Stomata) und Korkwarzen (Lenticellen) zerstreut. welehe als Ein- und Austrittspforten für Sanerstoff und Kohlensäure dienen.

Die beigefiigte Abbildung 31 zeigt besonders gesteigerte Ausbildung von Trägern für Lenticellen in tropisehen Mooren. nämlich Brettwurzeln, Luftwurzeh und Atemwurzehn (Pneumatophoren). Es handelt sieh dabei $ı$ m Bäume ans den Gattungen: 


\section{Calophyllum (ciuttiforae), Chisocheton (lleliaceac), Eugenia (Myrtateate), Canarium (Burseraceate)}

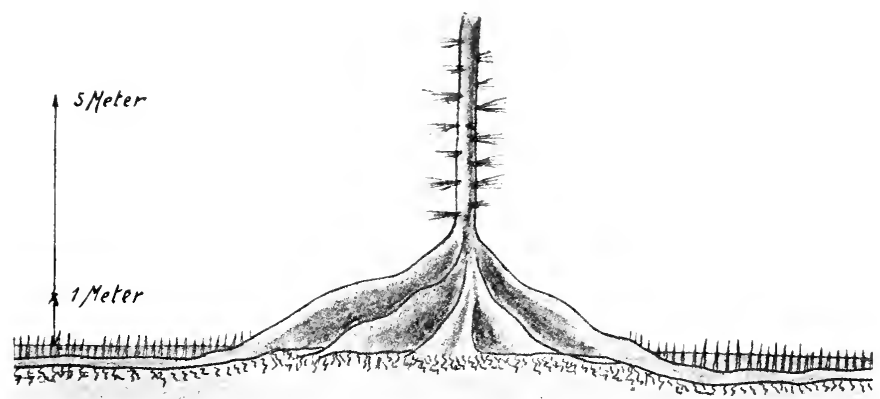

Abb. 31. Exemplar eines der Charakterbäume ans eirem Moore auf Sumatra mit großen Brettwurzeln, mit horizontal wachsenden ,besenförmigen Luftwurzeln" und aufrecht wachsenden, spargelförmigen Pnemmatophoren (Atemwurzeln). (Orig. von Koorders.)

\section{Versuch. Mechanik und Funktion der Spaltöffnungen.}

Die Spaltoffnnngen eines belichtren Blattes z. B. von Tradescantia, discolor (s. Abb.), Hyacinthus oder Iris sind offen, wie die mikroskopische Beobachtung lehrt. Werden sie plasmolysiert, so schließen sie sich. weil die offenspannende Wirkung des Turgors aufhört; jedes Welken bedingt mithin eine Verengerung der Stomataspalte und damit eine Herabsetzung der Transpiration. Vgl. s. Schwendener (1), G. Haberlandt (1).

Im Dunkehn pflegen sich die spaltöfnungen zu schließen, wemn anch wohl nicht immer hernetisch. Sie stehen offenbar wesentlich im Dienste der Kohlensäureversorgung bei dem an das Licht gebundenen Prozeß der Kohlenstoffassimilation. Über Versuche mit den spaltöffnungen der Nadelhölzer vgl. A. Dengler (1).

Holo-Saprophyten haben in der Regel keine stomata.

\section{Versuch. Wegsamkeit der Lenticellen.}

Ein Zweigstïck von Sambucus nigra, Syringa vulgaris u. a. II. wird an beiden Enden mit Paraffin verklebt und mittels eines Korkens so in ein Glasrohr geklemmt, daß ein Ende herausragt. Das Rohr wird mit ausgekochtem Wasser gefüllt und mit der Luftpumpe evakuiert. Danı 
steigen zahlreiche feine Luftbläschen aus den Lenticellen auf, wodurch ihre Wegsamkeit veranschaulicht wird. Man kann den Versuch auch so anstellen. daß man durch gelinden Quecksilberdruck unter Wasser Luft durchpreßt.

Lenticellen haben keinen spezifischen Mechanismus zum Öffnen und Schließen. Sie stehen, wic das mikroskopische Bild lehrt, immer offen, falls sie nicht durch sekundäre Vorgänge verstopft werden. Rindenstiieke mit Korkwarzen, z. B. von der Birke, eignen sich gut zu Präparaten auf den an anderer Stelle beschriebenen schwarzen Objektträgern. welche bei mikroskopischer Betrachtung mit einer gut brennenden elektrisehen Taschenlampe belentehtet werden kïnnen. Näheres iiber den Bau der Korkwarzen siehe bei (i. Haberlandt (1). 


\section{TEIL.}

Cryptogamen. 



\section{Vorbemerkungen.}

Wie bereits im Vorwort betont worden ist. sind die physiotogiseben und ökologischen Versuche und Beobachtungen bei den Kiryptoganen unter Zugrundelegung einer systematisehen Disposition behandelt worden. Eine solebe bietet den Vorteil, dab an jecler Stelle die Stoffanordumng leicht ïberblickt werden kann und daß verwandte Typen in gröberer Zahl nebeneinander verglichen werden können.

Eine gewisse Kenntuis der Physiologie der Kryptogamen bietet ein wertvolles Riistzeug auch fiir das studium der höheren Pflanzen nnd vor allem auch für das Verständnis des Kreislaufes der sitoffe in der freien Natur.

\section{Über Lupen und Mikroskope.}

Den Besprechungen iiber die Physiologie der Kryptogamen seien einige Erörterungen iber Lapen. Nikroskope und deren Nebenapparate voransgesehickt.

1. Lupen haben vor Mikroskopen den Vorzng eines mvergleichlich gröberen Ciesichtsfeldes und einer bemerkenswerten Tiefenwirkmo, während Jikroskope hanptsächlich nur in einer bestimmten Horizontalebene eine kleine Fläche abbilden.

Lupen vom Aplanatypus nach steinhoil wendet man in der Regel fiir schwärhere, solche vom Anastigmattvpus mehr fïr stärkere Vergrößerungen an*). Die anastigmatische Planktonlupe von C. Zeiß vergröbert $40 \mathrm{mal}$ linear.

2. Sebr starke Lupen, die auf Exkursionen schon ein schwach rergrößerndes Vikroskop teilweise prsetzen kömnen, machen es erwiinscht, die sie haltende Hand anfzulegen oder an eine (eventuell mit Wasser zu fïllende) kleine Beobachtungsglaskammer mit plan-

*) Nach meinen Erfahrungen ist für kleine Objekte eine 14-15 fache Vergröbernng din besonders gangbares llittelmaB, dann folgt ca. 25- mt endlich ea. tofache Vergrößerung. Auf Ausflügen führe ich stets drei solcher Lupen mit.

Alle groben Mikroskopfirmen fertigen Aplanatlupen in ausgezeichneter Qualitat als Exkursionslupen bis zu beträchtlichen Vergröberungen. 
parallel geschliffenen Grund- und Deckscheiben (Planktonkammer*) anzulegen.

3. Bei Benutzung stark vergrößernder Lupen hat man im allgemeinen nicht das richtige Empfinden von ihrer Leistungsfähigkeit. Es erklärt sich das aus psychologischen Grïnden. Die durch Annäherung des Auges an das Objekt bewirkte Vergrößerung wird nicht geniigend nathhaltig wahroenommen, weil der Vergleich fehlt.

4. Mikroskope erzeugen durch ihre objektive in Gegensatz zu Lupen reelle, linsenverkehrte Bilder. Die nebenstehende Abbildung stellt links ein kleines, mit dem Riicken der Feder auf einen

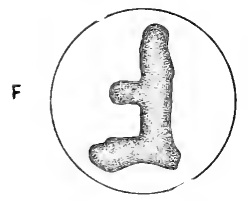

Abb. 32. Demonstration der vergrößernden und hildumkehrenden Wirkung des Objektivs. (Orig.) trockenen Objektträger gezeichnetes F dar. Das Bild dieses Gegenstandes, welches in 9 facher Vurgröbermo abgebildet ist, wird bei guter Beleuchtung im Mikroskop sichtbar, wenn man das Okular heransnimmt, Ölpapier auf den Rand des Tubus auflegt, die Einstellmog etwas regelt, das Ange in etwa 25 (.m Entfermung rom (j)papier bringt und zur Abhaltung auffallender Strahlen die Hand vor das Papier hält. Man kam dann auf dem Pauspapier bequem zeichnen, wenn man einen objektträger als stiutze unter dieses legt.

Das Mikroskop wirkt also wie ein Skioptikon. Das Okular kann man zum Auge rechnen, da es als Lupe für die Betrachtung des Bildes dient.

5. Zur ungefähren Orientierung über den (notwendigerweise geringen) Durchmesser des Gesichtsfeldes bei schwachen mikroskopisehen Vergrößerungen kann geeignetes mm-Papier verwendet werden, falls man kein Objektmikrometer zur Hand hat. Bei etwa 100farher Vergröberung pflegt das Gesichtsfeld mur etwa den Durehmesser eines mittleren stecknadelkopfes oder von vier dieht zusammenliegenden Feingrieskörnern aufzunehmen. Durch Anwendung schwacher (H)jektive und sehr starker Okmlare (z. B. Kompensation Nr. 12), kann man für bestimmte Fälle bei ziemlich starker Vergriberung ein verhältnismäßig großes Gesichtsfeld erhalten. Da auch der Objektabstand bedeutend ist, brancht man, was oft erwünscht soin kann, trotz beträchtlicher Vergrößerung kein Deckglästhen auf das Präparat zu legen.

6. L)as Zeichnen der vergröberten Objekte, soweit es nicht freihändig vorgenommen wird, geschieht zweckmäBig mittels spiegel-

*) Solche Planktonkammern liefern bzw. beschaffen alle groben Mikroskopfirmen oder Werkstitten fïr Chemie und Bakteriologie. 
zeichenapparates nach Abbe oder unter Verwendung des nit elektrischem Licht beleuchteten Zeichenprojektionsapparats nach Edinger, der mach Art eines Skioptikons wirkt (vgl. Abb. 3:3).

Durch Bilder, welche mittels Zeichenapparate gewonnen sind, kamn auch leicht die VergröBerung bestimmt werlen. Die direkte Größenbestimmung der Objekte mub durch Meßokulare ge-

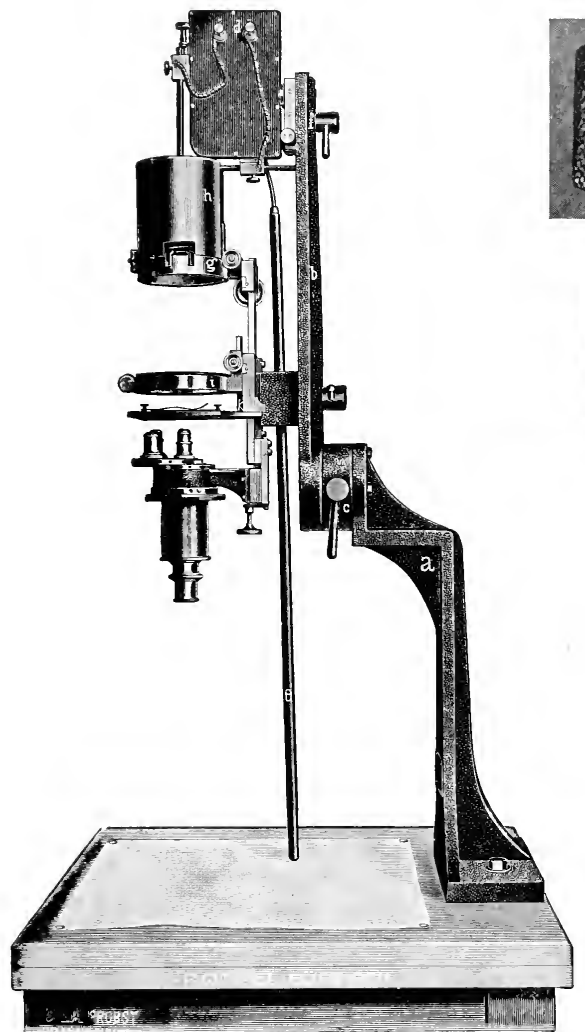

Abb. 33.
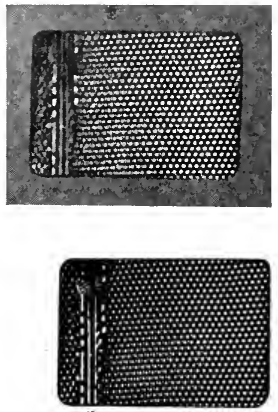

Abb. 34. Pleurosigma angula. $t u m$, Ausschnitt aus der Schale (links ein Stïck der Raphe). Bei Ölimmersion aufgenommen. Oben: Schale mit Raster anfgenommen. Unten: Schale ohne Raster, d. h. das bei der Ätzung der Autotypien erforderliche Netz. (Nach Rich. Volk.)

Abb. 33. ZeichenProjektions-

Apparat nach Prof. Dr. Edinger, mit elektrischer Lichtyuelle, Objektiven und Okularen. Das Bild wird direkt auf das Zeichempapier projiziert. (Nach R. W inkel-Göttingen).

schehen. Die Leistungsfähigkeit der Mikroskope kann bei starken Vergrößerungen leicht nach der Auflösung des abgebildeten Testobjektes Pleurosigma angulatum und noch feiner strukturierter Kieselalgen, wie sie anf J. D. Möllers Diatomeen-Typenplatte enthalten sind, beurteilt werden; je nach der Leistung der Objektive erkennt man Streifen, Punktreihen, Felder oder 
Sieblöcher auf den Schalen von Pleurosigma. Die genaue Form der Sieblöcher ist in der Regel erst bei Anwendung von Ölimmersionssystemen, deren Frontlinse nach innen zu halbkugelig ist, sichtbar zu machen.

7. Farbenerscheinungen an kritischen farblosen Objekten vermeidet man am besten durch Anwendung von Apochromatobjektiven in Verbindung mit Kompensationsokularen.

8. Strukturierte mikroskopische Objekte wirken als Beugungsgitter, ähnlich wie ein Planktonsieb (Phosphorbronze Nr. 260) eine brennende Kerze zerlegt. Zur Aufnahme der Beugungsbilder

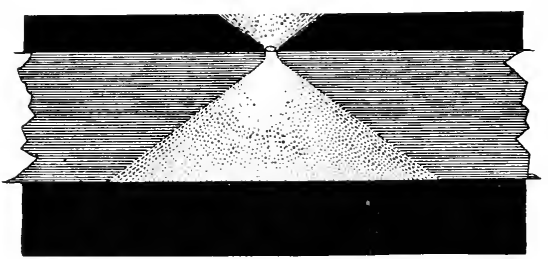

Abb. 35. Vereinigung der Lichtstrahlen $\mathrm{d} n \mathrm{rch}$ e in en $\mathrm{Ab}$ b e schen Kondensor. Die Strahlen gehen durch den Objektträger und vereinigen sich an der Stelle, wo sich das Objekt befindet. Vergr. ca. Sfach. Näheres siehe bei W. Scheffer (1). sind ein großer Öffnungswinkel des Objektives oder schiefe Beleuchtung nötig. Die nebenstehende $\mathrm{Ab}$ bildung zeigt den Strahlengang nach Durchgang durch einen Abbeschen Kondensor, aufgenommen beim Passieren derLichtstrahlen durch Uranglas. Dieser Strahlenkegel ist in voller Intensität, bei teilweiser Abblendung und in Schiefstellung ein wichtiges Hilfsmittel in den Händen des Mikroskopikers.

9. Die modernen Dunkelfeldbeleuchtungen unter Verwendung von Mikro-Nernstlampen oder ähnlichen starken Lichtquellen lassen die mikroskopischen Objekte auf dunklem Grunde anch bei starken Vergrößerungen bell erscheinen. Die Dunkelfeldbeleuchtung mit ihren auffallenden Lichtstrahlen entspricht den natïrlichen Verhältnissen mehr als die Beleuchtung der Objekte im durchfallenden Licht. Auch das polarisierte Licht kann bei Verwendung eines drehbaren Objekttisches sehr charakteristische Bilder mit vielen Feinheiten liefern.

10. Die äußerste Grenze, bis zu welcher kleine Objekte in ihren natürlichen Umrissen noch erkannt werden können, beträgt bei Anwendung von ultravioletten Strahlen und Mikrophotographie etwa $0,15 \mu$.

11. Zum Studium kleinster Suspensionen, besonders in Flüssigkeiten, dient das mit sehr starken Lichtquellen arbeitende Ultramikroskop von Siedentopf und Zsigmondy.

12. Zum Studium der Mikroskope und ihrer Nebenapparate ist die Durchsicht der Firmenkataloge sehr geeignet. Näheres siehe bei W. Scheffer (1). 


\section{Gruppe. Myxomycetes (Schleimpilze) und Amöben.}

\section{Myxomycetes (Mycetozoa, Phytosarcodina).}

\section{Fuligo varians $=$ Aethalium septicum. Lohpilz.}

(Name von fuligo $=\mathrm{RuB}$ und aithale $=\mathrm{RuB}$.)

Der Schleimpilz der Lohblüte ist durch sein auffälliges, gelbes, bei kompakter Gestalt an „Eierstich" erinnerndes Plasmodium allgemein bekannt. Er findet sich sehr verbreitet auf Gerberlohe, in der man den Pilz im Laboratorium längere Zeit in Rohkultur ziichten kann, auf Moos in Wäldern, auf Baumstiimpfen usw., entsprechend seinem Fenchtigkeitsbedürfnis meist im Innern des Substrates. Fuligo bildet, wenn man ihu sich anf dem Objektträger ausbreiten läßt, ein vorziigliches Objekt zum Studium der Bewegungen nackter Plasmamassen, zumal hier die Bewegung eine ziemlich rasche ist (vgl. Abb. 36).

Legt man Stiicke des Plasmodiums anf die Mitte einer Glasscheibe unter eine fenchte Glocke, so breitet es sich nach allen Seiten flach aus und liefert

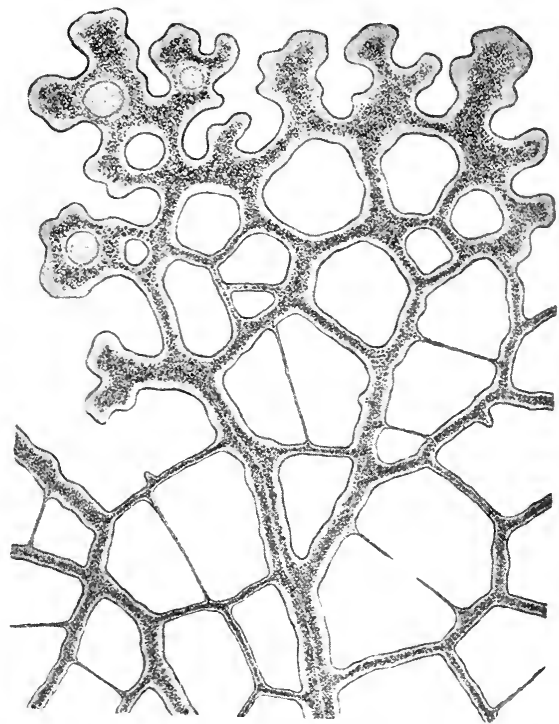

Abb. 36. Fuligovarians. Lohpilz. Rand eines Plasmodiums, an dem die Bewegnng nackter Plasmamassen gut studiert werden kann. Vergr. schwach. (Nach L. K n y.)

so bis tellergroße Präparate, die durch Antrocknen konserviert und mit einer schïtzenden Deckscheibe versehen in einem Rahmen aufgestellt werden können.

Junges Plasmodium ist

1. negativ heliotaktisch,

2. bei einer Temperatur bis etwa $35^{\circ} \mathrm{C}$ positiv thermotaktisch,

3. für Loheextrakt positiv ehemotaktisch,

4. für Kochsalz negativ chemotaktisch,

5. fuir mäßige Wasserströmung positiv rheotaktisch.

Die Reaktion des lebenden Plasmodiums ist alkalisch.

Die Sporen eignen sich nicht zu Keimungsversuchen. 
Näheres ïber experimental-physiologische Untersuchungen an Myxomycetes-Plasmodien siehe bei E. Küster (1) und L. Kny (1), Nr. 115.

Reticularia lycoperdon. Bovist-Schleimpilz.

Die Sporangien dieses Schleimpilzes haben, wie schon der Name sagt, bovistartiges Aussehen und finden sich in Wäldern an den unteren Partien der Bäume auf der Rinde, auf Baumstïmpfen, auf altem Holz usw., besonders in den Monaten April und Mai. Die Sporangien sind im Innern dicht erfiillt von Kapillitium und den umbrabraunen Sporen, welche nach den Darstellungen von E. Jahn (1) leicht keimen.

Frisch gesammelte, trockene Sporen können in destilliertem oder Leitungswasser schon nach 15 Minuten bei Zimmertemperatur im Licht oder im Dunkeln keimen, doch darf man nicht immer mit so schneller Keimung rechnen. Bringt man frisch gesammeltes Material aus dem Walde mit, so kann solches ohne weiteres verwendet werden. Die Sporen werden (in nicht zu geringer Menge) mit gewöhnlichem Wasser auf dem Objektträger verriihrt, damit sie gut benetzt werden, und dann mit einem Deckgläschen bedeckt. Man beobachtet nun bei mindestens 300-400facher Vergrößerung und bemerkt bald, daß die Sporen, soweit sie durch Schrumpfen etwas znsammengefallen waren, sich in kurzer Zeit durch Wasseraufnahme abrunden. Erfolgt die Keimung nicht sehr bald, so setzt man an der Seite des Deck-

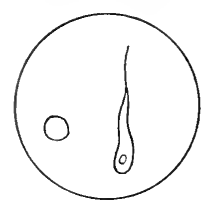

Abb. 37. Reticularia lycoperdon. Sporenhülle und Schwärmer bei starker Vergrößerung durch Trockensysteme. (Orig.) gläschens von Zeit zu Zeit etwas Wasser zu, falls man das Präparat nicht in eine feuchte Kammer legen will. Mehr als 2 Stunden wird man auf die Keimung wohl nie zu warten brauchen.

Zu Beginn der Keimung tritt durch einen Riß der Membran ein hyalines Plasmaknöpfchen hervor. und im Verlauf von etwa jo Minnten drängt sich aus der runden braunen Spore ein farbloses, längliches, nacktes Plasmagebilde hervor, welches sich zunärhst zitternd umherbewegt. Die vollkommen entleerten Sporen erscheinen damn ein wenig durchsichtiger als die noch ungekeimten. Will man die

Skulptur der Yembranen studieren, muß man Ölimmersion bei der mikroskopischen Beobachtung verwenden.

Die mehr am Rande des Deckgläschens liegenden Sporen keimen am reichlichsten.

Das entstandene Keimprodukt ist nicht wie bei vielen anderen Pilzen ein Faden, sondern ein bewegliches, ziemlich stark lichtbrechendes Gebilde (My xamöbe) von amöbenartigem Charakter. Bald erkennt man eine Geibel und am hinteren Ende eine pulsierende Vaknole: rgl. die Abbildung. Im Plasma findlet sich häufig Glykogen in Form von Kïgelchen. 
In einer Rohrzuckerlösung von ea. $4 \%(=2,5$ bis $3,0 \mathrm{Atm}$. osmotischem Druck) ist keine Keimung mehr möglich, leicht aber nach Überführen dieses Materials in Leitungswasser.

Die trockenen Sporen kann man in Papier oder in einem mit Watte verschlossenen Gläsehen aufbewahren. Haben sie 6-8 Monate lang trocken gelegen, so können sie bei etwa $21^{\circ} \mathrm{C}$ in destilliertem Wasser in ungefähr 30 Minuten keimen, werden sie aber in solchem Wasser 5 Minuten lang in einen Thermostaten von $37^{\circ} \mathrm{C}$ gelegt, so keimen sie schon in etwa 11 Minuten aus.

Amaurochaete atra. Dieser Schleimpilz, welcher sich anf Holz und Rinde der Kiefer findet, besitzt ebenfalls leicht keimente sporen.

Lycogala epidendron. Die großen Fruchtkörper bilden sich, in kleinen Herden zusammenstehend, auf altem Holz, besonders Baumstriinken. sie enthalten Sporen, welche zu Keimungsversuchen nicht geeignet sind.

Die speziellere Ernährungsphysiologie der Schleinpilze ist zurzeit noch wenig studiert.

\section{Plasmodiophora brassicae, Hernie*) der Koll larten.}

Plasmodiophora lebt als schmarotzer in Form von Schleimkïrpern in lebenden Zellen der Wurzeln von Kreuzblïtlern, an denen er gallenähuliche Bildungen hervorruft. Hauptsächlich werden Kohlpflanzen (Brassica oleracea) befallen, z. B. die Spielarten Wirsingkohl, Blumenkohl, Kohlrabi und Rosenkohl, ferner Kohlrübe (Br. napus) und weiße Riibe (Br. rapa). Es entstehen meist unförmliche, kropfartige Anschwellıngen an Haupt- und Nebenwurzeln, wodureh die Pflanze stark leidet; (siehe Abb. auf der Tafel: Parasitische Pilze).

Die Krankheit ist anßerdem an einer Reihe anderer Kreuzbliitler beobachtet worden, z. B.:

Raphanus sativus, Rettig,

Raphanus raphanistrım, Hederith.

Sinapis alba, weißer Senf,

Simapis arvensis, Ackersenf,

Camelina sativa, Leindotter,

Capsella bursa pastoris, Hirtentäschelkraut,

Thlaspi arvense, Pfennigkraut,

Cardamine pratensis, Wiesenschaumkrant,

Cheiranthus cheiri, Goldlack,

Iberis umbellata, Sehleifenblıme.

Wenn im Spätherbst die Sporen nach Verfaulen der erkrankten Wurzeln frei werden, infizieren sie den Boden. Im Frühling tritt aus der Spore ein Schwärmer herans, der sich in junge Wurzelfasern einbohren und dadureh neme Erkrankungen hervorrufen kann.

*) Hernie bedeutet die beim ...Bruch" entstehende sackartige Vorwölbung. 
Die Krankheit wird durch feuchten Boden begünstigt, durch trockneren kalkreichen gehemmt.

Die Einordnung von Plasmodiophora unter die Myxomycetes ist nicht sicher; wahrscheinlich bestehen Beziehungen zu den Chytridiaceae.

Nähere Ausführungen über Pilzkrankheiten der Kulturpflanzen siehe bei Appel u. Westerdijk(1), J. Eriksson(1) und P. Sorauer(1), über Gallenbildungen bei Kiister(2).

Bezüglich Abbildungen von Schleimpilzen vgl. Lister (1) und A. Kerner, Bd. I, S. 102 .

Wegen der Ähnlichkeit gewisser Entwicklungszustände der Myxomycetes mit Amöben und Rhizopoden überhaupt, sei hier kurz darauf hingewiesen, wie und wo man diese letztgenannten finden kann.

\section{Fundorte von Amöben und anderen Rhizopoden.}

1. In normalem Schlamm (bisweilen vermischt mit Heli o zoen): auch im organischen Filz biologischer Kööper (siehe die später folgenden Abbildungen und zugehörigen Erläıterungen).

2. In Flüssen, deren Schlamm durch starke Strömung aufgerïhrt ist (z. B. in der strömenden Elbe).

3. Zwischen sowie auf Schilf und anderen Sumpf- und Wasserpflanzen an flachen, schlammigen Ufern. Beim Fischen mit dem Planktonnetz unter Berühren der Pflanzenstengel und -blätter erhält man in der Regel Difflugia und dgl., auch Heliozoa (vgl. die Abbildungen tierischer Wasserorganismen).

4. In Uferbesatz (organischem Filz) in der Emersionszone von Gewässern verschiedener Art, besonders an Bohlenwerken und dgl.

5. An Deckgläschen, welche man an der Oberfläche geeigneter Aquarien schwimmen läßt. Das Einfetten des Gläschenrandes ist in der Regel mnuötig. Anch am Grunde der Aquarien und an den Glasscheiben (Objektträger einhängen!), besonders ganz nahe der Wasseroberfläche.

6. In Erde, auf Stroh usw., in der Regel als Cysten.

\section{Kultur von Amöben.}

1. In Fliissigkeiten, nach etwa 8 Tagen als Kahmhaut auftretend:

Wasser $250 \mathrm{ccm}$,

Mannit ca. $12,0 \mathrm{~g}$,

Nonokaliumphosphat . . ca. $0,5 \mathrm{~g}$,

Magnesiumphosphat . . $0,5 \mathrm{~g}$,

Schlamm, Pflanzenteile hnmöser Erdboden oder dgl. . Messerspitze. 
2. Auf festem Nälırboden:

$\begin{array}{rr}\text { Wasser . . . . . . . . . . } & 100 \mathrm{ccm}, \\ \text { Salatblätter . . . . . . . . } & 4 \mathrm{~g}, \\ \text { Agar . . . . . . . . . . . } & 1,5 \mathrm{~g} .\end{array}$

Das Nährmedium wird nach vorschriftsmäßiger Herstellung sterilisiert und in Petrischälchen verteilt.

Die Beimpfung kann durch Amöben aus der oben genannten Kahmhaut bewirkt werden.

In solchen Kulturen erhält man in der Regel nur kleine Amöben.

Näheres siehe bei Kisskalt n. Hartmann (1). Abbildungen von Rhizopoda s. Tafel: Tiere des Wassers.

\section{Gruppe. Schizomycetes, Bacteria (Spaltpilze).}

\section{Art der Beobachtung.}

Mit bloßem Ange im Freien sichtbar z. B.:

1. Rote Überzüge von Schwefelbakterien (z. B. Chromatium, Lamprocystis, Thiopolycoccus), auf zersetzlichem, schwefelwasserstoffhaltigem Schlamm, verrotteten Blättern und morschem Holz unter Wasser oder auf Fladen an der Oberfläche.

2. Schleierartige, weiße Schlammuiberziuge und zarte Uferbesätze von Schwefelfadenbakterien (Bcggiatoa, Thiothrix) in nach Schwefelwasserstoff riechendem Wasser.

3. Fellartige Besätze von Abwasserbakterien (Sphaerotilus).

t. Ablagerungen von Eisen- und Manganbakterien in Wiesengräben und Brunnen (Chlamydothrix. Gallionella, Crenothrix, Clonothrix).

5. Zoogloea*)-Klumpen, d. h. Massenanhänfungen von Bakterien zn Schleimklımpen oder -häuten.

Die beistehende Abbildung zeigt den ZaogloeaTest**), d. h. die Bildung einer mehr oder weniger schleimigen Schwimmschicht auf mittelgut gereinigtem, nic ht eigentlich f a ulenden Abwasser.

Bei etwa 300facher Vergrößerung gut sichtbar, z. B.:

1. Essigsäure- und Milchsäurebakterien (Bacterium) aus Weibbiersatz,

*) Wörtlich: Tierchen in schleim. Bakterien und andere Jikrobien wurden früher vielfach als Tierchen bezeichnet.

**) Dieser Test ist dadurch wichtig, daß er in einem halbgereinigten nicht mehr fäulnisfähigen Abwasser das Vorhandensein unvollkommen zersetzter Nährstoffe andentet. Durch Rieselböden oder Oxydations-(biologische) Körper gn t gereinigte Abwässer sollen eine solche schicht nicht bilden.

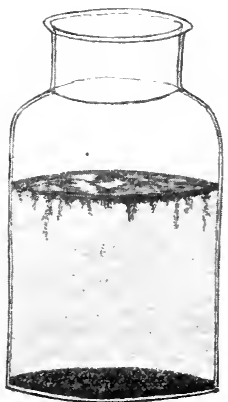

Abb. 38 . Zoogloea-Test, Schwimmschicht auf unvollkommen gereinigtem, gestandenen Abwasser; ca. ${ }_{1}^{\prime}, 3$ nat. Gr. (Orig.) 
2. Schraubenbakterien (Spirillum) aus fauligem Wasser,

3. Tafelkokken (Lampropedia) und Paketkokken (Sarcina) aus Schlamm usw.

Bei etwa 1000 facher Vergrößerung gut sichtbar:

Fast alle Bakterien. Geißeln müssen fast immer gefärbt oder bei guter Dunkelfeldbelenchtung betrachtet werden.

Man pflegt die meisten Präparate erst bei mittlerer Vergrößerung einzustellen, um die besten Partien herauszufinden.

Ultramikrobien, d. h. Lebewesen von solcher Kleinheit, daß sie mit Imseren stärkst vergrößernden Mikroskopen nicht mehr sichtbar gemacht werden können, sind bisher nieht nachgewiesen worden.

Dagegen ist es möglich, mit dem Ultramikroskop von Siedentopf und Zsigmondy unbelebte Teilchen, z. B. kleinste Goldteilchen, von ciner GröBenordnung nachzuweisen - wenn auch nicht der Form nach zu erkennen -, wie wir sie nach der kinetischen Gastheorie den Molekülen zuschreiben miissen.

Bei Dunkelfeldbeleuchtung, z. B. mittels Paraboloidkondensors, kann man sehr instruktive Bilder von Bakterien erhalten. Die Zellen erseheinen hell anf sehwarzem Grunde, und bei beweglichen Formen sind die Geißeln mit aller s'chärfe, cbenfalls hell, zu erkennen. Diese weitgehende Definition mikroskopischer Objekte iiberrascht 1 m so mehr, als sonst die Geibeln nur in seltenen Fällen an getrockneten Exemplaren direkt, sonst nur durch sorgfältige Färbung nath voraufgegangener Beizung wahrzunehmen sind.

Zur Belenchtung dienen bei solehen Beobachtungen, wie bereits bemerkt, in der Regel Nernstlampen oder andere besonders starke Lichtquellen.

Sollen viele Personen hintereinander das mikroskopische Bild beobachten, empfiehlt sich das Umstellen einer Zeissschen gläsernen schutzhiille um das Mikroskop, dessen Mikrometerschraube dann (durch Übertragung) von auben hin und her bewegt wird.

\section{Schnelle und einfache Beschaffung von Bakterienrohmaterial.}

1. Aus Weißbiersatz.

2. Aus Abwasser (Kanal-, Stalljauche usw.).

3. Aus Sumpfwasser usw., nach Einwerfen von Erbsen. Brotkriimeln, Semmelstiickchen, toten Pflanzenteilen, toten Flubschwämmen ttsw., auch aus dem Wasser der Blumenvasen, das meist anch vicle Infusorien enthält.

4. Durch Faulen einer Bohne (mit Schale) im Reagenzglas mit Wasser, das eine Spur Sehlamm enthält.

5. Durch Abdrïcken einer durchschnittenen Kartoffel oder von Mohrribenscheiben anf den Fubboden oder durch Bestreichen der Kartoffel mit Brot, das mit schlammigem Sumpfwasser durch- 
Kuchsalz . . . . . . . . . . . . . . . 0

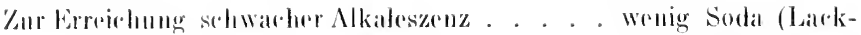
muspapier!)

Hie fliissigkeit wirl am beston im Dampltopl sterilisiort. Nähore Einzelheiten siohe bei ()hlmiiller n. Spitta (1), s. 251.

Jie meisten Bakterion bevorzmgen im Gegensatz zu Shommelpilzen alkalischen Nährbodon.

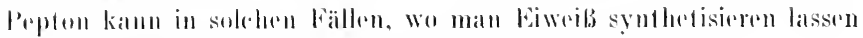
will, elureh Aspanagin und milehsames Ammon ersetat werden.

Nährgolatine.

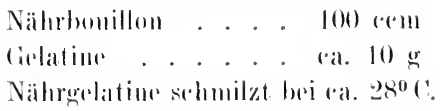

Näliragar.

Nabrbunillon . . . . 100 ('(6)

Anall. . . . . . 1, 1, 20

Nähragar sthmilat hei rewas iiber $40^{\circ} \mathrm{C}$.

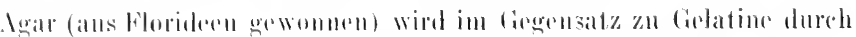

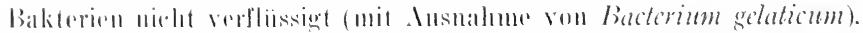

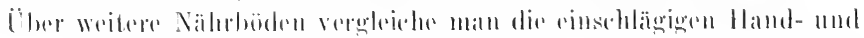

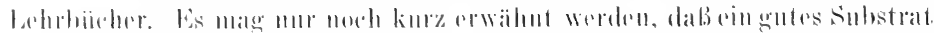

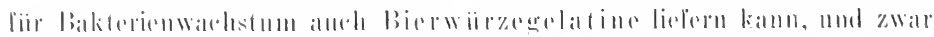

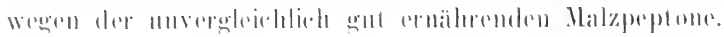

\section{Roinkulturen in Rishrohon.}

Ilan motersedudelet (s. Mbh. Il):

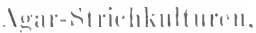

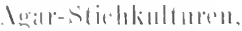

killollelkuluren,

lichatime-strichliulturen,

Cichattur-stichkulturen,

Cielattime-liollkulturen,

Bomillon-linlturen.

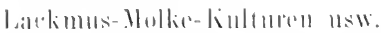

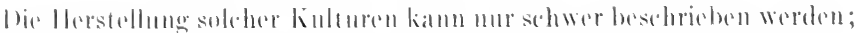

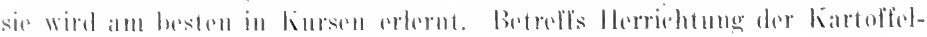

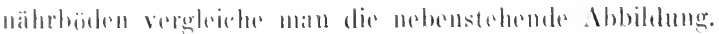

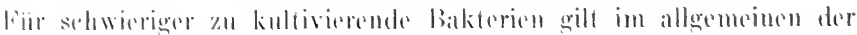

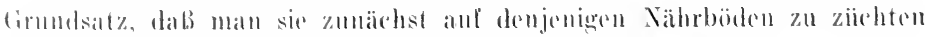

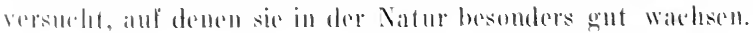



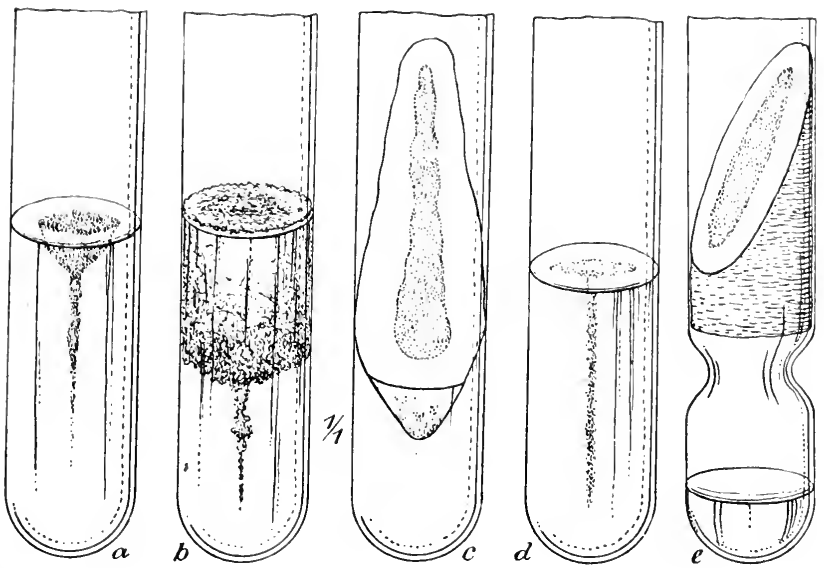

Ahb. 41. Bakterienkult uren in Reagenzgläsern. a Gelatine-Stichkultur; $b$ dgl.; Gelatine bereits stark verflüssigt; $c$ Agar-Strichkultur; $d$ Agar-Stichkultur; e Kartoffelkultur. (Nach R. Kolkwitz.)

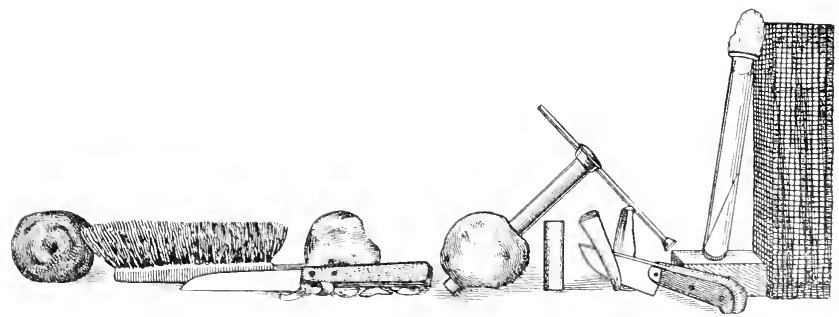

Ahb. 4․ Herstellung von Kartoffelnïhrböden. Die Kartoffeln werden gehïrstet, gewaschen, für Herstellung ron halbierten Zylindern mittels algeflammten Nessers geschält und damn sterilisiert. (X̃ach L. He im.)

\section{Kultur durch Plattenguß.}

Die Cielatimeplatten miissen gut erstart sein. Um die Verbreitnng der Bakterien in der Natur zu erläutern, seien einige praktisehe Beispiele angefiihrt.

liopthatar von ca. 2 cm Länge (s. Mbb.). . . . Zungenberïhrung Hallich*)

Zahl der lieime (ent-
teobachtet
sprechend den ge-
wachsenen Kolonien)
8

*) Fl ïg ge hat nachgewiesen. da B bei Hustenstößen ein äuBerst feiner Sprühregen entstehen kann, welcher als eine Art Nebel zum Teil stundenlang in der Luft schweben und dadurch etwaige Krankheitskeime verbreiten kann, ähnlich wie durch infektiösen Staub. 
Kupfermünze . . . . . . . . . . . . .

Nickelmünze . . . . . . . . . . .

Goldstück . . . . . . . . . . .

Leitungswasser*), 1 cсm (bei Rollröhrchen 0,25 bis $0,5 \mathrm{cem}$ verwendet) . . . . . . 2 oder mehr

Gestandenes Wasser aus Tischtrinkglas; $1 \mathrm{ccm}$ (zum Plattengn B 0,1—0,2 cem verwendet) . . 2 oder mehr

Luft (nach $1 / 2-1$ stündigem Offenstehen der Platte)

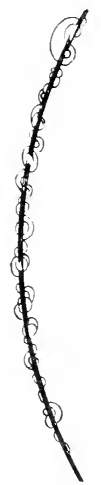

Kontrollplatte ........

Vgl. hierzu die Abbildungen.

Abb. 43. Bakterienkolonien an einem menschlichen Haar, auf Nährgelatine gezüchtet. Nat. Größe. (Orig.)

Abb. 44. Reinkultur in F-Form, hergestellt durch Ausstreichen nicht verflüssigender Bakterien (von einer der abgebildeten Petrischälchenkulturen auf eine Gelatineplatte) mittels Platinnadel. Nat. Gr. (Orig.)

Al). 43. ea. 20 jenachder Staubmenge 4 bis einige hundert (Bakterien und Schimmelpilze**)

8

0

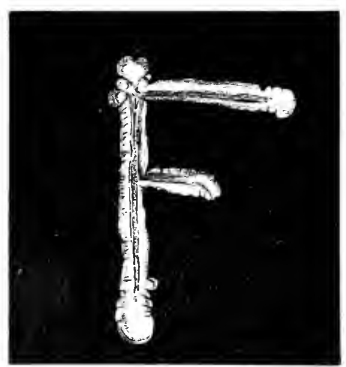

Abb. 44.

Zu diesen Versuchen waren erforderlich:

ca. 12 Petrischälchen (trocken sterilisiert in einer Kupferbüchse***)), ca. 12 Röhrchen mit 10 ccm Nährgelatine (für Rollkulturen 5 ccm), ca. 3 Pipetten à $1 \mathrm{ccm}$ (keine Auslaufpipetten), trocken oder durch Auskochen sterilisiert,

2 sterile, leere Reagenzröhrchen für Wasserentnahme †).

\section{Material für Sammlungen.}

Um zu Demonstrationen Bakterienkulturen vorrätig zu haben, kann man solche in verhältnismäßig starkwandigen Gläsern von Reagenzrohr-

*) Vgl. Ohlmïller-Spitta (1), H. Klut (1).

**) Unter den Fadenpilzen können Penicillium und Cladosporium herbarum häufig sein.

***) Eisenbüchsen sind nicht zu empfehlen, da sie leicht rosten. Im Notfall sind die Büchsen auch entbehrlich. Statt normaler Petrischälchen können für qualitative Untersuchungen im Bedarfsfalle kleinere Doppelschälchen verwendet werden.

$\dagger$ F Für Probeentnahmen aus tieferen Schichten eines Gewässers kann man den im Abschnitt Algen erwähnten Abschlagapparat benutzen. 


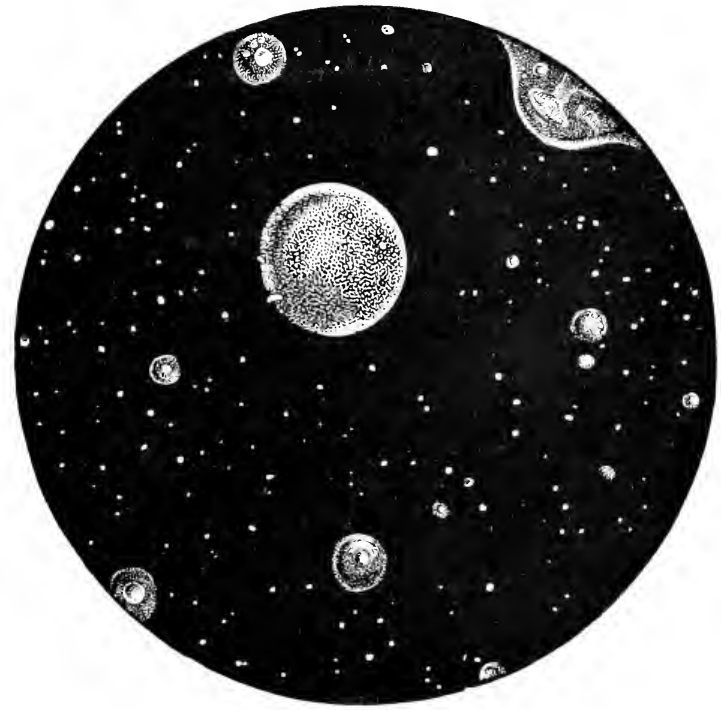

Keime ans Wasser (Bakterien).

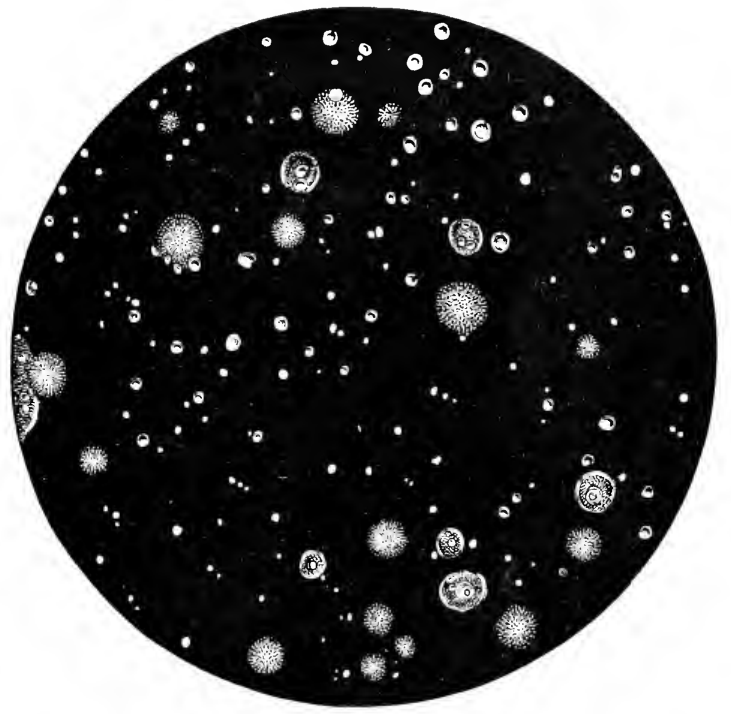

Keime aus Strafenluft (Bakterien und Schimmelpilze).

Zwei P'etrischälchen mit bakterienkolonien. Oben: Verflüsigende und nichtrerflüstgende Kolonien ans $0,1 \mathrm{ccm}$ Wasser, welches eine Woche lang in einem Trinkglase gestanden hat. Inten: Bakterien- und Schimmelpilzkolonien anf einer felatineschicht, welche stunde lang der Strabenluft exponiert war. Nat. (ir. (Orig.) 

form auf festem Nährboden züchten, durch Zusatz von einigen Tropfen Formalin konservieren und die Röhrchen zuschmelzen lassen. Die Röhrchen können dann in ähnlicher Weise in Etuis aufbewahrt werden, wie es fiur das Plankton empfohlen ist.

Man kann auch niehtverflïssigende Kolonien (z. B. von Bactcrium coli) auf Gelatine in Petrischälchen zuichten, die Innenseite des Deckels zum Abtöten des Materials mit etwas Formalin bestreichen und den spielraum zwischen Deckel und Boden mit Paraffin ansgießen*). Solche Präparate sind vorzuiglich haltbar, lassen sich auch in flachen runden Büchsen, am besten aus Kupfer, sehr bequem in der Tasche transportieren.

Zum Färben von Bakterien streiche man die zu behandelnden Objekte in diinner Schicht auf reinem Objektträger oder Deckgläschen aus (mit Platindraht oder Deckgläsehenkante) und lasse sie antrocknen. Hierzu und zu dem Folgenden vgl. Abel (1).

Hierauf wird mit friseh bereiteter Fuehsinfliissigkeit (destilliertes Wasser 50 ecm, konz. abs. alkoholische Fuchsinlösung $5 \mathrm{ecm}$ ) unter gelindem, kurzem Erwärmen gefärbt, abgespült, getrocknet und in Kanadabalsam oder Zedernöl eingebettet**). Bacterium tuberculosis (s. dort) muß ebenso wie Sporenmaterial seiner schweren Färbbarkeit wegen in wirksamerer Weise behandelt werden.

Das Färben der Bakterien zur bloßen Sichtbarmachung der äußeren Form hat in der Regel nur damn Wert, wenn man Dauerpräparate anlegen will.

Jan kann nach Burri auch in der Weise verfahren, daß man die Bakterien mit chinesischer Tusche (Pelikantusche) vermischt, auf dem Objektträger in dïnner Schicht ausstreicht und damn antrockmen läBt.. Die Bakterien erscheinen dann hell auf schwarzem Grunde.

Zur Geißelfärbung bei Bakterien ist in der Regel vorheriges Beizen mit Tanninlösung erforderlich [vgl. C. Giinther (1) u. a. m.].

An gutem, lebendem Naterial, das am besten nicht iiber 20 Stunden alt ist, kamn man die GeiBeln, wie bereits erwähnt, bei Dunkelfeldbeleuchtung sehen (Paraboloidkondensor).

Viel leichtere und einfachere GeiBel- und Wimperstudien lassen sich an lebenden Ciliaten und an Euglena machen.

*) Schalen von hierfür besonders geeigneter Form sind im Handel zu haben.

**) Will man auf die Objektträger direkt schreiben, so tanche man die betreffenden Stellen zuvor in eine Lösung von etwas Zelloidin in Alkohol-Äthergemisch. - Nenerdings verwendet man auch flüssiges Paraffin statt Cedernöl zum Einbetten der Präparate. 


\section{System und Physiologie der Schizomycetes (Bacteria)*).}

(Abbildungen siehe anf Tafel "Pflanzen des Wassers" und im Text.)

1. Coccaceae, Kugelbakterien.

Streptococcus mesenterioides, Lampropedia hyalina,

Micrococcus phosphoreus, Sarcina paludosa.

2. Bacteriaceae, Stäbchenbakterien.

A. Geißeln fehlend oder peritrich.

I. Ohne Sporen....... Bacterizm

II. Mit Sporen ....... Bacillus

B. Geißeln polar, einzeln oder in Büscheln; Zellen nicht schraubig.

Bacterium aceti

, lactis acidi

, coli

" prodigiosum

, vulgare

.. denitrificans

., nitrobacter

.. radicicola

., tuberculosis

3. Spirillaceac, Schraubenbakterien.

Microspira desulturicans

Spirillum undula.

4. Chlamydobacteriaceae, Scheidenbakterien.

Crenothrix polyspora

Sphaerotilus natans.

5. Beggiatoaceac, farblose Schwefelbakterien.

Beggiatoa alba.

6. Rhodobacteriaceae, Purpurbakterien (mit und ohne Schwefel).

Chromatium okenii

Rhodospirillum.

Besprechung von zahlreichen Beispielen siehe bei R. Kolkwitz (3).
Bacillus subtilis

,, amylobacter

" calfactor

", cellulosae

Pseudomonas fluorescens

, violacea

" europaea.

\section{Streptococcus mesenterioides. Froschlaichpilz.}

Bildet Kugelketten mit dicken Gallerthüllen in Baumflüssen; kann Dextrangärung des Zuckerrübensaftes verursachen.

Micrococcus phosphoreus. Leuchtbakterie.

Zur Kultur lege man ein Stiick käuflichen, möglichst nicht faulen Schellfischfleisches in eine Doppelschale von beispielsweise $15 \mathrm{~cm}$ Durchmesser und übergieße es soweit mit einer $3 \%$ igen Kochsalzlösung, daß der obere Teil des Fleisches noch aus der Fliissigkeit emporragt. Schon an nächsten Tage wird man im Dunkeln ein deutliches Lenchten des Fleisches wahrnehmen. Unter Umständen kann es vorteilhaft sein, die Schale in

*) Die Verwandtschaft vieler Spaltpilze mit den Spaltalgen unterliegt keinem Zweifel, doch stehen serolngische Versuche zur experimentellen Ermittlung der Verwandtschaft $\mathrm{z}$ wischen beiden Gruppen nach den Hethoden von Friedent hal, W. Magnus und C. Mez noch aus. 
den Eisschrank zu stellen, sie besonders im Sommer auf nicht mehr als etwa $6^{0} \mathrm{C} \mathrm{zu}$ halten, um die gleichzeitige Entwicklung anderer Bakterien, besonders Fäulnis bewirkender, zu hemmen.

Um Reinkulturen zu gewinnen, tupfe man die am stärksten leuchtenden Stellen mit einem sterilen Wattekügelchen (Reagenzglas, Trockenschrank!) ab und streiche mit diesem ïber erstarrte Nährgelatine mit $3 \%$ Kochsalz in Petrischälchen, und zwar mit demselben Bausch iuber drei Platten je ca. viermal. Dann erhält man nach 1-2 Tagen helleuchtende Striche und Punkte, von denen leicht Reinkulturen gewonnen werden kömnen. Bei Betrachtung mit 3-14fach vergrößernden Lupen sieht man das grïnliche Lieht besonders schön erstrahlen, auch im Halbdunkel.

Man kann ferner in der Weise verfahren, daß man ein Stück ungekochten Rindfleisches von reichlich WalnuBgröße in eine Kristallisierschale von mäßigem Durchmesser legt und mit einer $3 \%$ igen Kochsalzlösung soweit übergießt, daß es zum Teil noch iiber die Fliissigkeit hinansragt. Das ganze wird dann zum Feuchthalten in eine wasserhaltende Dopjelschale gesetzt und, vor grellem Licht geschützt, etwas kïhl anfbewahrt. Das Leuchten des Fleisches beginnt in etwa $80 \%$ der Versuche meist nach etwa 2 Tagen und dauert durchschnittlich 3-4 Tage. Sobald das Fleisch anfängt zu faulen, ist die richtige Zeit zum Beobachten des Phänomens schon verpaßt. Man vergleiche Lafar (1) und Molisch (2). Abbild. s. auf der Tafel ,Pflanzen des Wassers".

Das Leuchten scheint meist eine chemische Begleiterscheinung gewisser physiologischer Vorgänge zu sein. Beim Johanniskäfer (Lampyris) diurfte es als Erkennungsmittel der Geschlechter dienen. Das Leuchten vieler Tiefseefische, z. B. von Melanostomias, unterstïtzt offenbar die Funktion der Augen.

Wegen Meeresleuchten vergleiche auch Ceratium tripos und Noctiluca miliaris.

\section{Lampropedia hyalina. Farblose Tafelkokken.}

Bildet zierliche farblose Täfelchen oder größere Flächen von in einer Ebene gelagerten Kokken. Diese Anordnung ist dadurch bedingt, daB die Zellen sich, ähnlich wie bei der blaugrünen Spaltalge Merismopedia, nach zwei Richtungen des Rammes teilen. Vgl. Tafel: Pflanzen des Wassers.

Die Täfelchen können planktonisch sein, während größere Häute Überziige auf Schlamm oder auf der Wasseroberfläche iiber dem Schlamm bilden.

Der Organismus ist geeignet, die verwandtschaftlichen Beziehungen zwischen Spaltpilzen und Spaltalgen zu zeigen.

Die Parallelform unter den Schwefelbakterien ist Thiopedia rosea.

Lampropedia gehört zn den verhältnismäßig wenigen Spaltpilzen, zu deren sicherem Erkennen die Morphologie genuigt. 
Sárcina paludosa. Sumpt-Paketkokken.

Name von sárcina = Paket, nicht ron sarx (Fleisch). Verdeutscht sarcīnen betont.

Dieser spaltpilz lebt in Form eingeschnïrter paketartiger farbloser Kolonien, hamptsächlich in solchem Schlamm, der durch Zersetzung einen etwas teerigen Geruch angenommen hat. Er lebt offenbar anaerob und bildet wahrscheinlich Methan und Wasserstoff. Vgl. Tafel: Pflanzen des Wassers.

Weitere Vertreter der Gattung sind:

Sarcina aurantiaca, häufig im Staub der Luft, viscosa, verdirbt Bier, ventricul, im Magen von Menschen und Tieren gefunden.

Bacterium aceti. Essigpilz, Essigstäbchen.

Der Essigpilz kann in Gemeinsehaft mit Hefe leicht im Bodensatz von Weißbier aufgefunden und bei ctwa 300 facher Vergrößerung beobachtet

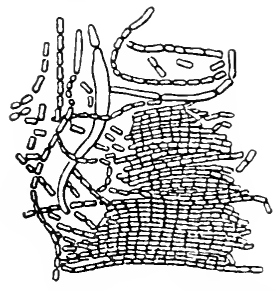

Abb. 45. Bacterium aceti, Essigsäurepilz, an einer Stelle zu einer Haut zusammengelagert. 1000 fach vergr. (Nach E. Chr. Hansen.) werden. Er bildet unbewegliche Stäbchen von mehr oder weniger langgestreckter, bisweilen etwas gebogener Form (s. Abbild. 45), welche in Essigsäurebottichen zusammenhängende, schleimige und zähe Hänte bilden können (Essigmutter). Näheres siehe bei Lafar (1), Bd. V.

Die Essigsäurebildung ist ein Oxydationsprozeß und verläuft nach der Formel:

$$
\underset{\text { Alkohol }}{\mathrm{C}_{2} \mathrm{H}_{6} \mathrm{O}}+\mathrm{O}_{2}=\underset{\text { Essigsänre }}{\mathrm{C}_{2} \mathrm{H}_{4} \mathrm{O}_{2}}+\mathrm{H}_{2} \mathrm{O} .
$$

Alle Essigsäurebakterien sind gegen Alkalien, anorganische Säuren und eine Reihe spezifischer Desinfizientien sehr empfindlich; Essigsäure wird bis höchstens $1 \%$ ertragen, Alkohol bis $10 \%$.

Das Temperaturoptimum liegt zwischen $25^{0}$ und $30^{\circ}$, das Maximum bei etwa $50^{\circ} \mathrm{C}$.

Ausreichende Beriihrung der oxydierenden Bakterien mit Luft ist durchans nötig, wie schon aus der Umsetzungsgleiehung hervorgeht.

Wenn man in ein Petrischälehen Gelatine-Tranbenzucker-Kreideplatten ausgießt und mit wenig Weibbiersatz vermischt, so bilden sieh um die Kolonien der Essigsäurebakterien durchsichtige Höfe, da sich hier der nngelöste kohlensaure Kalk in gelöstes essigsaures Kalzium umwandelt.

Bacterium xylimum bildet zähe Gallerthänte, die unter anderem auch anf schwach gezuckertem Tee leieht zu züchten sind. 
Bacterium lactis acidi. Milchsäurebakterium.

Der Milchsäureerreger kamn nach P. Lindner ähnlich gewomnen werden wie der Buttersäureerreger, nur wende man $50^{\circ} \mathrm{C}$ an.

Die Milchsäurebildung ist eine Spaltungsgärung nach der Formel:

$$
\underset{\text { Traubenzucker }}{\mathrm{C}_{6} \mathrm{H}_{12} \mathrm{O}_{6}}=\underset{2 \mathrm{C}_{3} \mathrm{H}_{6} \mathrm{O}_{3} .}{\text { Milchsäure }}
$$

Am bekanntesten ist die Säuerung der llilch dureh diesen und verwandte Erreger. Milchsäure findet sich reichlich auch in saueren Gurken, im sauerkohl und im sauertig.

$$
\begin{aligned}
& \mathrm{C}_{12} \mathrm{H}_{22} \mathrm{O}_{11}+\mathrm{H}_{2} \mathrm{O}=4 \mathrm{C}_{3} \mathrm{H}_{6} \mathrm{O}_{3} . \\
& \text { Nilchzucker Nilchsäure }
\end{aligned}
$$

Milchsäure wurde ursprïnglich aus Milch hergestellt, während sie jetzt technisch im Großen durch küustliche Gärung des Rohrzuckers oder der Stärke bereitet wirk.

Nach den Untersuchungen von Metschnikoff wirken Milchsäurebakterien wohltätig bei der Regelung des Stoffwechsels im menschlichen Darm (Yoghurt). Solche Bakterien finden sich neben Hefen auch im Kefir. einem schon seit alten Zeiten in den Kankasusländern aus Mileh hergestellten alkoholhaltigen Getränk. Kumys, ein ähnliches Getränk, wird meist aus Stutenmilch bereitet. Abbildungen und Beschreibungen s. bei F. Lafar (1), Bd. 2.

Bacterium lactis acidi liebt nur geringen Zutritt von Lnft. Es bildet unbewegliche Stäbchen. Sporen fehlen, wie bei Bacterium iiberhaupt.

\section{Bacterium coli. Darmbakterie.}

Lebt im Darm des Menschen und sehr vieler, besonders warmbliitiger Tiere; aber auch im Darm von Fliegen. Die Stäbehen dieses beweglichen Bacterium können leicht in Ausstrichen von Fäzes auf Objektträger beobachtet werden, besonders nach Färbung mit Fuchsinlösung. Ist äuBerlich dem Bacterium typhi ähnlich. Über die Gärungsprobe bei $46^{\circ} \mathrm{C}$ auf B. coli als Hilfsmittel bei der Trinkwasseruntersuchung vergleiche man C. Eijkman (1).

Bacterium phytophthorum. Pflanzenzerstörendes Bakterium.

Erreger der Schwarzbeinigkeit der Kartoffel, durch welche Kraut und Knollen geschädigt werden können. Vgl. Tafel: parasitische Pilze. Die Pflanzen pflegen plötzlich von unten her abzusterben und umzufallen. Dieses Bakterium ist auch pathogen für Tomate (Solanm lycopersicum), Lupinus, Gurke (Cucumis satious), Mohrribe (Daucus carota) ı. a. m.

Die gïnstigste Entwicklung findet dieser Erreger und der ihm verwandte Formenkreis in feuchtwarmen Jahren auf dem Felde und zur 
Winterszeit in den Kartoffelmieten. Bezüglich der Bekämpfung vgl. O. Appel (1).

Bacterium prodigiosum. Wundermonade, Hostienpilz.

Dieser Spaltpilz wird seiner intensiv roten Farbe $\left(\mathrm{C}_{38} \mathrm{H}_{56} \mathrm{NO}_{5}\right)$ und deshalb meist leichten Erkennbarkeit wegen vielfach als Versuchsobjekt verwendet: Er wächst gut auf Kartoffehn, Polenta, Agar und Gelatine.

Bacterium vulgare. Fäulnisbakterium.

Findet sich in fauligem Fleischwasser, Erbsenwasser, Kanaljauche usw., verursacht stinkige Zersetzung der Eiweißkörper unter reichlicher Bildung von Schwefelwasserstoff. Abbild. s. Tafel: Pflanzen des Wassers.

Es bildet schlanke, bewegliche Stäbchen von mannigfaltiger Form, besonders der Verbände. Man hat ihn deshalb auch Proteus genannt. Bacterium termo ist ein Sammelname für Gemische verschiedener Fäulnisbakterien. Bacterium vulgare wächst aerob und anaerob.

Aus Harnstoff wird Ammoniak gebildet, wobei aber wohl noch Micrococcus ureae mitwirkt.

Man fülle baterienhaltige Stalljanche in eine Kristallisierschale und bedecke diese vollständig mit einer Glasplatte. Nach einiger Zeit wird sich ein intensiver Ammoniakgeruch (z. T. aus Harnstoff) bemerkbar machen. Liiftet man die Glasplatte ein wenig und bringt einen Glasstab mit konzentrierter Salzsäure in die Nähe, so entwickeln sich weiße Salmiakdämpfe.

Bacterium denitrificans. Salpeterfresser.

Bildet a!̣s Nitraten und Nitriten freien Stickstoff und kann dadurch unter anderem den Wert, des Dunges beeinträchtigen.

Bacterium nitrobacter. Salpeterbakterie.

Wiewohl die Salpeterbakterien des Chlorophylls entbehren, sind sie - doch keine Saprophyten, sie vermögen sich autotroph zu ernähren, ähnlich wie es von Beggiatoa gilt. Den Gewinn ihrer Betriebsenergie (Atmung) ermöglichen sie durch Oxydation von anorganischen (nicht organischen) Stickstoffverbindungen zur höchsten Oxydationsstufe, den Nitraten, z. B.

$$
\underset{\text { Nitrit }}{\mathrm{NaNO}_{2}}+\mathrm{O}=\underset{\text { Nitrat }}{\mathrm{NaNO}_{3}}
$$

Es findet also keine Kohlenstoffatmung statt. Andere Bakterien sind imstande, den elementaren Stickstoff zu Salpeter zu oxydieren, während einige nur Ammoniakverbindungen in Nitrite umzuwandeln vermögen, z. B. Pseudomonas curopaea.

Salpeterbildung aus organischer Substanz findet reichlich in Rieselböden und biologischen Körpern statt (s. d. Abbild.), in welchen 


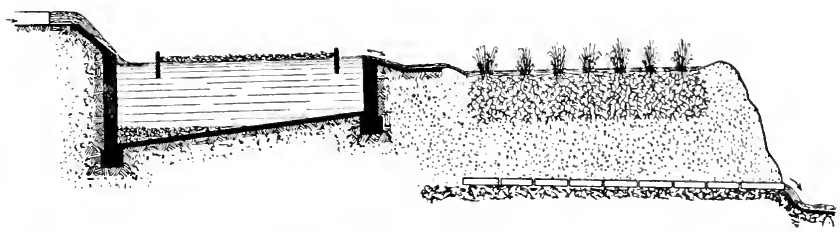

Abb. 46. Schematischer querschnitt durch ein Rieselfeld mit vorgeschaltetem Absitzhecken. Am Zulauf: Abwasser, vorwiegend eiweib- und ammoniakhaltig. In Vorbecken: Abwasser, Sinkstoffe und Schwimmschicht. Auf dem Rieselfeld: Graskulturen. Im Boden: Drainröhren; üher diesen der reinigende und filtrierende Sand. Am Auslauf: Nitrathaltiges Drainwasser. Das aufgeleitete Wasser braucht zum Passieren des Bodens etwa 1 Stunde. (Orig.)

Abb. 47. Biologiseher Tropfkörper. Das fänlnisfähige Abwasser wird durch einen Drehsprenger über einen Schlackekörper verteilt und beim Passieren desselben durch Organismentatigkeit in etwa $10 \mathrm{Mi}$ nuten fäulnisunfähig gemacht.
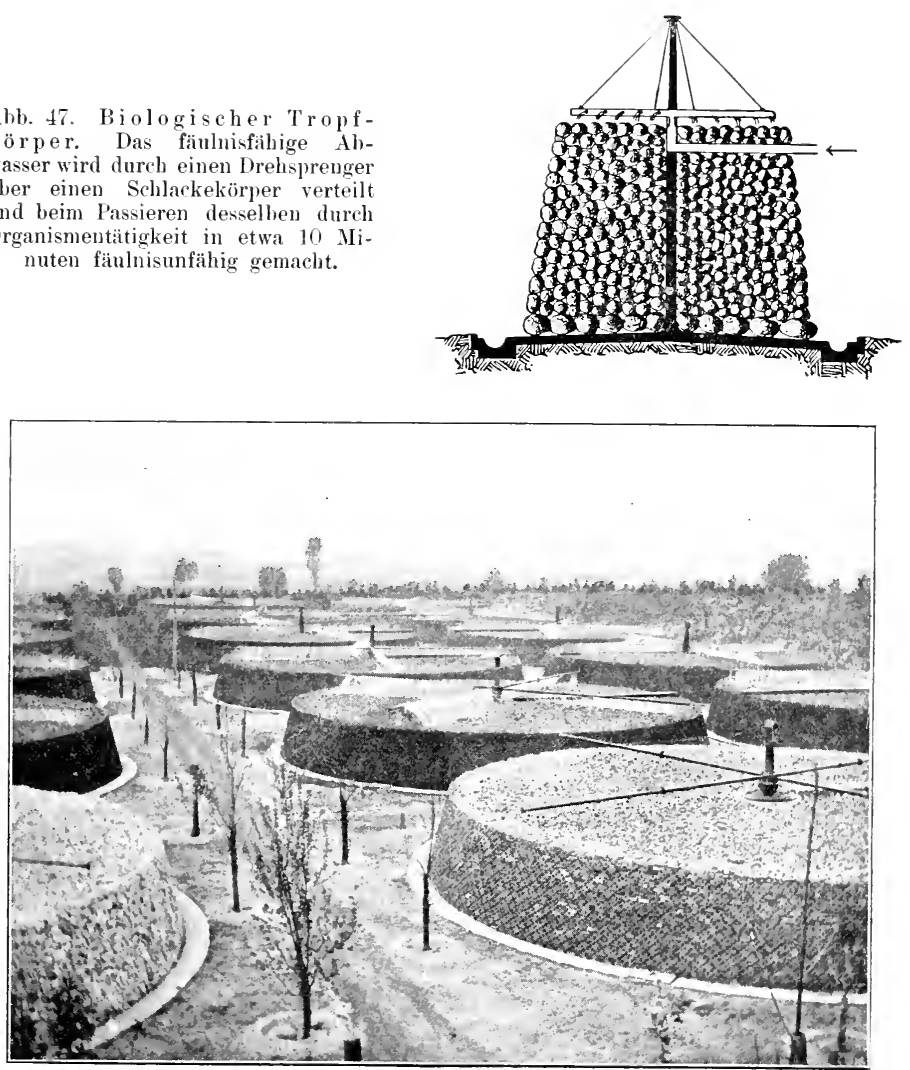

Abb. 4S. Biologische Tropfkörper der Stadt Wilmersdorf bei Berlin. Der Durchmesser jedes Körpers leträgt $20,0 \mathrm{~m}$, seine Höhe $2,5 \mathrm{~m}$. (Nach R. Kolkw it z.) 
gleichzeitig eine komplizierte biologische Oxydationsreinigung stattfindet, Absorption und Regeneration wechseln bei intermittierendem Betrieb miteinander $\left.a b^{*}\right)$. In den Drainabflïssen beider gelingt der Nachweis salpetersaurer Salze leicht, z. B. durch die Diphenylamin-SchwefelsäureReaktion (Blaufärbung). Ammoniak wird durch das Neßlersche Reagenz (ein in konzentrierter Alkalilauge gelöstes Doppelsalz von Kaliumjodid und Quecksilberjodid) nachgewiesen. Es bewirkt Gelbfärbung des Wassers: vgl. H. Klut (1).

Salpeterplantagen sind mit Jauche übergossene Kalkhaufen.

Rezept für Rohkulturen von Salpeterbakterien:

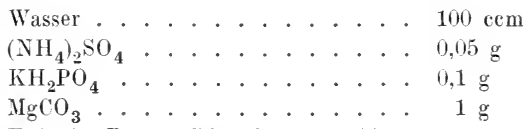

Erde (z. B. von Rieselfeld oder bio-

logischem Körper). . . . . kleine Menge

Wartezeit ......... bis einige Monate

Kulturgefäß . . . . . . Frlenmeyerkolben oder dgl.

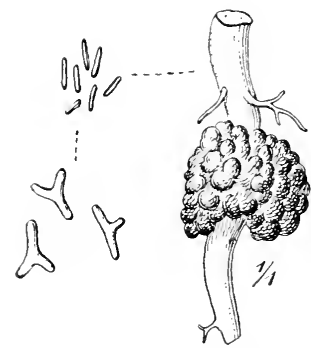

Alb. 49. Bacterium radicicola. Bakterienknöllchen der Lupine, dameben 1000 fach vergrößerte Bakterien und Bakteroiden.
Bacterium radicicola. Kinöllchenbakterium.

Die Knöllchenbakterien finden sich besonders in knotigen Wurzelanschwellungen der Leguminosen. Sie kömmen hier förmliche Nester bilden. Sie sammeln den Stickstoff der Luft, der dann den bewohnten Pflanzen zu gute kommt. Hierauf beruht der Wert von Griindiungung durch Lupinen.

Die Wurzeln mit den Knnöllchen eignen sich zu Formolpräparaten.

Bacterium tuberculosis. Tuberkelbakterie; s. Abb.

Sputumschleim wird zum Färben in dünner Schicht auf den Objektträger oder auf das Deckgläschen ausgestrichen, antrocknen gelassen und dreimal kurz durch die Flamme gezogen. Hierauf wird käufliche Ehrlichsche Anilinwasser-Farbstofflösung oder Ziehlsche Karbolfuchsinlösung auf das Präparat aufgetröpfelt, das ganze ïber der Gasflamme etwa eine halbe Minute lang bis zum Aufwallen erhitzt und noch eine Minute lang warm gehalten. Dann wird abgespiult, kurz mit 3\% igem Salzsäurealkohol $(100 \mathrm{ccm}$

*) Biologisehe Körper können für Laboratoriumsversuehe auch im kleinen hergestellt werden. 
abs. Alkohol, 3 (com Salzsäure) oder $\mathrm{H}_{2} \mathrm{SO}_{4}$-Alkohol ausgewaschen, wieder abgespiilt und mit schwacher, meist wässeriger Methylenblaulösung nachgefärbt. Hierauf wird das Präparat getrocknet und in Kanadabalsam oder Zedernöl eingebettet, nachdem man es vorher ohne Deckgläschen durchmustert hat. Die Tuberkelbakterien des Präparates erscheinen rot, die Gewebepartien blau; man benutze zur mikroskopischen Betrachtung Ölimmersion; vgl. auch C. Guinther (1).

Bacillus subtīlis. Heubazillus.

Dieser weit verbreitete Bazillus findet sich im Boden, im Abwasser, in Jauche, auf Mist usw. An der Oberfläche von Janche kann er Häute bilden. Bei $30^{\circ} \mathrm{C}$ wächst or reichlich

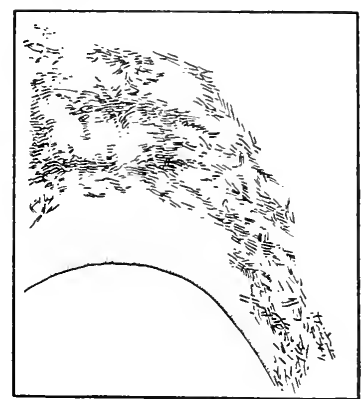

Abb. 50. Tuberkelbak terien aus einem gefärbten Schnitt durch eine Bronchialdrüse, in situ am Rand einer kleinen Arterie. Vergr. 500 fach. (Nach Rob. Koch.) auf ungehopfter Wïrze, findet sich auch in dïmnen Bieren, die in der Regel einen muffigen Himbeergeruch bekommen und dann, Limonadenbiere" genannt werden. Heubazillus heißt er deshalb, weil er anf Wasser, in welchem Heu abgekocht wird, Häute bildet. Seine sehr widerstandsfähigen, ovalen Sporen ertragen die Siedehitze. Gerade darauf beruht die Gewinnung reiner Kulturen durch Kochen von Heuinfus.

Nach den Untersuchungen von A. Nestler (1910) werden die Sporen des Heubazillus ïber 92 Jahre alt; sie fanden sich noch lebensfähig in der Erde von Moosen aus alten Herbarien.

Sporenpräparate werden — ähnlich wie Tuberkelbakterien in Schleim oder Gewebe - doppelt gefärbt, nur koche man 5-6mal mit der Fuchsinlösung auf. Die vegetativen Partien erscheinen im Präparat blau, die Sporen rot (Doppelfärbung).

B. subtilis gehört zu den schnell beweglichen Spaltpilzen: er legt bis $10 \mu$ pro Sekunde zuriick. Abbild. s. auf Tafel ,Pflanzen des Wassers“.

Bacillus amylobacter. But tersäurebazillus.

Zum Auffinden von Buttersäurebazillen (s. die Abbild.) übergieße man nach P. Lindner eine größere Portion zermahlener Malzkörner (vgl. das Kapitel über Stärkeverzuckerung) mit dem 2-3fachen Quantum Wasser in einem Erlenmeyerkölbchen und verschließe dieses mit einem Wattestopfen. Hält man das Ganze bei $40^{\circ} \mathrm{C}$, so wird bald Geruch nach 
Buttersäure (wie bei ranziger Butter) auftreten. Ihre Bildung erfolgt wahrscheinlich nach der Formel:

$$
\begin{aligned}
& \mathrm{C}_{6} \mathrm{H}_{12} \mathrm{O}_{6}=\mathrm{C}_{4} \mathrm{H}_{8} \mathrm{O}_{2}+2 \mathrm{H}_{2}+2 \mathrm{CO}_{2} \\
& \begin{array}{c}
\begin{array}{c}
\text { Trauben- } \\
\text { zucker }
\end{array} \\
\text { Butter- }
\end{array}
\end{aligned}
$$

Nach O. Emmerling (2) koche man Nilch und bringe sie in fest verschlossene Flaschen. Beim Aufbewahren bei ca. $37^{\circ} \mathrm{C}$ tritt eine sehr lebhafte Buttersäuregärung ein, deren gasförmige Produkte bisweilen die Flaschen zertrümmern. In diesem Falle wird die Buttersäure aus Milchsäure $\left(\mathrm{C}_{3} \mathrm{H}_{6} \mathrm{O}_{3}\right)$ gebildet. (Methode nach Botkin.)

Der Buttersäurebazillus findet sich auch in den meisten Erdbodenarten. Er entwickelt sich obligat anaerob, d. h. ohne Gegenwart von Saner-
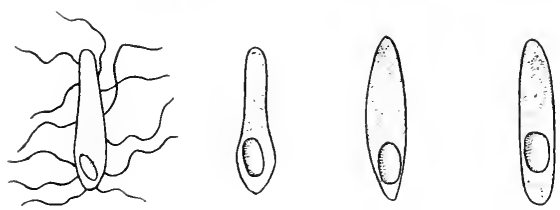
stoff. Es scheint aber auch Arten zu geben, welche aerob Buttersäure erzengen.

Anaerobe Bakterien

Abb. 51. Bacillus amylobacter. Zelle mit Geißeln (nach Löffler gefärbt), mit beginnender Sporenbildung. Verschiedene Formen sporenhaltiger Zellen bei sehr starker Vergrößerung. (Nach Bredem a n n.)

Die Stäbchen des Bacillus amylobacter sind beweglich; bei der Sporenbildung (die allen Arten der Gattung Bacillus eigentiimlich ist) werden sie, wie die Abbildung zeigt, meist spindelförmig, keulig oder trommelschlägelförmig. Sie sind imstande, den freien Stickstoff der Luft zu assimilieren und sind vielleicht im Verein mit Azotobacter an der stickstoffbereichernden Wirkung der Brache des Bodens beteiligt.

Zur Herstellung von Reinkulturen der Anaerobien kann man einen Buchnerschen Apparat verwenden.

Nach Herzfeld und Paetow sind Butter- nnd Milchsäureerreger Schädiger von Zuckersirupen. Man kann nach den genannten Autoren ihre schädigenden Wirkungen durch Zusatz von Flußsäure, Fluorammonium und Fluornatrium hemmen.

Bacillus calfactor. Heizungsbazillus.

Dieser Spaltpilz ist in erster Linie an der Selbsterwärmung des Heus beteiligt, in welchem er bei $70^{\circ} \mathrm{C}$ vegetieren kann.

Bacillus cellulosae methanicus. Sumpfgasbildner.

Der Erreger der Sumpfgasbildung ist durch die intensive Gasbildung bekannt, welche er durch Zersetzung von Zellulose erzeugt. Das brenn- 
bare Methan wird in Sümpfen, Teichen, Faulkammern (s. Abbild. und K. Thumm) oft in großen Mengen beobachtet, findet sich auch in dem

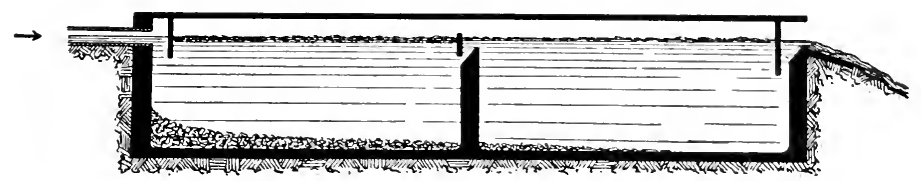

Abb. 52. Zwei hintereinander geschaltete Faulräume (englisch: septictanks) im Querschnitt. Stark verkleinert. Das einströmende Abwasser entledigt sich im ersten Becken seiner gröberen Sinkstoffe und bildet unter dem Schutze zweier Eintanchbretter eine feste Schwimmdecke; im zweiten Becken sind die Ablagerungen nur noch relativ gering. Aus dem Schlamm bildet sich unter dessen teilweiser Verzehrung viel Methan, aus den gelösten, oft weitgehend zersetzten Faulstoffen des Wassers viel Ammoniak infolge Mineralisation durch Bakterien.

Darm von Wiederkäuern. Reine Baumwollzellulose (z. B. Fließpapier) wird leichter angegriffen als Holzzellulose. Vgl. Näheres bei Omelianski in Lafar (1). Siehe auch H. Pringsheim (1).

Pseudomonas*) (fälschlich $B a c$.) fluorescens. Fluoreszierender Spaltpilz.

Ein ständiger Bewohner der Wässer und des Bodens. Auf Gelatineplatten an der Bildung eines griülich fluoreszierenden Farbstoffes kemntlich.

Pseudomonas (fälschlich Bac.) violacea. Veilchenblauer Spaltpilz.

Kenntlich an der Bildung dunkelvioletter Kolonien auf Gelatineoder Agarplatten.

Pseudomonas (Nitrosomonas) europaea. Nitritbildner.

Bildet ans Ammoniaksalzen Nitrite und ernährt sich autotroph.

$$
\underset{\text { Ammoniakverbindung }}{\left(\mathrm{NH}_{4}\right)_{2} \mathrm{CO}_{3}+3 \mathrm{O}_{2}}=\underset{\text { (Nitrit) }}{2 \mathrm{HNO}_{2}}+\mathrm{CO}_{2}+3 \mathrm{H}_{2} \mathrm{O} .
$$

Microspira desulfuricans. Gipszerstörer.

Die Techniker sagen bisweilen, Gips faule unter Wasser. Es handelt sich dabei nach den Untersuchungen von Beijerinck(1) un die Reduktionswirkungen durch diese im Sumpf lebende Microspira:

$$
\begin{gathered}
\mathrm{CaSO}_{4}+8 \mathrm{H}=4 \mathrm{H}_{2} \mathrm{O}+\mathrm{CaS}, \\
\mathrm{CaS}+\mathrm{CO}_{2}+\mathrm{H}_{2} \mathrm{O}=\mathrm{CaCO}_{3}+\mathrm{H}_{2} \mathrm{~S} .
\end{gathered}
$$

Man kann den Prozeß im Laboratorium, besonders bei höherer Thermostatenwärme, leicht nachahmen.

*) Pseudomonas ist, wie schon vorher bemerkt, polar begeißelt, Bacterium und Bacillus diffus, wenn überhaupt mit Cilien versehen. 
Spirillum undula. Schraubenbakterie.

Tritt fast stets auf, wenn man frisches städtisches Abwasser eine Zeit lang (einige Tage und mehr) stehen läßt. Solehes Wasser pflegt eine wahre Fundgrube fiir Bakterien und Protozoen,besonders farblose Flagellaten und Ciliaten, zu sein. Häufig auch in Tiimpehn mit stark zersetztem Laub und in Janche aus Kuhställen.

Berïhrt man mit der Fläche eines Deckgläschens die oberflächliche Schicht einer solchen (gestandenen) Flüssigkeit, so erhält man meist ausgezeichnete Klatschpräparate.

Eisenbakterien.

Crénothrix polyspora. Brunnenfaden (s. Taf. „Eisenbakterien“).

(Name von crenos $=$ Quelle. Brunnen und thrix $=$ Haar.)

Der Brunnenfaden gehört zu den Chlamydobacteriaceae, bei denen die Zellfäden wie ein Säbel in einer Scheide stecken. Er rechnet mit Chlamydothrix ochracea, Gallionella

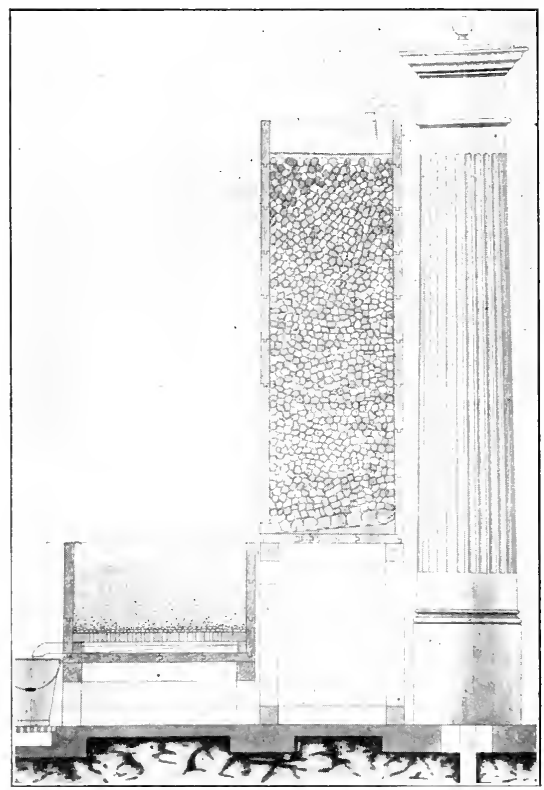

Abb. 53. Enteisenungsanlage für Brunnenwasser, bestehend aus Rieselkörper und Sandfilter. Es werden Eisenverbindungen und z.T. auch organische Substanzen entfernt. ferruginea, Clonothrix fusca und Siderocapsa treubii zu den Eisen- und Manganbakterien, welche sich gern an Lokalitäten finden, welche einen gewissen Gehalt an Ferrobikarbonat $\left[\mathrm{Fe}\left(\mathrm{HCO}_{3}\right)_{2}\right]$ aufweisen, z. B. Wiesengräben, Grundwässer, Fließufer.

In Wasserwerken, Brunnen usw. entwickehn sich Eisenbakterien oft massenhaft und können dann zı Kalamitäten beitragen. Diese werden in der Regel dadureh vermieden, daß man die Eisenverbindungen durch Rieseln unter Beliiftung (Enteisenungsanlagen) ausfällt und dann abfiltriert. (S. die Abbild. einer Enteisenungseinrichtung). Die Berliner Wasserleitung wurde besonders in den Jahren 1877 und 1878, in denen man Enteisenungsverfahren noch nieht kannte, von einer schweren Crenothrix-Kalamität heimgesucht. 

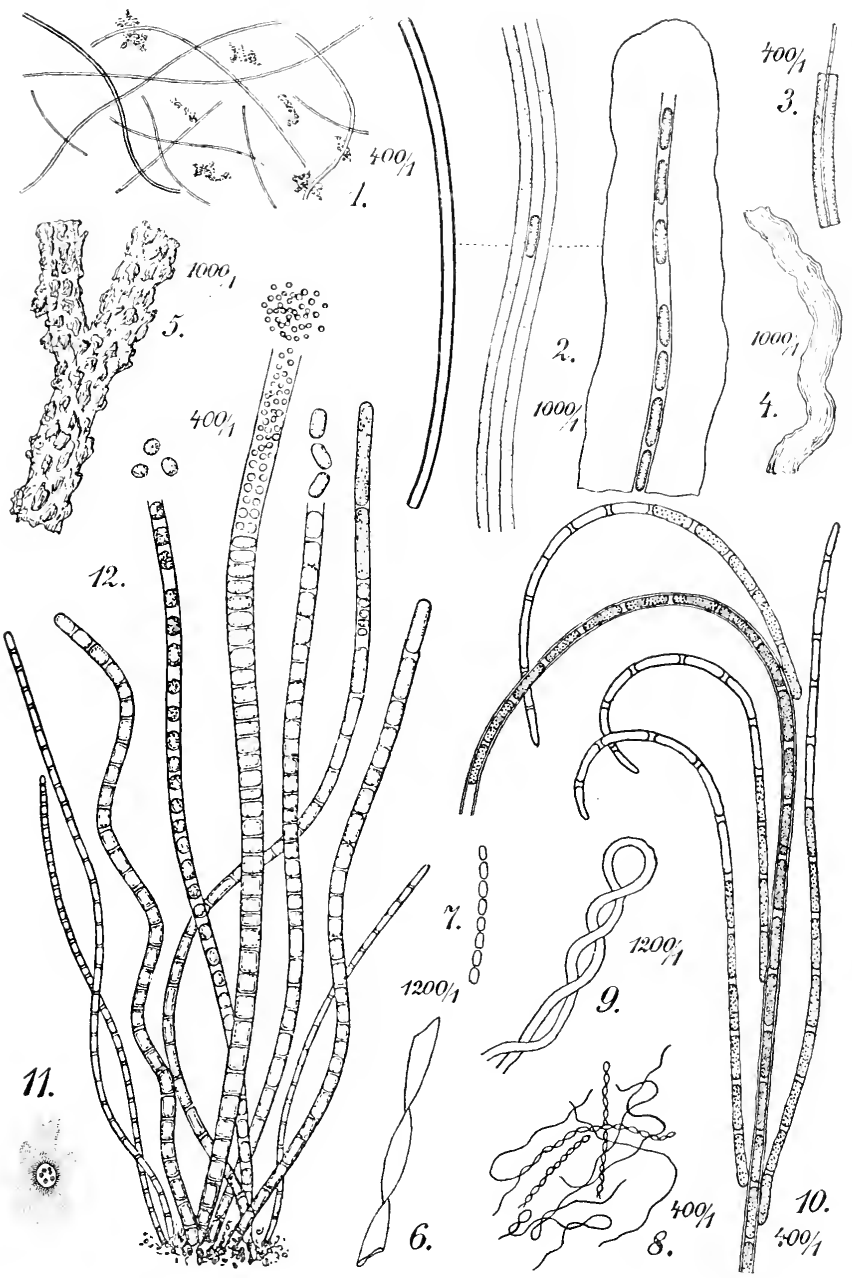

Eisenbakterien.

I Chlamydothrix ochracea, Scheiden und Flöckchen von Eisenoxydhydrat.

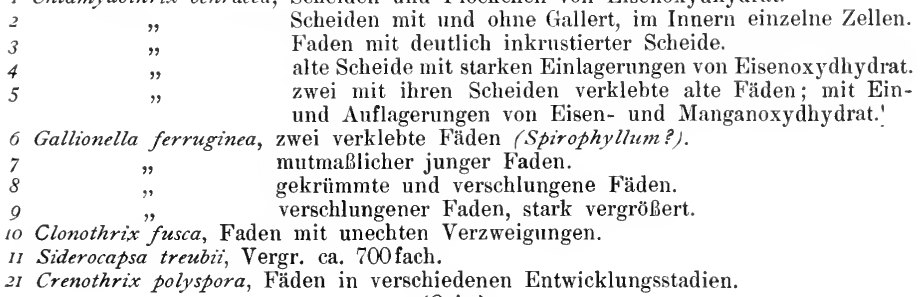


Über die Reinkultur von Eisenbakterien vergleiche man die Arbeiten von Molisch (3). Danach gelingt es, diese Organismen auch ohne nachweisbare Mengen von Eisenverbindungen zu normaler Entwicklung zu bringen, doch ändern solche Versuche mit Reinkulturen nichts an der Tatsache, daB die hier behandelten Bakterien in der freien Natur eisenhaltige Standorte bevorzugen. Wahrscheinlich verwenden sie hier Eisenazetat und ähnliche Verbindungen. Vgl. Kolkwitz(3). Es besteht die Annahme nicht zu Recht, daß alle Eisenbakterien mineralisch atmen nach der Formel:

$$
\underset{\text { (Ferrobikarbonat) }}{2 \mathrm{Fe}\left(\mathrm{HCO}_{3}\right)_{2}}+\mathrm{O}+\mathrm{H}_{2} \mathrm{O}=\underset{\text { (Eisenoxydhydrat) }}{\mathrm{Fe}_{2}(\mathrm{OH})_{6}+4 \mathrm{CO}_{2}}
$$

Fäden von Eisenbakterien erhält man oft, wenn man $100 \mathrm{l}$ und mehr Leitungswasser in starkem Strahl durch ein Planktonnetz oder Planktonsieb abfiltriert. Diese Methode, sich schnell Eisenbakterien zu verschaffen, ist an vielen Orten ïberraschend einfach.

Gute Exemplare der Eisenbakterien eignen sich ausgezeichnet zur Anfertigung von mikroskopischen Dauerpräparaten in Glyzeringelatine. Die Bräunung der Scheiden von Crenothrix durch Eisen- oder Manganverbindungen ist meist schwach, doch geben die Präparate gute Bilder von der Form und Entwicklung dieses hochdifferenzierten, fast größten aller Spaltpilze. Die Vermehrung geschieht durch Fadenzellen, große Sporen und kleine Sporen. Färlen, welche einem braunen Eisenockerschleimklumpen in größerer Zahl aufsitzen, gewähren nicht selten das Bild eines mit Erdballen ausgerissenen Grasbüschels.

Chlamydothrix ochracea. Gemeine Eisenbakterie (s. Taf.).

(chlamys $=$ Mantel, Scheide und thrix $=$ Haar. $)$

Sehr häufig in ockerhaltigen Wiesengräben, Grundwasserwerken usw. Zellen ohne Scheide meist ca. $1 \mu$ dick. Scheide in der Jugend diunn und wenig gefärbt, später sich verdickend und gelb bis braun werdend. Knorrige, alte Fäden sind bisweilen mit Stielen von Anthophysa verwechselt worden.

Gallionella ferruginea. Gedrehte Eisenbakterie.

(1823 nach Gaillon, Zolleinnehmer in Dieppe, benannt.)

Besonders in Eisenquellen häufig und unter dem Mikroskop durch seine gewundene Gestalt auffallend (s. Abbild.). Fäden häufig auch gestreckt. Es ist nicht ausgeschlossen, daß Gallionella nur eine Kümmerform von Chlamydothrix ist.

Clonothrix fusca. Verzweigte Eisen-und Manganbakterie. (Name von clonos $=$ Zweig.)

Eine stattliche und besonders durch ihre Verzweigung charakteristisch aussehende Eisenbakterie in Grundwässern und in der Uferregion von 
Oberflächengewässern. Scheide stets deutlich wahrnehmbar, im Gegensatz zu Crenothrix stark inkrustiert.

Farbe der Scheiden selten weißlich, meist gelbbraun (durch Eisen) bis dunkelbraun (durch Mangan). Kamn braun bis schwärzlich erscheinende, mehr oder weniger flockige Schlammabsätze in Brunnen und Hochbehältern von Wasserleitungen bilden. Oft in Gesellschaft von Crenothrix. Anhäufungen von manganhaltigen Fäden erscheinen dunkel wie Kaffeegrund, manchmal fast schwarz.

Das Mangan läßt sich leicht und einfach dadurch nachweisen, daß man eine Probe solchen Materials anf dem Platimblech mit einem trockenen Soda-Salpetergemisch in der bekannten Weise schmilzt. Es entsteht dann eine sehr deutliche blangriine Farbe.

Clonothrix ist physiologisch bisher so gut wie gar nicht studiert.

Siderocapsa treubii. Eis enkugelbakterie.

(Name von sideros = Eisen, capsa $=$ Kapsel, Hälle und Tre ub, holländ. Botaniker [1851-1910], früher Direktor des botanischen Gartens in Buitenzorg auf Java.)

Neuerdings von Molisch beschrieben. Bildet kleine (bis $20 \mu$ große) braume Flecken auf Elodea, V'aucheria, Cladophora u. a. m., welche in den Planktonkammern mit Lupen leicht beobachtet werden können. Bisweilen entstehen auch durch Verschmelzen von Kolonien förmliche Überziige. Zellen kugelig. Kolonien nicht mit Haftscheiben von Fadenalgen verwechseln! Physiologie noch nieht studiert.

Die Eisen- und Manganbakterien finden sich, wie oben bemerkt, vielfach in Wasserwerken, Brunnen usw. Viele Grundwässer, besonders solche der norddeutschen Tiefebene, zeigen einen beträchtlichen Gehalt an Eisen. Das aus dem Grunde geförderte Wasser ist anfangs oft klar, farblos und reich an Kohlensäure, welche Eisenverbindungen in Lösnng hält. Nach kurzer Beriihrung mit der Luft nimmt es eine leichte Trübung an, welche sich mehr und mehr verstärkt, bis ein gelbes bis gelbrotes, stark trübes Wasser entsteht [vgl. H. Klut(1)]. Es hat sich dabei folgender Prozeß abgespielt:

$$
\underset{\substack{\text { farbloses } \\ \text { Eisenoxydulkarbonat }}}{2 \mathrm{Fe}\left(\mathrm{HCO}_{3}\right)_{2}}+\mathrm{O}+\mathrm{H}_{2} \mathrm{O}=\underset{\substack{\text { rotbrannes } \\ \text { Eisenhydroxyd }}}{\mathrm{Fe}_{2}(\mathrm{OH})_{6}}+4 \mathrm{CO}_{2}
$$

Die Beliiftung unter gleichzeitiger Befreiung von zu reichlich vorhandener Kohlensäure erfolgt besonders ausgiebig, wenn das Grundwasser über Schlackebrocken oder dergleichen gerieselt wird, wie es die abgebildete Vorrichtung zur Enteisenung zeigt. Gleichzeitig fallen organische Substanzen teilweise aus. Nach der Filtration durch Sand oder Kies läuft ein ,blankes" Wasser ab, das weniger als 0,2 mgr Fe pro 11 enthält, beim Stehen einer größeren Quantität (z. B. 2 l) keinen gelben Bodensatz mehr 
bildet und Eisenbakterien keine Möglichkeit zu ïppiger Entwicklung bietet. Über das Dunbarsche Enteisenungsfaß vgl. O. Spitta (1) S. 99.

Das Rosten eiserner Wasser-

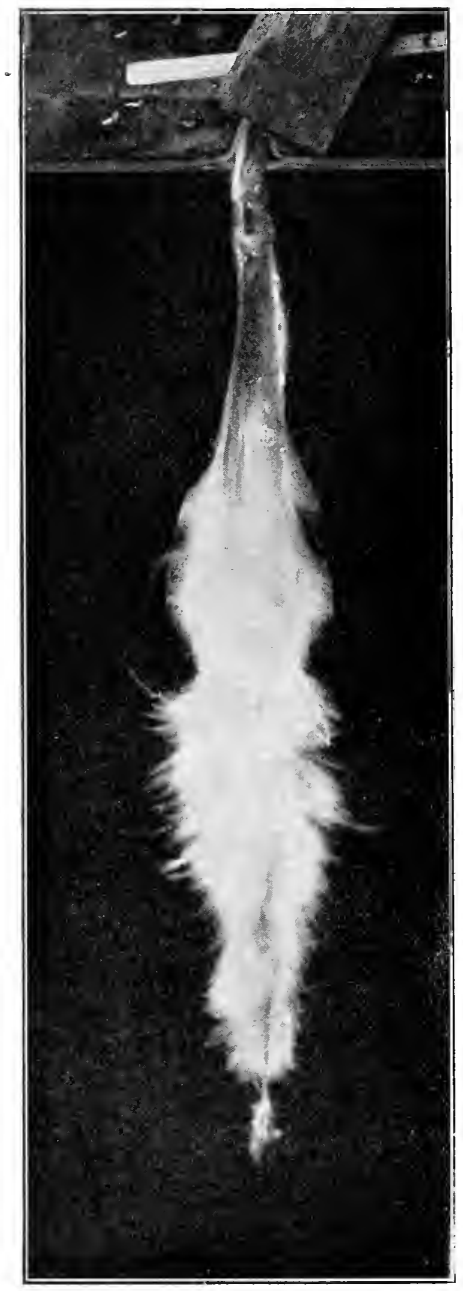

Abb. 54. Sphaerotilus natans, Besatz auf einem Schilfblatt. Nat. Gr. (Orig.) leitungsröhren wird durch chemische Prozesse bedingt, doch können Eisenrostpickel und -knollen in solchen Röhren ihren Anfang oft von einem organischen Partikel nehmen (z. B. von Eisenbakterienbiischelchen), um dann durch rein chemisthe Vorgänge weiter zu wachsen.

Die bleilösende Wirkung ron Trinkwässern auf Wasserleitungsröhren wird meist durch Kalkinkrustationen verhindert, doch scheinen anch manche Gallertbakterien einen biologischen Bleischutz zu bewirken.

Sphaerótilus natans, wichtigste Abwasserbakterie.

(Name von sphaeros = Kugel und tilos = Flocke.)

Der Pilz bildet, wie die Abbildnng zeigt, fellartige, weißliche Überziige in mit ernährenden organischen $\mathrm{Ab}$ wässern (aus Städten, Zellulosefabriken, Zuckerfabriken usw.) vermischten, fließenden oder durch den Wind bewegten Gewässern von pbis a m-Charakter (vgl. auch Leptomitus und die Abbild. auf Tafel „Pflanzen des Wassers"). Die zottigen, schleimigen Besätze erscheinen bei besonders guter Ernährung weiß-opak wie Stärkekleister, bei Festkleben von Eisenoxydhydrat und Detritus auch gelblich und grau. Bei guter Durehmischung undVerdïnmmg der dïngenden Zuflüsse kann die Entwieklung des Pilzes verhindert werden. Der Pilz findet sich festsitzend an Faschinen, Holzbohlen, Weidenzweigen, Schilf, Steinen usw. Sandufer bieten ihm keine genügenden Anheftungspunkte. 
Bei sehr starker Strömung kann er sich zwar am Uler und stellenweise am Grunde entwickeln, wird aber durch die Schärfe der Strömung ständig in feinen Fetzen abgeschoren. Wenn in cin verunreinigtes stehendes Ciewässer eine größere, reine Wasserader einfließt, kann in der Nähe dieser Stelle infolge der stattfindenden Bewegung und Beluiftung trotz gleichzeitig eintretender Verdinnung der latent vegetierende Pilz lokal zu iippigerer Entwicklung angeregt werden.

Das Zurïcktreten des Pilzes braucht nicht immer mit Abnahme der Nahrungszufuhr (Diingung) verbunden zu sein, da besonders beim Ansteigen der Temperatur Konkurrenten, die weniger auffällig sind, ihm erfolgreich die Nahrung streitig machen könne:. Damit mag die Erscheinung zusammenhängen, daß in den $80 \mathrm{er}$ Jahren, als die Zuckerfabriken noch bis in den Monat März hinein arbeiteten und Abwässer lieferten, der im Winter massenhaft entwickelte Pilz (,Pilzschleim") in manchen Gegenden schon Anfang März zurücktrat oder verschwand. Ähnliches mag rom Leptomitus gelten, der unter Umständen mit Sphacrotilus vergesellschaftet vorkommen kann.

Wie bereits bemerkt, verlangt der Pilz bewegtes Wasser; er ist also entweder stark sauerstoffbediurftig oder verlangt mechanische Durchspiilung, um nicht mit dem Getier zwischen seinen Fäden zu faulen. Zwischen seiner Wachstumsgeschwindigkeit und der Gefahr des Eindeckens durch Detritus, wobei er mehr zottig-filzig wie schleimig wird, besteht ein gewisses Verhältnis.

Sphaerotilus wächst auch bei niedriger Temperatur des Wassers schnell, falls die nötigen Nährstoffe vorhanden sind. Werden reichlich entwickelte Zotten entfernt, so wächst er im Verlauf einiger Wochen zu friiherer Ǘppigkeit heran, selbst wenn die Temperatur des Wassers nur $4^{0} \mathrm{C}$ oder noch weniger beträgt. Der Besatz eines einzigen Landungspfahles kann, wenn er abgekratzt wird (z. B. bei Eisgang), viele Kubikmeter Wasser mit unästhetisch erscheinenden Flocken erfüllen. Solche zum Teil klumpigen Flocken können sich in Fischernetzen festsetzen und diese verschleimen, auch an Stellen mit schwacher oder fehlender Strömung absinken und faulen (sekundäre Vermureinigung), während er sonst bei mäBiger Entwicklung für die Selbstreinignng eher niizlich sein kann, besonders in kleineren Wasserläufen. wofern er dort nicht die Ablage von Fischlaich hindert. In freien Wasser oder Schlamm kann der Pilz teilweise durch Schnecken (z. B. Paludina) u. a. m. gefressen sowie durch Insektenlarven zum Gehäusebau verwendet werden.

Unter ungiinstiger werdenden Ernährungsbedingungen treten die Scheiden und Pseudodichotomien (Cladothrix dichotoma) deutlicher hervor. Zellen etwa $2 \mu$ dick und $4-6 \mu$ lang, wegen der scheiden zu langen Fäden zusammengehalten. Bei mittlerer Vergrößerung erscheinen die Fäden wie feine Linien. Näheres s. bei Kolkwitz (3). 
Zoogloea ramigera (s. Tafel: Pflanzen des Wassers) kann durch Vergallertung der Fäden entstehen.

Sphaerotilus ist einer der wichtigsten Organismen zur Beurteilung der Gewässer; in nährstoffreichen Vorflutern ist er oft massenhaft entwickelt, in mineralisierten, reinen fehlt er.

Beggiatoa*) alba. Weiße Schwefelbakterie.

Beggiatoa bildet kriechend bewegliche Zellfäden, welche im auffallenden Licht weiß erscheinen, hauptsächlich wegen des Vorhandenseins feiner Schwefeltröpfchen, welche im Zellinnern durch Oxydation aufgenommenen Schwefelwasserstoffs entstehen. Bei $\mathrm{H}_{2} \mathrm{~S}$-Hunger verschwinden die Schwefeltröpfchen. Die Querwände, welche die Fäden gliedern, sind bei gewöhnlicher mikroskopischer Beobachtung meist nicht zu sehen, wohl aber bei Dunkelfeldbeleuchtung bei nicht ganz abgeschattetem Untergrund.

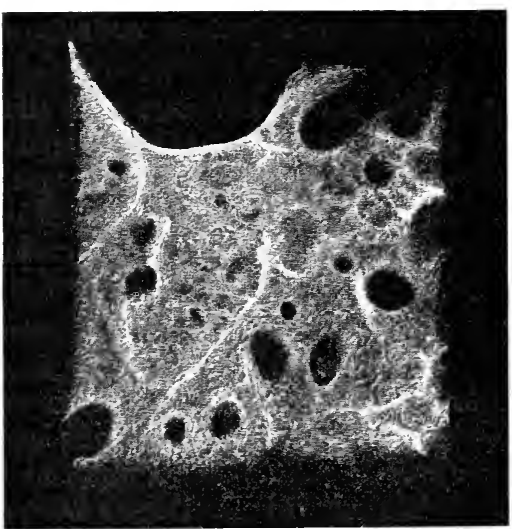

Abb. 55. Stück eines Schleiers von Beggiatoa in natürlicher Größe, auf schwefeleisenhaltigem Schlamm ausgebreitet. Die Löcher sind durch Hervorbrechen von Gärblasen erzengt. (Nach A. Engler.)

Bei Massenentwicklung bildet Beggiatoa in stehenden oder langsam fließenden Gewässern mehr oder weniger dichte weiße Hänte, welche in der Regel dem Schlamm anfliegen, wie die Abbildung zeigt. Sie kann nur da gedeihen, wo freier Schwefelwasserstoff vorhanden ist, da sie, wie Winogradsky zuerst fand, aus dessen Oxydation Betriebsenergie gewinnt.

$2 \mathrm{H}_{2} \mathrm{~S}+\mathrm{O}_{2}=2 \mathrm{H}_{2} \mathrm{O}+2 \mathrm{~S}$.

Der Schwefel wird weiter oxydiert zu Schwefelsäure, die durch Kalzium - oder Natriumsalze gebunden wird.

$$
2 \mathrm{~S}+3 \mathrm{O}_{2}+2 \mathrm{H}_{2} \mathrm{O}=2 \mathrm{H}_{2} \mathrm{SO}_{4}
$$

Nach den Untersuchungen von F. Keil(1) an reinen Kulturen können sich Beggiatoa und die verwandte Thiothrix rein autotroph ernähren, also ohne Aufnahme organischer Nahrung. Den Kohlenstoff liefert die freie Kohlensäure, während der Stickstoff aus Ammoniaksalzen anfgenommen wird.

Im Freien findet man fädige Schwefelbakterien in Schwefelquellen $\left(\mathrm{H}_{2} \mathrm{~S}\right.$ aus Sulfaten!) oder auf fanligem schlamm $\left(\mathrm{H}_{2} \mathrm{~S}\right.$ durch Fäulnis!),

*) Nach F. S. Beggiato, Arzt in Vicenza. (Der Name kann so gesprochen werden, wie er geschrieben wird.) 
z. B. solchem, auf dem sich zersetzte Wasserblüte von Spaltalgen angesammelt hat, ferner in Abwassergräben usw., häufig auch in Aquarien, auf deren Grund abgestorbene Daphnien abgesunken sind.

Rezept für Rohkulturen von Schwefelbakterien:

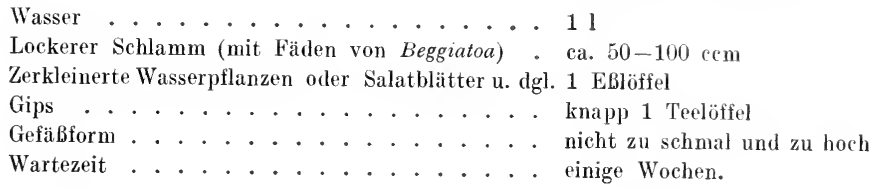

Man kann unter die Kulturglocke auch ein Schälchen mit Schwefelnatrium setzen, aus dem die Kohlensäure der Luft ständig Schwefelwasserstoff frei macht.

Nähere Einzelheiten über die Morphologie und Physiologie der Schwefelbakterien siehe bei Winogradsky in Lafar (1). Abbild. s. anf Tafel: Pflanzen des Wassers.

Zur Herstellung mikroskopischer Dauerpräparate ist Beggiatoa ihrer Zartheit wegen wenig geeignet; es verschwindet auch der in den Zellen eingeschlossene Schwefel sehr bald.

Eine sehr große, bis $45 \mu$ dicke Spezies, Beggiatoa mirabilis, findet sich an den Küsten des Meeres, z. B. am Grunde des Kieler Hafens.

Chromatium okenii. Rote Schwefelbakterie.

Die Zellen sind durch Geißeln beweglich, von roter Farbe und normalerweise mit deutlichem Gehalt an Schwefeltröpfehen. Der Organismus findet sich planktonisch in schwefelwasserstoffhaltigen Sümpfen, zwischen Algenfladen und an der Oberfläıhe von im Wasser zersetzten Substanzen. Auf Teichen, welche städtische Abwässer enthalten, bildet er nicht selten größere Flecken von der Farbe des Rotkohls. Manche Tümpel färbt er rot, daß sie wie mit Kirsehsaft erfuillt erscheinen (pro 1 ccm mehrere tausend Exemplare). Der Organis-

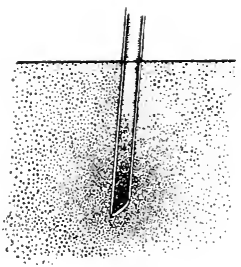

ci.

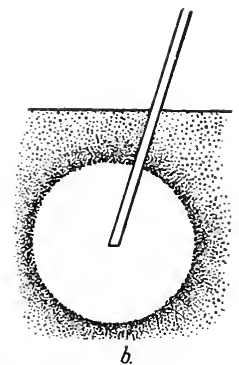

b.

Abb. 56. a Positive Chemotaxis von Chromatium weissii; die Kapillare enthält $0,3 \%$ Ammonnitrat; gezeichnet nnmittelbar nach dem Einschieben der Kapillare. $b \mathrm{Neg}$ a ti ve Che motax is von Chromatium weissi; die Kapillare enthält 0,5\% Apfelsäure. (Nach Mi yoshi.) mus ist heliotaktisch.

Chromatium weissii, das dem Chr. okenii ähnlich, aber etwas kleiner ist, wird nach den Untersuchungen von Miy oshi durch verdiinnte Lösungen 
von Schwefelwasserstoff, Ammoniumtartrat, Ammoniumphosphat und Kaliumnitrat positiv, dagegen durch höhere Konzentration dieser Stoffe

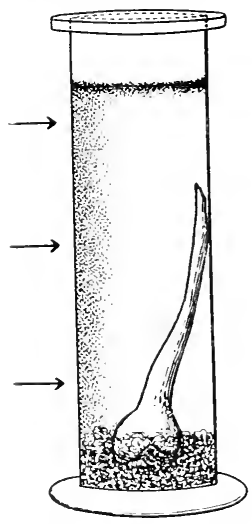

Abb. 57. Kulturvon Purpurbakterien. Im Gefäß, das mit einer halben Petrischale zugedeckt ist, Wasser, Schlamm und ein Stiick Knochen. An der dem Licht zugekehrten Seite hat sich ein Besatz von Purpurbakterien gebildet. Etwa $1 / 4$ nat. Gr. (Orig.) und durch $0,5 \%$ Apfelsäure negativ chemotaktisch beeinflußt (vgl. Abb. 56). Über die Natur des roten Farbstoffes vergleiche man das Kapitel betr. Karotin; ferner Molisch (4).

\section{Lamprocystis roseo-persicina. Pfirsichblït-} farbene Schwefelbakterie.

Dieser Spaltpilz ist eine unbewegliche rote Schwefelbakterie, deren Zellen zu Kolonien von oft charakteristischer Form vereinigt sind; rgl. Abbild. auf Tafel: Pflanzen des Wassers.

Rohkulturen von Purpurbakterien ver schafft man sich im allgemeinen leicht in der Weise, daß man Fanlfliissigkeiten oder Leitungswasser mit schlamm unter Zugabe eines frischen Knochens (nach H. Molisch) - in hohen, schmalen Ciefäßen (Glaszylinder, Präparatengläser, hohe Biergläser usw.) längere Zeit (bis monatelang) belichtet stehen läßt. Die hohen Gefäße werden gewählt, um den Luftzutritt zu erschweren; vgl. die nebenstehende Abbildung.

\section{Gruppe. Eumycetes, Fungi.}

\section{Hefen.}

\section{Vorkommen der Hefen.}

In der freien Natur kann man wilde Hefen vor allem da finden, wo zuckerhaltige Flüssigkeiten ausgeschieden werden, z. B. an Wundstellen siißer Beeren, in Baumfliussen und in den Honig (Nektar) sezernierenden Organen der Blïten.

Als Nektarorganismen sind bekannt: Etwa 10 Hefen, gegen 20 Bakterien und zwei Oidium-ähnliche Pilze.

Nektarhefe fand sich z. B. bei: Anthyllis vulneraria, Lathyrus silvester, Delphinium ajacis, Lamium album und Epilobium angustifolium.

Das Überwintern und längere Ausdauern der Hefen findet in der Regel im Boden statt.

Hefen finden sich häufig auch im Darm des Menschen und höherer Tiere, ferner auch in Insekten und Kleinkrebschen. 
Ganz allgemein bekannt ist die Verbreitung der Kulturhefen in Weinmost mnd Bier. thre Reinziiehtumg im Groben hat sehr viel zur sieherheit
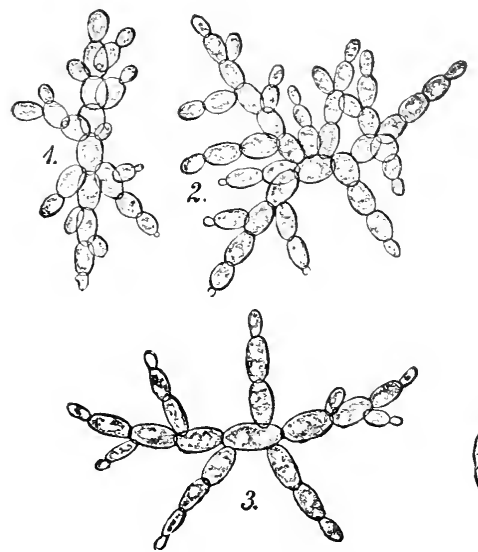

Abb. 58. Typen sparriger HefeSproßverbainde. Keimungsbilder von Preßhefen in der Lindnerschen Tröpfchenkultur. des Betriebes bei der Bereitung von Getränken durch Gärung beigetragen. Sishr leieht kamn man sich sehoine sprobibanmehen ron Hefen (s. die Abb.) aus Weibbiersatz versehaffen. Djo käufliche Prebhefe enthält in cler hegel meist nur Einzelzellen.
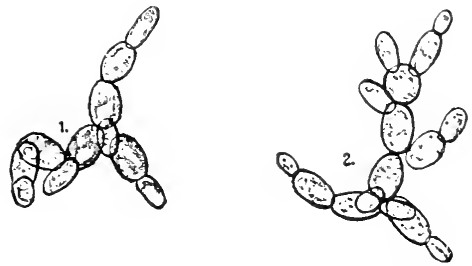

Ah. 59 Typen lockerer Hefe-Sprohverbände. Keinungsbilder von untergärigen Bierhefen in der $L$ indnerschen Tröpfchenkultur (nach 24 Stunden) Die einzelnen Glieder sind nur noch in lockerem Zusammenhang.

\section{System der Hefen.}

P. Lindner unterscheidet eine Reihe von durch wichtige Charaktere abgegrenzten Gruppen in der Orhmung der Sacrharomreetineae.

1. Gruppe:

Die Zellen bilden in zuckerhaltigen Nährfliissigkeiten sofort Bodensatzhefe. Die sporen sind glatt, rund oder oval. Die meisten Arten dieser Gruppe rufen Alkoholgärung hervor. Hierher gehört die bekannte, von Meyen 1838 aufgestellte Saccharomyces cerevisiae und die durch Kopulation der Zellen ausgezeichnete Zygosaccharomvees.

2. Gruppe: Die Zellen bilden in zuckerhaltigen Nährfliissigkeiten sehr rasch eine Kahmhant, also eine Oberflächenhaut (von stumpfem Aussehen). Die Sporen sind halbkngelig, eckig. hut-oder zitronenförmig. Die meisten Arten zeichnen sich durch ihre Esterbildung aus, einige rufen keine Gärung hervor. Viele wachsen, aber gären nicht. Sie fressen Alkohol, bilden ihn aber nicht. Hierher ge!rir z. B. Willia anomala (Syn. Saccharomyces anomalus).

3. Gruppe: Den Zellen fehlt das Merkmal der Sprossung: sie rermehren sich durch Teilung und heiBen deshalb Spalthefen, Schizosaccharomycetes. Sie finden sich ausschließlich in wärmeren Gegenden. Sch. pombc z. B. im Negerbier. 
4. Gruppe:

sporenbildung fehlt.

Mycoderma hat langgestreckte bis ovale Zellen mit Fetttröptichen.

Torula hat runde Zellen mit Fettröpfchen. Hierher gehören rote Hefen. Ihr Farbstoff ist ein Karotin; rgl. H. Will (1).

Die meisten Hefen haben ihren Ausgangspunkt in der Reihe der Endomycetes. in Formen ähnlich dem End. fibuliger [Abb. bei P. Lindner (2)]. Die Endomycetes finden sich an blutenden Birkenstümpfen, Bammrinden nsw. Sie bilden ein schimmelartiges Mycel mit seitlichen, sporenbildenden Zellen, mit Oidien und mit Chlamydosporen. Vgl. S. 109.

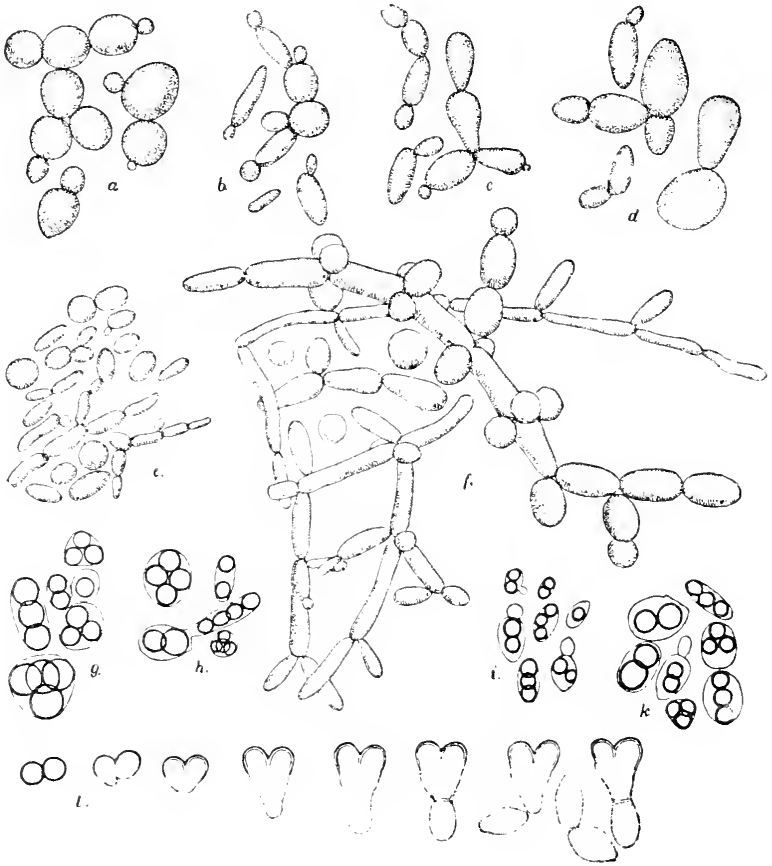

Abb. 60. Darstellung verschiedener Hefearten.

a Saccharomyces cerevisiae (Bierbefe).

$b$ Saccharomyces pastorianus.

Saccharomyces ellipsoideus I (Weinhefe).

d Saccharomyces ellipsoideus 11 .

- Saccharomyces ellipsoideus 1 als llaut wachsend.

$f$ Saccharomyces ellipsoideus 1 als Sproßmycel wachsend. $g$ Saccharomyces cerevisiae mit Sporen.

$h$ Saccharomyces pastorianus mit Sporen.

i Saccharonyces ellipsoideus I mit Sporen.

k Saccharonyces ellipsoideus $1 / \mathrm{mit}$ Sporen.

I Saccharomyces ludwigii, Sporenkeimung nach $18,20,26,28,29,30 \%$ und 33 Stunden. Die Verschmelzung zweier Keimlinge ist fakultativ. 
Als Inhaltsbestandteile der Hefen kommen vor allem in Betracht: Eiweiß, Fett und Glykogen.

\section{Kulturmedien und Kulturgefäße.}

Die Reinkultur der Hefen kann in Petrischälchen in ähnlicher Weise vorgenommen werden wie bei Bakterien, nur wird man einen anderen Nährboden nehmen, z. B.:

Malzextrakt $. \quad . \quad . \quad 5 g$
Pepton . . . . . . $0,2 \mathrm{~g}$
Gelatine . . . . . $10 \mathrm{~g}$
Wasser. . . . . . 100 cem

Pepton enthält Stickstoff und Kohlenstoff als organische Nahrung, ferner Phosphor, oft auch Kali, aber meist keinen Sichwefel. Der Malzextrakt ergänzt in geeigneter. Weise die bei alleiniger Gabe von Pepton fehlenden oder ungenügend vorhandenen Stuffe. Zum Herstellen von Reinkulturen auf Malz- oder Würzeagar verwendet man Lind nersehe Flase-hen (s. die Abb.) an stelle der Reagenzröluchen.

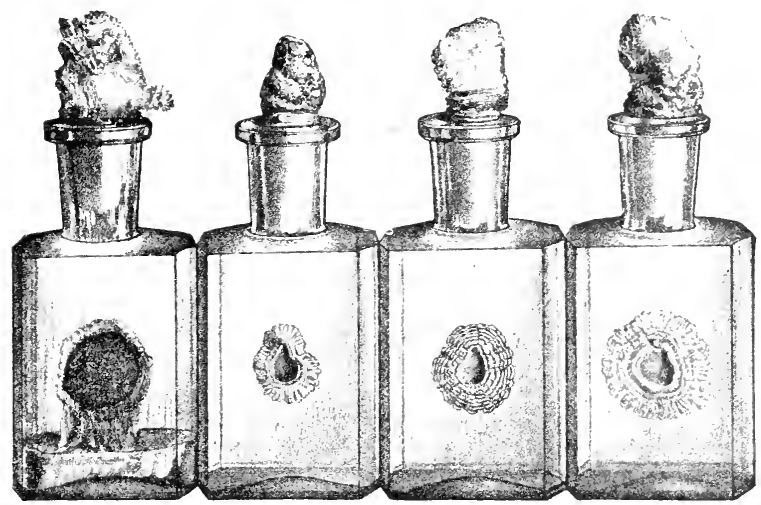

Abb. 61. Riesenkolonien von vier versehiedenen Hefen, ans einem kleinen Impftröpfehen entstanden. Das Alter beträgt etwa 4 Wochen. Die líolonic in der ersten Flasche hat die als Nährsubstrat dienende Gelatine verflüısigt. " der nat. Größe. (Nach P. Lind ner.)
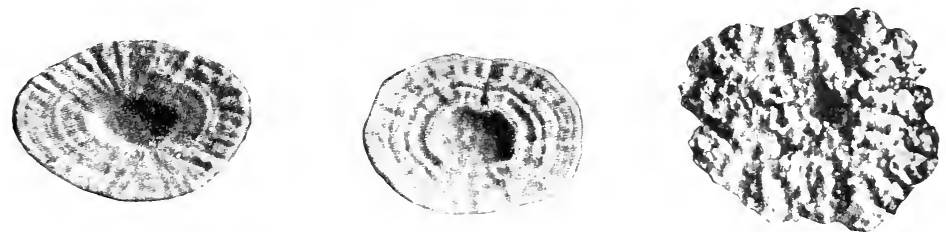

Abb. 62. Ii iesenkolonien von drei verschiedenen Hefen auf Würzegelatine, etwa 4 Wochen alt. Nat. Größe. Die Riesenkolonien geben sehr charakteristische Nerkmale zur Unterscheidung der Arten ab. (Nach P. Lindner.) 


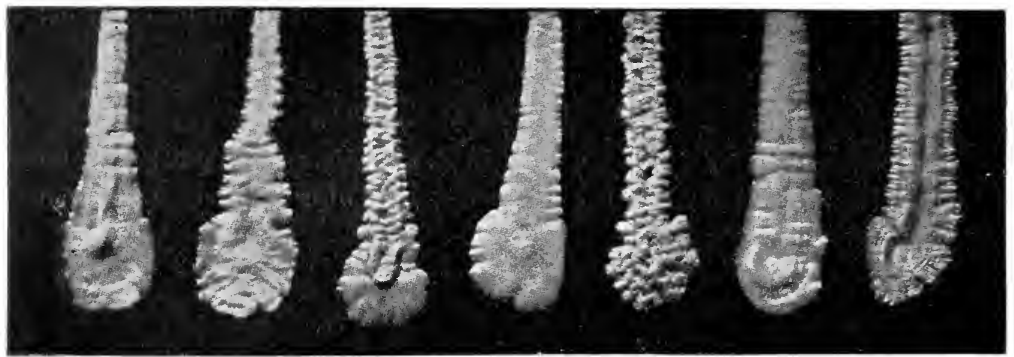

Abh. 63. Impfstrichkulturen von sieben verschiedenen Hefen anf Würzegelatine, etwa 4 Wochen alt. Die Kolonien sind nicht aus einer Zelle entstanden, sondern ans neheneinander liegenden Zellen, welche durch Ziehen eines Striches mit der Platinnadel aufgetragen worden sind. Nat. Größe. (Nach P. Lindner.)

Als Kulturflïssigkeiten kommen unter anderen in Betracht:

1. Kartoffelpreßwasser (sogenanntes Frucht wasser).

2. Gunt gärende Nährlösungen

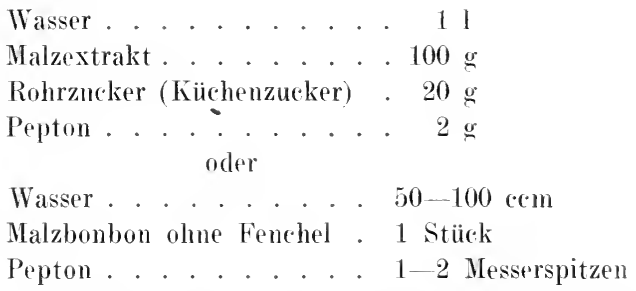

3. Pasteursche Nährlösung (zur Demonstration der Synthese des Eiweißes; s. anch dort).

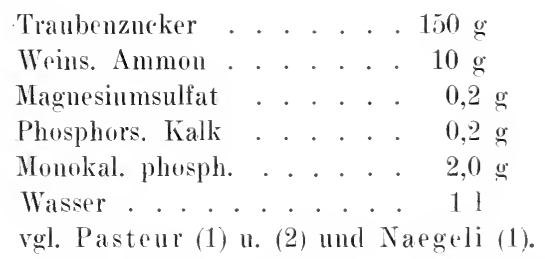

Die Lösung soll rein weiß, nicht gelb sein. Hier findet Eiweißsynthese aus weinsaurem Ammon und Traubenzucker statt. Das Eiweib in der gewachsenen Hefe gibt gute Rotfärbung mit Villons Reagens. Der Eiweibgehalt der Hefe ist hoch, so hoch wie der des frischen Fleisches.

4. Beijerincks Nährlösmng.

$\begin{array}{lr}\text { Traubenzucker . . } & 100 \mathrm{~g} \\ \text { Biammonphosphat . . } & 2 \mathrm{~g} \\ \text { Chlorkalium . . . . } & 0,1 \mathrm{~g}\end{array}$



Magnes. sulfat.
$0,(0,5)$
leitungswasser
11

Hinr wird Eiweiß aus Biammomphosphat und Traubenzucker gebildet.

5. Hayducksche Nährlösmmg

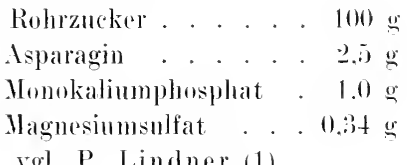

6. E. Chr. Hansensche Nährlösung:

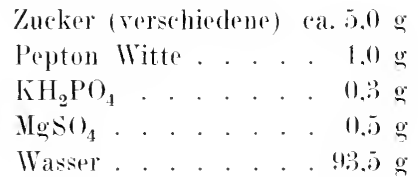

Als Kulturgefäbe kommen unter anderen in Betracht:

1. Cilaskolben vom 1, 1 I lnhalt.

2. Erlenmeyer-Kolben ron 100-200 ecm Inhalt.

3. Hohle (Objektträger mit Vaselinverschlul. am Rande des Deckyläschens. ()ft wird man dabei die fiir vicle wissenschaftliche Arbeiten monthehrliche Tröpfohenkultur von P. Lindner anwenden können, da sich in derseben rlie ungestörte Entwicklung der (Toanismen worhenlang rerfolgen läbt nnd dabei höchst charakteristische Habitushibler rntstehen.

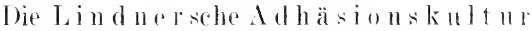
(diinme Nährlïsungstamellen an dem l)eckgläschem des hohben (0) jektträgers) gibt streng abene Kolonien. welehe für Mikrophotographir sehr geeignet sind und zum studium von Vegetationsgemischen im natiolichen Xährsubstrat (Speichel. Milch, Blut usw.) dirneu.

4. Ansgehöhlte kleine Gipsblöcke zur Förderung der sporenbildme: rgl. Linduer (1).

j. Gärlaschen von versohiedener Konstrultion.

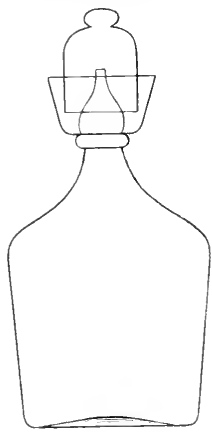

Abl, 6t. Gäplaseho. mithydranlischem fiarverschloli. Etwa 1 is mat. (irölie. l) nebenstehend abgebildete Gärfasche*) dient im praktiscben Grobbetrieh zum schmellen, orientierenden Vergälen von Vosten oder Fruchtsäfen bei Temperaturen von $18-25^{\circ} \mathrm{C}$. Hen friseben

* Von Ehrluardt n. Metzes in Darmstadt, Ph, Brann in Mainz msw. Flaschen von mehreren Litern Inhalı koston einige Mark. 
Sälten werden zur Erzielung regelmäBiger Gärung Reinzuchthefen (oder Bakterienkulturen) zugesetzt. Der Gärverschluß wird in einfachster Weise durch Einfiillen von Wasser in die den Flaschenhals umgebende Schale bewirkt (hydraulischer Gärverseblutb).

\section{Gärversuche.}

Ëne kräftige Gärung kann man in folgender Weise przielen:

Man füllt einen Literkolben zur Hälfte mit der Nährłösung Xr. 2 und verteilt darin ein etwa walunßgroßes Stuick käuflicher Preßhefe.

Nach 10-20 Minuten beginnt die Crärung, falls die Fliussigkeit nicht zu kühl ist: nach $1_{2}-1$ Stunde ist sie bereits sehr lebhaft. Yan giebt nun nach dem Lmschwenken der Flïsigkeit einen Teil derselben in ein Berberoder Wasserglas und stellt ein mit der gärenden Fliissigkeit bis zum Rand gefiilltes Reagenzglas hinein. Nach ctwa 30 Minuten wird dieses sich bereits bis etwa zur Hälfte mit Kohlensäure gefuillt haben. oboleich bei weitem nicht die ganze Kohlemsäure hineinsteigt. welehe in dem Becher- bzw. Trinkglas antsteht.

Durch Kalilaugestiickchen kïnnte man Absorption der Kohlensäure bewirken und diese so nachweisen, doch erfolgt die Absorption langsam. da die absorbierende Fläche verhältnismäbig kein ist.

Gibt man bei dem Versuch nicht acht. so kann das ganze Reagenzglas sich nach einiger Zeit mit Kohlensäure füllen, dadurch hochgehoben werden und herausfallen.

Einen einfachen Gärversuch kann man anch in der Woise anstellen. daß man in ein Reagenzglas Nährlösung und etwas Hefe füllt und mit einem Gummistopfen verschliebt. durch den ein rechtwinklig gehogenes Glasrohr gefiihrt ist. Dreht man das Ganze um. so tropft aus dem Rohr in dem Maße. wie sieh Kohlensäure bildet. Flüssigkeit heraus.

Will man die entstehendr Rohlensäure quantitativ bestimmen, so muß man sie in geeigneten Apparaten durch Barytlange leiten und deren Verbranch (infelge Bildung von Baryumkarbonat) durch Titrieren gegen Oxalsäure unter Verwendung von Phenolphthalein als Indikator bestimmen.

C̈ber genaue quantitative Gärversuche vergleiche auch den im I. Tril des Buches beschriebenen Lohnsteinschen Gärapparat.

Steckt man ein Thermometer in die gärende Fliissigkeit. so wird man leicht feststellen. daß eine Temperaturerhöhung um 2-30 C eintritt. Tabei darf man aber nicht vergessen, daß ein kleiner Teil der produzierten Wärme von der Lösung des bei der Gärung entstehenden Alkohols im Wasser herriihrt.

Hat der Gärversuch längere Zi it gedauert. so riecht die Fliissigkeit deutlich nath Alkohol, den man abdestillieren oder mit Hilfe der Jodoformmethode feststellen kann. Nan füge zu diesem Zweeke zu der filtrierten Fliissigkeit reichlich metallisehes Jod unter sthwachem Erwärmen und 
setze dann etwas nicht alkoholische Kalilauge hinzı. Beim Abkühlen wird man cinen Niederschlag von gelbem, typisch riechendem Jodoform erhalten. Die einzelnen Kristalle haben im allgemeinen die Form sechsseitiger Plättchen.

Setzt man zuckerhaltige Nährlösungen mit nektarienfiihrenden Bliiten an, so beginnt bei genïgendem Luftzutritt zunächst "iu Wachstum der Nektarhefen. Führt man dann die Gärmng unter Luftabschlub und Druck weiter, so entstehen kohlensäurehaltige, aber alkoholarme Getränke von besonderem Aroma.

Zur Demonstration einer ,Kleingärmethode“ bringe man aus dem Literkolben eine kleine Menge gärender Nährlösung auf einen hohlgeschliffenen Objektträger und schiebe unter Vermeidung von Luftblasen ein Deckgläschen ïber. Nan wird sogleich Bläschen von Kohlensäure entstehen sehen, welche man dureh seitlichesZufuigen von Kalilange absorbieren kann. Man beobachte diese Absorption unter dem Mikroskop.

Bei nichtgärenden roten Hefen entstehen naturgemäß bei dem Versuch mit dem hohlgeschliffenen Objektträger keine Kohlensäurebläschen. In diesem Falle wird Zucker mur zum Wachstmm der Hefezellen verbrancht. aber nicht durch enzymatisehe Wirkung zerstört.

Wie Versuche mit Indigokarmin- oder Methylenblanlissungen zeigen, kann anch während des Gärprozesses Verbranch rom Santerstoff stattfinden, aber nicht so intensiv wie bei der Atmung (s. dort).

Die Alkoholgärung ist in der Hauptsache ein Spaltungsprozeß. welcher, wenn man nur die Endprodulste beriicksichtigt, nach der Formel verläuft:

$$
\underset{\text { Traubenzucker }}{\mathrm{C}_{6} \mathrm{H}_{12} \mathrm{O}_{6}}=\underset{\text { Äthylalkohol }}{2 \mathrm{C}_{2} \mathrm{H}_{5} \mathrm{OH}}+2 \mathrm{CO}_{2}
$$

Rohrzucker wird erst durch Invertase in Monosaceharide verwandelt, ehe die Zymase ihn angreift.

Werden Hefen durch Einwerfen in Azeton getötet, so bleibt die von E. Buchner 1896 entdeckte Zymase als wirksamer Bestandteil zuriick, nachdem das Azeton verdunstet ist. Näheres s. bei F. Lafar (1).

Nach neneren Untersuchungen ist die Gärung mit der anaroben Atmung nicht identisch, obwohl bei beiden Alkohol gebildet wird.

Anßer der gewöhnlichen Alkoholgärung kommen auch noch andere Hefegärungen vor. So hat Felix Ehrlich (1) den wichtigen Nachweis geführt, daß höhere Alkohole, wie Amrlalkohol, und andere riechende Stoffe (z. B. Rosenduft), nicht durch Vergärung von Zuckern, sondern von Aminosäuren entstehen. 


\section{Schimmelpilze.}

\section{Rohkulturen einfachster Art.}

Das unvermeidliehe Verschimmeh vieler feuchter Substrate beweist, daß eine Reihe von Schimmelpilzen leieht ausreichende Ernährungsbedingungen findet.

Rohkulturen versehiedenster Art kann man sich in der Regel leicht verschaffen und zwar anf folgende Weise:

1. Nan tränke Brot, Semmel oder PflanzenpreBpapier mit verdiunntem Sirup, Pflanmendekokt, Malzextrakt oder dergleichen und bewahre es feucht auf. Dann werden in fast allen Fällen Schimmelpilze zu reichlicher Entwicklung gelangen, oft so reichlich, daß das ganze Laboratorium gleichsam versencht werden kann.

2. Frischer Pferdemist, unter einer (ilasglocke anfbewahrt. ist ohne jede Zutat ein vorziigliches Nährsubstrat, besonders fiir Incor.

$\therefore$ Nan driieke eine durchschnittene Kartoffel mit der Schnittfläehe auf dem Fubboden oder auf der Erde ab und lege sie unter eine Gloeke, welche mit etwas feuchtem FlieBpapier ansgekleidet ist und in einer wasserhaltigen schale steht.

4. Nan bewahre eine durehsehnittene Zitrone (am besten feucht) auf. Man kann damn mit Sicherheit die Entwieklung ron Pcnicillium auf den Schnittflächen meist nach etwa einer Woche erwarten. Dabei ist zu bemerken, daß frische Zitronen schwerer schimmeln als alte, brreits gedriickte.

Schimmelpilze bevorzugen im Gegensatz zu den meisten Bakterien sanere Substrate. Sie scheiden häufig anch selbst Sänren ans mnd vermögen dementsprechend Narmor|latten zn knrrodieren.

\section{Reinkulturen und Kulturgefäße.}

1. Petrischälchen mit Bakteriemmährgelatine geben die Nögliehkeit auch zur Entwicklung von Schimmelpilzen, wenn man die Platten einige Zeit (z. B. rine halbe Stunde lang) der Luft exponiert. Es entwickelt sich dabei in der Regel bald Penicillinm.

Läßt man dir Platte nach einer etwa halbstündigen Exposition noch 1-2 Wochen geschlossen stehen, so entwickelt sich oft noch das Cladosporium herbarum (s. lort).

2. In gleicher Weise kanm man statt Bakteriennährgelatine solche mit Malzextrakt, Pflaumendekokt oder dergleichen anwenden.

Pflanmenclekokt bereitet man in der Weise, daß man Batekpflanmen mit so viel Wasser iibergießt, daß alle Friichte qurade untertauchen. Der mit den Nährsalzen ans den Pflaumen 
auskristallisierte Zucker löst sich in diesem Wasser. Nath 24 Stunden gieße man dieses Wasser ab, ohne die Pflaumen auszudrïcken, da sich sonst Schleimsulsstanzen beimischen könnten. Hierauf filtriert man die lösung zwerkmäBig und diekt sie dann auf dem Wasserbade zu einem Sirup ein. Dieser ist seimer Konzentration wegen unbegrenzt halthar.

Um eine Nährlösung herzustellen, wird rinfath cin Teil dieses Sirups mit Wasser verdiinnt. Die Konzentration kann. wenn sie nicht ïbermäBig grob ist, ganz nach Belieben gewählt werden, da die meisten Schimmelpilze in bezug auf diesen Punkt absolut nicht wählerisch sind. Dic Lösung reagiert sauce und ist deshalb, wie bereits angedentet, fïr die knltur der meisten Bakterien wenig geeignet.

3. Diakonowsche Nährlösung:

\begin{tabular}{|c|c|c|}
\hline Wasser . . . . . & . & \\
\hline Chinasäıre (unvergärbar) & & \\
\hline Ammoniummitrat . . . & & \\
\hline Monokalinmphosphat & & \\
\hline Nagnesiumsulfat . . & & \\
\hline blorkalzium. & & \\
\hline
\end{tabular}

Gießt man von dieser farblosen Fliissigkeit, welehe die Synthese von Eiweib ans Chinasänre und Ammoniumnitrat zu demonstrieren gestattet, in flacher Schicht in rine Kulturschale aus, so kann man darin schimmelpilze sohr leicht kultivieren.

4. Raulinsche Nährlösung:

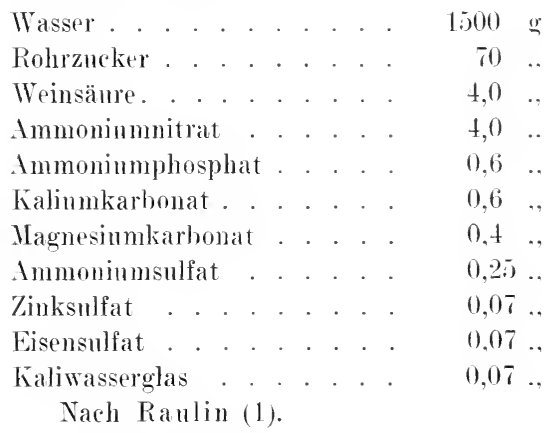

Diese Nährlösung liefert ein gntes Substrat, ist aber mmoötig kompliziert zusammengesetzt. 
5. Kultur in Lindnerschen Pilzgläsern anf Wiirzegelatine (vgl. (lie farbige Tafel).

P. Lindner hat 1913 auf folgende Verwendungsmöglichkeiten seiner (iläscr hingewiesen:

1. Kultur von Riesenkolonien, die zum Teil kïnstlerisch schöne Präparate lieferm.

2. Bestimnung der Wachstumsgeschwindigkeit ron Schimmelpilzkulturen.

3. Ermittelung der Keime der Luft unter Anwendung steriler Schachtehn aus Blech (z. B. Zigarettenschachteln).

4. Direkte Abbildung der gewonnenen Kolonien mit photographischem Papier.

5. Herstellung von allseitig sich im Raume entwickelnden Pilzkulturen (z. B. Mucor mucedo).

6. Kultur von geschlechtlieh differenzierten Pilzen nach Blakeslee (z. B. von Phycomyces nitens).

7. Sichtharmachung von Enzymwirkungen.

8. Sichtbarmachung von Desinfektionswirkungen.

9. Verwendung zu Gärversuchen.

Dazu sind in diesem .Jahre eine Reihe von Pilzen mit Anweisungen für ihre Kultur von P. Lindner in den Handel gegeben worden*).

Man läßt die Kulturen sich in den Gläsern beliebig lange entwickeln. Sir trocknen schlieflich rin und halten sich ohne jeden Zusatz von Konservierungsmitteln.

Die Lindnersche Nethode erinnert in manchen Punkten an die in der Bakteriologic erwähnten Esmarchschen Rollkulturen in Reagenzröhrehen.

Zahlreiche Photographien ron in Reinkultur gewarhsenen Schimmelpilzen finden sich in dem von P. Lind ner (2) veröffentlichten Atlas, Kulturmethoden von großer Einfachheit bei vollkommener Exaktheit in seiner ,,Mikroskopischen Betriebskontrolle"

\section{Übersicht über die Schimmelpilze.}

Phyeomyertes:

Hucor mucedo.

Phycomyces nitens.

Pilobolus crystallimus.

Saprolegnia monoica.

Leptomitus lacteus.

*) Bei Warmbrunn, Quilitz \& Co. in Berlin NW.. Heidestr. 

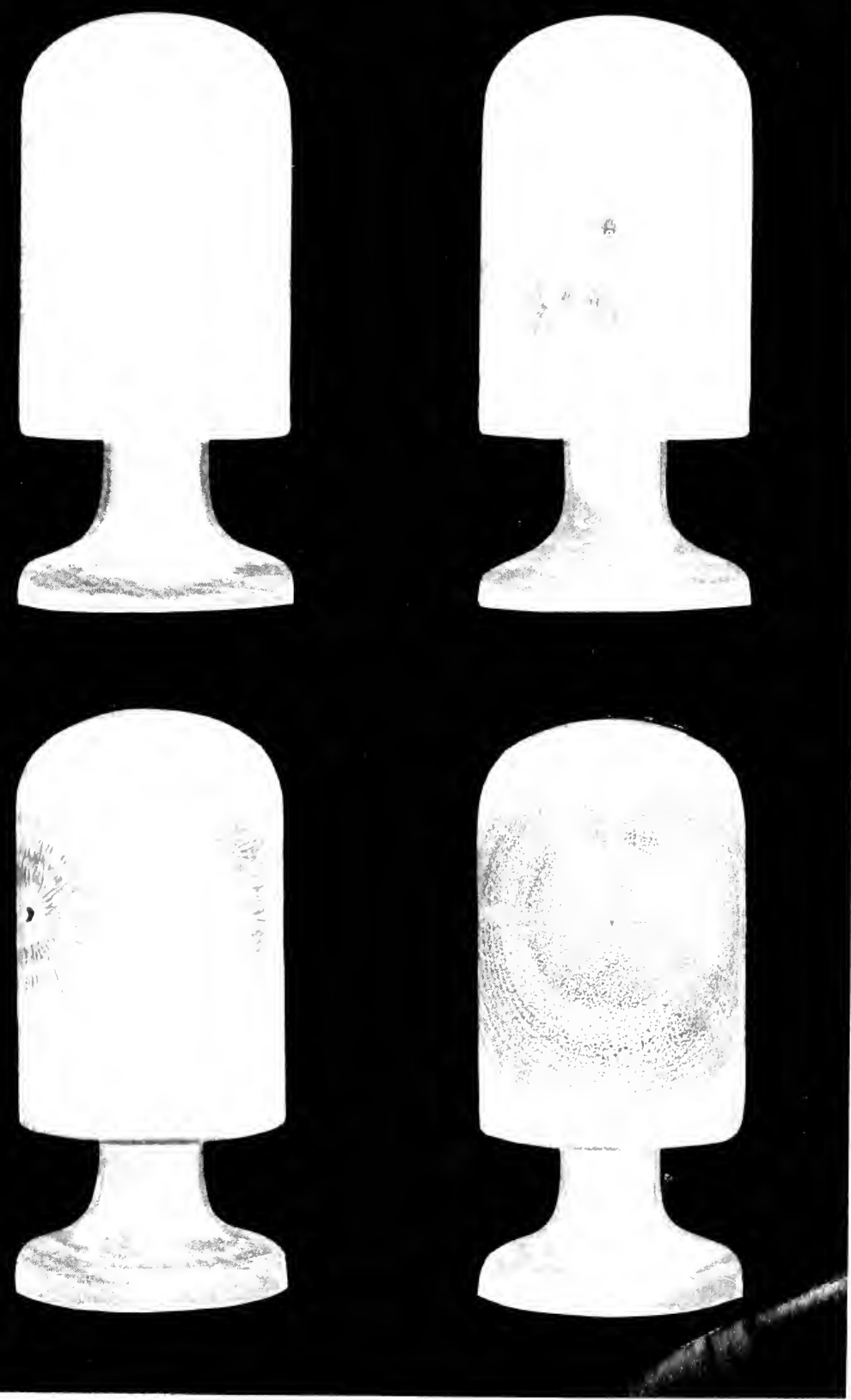

Milk aus Trebern

Monascus von Reiv isoliert
Pilzkulturen („Pilzrosen“) nach Lindner. : nat Grizse
Fusarimart won einem Rogyenteld. Prkindenschimurel 

Ascempretes:

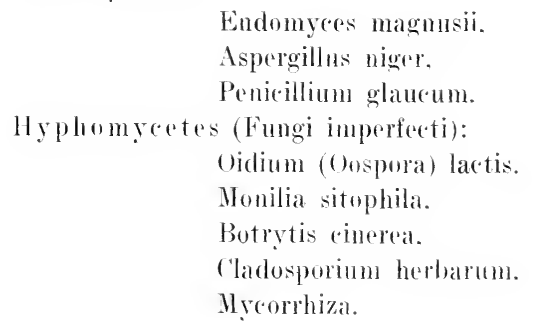

Mucor mucedo. Köplehenschimmel (Phycomycetes.

Es wurde bereits erwähnt. dab man Mucor sehr einfach und sicher auf frischem Pferdemist erziehen kann. doch wächst er anch auf anderen in Zersetzung befindlichen substraten.

Die Sporen der Kïpfehen sind ummittelbar nach erfolgter Reife keimfähig. In Mistdekokt iibertragen. sehwillt die Spore zunächst an und bildet damn den Keimschlauch, der sehr rasch in die Länge wächst und sich verzweigt. Das entstandene lyyel ist so gut wir querwandfrei.

Zygosporen sind bei Wachstum anf Pferdemist beobachtet worden.

Während M. muccdo ein Luftsehimmel ist, kïnnen M. raccmosus und M. (zygorhynchus) Wassersehimmel sein. wetele die Lfer nährstoffreicher Gewässer wie mit Schaffellen anszukleiden vermögen: vgl. das die Planzen des Wassers behandelnde Kapitel.

Ausfïhrliche Darlegungen ïber M. mucedo finden sich bri (). Brefeld (1).

Über. Mucor syzygites vol. L. Kuy. Wandtafehn 1099 nnd 110.

\section{Phycomyces nitens.}

Dieser durch seine groben, stark heliotropischempfindlichen S̈porangienträger bekannte Pilz (käuflich) eignet sich zn Kulturen in Lindnerschen Gläsern. Man unterseheidet nach Blakeslee + -Myeelien und - Mreelien. bei deren Zusammentreffen Zygosporen leicht entstehen. Das (wahrscheinlich weibliche) - - Mycol verarbeitet den Zucker besser als das + -Myeel. Der Pilz lindet sich besonders in G̈lmiblulen und Stearinfabriken an Fässern.

Pilobolus crystallinus. Hutwerfer.

Man sammele frischen (noch glänzenden) Hirsch- oder Rehmist in Walde und bewahre ihn unter einer Glasglocke auf. Es wird sich nach meinen bei Berlin gesammelten Erfahrungen mit absoluter Sicherheit der zierliche Pilobolus crystallinus entwickeln, an dem experimentelle Beobachtungen ïber Heliotropismus der köpfehentragenden Hyphen und iiber die Schleuder- 
kraft infolge bydrostatischer Entspammung angestellt werden kömnen: es sind die Sporen, welche durch diesen Hechanismns verbreitet werden.

Näheres s. bei 0 . Brefeld (1).

\section{Saprolegnia monoïca (11. a. Species).}

Wirft man tote Fliegen oder halbe Nehlwiirmer (wrlche man im Bedarfsfalle vorher durch Erwämen im Reagensglas sterilisieren kamn) in eine grobe Schale mit Wasser und etwas Sumpfschlamm, so entwickelt sich an den Wundstellen des Nährkörpers in den meisten Fällen der Wasserschimmel Saprolegnia in Form von weißen ansstrahlenden Büschehn.

Die Gattmugen Saprolegnia, Achlya, Aphanomyces n. a. m. befiallen anch Fische und Krebse; dabei liegt aber meist fakultativer Parasitismus vor, da vollkommen gesunde Tiere in infiziertem Wasser pilzfrei und lebenskräftig bleiben.

Eine Abbildung findet sirh in dem die Pflanzen des Wassers behandehden Kapitel.

\section{Leptomitus lacteus (= Apodya lactea).}

Der Pilz wächst wonfalls anf Nehlwïmen: man mub aber in der Regel eine kleine Probe des Mycels direkt anf die Schnitffläche aufimplen. Er ist die einzige Saprolegniacee. Welche in Massenbeständen im Frejen vorkommt und zwar als schaffellartiger Besatz in fließenden Ciewäsern mit organischen, cruährenden Substanzen. Näheress s. unter Nr. 102 der pflanzlichen Wasserorganismen.

Die nebenstehende Abbildung zeigt ein verzweigtes Fadenstiick mit Gemme, ein sporanginm mit reifen sichwärmsporen und junge Keimpflänzchen.
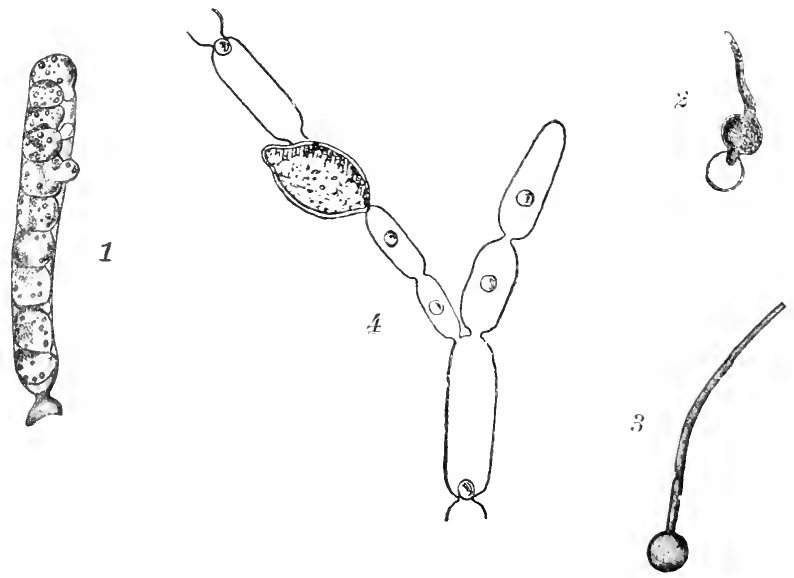

Ahb. 6.). Leptomitus lacteus. Verzweigter. Faden mit Gemme, Sporanginm mit reifen Schwämsporen, gekeimte schwärm-poren. Vergrößerung mittelstark. (O)rig.) 
Endomyces magnusii (Ascomycetes).

Der weiße Pilz (käuflich) eignet sich ausgezeielmet zu Kulturen in Lindnerschen Gläsern. Serine Myeel bilket in der Gelatineschicht zarte Verästelungen.

In der freien Natur lebt ar im gäirenten Stebleimfluls der biehen.

E. magnusii zeigt Beziehungen zu den spalthefen. E. fibutiger zu den siproßhefen. Ygl. S. 4 \&.

Aspergillus niger. Kolbenschimmel.

Der Pilz gedeiht sehr gut in Diakonowscher Nährlissung 11 . a. m.. eignet sich auch zur Kultur in Lindnersehen Gläsern. Sein Hyeel ist weib. während die Sporen schwarze Farbe besitzen. (welche in Ammoniakwasser löslich ist). Er scheidet krystallisierte, dendritische stoffwerhselprodukte aus, wahrscheinlich Tyrosin.

4. herbariorum entsteht, mit Askusfrüchten. ziemlich häufig zwischen feuchtem, gebrauchten Pflanzenprebpapier.

Penicillium glaucum. Grüner Pinselschimmel (u. i. Speciesı.

Derr Pilz ist 1874 von (). Brefeld besonders sorgfältig beschrieben und abgebildet worden. Die Sporen, welche ibberall verbreitet sind, keimen

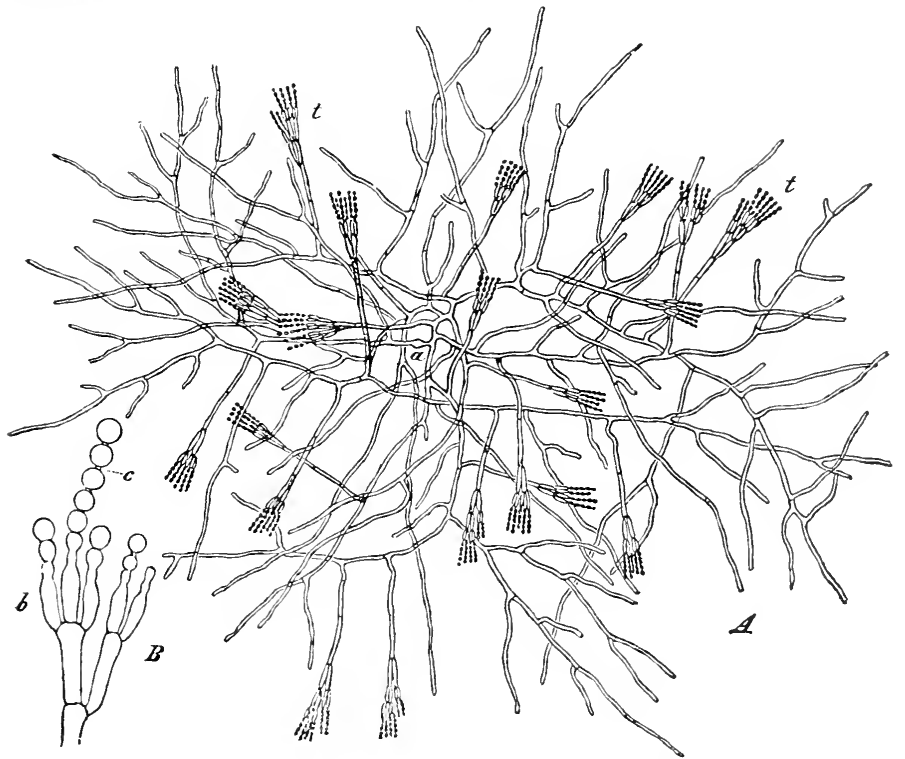

Abb. 66. Penicillium glaucum, Pinselschimmel. A 120 fach, B 730 fach vergrößert. $A$ stellt ein kleines Mycel des Pilzes mit ungeschlechtlichen Sporenträgern $t$ dar. Bei $a$ die Keimspore. $B$ zeigt den oberen Teil des Sporenträgers stärker vergrößert ; $b$ sind dessen Basidien, $c$ stellt eine Konidien-(Sporen-)Kette dar. Die jüngsten Sporen liegen an der Basis der Ketten. (Nach O. Brefeld.) 
mit 1-6 Keimschläuchen. Das entstehende Mycel ist reich gegliedert, benachbarte Äste können miteinander fusionieren. Die Form der pinselförmigen Konidienträger geht aus der Abbildung hervor. Die Bildung der Askusfrichte seheint selten stattzufinden.

Man kann den Pilz auf Gelatimeplatten leicht aus Luft einfangen. wie oben bereits bemerkt wurde. Solange seine Konidienträger noch umreif sind. d. h. noch keinc oder nur wenig grine Färbnng angenommen haben, eignen sie sich ansgezeichnet zum studium der Verzweigung der pinselartigen Träger. Man lege ein auf der Vnterseite befeuchtetes Deckgläschen auf und bringe die Petrischale mit der Kultur unter das Mikroskop. (Vergr. $200-300$ fach ).

P. luteum (käuflich) besitzt rin rotes Hycel und gelbe sporen. Es pignet sich gut zu Kulturen in Lindnerschen Gäsern.

$P$. brevicaulc dient zum Nachweis von Arsen; rol. Abel u. Buttenbere (1) und Lafar (1). Bd. I.

Bei Kulturen in Giasern und Petrischalen beobachtet man ofter ringförmiges Wachstum nach Art der Hexenringe. Bei manchen Schimmelpilzen, z. B. Penicillium lutenm, entstehen diese Ringe unter dem Einflub der Belichtung beim Wechsel von Tag und Nacht.

Oidium (Oospora) lactis. Milchschimmel (IIyphomycetes).

Dieser Pilz finclet sich häufig in Rahm sanrer Milch. erregt aber nicht die Nikchsäuregärung. Er gedeiht anch auf frischer siiber Milch. Brot, llist usw. Bei Kultur in Lindnerschen Gläsern tritt der Seidenglanz seiner Folonien besonders deutlich hervor. Der Pilz wächst ansgezeichnet in mineralischen Nährösmngen mit Alkohol als alleinige Kohlenstoffquelle.

\section{Monilia sitophila (E Oidium lupuli).}

Dieser Pilz zeichnet sich durch sein sehr schnelles Warbstum aus. Er ist känflich und zn Kulturen in Lindnerschen Gläsern geeignet. Das Mỵcol enthält nach Wrent Karotinoide.

M. fructigena und $M$. cinerea können auf Obstbäumen parasitären charakter tragen.

Botrytis cinerea. Grauer Schimmel.

Der Pilz lebt meist saprophytisch anf Pflanzenteilen und ist weit verbreitet. Bei einigen Arten der fattung finden sich ebenso wie bei den vorliegenden Sklerotien, welche an diejenigen von Sclerotinia fuckeliana erinnern. Er kann leicht anf Gelatinenährboden gezüchtet werden.

B. bassiana tötet die seidemanpen.

Cladosporium herbarum (= Dematium pullulans = Hormodendron cladosporioides, wahrscheinlich auch $=$ Mycosphaerella tulasnei).

ber Pilz entwickelt sirh oft auf (längere Zeit aufbewahrten) Gelatineplatten in Petrisehalen, welehe staubiger Luft ansgesetzt waren, in Form 
schwarzgriner Kolonien. In der freien Natur lebt er meist saprophytisch (selten parasitisch) anf Pflanzenteilen.

Nach neueren Untersuchungen von C'h. Ternetz und H. Froehlich scheint er den freien Stickstoff der Luft zu assimilieren.

\section{Mycorrhiza. Wurzelpilz.}

Der Name Mycorrhiza ist ein Sammelbegriff fiir gegliederte Pilzfäden, welche mit Wurzeln rerschiedener höherer Pflanzen in Symbiose leben, besonders bei Orchidaceae. Pinaceae, Fagaceae und Ericaceae. Mycorrhizen ron orchideen sind von H. Burgeff in Reinkulturen gezogen worden.

Abbildungen ektotropher und endotropher Mycorrhizen s. bei L. Kny nnd W. Magnus, Wandtafeln Nr. 116 und 117.

Zum näheren Studium der Formen niederer Pilze sei verwiesen auf G. Lind a u (2) и. (3) und P. Lindner (1) u. (2).

\section{Parasitische Pilze.}

Die durch Pilze an Pflanzen und Tieren erzeugten Krankleiten bzw. Lmbildungen beanspruchen ein eruährungsphysiologisches Interesse in ähnlicher Weise wie die Parasiten unter den Phanerogamen, welche im 1. Teil kurz behandelt sind. Die feinere Physiologie der Ernährung ist bei den s.hmarotzerpilzen noch verhältnismäBig wenig erforscht, wir sind deshalb in erster Linie auf die Schilderung solcher Erscheinungsformen in dieser Gruppe angewiesen, welche physiologische Ausblicke gestatten; vol. auch. H. Klebahn (1).

Beziglich der Bekämpfungsmethoden krankheiterzeugender Pilze sei anf die von der Kaiserlich Biologischen Anstalt für Land- und Forstwirtschaft in Dahlem herausgegebenen Flugblätter verwiesen, ferner auf die a. a. O. genamnte Literatur, auch auf G. Lindau (1). Die Abbildungen sind sämtlich Nenzeichnungen, teils Originale, teils nach den Arbeiten von Aderhold, Appel, Eriksson, Laubert n. a.

Eine kurze, aber inhaltsreiche Übersicht iiber die durch Pflanzen nud Tiere erzengten Krankheiten unserer Kulturpflanzen findet sich in der mit zahlreichen Abbildungen ausgestatteten Arbeit von O. Appel (2).

\section{Übersicht über einige Typen parasitischer Pilze.}

Myromycetes (s. dort).

Tafelfig. 1. Plasmodiophora brassicae.

Schizomycetes (s. dort).

Tafelfig. 2. Bacterium phỵtophthorum.

Phycomycetes.

Tafelfig. 3. Empusa muscae,

., 4. Cystopus (Albugo) candidus,

, 5. Peronospora viticola. 
Ascomycetes.

Tafeltig. 6. Exoascos pruni,

.. 7. Rhytisma acerinmm,

. 8 s. sphaerotheca mors uvae.

.. 9. Cordyeops militaris,

.. 10. Claviceps purpurea.

.. 11. Nectria einnabarina,

Monilia (siclerotinia) cinerea.

Basidiomyertes.

Talelfig.12. Ustilago avenae,

,. 13. Pnceinia graminis,

(Aecidium berberidis).

.. 14. Exobasidimm vaccinii.

Fungi imperfecti.

Tafelfig.15. Phoma rostrupii.

1. Plasmodiophora brassicae. Hernie.

Die Abbildung stellt eine Erkrankung der weiben Rübe dar. Näheres s. im Abschnitt s'chleimpilze.

\section{Bacterium phytophthorum.}

Erreger der schwarzbeinigkeit der Kartoffel. Näheres s. im Abschnitt Bakterien und im Flugblatt Nr. 28.

Die Krankheit wird dadurch bekämpft, dab man die befallenen Pflanzen vernichtet und fiir gesundes Saatgut sorgt, das vor dem Legen nicht zersehnitten werden darf. Dic zur Aussaat bestimmten Kartoffeln miissen im Winter trocken und kïhl lagern.

3. Empusa muscae. Schimmel ter Stubenfliege.

Der Pilz ist besonters anffällig an Fliegen, welche an Fensterscheiben verendet sind. Man erkennt dentlich einen weißen Hof rom Pilzsporen um die toten, anfgedunsenen Tiere.

Empusa ist stark pathogen und infiziert gesunde Tiere, welche man mit kranken unter eine Glocke bringt. Die keimenden sporen durcholringen die ('hitinhant. Die Kultur des Pilzes als saprophẹt auf geeignetem Nähragar ist möglich, aber sehwierig.

4. Cystopus (Albugo) candidus. Weißer Rost.

Die Abbildung zeigt den Pilz als weiben, beformationen bedingenden C̈berzug an den Fruchtstand des Hirtentäschelkrautes (Capsella bursa pastoris). Er befält an Berdem auch die stengel und Blätter. Andere ('ruciferen. wie Sinapis, Thlaspi usw., werden ebenlalls von dem Pilz bewohnt. Der durch ihn hervorgerufene landwirtschalthehe seloaten ist nur gering.

Näberess. bei de Bary (1) п. a. m. 

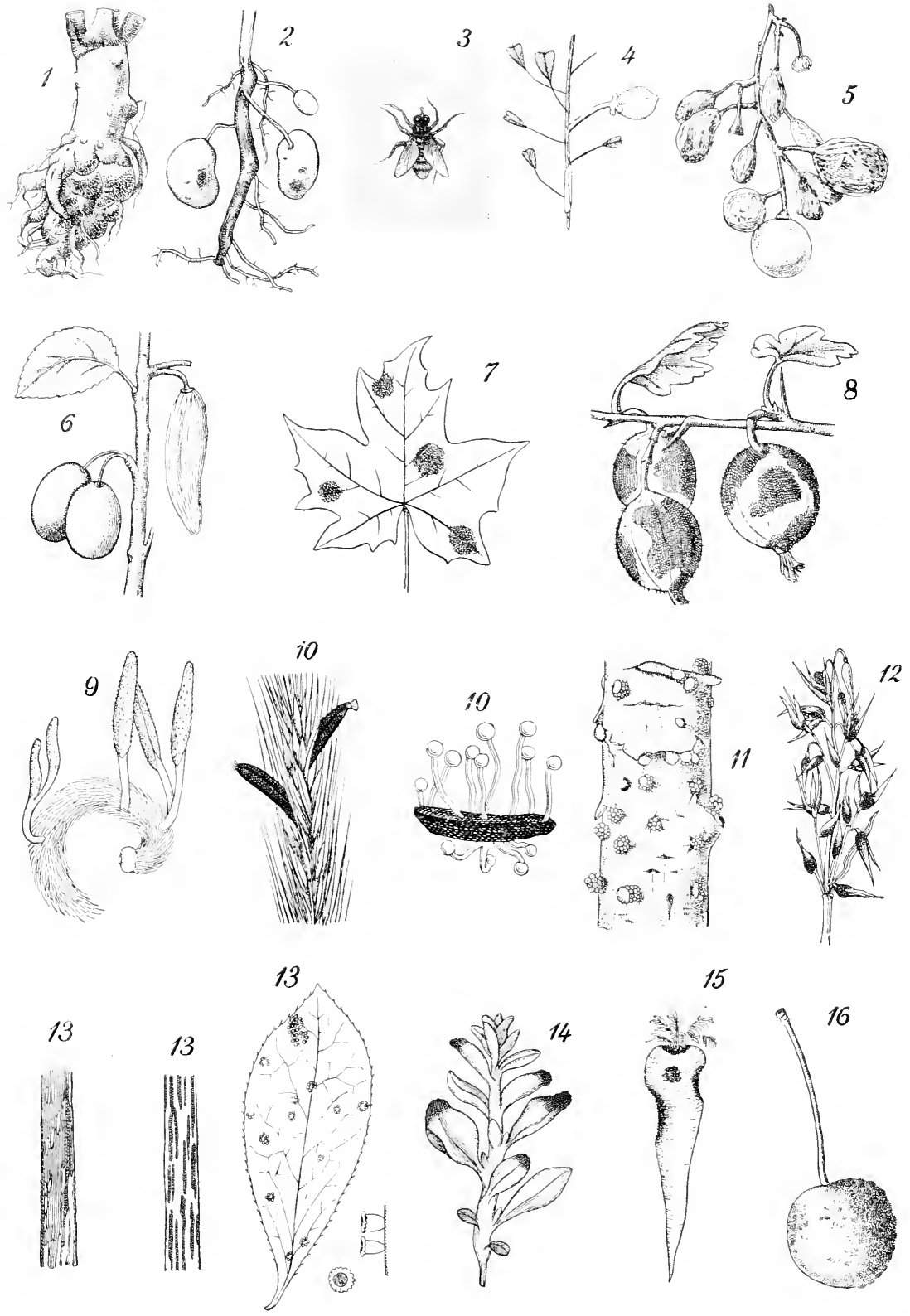

15

Parasitische Pilze.

Erläuterungen siehe S. 112. 

5. Peronospora Plasmopara) viticola. Falscher Mehltau des W'einstocks.

Der Pilz erzeugt weibliche sthimmelrasen besonders auf der Unterseite der Blätter, welche dadurch erkranken und abfallen. In den Trauben erzengt er "Lederberen“. Unter dem Mikruskou erscheinen diese Rasen zusammengesetzt ans bänmchenförmigen Konidienträgem, welche aus den spaltoffnungen hervorragen. Die Keimprodukte der Sporen infizieren die Weinstäcke von nenem und këmnen besonders bei reguerischer Witterung sehr zur Verbreitung der Krankheit und damit zul weitgehenden Verheerungen beitragen.

Der falsche Mehltan stammt ans Nordamerika; or ist fast noch gefährlicher als der echte (Oidium tuckeri $=$ Lncinula spiralis $=$ Aescherig), der in erster Linie Beerenkrankheiten, aher auch Blattbefall verursacht. Seine Bekämpfung geschieht durch Bespritzen der Weinstörke mit Kupferkalkbrihe, während gegen Oidium hauptsächlich schwefehn angewendet wird. Man vergleirhe Flugblatt Mr. 41.

Phytophthora infestans, ein schmutzigqraner Blattschimmel, bewirkt die Krautfänle der Kartoffelpflanzen. Xäheres siehe bei Appel u. Westerdijk (1).

- Olpidium luxurians (nicht abgebildet).

Parasitiert auf im Wasser schwinmenden Pollenkörnern, besonders der Kiefer. Läßt sich durch Aufstrenen von Pollen auf Oberflächenwasser einfangen. Eine gute Thersicht iuber die substrate, auf denen ('hytridineen und Aneylistineen leben, findet sich bei M. v. Minden (1). Über Chytridium olla vgl. Oedogonium.

6. Exoascus pruni. Taschenkrankheit der Pflaumen.

Der Pilz verunstaltet die Friichte bestimmter Pflaumensorten. Das Mycel durchzieht parasitisch auch Teile der Zweige und erzengt Askuslager als gelbgranen Reif auf den kranken Fritchten unter der Kutikula.

Diirre Witternng hemmt seine Entwickhng. Er wird in der Weise bekämpft, daßs man die kranken Früchte unschädlich macht (z. B. durch Verbrennen oder Eingraben) und die befallenen Zweige zuriacksehneidet. Näheres s. im Flughlatt Nr. 30.

7. Rhytisma acerinum. Teerfleckenkrankheit der Ahornblätter.

Das Bild zeigt die Krankheit anf einem Blatt des Spitzahorns (Acer platanoides). Die Membranen der Pilzfäden sind schwärzlich gefärbt. Askuslager entstehen auf den schwarzen Partien erst in Frïhjahr, nachdem die abgefallenen Blätter während des Winters auf dem Boden gelegen haben.

Der Pilz ist kein hesonderer Schädling. Man beseitigt ihn leicht, wenn man die kranken, abgefallenen Blätter verbrennt oder vergräbt (s. Flugblatt Nr. 29). 
$\therefore$ Sphaerotheca mors uvae. Erzeuger des amerikanischen Mehltanes des stachelbeerstrauclies.

Der Pilz befällt die Blätter, Triebe und Friichte des Stachelbeerstranches. Auf den Beeren crzeugt er branne, derbe Flecken, auf welchen Askusfrichte entstehen. Beziiglich der Bekämpfung vergleiche man Flugblatt Nr. 35.

\section{Cordyceps militaris.}

Der Pilz vermag, wie Versuche gezeigt haben, anch gesunde Rampen zu befallen und zn toiten. Sein weibes Mycel verbreitet sich in dem Körper der Raupe und treibt ans dieser die Asknsfrucht in Form gelbroter, auffälliger Keulen von mehreren, l,is 6 an Höhe.

Man findet den Pilz in manchen Jahren ziemlich häufig in Wäldern; die Raupen liegen flach unter der Erde, während die gelbroten Kenlen hervorragen.

10. Claviceps purpurea. Mutterkorn.

Der Pilz erscheint zunächst als sogenamnter , Honigtan“ an den Bliiten mancher Gräser, besonder's des Roggens, in seiner Konidienform. Mit dem Reifen der Ähren verdichtet sich das Mycel in den Fruchtknoten zu dem unter dem Namen Mntterkorn bekannten purpurschwarzfarbenen, Pesten Gebilde. Dieses, sklerotium" (Hartmycel) enthält Gifte [z. B. das Alkaloid Ergotinin $\left.\left(\mathrm{C}_{35} \mathrm{H}_{40} \mathrm{~N}_{4} \mathrm{O}_{6}\right)\right]$, sonst aber, wie alle speicherorgane, auch wertvolle Nährstoffe, wie Phosphor, Le(.ithin und Fett (bis $35 \%$ ).

Die sklerotien können zum Austreiben gebracht werden, wemn man sie bald nach der Getreideernte auf feuchten sand oder feuchte Erde legt und damit nur teilweise bedeckt. Bewahrt man die Kulturen etwas kiihl auf, so begimnen sich nach Verlauf von 3 ocler mehreren Monaten die in der Abbildung wiedergegebenen stiele mit rinem Käpfthen, in dem Perithecien mit Askusschläuchen eingesenkt sind, zu entwickehn.

Der Pilz wird dadureh bekämpft, dab man die Mutterkörner beseitigt und zur saat möglichst reines Material verwendet; vgl. anch Flugblatt $\mathrm{Nr}$. 221.

11. Nectria cinnabarina. Rotpustelkrauklıeit der Bäume.

Dieser Pilz macht sich besonders durch rötliche Knötchen auf meist abgestorbenen Ästen vieler Giehözarten bemerkbar: die Polster treten nach sprengen der Rindenpartién horvor.

Die Konidiendager sind hellrot, die Askushuehte dumkelrot. Die Farlstufle, welclue ihren sitz in den Membranen haben, sind mit siohwefelkohlenstofi extrabierbar.

I)er Pilz kamn anber als saprophyt anch als Wundparasit auftreten. 
Nectria ditissima erzeugt Krebs bei manchen Apfelsorten (Gravensteiner sind fast krebsfrei). Vgl. Flugblatt Nr. 17 u. 25.

Weitere Banmschätiger siche unter Polyporus.

- Monilia (Sclerotinia) cinerea. Abb. 16.

Diese Monilia belällt besonders Kirschen und macht die Früchte faul. Scl. fructigena findet sich mehr auf Kernobst.

Die Bekämpfung der Krankheit geschicht daturch, daß man alles Kranke verbremnt oter vergräbt. Näheres s. im Flugblatt Nr. 14.

12. Ustilago avenae. Flugbrand des Hafers.

Das Mycel des Brandpilzes wächst mit der sich entwickelnden Pflanze empor und zerstört die Bliiten, in denen sich die bekannten verstäubenden dunklen Brandsporen entwickeln. Die Abbildung zeigt einen Teil einer Haferrispe, in der tie Zerstörung an den unteren Partien der Spelzen sichtbar ist. Der Pilz kann die ganzen Ährchen in eine schwärzliche Hasse verwandeln.

Die Brandsporen keimen schon in Wasser, doch pflegen Nährlösungen die Keimung zu förtern.

Man bekämpft den Pilz durch vorsichtiges Behandeln des Saatgutes mit Formalin oder Heibwasser, wodurch die sporen abgetötet werden; vgl. Flugblatt Nr. 38.

Tilletia caries verursacht den Stinkbrand des Weizens. Der Geruch der Sporen wird durch Trimethylamin bedingt.

Näheres s. im Flugblatt Nr. 26.

13. Puccinia graminis. Rost der (ietreidepflanzen.

Nach Thomas Puccini, Professor der Anatomie am Lyzeum zu Florenz.

Der Pilz findet sich auf allen Getreidesorten und auf vielen anderen Gräsern; er erzengt hier rotgelbe Uredosporen und braune Teleutosporen. Die Aecidiumbecher entstchen auf den Blättern der Berberitze oder auf denen von Mahonia aquifolium (Wirtswechsel). Sie werden dort als Berberitzen-Fleckenrost oder-Becherrost bezeichnet (s. die Abb.).

Mit etwa 14 fach vergröbernden Lupen kann man oft ausgezeichnet (und besser als mit 25 mal vergrobernden) beobachten, dab die Teleutosporenlager (z. B. auf schilfblättern) unter der Epidermis hervorbrechen.

Will man von solchen sporen mikroskopische Danerpräparate anfertigen, so befenchtet man sie zuvor mit Alkohol und kratze sie damn mit einer Nadel oder dergleichen ab.

Die Aecidium-Becher*) eignen sich sehr gut zu mikroskopischen Trockenpräparaten anf schwarzen objektträgern mit anfgekittetem Ring. Die Präparate liefern bei sthwacher mikroskopisther Vergröße-

*) Solche Becher finden sich in der sammlung Brendelscher Moslelle. 
rung sehr gute Bilder, wenn man sie von oben her mit einer hellbrennenden elektrischen Taschenlampe beleuchtet. Auch Teleutosporen, besonders von Phragmidium rosarum, lassen sich auf diese Weise gut beobachten.

Klima und Boden sind von Einflub auf die Heftigkeit, mit welcher lie Krankheit anftritt.

Die bekannte Ungestaltung der Wolfsmilch (Euphorbia cyparissias) wird dureh das decidium-Stadium von Uromyces pisi bewirkt.

Näheres s. bei H. Klebahn (1 u. 2).

\section{Exobasidium vaccinii.}

Der Pilz schmarotzt auf den Arten der Gattung I'accinium, besonders anf den PreiBelbeeren ( $r$. vitis idaca), deren Blätter und Stengel er befält und fleisehig auftreibt. Die weiben Lager der Basidien (Hymenimmschicht) entstehen unter der Epidernis und brechen durch diese hervor.

15. Phoma rostrupii.

Dieser Pilz befällt dir Mohrriibe (Dancus carota) an den Wurzeln und Stengehn. Die geschädigten stellen bilden die Herde zur Entwicklung von Pykniden in Form von kleinen Knötchen. Die sporen treten aus diesen als wurstartige Gallertmassen aus.

Die durch den Pilz befallenen Nohribenpflanzen setzen in der Regel keine Früchte an. Die Krankheit tritt hauptsächlich in Gegenden mit Seeklima anf. Die Gattung Phoma hat anch Vertreter, welche sich im Wasser entwickeln und dort einen weiBen Wasserschimmel bilden.

16. Monilia cinerea. Siehe unter Ascomycetes.

- Fusicladium dendriticum (nicht abgebildet) lildet die bekamnten schorfigen, harten Flecken, besontlers anf Äpfeln, ohne sie eigentlich zu verderben. Anf der Birne findet sich F. pirimum. Näheress. im Flughlatt $\mathrm{Nr}$. 1. 5. Aufl., 1911.

\section{Höhere Pilze.}

Dis Physologie der hoheren Pilze ist zurzeit noch wenig erforscht. jedenfalls nicht so grimellich wio ihre Norphologie und zum Teil auch Entwicklungsgesehichte. Die standortsverhaltnisse und somstige Lebens- nud Formeneigentiunlichkeiten dieser Gruppe bieten aber soviele Hinweise anf ihre Ernährung und ihren stoffweehsel, dab sich immerhin ein einigermaben alogerundetes Bild von ihrer Lehenswoise in Beziehung zum ernährenden Medium geben läbt.

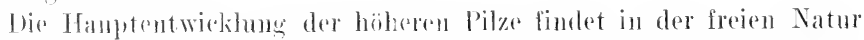
im suatsommer und Ilerbst statt, wemn vorwiogend fenchtes und warmes 
Wetter herrscht. Dureh die mm diese Jahreszeit im Boden stattlindenden Zersetzungsprozesse werden die Ausbreitung des Myeess") im Boden und das Hervorbrechen der Pilzkorper wesentlich begiustigen. Viele Pilze zeigen eine sehr schnelle Entwicklung, da sie iiber Nacht emporschieloen kömnen, sie sind aber vielfach auch schnell vergänglich, besunders dadureh, dabsio von den Maden der Fliegenmiicke der Pilze (Mycetophila) und ron Nacktschnecken (Arion subfuscus) zerfressen oder vom Bakterien zersetzt werden. Die zur Herbstzeit lebhaften Vermoderungsprozesse kommen besfnders in Buchenwald zum Ausdruck, der zu manchen Zeiten und bei gröberer Fenchtigkeit etwas nach dumperer Kellerhuft riechen kann.

Die näheren Bezichungen zum Standort treten besonders bei mistbewohnenden Pilzen hervor, ferner bei solehen auf morschem Holz; anch hier zeigen sich offensichtlich die Beziehungen zu organischen substanzen, die bei saprophytischer Lebensweise vin Bedentung sind. Die Ernährnng der sandbewohnenden Pilze bedarf noch eines näheren studiums; vielleicht sind diese mit besonderen physiologischen Fähigkeiten ausgestattet.

\section{Übersicht über die höheren Pilze.}

Fiir die Besprechung hauptsächlich physiologischer und ökologischer Fragen sollen die folgencien Vertretor etwas näher behandelt werden. Alle Abbildungen sind Nenzeichnungen, teils Originale, teils nach den Arbeiten von Cooke, Hennings und Michael.

Ascomycetes.

Tafelfig. 1. Peziza aurantia.

, 2. Morchella ronica. Tuber melanosporum.

, 3. Xylaria hypoxylon.

Basidiomycetes - Keulenpilze.

Tafelfig. 4. Clavaria pistillaris.

Clavaria botrytis.

sparassis crispa.

Basidiomycetes - Stachelpilze.

Tafelfig. 5. Hydnum anriscalpium.

Hydnum imbricatım.

Basidiomycetes - Löcherpilze.

Tafelfig. 6. Merulins lacrymans.

, 7. Polyporus versicolor.

, S. Boletus bulbosins.

*) Mycelium $=$ Pilzmutter. 


$$
\begin{aligned}
& \text { Basidiomycetes - } \text { Blätterpilze. } \\
& \text { cantharellus ribarias. }
\end{aligned}
$$

Tafelfig. 9. coprimus romatus.

, 10. Marasmius alliatus.

, 11. Nyctalis parasition.

, 12. Lactaria deliciosa.

, 11. Russula adusta.

, 13. Cialera (Dermims) hypni.

, 14. Omphalia fihmla.

, 15. Mycena sanguinolenta.

, 16. Collybia tuberosa.

, 17. Tricholoma erpuestre.

Hypholoma lasciculare.

cortinarius Species.

Psalliota campestris.

., 18. Armillaria mellea.

Lepiota procera.

., 19. Amanita mappa.

Amanita muscaria.

Basidiomycetes - Banchpilze.

Phallus impudícus.

'lafelfig. 20. Lycoperdon gemmatım.

, 21. Sicheruterma vulgare.
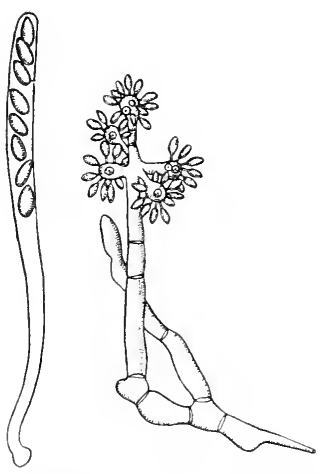

Abh. 67. Peziza repandu, Fruchtformen. Links: Askms mit 8 Sporen; rechts: Konidienträger (Nach O. Brefeld.)
1. Peziza aurantia. Orange-Becherpilz.

Die Pezizen wachsen meist herdenweise auf bober Erde oder auf verschedenen zersetzlichen Pflanzenteilen. Die Fruchtlörper sind in der Regel fleischig weich und kahl. Die Asci sitzen auf der Innenseite der Becher. Die reifen Askuspor'n werden in feinen Wölkchen ansgestobern, sobald man den Pilz in trockene Luft bringt.

Einige Verwandte von Pcziza leben im Masser.

Periza ist ein hochstehender Askomyaet mit zwei Fruebtformen (s. Abh.).

2. Morchella conica. Spitzmorchel.

bie Fruedetiöpere dieses Pilzes entwickeln sich besonders vom März bis

Mai, selten rom August his thtober. Sie sind wie diejenigen vom $M$. esculenta wowen ihres Aromas als Zutat zu speisen sehr geschätzt. 

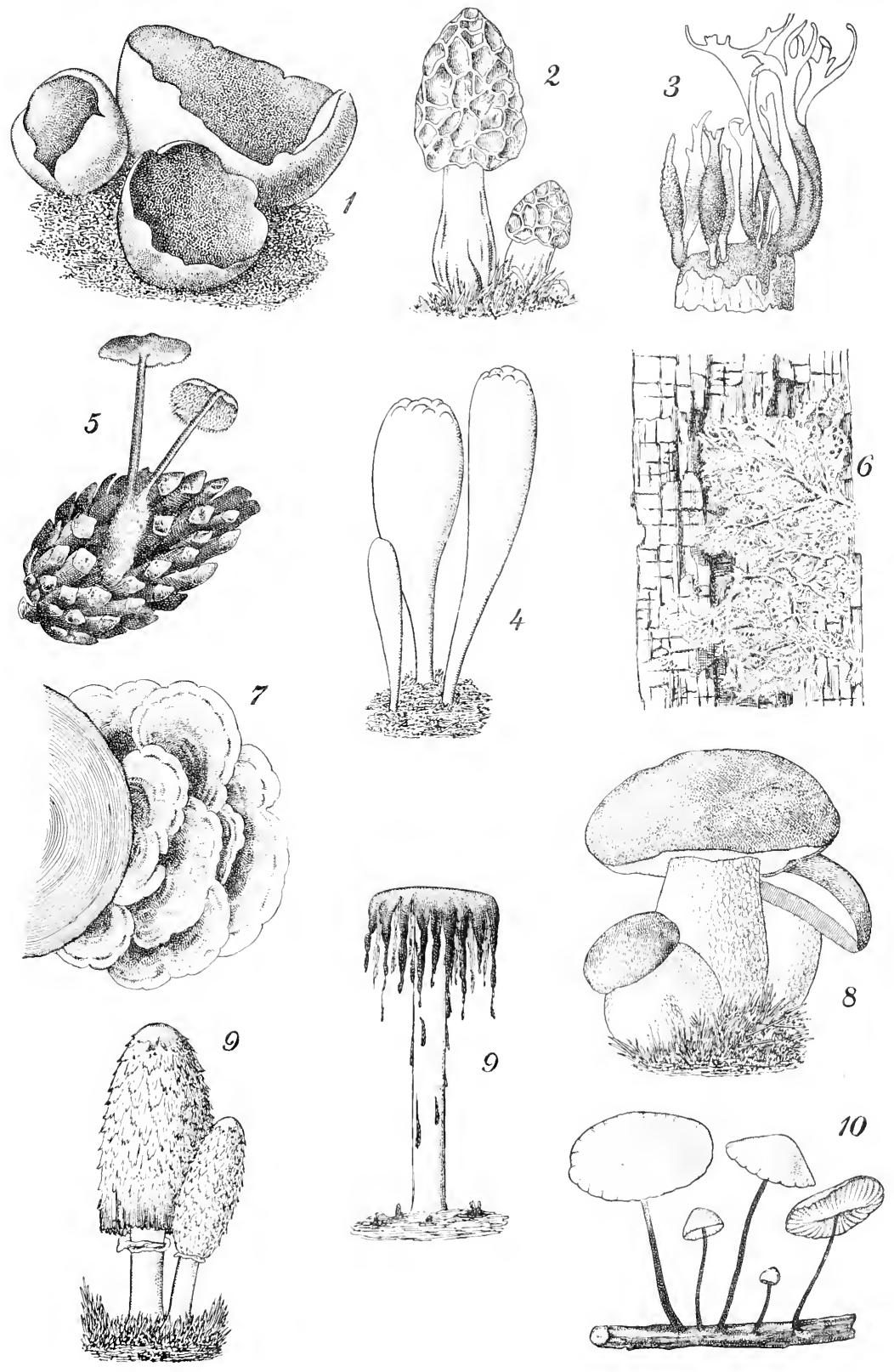

Höhere I'ilze I.

Erläuterungen siehe S. 11 s. 

Tafel $V b$.
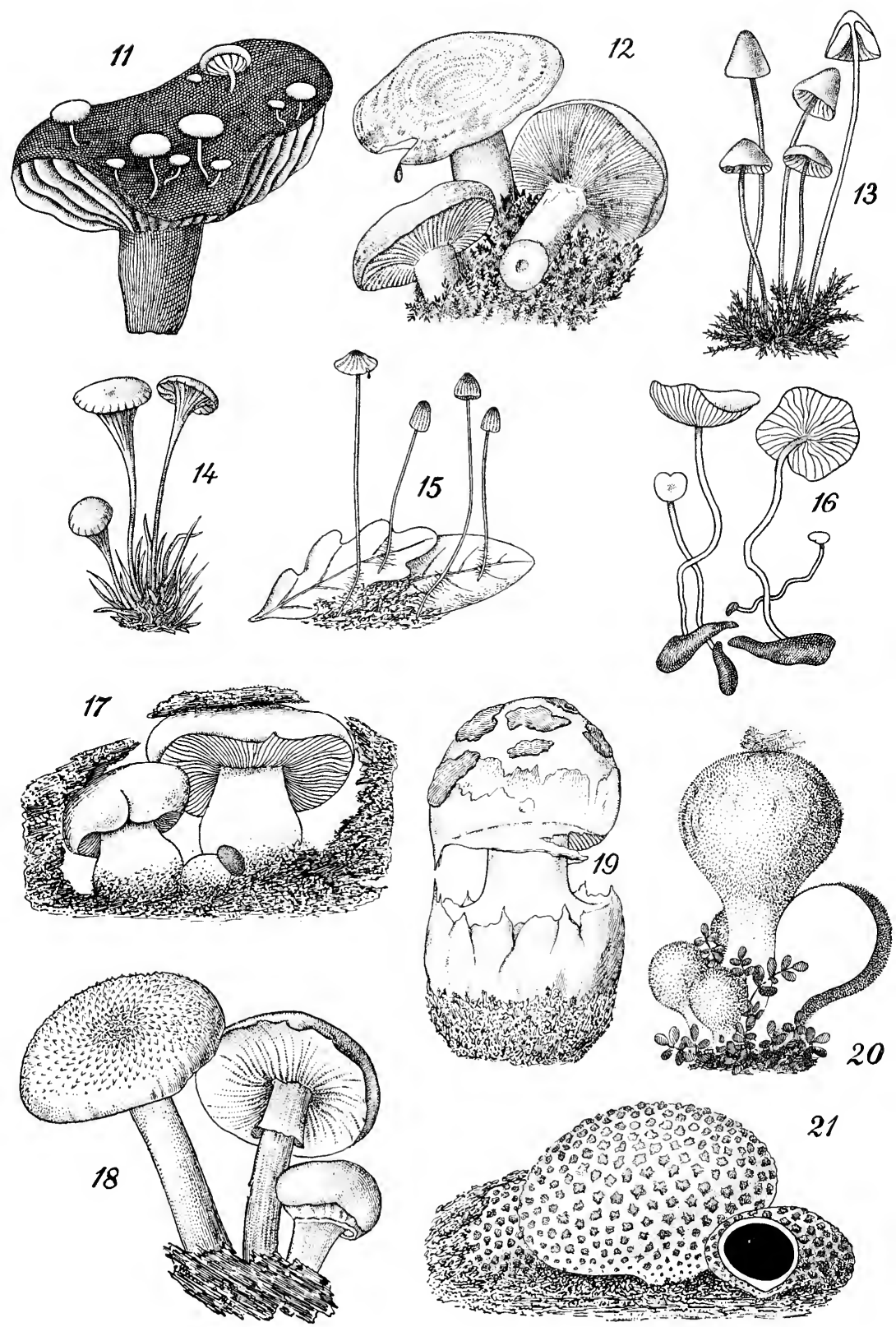

Höhere Pilze II.

Erläuterungen siehe S. 122.

Verlag von Gustav Fischer in Jena. 

Helvella esculenta, die Lorchel, kann in rohem \%astande hisweilen dentliche Mengen der sehr flüchtigen Helvellasianre $\left(\mathrm{C}_{12} \mathrm{II}_{20} \mathrm{O}_{7}\right)$ rnthalten, welcher schwach giftige (hämolytische) Eigenschaliten zugeschrieben werden. Durch Erhitzen und Trocknen des Pilzes wird das Gift zerstört. (Vergl. Lafar [1]).

Tuber melanosporum. Perigorltrïffel.

Die als Trïfeln bekannten Askusfruichte finden sich meistens 5-6 cm tief unter der Oberfläche im Humus der Wälder, besonders der auf kalkhaltigem Boden gedeihenden Eichenwälder. Das Iycel des Pilzes steht mit den Wurzeln der Bäume in Verbindung.

Die sehr aromatische Perigordtriiffel, eine Form vom Tuber brumale, findet sich besonders in Frankreich nnd ttalien, sehr reroinzolt auch in den Rheinwäldern Badens.

Die Frnchtkörper des Pilzes (welche känflich sind), eignen sich sehr gut zu mikroskopischen Präparaten zur Demonstration dor Askussporen. Als Einbettungsmittel kann Glyzerin wder Glyzeringelatine verwendet werden.

3. Xylaria hypoxylon. Geweihförmiger Holzpilz.

Das Stroma des Pilzes mit den eingesenkten Perithecien ist meist schwarz, anfangs durch dic Konidien weib bestäubt. Er wächst meist auf Baumstiimpfen.

4. Clavaria pistillaris. Herknleskeule.

Der Pilz trägt die Basidien anf der Oberfläche der Kenle. Er findet sich meist einzeln anf grasigem Boden, besonders in Laubwäldern. Er wird bis $25 \mathrm{~cm}$ hoch.

Clavaria botrytis. Hirsehpilz, Korallenpilz.

Die Gestalt dieses Speisepilzes erimnert an Blumenkohl (Brassica oleracea f. botrytis). Er wächst besonders in Buchenwäldern zwischen Moos und Gras.

Sparassis crispa. Krauser Ziegenbart.

Die Fruchtkörper von Sparassis erinnern in der Form an einen großen Schwamm oder an Sehwammkorallen mit blattförmig zusammengedrïekten Ästen. Sie können his $60 \mathrm{~cm}$ Durchmesser erreichen. Man findet sie an Stïmpfen von Kiefern und anf der Erde, vorwiegend in Kiefernwäldern.

5. Hydnum auriscalpium. Ohrlöffelpilz.

Dieser Stachelpilz wächst auf in Zersetzung befindlichen Kiefernund Tannenzapfen.

Hydmum imbricatum (jung eBhar) gedeiht auf Erde in Kiefernwäldern. Sein Aussehen von oben hat zur Bezeichnung Habichtspilz, sein Anblick von unten zur Bildung des Namens Rehpilz Anlaß gegeben. 
6. Merulius lacrymans. Hausschwamm.

Der l'ilz ist mehrach als Saprophyt in CilasgefäBen rein geziichtet worden. Lebenskräftige sporen des Mcrulius keimen bei 250 ('innerhalb 24 Stmolen in a. 2, 5\% iger Malzextraktlösmng mit 1\% Mono-Anmoniumphosphat.

Der Hansschwamm ist als Holzzerstöer berichtigt. Er macht wie versehiedene andere Pilze das Holz mïrbe und rissig. Sein Mreel bildet weiße Watten mit derben Leitsträngen (Tährmyeel), wie sie die Abbildung zeigt. Fr dringt anch in Mauerwerk ein und kann sich rom dort ans wioler auf Holzteile weiter ansbreiten. SchlieBlich bikten sich lappige Fruchtlärper mit brauner, grubiger Oberfläche. Ausgezejchnete Abbildungen des Hansschwammes finden sich bei R. Falck (1). Tel. auch A. Möller (1) und r. Tubeuf (1).

An mikroskopischen sichnitten dureh befallenes Holz erkennt man, dab der Pilz die Zellulosemembramen durchdringt. (Cytasewirkung). Vergl. F. Czapek (2). Der Pilz enthält anch Diastase.

\section{Polyporus versicolor. Bunter Löcherpilz.}

Die perennierenden, lederig-holzigen, mit bunten Zonen versehenen Fruchtkïrper dieses Pilzes finden sich sehr häufig an Baumstimpfen, meist in dachziegelartiger Anordnung: er lebt saprophytiseh. Andere Polyporeen sind Banmzerstarer und vieltath echte Parasiten. Näheress. bei R. Hartig (1), A. Mäller (1), Engler-Prantl (1). Nach den eingehenden Untersuchungen von H. Miinch (1) ist wassersattes und dabei luftarmes Holz ziemlich immun gegen den Befall durch zallereiche Pilze.

Über das Verhalten der inkrustierenden Holzsubstanzen (Hadromal nnd Lignin) gegeniiber Pilzen vergleiche man J. Lindroth (1).

8. Boletus bulbosus. (edülis). Steinpilz.

Name von bolites, bei den Griechen ein eBbarer I'ilz.

Der Strimpilz ist an seiner Form, der Netzzeichmmng am Stiel und an den braunen Sporen, welche an den Wänden der Löcher sitzen, lienntlich (Versurh s. bei Psalliota). Fehlt das Netz. so liegt in der Regel Boletus (= Suillus) castancus mit weiBem sporempulver ror.

Der steinpilz onthät. wie viele andere speisepilze und fristhes Gemiise, (a. $87-90 \%$ Wasser*). Neben Eiwcib sind durch die Analyse nachgewiesen: Mannit, Zucker, Fett, an Bordem ziemlich reichlich Kali und Phosphorsäme: vgl. A. König (1).

Die Blaufärbung des Fleisches maneher Boletus-Arten seheint durch lacease-ähnliche Oxydasen bewirkt zu werden.

Wem inm Steinpilz Gifte entstehen. handelt es sich mm alte, zersetzte Exemplare. in welchen sich tureh EiweiBzerfall P'utrescin bildet.

*) Rindfleiseh enthält "al. $75 \%$ Wasser. 
Cantharellus cibarius. Pfefferling.

Dimimutiv von cantharus, Name fiir rin herherartiges, weitbauchiges Trinkgefäß (Hımpen).

Der Pilz, welcher allgemein genossen wirch, wärhst mit Vorliebe in Kiefernwählern. Im rohen Zustande hat er cinens schwach pfefferartigen Geschmack.

9. Coprinus comatus $(=$ forcellanus). Tintenpilz.

Name von copros = Dung, Mist.

Der Pilz zerfliebt, wie auth die Abbildung zeigt, beim lbsterben zu einer schwarzen, tintenartigen Nasse, an deren Bildung anch Mikrobien beteiligt sind, welche dem Bacterium chitinovortm nahe stehen. Die Membranen zeigen nach der chemischen Aualyse chitinartige Bestandteile. Das Zorfliefen findet auch bei jungen, festen Exemplaren statt, wemn man sie vom substrat abtrennt und in ein Glas legt. Nach einigen Tagen wertlen die Fruchtkörper weich, sehwärzlich und zum Teil verfliissigt.

Die schwarzen eiförmigen Sporen der zerflossenen Exemplare dieser Art, anch von Coprinus atramentarius (atramentum = Tinte), kam man in größerer Menge in mit Formalin versetztem Wasser aufbewahren und zu mikroskopischen Sporenpräparaten in Glyzeringelatine verwenden.

Coprinarius (Panacolus) campanulatus und indere sehwarzsporige Pilze (Atrosporeae) mit kleinen Hiiten kann man nach Entfermung des Stieles direkt auf einen Objektträger legen und die Lamellen durch das Ausfallen der Sporen abbilden lassen und konservieren. Luf diese Weise gewinnt man lehrreiche makroskopisehe und zugleich mikroskopische Sporenbilder.

Nanche Coprinus-Arten sezernieren in feuchter Luft nach F. Knoll (1) mittels Hydathoden am Stiel Wassertröpfchen, welehe Kaliumoxalat, ein bei Pilzen nicht seltenes Ansscheidungsprodukt, enthalten.

Coprinus stercorarius, ein typischer Mist-Tintenpilz, entwickelt sich leicht, wenn man frischen Pfertemist einige Zeit unter einer Glocke stehen läßt. Er bildet sklerotien, bei deren Austreiben man die Nhnahme von Eiweil. leicht feststellen kann. Stärke fehlt, wie ïherhaupt bei Pilzen, anch in diesen slilerotien.

10. Marasmius alliatus ( $=M$. scorodonizus). Musseron.

Name ron marasmos = Verwelken, da der Pilz meist vertrocknet und nicht verfault.

Der Pilz riecht und sehmeekt nach Knoblauch und dient als Gewïrz an Speisen. Die Spezies $M$. alliaceus riecht so stark, daß der durch ein einziges Exemplar erzeugte Geruch im ganzen Zimmer wahrgenominen werden kann. 
Der Musseron wächst besonders an Waldrändern an Graswurzehn, auf abgefallenen Zweigen und an Baumstiimplen.

$M$. rotula, der dem Musseron ähnlich sieht, aber nicht riecht, wächst herdenweise an diunnen Zweigen und zeigt dentlich geotropische Krïmmnngen der Hutsticle.

Tricholoma graveolens, der Maischwamm, wird ebenfalls als Musseron bezeichnet.

11. Nyctalis parasitica ("yctalos = schläfrig, schlaff।.

Der Pilz wächst, wie die Abbildung zeigt, auf Hiiten von Russula adusta und auf den verhältnismäBig widerstandsfähigen Fruchtkörpern ron Russula nigricans (enthält Tyrosin).

\section{Lactaria deliciosa. Echter Reizker.}

Dieser Speisepilz enthält reichliche Mengen eines lebhaft gelbroten Milchsaftes. Dieser findet sich in dureh Fusionen gebildeten Röhren von verhältnismäBiø weitem Volımen.

Die Milehsaftröhren der Pilze seheinen wie bei den höheren Pflanzen der Leitung plastischer Baustofle zı dienen. Der Pilz ist ziemlich reich an Fetten $(5-6 \%)$; nach Em. Bonrquelot enthalten die Lactarien auch ziemlieh viel Mamit.

Lactaria piperata enthält cinen bei V'erletzung wie Milch fließenden Saft von scharf brennendem Gesehmark, von dem keine Giftwirkung bekannt sind. Das Bremnen auf dor Zunge wird nicht dureh Rhaphiden erzengt. Stärkeköner fehlen wie bei Pilzen iiberhanpt.

Russula Species. Abb. s. unter $N$ yctalis. Täubling.

Die Gattung der Täublinge ist sehr artemreich. Sie ist anatomisch grekennzeichnet durch zwei Hyphengewebe (wie Lactaria), aber es fehlt der Milchsaft. ÄuBerlich fallen die Russula-Arten durch die straffen

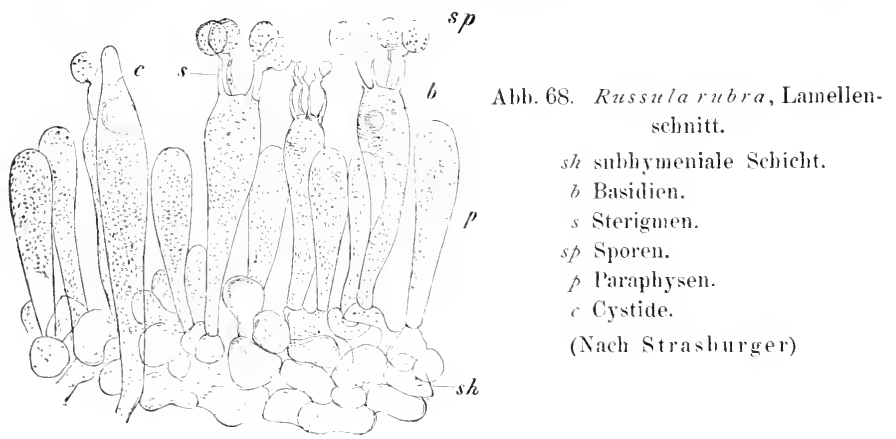

Lamellen auf, welche sich gut zu Solnitten zum Demonstrieren der Basidien rignen (s. (lie Abb.). Russula hat weibr. Russulina gelbliche sporen. 
Der bei Russula weit verbreitete rote Farbstofl der Hutoberfläche läbt sich mit Wasser oder verdiimntem Alkohol auszielan; rol. \%opf (1).

Russula-Arten, sowrit sie hisher nutersucht sind, enthalten das Ferment Tyrosinase, welches Aminosämen angreift.

Die bei der vorliegenden Gattung (inkl. Russulina) sich findenden verschiedenen Farben kommen in folgenden Artennamen zum AusIruck: lutea, ochrolenca. acruginosa (kein ('blorophyll), virescens, cyanoxantha, sanguinea, rosacea, xorampelina (wie ringetrockneter Rotwein) nsw.

\section{Galera (Derminus) hypni.}

Name von galèrmm = Kapple.

Hut sehr diinnfleischig, fast nur häntig, ohne schleier am Rande (Evelatae). Sporempulver und Pilz brann. Gern auf feuchter Erde zwischen Moos wachsend, his ins Hochgehirge verberitut.

Eine Übersicht iiber Evelatae, Telatae nsw. siehe hei P. Hennings in Engler-Prantl (1), S. 232.

14. Omphalia fibula. Nabelpil\%.

Name von omphalos = Nabel, Buckel und filula - IIeftnadel, Bolzen.

Die gelblichen kJeinen, zarten Pilze wachsen an fenchten Waldstellen zwischen Moos.

\section{Mycena sanguinolenta.}

Name wahrscheinlich von mykes = Pilz, sanguinolentus = blutig.

Der zarte Pilz wächst in Wäldern zwischen Blättern, Moos usw. Er enthält einen blaßschmutzigroten saft.

Mycena zephira: riner der hänfigsten Waldpilze.

,, cpipterygia: herdenweise zwischen $1100 \mathrm{~s}$.

, galcriculata: biischelweise an Banmstimpfen.

, alcalina: riecht stark langenartig.

", metata: riecht schwach langenartig, auch an salpetrige Sänre erimnerud.

, pura: riecht rettigartig.

\section{Collybia tuberosa}

Name von kollybos $=$ kleine Münze, wegen Ähnlichkeit der oft kleinen und flachen Hüte mit Geldstïcken.

kleinen und flachen Huite mit Geldsticken.

Der Stiel der Collybia-Arten hat eine knorpelige Hant und ist innen hohl oder mit schwammigen Nark erfiillt. Die Fruchtkörper der vorliegenden Art wachsen ans sklerotien (Hartmyerl) hervor.

17. Tricholoma equestre. Grïnling.

Der Hut ist anfangs fast kugelig, später ausgebreitet. Der Stiel, das Fleisch und die Lamellen sind gelb, oft mit einem Stich ins Griinliche. 
Der Pilz wächst in sandigen Kiefernwäldern und bricht meist erst nach ziemlich weiter Entwicklung aus dem Boden hervor. Er ist ein guter speisepilz.

Hypholoma fasciculare. Schwefelkopf.

Der Pilz wächst in Biischeln an Banmstiimpfen, morschem Holzusw. seine purpurschwarbraunen Sporen tallen leicht aus. Die Lamellen sind in (ler Jugend ron einem Schleier (velum partiale) bedeckt, welcher nach der Entfaltung am Rande als kleine Fetzen zuriickbleibt ( Telatae).

\section{Cortinarius Species.}

(cortina $=$ Intsaum. Randschleier).

Die Arten der Gattung Cortinarius sind brannsporig (Phaeosporeae), haben ein mehr obler weniger deutliches Velum partiale und zeichnen sich häufig durch schleimbildung aus.

Psalliota campestris ( - Igaricus campestris), Champignon.

ber Champignon besitzt dunkelpurpurne sporen (Amanrosporeae), welche in llasse gabildet werden und reichlich ansfallen (s. die Abh.). Ein Exemplar kann einige Kubikzentimeter Sporenmasse
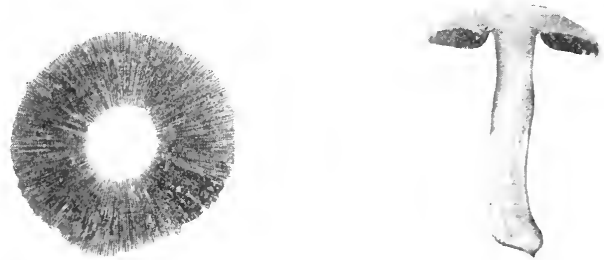

Abb. 69. Psalliota campestris, Champignon. Links: Sporen ans dem Kopf auf Papier ausgefallen; rechts: Längsschnitt durch den Pilz, nach einem Herharexemplar. $1 / 2$ nat Größe. (Orig.)

raengen. Der Stiel trägt einen hing (Annnlatac). Der Pilz wird im Großen knltiviert, im ansgedehntesten Mabstabe in den Katakomben von Paris. Ebenfalls knltivierbar (meist ans in Wasser aufgeschwemmten s'poren) sind von höheren P'ilzen noch:
Morcholla esculcuta,
Plcurotus ostreatus,
Helvella esculenta,
Clitopilus prunulus,
Rússula virescens,
Pholiota mutabilis,
Collybia Species,
Armillaria mellea,
russuliopsis laccata.
Amanita rubeseons

II. a. 111 . 
Nebenstehend ist das ('hampignonhaus der Kol. Crätnerhehranstalt zu Dahlem abgebildet*), welches sich durch gut durchlachte Konstruktion auszcichnet.

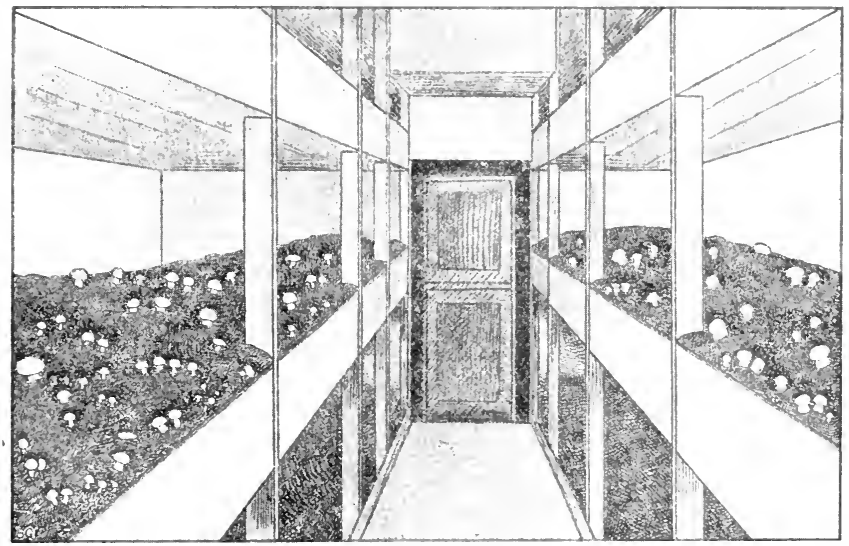

Abb. T0 Blick in das Champignonlaus der higl fiärtnerlehranstalt zu Dahlen

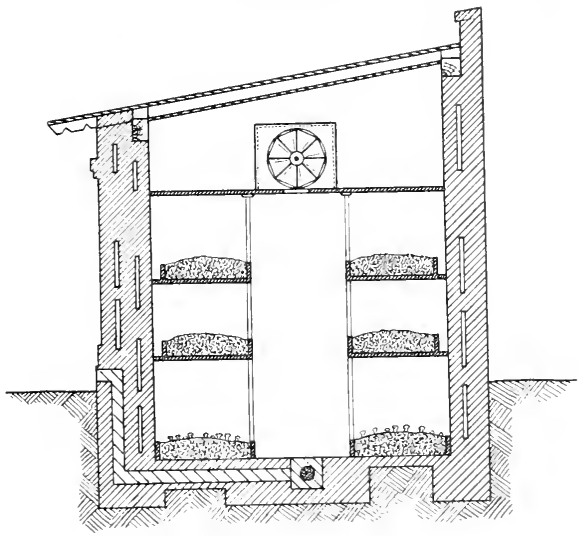

Abb. 71. Querschnitt durch das Champignonhaus, die Kulturbeete und die Ventilationseinrichtungen zeigend.

Zu erfolgreicher Kiulur ist die Innehaltung einer Roihe von Bedingungen unerläßlich:

*) Die Abbildungen sind dem mir fremndlichst von Herrn Direktor Ökonomierat Th. Echtermeyer zur Verfügung gestellten Bericht der Kgl. Ciärtnerlehranstalt in Berlin-Dahlem für die Jahre 1906 bis 1907 entnommen worden. 
a) Die Innentemperatur des Hauses muß ziembich mabhängig gehalten werden von der Aubentemperatur. Sie soll nicht unter $+10^{\circ} \mathrm{C}$ und nicht über $+17^{\circ}$ (' betragen. Gewöhnliche Zimmertemperatur ist in der Regel schon zu warm; eine gute Mitteltemperatur ist $+14^{0} \mathrm{C}$, mindestens $+12^{\circ} \mathrm{C}$.

Für den Winter mub eine Heizvorrichtung vorgesehen sein, wenn man während dieser Zeit Pilze züchten will. Bei primitiven Anlagen sind Frühling und Herbst die besten Kulturzeiten.

b) Der Raum mubs sich in allen Teilen gut lüften lassen, d. h. man muB frische Luft zufiihren und die rerbrauthte ableiten können. Das Kulturhaus muB mindestens 2-21/2 m hoch und darf nicht naB sein.

c) Der Raum wird ror Beginn der Kultur griindlich geschenert und mit frischer Kalkmileh ausgespritzt, weleher zur Belï̈mpfung der sogenannten champignonflicge etwas Alaun zugesetzt ist.

d) Der für die Kulturbeete benutzte P'ferdemist wird mit stroh (Mycelleiter) und Lehm vermischt. Er muß abgären, darf also nicht mehr sterhend riechen, und muß noch eigene Feuchtigkeit besitzen.

e) Champignonbrut kann im Freien gesammelt werden, wird aber besser von guten firmen gekauft, da man in diesem Falle bestimmte, bewährte sorten ziehen kann. Psalliota campestris ist vollfleischiger als Ps, arvensis.

\section{Armillaria mellea (= Igariciis mellens). Hallimasch.}

Name von armilla = Armband, Nanschette.

Der Hallimasch ist auBer am Habitus sehr leicht kenntlich an der charakteristischen fleckigen Beschuppung seiner oft honiggelben Hutoberfläche. Das Hycel des Pilzes wächst im Holz und in der Rinde hauptsächlich von Bänmen, besonders Kielern, und tötet diese allmählich ab. Durch Beschädigung der Harzkanäle entstehen Harzeroiisse nach auben.

Die Rhizomorpha subterranea, eine strangartige, auben schwärzliche, derbe Mycelform, besitzt in ihren jungen Teilen (spitzen) die Fähigkeit, im Dunkeln zu leuchten. Rhizomorphen kömmen auf Wiesen in Drainröhren eindringen und diese durch Bildung armstarker Biintel verstopfen, also anch turch nicht parasitäre Eigenschaften lästig fallen. Der salt des Hutes reagiert dentlieh sauer.

Der Pilz ist bei geedguter Versuchsanstellung im Laboratorium auf Brot kultivierbar; rel. v. Tubeuf (1). Siehe anch Fhublatt Nr. 22.

Lepiota procera. Parasolpilz.

Name ron lepion = kleine schuppe, wegen der Schuppen anf seiner Oherflache.

Der erwatesene Pilz besitzt die Ciestalt eines anfuespannteu Sehirmes; die Breite des Hutes kamn bis 30 en betragen. Der Pilz ist unter ten $\mathrm{A}$ inulatar der stattlichste deutsehe Vertereter. Er wäthst in Wähdern, Gelsiisclen, anf Feldern usw. 
19. Amanita mappa. Knollenblätterpilz.

In der Gattung Amanita linden sich ebbare (A. pustulata $=$ rubescens und d. umbrina = pantherina $)$ und giftige Arten. Unter diesen ist der Phallin und andere Gifte enthaltende Knollenblätterschwamm der gefährlichste; der Genuß zweier Exemplare dieses Pilzes kam schon einen Menschen töten. Die sporen des Pilzes sind weiß.

Die Erscheinung, dabin in ein derselben (iattung efbare und giftige Arten vorkommen, ist nichts Seltenes. Unter den Bakterien z. B. beobachtet man ähnliches; so ist Bactorium typhi pathogen, das mahe verwandte Bactorium coli dagegen nicht.

Amanita muscaria. Fliegenpilz.

(Frisch Fliegen tötend).

Die Gifte dieses Pilzes, das Alkaloid Mlıskarin $\left(\mathrm{C}_{5} \mathrm{H}_{15} \mathrm{NO}_{3}\right)$ und ein Toxin, scheinen an manchen standorten und in manchen Gegenden zu fehlen.

Aus der roten, abgezogenen (Oberhaut kann der Farbstoff mit Wasser teilweise ausgezogen werden; besser noch wirlit Alkohol. Der extrahierte Farbstoff fluoresziert griin.

Der Pilz läßt besonders gut die Eigentümlichkeiten der Volvatae erkennen, bei denen die Gesamthiulle (Velnm universale) nach der Entfaltung teils am Grunde als scheide (volva), teils anf dem Hut als Fetzen zuriiekbleibt. Die Kraft, mit der sich der Hut entfaltet, ist ziemlich erheblieh, da er kleine Gesteinsplatten emporheben kann.

\section{Rozites gongylophora.}

Name von gongylis = runde Rïbe, Kohlrali.

Der Pilz wird nach den Angaben ron A. Moeller in Brasilien ron Ameisen kultiviert. Diese ernähren sich von kohlrabiähnlichen Gebilden, welche am Nycel des Pilzes entstehen.

Phallus impudicus. Stinlipilz.

Die Abbildung des Pilzes ist die photographische Wiedergabe einiger ron G. Herpell fiir das Herbar präparierten Exemplare (vgl. auch ,Präparieren der Pilze $\left.{ }^{66}\right)$.

In der Jugend besitzt der Pilz ungefähr die Gestalt und Farbe eines Hühnereies. Er sitzt der Erde auf und entnimmt seine Nährstoffe durch starke, wurzelähnliche Hycelstränge. Legt man ein solches eiartiges (vïllig reifes) Jugendexemplar, das man vom substrat losgelöst hat, in ein Wasserglas mit fenchtem. weiBem Sand, so kann sich der Stiel des innerhalb der gallertigen Hïlle vorgebildeten Pilzes innerhalb einiger Stunden zu seiner vollen Länge strecken. Während das eiartige Stadium geruchlos ist, verbreitet der entwickelte Pilz einen widerlichen Duft, der Insekten, welche die sporen verbreiten, anloekt.

Nach den Untersuchungen von Errera enthält der Pilz Glykogen.

Die Familie der Phallaceae hat ihre Hauptverbreitung in den Tropen. 
20. Lycoperdon gemmatum. Bovist.

Die Boristpilze sind his in das Hochgebirge weit rerbreitet. Ihr Imneres ist im Alter trocken und mit Kapillitium und sporen erfüllt. Diese verstänben durch einen Rib am scheitel bei trockenem Wetter. Lyeoperdon bovista erreicht einen Durchmesser bis zu $30 \mathrm{~cm}$.

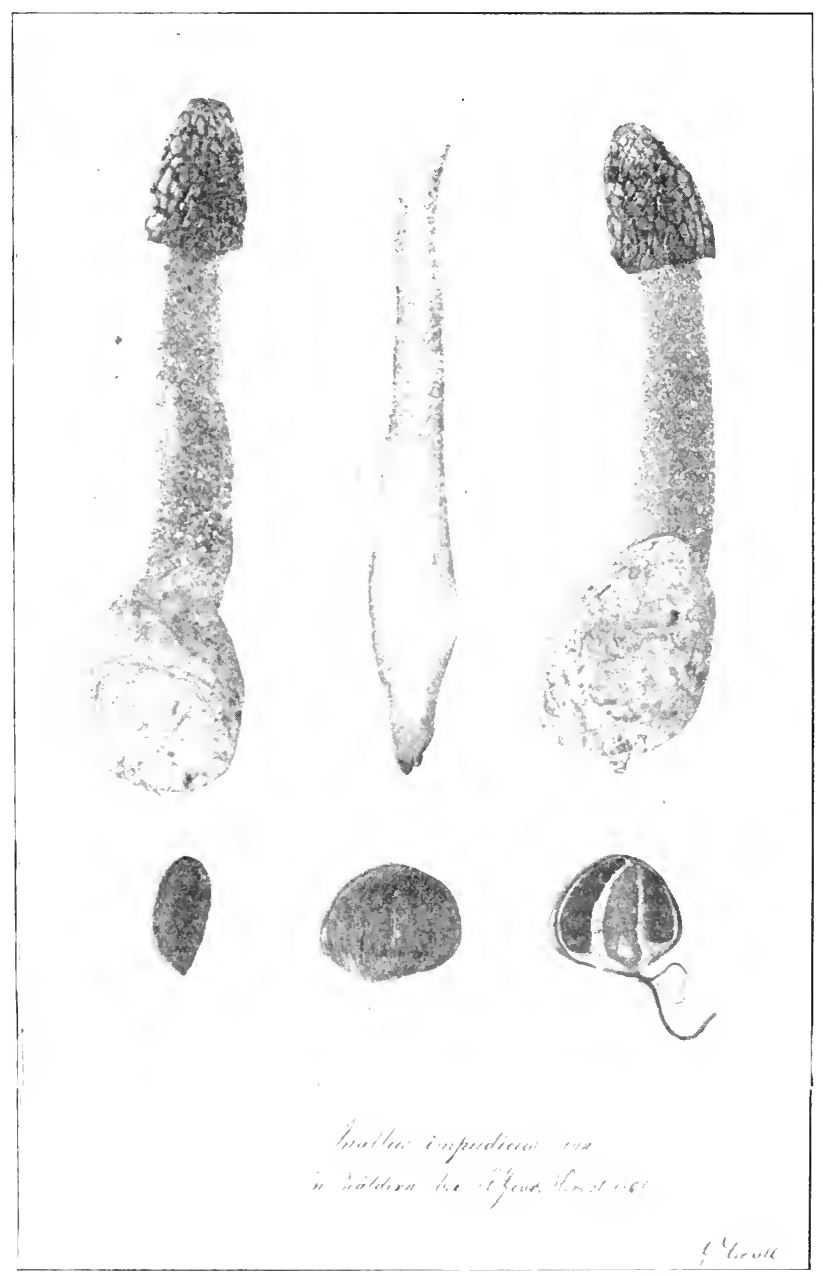

Ahl. 72. Jhallus impudians Linn. Herbarexemplate ans den Wabdern hel st. (ioar. Herlost 1s9s. Innge und entwickelte Exemplare in der Aufsieht und im Guersehnitt. $1 / 2$ nat. Giröbe 
21. Scleroderma vulgare. Hartbovist, falsche Trüffel.

Der Fruchtkörper dieses Pilzes wächst auf der Erde oder halb unterirdisch. Der Pilz gilt als giftig.

\section{Präparieren der höheren Pilze.}

Viele höhere Pilze lassen sich, was vielfach nicht bekannt ist, ähnlich den höheren Gewächsen und gröBeren Algen, in Pflanzenpressen trocknen. Besonders die Hutpilze eignen sich dazu vielfach ausgezeiclnet. Tremnt man durch zwei Längsschnitte mittels eines Rasier- oder Taschenmessers ein dümnes (bis einige Millimeter starkes) Mittelstiick heraus, so gibt dieses schon ein ziemlich anschauliches Bild vom Gesamtcharakter des Pilzes. Dieses Bild wird vervollständigt durch zweckentsprechend präparierte Oberflächenpartien und durch einen Naturselbstdruck der Lamellen mit ihren sporen durch Auflegen des vom Stiel befreiten Hutes auf Papier, einen Teller oder dergleichen. Die sporen sind nach etwa 10) Stunden und mehr auf die Unterlage reichlich ausgefallen und haben dadurch anf dieser den Verlauf der Lamellen abgebildet. Man vergleiche auch das bei Coprims Gesagte und die Abbildung bei Psalliota. Die sporen werden dann auf dem Papier fixiert, und zwar dadurch, dab dieses vou unten her mit Alkohol befenchtet wird, in welchem etwas Kolophonium gelöst ist. Die Lösung darf nicht zu gelb sein, damit die für die Bestimmung eines Pilzes wichtige sporenfarbe (schwarz, purpurschwarz, braun, gelb, rosa, weiß) nicht verändert wird.

Dieser Abdruck und die übrigen Teile des Pilzes werden in geeigneter Form auf einen weißen Karton von Herbarformat anfgeklebt nnd geben dadurch ein anschauliches Bild des betreffenden Pilzes. Um seinen s t and ort zu kennzeichnen, kann man die Basis des Stieles mit Moos, Holzpartikeln, Blattresten und dergleichen nmgeben.

Diese Präparation der höheren Pilze gelingt sehr leicht und erfordert wenig Miuhe.

Nähere Angaben ïber die feineren Einzelheiten der Methode finden sich bei Herpell (1).

Will man solche Pilze unzerschnitten in ihrer natiulichen Form konservieren, so kann man sie mit mehr oder weniger großem Erfolg in eine etwa 10\% ige Formalinlösung cinlegen, mub aber diese Lösung zu Anfang mehrmals wechseln, da sie sich zu verfärben pflegt.

Es wird auch empfohlen, die Pilze in konzentrierten farblosen Ruibensirup einzulegen, doch besitze ich über diese Art der Behandlung keine Erfahrungen.

\section{Literatur über höhere Pilze.}

$\begin{array}{ll}\text { Cooke (1), } & \text { Kopf (1), } \\ \text { Gillet (1), } & \text { Lindall (1), } \\ \text { Hennings (1), } & \text { Michael (1), } \\ \text { Schroeter (1), } & \text { Gramberg (1), } \\ \text { Ricken (1), } & \text { Herter (1). }\end{array}$


Zur kurzen Orientierung sei noch verwiesen auf das:

Pilzmerkblatt. Bearbeitet im Kaiserl. Gesundheitsamt. Hierzı eine Pilztafel mit farbigen Abb. Preis 0,10 M. Verlag von Jul. Springer, Berlin.

\section{Gruppe. Lichenes (Flechten).}

Flechten sind nach den Untersuchungen von Schwe ndener (2 und 3) Doppelwesen, zusammengesetzt aus Fadempilzen und meist einzelligen Algen, in der Regel grüne Cystococcus oder Protococcus. Beide leben in Symbiose (= ergänzender Haushalt nach de Bary) miteinander: der Pilz bezieht von der Alge meist reichlich organische Nährstoffe, die Alge vom Pilz anorganische, aber wahrscheinlich auch gewisse spezifische organische [z. B. organische Säuren nach Tobler (2)], wenigstens bei einer größeren Zahl von Flechten. In einzelnen Fällen dringen die Pilzfäden in das Innere der Algenzellen ein und parasitieren somit in diesen. Die Bildung der farbigen Flechtensäuren scheint erst durch das Zusammenleben beider Komponenten bedingt zu sein. Hhre physiologische Bedeutung ist unbekannt; man vermutet in ihnen ein schutzmittel gegen Tierfrab.
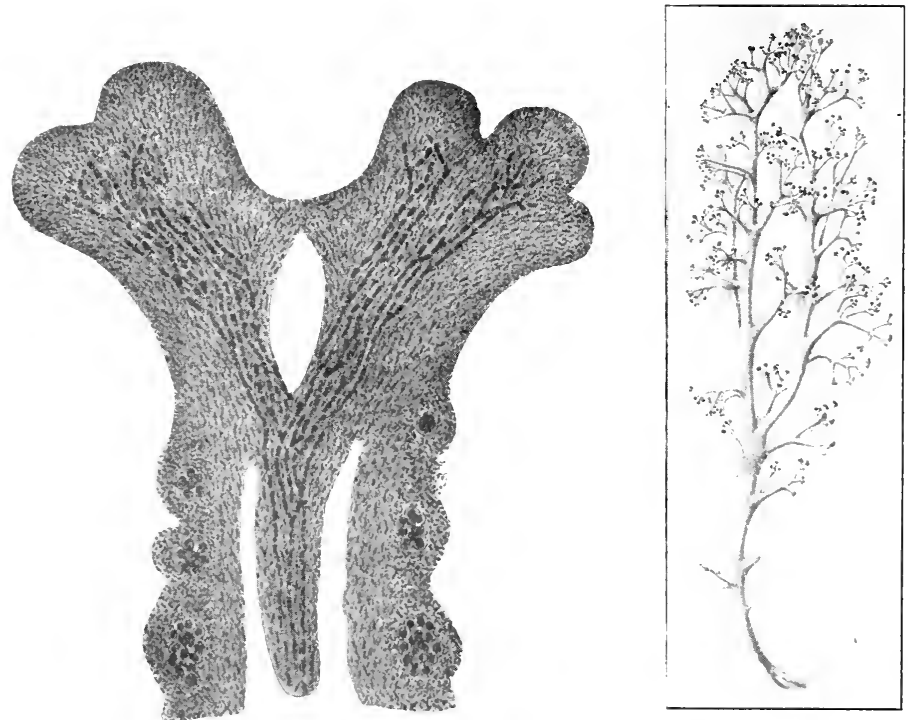

Alh. 73. Cladonia rangiferina (silzatica). Rechts Habitusbild.

Links Cladomia stellata. Längsschnitt durch den Sehejtelteil eines Astes emer Askusfrucht. Im Innern das Schlanchfasergewebe. In dem lockerfilzigen, peripherischen Gewehe sind die ersten Algengruppen sichtbar. Tergr. ca 300fach. (Nach G.Krabbe.) 
Als Beispiel zur Kennzeichnung des Lebens der Flechten ist die weitverbreitete und häufige Remutierllechte, Cladonia rangiferina (trotz mancher komplizierter Verhältnisse) besonders geeignet.

In beistehender Abbildung ist ein Habitusbild von Cladonia rangiferina (silvatica) und eine mikroskopische Ansicht einer spitzenpartie nach G. Krabbe (1) wiedergegeben. Lis handelt sich bei diesem Bilde um die Darstellung eines thallus verticalis (Fruchtkörper), während der eigentliche spezifische Vegetationskörper, der thallus horizontalis, bereits vergangen ist. An der Anlage dieses Fruchtkörpers ist nur die eine Komponente der Flechte, der Pilz, beteiligt, hauptsächlich dessen Schlauchfasergeflecht (askogene Hyphen).

Die Bekleidung der unebenen Peripherie des sich entwickelnden Fruchtkörpers geschieht durch die bei Cladonia sehr häufigen Soredien*) (welche zahlreich hauptsächlich durch den Wind angeweht werden), in selteneren Fällen wohl auch durch anfliegende Algen (Protococcaceae). Die Oberfläche wird dadurch allmählich körnig rauh. Bei manchen Arten (z. B. Cl. squamosa) wachsen diese soredialen Bildungen zı Thallusschüppchen aus, welche gleichsam als Blätter erscheinen; bei $\mathrm{Cl}$. rangifcrina bilden sie nur eine Art grüner Rinde, die durch seitliches Verwachsen der SoredienBruthäufehen entsteht. Soweit bisher bekannt, entwickeln sich auf einer bestimmten Cladonia immer nur die Soredien der gleichen Art, doch können Algen wohl auch von anderen Flechten stammen, wenn diese die gleichen besitzen wie $\mathrm{Cl}$. rangiferina.

Die Soredien und Thallusbildungen an der Peripherie der Fruchtkörper sind von hoher ernährungsphysiologischer Bedeutung, da sie als Assimilationsorgane wirken, ähnlich wie grüne Blätter und Rinden.

Diese Funktion ist gerade für $\mathrm{Cl}$. rangiferina von ausschlaggebender Bedeutung, weil hier nicht bloß der thallus horizontalis, sondern auch die Basis des Fruchtkörpers abstirbt. Der Basalteil vermag dann nur solche Nährstoffe aus dem Substrat zu beziehen, welche innerhalb des abgestorbenen Teiles mit dem Wasser kapillar emporsteigen. Eigene Stätten zur Bildung organischer Nährstoffe sind deshalb für die Fruchtkörper von $\mathrm{Cl}$. rangiferina unerläßlich. Wir erkemnen also in diesen Fruchtkörpern ernährungsphysiologisch vollkommen selbständige Gebilde, die dadurch befähigt sind, lange zu wachsen (jährlich etwa $3-5 \mathrm{~mm}$ ), sicher über 100 Jahre lang, wenn sich an den Spitzen der Fruchtkörper nicht Askus-Hymenien bilden.

Die Standorte der Flechten kömnen sehr verschiedener Natur sein: Erde, Baumrinden, Bretter, Steine, Felsen. Sie lieben in der Regel einen hellen, den Witterungseinflüssen ausgesetzten standort, die Wetterseite.

*) Name von soros $=$ Häufchen. Soredien sind Thallıskrïmel, welche ans Pilz und Alge bestehen. 
Gewisse Steinflechten sind, stellenweise in Gemeinschaft mit manchen Lanbmoosen, die letzten Pioniere des pflanzlichen Lebens bis an die Schneegrenze und dariiber hinaus. Nie ertragen dort grobe Kälte, Trockenheit und intensive Somnenbestrahlung.

Die Gesteinsflechten diirften, nach ihrem standort zu urteilen, ganz besonders auf die von ihren Algen produzierte organische Nahrung angewiesen sein. Jurch Abscheidung von Kohlensäure mnd Flechtensäuren dïrten sie zur Vorwittrung des Gesteins, vor allem zur Lösung des Kalkgesteins, beitragen.

Übersicht über Habitustypen der Flechten.

\begin{tabular}{|c|c|c|c|}
\hline Strauchflechten & Blattflechten & Gallertflechten & Krustenflechten \\
\hline $\begin{array}{l}\text { Clactonia } \\
\text { Evernia } \\
\text { Usnea }\end{array}$ & $\begin{array}{l}\text { Tanthoria } \\
\text { Parmelia } \\
\text { Peltigera }\end{array}$ & $\begin{array}{l}\text { Collema } \\
\text { Ephebe } \\
\text { Lichma }\end{array}$ & $\begin{array}{l}\text { Lecanora } \\
\text { Rhizocarpon } \\
\text { Graphis }\end{array}$ \\
\hline
\end{tabular}

Die einzelnen Gruppen sind durch Übergänge niteinander verbunden. Die Einteilung nimmt auf die verwandtschattlichen Verhältnisse keine Rïcksicht.

Die Blattflechten unterscheiden sich von den Krustenflechten durch cine weniger innige Versehmelzung ihres Thallus mit dem Substrat.

Sämtliche Figuren der nachfolgend behandelten Flechten (vgl. die Tafel) sind nach der Natur gezeichnet. Anf genauere physiologische Einzelheiten komnte nur an cinigen Stellen hingewiesen werden, da die Ernährung der Flechten gegenwärtig nur wenig eingehend studiert ist.

- Cladonia rangiferina, Renntierflechte.

Name Cladonia Diminutiv von clados $=$ Sproß, Zweig. Dem Renntier (cervus rangifer) nützlich.

Diese Spezies ist im Vorstehenden anstiihrlich besproehen.

1. Cladonia macilenta. Säulchenflechte.

macilentus $=$ mager.

Die Podetien*) haben stifteormige Gestalt, sind hisweilen etwas verzweigt und tragen hochrote Apothecien; die Farbe hat ilmen sitz in der Membran der Paraphysen. Tie Flechte ist anf Holzstimplen und Erde weit verbreitet. An der Zeichmung ist anch der thallus horizontalis deutlich kemontich.

2. Cladonia pyxidata. Becherflechte.

pyxidatus = mit Becher versehen.

Die Podetien sind becherförnig. Die Art wächst vorwiegend auf Sand- und Waldhoden. Vgl. auch Kerner (1) Bel. I, Taf. bei s. 234.

*) podetimm = Gestell, d. s. die aus dem thallus horizontalis hervorwachsenden, die spothecien tragenden Teile. 

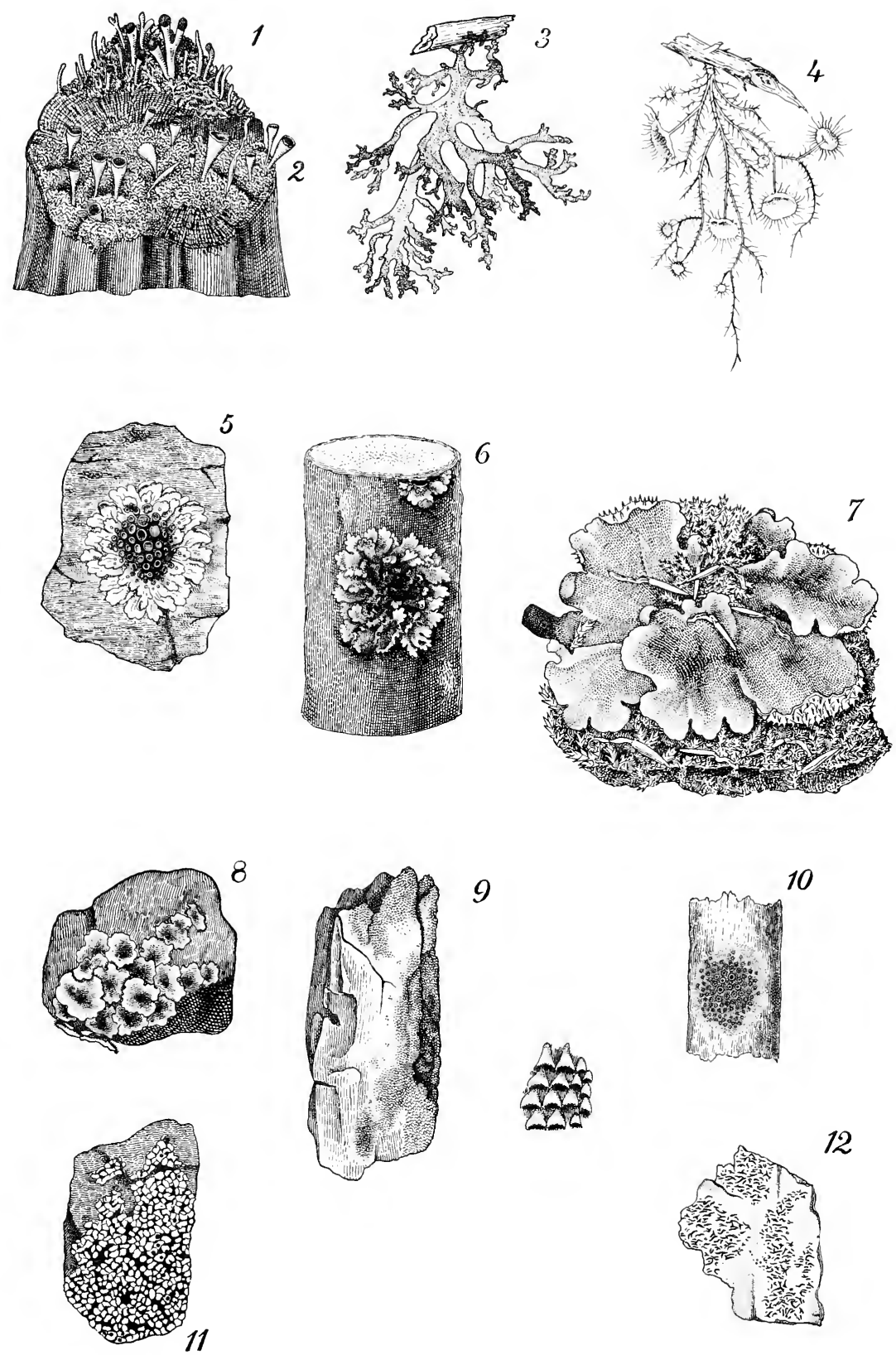

Typen charakteristischer Flechten. Erläuterungen siehe S. 132-136. 

- Cetraria islandica. Sogen. „isländisches Moos".

Name von cetra $=$ kleiner, lederner schild.

Der anfrechte, glänzende Thallus ist groblappig, flach, geweihartig nnd bis $10 \mathrm{~cm}$ hoch. Er enthält Dextrane und Cialaktane.

Die Flechte wächst auf dem Boden zwischen Hoosen und Heidekrant und iberzieht oft weite strecken. Sie ist besonders in Gebirgen und in arktischen Gegenden verbreitet.

3. Evernia prunastri. Banıflechte.

Name ron enernes $=$ schön sprossend. prunastrum = Ṕflaumenbaum

Der mit Haftscheibe befestigte Thallus ist stranchig und meist hängend; seine einzelnen Lappen sind flach. Die Farbe ist oberseits weißgriin, unterseits weiß. Apothecien werden nur sehr selten gebildet.

Die Flechte ist an der Rinde von Laub- und Nadelbäumen iiberall gemein, von der Ehene his ins Gebirge. sie enthält Evernsäure $\left({ }_{17} \mathrm{H}_{16} \mathrm{O}_{7}\right)$ 11. a. $\mathrm{m}$.

Parmelia furfuracea ist ihr in manchen Jugendstadien ähnlich, doch auf der Unterseite schwarz.

Die Flechte kann, ohne ihre Lebensfähigkeit zu verlieren, rollkommen anstrocknen, so stark, daß sie sich zwischen den Fingern zu Pulver zerreiben läßt.

4. Usnea barbata. Bartflechte.

usnea vielleicht von uson $=$ Strick abgeleitet.

Der Thallus bildet, besonders an den Zweigen alter Tannen, wehende, phantastische Flechtengehänge, findet sich aber beispielsweise auch an Birken und altem Holzwerk.

Die von der Bartflechte befallenen Zweige sterben oft ab) es handelt sich dann aber um Zweige, welche durch Lichtmangel oder sonstige ungünstige Einfliisse bereits geschwächt waren.

Die Bartflechte enthält die anch bei vielen anderen Flechten verbreitete, chemisch wohl charakterisierte Usninsäure $\left(\mathrm{C}_{18} \mathrm{H}_{16} \mathrm{O}_{7}\right)$; rgl. E. Abderhalden (1) und Fr. Czapek (1).

- Roccella tinctoria. Lackmusflechte.

roccella ans dem franzüsischen Wort roche $=$ Felsen von Linné gebildet.

Der stranchige Thallus enthält die Alge Trentepohlia; er liefert den Lackmusfarbstoff $\left(\mathrm{C}_{7} \mathrm{H}_{7} \mathrm{NO}_{4}\right)$.

Die Flechte findet sich anf Felsen an den Küisten Afrikas (z. B. der Kanaren) und an anderen Orten.

5. Xanthoria pariétina. Gelbe Wandflechte.

Name von xanthos = gell; paries = Wand.

Der durch Physeiol*) $\left(\mathrm{C}_{16} \mathrm{H}_{12} \mathrm{O}_{5}\right.$, frïher Chrysophansäure genannt) gelbe Thallus ist blattartig ansgeloreitet und liegt dem Substrat

*) Dieser gelbe Farbstoff (Parmélgelh), welcher in Form von Köruchen auf den Hyphen abgelagert ist, läßt sich durch Einlegen der Flechten in Alkohol ausziehen. 
an; bisweilen nimmt er etwas krustige Beschaffenheit (friiher Lepra genannt) an. Die Apothecien sind meist reichlich entwickelt. Die Anlage der Schlauchfriichte erfolgt, wie wohl bei allen Flechten, zur kalten Jahreszeit.

Die gelbe Wandflechte ist ïberall gemein an Rinden, Zäunen, Mauern usw.

Die Apothecien von Xanthoria eignen sich gut zur Demonstration der Asci. Man bettet sic zum Schmeiden zweckmäBig in Paraffin ein, das man von einer brennenden Kerze anf sie tropfen läBt. Im Bedarfsfalle kamn man das Paraffin (z. B. durch eine brennendes Nachtlicht) längere Zeit flüssig erhalten.

6. Parmelia physodes. Blasige Schiisselflechte.

Name von parme $=$ runder Schild, wegen der Gestalt der Apothecien.

physodes gebildet aus physa $=$ Blase und eidos $=$ Ansehen, nach dem Hohlraum zwischen Rindenschicht und Mark.

Der Thallus bildet die allgemein bekannten, grauen, rundlichen und gelappten Gebilde auf Kiefern, Tannen, Brettern usw. Er bleibt infolge meist reichlicher Bildung von Soredien in der Regel steril, wenigstens im Flachlande.

Die Flechte enthält Physodin $\left(\mathrm{C}_{20} \mathrm{H}_{12} \mathrm{O}_{15}\right)$. Sie ist wegen ihrer Fähigkeit, vollkommen auszutrocknen, sehr lebenszäh nnd ist die häufigste aller in Nadelwäldern vorkommenden Flechten.

7. Peltigera canina. Schildflechte.

Name von pelte $=$ kleiner Schild.

Peltigera ist eine typisehe, leicht kemntliche große Laubflechte, welche als lappenförmiges, im feuchten Zustand oberseits bräunliches bis griinliches Gebilde am Boden von Wäldern, z. B. Buchenwäldern, gedeiht, besonders an Wegrändern. Die Abbildıng zeigt die Flechte zwischen Moos und Buchenknospenschuppen.

Die Askusfrichte entstehen in Form brauner Scheiben am Rande des Thallus. Die Asei mit ihren langgestreckten, farlenförmigen Sporen (6-8 in einem Askus) sind an Querschnitten dureh die Apothecien leicht zu demonstrieren.

Die Arten von Peltigera fuihren als Algenkomponente Nostoc odter Cystococcus.

8. Gyrophora cylindrica. Kreisblattflechte, Felsblatt.

Name von gyros = Kreis und pherein - tragen.

Die in trockenem Zustand schwarzgrane Flechte wächst, meist zu Gruppen vereinigt, an naektem, somnigem, fast inımer kieselhaltigen Felsgestein. Sie ist anf diesem mit einem mehr oder weniger zentralen, etwa 4 qum groben Nabel befestigt.

Die anf der Fläche stehenden Apotherien, welehe an den abgebildeten Exemplaren fehlen, entwickeln sich besonders reiehlich auf Gebirgshöhen.

Die gezeirhneten Exemplare stammen von der Schneckoppe. 
9. Psora ostreata. Krätzeflechte.

Name von psora $=$ Krätze.

Der Thallus besteht aus kleinen, schimnenartigen schuppen, welche dachziegelig gedrängt stehen (s. die vergrößerte Abb.) und eine gewisse Ähnlichkeit mit Austernschalen (ostrea = Auster) haben können. Die Farbe ist meist stumpf olivgrim. Die Apothecien werden ziemlich selten gebildet.

Psora ist besonders auf der Borke am Grunde alter Kiefern häufig. Sie enthält Lecanorsäure $\left(\mathrm{C}_{16} \mathrm{H}_{14} \mathrm{O}_{7}\right)$.

Die Flechte eignet sich gut zu Dauerpräparaten in Luft auf schwarzen Objektträgern (s. später). Als Beleuchtung dient zweekmäBig eine gut brennende elektrische Taschenlampe.

Psora darf nicht mit Soredienanflügen verwechselt werden.

- Collema pulposum. Gallertflechte.

Name von kolla $=$ Leim, Gallert, pulposus $=$ wie weiches Fleisch (pulpa).

Der rosettenförmige, ziemlich dicke, in feuchtem Zustand gallertartige Thallus ist meist von grimlich-sehwarzer Farbe. Er enthält Nostoc als Alge. Die Flechte findet sich an Baumstimpfen, Moosen, Mauern usw.

Ephebe (im Gebirge) enthält Stigonema, Lichina (an Granitblöcken im Meer, z. B. Ostkiiste von Riigen) die Rivulariacee Calothrix als Alge.

10. Lecanora subfusca. Tellerflechte.

Name von lecane $=$ Teller, Schïssel.

Eine der gemeinsten Flechten, die sich anf der ganzen Erde findet; an Bäumen, auf Holzwerk und an Gestein. Sehr variabel.

Der meist weißlich graue Thallus ist krustenförmig. Die braunen $0,5(-1) \mathrm{mm}$ großen Apothecien sind kreisrund und deutlieh berandet.

Lecanora esculenta, die Mannaflechte der Wiiste, muß in der freien Natur im heißen Sand Erhitzung bis zu $70^{\circ} \mathrm{C}$ aushalten. (Abb. s. bei Kerner, Bd. II, S. 537).

Lecidea (Scheibenflechte) ist eine krustenförmige, in verschiedenen Species echte Steinflech te (zum Teil endolithisch) mit schwarzen Apothecien; sie wächst z. B. auf Granit, Porphyr und Basalt. Die Steinflechten können mit ihren Rhizinen sogar in Glas eindringen. Farbige Abb. von Steinflechten auf Felsen finden sich bei Kerner, Bd. II, Tafel bei S. 643 .

11. Rhizocarpon (Lecidea) geographicum. Landkartenflechte.

Name von rhiza $=$ Wurzel und carpos $=$ Frucht, weil die Frïchte auf dem unteren Thallusteil entspringen. geographicus wegen der Ähnlichkeit des gefelderten Thallus mit einer Landkarte.

Rhizocarpon wächst fast immer auf kieselhaltigem Gestein, besonders an Felsen, seltener auf Kalk (hier verblassend) oder auf Dach- 
ziegeln, in Gebirge und in der Ebene. Sie steigt am Monte Rosa bis ca. $4638 \mathrm{~m}$ Höhe.

Die Flechte kann ganze Felsen wie mit einer weithin sichtharen, durch Usninsäure gelben bis gelbgrïnen, nicht abwischbaren Kruste äberziehen. Jer Thallus ist durch das Hervortreten fles schwarzen Hypothallus fein gefeldert. Die Apothecien sind zwischen den Feldern als schwarze Fleckehen eingesprengt.

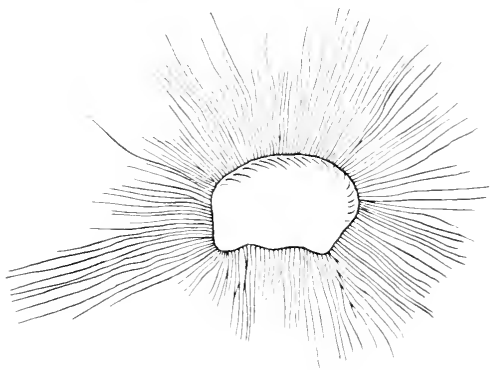

Abb. 74. Rhizocarpon geographicum, erster Thallusanflug. Die Ausstrahlungen sind die blansehwarzen Pilzfäden des ,Prothallus", welche im Weiterwachsen auf dem Gestein Algen zur Flechtensynthese finden. Im Zentrum hat sich die erste grïngelhe ,Thallusareole" hereits gebuldet. Tiele solcher ,Areolen" hilden schließlich, wenn sie zusammengestoßen sind, den Gesamt-Thallus. Vergr. 500 fach. [Nach P. Beckmann in C. Schroeter (1).]

12. Graphis scripta. Schriftflechte.

Name von graphis $=$ (iriffel $\mathrm{zum}$ Schreiben. Also die mit Griffel Geschriehene.

Lie sehrifflechte gehört zu den wenigen Hlechten, welche nirht Cystococcus oder Protococcus als Flechtenkomponente besitzen: sie enthält Trentcpohlia*). Sie wächst wie diese auf der Rinderon Bänmen, namentlich der watten der Buchen und Eschen. Der Thalhus entwiekelt sich erst unter ter Rinde und bricht tann später zum Teil hervor, meist als sehr zarter, weibgrauer Schorf. Die schwarzen Apothecien sehen wie Sehriftzeichen ans.

Die Flechte ist besonders an den Zweigen, weniger an den stämmen der Bäume häufig.

- Pertusaria commune und andere Arten.

Name von pertusus $=$ durchlöchert, wohl wegen der wie l'oren erscheinenden Apothecien.

Die soredientosen Pertusarien und soredienbildenden Tariolarion (variola $=$ Blattern) finten sich besonders an den Stämmen der Buchen in Form weiBer, Anstrich ähnlicher, oft auffallender C̈herzïge.

Die gelben oder gelberiinen lockeren Krusten von Coniocybe chlorina finden sieb häufig an sandsteinfelsen.

\section{Literatur.}

Engler-Prantl, T. Teil, Abt. 1* 1907, bearbeitet ron II. Finfstiok nut A. Zahlbruckuer.

*) Die (iattung Trentipohlia ist farhig abgehildet (an ihrem standort im Freien) bei lierner, Bd. II, Tafel bei S. 605 (in einer anderen species als bei Graphis). 
G. Lindan (5).

Joh. Lennis (1).

Weitere Zitate finden sich in len genannten Werken.

\section{Gruppe. Algen, Plankton und Ökologie der Gewässer.}

\section{Algen.}

Dic Ernährung der Algen ist in neuester Zeit erfolgreich und ringehend studiert worden, vorwiegend nath der physiologischen seite in heinkulturen. Dabei ist zu beachten, dab das ph ysiologische Verbalten im Laboratorium siel mit dem hier mehr betonten äkologischen in der freien Natur nicht in allen Punkten zu decken braucht. Fin gutes Beispiel zur Erläuterung von in dieser Hinsicht bestehenden Differenzen ist seit riniger Zeit für die Eisenbakterien bekannt. Diese kömmen in Reinkultur des Eisens (in irgendwie nemenswerter Henge) entbehren, kommen aber in der freien Natur ansgesprochen an eisenhaltigen standorten vor, nehmen es hier anch auf. Viele Algen ernähren sich an ilıren natiorlichen Stanchorten mit Vorliebe mixotroph, während sie in kiinstlichen Reinkulturen autotroph leben können. Dieser Unterschied diurfte sich leicht dadurch erklären, dab sie in der freien Natur oft mit Bakterien und anderen Organismen in Konkurrenz treten und diesen die organischen Stoffe wegzunehmen genötigt sind, wrnn sie nicht von den Bakterien, welehen meist wirksamo Kampfenzymo zur Verfïgung stehen. Interdriickt werden wollen.

Die meisten Algen leben in Wasser: sie finclen aber, wie sehon ihr Vorkommen in Flechten beweist, anch auberhalb dieses Medinms Existenzbedingungen, z. B. manche Verteter unter den Oscillatoriaceae, Nostocaceac, Bacillariaceae, feruer Plcurococcus (als Anflug an Bänmen), Hormidium, Trentepolhlia, Botrydium und manche Arten von Vaucheria.

\section{System der Algen.}

Schizophyceae (Cyanophyceae, Spaltalgen). Anhang: Schizomycetes Flagellatae*) mit Chlorophyll.

Perilliniales Peridine en).

Zygophyceae $\left\{\begin{array}{l}\text { Bacillariales (D) iato meen). } \\ \text { Coujuoatae. }\end{array}\right.$

Chlopophyceat $\left\{\begin{array}{l}\text { Protococeales. } \\ \text { confervales, } \\ \text { siphoneae. }\end{array}\right.$

Phacophyceae (Braunalgen, Tange).

Rhodophyceae (Rotalgen, Florideen).

Chamales (Armlenchtergew ächse) als Anhang zu den Algen.

*) Die chlorophyllführenden Flagellaten sind aus physiologischen Grinden zu den Algen gerechnet. 
Pflanzen des Wassers.

(Entsprechende Abb. von Tieren s. Taf. VIII.)

Schizophyceae:

1. Chroococcus limneticus.

2. Polycystis aernginosa.

3. Merismopedia glanca.

4. Oscillatoria agardhii.

5. - limosa.

6. Spirulina (Arthrospira) jenneri.

7. Phormidium uncinatum.

8. Nostoc verrucosum.

9. Anabaena spiroides.

10. Aphanizomenon flos aquae.

11. Tolypothrix lanata.

12. Rivularia (Gloeotrichia) echinulata.

Schizomycetes (als Anhang):

13. Micrococcus phosphorens.

14. Lampropedia hyalina.

15. Sarcina paludosa.

16. Azotohacter chroococcum.

17. Bacterium vulgare.

18. Bacillns subtilis.

19. Pseudomonas fluorescens.

20. Spirillum undula.

21. Sphaerotilus natans.

22. Clatothrix dichotoma.

23. Zoogloea ramigera.

24. - nva.

25. Beggiatoa alba.

26. Thiothrix nivea.

27. Lamprocystis roseo-persicina.

28. Chromatmm okenii.

Chrysomonadales:

29. Mallomonas acaroides.

30. Synura nvella.

31. Uroglena volvox.

32. Dinobryon sertularia.

Silicoflagellata:

33. Distephanus speculum.

Coccosphaerales:

34. Pontosphaera huxleyı

Cryptomonadales:

35 . Cryptomonas erosa.

Englenales:

36. Englena viridis.

37. Phacus longicanda.

38. Trachelomonas hispida.

39 . - volvocina.

Peridiniales:

40. Ceratium hirundinella.

41. Ceratium tripos.

42. Peridinium divergens.

43. - talıulatum.

Bacillariales (Diatomaceae):

44. Melosira granulata.

45. - varians.

46. Stephanodisens hantzschianus.

47. Triceratinm favus.

48. Fragilaria crotonensis.

49. - capucina.

50. Synedra ulna.

51. - acus.

52. Asterionella formosa.

53. Diatoma elongatum.

54. Tabellaria flocenlosa.

55. - fenestrata.
56. Rhoicosphenia curvata.

5i. Cocconeis pediculus.

58. Navicula (Pinnularia) nobilis.

59. - - viridis.

60. Navicula cryptocephala.

61 - atomus.

62. - cuspidata.

63 Stauroneis phoenicenteron.

64. Amphipleura pellucida.

65. Plenrosigma acuminatum.

66. Gomphonema acuminatum.

67. Cymbella lanceolata.

68. Amphora ovalis.

69. Epithemia turgida.

70. Nitzschia sigmoidea.

71. - acicularis.

72. Hantzschia (Nitzschia) amphioxys.

73. Cymatopleura solea.

74. Surirella biseriata.

Conjugatae:

75. Closterinm moniliferum.

76. Cosmarium botrytis.

77. Staurastrum gracile.

78. Nongeotia genuflexa.

79. Spirogyra porticalis.

So. Zygnema stellinum.

Protococcales:

81. Chlamydomonas species.

82. Polytoma uvella.

83. Pandorina morum.

84. Eudorina elegans.

8.i. Volvox aureus.

86. Rhaphidium polymorphum.

87. Scenedesmus acutus.

88. - quadricanda.

89. Pediastrum boryanum.

90. Actinastrum hantzschii.

91. Richteriella botryoides.

Confervales:

92. Ulothrix zonata.

93. Conferva bombycina.

94. Stigeoclonimm tenue.

95. Oedogoninm rivulare.

96. Cladophora fracta.

97 . Vancheria species.

Florideae:

95. Lemanea fluviatilis.

99. Chantransia chalybaea.

Enmycetes:

100. Fusarium aquaednctum.

101. Saprolegnia monoica.

102. Leptomitus lacteus.

103. Nucor (zygorhynchns).

104. Nitella flexilis.

liryophyta:

105. P ontinalis antipyretica.

P'teridophyta:

106. Isoetes lacustris.

Honocotyledoneae:

$10 \%$. Hydrocharis morsus ranae.

108. Lemna arrhiza.

Dicotyledoneat:

109. Ayriophyllum spicatum.

110. Ceratophyllum demersum. 


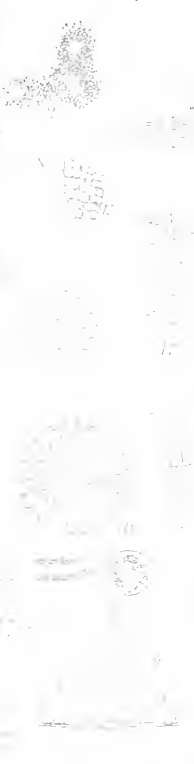

Pflanzen worwiegend Algen, des Wassers.

Verlag von Gustar Fischer in Jena. 

An die Besprechumg der Algen schliebt sich die oiniger hïher organisierten Pflanzen, un den Blick anf die Gesamtregotation in Wasser zu lenken.

Über das System der Wasserorganismen mach emälnungsphysiologischen Gesichtspunkten vergleiche man Kolkwitz und Marsson (1), sowie die farbigen Tafeln in Rubners Handbuch. Üher die C̈kologie der marinen Saprobien vergleiche man J. Wilholmi (1).

\section{Pflanzen (vorwiegend Algen) des Wassers, s. Taf. VII.}

Die Abbildungen sind durchgehends Neuzeichnungen, ehenso wie die der anhangsweise hesprochenen Tiere. Es handelt sich teils um Originale, teils un Zeichungen nach den Werken von Blochmann, Ehrenberg, Lampert, Lemmermann

Ich legte Wert daranf, das zu hehandelnde Material soweit zn sichten, daß es auf je einer Tafel vereinigt werden konnte.

Schizophyceae, Spaltalgen.

Der Name leitet sich von schizein = spalten ah, da die Vermohrung der Zellen dureh Zweiteilung erfolgt. Sie leben im Wasser und an feuchten Orten in der Luft. Fast alle planktonischen Tertreter dieser Gruppe sind unbeweglich.

\section{Chroococcus limneticus.}

Name von chroa - Farbe.

Zellen blaugriin, zu mehreren in einer Gallerthiille veroinigt. Durchmesser der Zellen etwa 6-12 «. Planktonisch.

\section{Polycystis aeruginosa.}

Name von aerngo = Grünspan.

Zellen klein, sich nach drei Richtungen des Ranmes teilend, mit Schwebevakuolen, zu vielgestaltigen Kolonien vereinigt, welche wie Staubkliumpehen, Kringel und dergleichen erscheinen, häufig auch gitterartig durchbrochen sind (daher frïher Clathrocystis genannt). Bildet bei ïppiger Entwicklung zur warmen Jahreszeit hesonders in der Uferregion der Gewässer dicke grünspanfarbige Überziige auf der Wasseroberfläche. (In Planktonkammer beohachten!) Kolonien bisweilen mit Vorticelliden und kleinen Kieselalgen besetzt. Sehr häıfig; im Winter meist nur ganz yereinzeltim Plankton. - meist o -

3. Merismopedia glauca. Tafel-Blanalge.

Name von merisma $=$ Teil und pedos $=$ Platte, Tafel.

Parallelform zu Lampropedia. Zellen blaugriin, 3-6 k diek. Zellteilung nach zwei Richtungen des Raumes. Wohl meist nur erratisch planktonisch.

${ }^{*}$ ) Wegen den Bezeichnungen $p, \alpha m, \beta m$ und o vergleiche man das Kapitel Ökologie. 


\section{Oscillatoria agardhii.}

Benannt nach dem scheinbaren Pendehn der Spitze beim Kriechen der Grundformen. Planktonisch in Seen, Fliissen usw., das Wasser besonders zur warmen Jahreszeit oft triibgriun verfärbend. Vgl. Aphanizomenon u. a. m. Mit Schweberakuolen.

P'r" 1 cem oft iiber tausend Fäden. Beim Absterben geben angehäufte Massen, ebenso wie bei anderen spaltalgen, leicht einen wasserlöslichen blanen Farbstoff (Phycoeyan) ab), unter Umständen bei manchen Spaltalgen so massenhaft, daß das Wasser wie mit Indigo gefärbt erscheint. Han nennt die Schizophyceae daher auch Cyanophyceae. Die physiologisehe Bedeutung des Farbstoffes ist unbekanut.

- o bis $\beta \mathrm{m}-$

\section{Oscillatoria limosa.}

Fäden gegen $15 \mu$ dick, mit niedrigen Zellen wie Talerrollen: von triibgriiner Farbe, unter Drehung kriechend.

Versuch: Man bringe Fäden auf den objektträger in einen mit ehinesischer Tusche (festes Stück, dessen Reibfläche nach Benutzung wieder getrocknet wird!) verriebenen Wassertropfen. Die Tuschepartikel werden bald festkleben und, anch went der beobachtete Faden still liegt, entsprechend der Bewegung des extramembranösen Plasmas, in spiralwindnngen um den Faden bernmwandern.

Häufig in Gemeinschaft mit kriechenden Kieselalgen sogenannte ()scillatorien-Diatomeen-Filze bildend, welche als Fladen, durch Assimilations- oder Gärungsgase getragen, an die Oberfläche steigen können. Über Kulturversuche mit Osc. limosa vgl. B. Schindle (1); s. auch F. G. Pringsheim (1).

$-\beta \mathrm{m}-$

6. Spirulina (Arthrospira) jenneri.

Blangrine, nnter Drehen kriechende spaltalge, welche in die polysaprobe Zone vorrickt. Meist in Gemeinschaft mit Beggiatoa.

\section{Phormidium uncinatum.}

Name von phormos $=$ geflochtene Matte.

Bildet oft dunkle häntige Lager, Zellen mit scheiden. - a m-

\section{Nostoc verrucosum.}

Von dem dentselsen Wort Nostok fiir solehe gallertige Kilumpen. Herkunft des Namens völlig unbekannt. Gallertiges Lager bis $1 \mathrm{dm}$ groß. Fäden perlschnurartig.

Nostoc punctiforme auch endophytisch in cyeadeen-Wrurzeln u. a. m. Nostoc kann Flechtengonidien bilden.

Gallertkolonien grüin, bläulich, rötlich usw.: Nostoc.

$\begin{array}{lll}. & \text { meist griin: } & \text { Ophrydinm. } \\ , & \text { bram bis oliv: } & \text { Rizularia natans. } \\ \text { ", } & \text { farblos: } & \text { meist Schneckenlaich. }\end{array}$




\section{- Nodularia spumigena.}

Name von nodulus $=$ Knoten.

Fäden nit kurzen, seheibenförmigen Zellen, Grenzzellen und zı Zeiten auch Sporen, $8-12 \mu$ breit. Im Plankton der Ustsee, anch in siißem Wasser.

9. Anabaena spiroides. Das Löckichen.

Nime von anabainein $=$ sich erhelren.

Typisch planktonisch. Korkzieherartig gedreht. Mit deutlichen Grenzzellen nnd schwebevakuolen. Die Grenzzellen (Heterocysten) sehen zwischen den ïbrigen Fadenzellen wie helle Öltröplchen ans. Im mikroskopischen Präparat schweben die Fäden meist dicht unter dem Deckgläschen. A. flos aquac, circinalis, solitaria II. a. sind die bekanntesten Arten. Kamn Wasserbliite bilden, anch in Gemeinschaft mit Polycystis und Aphanizomenon.

$-0-$

10. Aphanizomenon flos aquae. Sägespan-Alge.

Name von aphanizein = msichthar machen; weil die Wasserblite schneH erscheint und dann schlieBlich wieder für das Ange ganz verschwindet.

Fäden meist mit Grenzzellen und oft mit Sporen, bei typischer Entwicklung zu sägespanähmlichen Bïndehn paketartig vereinigt. Mit Schwebevakuolen. Unter normalen Verhältnissen unbeweglich. Farbe grangriin, abgestorben blangriin. Sehr wichtiger Planktonorganismus. Bildet bisweilen eine Sahne von Wasserbliite. In Haffen neben anderen als Haffbliite bezeichnet. Vgl. auch die Farbentafel. Die Farbe der konservierten Probe ist nubegrenzt haltbar.

Osc. agardhii ist vielleicht identisch mit Aphanizomenon.

\section{Tolypothrix lanata.}

- o bis $\beta \mathrm{ml}$

Name von tolype = Knäuel.

Fäden (ca. $10 \mu$ dick) mit Basis und spitze, von einer scheide $11 m-$ geben. Psendodichotomie unter einer Grenzzelle erfolgend. Ähnliche Pseudodichotomie besitzt Cladothrix. An untergetanchten Pflanzen festsitzend.

\section{Rivularia (Gloeotrichia) echinulata.}

Name von rivulus = Bächlein, weil einige Arten der Gattung in Bächen lelien.

Kolonien etwa 1 mun grob, durch Teilung und Verzweigung der Fäden entstehend, meist grangrün, von der Gestalt eines gekugelten Igels. (Planktonkammer!) Fäden peitschenförmig mit Endknopf (Grenzzelle) und Spore wie Handgriff (mambrium).

Besonders in Seen mit grüner Eigenfarbe des Wassers. Tritt meist erst vom August an anf und verschwindet nach der sporenbildung im Herbst. Die sporen sinken zu Boden. Deshalb typisch periodisch planktonisch. Betreffs der Biologie vgl. anch U. Plïmecke (1). 
R. natans bildet weiche, schwimmende Gallertmassen (braun bis oliv) von Wahnugröße und darüber. Vgl. Nostoc.

R. hacmatites speichert Kalk.

Schizomycetes (als Anhang zu den Spaltalgen).

- Streptococcus mesenterioides.

Name von streptos $=$ Halskette.

Vol. Kap. Schizomycetes.

13. Micrococcus phosphoreus. Lenchtbakterie.

Vgl. Kap. Schizomycetes. Weitere Arten sind von H. Molisch (2) beschrieben.

14. Lampropedia hyalina. Tafelkokken.

Name von lampros $=$ glänzend und pedos $=$ Platte.

Vgl. Kap. Schizomycetes. Im Plankton, wohl auch auf Schlamm.

15. Sárcina paludosa. Paketkokiken.

Vyl. Kap. Schizomycetes. Die Abbildung zeigt eine stark entwickelte Kolonie. Größe der einzelnen Zellen einige Nikromillimeter.

\section{Azotobacter chroococcum.}

- meist p -

Name von l'azote $=$ Stickstoff.

Besitzt die Fähigkeit, reichlich freien Stickstoff zu assimilieren. Heltet sich auf planktonischen und benthonischen Schlamm- und Uferorganismen fest. Auch im Boden. Größe der Zellen meist gegen $4 \mu$.

17. Bacterium vulgare.

Eine der häufigsten Fäulnisbakterien. V'gl. Bacillus subtilis und Kap. Suchizomycetes.

18. Bacillus subtilis. Heubazillıs.

Bewegliche Fäden, 0,8-1,2 $\mu$ im Durchmesser, für Bakterien also ziemlich dick. Vgl. Kap. Bacteria. Die Fäden von Bacterium (Proteus) vulgare sind zarter und biklen keine sporen.

19. Pseudomonas fluorescens. Ygl. Kap. Schizom yeetes.

20. Spirillum undula.

Häufig in verdorbenem Wasser. Vol. Kap. Schizomycetes. - p bis a $\mathrm{m}$ -

- Eisenbakterien s. unter Kap. Schizom ycetes.

21. Sphaerótilus natans.

Name von sphaera $=$ Kingel und tile $=$ Flocke.

Typischer Lbwasserorganismus. Biklet fellartige Besätze. Fäden 2 pe loreit, also viel diumer als Leptomitus. Vgl. anch Kap. Scehizomy yetes.

- p bis a $\mathrm{ml}$ -

Sph. roseus ist von rosenroter larbe, nicht, wie bisweilenFusarium, ziegehrot. 


\section{2:. Cladothrix dichotoma.}

Farblos. Mit Pseudodichotomien. Entwicklungsform vou Sphacrotilus bei Nahrungsabnahme.

- meist $\beta \mathrm{m}-$

\section{Zoogloea ramigera.}

Bildet weiBliche, hirschgeweihartige Kolonien von $1-1,5 \mathrm{~mm}$ Länge.

๖4. Zoogloea uva. Traubenförmige Zoogloea.

Tritt an untergetauchten Wurzeln, Halmen usw. in Form von ctwa erbsen- bis lirschengroßen, traubig gehäuften, neist ungefärbten Gebilden anf. Stäbchen in der schleimmasse meist langgestreckt und etwas iiber $1 \mu$ dick.

- meist p -

\section{Beggiatoa alba.}

Fäden nach Art der Oscillatoria auf (schwefelwasserstoffhaltigem) schlamm usw. kriechend. Vol. auch liap. Schizomycetes.

\section{Thiothrix nivea.}

- p bis m bis o-

Bildet weiße Besätze in schwefelwasserstoffhaltigen Gewässern (auch in Wasserleitungen). Fäden im Gegensatz zu Beggiatoa unbeweglich. Die Abb. zeigt die Fäden auf Cladophora festsitzend.

\section{7 . Lamprocystis roseo-persicina.}

Kolonien pfirsichbliitenrot (in Planktonkammer beobachten!), oft gitterartig durchbrochen. Parallelform unter den schwefelbakterien zu Polycystis acnginosa. In schwefelwasserstoffhaltigen Gewässern.

\section{Chromatium okenii.}

Kirschrote Schwefelbakterie, meist ca. $8 \mu$ lang. Oxydiert Schwefelwasserstoff. Vgl. Kap. Bacteria.

- Rhodospirillum. Purpurspirillum.

Zellen rot, schwefelfrei. In Sumpfwasser. Über Kultur der Purpurbakterien vgl. das Kap. Schizomycetes.

Chrysomonadales. Golılgelbe Monaden.

Zu dieser Gruppe, welche bewegliche Formen umfaßt, gehören viele Vertreter des Planktons; größere seit langem bekannte, und kleinere (Nannoplankton), erst in nenerer Zeit studierte. Viele besitzen charakteristisch gestaltete Gehäuse. Die Ernährung erfolgt pflanzlich oder tierisch. Als Assimilate treten Fett oder fettähnliche Bestandteile auf. Die Chrysomonadales sind häufig und weit verbreitet. thre sehr vergängliche Natur erfordert meist ein studium am lebenden Objekt.

29. Mallomonas acaroides. Pelzmonade.

Name von mallos = Zotte, Haar und acarus = Milbe.

Planktonisch; meist ca. $25 \mu$ lang, gelh. Pro 1 cem bisweilen Dutzende. Stacheln mit feinen Blättchen festsitzend. - o - 
- Chromulina rosanoffii. (Nicht abgebildet.)

Vermag auf die Wasseroberfläche emporzukriechen und dort durch Lichtreflex Goldglanz zu erzengen. Vorwiegend in Tümpeln und Wasserkübeln.

\section{Synura uvella.}

Kolonien freischwimmend, rundlich (ca. 60 «) odler länglich. Farbe gelb, Geruch nach frischen Gurken. Entwickelt sich mit Vorliebe in der kälteren Jahreszeit.

\section{Uroglena volvox.}

Kolonien gelblich, echt planktonisch, bis $300 \mu$ grob. (Mit Planktonkammer beobachten!) Geruch unangenehm fischig-tranig. sich bisweilen der umgebenden Luft mitteilend. Pro $1 \mathrm{ccm}$ Wasser bis gegen 25 liolonien. Meist in Seen; in den oberen Wasserschichten.

32. Dinobryon sertularia. Trichterbäumchen ${ }^{1}$ ).

Die umherschwimmenden Trichterbüschel (meist buschiger als abgebildet) sind für das Plankton vieler Gewässer charakteristisch. Bei Massenentwicklung (Dutzende von Kolonien pro $1 \mathrm{cem}$ Wasser) erscheinen die Netz- oder Siebfänge gallengelb mit Stich ins Grüne.

IUäufige Varietätcn sind D. stipitatum and D. divergens. Die Trichter bestehen vorwiegend aus Zellulose.

$-0-$

Silicoflagellata.

33. Distephanus speculum.

Gehäuse aus Kieselstäben gebildet. Namnoplankton; marin.

Coccosphaerales.

\section{Pontosphaera huxleyi.}

Zellen mit Kalkplatten (Coccolithen). Nannoplankton; marin.

Cryptomonadales.

\section{Cryptomonas erosa.}

Länge 15-32 $\mu$. Farbe meist olivgrün. Bildet Stärke. Schwimmbewegung oft durch Springen unterbrochen. Äuferst typisch als $\beta$-mesosaprober Planlitont. Wird von vielen Rädertieren u. a.m. gefressen. Pro $1 \mathrm{ccm}$ Wasser sehr oft Dutzende und viel mehr Exemplare. Näheres bei A. Pascher (1).

Euglenales.

36. Euglena viridis. Mit Augenfleck (Euglena $=$ schönes Ange).

Bildet bei massenhaftem Vorkommen (viele Tausend pro $1 \mathrm{ccm}$ Wasser) saftgrüne Überzüge auf der Wasseroberflïche: kamn auch grüne Verfärbung des Ciesamtwassers bewirken. Besonders in verumreinigten Dorfteichen und Abwasserpfützen.

$-\mathrm{p}$ his $\alpha \mathrm{m}$ -

*) Nach frdl. Vorschlag von Fran Dr. L. V. M e y er. 
Sehr geeignet zu heliotaktischen Versuchen und zum Nachweis von Geißehn durch Jodfärbung. Körper metabolisch. Im Zimmer hält sich diese Spezies leider nicht lange: Euglena deses pflegt widerstandsfähiger zu sein.

Versuch: Bringt man ein gewöhnliches objektträgerpräparat mit zahlreichen, lebhaft beweglichen Exemplaren von Euglena viridis unter das Mikroskop, so wird man leicht beobarhten, daß alle normalen Individuen direkt nach der dem lichte zugekehrten seite des Decknläschens hinschwimmen. Dreht man den Objektträger um $180^{\circ}$, so wird dessen vorher dunklere Seite stärker belichtet und die Euglena kehren sämtlich $11 \mathrm{~m}$; vol. anch das Kap. Assimilation. Hat man reichliche Mengen von Material zur Verfügung, so kamn nan diesen Versuch auch makroskopisch anstellen, am besten unter Verwendung einer parallelwandigen Glaskiivette, deren Schmal- oder liängsseite man dem Licht zukehrt.

Durch Zusatz starker Jodjodkalimmlösung zu mikroskopischen Präparaten kamn man bei Euglena viridis leicht die Geißel nachweisen. Als Assimilationsprodukt tritt Paramylum auf, das sich mit Jodlïsung nicht blan färbt.

Der sogenannte Angenfleck am vorderen Teil der Zellen ist für die Perzeption des Lichtes wahrscheinlich nicht maßgebend, da es gänzlich farblose Flagellaten gibt, welche ebenfalls heliotaktisch sind.

P. Rabbas hat von griinen Flagellaten Lumière-Momentaufnahmen gemacht, an denen der rote Augenfleck gut sichtbar ist.

Euglena sanguinea siehe auf der Farbentafel IX. Der Farbenton des Organismus spielt öfter ins Braumrote.

\section{Phacus longicauda.}

Name von phakos $=$ Linse.

Zellen flach, grïn, gegen $100 \mu$ lang, mit einer Cieißel. Paramylumkorn scheibenförmig.

- o bis $\beta \mathrm{m}$ -

\section{Trachelomonas hispida.}

Name von trachelos $=$ Hals.

Die Gehäuse haben bisweilen einen kragenartig aufgesetzten Hals. Sie sind meist brann, 20 - $30 \mu$ lang und enthalten innen grime Chromatophoren.

$-\beta \mathrm{m}-$

\section{Trachelomonas volvocina.}

Zellen meist kugelig, in der Regel gegen $10 \mu \mathrm{im}$ Durehmesser. Membran oft schwarzbram. Nach E. Naumann (1) bisweilen gegen 40000 Zellen pro 1 rem Wasser.

$-\beta \mathrm{m}-$

Peridiniales.

Zellen mit zwei Geißeln, von denen die eine äquatorial verläuft. Chromatophoren gelbbraun. Rein planktonisch. 


\section{- Gymnodinium palustre.}

Ähnlich manchen Arten von Peridinim, aber ohme Panzer. Im siißwasser und Veere finden sich ziemlich häufig kleine farblose Arten, welche noch wenig studiert sind.

41. Coratium hirundinella. Schwalhenschwanzalge.

Sehr charakteristisch gestaltet. Durch Längs- nnd Äquatorialgeißel beweglich. Nit getäfeltem, vowiegend ans Zellntose bestehendem Panzer. Besonders im Plankton der Seen.

\section{Ceratium tripos.}

Marin, anch in der ()stsee. Einzeln oder in Verbänden. Erzengt wie Noctiluca miliaris und manche Bakterien Meeresleuchten. Dieses entsteht schon, wemn etwa pro $6 \mathrm{cem}$ Wasser eine Noctiluca vorhanden ist.

\section{Peridinium divergens.}

Marin. Oft häufig, z. B. acht Zellen pro $1 \mathrm{~cm}$.

\section{Peridinium tabulatum.}

Gelbbram, meist lebhaft und wackehnd beweglich, mit gefeldertem, vorwiegend aus Zcllulose bestehendem Panzer. Körper etwas flach gedriickt. Typisch planktoniseh.

\section{Bacillariales (Diatomaceae). Kieselalgen.}

Uembranen stark kieselsäure- und wahrscheinlich anch pektinhaltig. Zellen von schachtelban, ans zwei schalenhälften bestehend. ('hromatophoren meist gelb bis gelbbram. assimilierend, erstes sichtbares Assimilationsprodukt meist öl. Ansgeschiedene Sanerstoffbläschen sieht man ïher Diatomeenïberziigen oft in großer Menge wie silberne Kïgelchen stehen.

Die Raphe bildet den Austrittsepalt fiir das bewegende Plasma. Fast alle planktonischen Kieselalgen sind raphefrei nnd unbeweglich. Das Präparieren der Kieselschaten robnsterer Formen geschieht durch Gliihen möglichst reinen Materials auf dem Platinblech oder durch Kochen in Schwefelsäure unter Zufïgen ron Salpeter zum Oxydieren der organischen Substanzen. Planktonformen enthalten meist weniger Kieselsäure, dagegen findet man die Schalen benthonischer Vertreter, von der Natur selbst präpariert, häufig im Schlamm. Als Einbettungsmittel dient am besten Styresin. Vgl. StrasburgerKoernicke (1), Abschn. XX. Luftblasen entfernt man unter der 
Luftpumpe. Diatomeentypenplatten sind im Handel käuflich. Hie Rohkultur geschieht am hesten in flachen schalen bei niedriger Wasserschicht und kiihler Temperatur. Man kann dem Wasser einigo Grasstiicke oder andere Pflanzenreste boifiugen.

l'ür Reinkulturen, z. B. von Variculetn, benutzt man folgendes Nährmedium:

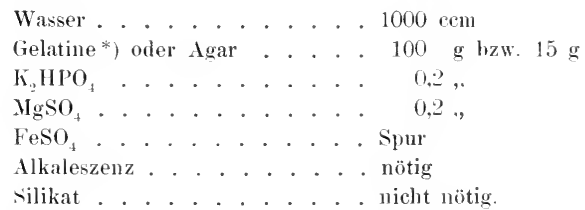

Als Stickstoffquelle giltt man $0.2 \mathrm{~g} \mathrm{KNO}$ oder Asparagin; vgl. anch 0 . Richter (1).

\section{Melosira granulata.}

Name von melos $=$ Glied und seira $=$ Schnur.

Zellwände mehr oder weniger dentlich punktiert. Schlubzellen mit stachel. (.M. helvetica 11 . a. m. ohne stacheln, M. binderiana besonders zartwandig.) Pro 1 rem Wasser bisweilen rinige tansend Fäden.

\section{Melosira varians.}

Uferorganismus oler erratisch planktonisch. Die diimnen Fäden verhältnismäßgig hänfig Auxosporen bildend. Leicht kenntlich an den Einkerbnngen der Fadenaußenwände zwischen zwei Zellen. Kann branne C̈berzüge bilden. Kennzeichnet die Zone abklingender Selbstreinigung: - typisch $\beta$ m-

\section{Stephanodiscus hantzschianus.}

In Norddeutschland die Form pusillus im Plankton besonders häufig. Bisweilen mit langen, sehr zarten Randstacheln, welche besonders bei 1)unkelfeldbeleuchtnng gut zu sohen sind. Nanchmal zu Fäden vereinigt. Pro 1 cem Wasser nicht selten gegen 6000 Zellen der kleinen, etwa 10 im schalenturchmesser hetragenden Form.

\section{Rhizosolenia semispina.}

- typisch $\beta$ m-

Hänfiger Planktont der Neere; in der Ostsee, Nordsee nud besonders den mordischen Meeren.

*) Die Gelatine muß von feinster Qualität, der Agar 2-3 Tage gewässert, zuletzt mit destilliertem Wasser ausgespïlt sein. 


\section{- Chaetoceras whighamii.}

Zwischen den Stacheln Gallerthäute, welche die Schwebefähigkeit erhöhen können. Chaetoceras ist ein charakteristischer Meeresplanktont, besonders in nördlichen Meeren.

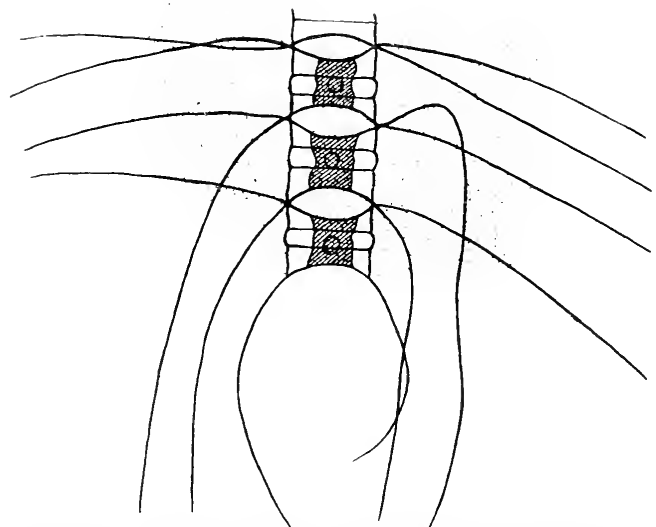

Abb. 75. Chaetoceras whighamii mit Hüllgallerte (sichtbar nach Einlegen in Tusche). Vergr. 700 fach. (Nach Br. Schröder. 1911.)

\section{Triceratium favus.}

Marin. Nicht planktonisch. Wird auch fossil gefunden.

48. Fragilaria crotonensis. Kammalge.

Zellen zı einer Art Doppelkamm aneinander gereiht. Häufig im Plankton der Fliisse und Seen. Oft mit regelmäBig angeordneten öltröpfchelı.

- o (bis $\beta$ m) -

\section{Fragilaria capucina.}

Biklet flache, auth bei ziemlich starker VergröBerung ebene (kaum gewöbte) Bänder, die iberraschend lang' werden können. Im Plankton häufig.

50. Synedra ulna. Die Elle.

synedra $=$ zusammensitzend.

Sehr häufig, in mesosaprobem Wasser hisweilen branne Überzige bilkend. Nlit ihren Varietäten.

- o bis $\mathrm{m}$ -

\section{Synedra acus.}

Unbeweglich. Häufig im Plankton: pro 1 ecm Wasser bisweilen mehrere tansend. Passiert leicht die Maschen des Planktonnetzes und -siebes. Lang nadelförmig gestreckte Formen werden als S. delicatissima bezeichnet.

- o bis $\beta$ m -

\section{Asterionella formosa.}

Diese ,.Sternalge" lebt peremierend planktonisch. Die Kolonien sind 4-17- (u. mehr-)strahlig. Im letatgenamnten Falle sind sie in 
flacher Schraubenlinie angeordnet, welche drei Ungänge haben kann. Normale dreistrahlige Kolonien scheinen nicht vorzukommen; beobachtet man sie, so handelt es sich um zerbrochene mehrstrahlige oder um die der Asterionclla bisweilen ähnliche Diatoma elongatum. strahlen in den lïcken (nach A. Voigt) oft durch Gallertfäden verbunden. In selteneren Fällen tritt Asterionella auch in Form von Zickzackketten oder kurzen Bändern auf. Wie Planktonkammerstudien ergeben haben, künnen pro 1 '‘m Wasser mehrere Tausend Kolonien von Asterionella vorkommen, besonders bei Beginn der wärmeren Jahreszeit (Frihlingsmaximum). sind die sterne vierstrahlig, so erscheinen sie bei Beobachtung in der Planktonkammer mit Lupen wie feime +-Zeichen. Nicht selten mit Diplosiga u. a. besetzt. Beziiglich der Reinkultur von Asterionella vgl. man O. Richter (1).

Bringt man mit dem Planktomnetz oder -sieb gewonnene Anhäufungen von Asterionella, Diatoma oder Melosira in ein dem direkten Sommenlicht ausgesetztes Gefäß (z. B. Planktonglas), so steigen infolge der Assimilation Samerstoffblasen empor, meist in Abständen ron rinigen sekunden. Das in den Zellen vorhandene ('hlorophyll kann man dadurch sichtbar machen, daß man die gelbliche Kieselalgen-Planktonmasse erwärmt, wodurch sie deutlich grün wird.

Von der Sternalge kann man in einfacher Weise durch Antrocknenlassen auf dem Objektträger oder Deckgläschen bofricdigende Danerpräparate in Luft herstellen (vorher in destilliertes Wasser!).

- o bis p m -

53. Diatoma elongatum ( $=$ Dlatoma vulgare var. elongatum).

Längswände fein punktiert. Planktonisch. In der śpree und Havel besonders häufig. Pro 1 cem oft Dutzende und mehr. - " bis $\beta \mathrm{m}$ -

\section{Tabellaria flocculosa.}

Zellen ähnlich der $T$. fenestrata, aber gedrungener. Im Plankton.

\section{Tabellaria fenestrata.}

Zellen im Innern mit unvollkonmenen scheidewänden, gestreckt. statt im Zickzack auch on sternförmigen Verbänden (var. asterionelloides). Planktonisch, besonders in seen.

\section{Rhoicosphenia curvata.}

Name von rhoicos $=\mathrm{krumm}$ und sphen $=$ Keil.

Zellen, von der Gïrtelseite ans betrachtet, gekriimmt.

$$
\text { - typisch } \beta \text { m bis a m - }
$$

57. Cocconeis pediculus. Schildlaus-Kieselalge.

Name von kokkus $=$ Korn und naus $=$ Schiff.

Häufig; festsitzend auf vielen Fadenalgen, besonders Cladophora. 


\section{Navicula (Pinnularia) nobilis.}

Große Schlamm-Diatomee. Bis etwa $400 \%$ lang. Auch an Bruchstiicken erkennbar. In der Seitenlage ist oft die Schachtelstruktur gut sichthar.

- meist "-

\section{Navicula (Pinnularia) viridis.}

Ziemlich grobe Schlamm-Diatomee. Bis $125 \%$ lang. Oft ron griinlicher Varbe im Gegensatz zu den sonst meist braungetben Vortretern dieser Gruppe.

- meist $0-$

60. Navicula cryptocephala.

Meist nur gegen 25 p. lang. Im Verein mit anderen kleinen Vavicula und Nitzschia oft massenhaft anf schlamm. Beweglich, wie alle Arten von Navicula.

- $\beta \mathrm{m}$ m -

61. Navicula atomus.

Kleinste (atomhafte) Navienlee. Länge $5-17 \mu-\beta m-$

62. Navicula cuspidata.

Schön gestaltete Lferdiatomee; bis 140 p lang. Einden der schalen etwas vorgezogen. $-\beta 111$

63. Stauroneis phoenicenteron.

Charakteristisch dureh das weiße kirenz auf der schale. Im schlamm.

$-\beta \mathrm{mll}$

64. Amphipleura pellucida.

Leicht kemntlich an den Verdickungen auf den Flächen der Euden. Benthonisch.

- o his $\beta \mathrm{m}$ -

65. Pleurosigma acuminatum.

Veist Ufer-Diatomee, aber auch planktonisch.

- meist "-

Pl. angulatum dient als Testobjekt bei der Prifung der Mikroskope (s. dort).

(iii. Gomphonema acuminatum.

Name von gomphos = Nagel, Keil.

Festsitzende [Ter-I)iatomee ron charakteristiseher form.

67. Cymbella lanceolata.

Name von cymbe hahn.

An Gallertstielen festsitzente Tfer-Diatomee.

6is. Amphora ovalis.

amphora hedentet Gefäß.

Ufer-l)iatomee von tharaliteristischem Aussehen.

(i). Epithemia turgida.

Nach epithema, das Aufgesetze.

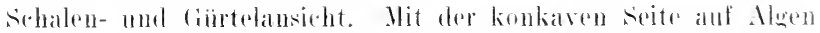
und anteren Wasserpflanzen festsitzend. Qnerrippen in der Mitte konvereierend. länge ot wa 25-100 $\mu$. 
- Bacillaria paradoxa. (Nicht abgebildet.)

Stabförmige Zellen zn bandförmigen Ketten verbunden. Beim Kriechen werden die Zellen wie die Glieder einer Fenerwehrleiter gegeneinander rerschoben. In Brack-und siißwasser. Hier besonderzur kälteren Jahreszeit. Die Zahl der Permutationen durch Ligeränderung der Zellen gegeneinander ist als endles zu bezeichmen. - - -

70. Nitzschia sigmoidea. Nach C. L. Nitzsch (Halle).

Grobe schlamm-Diatomee, bis $1 / 2 \mathrm{~mm}$ grob.

71. Nitzschia acicularis. Bis 70 "lang; beweglich.

ins -

Die etwas ähnliche Synedra acus ist unbewegliclt.

72. Hantzschia (Nitzschia) amphioxys. Nach C. A. Hantzsch (Dresden).

Ziemlich leicht kenntlich an der einseitigen schwachen Konkavität und den meist ein wenig vorgezogenen Enden. Länge bis gegen $100 \mu$, aber meist erheblich kleiner.

- typisch a m-

73. Cymatopleura solea. Pantoffel-Diatomee.

Name von kyma $=$ Welle und pleura $=$ Seite.

Schlamm-Diatomee, von schwankender Gröbe, wie dir Abhildungen zeigen. $300 \mu$ und mebr lang.

$-0-$

\section{7t. Surirella biseriata.}

Herkunft des Namens unbekannt.

Große Schlamm-Kieselalge, bis gegen $300 \mu$ lang.

$-0-$

Conjugatae.

75. Closterium moniliferum. Spindelalge.

Zellen bis $1 \frac{1}{2}$ mm lang, jedoch meist kiirzer. Häufig in der Uferregion. Anch im Plankton, z. B. mancher Fliisse; an den Enden der Zellen wie bei vielen Desmidiareen Vakutelen mit zitternden (iipskristallen (Tanzstiibehen).

Weitere bekannte Arten sind: Cl. acerosum, lumula, dianac und moniliferum.

76. Cosmarium botrytis.

Name von kosmos $=$ sehmuck.

Zellhälften schwach trapezförmig. Dlembran etwas warzig. larbe der chromatophoren reingrün. In Teichen. Torfeewässern u. dgl.

\section{Staurastrum gracile.}

$-\beta m-$

Name von stauros $=$ Pfahl, hreuz und astron $=$ Stern.

Fine der wenigen echt planktomischen Desmidiaceate - - -

\section{7s. Mougeotia genuflexa.}

Nach dem Arzt und Botaniker Ifougeot (1776-1858). Fäden gegen $30 \mu$ dick. Bildet auf Teichen und in Grähen oft Fladen von meist 
hell- und gelbgrüner Farbe und weichsträhniger Konsistenz. Jede Zelle mit plattenförmigem ('hromatophor, welches sich bei starker Belichtung hochkant stellt (Versuch!). Im Plankton finden sich bisweilen sehr feinfädige Arten (z. B. M. quadrangulata). Kopulation meist in der Weise, daß sich zwei Fäden knieartig gegeneinander biegen (genu = Knie).

\section{Spirogyra porticalis.}

Dic ,Schranbenalge" ist als Objekt tiir physiologische Versuche, z. B. solche betreffend Assimilation, und für mikroskopische Zellstudien sehr bekannt. Die Zahl der ('hlorophyllbänder beträgt je nach der spezies $1-6$. Sp. porticalis $(=S p$. quinina) hat in jeder Zelle ein ('hlorophyllband. Der Zelldurchmesser beträgt c a. $40 \mu$. Die Beobachtung gestaltet sich beim Vorhandensein nur eines Bandes am einfachsten. Der Kern kann unter einem solchen Band liegen und ist dann schwer zu sehen oder er ist an Plasmafäden. welche ihn mit den stärkeherden [Pyrenoiden*)] verbinden, in der Mitte der Zelle anfgehängt und dann ohne Anwendung von Färbungsmitteln ausgezeichnet zul sehen. Solche Fäden liefern vorzuigliche objekte zur anschaulichen Demonstration von Zellen. ebenso wie die an frïherer Stelle erwähnten Zellen von Elodea und wie die Epidermis der Zwiebel (Allium cepa). Man findet sie in der Regel in der Form schwimmender Watten in der Uferregion von Teichen, Wasserbecken botanischer Gärten, in FluBbuchten und in Gräben mit vorwiegend stehendem Wasser. In Rieselfelddrainwasserteichen kommt sie, besonders in der Spezies crassa (etwa $100 \mu$ dick), in zentnerschweren Anhäufungen vor. Über Assimilationsversuche vgl. Teil I.

Die bekannte Kopulation zwischen zwei Fäden. wobei der eine der aufnehmende ist (s. d. Abbild.), ist in der freien Natur nicht iiberall häufig zu beobachten, sie kann aber im Laboratorium kiinstlich hervorgerufen werden, indem man kleine Watten in flache schalen mit Wasser oder 2-4\% iger Rohrzuckerlösung bringt und, was wichtig ist, gut belichtet [vgl. Klebs (2)]. Manchmal findet Kopulation zwischen zwei benachbarten Zellen eines und desselben Fadens statt (friiher Rhynchonema genannt).

Fäden mit reifen Zygosporen können in Schalen einfrieren und nach dem Auftauen im selben Waser auskeimen, wobei die sporenhaut anfreißt.

*) Bei allen Arten von Spirogyra tritt als erstes sichtbares Produkt der Assimilation Stärke auf. 
Die Spirogyra-Zelle ist in der Sammlung Brendelscher Modelle vorhanden. Spirogyra setiformis ist anf einer Wandtafel von L. Kny dargestellt (Taf. Nr. 103).

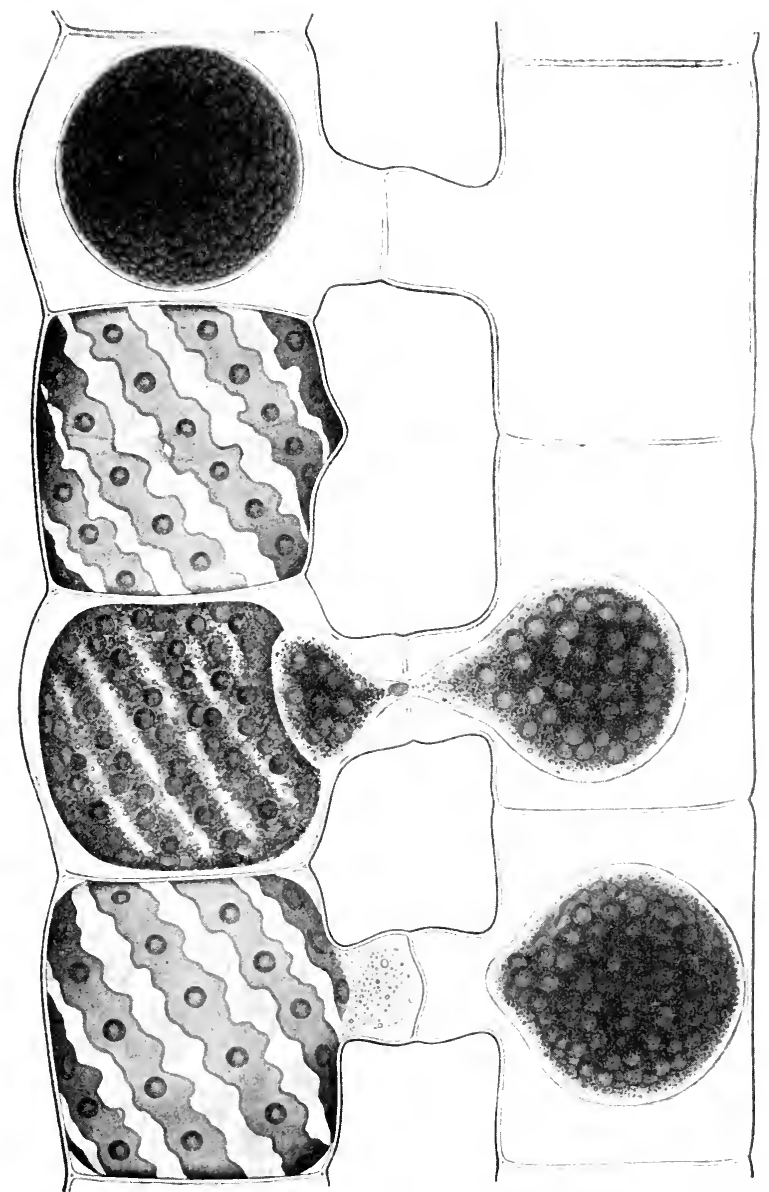

Abb. 76. Spirogyra (nitida), zwei Fäden in Kopulation. Links oben Zygospore. Vergr. ca. 400 fach. (Nach L. Kny).

\section{Zygnema stellinum.}

Name von zygon $=$ Joch.

Unverzweigte Fäden, mit je zwei sternförmigen ('hromatophoren in jeder Zelle. Breite der Fäden oft etwa $50 \mu$. Farbe blaßgrün. 
Protococeales.

\section{Chlamydomonas species.}

Häufig in Massen in Regenpfiitzen, Taimpeln, Dorfteichen 11 a. auftretend. Nach E. Naumann (1) bisweilen 240000 Zellen pro $1 \mathrm{rem}$ Wasser. Liefert, wenn reichlich Material zur Verfignng steht, instruktive Bilder bei Dunkelfeldbelenchtung. Alle Volvocacear sind planktoniseh und mit GoiBeln ansgestattet.

- meist $m$ -

\section{Polytoma uvella.}

Zellen larblos, etwa 25 4 lang. Häufig in gestandenen städtischen Abwasser sich entwickelud.

$-\mathrm{P}-$

\section{Pandorina morum.}

Kolonien meist 16 zellig, mit ziemlich dentlich abgegrenzter Gallerte. Zellen in der Mitte der (meist etwas ovalen) Kolonien znsammenstobend. Pro 1 rm Wasser bisweilen zahlreiche Kolonien.

\section{Eudorina elegans.} - o bis $\beta \mathrm{m}$

Kolonien beweglich, meist mindestens 32zellig: Zellen peripher. Verbreiteter Planktonorganismus. Kolonien viel kleiner als diejenigen von Iolvox. Pro 1 cem Wasser bisweilen loutzende von Kolonien. Vol. anch die Farbentafel $1 \mathrm{X}$.

- meist o -

85. Volvox aureus. Kugelalge.

Kolonien mit tausenden von peripher gelagerten, begeißelten Zellen. (ln Planktonkammer beobachten!) Oospore glatt. wie die Abbild. zeigt. Im Innern der Kolonien bisweilen Enkelblasen. Zellen durch feine Pasmafäden, bei $T^{\circ}$. globator dureh dicke Plasmastränge, verbunden. Die Ahbild. zeigt die Kolonie bei geringer Vergrößerimg.

- o bis $\beta \mathrm{m}-$

Unter den Phanerogamen ist der knopfgrobe same der Loogniacee Strychnos mux vomica ein gutes Objekt zum Beobachten von Pasmaverbindungen. Nan fertige Flächenschnitte von der breiten Seite und lege sie in Jodtinktur. Vgl. E. Tangl (1), A. Zimmermann (1), A. Meyer (1) und L. Jost (1). l)a Plasmaverbindungen nicht bei allen Pflanzen macherewesen sind, steht zurzeit nicht fest. ob alle leberuelen Zellen einer Pflanze dureh Plasmafäden miteinander verbundent sind.

\section{- Botryococcus braunii.}

Kobonien mbeweglich, dem bloben Ange als körnehen erscheinend, hisweilen siegellateliot dureh älartige substanz. Spez. Ciew. oft kleiner als Wasser, Wher an der (Oberläbhe sehwimmend. Zellen selbst griiu, radiär angeordnet, Termehrung durch schwärmer. Tol. anch Abh. S:i. 


\section{- Chlorella species.}

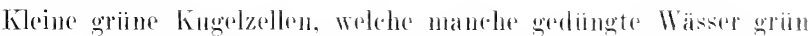
färben. Pro 1 aem Wasser dann ca. 1 Mlilion Zellen. Woil diese nur einige Mikromillimeter im Inorehmesser haben, passiert solehes Wasser das Planktometz abenso griin, wie as hineingegosen wirl. ('hlorellen leben anch in Spongilla. Hydra viridis, Ophrydium, im Flechetenthallus, in Trinkwasserkaralfen, Liosungen in rhemischen Lahoratorien usw. Meist mixutroph. In Roinkultur gomogen.

\section{$\therefore 6$. Rhaphidium polymorphum.}

- meist a m null $\beta$ m-

Name von rhaphidion $=$ kleine Nadel.

Zellen gerade oder gekriimmt, nadelförmig, einige Nikromillineser dirk, zu Bïscheln vereinigt. Im Planktonder LTerregion. - o bis $\beta m-$

\section{Scenedesmus acutus.}

Name von skene $=$ Hütte und desmos $=$ Band.

Zellen zu Kolonien vereinigt, an beiden Enden zngespitzt.

88. Scenedesmus quadricauda (= cautatus).

- $\beta$ m bis a -

Zellen zu vier und molur vereinigt. Sechr häuligg. Necist planktonisch in der I'ferregion. - o bis $\beta \mathrm{m}-$

89. Pediastrum boryanum. Tafelsternalge.

Name von pedos = Platte, und dem französ. Reisenden Bory $(1780-1540)$.

Neist 32- bis 6tzellig. Zellen, aus denen die schwärmer (welehe sich zu neuen Kolonien zusammenlegen) ansgetreten sind, lassen meist dentlich ein langgestrecktes Loch in der Membran erkemmen. Meist nicht typisch planktonisch, sonderm mehr der Lferregion angehörig.

- 0 bis i m -

P. duplex, dessen Platte netzartio durchbrochen ist, typiseloer planktonisch.

P. horvanum ist in der Sammlung Brendelscher Modelle rertreten.

\section{Actinastrum hantzschii.}

Kolonien meist t-oder szellig. Zellen meist schwach kugellörmig. ('harakteristiseluer Planktomorganismus.

91. Richteriella botryoides. Nach P. Richter, Algologe in Leipzig.

Im Plankton. Leicht kenntlich an den ziemlich derben, nach dem Ende zu verjiungten Stacheln. Erscheint bei etwa 100 facher Vergröberung wie ein grïnes Heliozoon. Nur in B-mesusaprobem Wasser üppig entwickelt, sonst mehr rinzehn. 
Confervales.

Ulva lactuca. Meersalat. (Nicht abgebildet.)

ulva $=$ Name einer Sumpfpflanze bei Virgil.

Bildet salatblattartige grïne Flächen, welche an Steinen usw. festgeheftet sind, im Laufe der Entwicklung sich aber loszulösen und frei am Boden zu liegen pflegen. Ulva bedarf nach Angaben in der Literatur zu seinem Wachstum des Natrinms. Verbreitet im nördlichen Eismeer, an der Ostliiste von Nordamerika, in der Nordsee, Ostsee, an der englischen, französischen und spanischen Kiuste, im Mittelmeer. Die Entwicklung dieser Pflanze wird durch ins Meer geleitete organische Abwässer begiinstigt; durch Massenentfaltung, verbunden mit Fäulnis, kann sie dann lästig werden.

- Enteromorpha intestinalis. Darmalge. (Nicht abgebildet.)

Bildet unregelmäßig-darmartig gestaltete griine schläuche, von mehreren Millimetern Durchmesser, öfter zu schwimmenden Massen vereinigt.

Ent. linza ॥. a. m. im Meere an steinen und Holzpfählen.

92. Ulothrix zonata. Kraushaaralge.

Name von ulos $=$ kraus.

Fäden unverzweigt, bisweilen sehr dick $(75 \mu)$. Chronuatophor sattelförmig, in der Einzahl in jeder Zelle. Oft schliipfen unter den Augen des Beobachters die Schwärmsporen aus.

Manche Arten von Ulothrix bevorzugen abwasserfiihrende (iewässer.

- meist o -

\section{Conferva bombycina.}

Name von einer Wasserpflanze bei Plinius, welche gebrochene Knochen zusammenheilen soll (confervere).

Fäden ron 5-15 $\mu$ Dicke, unverzweigt, an der H-strulitur und den ïlassimilierenden ('hromatophoren kenntlich. Bildet schwimmende nder schwebende, öfter an Wasserpflanzen festhaftende griine Watten. Teiche, welche durch diese Fadenalge verkrauten, können unter geeigneten Verhältnissen durch Einsetzen von Schwänen rein gehalten werden.

- pim -

\section{Stigeoclonium tenue.}

Die etwa 10-15 u dicken Fäden bilden Pestsitzende, saftwriine Rasen, manchmal auch nur eine sogenamnte Stigeoclonium-sohle.

- a m bis $\beta m$ -

Sehr polymorph, z. B. rerzweigt und murerzweigt. Trotzdem meist daran kemntlich, daß jede Zelle ein sattelförmiges Chromatophor enthält, welches die Mitte der Zelle einnimmt, während der freie Teil weiß bleibt, daher Stigeoclonium, d. l. gefleckter Zweig, genannt. Die Schwärmsporen besitzen vier Gieißehn. Nan erhält sie meist leicht, wenn man das eingesammelte Naterial anf einen weißen Teller in 
Wasser legt und an das Fenster stellt. An nächsten Tage wird man einen grïnen Samm ron Schwärmsporen an der dem Licht zugekehrten Seite des Tellers beobachten. Eine der hänfigsten Fadenalgen.

Draparnaldia und Chaetophora sind mit Stigeoclonium verwandt.

\section{Oedogonium rivulare.}

Name von oidan $=$ anschwellen.

Fäden nnverzweigt, ziemlich dick (bis etwa $45 \mu$ ), die männlichen etwas zarter als die (hier ahgebildeten) weiblichen. Fäden an Kappen und Scheiden (wie alle Oedogonimm-Arten) meist leicht kenntlich. Diese hochorganiiserte Alge lebt in der Regel festsitzend anf Schilf a. 11. m. Auf den Oogonien schmarotzt Chytridium olla. $\quad-\beta \mathrm{m}-$

\section{Cladophora Species.}

Diese Fadenalgen bilden mehr oder weniger anffällige griine, nicht schleimige Besätze in Flüssen, Gräben, an Meeresküsten usw.; sie sind im allgemeinen daran leicht kenntlich, daß die Fäden ziemlich fest sind und dementsprechend dem Zerreißen einen gewissen Widerstand entgegensetzen. Jungbrut von Fischen kann sich in dem festen Algenfadengewirr verfangen und darin absterben. In Fliissen können sie unter Umständen abseihend auf das Plankton wirken, vergleichbar den Barten des Wales. Infolge der Anhäufung kann damn allmählich eine geringe Zersetzung eintreten, welche eine stärkere Entwicklnng mancher Rädertiere zur Folge hat.

Während $\mathrm{Cl}$. glomerata meist ziemlich kmre Besätze bildet, kann Cl. crispata an Wehren und in Rieselfeldgräben in riesenhaften Strähnen von $9-10 \mathrm{~m}$ Länge auftreten. Werden Wiesen ibberschwemmt, können sie anf diesen eine Art Wiesenpappe (anch Meteorpapier genannt) bilden.

$\mathrm{Cl}$. profunda tritt als bemerkenswert wenig lichtbediurftige Alge in kurz-biischeligen, straffen Besätzen in 10 nnd mehr Metern Tiefe in großen klaren seen auf.

Cl. (Aegagropila) santeri bildet in manchen seen griine, massige, nicht schleimige Kolonien bis zur Größe einer kleinen Kegelkngel. Diese Alge wird im Botanischen Garten in St. Petersburg in mit Wasser gefïllen großen Bhmentöpfen, deren Boden mit Sand bedeckt ist, im Licht mit bestem Erfolg seit langem kultiviert.

Cl. rupestris bildet fellartige, zottige Besätze an steinen und Felsen der Meereskiisten, was anf Festigkeit der Anheftung und der Fäden schließen läßt wie sie im Siißwasser kaum beohachtet wird.

Die Fäden von Cladophora sind häufig mit Kieselalgen wie Cocconeis, Rhoicosphenia und Gomphonema besetzt.

97. Vaucheria. Nach dem Botaniker Vaucher in Genf (1763-1841).

Die ,Schlauchalge" findet sich im Wasser und auf feuchter Erde. Im Drainwasser von Rieselfeldern und in manchen Bächen kommt sie 
oft zu clerartig massenhafter Entwicklung, dab sie zentnerweise eingesammelt werden könnte. Die Fäden stehen dann vom substrat oft wie die Hatre eines straffen Fuchsfelles ab. Auf feuchtem Torfmull (Korngröbe möglichst nicht über j mm) können manche Arten leifht knltiviert werden, wemn man fiir geniigende Fenchtigkeit sorgt and die Kinturgeläbe mit einer Glasscheibe iberdeckt.
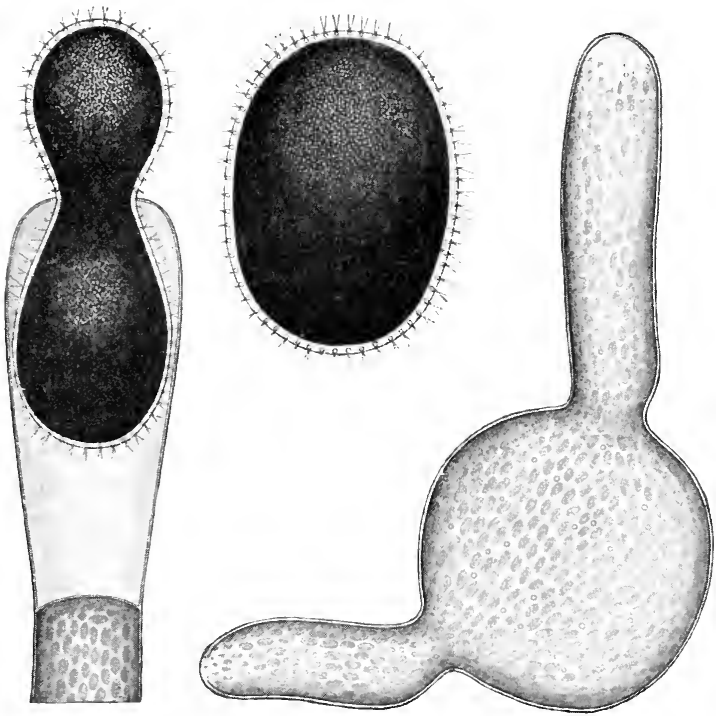

Alb. \%. Laucheria ungeri. Schwärmspore, aus dem Sporangium hervortretend. Schwärmspore frei beweglich. Schwärmspore keimend. ca. 200 mal vergr. (Nach L. Kny.)

Die Erzeugung von Geschlechtsorganen gelingt in der Regel leicht bei Kultur in 2-4\%iger Rohrzuckerlösung. [Vgl. Klebs (2) und Heering (1)].

Bringt man anf Exkursionen Fäden von Taucheria in eine Planktonkammer, so kann man sie mit ciner etwa 25 mal vergrößermen Lupe in bezug anf Einzelheiten sehr gut beobachten. Die Fäden sind bisweilen mit Eisen- und Mangankriimeln beteckt, welche durch die Eisenbakterie Siderocapsa erzengt sein können.

Caulerpa ist eine reich gegliederte Gattmng der siphoneen in den wärmeren Meeren.

Pha o phy cea e. Braunalgen.

Laminaria saccharina. Zuckertang.

Reich an Mannit, der beim Trocknen an der Oberfläche der Alge als weißliches Pulver auswittert. 
In Beständen lebend und bei Ebbe hervortauchend. Die Laminarien sind Charakterpflanzen der nördlichen Meere; sie fehlen dementsprechend in den Tropen. Die Fortpflanzung findet in Winter statt. sie wurden friber zur. Jodbereitung verwantt. Mbb. s. beistehend.

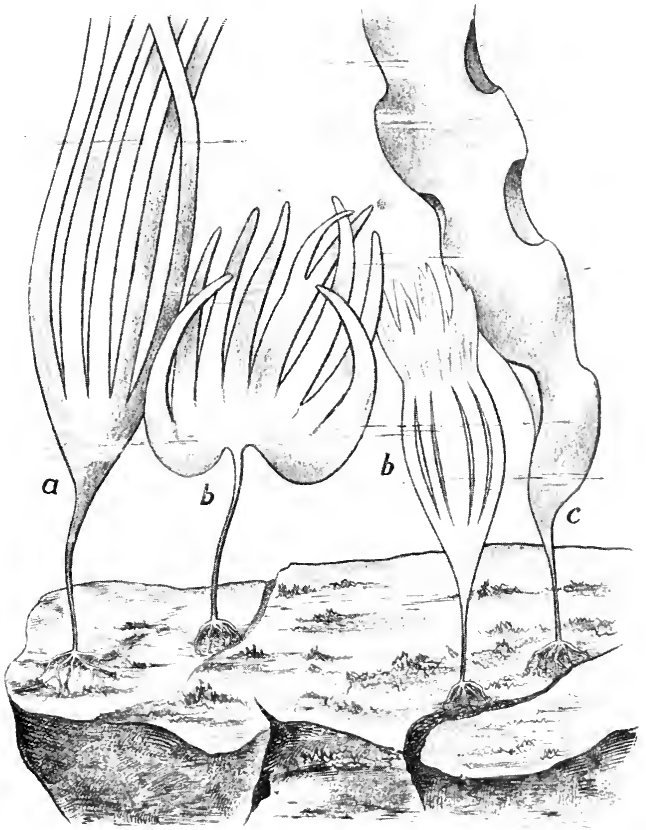

Ahb. 75. Laminaria species, a L. digitata. b L. huperborea (alt und jung). c L. saccharina. ca. $1 / 1$, nat. (iröße. (Neuzeichnung nach P. Kuckuck.)

- Laminaria digitata (= Lam. flexicaulis). Fingertang.

Beim Durchschneiden des stieles quillt keine Gallerte bervor. Bei Helgoland häufig, in der westlichen Ostsee nicht selten.

- Laminaria hyperborea (= Lam. cloustoni). Palmentang.

Beim Durchschneiden des stieles tritt in Menge Gallerte hervor. Laminarien eignen sich gut zum Nachweis von Jod in Neeresalgen. Nach H. Molisch werden diunne späne getrockneter Laminaria in eine Glaskanmer (z. B. Planktonkammer) gebracht und mit einigen Tropfen konzentr. HCl befeuchtet. Auf die Unterseite der Deckscheibe bringt man mit einem Tröpfchen Wasser etwas Stärke, deckt die Platte auf und beobachtet die Bläınng der Stärke durch 


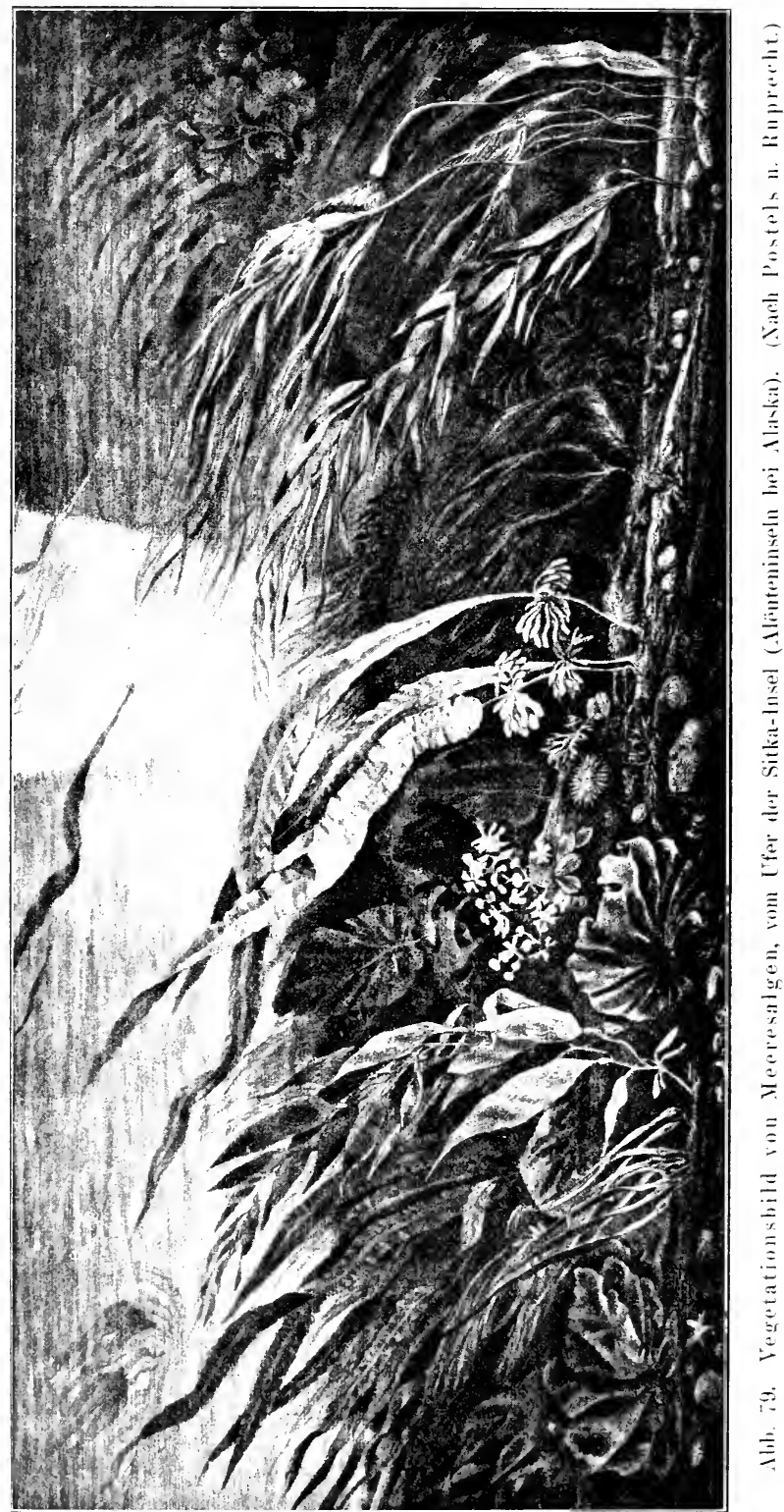


das freiwerdende Jod. Die stattindende Umsetzung kann man sich durch folgende Formel veranschaulichen:

$$
\mathrm{NaJ}+\mathrm{HCl}=\mathrm{NaCl}+\mathrm{H} . \mathrm{J} \text {; }
$$

ans den HJ wird Jod leicht frei. Ähnlich wird die Unsetzung verlaufen, wenn das Jod in der Pflanze organisch gebunden ist. Vgl. J. Babiy (1). Will man grïßere Stucke von Tang (anch Fucus, Nordsee, Mittelmeer!) verwenden, so koche man etwa fingerlange stiucke im Reagenzrohr aus und mache das Jod durch etwas rauchende Salpetersänre frei. Stärkekleister wird jetzt tief blau gefärbt; Chloroform oder Schwefelkohlenstoff nehmen violette Farbe an.

Trockene Laminaria-stiele, welche auch in Apotheken käuflich sind, eignen sich sehr gut zu Quellungsversuchen. Sie vermehren nach Einlegen in Wasser ihr Volumen sehr bedentend. Man sehe anch das mikroskopische Bild an.

Die beigefïgte Abb. gibt ein Bild*) von der Vegetation mariner Algen (hauptsächlich Laminariaceae) von der Küste der Alëuteninseln nach Postels u. Ruprecht. Es zeigt links Iridaea (Florideae) und Laminaria, in der Mitte Constantinea rosa marina (Florideae), Alaria und Agarum, rechts Macrocystis, Nercocystis und Thalassiophyllum.

- Macrocystis pyrifera (Laminariaceae). Tang der Südsee. Längste Pflanze, bis $330 \mathrm{~m}$ lang.

- Fucus vesiculosus. Gemeiner Blasentang. fucus $=$ Tang. $\quad$ (Nicht abgebildet.)

Die mit wenigen Ausmahmen marinen Branntange weisen sehr mannigfach gestaltete Vertreter auf: einfach-fadenförmige, wie Sphacclaria und Ectocarpus, aber anch massig entwickelte, hochgegliederte, wie Fucus, Ascophyllum 11. a. m. Der Blasentang ist in der NordItnd Ostsee häufig und oft bestandbildend, z. B. auf steinigem substrat und an Holzwerk. Auf sandigem und geröllhaltigem Strand ist naturgemäß keine Entwicklung möglich.

In der Ostsee nimmt er mit fallendem Salzgehalt des Wassers ostwärts mehr und mehr ah. Für

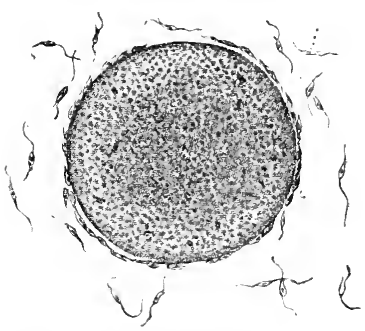

Abb. 80. Eizelle von Fucus, umschwärmt von Spermatozoiden. Stark vergrößert. (Nach Thuret.) seine Verbreitung in vorwiegend oberflächlichen Schichten ist das Licht maßgebend. Die Vegetation der Blasentange wird im Winter nicht unterbrochen.

*) Ich verdanke die Vorlage zu dem Bilde der Freundlichkeit des Herrn Prof. Dr. $\mathrm{N}$ a d son in St. Petersburg. 
LäBt man lebende fertile Thahusteile von Fucus, z. B. F. serratus. ein wenig eintrocknen, so tritt aus den männlichen Konzeptakeln cine orangefarbige schleimmasse, welche makroskopisch deutlich sichtbar ist, hervor. Sie besteht aus zahllosen, acrotaktischen spermatozoiden. Die umstehende Figur giht ein Bild von der Art. wie die männlichen Befruchtungskörper ein Ei von Fucus umschwärmen. Nach Befruchtung durch einen Schwärmer bildet das Ei eine Hiille und begiunt mit Teihung und Wachstum.

Sargassum bacciferum. Golfkraut.

sargasso im Portugiesischen $=$ Seegras.

Im Sargassmeor zusammengeschwemmt.

Floridea e, Rotalgen.

floridus = von lebhafter Farbe.

Zarte Rotalgen präpariert man für das Herbar in der Weise, daß man sie in einer schale oder einem Teller mit Wasser (auch siißwasser) in ihrer natiolichen Lage iiber cinem mntergetanchten Bogen Papier oder einem Karton ausbreitet. Dann hebt man sie vorsichtig heraus und prebt sie gelinde zwischen Fließpapier. Geeignete Exemplare haften dam rom selbst so fest, dab sie als offene Postkarten verschickt werden können.

Johnstone n. Croell (1) haben zarte Meeresalgen anf Zinkstäeken festtrocknen und die geätzten Platten direkt zum Iruck (einer Art Naturdruck) verwenden lassen.

98. Lemanea fluviatilis. Borsten-Floridee.

Nach dem französ. Botaniker S. Leman (1781-1829).

Die Fäden dieser Alge sind meist gegen 10 cm lang und im mittleren Teil etwa 2 nmm dick. Sie leben mit Vorliebe in den Kaskaden der Ciebirgsbäche, aber auch an Wehrabstïrzen in Fliissen. Ausgiebige Beluiftung ist die Hauptbedingung fiir ihre Entwicklung. Manche Chantransia sind Jugendstadien von Lcmanca.

- Batrachospermum moniliforme. Froschlaichalge. (Nicht abgebilket.)

Diese Alge bildet schliipfrige zottige Besätze in Teichen, Bächen usw., an stengehn, Holz, schnecken, schneckengehänsen und steinen. Wegen der bischeligen Wirtel erseheinen die Fäden perlschnurartig nnd im Verein mit der gallertigen Beschaffenheit froschlaichartig. Bei ra. tofacher Vergröberung hat die Pflanze cine gewisse äubere Ahnlichkeit mit Ccratophyllum.

Die Farbe der Rasen ist häufig purpurvot oder blangriin: in letztgenannten Falle orinnern sie makroskopisch kamm noch an Florideren. Die versehiedene Fäbung wird, wie anch bei anderen florideen, dureb liombination versehiodener Farbstoffe bediugt, die entsprechend

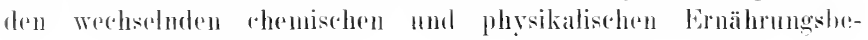


dingungen bald in dieser, bald in jener Niiance iiberwiegen. Fs sinel das nach den Untersuehmogen von H. Kylin:

1. Chlorophyll, der alkohollösliche Assimilationsfarlstoff;

2. Phyeoerythrin, das wasserlisliche Rot der Florideen,

3. Phycocyan, das wasserlösliche Blan der spaltalgen.

Man nimmt an, dab tie Farbstoffe 2. unt 3. bei sehwächerer Belenchtung Lichtstrahlen absorbieren, tie tem chlorophyll bei seiner assimilatorischen Tätigkeit zugnte kommen. - meist o-

99. Chantransia chalybaea. Nach đlem französ. Algologen (i. Chantrains in Besalıcon.

Die Fäden dieser besonders in Geloirgsbächen hänfigen, aber anch in Fliissen verbreiteten Alge bilden kurze Rasen (auf stengeln und steinen)

Abb. S1. Delesseria sanguinea. Thallus eines neu ausgeschlagenen Frühlingsexemplares Nat. Gr.

Auf der alten Rippe sitzen anßer den jungen ,Blättchen" die in Laufe des Winters zur Reife gelangten Cystokarpien. Pflanzen mit Tetrasporen sehen ähnlich ans, nur treten an die Stelle der kugeligen, gestielten Früchte Blättchen von fast gleicher Größe. Die männli chen Organe entstehen ebenfalls an solchen kleinen Thallusläppchen, sind aber im Frühling längst vergangen, da sie nach Befruchtung der liarpogone vergehen.

Winterexemplare bestehen nur aus alten Rippen, Sommerpflanzen entfalten die, Blätter66 fast bis zu Spannenlänge.

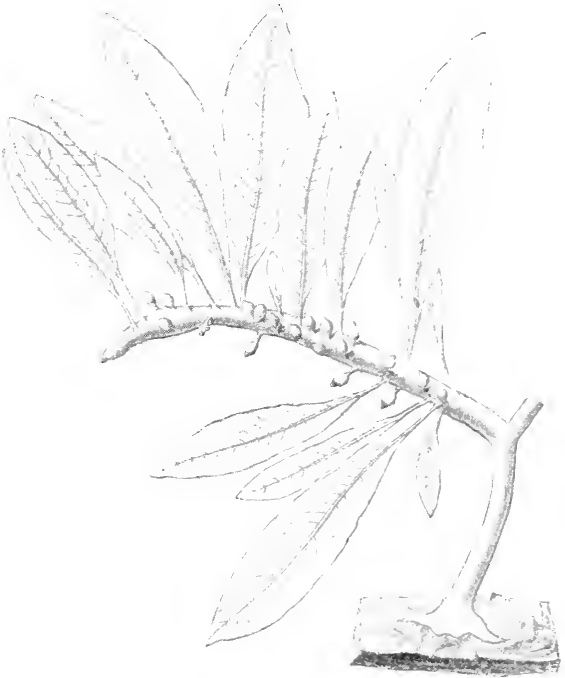

Die alten, zweigarti-

gen Rippen zeigen einen so reichlichen Vorrat an Stärke, daß diese dem (unerschnitt durch dre Rippe ein elfenbeinweißes Anssehen verleiht. (Nach R. Kolkwitz.)

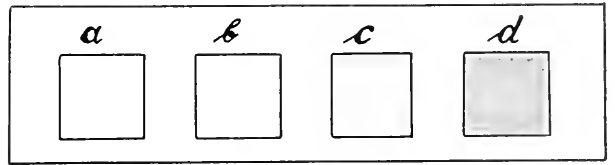

Abb. 82. Stärkereaktion mittels Jod - Chloralhydratlösung. a Myristica fragrans. MuskatumBarillus (Amylodextrin). b Laurencia pinnatifida (Tetrasporen), Cystoclonium. i Delesseria, Furcellaria. d Solanum tuberosum, Kartoffel. (Nach R. Kolkwitz.) 
vonstahlblaner (chalybaeus) bis brännlicher Farbe. T)ie seitenäste sind aufgerichtet und den Hauptästen parallel gestellt. Hit dieser Alge kann das mesosaprobe Carchesinm vergesellschaftet sein, wenn nur geniigender samerstoff vorhanden ist.

- meist o bis $\beta \mathrm{m}$ -

- Delesseria sanguinea. Nach dem französ. Botaniker B. Delessert $(1773-18+7)$.

Hochentwickelte Rotalge der Nordsee usw., reichlich z. B. bei Helgoland. Der Thallus erscheint in Stamm und Blatt gegliedert. bie,,Blätter" werden im Winter abgeworfen.

Unstehend sind auBer der Alge verschedene Reaktionen des Jod auf Florideenstärke, die von der gewohnten Blaufärbung vielfach abweichen, im Vergleich zu denen von Kartoffel und Macis abgebildet. Die Abweichungen sind auf verschiedene chemische Znsammensetzung der stärkekörner zuriickzufiihren.

Näheres vergleiche man in meiner Arbeit ïber Assimilation, Stärkeumsatz und Atmmng der Florideen in: Wissenschaftl. Meeresunters., Abt. Helgoland, 1900.

- Ceramium rubrum. Horn-Rottang. (Nicht abgebilklet.)

Die festsitzenden, verzweigten bis 1 dm langen, fädigen Büschel dieser Floridee sind von hell oder dunkel braumroter Farbe. Coramium deslongchampii besitzt schwärzlith griine Färbung. Die paarweise stehenden Endzweige sind zangenförmig einander zugekriimmt. Der Horn-Rottang ist während des ganzen Jahres an den Meereskiisten weit verbreitet und fast iiberall sehr häufig. Er findet sich in den oberen sowohl als auch in den tieferen Wasserschichten.

- Corallina officinalis. Korallenalge. (Nicht abgebildet.)

Corallina, Lithothamnion und Mclobesia bilden die Kalkalgen unserer heimisehen Meere. Nie besitzen steinharte lionsistenz infolge Einlagerung von kohlensaurem Kalk in ihre Membranen. Die Aufnahme des Kalkes geschieht aus dem Wasser unter allmählicher Anreicherung. Das Meerwasser ist durch seinen Gehalt an Gips und Magnesiumchlorid sehr hart. Vgl. auch das Kap. Plankton.

Manche Kalkalgen, besonders Lithothamnion, sind an der Bildung fossiler Kalkablagerungen beteiligt. Sie bilden stare Kalkmassen, welche wie Korallen aussehen.

Eumycetes.

100. Fusarium aquaeductuum und andere spezies.

Bildet ansgedehnte fell- und troddelartige Besätze von weiblicher oder rötlicher Farbe in Bächen mit Faschinen, an Wehren usw., wenn die Vorfluter Abwässer aus Zellstoffabriken u. a. m. anfnehmen. Verträgt sehwath samre Abwässer. Manche Arten scheinen Kohlen- 
hydrate, andere meist mehr eiweibartige stolle zu bevorzugen. Vol. auch Appel n. Wollenwelier (1).

- $\alpha$ III

\section{Saprolegnia monoica.}

Name von sapros $=$ fanl und legnon = Samm (weil einen Sanm $n$ tote Tiere bildend)

Bildet sich loieht. wemm man rerletzte Fliegen, Asseln, Mehlwiirmer oder dol. in Teich-, Fub- und ähnliehes Wasser wirft. Es entstehen schwärmsporen, Oogonien umd Antheridien. (Vol. anch das Kapitel simimmelpilze.)

1(12). Leptomitas lacteus $(=$ Apoulya lactea).

Besonders in Vorfluter mit städtiselon und Znekerlahrikwässern entwirkelt, besonders zur kalten Jahreszeit.

- a $\mathrm{m}-$

Der Leptomitus ist kenntlich dureh:

1. Fadenglieder, welche durch Einschnimumgen vomeinander at)getrennt sind nnd bei Verletzungen dnreh zelluloseartige Kingeln ahgeschlossen werlen. Der Mechanismms rinnert an manche Verschliisse von siclterswasserflaschen:

2. erheblichen Durchmesser (ca. $16 \mu$ ) der Fäden; in der Planktonkammer mit starken lupen sehr gut kenntlich.

Die Fäden rom Sphacrotilus (2 $\mu$ breit), welche ca. arehtmal feimer sind, erseheinen nur wire lange, zarte striche:

3. die Konsistenz der nakroskopischen Zotten und Fladen, welehe an fenchte Watte erimmern. Sphacrotilus ist viel schleimiger mul weniger fest :

4. federiges Aussehen der losgerissenen, treibenden Massen. Diese sind bei Sphacrotilus mehr gleichartig.

Mucor hat keine Einschmirungen, Fusarim ist stark verzweint.

\section{Mucor (zygorhynchus). Wasser-Mukor.}

mueor $=$ Schimmel; zusammenhängend mit mueus = schleim.

Während die meisten Mucor (z. B. M. mucedo) kohlenhydratliebende Luftschimmel sind, vegetieren einige unter Wasser nnter Berorzugnng von mehr eiweibartiger Nahrmng: dabei bilden sie weibliche fellartige Besätze (z. B. an Faschinen) von erheblicher Ausdehnung. Nakroskopisch dem Leptomitus ähnlich; auch Mucor racemosus kann solche Felle hilden. I)icke der Fäden hänfig ähnlich wie bei Leptomitus, aber Einschniirtmeng fehlen.

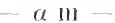

Charales. Armleuchtergewächse. Stellung im System etwas unbestimmt.

\section{Nitella fléxilis.}

Name von nitella $=$ Glanz.

Zellen im Gegensatz zn Chara ohne Berindungsfädrn. Jedes Cilied einzellig. Zellen also sehr grob (bis 12 ('m lang). In Gräben, Teichen und der Tferpartie von seen festgewurzelt. 
Die Zellen von Nitella sind sehr geeignet zum Studium der Plasmaströmung, die hier nicht erst durch Verletzungsreiz ausgelöst wird. Umgibt man das Deckgläschen mit Eisenstaub, so kommt die Strömung des Plasmas infolge Mangels an Sanerstoff zum Stillstand, um nach 'Entfernen des Eisenpulvers wieder zu beginnen.

- Chara foetida. Armleuchtergewächs. Vgl. Vegetationsbild.

Bildet oft große untergetanchte Hangwiesen am Ufer reiner Gewässer. Verträgt keine Beeinflussung durch Abwässer. Viele Arten von Chara sind stark mit kohlensanrem Kalk inkrustiert. Die Antheridien (rot) und Oogonien (griin bis brann) sind sehr gut in ter Planktonkammer zu beobachten.

Bei Chara crinita ist Parthenogenesis festgestellt worden.

Bryophyta.

105. Fontinalis antipyretica. Quellmoos.

Wächst meist in dunkelgriinen oder braun erscheinenden Bïschen. welche oft viele Detrituspartikel und Organismen zwischen ihren Zweigen beherbergen; an Steinen, Bohlen nsw. Vgl. auch das Vegetationsbild und den Abschnitt Moose.

- meist o-

Pteridophyta.

\section{- Salvinia natans.}

Name nach A. M. Salvinius in Florenz.

Im Herbst besonders zwischen Floßhölzern an der Oberfläche des Wassers schwimmend. Vgl. Pteridophyta.

106. Isoëtes lacustris. Brachsenkraut.

Name von isos $=$ gleich und etos $=\mathrm{Jahr}$, weil das ganze Jahr hindurch gleichbleibend.

Einziges heimisches Farnkraut, welches ganz untergetancht lebt. In reinen Seen bisweilen förmliche Wiesen bildend. Mit Makro- und Mikrosporen.

Monocotyledoneae.

- Potamogeton perfoliatus. Laichkraut. Abb. auf Vegetationsbild.

Am Ufer oft dichten Krantbestand bildend.

- Zostera marina. Seegras. (Nicht abgebildet.) zoster $=$ Name einer Pflanze bei Theophrast.

Zu den Potamogetonaceae gehörig. Ist der eimzige Vertreter der höheren Pflanzen in unseren nordischen Meeren. Es pflegt große unterseeische Wiesen zu bilden.

- Alisma plantago. Froschlöffel.

Vgl. das Ufervegetationsbild nnter "Ökologie". 
107. Hydrocharis morsus ranae. Froschbiss. Abb. s. anch auf dem Vegetationsbild.

In der Uferregion stehender Gewässer. Überwintert durch ruhende Knospen.

- Elodea canadensis. Wasserpest.

Name von elodes $=$ sumpfig. S. Tafel I hei: Assimiltaion.

Phragmites communis. Schilf.

Vgl. Vegetationsbild im Kap. Ökologie.

Glyceria aquatica. Schwadengras.

Vgl. Vegetationsbild.

- Carex vulgaris. Sumpfsegge.

Name von carere $=$ kratzen, weil das Kraut zum Blankmachen dient. Vgl. Vegetationsbild.

- Lemna trisulca. Untergetanchte Wasserlinse.

Vgl. Vegetationsbild und das Kapitel iiber Assimilation.

- meist $0-$

10๙. Lemna arrhiza. Kleinste Phanerogame.

Bildet 1-2 $\mathrm{mm}$ große, grïne Polsterchen, welche an der Oberfläche des Wassers schwimmen. Selten. Vgl. das Kapitel über Wasseraufnahme durch Wurzeln.

Dicotyledoneae.

- Callitriche vernalis. Wasserstern.

In Gebirgsbächen lang flıtend, in stehenden Gewässern mit sternförmiger Blattrosette. Gelegentlich anch anf fenchtem schlamm als niedrige Landpflanze (Dicotyledoneae).

- meist $0-$

109. Myriophyllum spicatum. Tausendblatt.

Uferpflanze stehender Gewässer. Bliitenähre iiber Wasser sich entfaltend. Stengel bis $2 \mathrm{~m}$ lang.

110. Ceratophyllum demersum. Hornkraut.

Uferpflanze stehender Gewässer. Bei iippiger Entwicklung Blattwirtel quastenartig.

Tiere des Wassers (als Anhang).

An dieser Stelle seien in einem besonderen Kapitel einige ökologisch wichtige Tiere des Wassers abgebildet, weil sie als Algen-, Bakterienund Detritusfresser usw. großen Einfhß auf das Schicksal der Kleinpflanzen haben und dadurch ein wichtiger Faktor für die Ökologie der Gewässer sind. Sie kommen anch als Zerstörer pathogener Keime im Wasser in Betracht. Sie spielen ferner als Schlammverzehrer zum Teil eine wesentliche Rolle, regeln das ökologische Gleichgewicht und sind 
Tiere des Wassers.

(Entsprechende Abh, von I'flanzen s. Taf. VII)

Rhizopoda:

1. Amoeha proteus.

2. Amoeba (Hyalodiscus) limax.

3. Difflugia pyriformis.

4. Arcella vulgaris.

5. Cyphoderia margaritacea.

6. Euglypha alveolata.

7. Trinema enchelys.

๖. Diplophrys archeri.

Heliozoa:

9. Actinophrys sol.

10. Actinosphaerium eichhorni.

Flayellata:

11. Diplosiga frequentissima.

12. Monas vivipara.

13. Bodo ovatus.

14. Anthophysa vegetans.

15. Spirochaete plicatilis.

Ciliata:

16. Coleps hirtus.

17. Lionotus (Loxophyllum) fasciola.

18. Colpidium colpoda.

19. Chilodon cucullulus.

20. Glancoma scintillans.

21. Paramaecium caudatum.

22. Ilalteria grandinella.

23. Spirostomum ambiguum.

24. Stentor roeseli.

25. Stylonychia mytilus.

26. Euplotes charon.

27. Vorticella microstoma.

24. Epistylis plicatilis.

29. Carchesium lachmanni.

suctoria:

30. Acineta grandis.

silongiae:

31. Spongilla (Euspongilla) lacustris.

11 ydroidea:

32 . Hydra fusca.

Vermes:

i:. Planaria gonocephala.

34. Nephelis vulgaris.

35. Tulifex rivulorum.

liotatoria:

36. Callidina elegans.

:37. Rotifer actinurus.

38. Philodina aculeata.

39. Asplanchna priodonta.

10. Symchaeta tremula.

41. Polyarthra platyptera.

42. Euchlanis dilatata.

43. Colurus species.

44. Brachionus urceolaris.

45.) Inuraea aculeata.

46. Anuraea cochlearis.
Bryozoa:

47. Plumatella repens.

Nollusca:

48. Limmaea stagnalis.

49. Limnaea (Gulnaria) auricularia.

50. Planorbis corneus.

51. Paludina vivipara.

52. Bythinia tentaculata.

53. Valvata piscinalis.

54. Spliaerium (Cyclas) cornenm.

55. Dreissensia polymorpla.

Crustarea:

56. Asellus aquaticus.

57. Gammarus pulex.

is Cyclops lenckarti.

59. Nauplius.

60. Diaptomus graciloides.

61. (ypuis fusca.

62. Daphnia pulex.

63. Hyalodaphnia cucullata.

64. Bosmina longirostris.

65. Bosmina coregoni.

66. Chydorus sphaericus.

67. Leptodora hyalina.

Hl ydrachnidae:

68. Hydrachna globosa.

Tardigrada:

69. Nacrohiotns macronyx.

Thysanura:

70. I'odura acuatica.

Orthoptera:

¡1. Perla bicaudata.

72. Clöe diptera.

73. Agrion puella.

Nenroptera:

74. Mryganea grandis.

75 . Hydropsyche.

76. Sialis lutaria.

Hemiptera:

77. Notonecti glauca.

78. Corixa striata.

Diptera:

79. Eristalis tenix.

80 . Strationys chamaeleon.

s1. Simuliunu ornatum.

\$2. Chironomus plumosus.

४3. Ceratopogon communis.

84. Corethra plumicornis.

85. Culex pipiens.

coleoptera:

86. Dyticus marginalis.

87. Acilius suleatus.

Pisces:

88. Alburnus lucidus.

Amphibia:

89. Liana esculenta.

90. Triton taeniatus. 
Tiere des Wassers

(Algen-, Bakterien-, Detritusfresser usw.)

Verlag von Gustar Fischer in Jena. 

wiehtig bei Aquarienstudien [vol. E. Bade (1)]. Es sind ateh hibler orga-

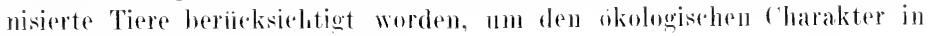
fler Darstelhung zu betomen.

Die normalerweise ehlorophylfiihrenden Flagellaten sincl ans physiologisch-ökologischen Grïnden zu den Pflanzen gerechmet worden.

\section{Ausführungen zu Taf. VHI.}

Rhizopota. Wurzelfüßler.

1. Amoeba proteus ( $=$ A. princeps).

Der nackte, etwa $1 / 2 \mathrm{~mm}$ grobe Körper ist durch Formveränderumy der Psendopodien amöboid beweglich. Lebt mit Vorliebe in krautreichen Gewässern auf schlamm, stengeln usw. - $0-{ }^{*}$ )

\section{Amoeba (Hyalodiscus) limax.}

Meist langgestreckt und regelmäBig gestaltet wie eine Nacktschnecke. Sammelspezies. Länge gegen 100 u. In Abwässern, biologischen Tropfkïrpern**) und nährstoffreichen (iewässern, z. B. im organischen Filz.

\section{Difflugia pyriformis.}

Gehänse ans Fremdkörpern anfgebaut, mehr ofler weniger flaschenfärmig. länge bis $1 / 2 \mathrm{~mm}$. Vorwiegend in krauthaltigen cewässern.

\section{Arcella vulgaris.}

-

Obere Schalenseite nhrolasförmig, nntere flach, schale meist bräunlich, areoliert, bis otwa 150 o breit. Lobt mit Vorliebe auf sehlamm verkranteter Gewässer nnd in Wasser von biologischen Tropfliörpern, das man einige Zeit stehen läßt. - $\ell$ m bis $\beta$ m -

5. Cyphoderia margaritacea. (= C. ampulla).

schale retortenfïrmig, aus feinen Plättehen zusammengesetzt. länge $100-170 \mu$.

\section{Euglypha alveolata.}

Schale farblos, ans rundlichen Platten besteliend. Miindung gezackt. Hinterende mit mnd ohne stacheln. Länge gereen $100 \mu$ e.

\section{Trinema enchelys.}

śchale mehr oder weniger dentlich gefeldert, bis 100 p. lang. Die Öffumo der sehale befindet sieh an der sejte. Der Oroanismus ist typisch fïr reinere Partien von Rieselböten und Troptkörpern.

*) Über die Bedentung dieser Bezeichnmgen vergleiche man den Abschnitt über (̈kologie der Gewässer.

**) Näheres siehe im Abschnitt Schizomycetes. 


\section{Diplophrys archeri.}

Schale kngelig. Körper innen mit großem öltropfen, der dem Beobachter bisweilen das ganze objekt als Öltropfen erscheinen läBt. zumal die Psendopodien nicht immer zu sehen sind. - $\iota \mathrm{m}-$

\section{Heliozoa. Sonnentierchen.}

\section{Actinophrys sol.}

Körper etwa 50 $\mu$ im Durchmesser. Entwickelt sich, häufig in Gemeinschalt mit Arcella vulgaris, of reichlich in biologisch gereinigtem Wasser, wenn dieses einige Zeit steht. Häufigstes sonnentierchen.

\section{Actinosphaerium eichhorni.}

- $\alpha \mathrm{mbis} \beta \mathrm{m}$ -

Erreicht einen Durchmesser von $1 \mathrm{~mm}$, ist also größer als Actinophrys. Lebt ron anderen Kleintieren. Findet sich in Gewässern mit lockerem, beliiftetem sichlamm.

- $\alpha$ m bis $\beta m-$

Flagellata.

11. Diplopiga frequentissima. Doppelkragenmonade.

Dieser Organismus ist dureh sein Vorkommen benerkenswert. Er sitzt oft massenhaft den Strahlen der Sternalge Asterionella auf und bewegt diese oft durch das schlagen seiner GeiBeln fort (passir planktonisch). Gröbe gegen $12 \mu$.

- meist 0 -

\section{Monas vivipara.}

Bis etwa $30 \mu$ lang. Freibeweglich und lestsitzend. $-\alpha m-$

\section{Bodo ovatus.}

Mit drei kontraktilen Vakuolen an der GeiBelbasis. Mit anteren Bodonen häufig in Aufgiissen und halbmineralisierten Wasser. Bakterienfresser, wie experimentell ermittelt. Bodonen sind im Wasser sehr verbreitet.

\section{Anthophysa vegetans.}

stiele der Kolonien meist bram (durch Eisenoxydhydrat, auch (lureh Humate). Können mit Eisenbakterien verwechselt werden, sind aber von ihnen durch ihre seilartige struktur verschieden. Zellkolonien farblos. Anthophysa entsteht in großer Menge fast regelmäßig, wenn städtisches, nicht stark faulendes Abwasser einige Zeit steht, hesonders in der darauf sich bildenden Zoogloca-Schwimmschicht. Gut in ter Planktonkammer zu beobarhten!

- typisch $\alpha \mathrm{ml}$ -

15. Spirochaete plicatilis. Sumpf-Spirochaete.

Körper sehr biegsam und beweglich. Häulig in unteren sehichten biologischer Tropfkörper und in schlamm, weleher nach $\mathrm{H}_{2}$ s riecht, aber von reinerem Wasser bedeckt ist. Systematische Stellung noch IIIsithere.

- meist $u$ III - 
Ciliata.

16. Coleps hirtus. Tönncheninfusor.

Körper von tömnchenartiger Gestalt; Bewegung schwankend. Mundöffmung mit sägenartigem Samm. Schr gefräBig. Kann sich reichlich in mesosaprobem Wasser entwickeln, dem man einige semmelkriimel zusetzt.

- $\beta$ m his a $111-$

\section{Lionotus (Loxophyllum) fasciola.}

Bis $200 \mu$ lang, abwechsehnd vorwärts und riickwärts schwimmend.

\section{Colpidium colpoda.}

$-\beta \mathrm{mbis}$ a $\mathrm{m}-$

Körper etwas nierenförmig, gegen $100 \mu$ lang. Häufig in fäulnisfähigem Wasser. Kann schlecht gereinigtes firabenwasser milchig triiben.

\section{Chilodon cucullulus.}

Körper abgeplattet. Die fischrensenartigen sichlundstäbe sind charakteristisch. Frißt besonders Kieselalgen. $\quad-\beta$ m bis a m-

\section{Glaucoma scintillans.}

Der eiförmig gestaltete Organismus ist an den ständig sich bewegenden undulierenden Membranen des Mundsanmes kenntlich. Findet sich in Gesellschaft von Bodo und vielen anderen sehr häufig im Wasser der Blumenvasen usw.

- $\alpha \mathrm{m}$ bis $\beta \mathrm{m}-$

Viele Protozoen kann man in Rohkultur erhalten, wemn man temperiertem Teich-, Flußwasser oder dgl. eine der aufgezählten substanzen hinzufügt:

Bananensehale,

Pflanzenstengel.

Hell.

Salat (getrocknet),
Nilchtropfen, Bluttropfen,

Abwaschwasser von Fleisch.

Fleischextrakt.

Von Zeit zn Zeit impft man in neu zubereitete Fliissigkeiten iiber.

\section{Paramaecium caudatum. Pantoffeltierchen.}

Mund in der Mitte der Banchseite, die Nahrung in Vakuolen befördernd, welche die unverdauten Partikel an der Oberfläche wieder entleeren. Hinterseite des Körpers mit längeren Zilien. In der Planktonkammer mit Lupe sehr gut zu erkennen. Planktonísch in nährstoffreichem Wasser.

\section{Halteria grandinella.}

Kleiner $(30-40 \mu)$, ziemlich häuliger Planktonorganismus; passiert meist die Maschen des Planktomnetzes. Typisch ist fiir diesen Organismus die springende Fortbewegung.

- meist $\beta \mathrm{m}$ -

\section{Spirostomum ambiguum.}

Größtes Wimperinfusor, bis mehrere Millimeter lang. Körper sehr flexil. 
24. Stentor roeseli. Trompetentierchen.

lleist festsitzend, bis $1 / 2$ mm lang. Kern langgestreckt, nicht rosenkranzförmig. Die Trompetentierchen fressen Cryptomonas und andere Kleinorganismen.

- a $\mathrm{m}$ bis $\beta \mathrm{m}-$

- Stentor coeruleus (nicht abgebiltlet).

Blau bis blangrïn.

- typisch $थ$ m-

\section{Stylonychia mytilus.}

Körper mehr oder weniger keilförmig. Bewegung meist laufend. oft stobweise.

$-\alpha \mathrm{m}$ bis $\beta$ m -

\section{Euplotes charon.}

Länge $70-80$ p. Körper llach. Die Tiere pflegen auf den starken (irren zul laufen und zu stehen. Die Seitenansicht ist in der Abbild. bei stärkerer VergröBerung wiedergegeben als die Flächenansicht.

\section{Vorticella microstoma. Glockentierchen.}

$-\beta$ mbis a m-

Körper auf nicht verästelten, kontraktilen stielen, mehr ofler weniger eiförmig, am Peristomende verengt. Typisch für mehr oder weniger faulige Wässer. Frißt Bakterien. - p bis a $\mathrm{ml}-$

Forticella nebulifera findet sich in reinem Wasser.

Betrathtet man Glockentierchen, welche anf einem Pflanzenrest festsitzen mit Lupe in einer Planktonkammer, so kamn man schon bei tofacher Vergrößerung das Herbeistrudeln der Nahrungspartikel beobachten, wenn man durch geeignetes Abschatten mittels des Fingers rine Art Dnnkelfeldbeleuchtung erzengt.

\section{Epistylis plicatilis.}

Körper kontraktil, stiele nicht kontraktil. Länge der Zellen gegen 100 p. Letht oft auf den Gehäusen von sichnecken.

\section{Carchesium lachmanni.}

$-\alpha \mathrm{mbis} ; \mathrm{m} \mathrm{m}-$

Sehr leicht kenntlich. Kontraktile stiele der Kolonien verzweigt: joder Nebenast mit besonderem Nuske]. Fribt Bakterien, ernährt sich aber wohl auch durch gelöste organische Substanzen. Sehr typiseh fiir mittelstark versehmutzte Gewässer, hier oft weibe, kuryrasige Üherziige an Stengeln, Blättern usw. bildent. In ter Planktonkanmmer leieht zu erkemnen. Abgerissene, treibente Fladen wie bei $\mathrm{Ab}$ wasserpilzen werden nieht beohachtet.

- $a ! 11$

Ophrydium versatile (nicht abgebildet).

Bildet bis faustgroße, wässerig-gelatinöse Kolonien (von durch ('hlorellen meist griiner Farbe), welche in der lferregion vorwiegent in der Nähe der Wasseroberfäthe schwimmen. Wird bisweilen nit Vostoc verwethselt, doeth können dir golockentierälnnlichen binzel"rganismen an ort und stelle in der Planktenkammer leicht erkannt weritril. 
Silctoria.

30. Acineta grandis. Sanginfusor.

Fängt mit seinen Tentakeln andere Protozoen und saugt sie aus.

An Pflanzen, Detritus usw. festsitzend.

- p'm-

Spongiae.

31. Spongilla (Euspongilla) lacustris. Süßwasserschwamm.

Störke gedblich oder ourch Algen griin. Larven frei nmherschwimmend, weib. fast mit blobem Auge erkennbar. oft $\beta$ m

Auf der Tafel ist auch eine Nadel (chitinartige substanz) abgebildet.

- meist $\beta$ m -

Hydroidea.

32. Hydra fusca. Branner Sïßwasserpolyp.

Fängt mit seinen Armen und Nesselkapseln häufig Daphnia

11. a. m. Verbreitet, besonders an Wmrzeln von Wasserlinsen.

Hydra viridis ist griin dureh Chlorella.

- o bis $\beta m-$

Vermes.

33. Planaria gonocephala. Strudelwurm.

Körper mit feinen Wimpern iiberzogen, die in ständiger Bewegung sind. Leben zwischen Wasserpflanzen, unter steinen im Wasser usw. Kriechen an die Glaswände, wemn man Kraut in ein Gefäß tut. Nahrung meist mineralisch. Eikapseln kugelig, gestielt. - - -

34. Nephelis vulgaris. Schlammegel.

Meist einige Zentimeter lang, von grauschwärzlicher Farbe. An vielen stellen sehr häufig in sich frisch zersetzend('m Schlamm. Sehr widerstandsfähig. Ernährt sich von Protozoen mul Crustaceen, soll anch Paludina aussangen. meist $\beta$ m bis $\alpha$ mi -

- Haplotaxis gordioides = Phreoryctes menkeanus. (Nicht abgebildet.)

Drahtartig starrer, rötlicher Wurm von etwa 1 Fub Länge, welcher bisweilen durch fenchten Boden in Grundwasserleitungen, besonders in Ciebirgsgegenden gelangt und aus den Kaplihähnen der Leitungen hervorkommen kamn. Er ist hygienisch mnschädlich und kann durch geeignetes spïlen entfornt werden.

3i). Tubifex rivulorum. Schlammwurm.

Die in etwa natiorlicher Grobe ahowbildeten Tiere stecken mit dem Kopfteil im sichlamm mnd bewegen den frei ins Wasser ragenden hinteren Teil hin und her. Sie fressen den schlamm durch ihren Kärper und wirken dadurch ähnlich wie Regenwiirmer. In Rauligem schlamm oft so massenhaft, daß sie Überziige von roter Farbe bilden. Stampft man an Ifer krättig mit dem Fuß, ziehen sie sich plötzlich in den schlamm zuriick. Scheint in saurstoffreiem Wasser leben zu kïnnen. 
- Nematoden. Fadenwürmer. (Nicht abgebildet.)

Vom Aussehen des Essigälchens. Sehr verbreitet im schlamm und organischen Detritus; bei reichlicherem Auftreten auch erratisch im Plankton. Vielfach irrtïmlich als Anguilula bezeichnet.

Rotatoria. Rädertiere. - $\alpha \mathrm{mbis} \beta \mathrm{m}-$

Viele Rädertiere fressen Algen. Da ihr Körper durchsichtig ist, erkennt man die Farbe der Algen im Darminhalt. Dieser kann erscheinen:

griunlich durch Chlorella und Cryptomonas,

gelblich durch Stephanodiscus,

schwarzbram durch Trachelomonas.

weinrot durch Chromatium.

\section{Callidina elegans.}

Lebt vorwiegend in der Ufer-und schlammregion. Angen fehlend. Häufig.

\section{Rotifer actinurus.}

Körper lang teleskopartig ausziehbar. Vermag in sehr sauerstoffarmem Wasser zu leben.

$-a \mathrm{mbis} p-$

\section{Philodina aculeata.}

Augen im Nacken, nicht am Rïssel wie bei Rotifer. Räderorgan bei dem abgebildeten Tiere eingezogen. Vorwiegend in der Uferregion.

\section{Asplanchna priodonta.}

-0 bis $\beta \mathrm{m}-$

Körper ziemlich hyalin, bis $1 \mathrm{~mm}$ lang. Frißt Algen, Rädertiere (z. B. Anuraea cochlearis: s. Abbild.) und Kleinkrebschen. Echt planktonisch.

- o bis $\beta \mathrm{m}-$

40. Synchaeta tremula.

Planktonisch. Länge $0,1-0,2 \mathrm{~mm}$. (Die ähnliche S. pectinata ist etwa $0.3 \mathrm{~mm}$ groß.)

$-\beta \mathrm{m}$ bis $0-$

\section{Polyarthra platyptera.}

Bewegt sich schwimmend und stobweibe fortschnellend. Im Plankton häufig.

$-\beta$ m bis o -

\section{Euchlanis dilatata.}

Planktonisch, vorwiegend in tex Uferregion. Länge $0,3-0,4 \mathrm{~mm}$. - o bis $\beta$ nl -

\section{Colurus Species.}

Körper mit Panzer. Fuß mit zwei Zehen. $\quad-\beta$ mbis $\alpha \mathrm{m}-$

\section{Brachionus urceolaris.}

Der Vorderrand des etwa 0,3 mm groben Tieres trägt sechs Dornen. Planktoniselı. In der Kammer mit Lupen gut zu erkennen. Häufig im Plankton von $\beta$ m- Wässern. 
45. Anuraea aculeata.

Sehr verbreitet im Plankton. Frißt 11. a. Cryptomonas.

- 0 bis $\beta \mathrm{m}$ -

46. Anuraea cochlearis.

An ähnlichen Orten wie A. aculcata. Sohr charakteristischer Planktonorganismus. - o bis $\beta \mathrm{m}$ -

Bryozoa.

47. Plumatella repens. Moostier.

Bildet oft dicke, filzartige Überzüge von knolliger und lappiger Form an Brückenpfeilern, Pfählen und Steinen. Kann Rohrleitungen verstopfen. Die moeschlechtlich entstehenden statoblasten (mit schwimmring) im Plankton.

$-\beta \mathrm{m}-$

Mollusca.

48. Limnaea stagnalis. Schlammschnecke.

Frißt besonders Wasserpflanzen und weidet ihren Algenbesatz ab. $-0-$

49. Limnaea (Gulnaria) auricularia. Ohrschnecke.

Lebt mesosaprob. Ist ziemlich widerstandsfähig. $\quad-\beta \mathrm{m}-$

50. Planorbis corneus. Posthornschnecke.

Häufig in sümpfen.

- o bis $\beta \mathrm{m}-$

51. Paludina vivipara (= T'ivipara vera). Sumpfschnecke.

Gehäıse gebändert, durch einen Deckel verschließbar. Lebt gern auf nährstoffreichem Schlamm. Kann Abwasserpilze fressen.

\section{Bythinia tentaculata.}

$-\beta \mathrm{m}$ bis $\alpha \mathrm{m}-$

Höhe der Schale $10 \mathrm{~mm}$. Häufig im Schlamm der Fliisse usw. Verwandt mit Paludina. Junge Exemplare in der Planktonkammer beobachten!

- $\beta \mathrm{m}$ bis $\alpha \mathrm{ml}$

53. Valvata piscinalis. piscina $=$ Fischteich.

Höhe der Schale $6-8,5 \mathrm{~mm}$. Lebt anf schlammigem Grunde.

54. Sphaerium (Cyclas) corneum. Kugelmuschel.

Lebt im Schlamm, besonders an nährstoffreichen Stellen.

- meist $\alpha \mathrm{m}$ -

- Anodonta mutabilis. Teichmuschel. (Nicht abgebildet.)

Länge ca. $11 \mathrm{~cm}$. Verträgt auch sanerstoffarmen, schwefeleisenhaltigen Schlamm. Strudelt das Wasser durch das Innere der Schalen. Schloßrand mit schmaler Leiste, ohne Zahn (im Gegensatz zu Unio pictorum, der ebenfalls häufigen Malermuschel). $\quad$ - o bis $\beta \mathrm{m}$ - 
5\%. Dreissensia polymorpha. Wandermuschel, Dreikantmuschel oder Schafklaumuschel.

Lebt meist gruppenwoise aut Holz, schilfstengch, Steinen usw. Larven beweglich, planktonisch. Sehr bezeichnend fiir die gute Beschaffenheit eines Wassers.

Crustacea.

56. Asellus aquaticus. Wasserassel.

Kann in der a-mesosaproben Zone zu iipplger Ent wicklong kommen. Fribt vorwiegend Detritus und Pflanzenreste. Slielettiert vermotete Blätter. Lebt meist auf Sehlamm und zwischen Kraut. Gut in dee Planktonkammer zu beobachten. Dient Fischen zur Nahrung.

57. Gammarus pulex. Flohkrebs.

- $\alpha$ m bis $\beta$ m -

In natiorlicher Grobe abgebildet. Riicken obne bornen. Leht besonders in sauerstoffreichen fiewässern.

G. fluciatilis, am Riirken mit bornen, ist widestandsfähiger als G. pulex.

Der Flohkrebs läbt sich sehr gut in der kleinen Planktonkanmer heobachten, wo er in dem engen Raum mit der Lupe in allen Trilen leicht iibersehbar bleibt.

Der verwandte sitrandfloh, Orchestia littorea, der im Nord- und ostsecgebiot verbreitet ist, lebt gem zwischen ausgeworfenem Tang und rährt sich zum Teil ron diesem.

5.. Cyclops leuckarti. Wasserfloh, Hüpferling.

llit anderen spezies häufig und weit verbreitet. Ciefräßig: verzehrt oreanismen und Detritus. Ziemelich widerstandsfähig. - $\beta$ m -

59. Nauplius. Krebschenlarve. Heist Larve von Cyclops.

sehr häufig in der planktonischen Region. Ziemlich widerstandslähig.

- meist $\beta$ m bis a $\mathrm{ml}$

- Canthocamptus staphylinus. (Nicht abgebildet.)

Krebschen von ra. 1 mm Länge. Meist mmherlaufend. nirht schwimmend. Lebt besonders in der Eforregion: hänfig anch in don sandschichten mancher Trinkwasserfilter, durch diese sich hindurcharbeitend.

- meist $\beta$ m -

60. Diaptomus graciloides. Schumrrbartirebschen.

Ansqezeichnet dureh lange fibliler. In groben sätzen umberschwimnend. Mit Lapensehrenterkenuhar. Im Plankton (in Kimmer heobatehten!).

1). gracilis in Gebirgsseen. In Meeren Calamus. 
61. Cypris fusca. Muschelkrebschen.

länge ca. 1,5 mm. Lebt auf schlamm und in den Clerregionen; sehr häufig.

- "bis $\beta$ m

ti. Daphnia pulex. Der gemeine Wasserfloh.

Liefert die bekannte Fischmahrme. In l)orfedehen. Tiimpeln usw. oft in solchen schwämen, dab er clas Wascer rötlich färbt. In Planktonkanmer beobachten!

a 11 his $\beta$ mi -

Bringt man Wasserflibe in ein Gefäb, das dureh Baliterien getriabtes Wasser enthält (d. h. pro 1 (rm writ mehr als 1 Million), so machen diese das Wasser bis zum nächsten Tage klar.

Massenkulturen von Daphnien gewimnt man dureh Zusatz von frischem Kuh-oder Taubenmist: vgl. z. B. v. Depl) (1).

(i⿱i). Hyalodaphnia cucullata. Hehn- VTasserfloh.

Torwiegend in seen. Euplanktonisch. Variert mit der dahreszeit: ist mit I)aphnia pulcx durch C̈beroänge verbunden. - - -

(it. Bosmina longirostris. Rüsselkrebschen.

Hänfig im Plankton. Variabel. Vol. Brance (1). Fribt Algen, Detritns 11 a. (In der Planktonkammer beobachten!) - o bis $\beta$ m -

65. Bosmina coregoni. Buckelkrebschen.

Euplanktoniseh in seen. Während B. longirostris mehr Uferform ist, bevorzugt B. coregoni las freie Wasser gruber seen. Beide spezies kïnnen sich ähnehn, doeh sind die extremen Formen von B. coregoni leicht kenutlich: vgl. anch dic Arbeiten von Rïhe.

\section{ibi. Chydorus sphaericus.}

In der Eferregion und auf schlamm, aber auch pelagisch: rel. (). Pliimecke (1).

$\beta \mathrm{n}$

67. Leptodora hyalina (= L. kindtii). Glaskrebs.

Gröbtes siißwasserkrebschen (bis 1 cm lang). Kamm dureh seine kräftigen schwimmbewegungen leicht dem Fang durch das Planktonnetz entgehen: man verwendet deshalb Netze aus Kongreßstoff (z. B. die Dretsche). Das Tier ist so zart, daß man es in den Fängen zunächst nur an einer gewissen rhythmischen Bewegnng der Wasserpartien in seiner Nähe erkennt. Šehr räubcrisch.

Hydrachnidae.

68. Hydrachna globosa. Rote Wassermilbe.

Planktonisch in der Uferregion meist stehender Gewässer. Erscheint wie eine blutrote kugel, his $5 \mathrm{~mm}$ grob. 
Tardigrada.

159. Macrobiotus macronyx. Wasserbärchen oder Bärtierchen.

Bis $1 \mathrm{~mm}$ lang. Zwischen Algen und anderen Wrasserpflanzen.

Thysanlla.

70. Podura aquatica. Wasser-Springschwanz.

sichwarzblau, (a) $1 \mathrm{~mm}$ lang. Auf stehenden Wasser.

- meist $\beta \mathrm{m}-$

Orthoptera.

71. Perla bicaudata. Larve der After-Frühlingsfliege.

Räuberisch.

7巳. Cloë diptera. Vertreter der Eintagsfliege.

Larve mit kräftigen Mundwerkzengen und mit flimmernden Kiemenblättchen. An Wasserpflanzen und unter Steinen, schwimmen aber auch sehr behende.

- o bis $\beta \mathrm{m}$ -

73. Agrion puella. Räuberische Larve der Wasserjungfer.

$-0$

Neuroptera.

74. Phryganea grandis. Sprock. Larve der Köcherfliege.

Links Gehäıse aus sand, rechts ans Pflanzenresten (Schilf, Erle, Chara usw.), die längs und quer liegen können. - o -

75. Hydropsyche. Larven in der Uferregion.

In manchen Fliissen häufig, z. B. im Mittellauf der Elbe.

$-\beta \mathrm{m}-$

76. Sialis lutaria. lutum $=$ Schmutz. Larve der Wasserflorfliege.

Sehr widerstandsfähig.

- meist $\alpha \mathrm{m}$ -

Hemiptera.

77. Notonecta glauca. Rückenschwimmer.

Mordlnstiger Fleischfresser: sticht empfindlich. Greift anch Fischbrut an. Kamn umherfliegen.

- meist o-

78. Corixa striata. Ruderwanze.

Fleischfresser, fliegt auch umher.

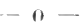

- Nepa cinerea. Skorpion-Wasserwanze.

Ergreift andere lnsekten und sangt sie aus.

- Hydrometra lacustris. Wasserläufer.

Auf der Wasseroberfläche. Nährt sich von anderen Insekten. 
Diptera, Fliegen, Niicken.

79. Eristalis tenax. Rattenschwanzlarve.

Larven der sogenannten, schlammbiene." Leben in schmutzigem Wasser. Fiihren ihre teleskopartig ansziehbaren Atemröhren an die oberfläche des Wassers empor.

- p bis a $\mathrm{m}$ -

80. Stratiomys chamaeleon. Larve der Waffenfliege.

Jeist im schlamm von Gräben und Tiimpeln.

$-a m-$

81. Simulium ornatum. Larve der Kriebelmücke.

Festsitzend mur in flieBendem Wasser. Strudelt sich als Nahrung Kieselalgen, Detritus n. a. herbei. Die Miicken stechen Menschen und Tiere empfindlich (sie sind rorwant mit der (olumbaczer Miicke).

\section{8.. Chironomus plumosus.}

- $\beta \mathrm{m}$ bis $\alpha \mathrm{m}-$

Die kirschroten Larven dieser Znckmïke sind besonders in stinkigem, sauerstoffreien oder -armen Schlamm häufig. Können Flocken von Sphacrotilus in ihren Röhrenban verweben. Kleinere, golnliche Larven finden sich in reineren Gewässern. Gattung sehr artemreich. Chironoms ( = Tondipes)-Larven bilden eine gute Fisehnahrung. Bewahrt man sie in Gläsern anf, entwickeh sich die Mïcken oft schon nach kurzer Zeit. Sehr eingehende studien iiber Chironomus (Tendipes) verdanken wir A. Thienemann. - p bis m -

83. Ceratopogon communis. Larve der Bartmïcke.

In der Uferregion der Gewässer. $\quad-\beta \mathrm{m}-$

84. Corethra plumicornis. Larve der Büschelmücke.

Nit zwei Luftsäckchen zur Erhaltung der Horizontallage. Sehr gefräßig. Widerstandsfähig.

85. Culex pipiens. Larve mol Puppe der Stechmücke.

Die Larven leben vou pflanzlichen Stoffen. Larven und Pnppen wrolen durch Fische vertilgt.

- meist $\beta \mathrm{m}$ -

Coleoptera, häfer.

si. Dyticus marginalis. Felbrand.

Larven und Käfer sehr räuberisch; saugen ihre Bente aus.

- o bis $\beta \mathrm{m}-$

87. Acilius sulcatus und Verwandte. Ränberische Larve eines Schwimmkäfers.

Der zugehörige Käfer ist $15-16 \mathrm{~mm}$ lang. 1/2 nat. Ciröße. Sangt Mollusken, Insekten. junge Fische und Amphibien aus. - 0 -

Pisces, Fische.

๙8. Alburnus lucidus. Uekelei.

Junges Fischchen (Brut) in nat. Größe. Frißt, wie Fischbrut iberhaupt, mit Vorliebe Plankton.

- meist $\beta \mathrm{m}$ - 
Amphibia.

89. Rana esculenta. Kaulquappe des Wasserfrosches.

Weidet mit Vorliebe Algen- und Detritusbesätze ab.

90. Triton taeniatus. Kleiner Wassermolch.

$$
\text { - meist pin }
$$

Dio Larven leben in der Uferregion.

\title{
Zur Kenntnis des Planktons.
}

\author{
Al), s. Taf. VII-XI.
}

1. Plankton, d. lo. nach $V$. Hens:n (1887) dir Gesantheit der im freirn Vasser willenlus umhertreibenden schwebewesen. wird genaner deliniert als:

Die natiorliche Lebensogmeinschalt derjengen organismen, welche im Wasser, bei strommng willenlos treibend, Treilebend nornale Existenzbedingnngen haben.

Algen, Protozoen, Radertiere und Kloinkrebschen bilden die Hauptbestandteile des Panktons; Quallen und Fischbrut einerseits, Baliterien andererseits rerhnen, streng genommen, ebenfalls dazu*).

Benthos (d. h. Grund, Tiefe) umfabt die festsitzenden oder kriechenden Ufer- mel Grundorganismen.

2. Plankton wird qualitativ und quantitativ erbeutet mit feinen Notzen (s. später), Sieben, dichten Filtern und durch schöpfen von Wasserproben (direktes Beohachten, Sedimentieren, Zentrifugieren). Grundsatzlich gilt die Regel: Kloine formen werden geschöpft, grobe abgesiebt.

Zur Beurteilung der Fangmethoden.

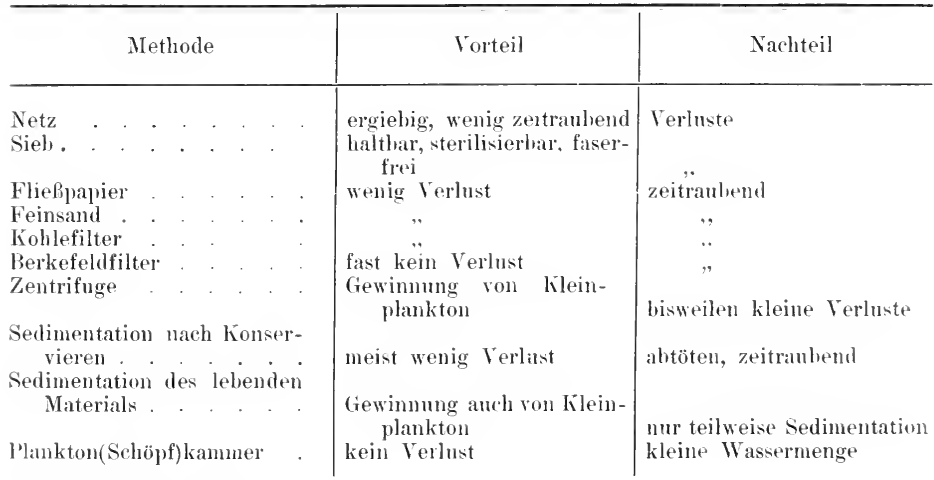

*) Als Gegenstück zu Plankton hezeichnet R. H. Francé (1) die Gesautheit 4er im Boden lebenden Kleinorganismen als Edaphon (edaphisch nach F. Schimper - den Boden hetreffend). planktos $=$ in die Irre getrieben. nmherschweifend. 
Aus vorstehender Übersicht ergibt sich, dab es eine Einheitsmethode, welche allen Anlorderungen gerecht wird, nicht gibt und daß deshalb, wenn es sich nm die Gewimnng des Gesamtplanktoms handelt, verschiedene Hethoden kombiniert werden müssen.

Das in groberer Mrnge eingesammelte Material kann folgendermaßen behandelt werden:

\begin{tabular}{l|l|l}
\hline Lebend & lionserviert & Gefärbt \\
\hline
\end{tabular}

a) sogleich untersucht

b) nach ca: 24 sitd. untersucht (Sammelflasche kïlıl halten, z. B. bej 10 " ()

c) Lebendfürbung diurch Methylenblan, Lehendfärbung durch Chresylviolett

d) stark bewegliche in (uittenschleim gehracht a) lurelı $0,5-1,0$ cem käuflichen Formalins fast allgemein angewendet)

b) dureh Alkohol

c) durch die ïblichen Fixierungsmittel (z. R. PikrinEssigsäure) a) durch Hämatoxylin (für feinere liemstmdien)

b) durch Nigrosin (rolie Färhungen)

c) durch mehrere Farbstoffe (Doppelfärhing แ1พW.)

2. Das Studium des Planktons wird dadurch sehr erleichtert, dab man das Material miihelos erbenten und fiur viele Studien, ohne zu schneiden oder zu präparieren, direkt betrachten kann, oft zweckmäBig zunächst mit guten Lupen, damn nit dem Mikroskop.

4. Die Bedentung der planktonischen Algen liegt vor allem darin, dab sie die Vrnahrnng in den Meeren ausmachen. Auch im siibwasser spielen sie als Nahrung eine Rolle, auBerdem als Faktor der Selbstreinigung und bei Beurteilung der chemischen Beschaffenheit der Gewässer.

5. Die moderne Planktologie hat gezeigt, daß in methodischer, physiologischer und ökologischer*, Hinsicht nahe Beziehungen zwischen Planktonkunde und Bakteriologie bestehen (Methoden, Reinkultur, Verbreitung).

\section{Tabelle zur Veranschaulichung der ökologisch-physiologischen Beziehungen zwischen Planktonalgen- und Bakterienentwicklung in der freien Natur.}

\begin{tabular}{|c|c|c|c|}
\hline & Polysaprohien **) & Mesosaprohien & Oligosaprobien \\
\hline Organische Nahrung & ohligatorisch & meist obligatorisch & fakultativ \\
\hline Chlorophyllfunktion & fakultativ? & obligatoriselı & obligatorisch \\
\hline Beisp. von Organismen & Englena viridis & $\begin{array}{l}\text { Stephanodiscus } \\
\text { hantzschianus }\end{array}$ & Asterionella formosa \\
\hline Davon Zellen pro cem & $\begin{array}{l}\text { bei Wasserblüte } \\
\text { ïber } 100000\end{array}$ & bis 58000 & his 6000 \\
\hline Bakterien pro cem & ca. 1000000 & meist $<100000$ & meist $<500$ \\
\hline
\end{tabular}

*) Ökologie = Lehre vom Genossenschafts- und Wirtschaftslehen.

**) Vgl. Kap. Ökologie 
Lein Kubikzentimeter normalen Oberfläthenwassers kamn frei sein von Kleinplankton, da ein kleiner Planktonorganismus (10 $\mathrm{u}^{3}$ )

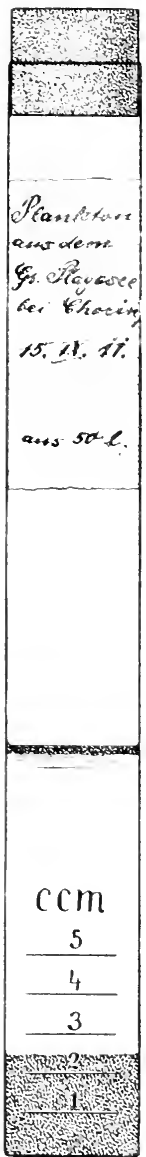

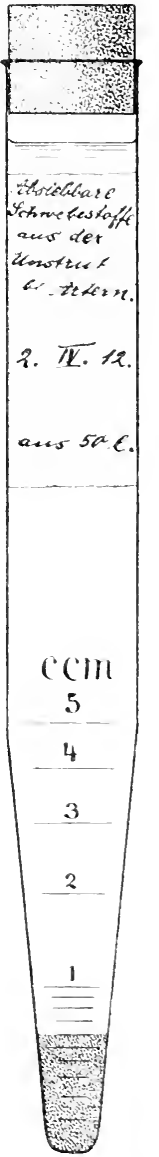
in $1 \mathrm{cem}$ ebensoviel Platz hat wie ein mittelgrober Fisch $\left(1 \mathrm{dm}^{3}\right)$ in einem see ron 1 Million Kubikmeter Inhalt:

$$
\begin{aligned}
& 10 \mu^{3} \quad 1 \mathrm{dm}^{3} \\
& 1 \mathrm{cem}=1000000 \mathrm{cbm}
\end{aligned}
$$

Anch der Staub der Lutt wird pro 1 (em gemessen: vgl. Kählor (1).

6. Die stowebefihigkeit der Planktonten wird gewährleistet durch geringes spezifisehes Gewiclit, Frhöhmo der Reibung eregen das Wasser und durch aktive Bewegungen, also dureh:

Abb. 83. Planktonröhrohen in nat. (iröße. (Schreibflichen matt geätzt.) Links: anf dem Wasser Botryocoicus. am Boden vorwiegend (rustacen, wenig Detritıs. Im ganzen 2, 5 cem; mit I'lanktometz erbeutet. Konserviert. Rechts: Vorwiegend betritns. mehr vereinzelt Kieselalgen und Kleinkrebsehen. $0.6 \mathrm{~cm}$. Die Befunde lassen sich bequem anf Millimeterpapier eintragen, bezogen auf Röhrehen von $16 \mathrm{~mm}$ lichtem Durchmesser. (Original.)

Zilien,

Geiboln,

RuderfiiBe.

İbergewicht

sinkeneshwindigkeit

Borsten.

Bantelform.

$$
\text { (2) }
$$


Gallerthüllen weist man besunders leicht dadurch nach, daß man die Zellen in eine diimne Lage von ehinesischer Tusebe unten das Deckglat: bringt.

7. In nährstoffarmen liewässern. \%. B. in klaren Seen, ist das Plankton der Menge nach viel weniger reichlich entwickelt (manchmal mit Ausnahme der Zeit der Frïhlingsumwailzung der Wassermassen) als in nährstoffreichen Tümpehn unel langsam fliebenden Fliissen. S'chnelltheBende, kurze Ciebirgswässer sind planktonarm, da es zor Entwicklung von schwebewesen an Zeit fehlt (24 stunden genügen bei fliebendem Wasser nicht). Vgl, auch Abb. 83.

Einen Anhalt fïr die Beurteilung der erbenteten Plankton- bzw. abgesiebten Sēstonmengen gibt die beigefügte Abbildung, in welcher das Material (nach dem Konservieren) bis zur Konstanz des Volnmens alogesetzt dargestellt ist.

Trinkwasser ist gut geschönt (geklärt), wemn es pro 1 (b) weniger als 1 cem Abgesiebtes) (Seston) enthält: rgl. Bruns, Kolkwitz, Schreiber (1). Abwasser ist mechanisch gut geklärt, wenn es pro 1 chum möglichst unter 100 acm (pro 50 l nuter 5 ecm) Abgesiebtes (nicht durch Stehenlassen der (iesamtwassermenge Abgesetzies) enthält.

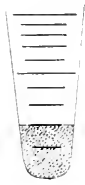

$\operatorname{cem} 0,2$

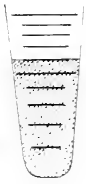

0.6

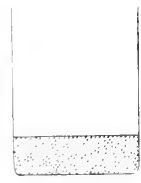

1,0

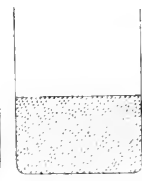

2,0

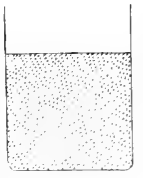

3.0

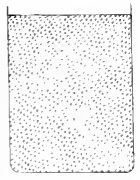

4,0

Abl. S4. Netz - oder Siebplankton bzw. - Seston ans 50 l Oberflächenwasser; am Grunde von mit Wasser gefüllten Normalplanktonglisern abgesetzt.

$1 \mathrm{~cm}$ Höhe $=2 \mathrm{ccm}$ Inhalt. Nat. Größe. (Original.)

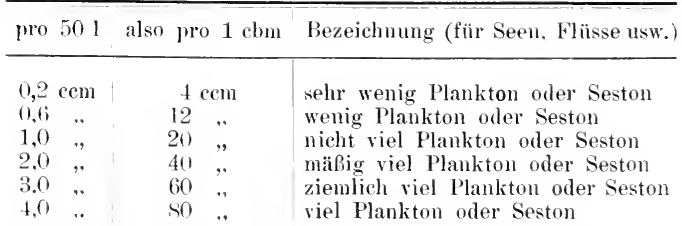

Anch bei schnell strömenden Flüssen, welche mehr Schlick als Organismen führen, liegt die Menge des Abgesiebten meist unter $4.0 \mathrm{~cm}$ mo 501 Wasser.

*) Ahgesieht werden im vorliegenden Falle hauptsächtich diejenigen Partikel, welche größer sind als $\frac{1}{15} \mathrm{~mm}$, d. h. im Minimum mit bloßem Auge einzeln noch gerade wahrgenommen werden kömen. 
Das Verbältnis beträgt im ersten Falle $\frac{1}{1000000}$, in zweiten $\frac{1}{10000}$.

\section{Tabelle zur Veranschaulichung der Beziehungen zwischen physikalischen, chemischen und biologischen Faktoren.}

\begin{tabular}{l|ccc|c}
\hline & $\begin{array}{c}\text { Iaximale } \\
\text { Sichttiefe }\end{array}$ & $\begin{array}{c}\text { Farbe im durch- } \\
\text { fallenden Licht }\end{array}$ & $\begin{array}{c}\text { Kaliumperman - } \\
\text { ganatverbrauch } \\
\text { pro 1 }\end{array}$ & $\begin{array}{c}\text { Planktonmenge } \\
\text { pro 1 cbm }\end{array}$ \\
\hline Genfer See & $21 \mathrm{~m}$ & blau & $1-3 \mathrm{mg}$ & ca. 1 cem \\
\hline Barmer Talsperre & $9,5 \mathrm{~m}$ & grün & (a. $6-7 \mathrm{mg}$ & $\begin{array}{c}\text { Jahresdurch- } \\
\text { schnitt } \\
\text { ca } 4,0 \text { ccm }\end{array}$ \\
\hline Tegeler See & $3 \mathrm{~m}$ & gelb & $25-40 \mathrm{mg}$ & $\begin{array}{c}\text { bei Wasserblüte } \\
\text { über } 100 \text { ccm }\end{array}$
\end{tabular}

s. Im Winter kann Plankton anch unter dem Eis gesammelt werten. in ler Regel aber in geringerer Menge und nn einförmigerer Zusammensetzung als im sommer. In nährstoffeichen Teichen kann aber aurh im Winter ein reicher Gehalt an Plankton vorhanden sein. Überhaupt seheint der chemische Einflub der Ernährung weit hänfiger eine ausschlaggebende Rolle zu spielen als der physilialische Faktor der Temjeratur.

9. Seen mit blaner Eigenfarbe des Wassers (reines $\mathrm{H}_{2}()$ ist in diclier Sehicht im durchfallenden Licht blau; s. Taf. IX) und blane Meere sind im Vergleich zu solchen mit griiner oder gelber Figenfarbe (blanes $\mathrm{H}_{2} \mathrm{O}+$ gelbe Huminstoffe + farblose begleitende Nährstoffe) planktonarm. Vgl. anch Kolkwitz (o).

streng wissenschaftliche Vergleiche der verschiedenen Gewasser mutereinander, z. B. zwischen tropischen und arktischen Mreren, sind zurzeit nur nuvollkommen durchgefüht, da vergleichende Werte fast nur für abgesiebtes, nicht auch fïr geschöpftes Plankton vorliegen. Ind gerade das geschöpfte Kleimplankton kamn für die Beurteilung des Chemismus der Gewässer, der Meere sowohl wie des siibwassers. besonders wichtig sein.

Vergleichende Untersuchungen ïber die biologische Produlitionskraft der versehiedenen Meere sind auch dadurch schwierig. daß man nicht sicher weib, ob die Planktonten sich ständig rasch vermehren und fortwährend anch ahsterben und zu Boden sinken, doch ist wahrscheinlich, daß allein schon die gröbere oder geringere Nenge des Kleinplanktons auch en direkter Insdruck fiir die größere oder geringere Produktionskiaft ist.

Wasserströmmngen können ans der Tiefe Nährstoffe in die oberen sichichten führen und dachurch die Entwicklung der Planktonorganismen heeinflussen. Vgl. dazu Nathanson. 


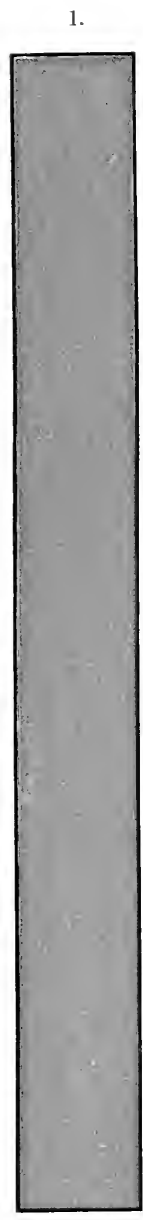

2.

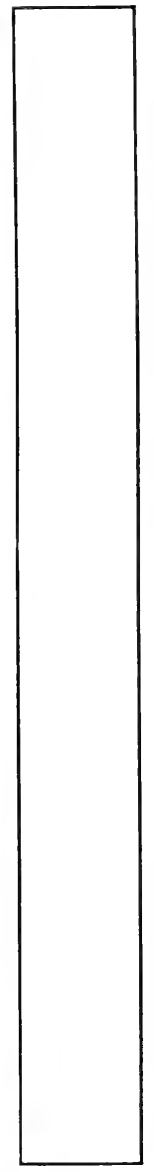

3

4.

5.

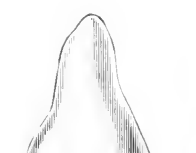

P
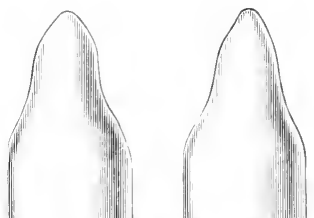

.
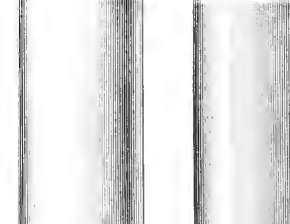

(
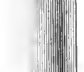

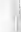

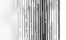

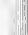
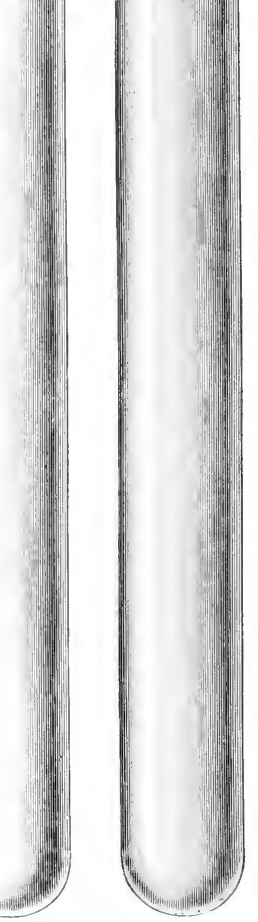

Wasser- und l'lanktonfarben.

1. Genfer See.

3. Euglena sanguinea.

2. Tegeler see.

4. Eudorina elegans.

5. Aphanizomenon flos arpuae.

Die mit I'lankton gefüllten Röhrchen sind in natürlicher Größe wiełergegelen. 

10. Die \%usanmensetzung des Planktons ist meist terart, dab man von einen Nischplankton sprechen kamn. Uberwiegen einzelne Kumponenten, und zwar sostark, daßs sie in ihrer Mengenentfaltung fiir das bloße Ange siehthar*) wrolen (vgl. die Farbentafel), so spricht man ron Wasserbliiten. Es gibt Wasserbliiten in allen Farben des spektrums. Bekannte Beispiele sind
Polvevstis acruginosa,
Englena vividis,
Aphanizomenon flos aquae,
Rivularia echinulata,
Euglena sanguinea,
Lamprocystis roseo-persicina.

Ziemlich häufig beobachtet man, dab Grganismen. denen man im Plankton in der Regel vereinzelt begegnet, an stellen mit fiir sie gïnstigen Ernährungsbedingungen Wasserbliite bilden.

Die blangrionen Wasserbliiten im hesonderen kömen neben der Durchsetzung der oberen Wasserschichten wegen ihres geringen spezifischen Gewichtes anch eino Art siahno an der Oberfläche bilden, welehe wie griine (ilfarbe erscheint.

11. Die Hauptentwicklung des Planktons findet im siißwasser in den oberen 10-40 m statt, im Meere bis zul emigen $100 \mathrm{~m}$ Tiefe. Maßgebent fiir diese Verteilmng ist hauptsäehlich das Licht, welches auch fïr die mit zmohmender Tiefe verbmole Abnahme der Ufervegetation bestimmencl ist.

12. T̈her die Verteilnn und Impassmng der gröBeren planktonischen Tiere (inkl. Nekton) in ten verschiedenen Tiefen dor Hochsee gribt die folgende Tabelle eine Übersicht.

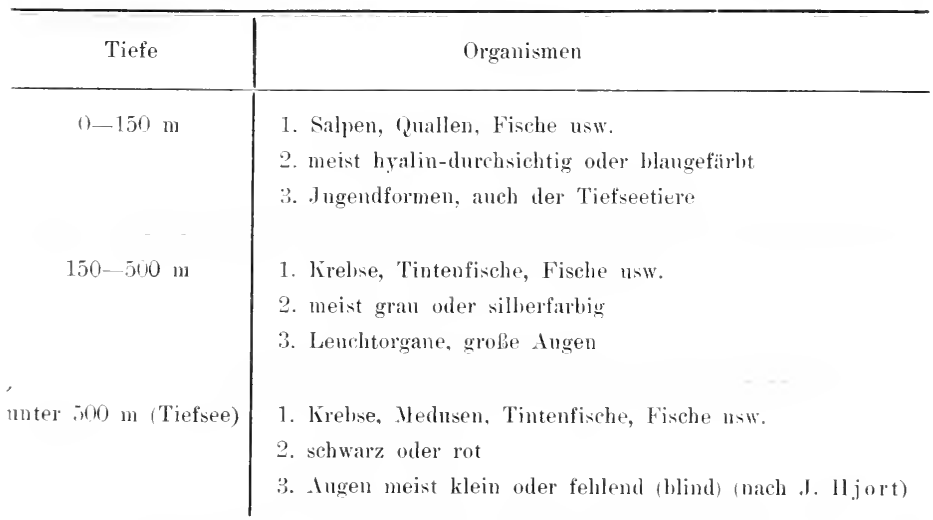

Die tieferen Zonen erhalten mehr oder weniger verinderte Planktonnahrung aus len oberen.

7) Man kann Planktonprolıen in gröBeren Vengen mit $1-2$ ccm käuflichen Formalins konservieren, in Gliischen einschmelzen, wie es die Farbentafel zeigt. und in Etuis aufbewahren. 
13. Beispiele.

Mischplankton (nach Netzfängen) aus dem Kleinen Wannsee hei Berlin; 20. Juli 1913).

Lampropedia hyaliua

Polveystis aeruginosa

Jierocystis iehthroblabe

$$
\text { ,. stagnalis }
$$

Merismopedia glanca

Aphanizomenom flos aquae

Anabaena spiroides

Phacus lomgicanda

Melosira helvetica

.. binderiana

Cyclotella kuetzingiana

Stephanodiscus h. pusillus

Asteriomella formosa

synedra acus

Closterimm acerosum

Stanrastrum gracile

Pteromomas alata
Selenastrum bibraianum

sicenedesmus quadricanda

.. opoliensis

.. obliqums

., acuminatus

Pediastrum boryamum

, dipplex

, ehrembergii

Actinastrum hantosehii

Richteriella botryoides

folastrum microporum

crucigenia rectamgularis

Lirchneriella lumata

Brachiomus pala

Ammara rochlearis

, aculeata.

cycolops. Nauplius

Im ganzen 34 spezies.

50 - 80 und mehr verschiedene spezies in einer Probe sind rerhältnismäßig salten zu konstatieren.

Ententeich bei Wemdisch- Wilmerselert.

Mitte Juli 1!10.

Kammerplankton pro 1 e.m Watsere

chromatium okenii . . . . . . . . . . . . ea. 2000)

Thiospirillum sanguinemm . . . . . . . . . . . . (a. 6000

Lamprocystis roseo-persicina, kleine Kulonien . . . . (a) 700

Thioperelia rosea, Koloniens . . . . . . . . . . . . (*il. foll

Phacus raudatal. . . . . . . . . . . . . . . I (al. 10000

Englena acus val. rigida . . . . . . . . . . . fal

Thas Wasser erschien in der Flasehe rot wie diimmer Kirsehsaft.

Kreuzptuhl hei Berlin.

18. 11 är 1910.

pro $1(* m$

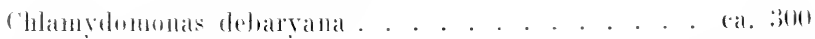

chlorella . . . . . . . . . . . . . . 10000000

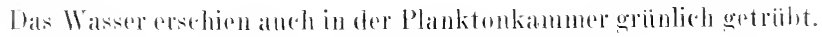


Plankton des Nils bei den Pyramiden von Gizeh (hei Kairo). 5. .Juli 190 s.

Nach konservierten Proben, die mir IIerr Prof. Bitter (Kairo) fremdlichst gesandt hatte. Das Plankton war nicht durch Netze erbeutet, sondern durch Berkefeldfilter abfiltriert worden. Es konnte demnach nichts Konservierbares verloren gehen.

Organischer u. mineralischer Detritus sehr reichlich

Aphanizomenon flos aquae

Anabaena spiroides

Melosira granulata

Amphora ovalis

Symedra delicatissima

Gomphonema angustatum

Surirella ovalis

Coelastrum microporum

Scenedesmus quadricanda

Pediastrum simplex

Dieses Beispiel zeigt, daß die bekannten Planktonorganismen weit über die Erde verbreitet sind.

Toma-See, Quellsee des Vorderrheins. 27. August 1911.

$$
\text { pro } 1 \mathrm{ccm}
$$

Gesteinssplitterchen, sehr fein . . . . . . . Tausende

Chrysomonadinen . . . . . . . . . . . . . . 8

Gymnodinium . . . . . . . . . . . . . . 1

Kleine Protozoen . . . . . . . . . . . . . vereinzelt

Bodlensee, zwischen Romanshorn und Friedrichshafen. 28. August 1911. pro $1 \mathrm{ccm}$

Tonartige Körperchen. änßerst fein . . . . . . . Hunderte

Detrituspartikel, kleine . . . . . . . . . . ca. 30

(Coccen)-Zoogloea . . . . . . . . . . . . . . . 1

Cryptomonas . . . . . . . . . . . . . . 3

Uroglena volvox . . . . . . . . . . . . . $0-1$

\begin{tabular}{l|llllllll} 
Gymnodinium \\
Peridinium
\end{tabular}

Glenodinium . . . . . . . . . . . . . . 1

Ceratimm hirundinella . . . . . . . . . . . $1-2$

Cyclotella-Zellen, in talerartiger Rolle . . . . . . 8

Schroederia setigera . . . . . . . . . . . . 1

Bilılliche Darstellungen von Kammerplankton pro $1 \mathrm{ccm}$ Wasser siehe bei E. Nitardy (1). 
Rhein bei Koblenz. Oberhalb der Stadt bei ter Eisenbahnbrücke. Linke Stromseite. 1. September 1911.

pro $1 \mathrm{ccm}$

Sphaerotilus-Fälen

Anabaena-Faden

Cryptomonas erosa

einzeln

Flagellaten, klein

Gymnodinium

Dutzende

Chlamydomonas.

Phacotus lenticularis

Lepocinclis ovum

Stephanodiscus .

Nitzschia acicularis.

communis

Synedra actinastroides, Kolonien zu 6 und 12 Zellen 2

Dictyosphaerium|

Hariotina

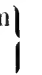

10

Scenedesmus obtusus

, $\left.\quad \begin{array}{l}\text { caudatus } \\ , \quad \text { acutus }\end{array}\right\}$ Kolonien . . . . . 6

Conferva (depauperata), Fäılen . . . . . . . .

Anthophysa mit Kopf . . . . . . . . . . . 1

Detritus, gröbere Partikel . . . . . . . . . Dutzende

" feinere Partikel . . . . . . . . . . einige 100

Nordsee an der Mündung des Rheins (zur Zeit der Flut).

5. September 1911.

$$
\text { pro } 1 \mathrm{ccm}
$$

Ceratium tripos. . . . . . . . . . . . . . .

fusus. . . . . . . . . . . . . . 2

Peridininm divergens. . . . . . . . . . . . 1

Chaetoceras, lebend . . . . . . . . . . . . . . 8

Schalen . . . . . . . . . . 2

Rhizosolenia . . . . . . . . . . . . . 2

Eucampia-Zellen . . . . . . . . . . . . . 3

Coscinodiscus . . . . . . . . . . . . . . 2

Cyclotella-Schalen . . . . . . . . . . . . 2

Plenrosigma . . . . . . . . . . . . . . . 1

Navicula . . . . . . . . . . . . . $2-4$

Tintimnopsis . . . . . . . . . . . . . . . 1

Protozoen, klein . . . . . . . . . . . . vereinzelt 
Atlantiseher Ozean (freies Meer).

pro 1 (*)

Coceolithophoridae.

(nateh H. Lohnann).

Christianiafjord.

pro 1 rem

Coccolithophoridat.

5000

(Hateh H. H. (iran).

Mittelländisches Meer bei Monaco. 20. März 1911. pro 1 cem in $100 \mathrm{~m}$ Tiefe:

Chrysomonadinen, natkt.

Coccolithophoride

Mineralische und organische lotrituspartikel. . . . Dutzende

Holzfaserreste. . . . . . . . . . . . . . . 2

Eisenoxydhydratpartikel . . . . . . . . . . . 1

(nach R. Kolkwitz).

$\equiv$

14. Die Sauerstoffproduktion dureh das assimilierende Plankton ist von wesentlicher Bedeutung für die Durchlüftung des Wassers. Es möge deshalb hier die Bestimmungsmethode fïr in Wasser gelösten Sanerstoff nach L. W. Winkler [vgl. auch H. Klut (1)] folgen (Abbildumg der nötigen Meßinstrumente s. Tat. X muter Ökologie der Gewässer).

In biologiseher Beziehung sind solche Bestimmungen besonders für die mesosaprobe Zone wichtig, da in dieser beachtenswerte Zunahme und Abnahme an Sanerstoff stattfinden kann. Ist der Gehalt an pflanzlichem, chlorophyllführenden Plankton in einem Gewässer nicht zu groß, so kamn die durch die rhemische Entersuchung ermittelte Salterstoffzehrung und das sauerstoffdefizit in bezug anf Sättigung einen Anhalt für die Menge der im Wasser vorhandenen organisehen zersetzbaren Stoffe liefern. Die Bestimmung des Sanerstoffs im Wasser geschieht unter Benutzung folgender Umsetzungen:

$$
\begin{aligned}
& \underset{\text { Manganchiorur }}{2 \mathrm{MnCl}_{2}}+\underset{\text { Natronlauge }}{4 \mathrm{NaOH}}=4 \mathrm{NaCl}+\underset{\text { weißes Minganohydroxyd }}{2 \mathrm{Mn}(\mathrm{OH})_{2}} \\
& 2 \mathrm{Mn}(\mathrm{OH})_{2}+\mathrm{O}+\mathrm{H}_{2} \mathrm{O}=2 \mathrm{Mn}(\mathrm{OH})_{3} \\
& \text { weiBes Manqanohydroxyd Sauerstoff braunes Manyanihydroxyd }
\end{aligned}
$$

Die Menge des ausfallenden bramen Manganihydroxydes gibt den Maßstab für den Sauerstoffgehalt des Wassers. Die genaue Zahl wird durch Titration gegen $\frac{n}{100}$ Natriumthiosulfat unter Verwendung von Stärkelösung als Indikator bestimmt. Eine solehe Sauerstoffbestimmung erfordert etwa 15 Minuten (ausschließlich 1 Stunde zum Absetzen des Niederschlages). Kann sie nicht sogleich an Ort und Stelle erfolgen, 
so setzt man ein festes Stück Natronlange von ca. 1 g Gewieht zu, wodureh die Probe gleichsam konserviert wird. und fügt später zur Bildung des Niederschlages nur noch Manganchlorür hinzu.

Sättigungsmenge des Sauerstoffs pro 11 Wasser.

(Erhalten durch Schütteln mit Luft; nach L. W. Winkler.)

\begin{tabular}{|c|c|c|c|c|c|}
\hline $\mathrm{t}$ & $\mathrm{cem}$ & $\mathrm{mg}$ & $\mathrm{t}$ & $\mathrm{cem}$ & $m g$ \\
\hline $0^{\circ} \mathrm{C}$ & 10),19 & $=14,56$ & $13^{\circ}$ & 7,35 & $=10.50$ \\
\hline $1^{\prime \prime}$, & 5,91 & $=14,16$ & $14^{\circ}$ & 7,19 & $=10,2 \mathrm{\diamond}$ \\
\hline 20 & 99,64 & $=13.78$ & $15^{\prime \prime}$. & 7.04 & $=10,06$ \\
\hline $3^{\prime \prime}$, & 9,39 & $=13,42$ & $16^{\prime \prime}$. & 6,59 & $=9,8.7$ \\
\hline $4^{n,}$, & 9,11 & $=13,06$ & $17^{\circ}$ & 6.75 & $=9,65$ \\
\hline $5^{\prime \prime}$, & $\checkmark, 91$ & $=12,-3$ & $18^{\circ}$ & 6,61 & $=9,45$ \\
\hline $6^{\circ}$. & $8.6 \mathrm{~s}$ & $=12,41$ & $19^{\circ}$ & 6,48 & $=9.26$ \\
\hline $7^{\circ}$, & $\$, 47$ & $=12,11$ & $20^{\circ}$. & 6,36 & $=9,09$ \\
\hline so & 5,26 & $=11, \mathrm{~S} 1$ & $21^{\circ}$ & 6,23 & $=8,90$ \\
\hline $9^{\circ} "$ & 8,06 & $=11,52$ & $20{ }^{0}$ & 6,11 & $=8,73$ \\
\hline $10^{\circ}$ & $7, \infty \tilde{6}$ & $=11,25$ & $23^{\prime \prime}$, & 6,00 & $=8,58$ \\
\hline $11^{\prime \prime}$. & 7.69 & $=10,99$ & $24^{\circ}$. & 5,89 & $=8.42$ \\
\hline $12^{\circ}$, & 7,52 & $=10,75$ & $255^{0}$, & $5,-18$ & $=\quad-, 26$ \\
\hline
\end{tabular}

Die Volumina beziehen sich auf $760 \mathrm{~mm}$ Druck.

Auf gelegentlich ron der Norm abwoichende schwankmugen im Saurstoffgehalt der Gewässer, welche nicht durch Organismentätigkeit bedingt werden, haben O. Krïmmel(1). K. Dost (1) und GrosseBuhle (1) hingewiesen.

15. Da es fiir Planktonstudien im Brackwasser und im Meere häufig ron Bedentung ist, die Menge der im Wasser vorhandenen Chloride festzustellen, folgen hier Angaben iiber die Methode. Näheres s. bei H. Klut (1).

Die Bestimmung der Chloride im Wasser geschieht unter Ermittelung der Chlorzahl, berechmet auf Milligramme pro 1 1. durch Titration gegen silbernitratlösnng.

$$
\mathrm{NaCl}+\mathrm{AgNO}_{3}=\mathrm{AgCl}+\mathrm{NaNO} .
$$

Zur quantitativen Bestimmung dienen:

1. Titerlösung. Bei 4, $7949 \mathrm{~g} \quad \mathrm{AgNO}$. mit Wasser zul 1 I gelist. entspricht 1 rem Lösung = 1 mg Chlor.

2. Indikator: 1 rem (nach Tillmanns heserer als nur :) Tropten)

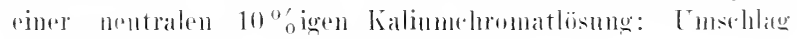
von sehwarheell, in leieht bramritliels.

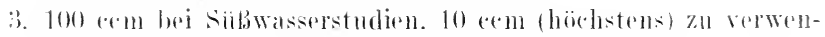
denden llassers bei lleeresuntersuehmongen.

Beispiele für Cl-Zahlen. Vol. anch H. Klut (1).

spree bei Berlin . . . . $30-60 \mathrm{mg}$ Cl pro 1

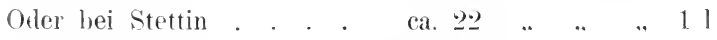

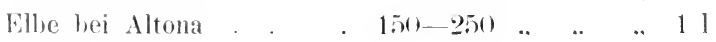




\begin{tabular}{|c|c|c|c|c|c|}
\hline stsee bei Rïgen. & . & . & $8-10$ & $\underline{g}$ & $\mathrm{~N}$ \\
\hline Nordsee, Oberfläche & . & & 35 & $\underline{m}$ & \\
\hline odensee . . . & & & 0.4 & & $g$ \\
\hline
\end{tabular}

Ist nur Chlornatrium vorhanden. wird mugerechnet nath der Gleichung $\operatorname{mg}(\mathrm{ll} \times 1,65=110 \mathrm{NaCl}$.

schwankungen im salzgehalt eines Wassers werden besonders leicht und schmell durch die elektrische Leitfähigkeit ermittelt, bestimmt durch die Pleißnersche Tauchelektrode [vgl. H. Klut (1)].

16. Die Härte des Wassers kann für das Vorkommen gewisser Planktonten, besonders anch mancher Ufer- und Grundformen, von Bedeutung sein. Es sei deshalb anf diesen Faktor näher hingewiesen.

Die Härte des Wassers wird durch die Gegenwart von Kalkund Magnesiasalzen bedingt. Meereswasser ist sehr hart, da es einen ziemlich hohen Gehalt an Gips und ror allem an Magnesiumchlorid anfweist.

Die Bestimmung der Härte durch schütteln mit Seifenlösung gibt weniger genaule Werte als die neuerdings von C. Blacher veröffentlichte Titriermethode unter Verwendung einer 1/10 n-glyzerinäthylalkoholischen Kaliumpalmitatlösung (in chemischen Fabriken käuflich). Näheres darïber s. u. a. bei H. Kilut (2).

Härteskala.

1 dentscher Härtegrad $=10 \mathrm{mg} \mathrm{CaO}$ in 1 l Wasser

1 französischer Härtegrad $=10$, $\mathrm{CaCO}_{3}, \ldots 1 \quad 1$,

1 englischer Härtegral $=10, \mathrm{CaCO}_{3} .0 .7 \quad 1 \quad$.

$\mathbf{1 , 0 0}$ deutsch. Härtegrad $=1,25$ engl. Härtegrad $=1.79$ franz. Härtegrad $0,8 \quad . \quad$.. $\quad=1,00 \quad . . \quad . . \quad=1.43 \quad . . \quad$.. $\begin{array}{llllll}0.56 & . & . & =0,7 \quad . . & . & =1,00\end{array}$

Dis Magnesia wird anf den Kalkwert nmgerechnet:

$$
\mathrm{HgO}: \mathrm{CaO}=40: 56=1: 1,4 \text {. }
$$

Deutsche Härtewerte.

$$
\begin{array}{rlrl}
0-4^{0} \text { Gesanithärte } & =\text { sehr weich } \\
4-8^{0} & . . & & =\text { weich } \\
8-12^{0} & . . & & =\text { mittelhart } \\
12-18^{0} & . . & & =\text { ziemlich hart } \\
18-30^{\circ} & . . & & =\text { hart } \\
\text { iiber } 30^{\circ} & . . & & =\text { sehr hart. }
\end{array}
$$

*) Etwa $180 \mathrm{mg} \mathrm{Cl}$ (ca. $300 \mathrm{mg} \mathrm{NaCl}$ ) können unter Unständen schon durch den Geschmack wahrgenommen werden. Mehr soll ein gutes Kesselspeisewasser auch nicht enthalten. 
Als Beispiele seien genannt:

Oder bei stettin $=9-10^{0}$ Härte.

Trinkwasser ron Berlin = $\cdot$ a. $12^{0}$ Härte.

Talsperre bei Remscheid $=1-4^{0}$ Härte.

\section{Literatur.}

$\begin{array}{ll}\text { Fr. Blochmann (1). } & (\text { Hez }(1) \\ \text { B. Eyferth (1). } & \text { W. Migula (1). } \\ \text { F. A. Forel (1). } & \text { A. Pascher (1). } \\ \text { O. Kirchner (1). } & \text { P. Regnard (1). } \\ \text { Kolkwitz. Reichle. } & \text { Ad. Stener (1). } \\ \text { Schmidtmann, } & \text { R. Volk (1) } \\ \text { Spitta. Thumm (1). } & \text { Wesenberg-Lund (1). } \\ \text { K. Lampert (1). } & \text { Woltereck (1). } \\ \text { O. Lemmermann (1). O. Zacharias (1 11. 2). }\end{array}$

\section{Ökologie der Gewässer.}

Dir Ökolegie*) gibt uns einen rertieften Einblick in das Zusammenleben der Organismen in der freien Natur. Dieses Studium ist sehr reizvoll, aber wegen des Ineinandergreifens zahlreicher Faktoren ziemlich schwierig.

Die hier zu behandelnde Ökologie der Giwässer ist indessen immer noth einfacher und ïbersichtlicher als diejenige der Landorganismen. da das Medium Wasser verhältnismäBig einförmig ist. Dementsprechend haben viele studien allgemeine Geltung. zumal zahlreiche Wasserorganismen Kosmopoliten sind.

\section{Die Regionen der Gewässer.}

L'm den Zustand eines Gewässers zu charakterisieren, ist nach Mögliehkrit die Beriecksiehtigung der drei Regionen des freien Walssers, dess Ufers und des Grundes geboten. Im diese drei Regionen kurz charakterisieren zu kömnen, sai auf die beistehende Abbildung verwiesen, welche den Quersehnitt durch einen Teich, eime FluBbucht od. dgl. zur Darstellung bringt.

Die Planktomregion (das freie Wasser), welche hier von uröberer Flora und Fanna frei ist, dagegen zahlerehe Vertreter niederer Organismen, "lie ihrer Kleinheit wegen in diesem Übersichtsbild nicht wiedergegeben werden konnten, zu enthalten pflegt, ist an der rechten Seite zu erkennen. Auf der (b)erfläche des Wassers sieht man eine durch Anhäufung entstandene sthmale Sedhicht der wasserbliitebildenden Spaltalge Polvcystis acruginosa.

") Okologie (Haus, Lehre) = Lehre rom Genossenschafts- und Wirtschaftslehen. 
Die Uferregion zeigt auf vorstehemtem Bilde sumptige Partien mit Carex vulgaris und Alisma plantago, an den flachen Wasserstellen schwimmente Watten vom Spirogyra crassa, longata. 11. a. m. Hieranf folgen das schwadengras, Glyceria aquatica, und sichilf, Phragmites communis. Die Rohrsumpfgewächse mit ihren meist horizontal fortwatelsenden Cirundstöcken kïmnen im Verein mit anteren P'flanzen zar Verlantumg beitragen und durth iluen dieliten Wuchs den Wellemsehlag des offenen Wassers am Lfer abschwärhe'n. So werden fïr die hier schwimmenden Wasser-

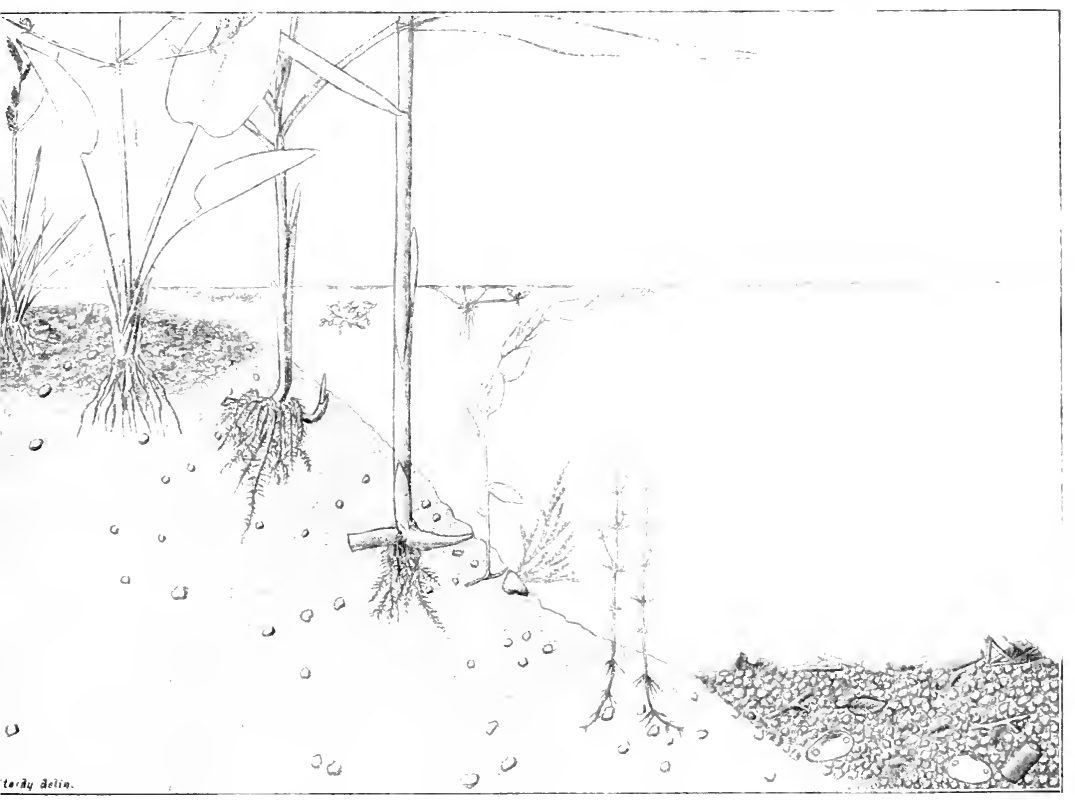

Ah. 85. Quershnitt dnreh die Randpartie eines Gewassers. 1/10 nat. Grölie. (Nach li Kolkwitz.)

pflanzen, wie Wasserlinse. Lemna trisulca, und liroschbif. Hydrocharis morsus ranac, günstige Lebensbedingmngen weschaffen, ebenso für schilfstengel bewohnende Algen und Tiere. Weiter in der Tiefe wurzeln damn Laichkräuter, wie Potamogeton perfoliatus, Teichrosen 11. a. m.

Verfolgt man damn in dem Bilde die Vegetation weiter abwärts, so hören die höheren Gewächse anf und an ihrer stelle finden sich Quellmoos, Fontinalis antipyretica, und Armlenchtergewächse, Chara fragilis, sowie antere mebr. Dazwischen und weiter alıwäts kömnen im organischen Fil\% des Hanges mikroskopisch kleine Algen, meist Diatomaceate, und diinne Hänte bildende Spaltalgen. Schizophyceae. auftreten. 
Die Grundregion endlich, auch Tiefen- und sichlammregion genannt, enthält, wie die Abbildnng zeigt, zum größeren Teil Reste abgestorbener und abgesunkener Pflanzen und Tiere, an deren Zersetzung wieder pin sehr mannigfach gestaltetes Heer von lebenden schlammorganismen beteiligt sein kamn.

Zur Lntersuchung der drei Regionen der Gewässer sind eine Reihe von Instrumenten erforderlich, deren Besprechmo und bildliche Wiedergabe hier eingeschaltet sein möge. Ile Reihenfolge ist so gewählt, daß mit dem Instrumentarimm der Planktomregion begomnen wird, und dab damn die fiir die Untersuchumg der Tfer- und Grundregion nötigen lnstrumente folgen.

\section{Planktonnetz.}

Netze von Riesendimensionen werden fïr quantitative biologische Veeresuntersuchungen, kleinere fiir das studium der siißwässer angewendet. Der stoff der Netze bestcht aus Seidenstoff (meist Miillergaze Nr. 20 oder 25 ). Die Maschenweiten betragen (a. ${ }^{1 / 15}-1 / 20 \mathrm{~mm}$. Tie einzehnen Maschen können mit hlobem Ange gerade noch wahrgenommen werden, viele Planktonten aber nicht mehr. Jithin kamn man mit Netzen mur einen Teil des Planktoms (d. h. des Tumberschwebenden) erbenten. Bei größeren Gewässern durchfischt man die Planktonregion an besten vom Boot ans, wobei das Netz an einer S.hnur oder am Ausziehstock befestigt wird. Tiefenfänge werden mittels Schließnetz oder Planktonpumpe ausgefiihrt. Der Netzbecherriekstand wird in ein Planktonglas gefiillt und im Bedarfsfalle mit 1.-1 com Formalin konserviert. F. Romijn hat ein Planktomnetz konstruiert, welches in der oberen Hälfte grobmaschig, in der unteren feinmaschig ist. Dadurch entgehen gröbere Organismen weniger leicht dem Fange. Man veroleiche anch das Kapitel Plankton.

\section{Planktonsieb.}

Ähnlich dem Planktomnetz dient das Planktonsieb zum Abfangen von Planktonorganismen und ihren Beimengungen. Bei einem Kupfersieb $\mathrm{Nr}$. 260 enthalten die an gegeniiberliegenden seiten anfugelöteten siobfläehen à 50 qem im ganzen eine Hillion Maschen à $1 / 15 \mathrm{~mm}$ scitenlänge, fast doppelt so viel als die gleiehe Fläche Netzseide enthält. Man kann auch siebe mit nur einer filtrierenden Fläche mit Vorteil verwenden. Die siebe lassen sich mit mehrprozentiger heißer Sodalösung med Salzsäure reinigen und durch Alkohol ofler Hitze sterilisieren. Abgesiebtes bzw. Absiebbares, gleichgiiltig welcher Natur, kamn als seston bezeichnet werden. Die Siebe finden in erster Linie für quantitative Fänge Verwendung, kömnen aber anch für qualitative Fänge und zum Answaschen ron Algenwatten .11 del. benutzt werden.

Jer Bodensatz in den kleinen Sieben wird durch Umkippen in Planktongläser pingefiullt. 

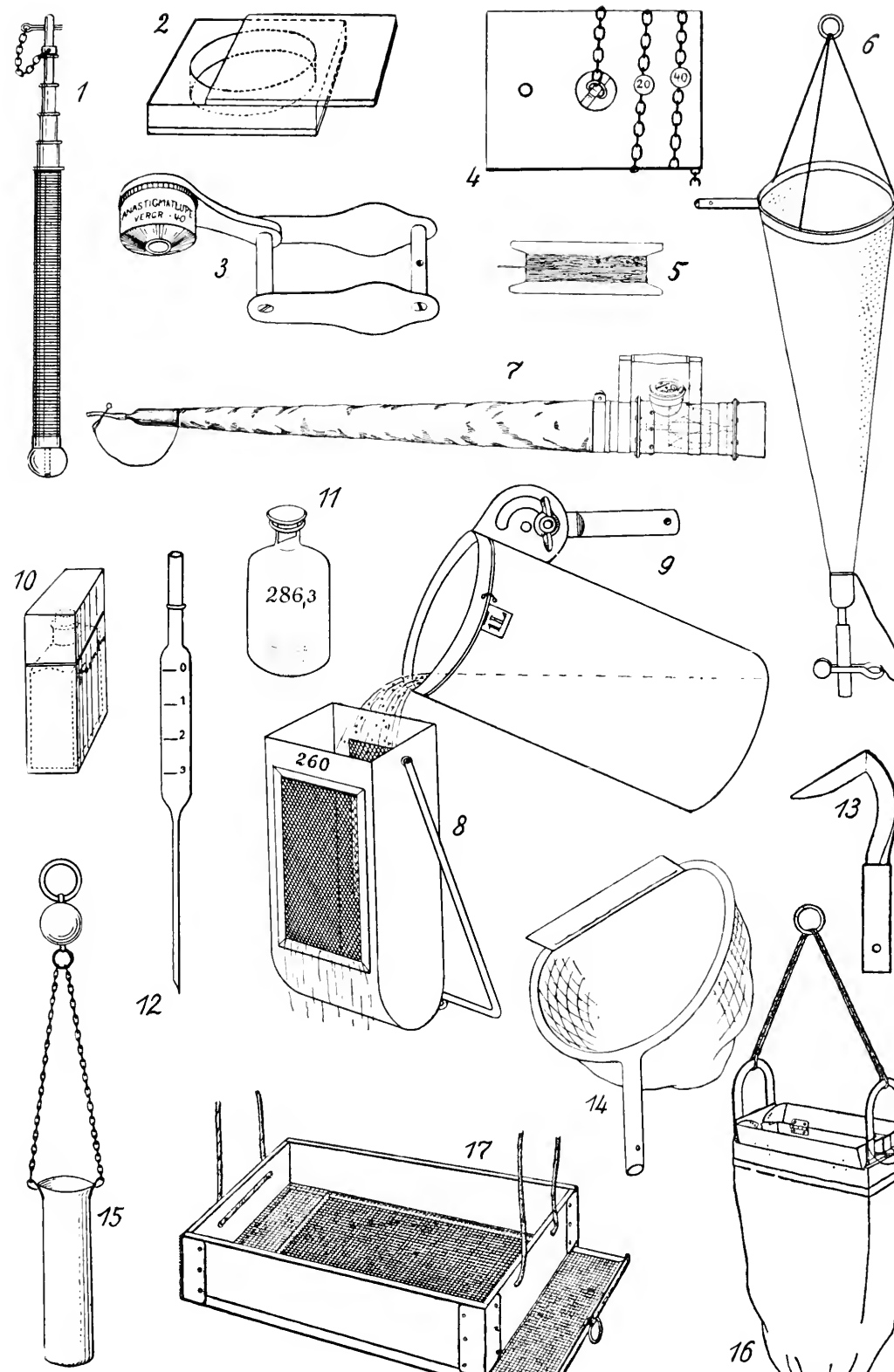

15
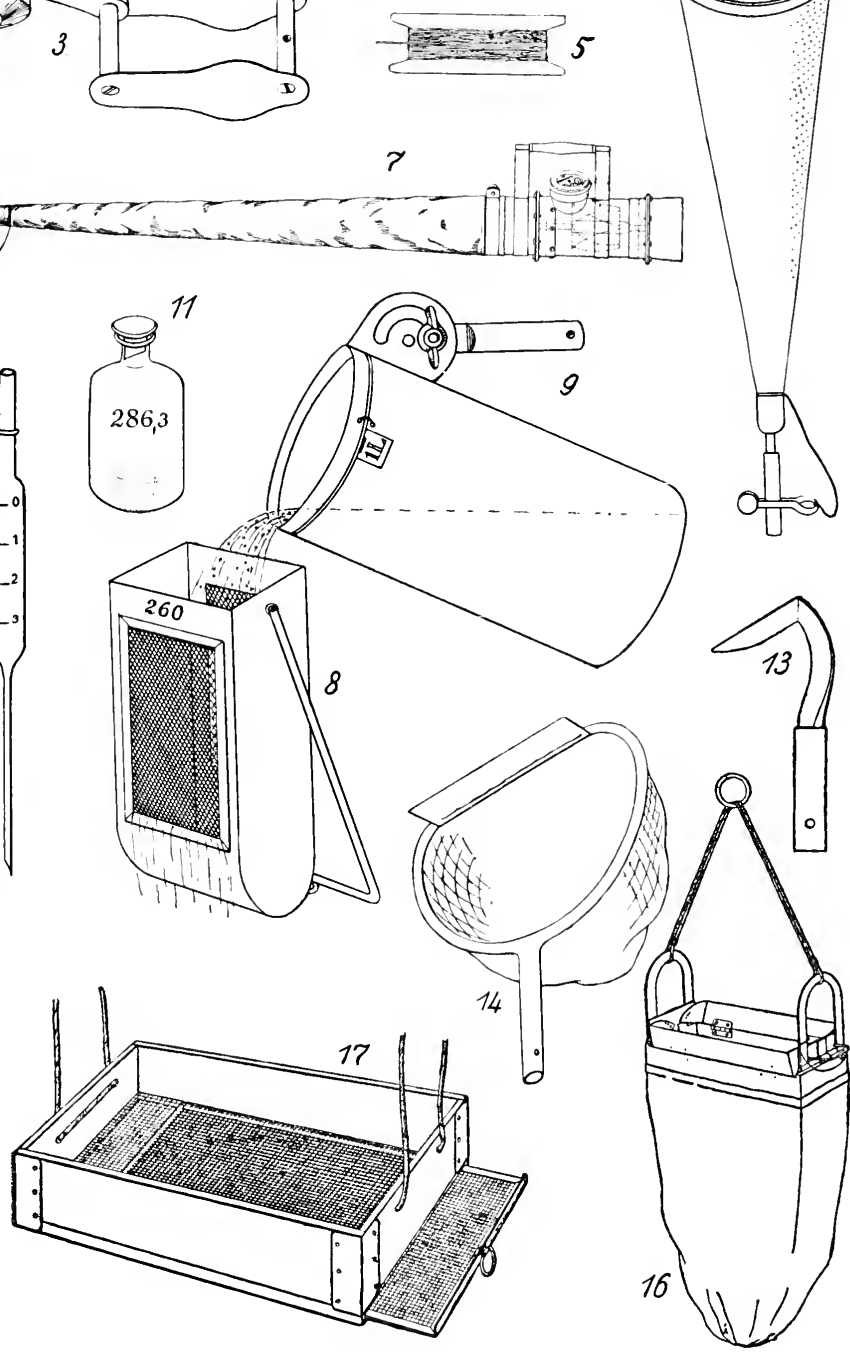

Entnahme- und Untersuchungs-Instrumente.

1. Ausziehstock $1 /$

2. Planktonkammer $1 / 1$

3. Planktonlupe $1 / 1$.

4. Sichtscheibe $1 / 4^{*}$

5. Schnurbrett $1 / 1 \%$

6. Plank tonnetz $1 / 6$
7. Netz mit Wassermesser $1 / 11$.

8. Planktonsieb $1 / 4$.

9. Aluminiumbecher $1 / 4$

10. Formalinflasche $1 / 4$.

11. Sauerstofflasche $1 / 5$

12. Sauerstoffpipette $1 / 4^{*}$. (Origlnal.)
13. Schilfmesser $1 / 2$.

14. Pfahlkratzer $1 / 4$.

15. Schlammheber $1 / 6$.

16. Dretsche $1 / 9$

17. Sieb $1 / s$. 



\section{Literbecher aus Aluminium.}

Der Becher besitzt eine verstellhare Ansatzhïlse fiir den Ausziehstock und einen konkaven Wulst als Aichungshie (besonders bei bewegtem Waser istesim Freien schwer,

ain Litermab ge-

strichen voll zı schöpf('ll).

Mit dem Literboeher schöpft man IVasser bis zul etwa $1 \mathrm{~m}$ Tiefe und gießt es (meist am besten b) 1) durch pin Netz veler sieb. l)as Kimpfersieb wird bein Transport in den Becher gesterkt.

\section{Ausziehstock.}

Der aus Messing gefertigte stock ist teleskopartig ansziehbar und zum Aufstecken einer Reihe

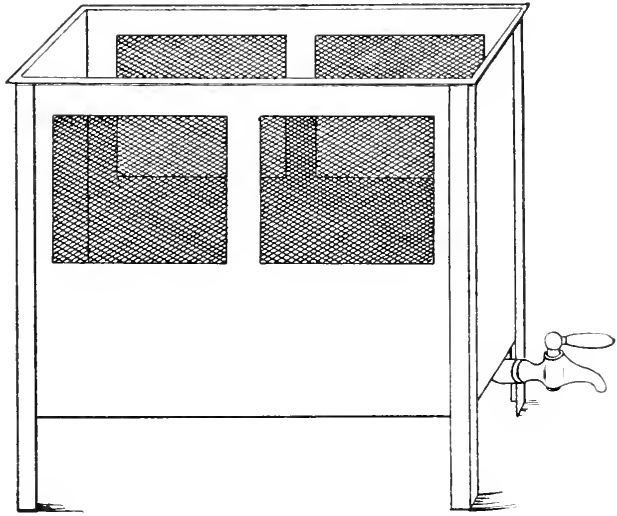

Abb. 86. Kupfersiebkasten. Dient zum Absieben großer Wassermengen. Die $4 \times 100$ ycm messenden Siebflächen bestehen aus Phosphorbronze Nr. 260. Jedes der vier Sielıfenster enthält 1 Million Maschen. Der verbleibende Rest wird durch ein Planktonsieb weiter eingeengt. Linear $1 / 4$ nat. Gr. (Orig.)

von Instrumenten bestimmt. Das bequemste Format dieses Storkes ist ausgezogen 1.20 m. zusammengeschoben etwa 30 em lang.

\section{Planktongläser.}

bie Planktongläser (s. Abbild. ‥ 180)besitzen in allgemeinen reagenzglas-ähnliche Form. Ihre Länge beträgt 14 (oder 28$)$ (cm, ihr lichter Durehmesser $16 \mathrm{~mm}$. Dabei ist $1 \mathrm{~cm}$ Höhe $=2 \mathrm{ecm}$ Inhalt. Sie dienen dazı, das abgesiebte, kouservierte setzvolumen aus möglichst jo 1 (auch umgerechnet auf 1 (b) Oberflächenwasser (bzw. Abwasser) oder ans mïglichst $1 \mathrm{cbm}$ Trinkwasser zu bestimmen. Vergl. S. 181.

1)a sich das Absetzen in zylindrischen Gläsern an einwandfreisten vollzieht. wählt man konisch zugespitzte Gläser zweckmäBig nur zum Abmessen kleiner Vohmmina. I) Röhrehen sind von 1-5 cem graduiert.

Fiir den Transport bestimmte Proben sollen fast bis zum Korken mit Wasser gefüllt sein.

\section{Planktonkammer.}

Die 1 ccm-Planktonkammer besteht aus einer flachen Glaskiivette von $2 \cdot 2 \mathrm{~mm}$ Durchmesser und 2,63 mm Höhe mit planparallel geschliffenen Scheiben. Die Deckscheibe kann mit Teilstrichen versehen sein. Im das Auszählen der umgekehrt gelegten Kammer zu erleichtern. Sie ist in eine 
Nessinghülse eingepaßt, an der ein Stift oder Bügel das Hinausgleiten verhindert. Siehe auch Taf. I.

Die automatische Entnahme eines Kubikzentimeters Wasser gesthieht durch einfaches Untertanchen (samt Hülse, ohne den Stift herauszuziehen) bei genügend weit zurückgeschobener Deckscheibe. Diese hält nach der Fiillung durch Adhäsion von selbst fest und schließt su dicht ab, daß sich das Wasser wochenlang darin hält.

Die Kammer wird auf ihren Inhalt im durchfallenden Licht (unter Wahl eines geeigneten Hintergrundes oder Hinterhalten eines Fingers) zunächst mit guten Steinheil- oder Anastigmathupen von ca. 14facher Vergrößerung (zur Orientierung), 25facher (zum teilweisen Bestimmen) oder 40 facher (als Mikroskop) durchmustert und dann bei stärkerer Vergrößermng unter das Mikroskop gelegt. [Vergr. 100-250fach (eventuell Apochromate und Kompensationsokulare!)]. Hat die Kammer etwa 10 Mlinuten lang horizontal gelegen, so sinke'n die meisten Organismen allmählich auf die Bodenscheibe ab; bewegliche kann man in Wärmestarre versetzen. Manche Spaltalgen. deren spezifisches Gewicht kleiner ist als das des Wassers, sammeln sich unter der Deckscheibe an. Einen gewissen Grad von Dunkelfeldbeleuchtung kann man schon auf einfache Weise dadurch erzeugen. dab man den Finger ïber die Mitte des Spiegels legt.

Bei solchen Planktonfängen beobachtet man die Organismen und ihre Beimengungen unter den natiirlichsten Verhältnissen gleichsam in einem Mikroaquarium. Will man das Kleinplankton (Nannoplankton Lohmanns) konzentrieren, so wird es aus den Wasserproben auszentrifugiert. Bei sehr großem Reichtum an Kleinplankton kann man zum Zählen auch eine $1 / 20$ (cm-Kammer (Tropfenkammer) benutzen.

Das Reinigen der Planktonkammer geschieht mechanisch am einfachsten durch ein zugespitztes Streichholz.

Für das quantitative Studium größerer Organismen (z. B. Gloeotrichia und Daphnia) kann eine 20 (cm-Plankt onkammer verwendet werden. wofern nieht Netzfänge besser sind.

Beide. dir kleine und die große Kammer, werden zweckmäßig anch zum Beobarhten konzentrierten Planktons (Eingießen. ohme Pipette). ferner von Moosen, lusekten und dergleichen im durchfallenden, manchmal auch auffallenden Licht benutzt [vgl. H. Bethge(1)]. und zwar unter Verwendung ron Lupen, Projektionsapparaten oder des Mikroskops (Grobschraube!). Die Bilder werden nicht verzerrt, da man durch planparallele Scheiben sieht, vertragen also gut starke Lupenvergrößerung. Man kann sie leicht ständig bei sich führen, so daß man stets ein Sanmel- und ein Beobachtungsgläschen zur Hand hat.

Zur Entnahme von Wasserproben von Briicken und hochbordigen Dampfern (auch während der Fahrt) kaun man mit bestem Erfolg ein Fläschehen von 25-30 ecm Inhalt mit weitem Hals und Korkstopfen be- 
nutzen. Die Halteschmur (von $3 \mathrm{~m}$ Länge und etwa 1 mm Durchmesser) wird beim Transport 1 m den Hals der Flasehe gewickelt.

Um Wasserproben zu planktologischen Untersuchmgen aus großer Tiefe zu entnehmen, bediene man sich der in der Bakteriologie ïblichen Abschlagapparate, der R. Volkschen Planktompumpe oder des bei Mleeresuntersuchungen angewendeten Richardschen Wasserschöpfers. Stehen bei Übungen nicht geniigend viele Kammern zur Verfiigung, so kann man auch große, ausgehöhlte Objektträger für Beobathtung bei schwacher oder mittlerer Vergroßerung verwenden (Fornat otwa $42 \times 74$ cm, Dnurehmesser der ausgeschliffenen Höhlung etwa $32 \mathrm{~mm}$ ).

\section{Weiße Sichtscheibe.}

Fiir marine ['ntersnchmngen wurden Scheiben ron 1-3 m Durchmesser und Beschwerungsgewicht benutzt. fiur solche im siißwasser sind erheblich kleinere, meist aus Porzellan gefertigte, im Gebrauch. Schon scheiben von $9 \times 12 \mathrm{~cm}$ Größe (mit Hessingkette und Teilmarken in $20 \mathrm{~cm} \mathrm{Ab}$ stand) kömnen gute Dienste leisten. Die eckige Form wählt man deshalb, um dic Aufhängekette besser herumwickeln zu können. Bei Untersuchung in strömendem Wasser steckt man die spitze des Ausziehstockes durch das seitliche Loch der Scheibe, 1 m deren Seitwärtstreiben zı verhindern.

Das Instrument dient zur Bestimmung der Farbe des Wassers im durchfallenden Licht und zur Ermittelung der sichttiefe, d. h. derjenigen Entfermung unter der Wasseroberfläche. bei welcher die Scheibe für das Ange verschwindet.

Die sichttiefe kann von den folgenden Faktoren abhängen:

1. gelöste Farbstoffe,

2. Planktonorganismen,

3. feine unbelebte Triibungskörper,

t. gröbere unbelebte Triibungskörper.

Beispiele für sichtticfen s. S. 182.

\section{Pfahlkratzer.}

Rahmen und Schneide dieses wichtigen Instrumentes bestehen ans Messing, der Bentel aus Kongre Bstoff. Er dient zum Abkratzen bewachsener Pfähle, von Bohlenwerk und Steinen. kamn aber anch mit bestem Erfolg zum Einsammehn von Schlamm. Krantmassen. Algenwatten, Kleinkrustern und Fisehbrut sowie zum Aussieben von Schlamm verwendet werden. Fiir manche Untersuchungen ist ein gröBerer und fester gebanter Pfahlkratzer zu empfehlen.

\section{Schilfmesser.}

Dieses Instrument besteht in seinem Hauptteil ans einer kräftigen Stahlklinge und wird am Ausziehstoek befestigt. Es kamm mit bestem Er-, folg dazu verwendet werden, Schilf-, Rohrkolben-, Seerosenstengel usw., deren Besatz an Algen, Schwämmen 11. a. m. eingesammelt werden soll, 
tief unter IVasser mit einem kurzen Ruck abzuschneiden. Das so gewonnene Material wird oft zweckmäBig ohne Zugabe von Wasser transportiert.

\section{Schlammheber.}

Der etwa $250 \mathrm{~cm}$ fassende Metallbecher wird an eine feste s.hnur gekniipft mnd zur Entnahne von Grundproben (meist der oberen sehichten) eine strecke weit iiber den Boden hingezogen.

\section{Scharrnetz (Dretsche) und Sieb.}

Die viereckige Klappdretsche dient zur Entnahme gröberer Grund-

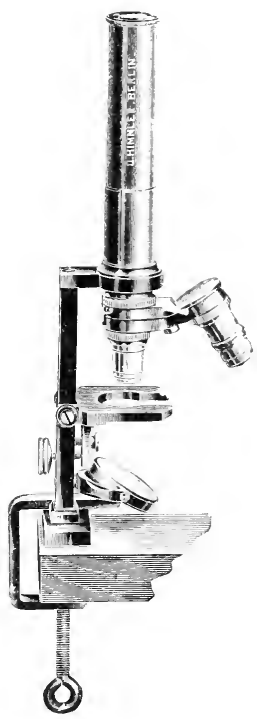

Abb. 87. Exkursionsmikroskop. Das Instrument besteht aus Aluminiummickellegierung (FuB, Säule, Tisch). Die Optik ist die normale. Pleurosigma angulatum wirl aufgelöst. ca. $1 / 3$ nat. $\mathrm{Gr}$. proben. Wegen ihrer schwere (2.6 kg) greift sie anch tieferliegende schlanmpartien und liefert deshalb einwandfreiere Proben als der Schlammheber. Die (ileitbiigel halten das scharmetz während des Ziehens in der richtigen Lage und garantieren so eine grobe (ireifsieherheit.

Das erbeutete Material kann teils direkt untersucht. trils auf geeigneten Schlammsieben ansgewasthen werden.

Näheres über Fangmethoden siche auch bei Heymons, Kolkwitz. Lindan. P. Magnus und Ulbrich (1).

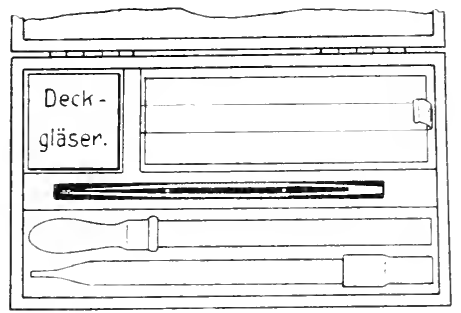

Abh. 88. Exkursionsbesteck. Mit Olyjekt1rägern, Deckgläschen, Pinzette und Pipette. ca. $1 \%$ lin. nat. Gr. Orig.

\section{Exkursionsmikroskop.}

Auf Reisen verwende irh seit 15 Jahren mit bestem Erfolg ein, einschließlich Verpackung nur $600 \mathrm{~g}$ wiegendes Exkursionsmikroskop mit 100)und tonfacher Vergröbermng, an dem bisher keine Reparatur nötig war.

Kohren wir zu demam Anfang dieses Kapitels besprochenen Vegetationsbilde zurick. so werden wir ihm an seinen (Organismen sogleich ansehen. 
(ab) as sich num einen relativ stationär gewordenen Zustand handelt, in dem die Organismenbestände ihr Bild imnerhalb gewisser Zeiträmme nirht wesentlich ändern werden.

Ganz anders werden sich die Verhälnisse gestalten. wemn einer der wichtigsten Faktoren, die Ernährung. eine wesentliche und durchgreifende Antermog erfährt. z. B. durch nachlaltige organisehe Diingung (Experimentalökologio). Ist diese stark. z. B. dureh Abwässer, so kann sieh eine Fäulniszone mit l'berwiegen von Fänlnisorganismen mul ihnen nahestrhenden Lebewesen bilden (l’olysaprobien).

Fine solche Zone ist immer mur im Gleichgewicht. solange tie Nahrung zufließt. Härt die Zufuhr der organischen Nährstoffe anf. so beginnen die Fänhnisbewohner zuriickzutreten und den früheren normalen Beständen wiecler Platz zu machen. Sehlieblich tritt ein neues biologisehes Gleichgewirht ein. letzten Endes der Art, wie es rorher war.

Man nennt diesen wiehtigen ProzeB die biologisehe selbstreinigung, rhemiseh gesprochen die Mineralisation. Weil Eiweißsubstanzen zı Kohlensäure. Ammoniak usw. abgebaut werden; man vol. anch H. Marsso 13 (1).

In diesem Prozeb lassen sich in ansgeprägten Fällon drei wichtige Plasen nnterscheiden:

1. die Phase der iiberwiegenden Reduktion,

2. die Phase der Z̈berwindung der Reduktion und des lohhaften Einsetzens der Oxydation.

3. die Phase der (möglichen) Vollendnng der Oxydation.

ber Torgang kam anch sogheich mit der zweiten Phase cinsetzen.

Diese Prozesse und einige ilner Begleiterscheimungen seien an dem beigetiigten Schema auf Taf. Xl reörert. Die Erlänterungen zu den versehiedenfarbigen Feldern sind dem Bilde beigefiigt. Lie drei Zomen stellen Querschnitte dar dureh drei anfeinanderfolgende Teiche. Welche durch Gäben verbunden sind. oder drei anfeinanderfolgende. dann dureb l'bergänge verdundene Flubstrecken.

I. Zono der Reduktionou (rehemiseh definiert).

Zone der Polysaprobien*, (biologisch definiert).

Zone der Diingung (Ahwässer) (praktisch definiert).

$$
\mathrm{p}=\text { polysaprob. }
$$

In dieser Zome finden ausselulieblich oder vorwiegend Fäulnisprozesse dureb Reduktionen mud spaltungen statt. Zersetzt werden hauptsächlich Eiweibstoffe, Polypeptide und ihre höheren Abbauprodukte**). An der Oberfläche. welehe in dem Sehema nach oben gekelut ist, findet man oft reichliche Besätze von Abwasserorganismen, an Gimnde dumklen sehlick und schwarzes Schwefoleisen (Fes) nnd endlich im Wasser (in cler Mitte)

${ }^{*}$ poly $=$ viel, sapros $=$ Zersetzmng, hios $=$ Leben.

*) Beggriatoa ist anf $\mathrm{H}_{2} \mathrm{~S}$ (hier Produkt der Fänlnis) angewiesen. 
zahlreiche Bakterien, unter Umständen mehr als eine Million pro 1 cen Wasser. Der Sauerstoffgehalt des Wassers ist Null oder sehr niedrig. Sedimentation findet meist reichlich statt.

Beispicle von Vertretern dieser Zone sind im Vorstehenden genannt in Bactcrim vulgare. Polytoma nvella.

Bacillus subtilis. Colpidium colpoda.

Chromatim okenii. Zoogloea ramigera.

chlorophyllfürende. Organismen treten in der Regel zuriick. Sphacrotilus leitet schon zu Zome II iiber.

II. Zone der einsetzenden Oxydation (chemisch definiert).

Zone der Mesosaprobien (biologisch definiert).

Zone des Übergangs.

$$
\mathrm{m}=\text { mesosaprob }
$$

Mit dieser Zone begimnen lebhaftere Oxydationsprozesse. vorwiegend biologischer Natur, infolge reichlichen Auftretens chlorophyllfiihrender Belïfter, aber auch rein chemische Oxydationen, z. B. Überführung von schwarzem schwefeleisen in gelbbraunes Eisenoxydhydrat, wie es in der Schlammregion angedentet ist. Die Mesosaprobien vollfiihren den eigentlichen spezifischen Prozeß der Selbstreinigung, die Bio-Oxydation im Gegensatz zur Bio-Reduktion, der Fäulnis. Die Bio-Oxydation bewirkt weitgehende Entfaulung ohne starkes Auftreten stinkiger Gerüche, ähnlich der Bodenwirkung und der Wirkung von Oxydationskörpern, also Mineralisation unter Ausschaltung der Fäulnis. Vergl. Abb. 48.

Erst jahrelange studien dieses sthwierigen. noch jetzt nicht in allen Einzelheiten zergliederten Problems haben die wissenschaftliche Ausdeutung dieser Vorgänge gebracht. Über die geschichtliche Entwickhnng in der Erforschung des Problems vergleiche man meine Ausführungen in Lafar (1).

Die Zone der Mesosaprobien, in welcher die Mineralisation bis zu einer mittleren Stufe fortgeschritten ist, zeigt dadurch eine deutliche Asymmetrie. daß der in der Figur nach links gelegene Teil $(\alpha)$ naturgemäß stärkere Zersetzungen anfweist als der nach der Reinwasserzone gekehrte $\beta$-Teil. $a$-mesosaprob $=a \mathrm{~m}$ ist im allgemeinen vorwiegend die Zone der beim Abban hochmolekularer Verbindungen entstehenden Aminosäuren u. a. n. $\beta$-mesosaprob $=\beta \mathrm{m}$ ist im allgemeinen die daranffolgende Zone der (einen weiteren Abban bedentenden) Ammoniakverbindungen der Fettsäıren usw.

In der Abbildung ist die Asrmmetrie durch die Abnahme der Bakterienzahl angedentet.

sind auch noch Anklänge an die p-Zone geblieben. so sieht man auf "inen Bliek die veränderte Sachlage. Das lebenspendende Atmungsgas sinerstoff hat das Anftreten eines reichen Lebens an Tieren oniederen mud höhreen) rmöglieht, die wegen ihrer Frebtätigkeit oin wichtiger Faktor der Reinigme sind. teils durch Verdaunng. teils durch Tnkarmation des Gefressenen. Im a-Tril kiinnen Fische leben. aber in warmen. dunklen Nächten 


\section{Normale biologische sellsstreinigung}
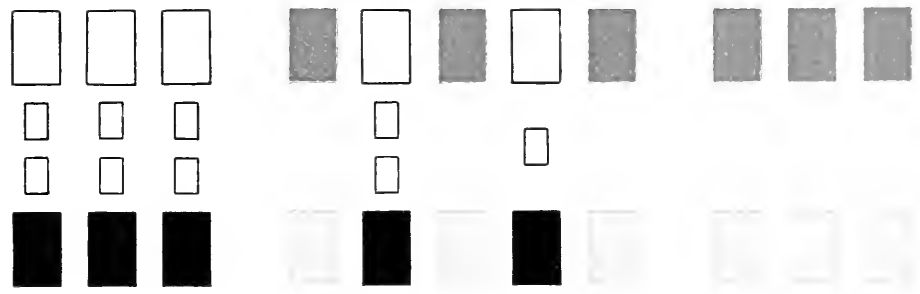

I. Poly-Saprobien (Aliwasserzone)
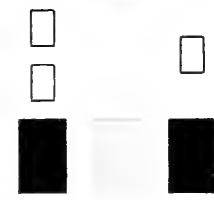

$$
a \text {-Teil } \beta \text {-Teil }
$$

II. Meso-Saprobien (Chergangszone)

III. Oligo-saprobien (Reinwasserzone)

\section{Gestörte biologische selbstreinig̈ung}
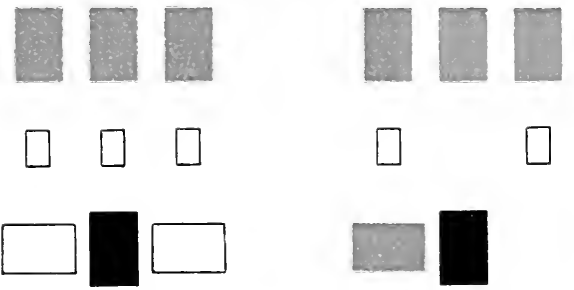

Sekundäre Verunreinigung

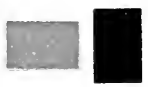

Selbstrerunreinigung

\section{Erlïuterungen}

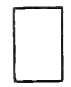

Abwasserpilze und -Protozorn (Entfäuler)

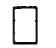

Bakterien (Fäulniserreger und Entfäuler)

Pflanzen mit Blattgrün (Durehliifter)

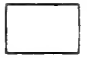

Ibgc sturbene Abwasserpilze

\author{
Tiere (Entfäuler und \\ Fischfutter)
}

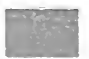

Pflanzen mit Blattgrün

\section{Normaler sichlamm} (mit Eisenoxydhydrat)
Ilochwasser-

wirknng

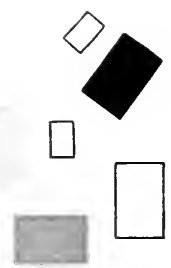

Schema betr. den Verlanf der biologischen Sellostreinigung. (Hriginal.) 

kann durch Sanersteffmangel Atemnot eintreten. Angesammelte Drainwässer von Rieselfeldern pflegen mesosaproben ('harakter zu tragen. Sie sind reich an Fischnahrung.

Die Uferbesätze, welche im p- und a m-Teil mehr zottiger und sehleimiger Natur sein können, pflegen vom $\beta$ m-Teil an mehr erdig-filzigen Überzïgen Platz zu machen.

Im Laboratorium kann man die p-, $\alpha$ m- und $\beta$ m-Wässer angenähert nachahmen:

p-Wasser ist z. B. Wasser mit mehr oder weniger stark wahrnehmbarer Fäulnis (Blnmenvasenwasser usw.),

a m- Wasser ist Wasser, das mit Hen. etwas zersetzten Algenwatten usw. einige Zeit gestanden hat.

$\beta$ m-Wasser ist $\mathrm{z}$. B. solches. Welches in dimner sehicht iiber normalem Schlamm steht.

Alle diese Wässer reinigen sieh bei längerem Stehen selbst, wemn nieht von neuem sekundäre Zersetzungsherde entstehen.

Als Vertreter seien beispielsweise genannt:
Oscillatoria limosa.
Arcella vulgaris.
Cryptomonas crosa,
Iorticella campanula,
Melosira z'arians.
Brachionus pala,
Stephanodiscus hantzschianus,
Gammarus fluviatilis.

111. Zone der vollendeten Oxydation (Mineralisation) (ehemisch definiert).

Zone der Oligosaprobien*) (biologisch definiert),

Zone des Reinwassers (praktisch definiert).

$0=$ oligosaprob $^{* *}$ ).

Diese Zone wird durch das rechte Bild des Schemas dargestellt. Der Schlamm ist vollkommen oxydiert, die Bakterien sind stark zuriickgetreten (wemn anch nicht verschwunden), normales Pflanzen- und Tierleben ist reichlieh entwickelt. Alle stiirmisch verlanfenden Zersetzmosprozesse haben im Wasser aufgehört, doch kann naturgemäß der Schlamm als Ablagestelle aller natiirlichen Abfallprodukte stellenweise noch mesosaproben Charakter tragen. Anhäufungen von p-Organismen finden in der o-Zone keine Existenzbedingungen.

Den Grganismen dieser Zone stehen vorwiegend mineralisierte stickstoffverbindungen zur Verfügung.

Das Wasser dieser Zone ist meist klar und samerstoffreich. Viele biologische Seenstudien fallen unter diesen Absehnitt. Über die Physik der Seen vergleiche man Forel (1), Penck (1) und Herz (1 und 2).

*) oligos = = wenig.

**) Die Bezeichnungen $\mathrm{P}, \alpha \mathrm{m}, \quad \beta \mathrm{m}$ und o sind mehr fuir das äkologische als für das physiologische Verhalten geprägt. 
Wir sind wieder bei dem Zustand angelangt. den unser Vegetationsbild zeigt und von dem wir ausgegangen sind.

Beispiete für diese Region siehe bei Kolkwitz nnd Marsson (1) und in den Listen.

Katharobien*) endlich. eine Bezeichnumg in dem das Wort sapros fehlt. kann man die Organismen tes ganz reinen Wassers nennen. doeh ist
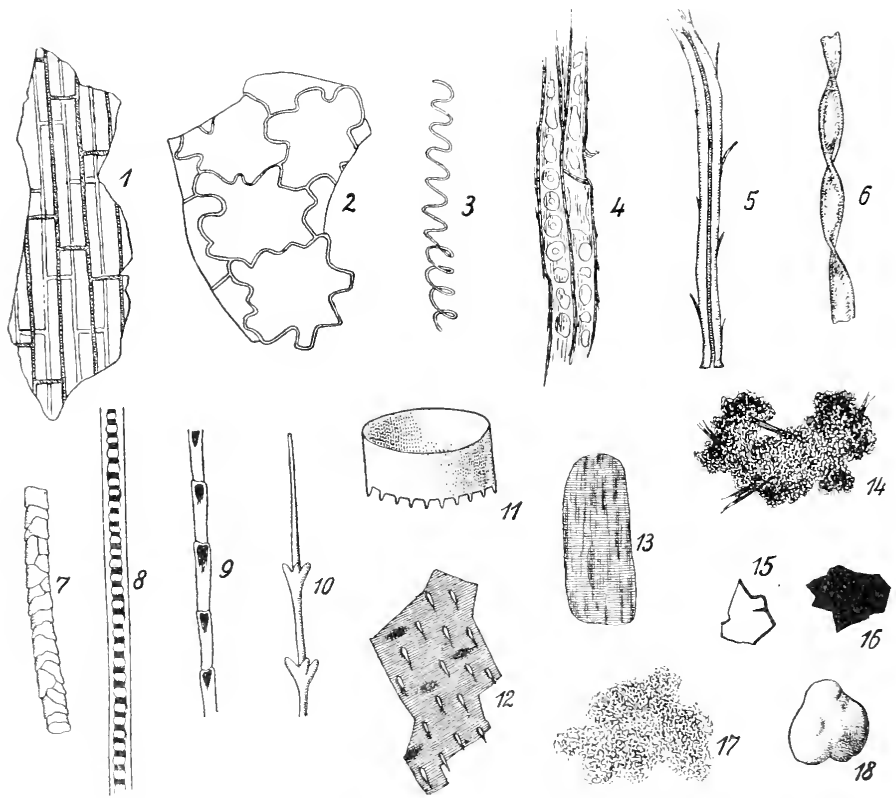

Ahb. 89. Unhelebte Bestandtteile des Sestons bei miknoskopischer Betrachung.
1. Stengel-oler Wrizelrest.
T Wolllfaser.
8. liattenhaar.
2. Blattrest.
3. Spriralfaser.
4. Holzfasern, zersetzt.
†. Hanffaser.
6. Bammwollfaser.
9. Togelfederstrahl.
10.
11. Leibesring (Insekt)
12. Chitimrest.

(Original.)
13. Fleischmolielfarer.

14. organischer Det?itus.

15. Gesteinssplitter:

16. Kohlepartikel.

17. Eisenoxydhydrit.

1S. Sandkörnchen.

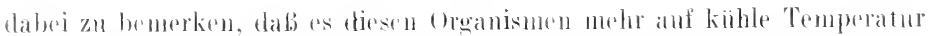

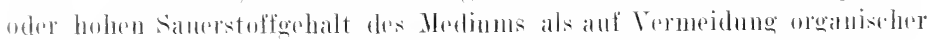
Substanze'n anzukommen pflegt.

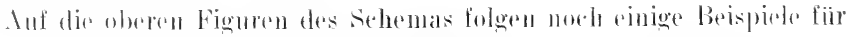

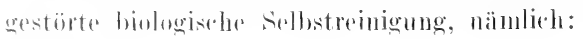


1. Seknndäre Verunleinigung: Aurch Abreiben von Pilzfladen usw. und deren Absinken nach Passieren von Zonen. in denen die stadien der Mineralisation seloon durchschritten sind.

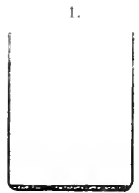

1). 1 (2)

Tinma-sep

() $\mathrm{km}$

$\bar{i}$.

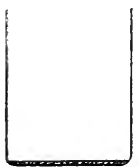

0.1 cem Tor Rhpintall (a. $255 \mathrm{~km}$.

13.

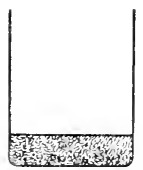

$0.9 \mathrm{cem}$

Tor Binger 1*a. $736 \mathrm{~km}$.

19.

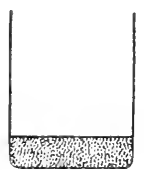

1). $9 \mathrm{~cm}$

fir Ciiln (अi. $\$ 96 \mathrm{~km}$,

$$
25 .
$$

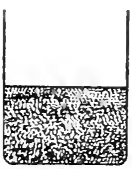

$2.0 \mathrm{eem}$ Bei Orsor (Emschermündung ca. $999 \mathrm{~km}$.

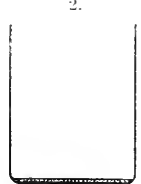

(il. 1). 1 cent

Tsehamut

(1). $4 \mathrm{~km}$.

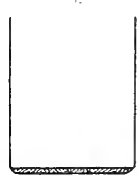

$0.15 \mathrm{ccm}$ Hinter Rleinfall ea. $25 \mathrm{~km}$.

11

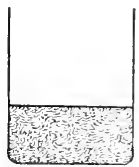

$1,5 \mathrm{cem}$ Rìdəsheim e. $737 \mathrm{~km}$

201.

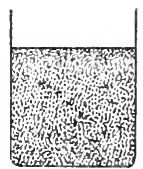

$30 \mathrm{cem}$

NithI-Flittard links. $91,904 \mathrm{~km}$.

26 .

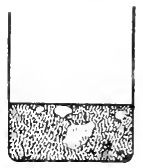

$1.5 \mathrm{cem}$ B.i Rheinbers rechts a. $1010 \mathrm{~km}$.

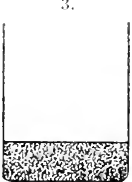

$1,0 \mathrm{ecm}$ Vir RejehenauTamins ea. $67 \mathrm{~km}$

9.

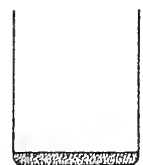

$035 \mathrm{cen}$

Waldshut

(a. $313 \mathrm{~km}$.

15

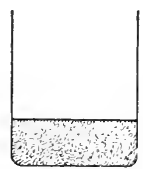

$1.2 \mathrm{~cm}$ Plinsstrommitte ("il. $791 \mathrm{~km}$.

21.

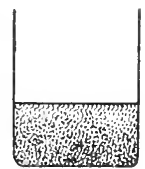

1.6 геш

Ilitdorf links +a. $913 \mathrm{~km}$.

27

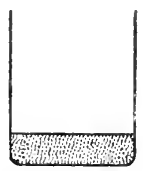

$0.5 \% \mathrm{~m}$

Vor Wesel links (a. $1019 \mathrm{~km}$.
4.

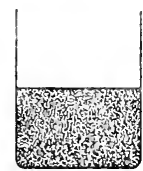

$2,0 \mathrm{cem}$

$\mathrm{Nach}$ Hinterrheis

ca. $6 \mathrm{~s} \mathrm{~km}$.

10.

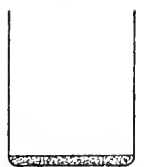

$0.25 \mathrm{cem}$

Basel

(a. $377 \mathrm{~km}$.

16

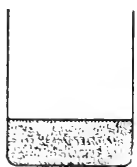

$1.2+4 \mathrm{~m}$

Vir Kublenz

a. $799 \mathrm{~km}$.

2.9.

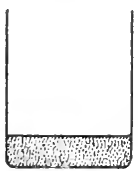

0.8 aent Bei DüsseIdori
(2). $951 \mathrm{~km}$.

24 .

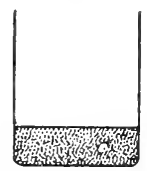

1.t) (. $\cdot 1 \mathrm{~m}$

Emmerieh (a. $105 \times \mathrm{km}$.

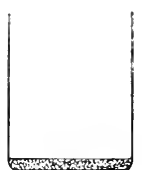

$0.3 \mathrm{cr} \times \mathrm{m}$ st. Margarethen (ad. $160 \mathrm{~km}$

11.

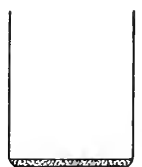

\section{2 een}

strabburg

ca. $504 \mathrm{~km}$.

17.

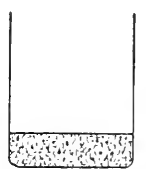

$0.9 \times 10 \mathrm{~m}$

Andernati (a) $\$ 21 \mathrm{~km}$.

23.

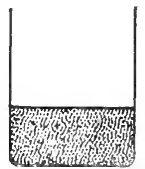

$1.5 \mathrm{x} \times \mathrm{m}$

I'ranuen-Krefeld rechfs. $4.97 \mathrm{~km}$.

29.

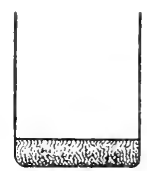

0.7 eem

Rotterdan ad. $1199 \mathrm{~km}$.

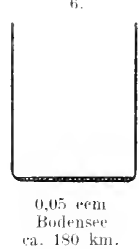

12.

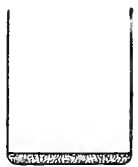

0.3 eern

Vor Mannheim (a. $634 \mathrm{~km}$.

18.

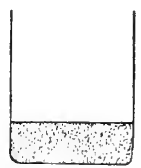

$1.1 \mathrm{rem}$

Hinter Bom (2a. $866 \mathrm{~km}$

21.

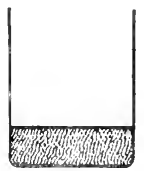

$1,0 * \cdot \mathrm{m}$

Rulirort ca. $957 \mathrm{~km}$.

30 .

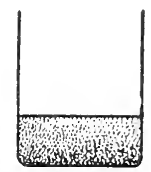

$1.3 \mathrm{cem}$

Hoek van Holland (a. $1230 \mathrm{~km}$.

Abb. 90. Seston ans je 501 Wasser, am Grunde von mit Wasser gefïllten Normalplanktongläsern abgesetzt (nicht zentrifugiert). $1 \mathrm{~cm}$ Höhe $=2 \mathrm{~cm}$ Inhalt. Nat. Gr. [Nach Kolkwitz (4).] 
2. Salbstverunreinigung: durch Absterben von Pflanzen im Herbst und durch Absinken von Tieren. (Massenhaft absinkendes Plankton z. B. kamm zu ziemlich starken Zersetzungen im schlamm fïhren). Die erstgenannte Verumreinigung pflegt stärker zu sein als die selbstverunreinigung. Sehr bekannt sind die vom Meeresstrande dureh ausge worfenen Tang entstehenden Zersetzungen.

Beide Prozesse kommen oft in Kombination vor.

3. Tie Einwirkung von Hochwasser endlich pflegt die biologische Formationsgliederung zu stören und die Wucht mechanischer Faktoren zur Geltung zu bringen.

Die in der freien Natur als Abfall auftretenden organischen stoffe unterliegen nicht allgemein so weit der Mineralisation, daß mit ihnen reiner Tisch gemacht wiirde. Wir sehen deshalb schlammanhäufungen auftreten,
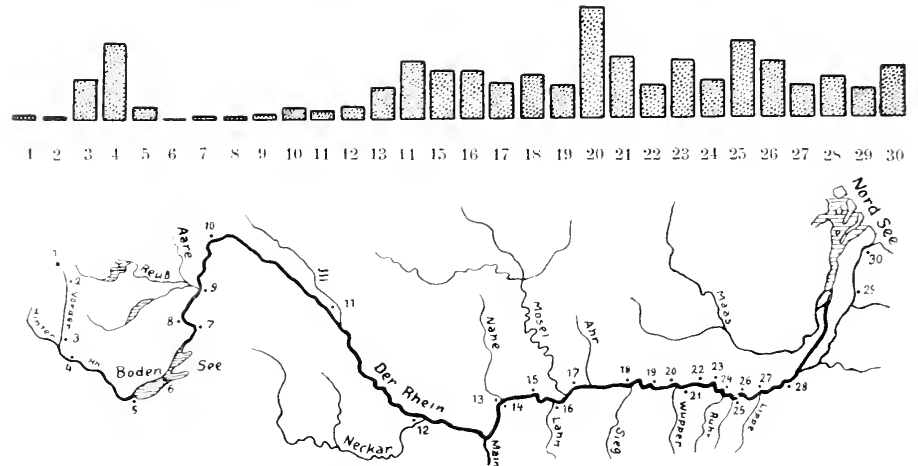

Abb. (1). Séstonkurve und Rheinlauf mit den Untersuchungsstellen; rgl. auch Abb. 90. Die eckigen Felder sind senkrechte Ausschnitte aus den in der vorhergehenden Abbildung dargestellten Bodensätzen (in derselben Größe wie dort). (Original.)

de zur Kohlenbildung [vol. Potonić(1)] führen können, ferner Verlantungsprozesse sich abspielen und Torfmassen in Mooren entstehen.

In den Meeren und großen reinen Seen pflegen Sedimente (Radiolarien, Globigerinen, Diatomean) von ihren organischen substanzen ziemlith weitgehend befreit zu werden. da die relative Armut an Plankton in diesen Cewässern an die biologisthe Selbstroinigung keine sehr großen Anforderungen stellt.

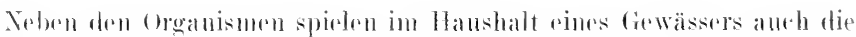

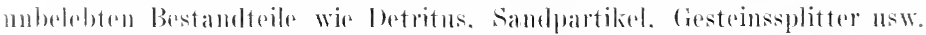

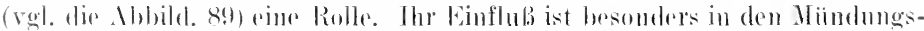

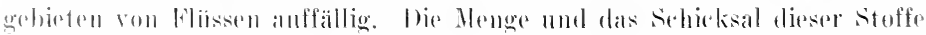

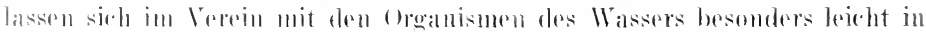


schmellströmenden Fliissen ohne nennenswerte sedimentation (außer in eingeschalteten seen) quantitativ und qualitativ studieren.

Beriicksichtigt man in der Hanptsache diejenigen Bestandteile, welche im Wasser durch gute Angen gerade noch einzeln wahrgenommen werden können [>1/15 mm]. so kann man sie durch Netze ofler siebe schnell aus größeren Wassermengen (z. B. 50) 1) absieben und in Giäsern bis zur Konstanz des Volumes sedimentieren lassen (rgl. S. 181).

Auf solebe Wreise Abgesiebtes (Seston) ist auf den beigefiigten Abbild. fiir den Rhein aus dem regenarmen sommer 1911 dargestellt. Man erkennt leicht den Einflub gesteinsführender Gebirgswässer. des Bodensees mit seiner sedimentierwirkung, der Industrie- und Wohnzentren mit ihren Abfallstoffen und die Beseitigung dieser dureh Verdiumnng und biologische Sellostreinigung. Bei Wesel war die Sestonmenge nicht wesentlich anders als bei Andernach: eine merkliche Addition findet also nicht statt. Im Jïndungsgebiet mit seiner Stauwirkung dureh die Flut des Meereswassers endlich findet neben der sedimentation auch eine wesentliche Beeinflussung des Planktons statt. Näheres siehe bei R. Kolkwitz (t).

Ein remer see ist ein Mikrokosmos, der sich selbst geniigen wiurde, da Produkte und Bediurfuisse (besonders ()$_{2}$ und $\left(\mathrm{C}_{2}\right.$ ) bei Pflanzen und Tieren entgegengesetzt sind. Ein dicht verschlossener gröBerer Glasbehälter bewahrt sein Leben jahrelang.

Jie organisierte Materie geht von einem Wesen zum anderen und macht eine Reihe von Inkarnationen dureh, ehe sie in die fundamentale Masse der toten Materie zuriickkehrt: diese kann dann von nenem in den Kreislauf gezogen werden.

\section{Gruppe. Bryophyta (Muscineae) Moose.}

\section{Systematische Übersicht.}

1. Hepaticae (Lebermoose).

Marchantiales.

Jungermanniales.

2. Musci (Laubmoose).

sphagnales.

Bryales.

Die Moese wathsen in allgemeinen nnter ziembeh äbnliehen Lebensbedingungen wie die Flechten. Man findet sie deshalb vielfach miteinander vergesellschaftet. Absterbende Moose findet man hänfig von Flechten iiberworhert. An besonders exponierten Stellen jedoch, wie z. B. anf den höchsten Alpenspitzen, in heiben Wiisten, an den Enden dimner Baumzweige usw. nehmen es die Moose im Wettstreit mit den Flechten meist nicht auf. da die Moose immer etwas Detritus (in Ritzen) nötig haben und nie auf ganz glattem Gestein wachsen. Woch dringen einige. z. B. Grimmia alpestris und Andreaea nivalis (kieselliebend). weit anf die Gipfel der Alpen in die schnee- 
region vor. Anf strohdächern machen die Flechten den Moosen meist keine Konkurenz, wohl weil das substrat fïr die sehr langsam wachsenden Flerhten zu wenig damerhaft ist.

In den arktischen Gegenden ist die Moosvegetation verhältnismäbig rinförmig: Sphagnum und Rhacomitrimn hypnoides (=Rh. lanuginosum) sind hier bekannte Vertreter, besonders in den Tundren.

In den Tropen dagegen kommen die Moose nach Gattungen und Arten vielfach zu sehr iippiger Entwicklung, vor allem in nebeligen Bergwäldern. Auch bei uns sind feuchte sichluchten. Buchenwälder nsw. argiebige Fundstellen fiir Moose.

An gediingten stellen und in sthlechter stadthuft fehlen Flechten, nicht aber Hoose, unter denen es ansgesprochene saprophyten gibt, z. B. splachnum ampullacenm auf Kuhmist in fenchten Waldmooren und die hochalpine Toitia nivalis anf Mist an Lagerstätten von s.haf- mo Rinderherden. Die Sporen solcher Hoose werden oft durch schmeibfliegen verbreitet. Moose ron so ansgesprochenem Saprophytismns, dab sie chlorophyllfrei wiirden. gibt es nicht.

Im Wasser treten die Flechten hinter den Moosen so vollisommen zuriok, daß sie hier so gut wie als fehlend zu bezeichnen sind. während die Moose oft iippige Bestände bilden kömmen. Sie fruchten aber nicht muter Wasser. Während indessen die Flechte Lichina in Meerwasser gecleiht, fehlen hier Moose vollständig.

Die Kultur der Moose anf Agarnährboden wird von P. Janzen (1 и. 2) geschildert. Man verwende z. B.:

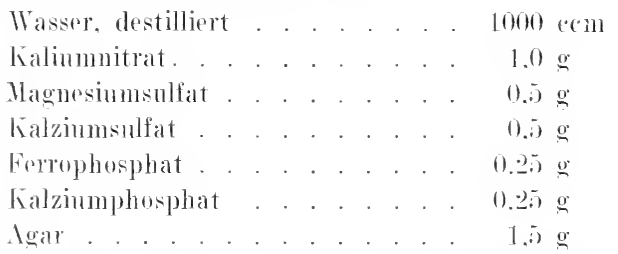

Dir Keimmong der sporen erfordert. Wemn die Anssat in den ersten Ionaten des dahes vorgenommen wird, wach den bisherigen Wahrnehmungen + Tago bis otwa + Wochen. Als bestes Versuchsobjekt gilt z. Z. das sehr kleine, xerophytiseh auf Mereel- und Lehmboden warhsende Phascum curiricollum.

Das Wathstmu des Protonemas der Mouse ist in der Regel sehr von der Wahl einer richtigen Belenchtmng fïr die Kulturplatten abhängig. Nan vergleiche auberdem C. Servettaz (1).

Weitore Feststellungen, welche bei den Moosen wesentliche. hier in Betratht kommende Gesiohtspmnkte bieten, aber in den ,Physiologien" meist wenig beriicksiehtigt sind, mögen im folgenden bei den einzelnen als Typen loransgegriffenen, bekannten Vertretern besprochen werden. 


\section{Marchantia*) polymorpha.}

Von Limmé nach N. Marchant († 1678), (rartendirektor des Herzow. Gaston r. Orléans in Blois, benamt.

Dieses diöeisehe hochorganisierte Moos (s. die Abbildungen) gedeiht am besten an fencliten Felsen, Manern (stein mud Holz). an (zuellen. an

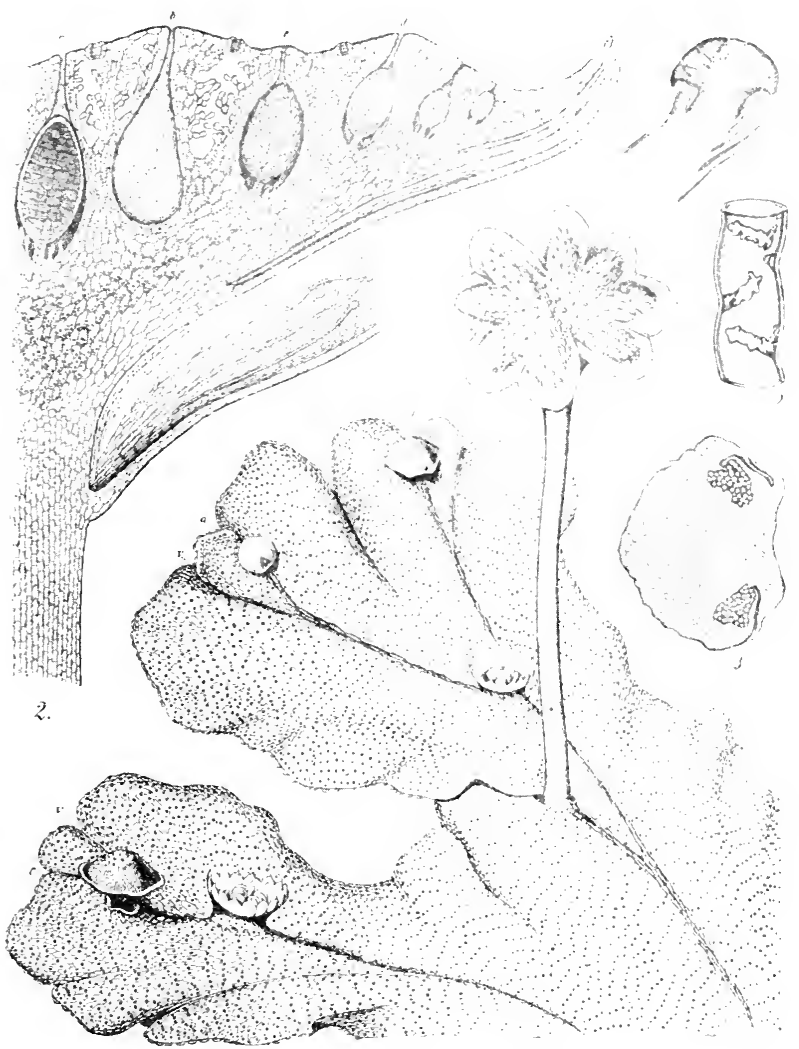

Ahb. !2. Marchantia polymorpha. Männliche l’flanze, mit Brutkörhehen. (Nach L. Kny.) Teilfiguren stärker vergrößert,

Bächen, anf nassen Wiesen usw. Es scheint eine gewisse Vurliebe fiir nitrathaltige standorte zu haben. Kultivieren läßt sich Marchantia anf lehmiger Rasenerde, welcher man Kuhdung und etwas sand znsetzt. Die Gärtner können sich stellenweise vor dem Wuebern dieses Jloeses kallm retten.

*) Marchantia findet sich in der Sammlung Brendelscher Modelle. 
Die Geschlechtsreife tritt mehr im Friihling, die sporenreife meist im Hochsommer ein. Die vegetative Vermehrung geschieht durch flache

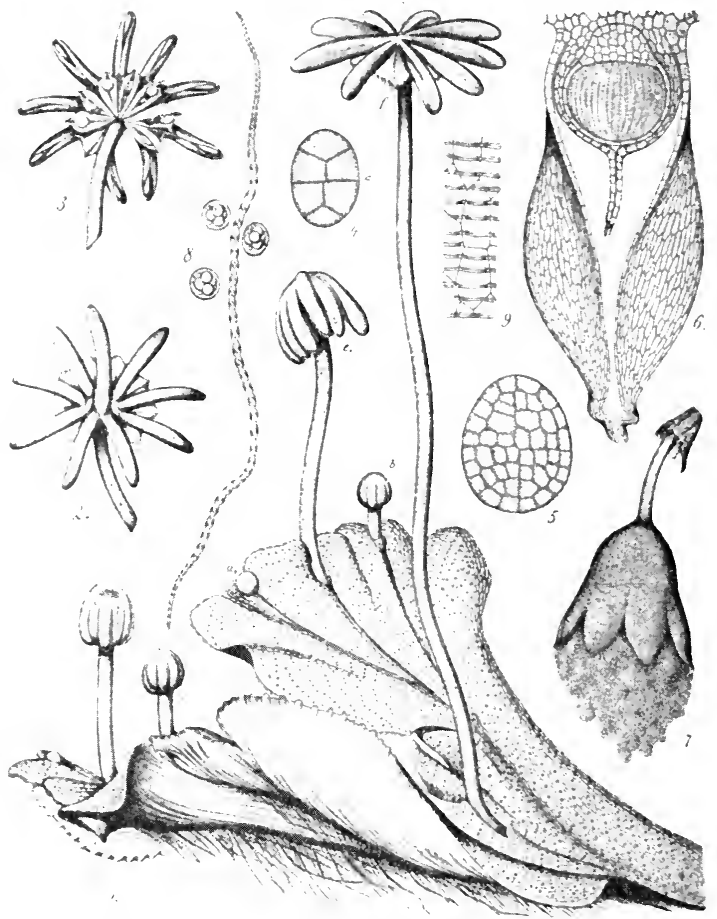

Abb. 93. Marchantia polymorpha. Weibliche l'flanze. (Nach L. Kny.)

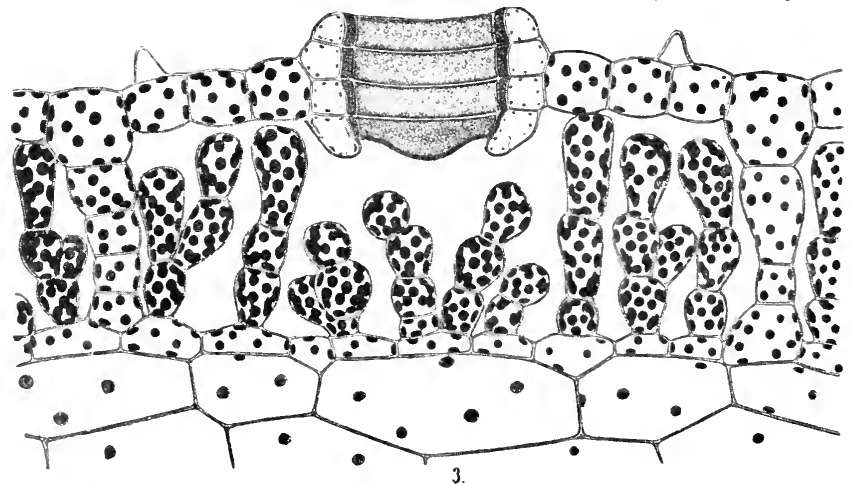

Ahi. 94. Marchantia polymorpha. Längsschnitt durch eine Luftkammer des Thallus, mit Assimilationszellen und Atemöfnung. Nittehtark vergr. (Nach L. Kny.) 
Brutkörper, welche ihre Rhizoiden aus besonders vorgebildeten Zellen an der dem Lieht abgekehrten seite entwickeln, was sich experimentell leicht zeigen läßt [vgl. L. Kny (1) und W. Pfeffer]. Das Assimilationsgewebe (s. die Abbild. 94) ist gut entwickelt. Das Innere eines jeden der kleinen Thallusfelder steht durch eine Öffnung mit der Atmosphäre in Verbindung.

AuBer Marchantia gibt es bei uns noch zwei besonders stattliche Lebermoose:

Fegatella conica (Name von fegato = Leber) mit sehr deutlichen, bei Lupenbetrachtung fast warzenartigen Beliiftungsporen auf den Thallusfeldern.

Preissia commutata (benannt nach Balthasar Preiß, 1765-1850, Regimentsarzt in Prag). Mehr im Gebirge lebend, mit klein und zart gefeldertem Thallus.

\section{Riccia fluitans.}

Von Micheli 1729 nach Pietro Francesco Ricei. Senator und Vitglied der lotan. Ges. in Florenz, benannt.

Dieses an seiner regelmäBigen Gabelmng leicht kemutliche Lebermoos lebt häufig im Wasser untergetancht, meist zwischen schilf und anderen Uferpflanzen, und ist bei solcher Lebensweise stets steril. Geschlechtsorgane und Rhizoiden werden nur von der etwas derberen Schlammform gebildet. Die Pflanze wird häufig in Aquarien gehalten.

$R$. natans schwimmt auf dem Wasser, andere Arten sind Landbewohner.

\section{$\therefore$ Lophocolea [frïher Jungermammia*)] heterophylla.}

Name von lophos = Hahnenkamm und koleos = Scheide, wegen der gelappten und kammartig gezackten Kelehmündung; heterophylla wegen der ungleichen Gestalt der hasalen und der näher der Spitze des Stengels stehenden Blätter.

Dieses zierliche Lebermoos wächst dem Substrat meist dicht angeschmiegt, mit besonderer Vorliebe auf morschen Banmstiimpfen an Waldwegen. Man findet es fast immer mit sporogonen, deren sthwarze Kapseln auf weiBen Seten stehen. Bei Kultur unter einer feuchten Glocke ent wickeln sich die Frnktifikationsorgane besonders reichlich. Wie die Abbildung eines vergrößerten Zweiges zeigt, decken sich die Blätter dachziegelig. Die dritte Blattreihe, an der Lnterseite, ist in der Zeichnung nicht sichtbar.

Lepidozia reptans (Name von lepis = Schuppe mul ozos = Zweig) ist pines der zartesten und zierlichsten Lebermoose anf Waldboden.

*) Von Linné benannt nacb Lndw. Jungermann (1572-1653), aus Leipzig, Professor der Botanik in Gießen. Die beblätterten Zweige der Jungermanniaceen erscheinen im Gegensatz zu denen der meisten Laubmoose in der Regel flach, gleichsam Selaginella-artig.

Kolkwitz, Pflanzenphysiologie. 
zersetzten Baumstimplen nsw. Es ist mit blobem Auge kaum noch als echtes Moos zu erkemmen.

Frullania dilatata (1820 bemannt nach dem Geh. Staatsrat Leonardo Frullani in Florenz) lebt als Xerophyt an Rinden, besonders an Buchenstämmen. Die Farbe ist dunkelgrün oder brann. Die Oberblätter haben bentelförmige Lappen und we ren bisweilen ron Rädertieren bewohnt. Vergl. Kerner, Bd. I, S. 243.

\section{Metzgeria furcata.}

Von Raddi 1820 nach dem ihm hefremndeten Kunferslecher .. Metzuer ans Stanfen i. Br, benannt.

bieses xerophytisch lebende Lebermoos erimnert in seiner Gestalt an Riccia fluitans. Es findet sich besonders an der Rinde von Burhen und Eirhen.

3. Sphagnum cymbifolium. Torfmoos $\left.{ }^{*}\right)$.

Die Torfmoose, Welehe die Moore rharakterisieren, zeichnen sich dureh ihre Fähigkeit, besonders große Mengen ron Wasser aufzusaugen. in benterkenswerter Weise ans. Beim Ausdriicken ïppig entwickelter Polster flieben iiberraschend grobe Wassermengen ab. welche kapillar durch die perforierten Wasserzellen der Stengel und Blätter festeralten waren. Die Pflanze besitzt keine Rhizoiden. Die Turfbildung der Sphagnen beruht auf ihrer Widerstandsfähigkeit gegen Zorsetzung. Wohl infolge ihres (iehaltes an säure (Lackmuspapier!): vol. Pall (1).
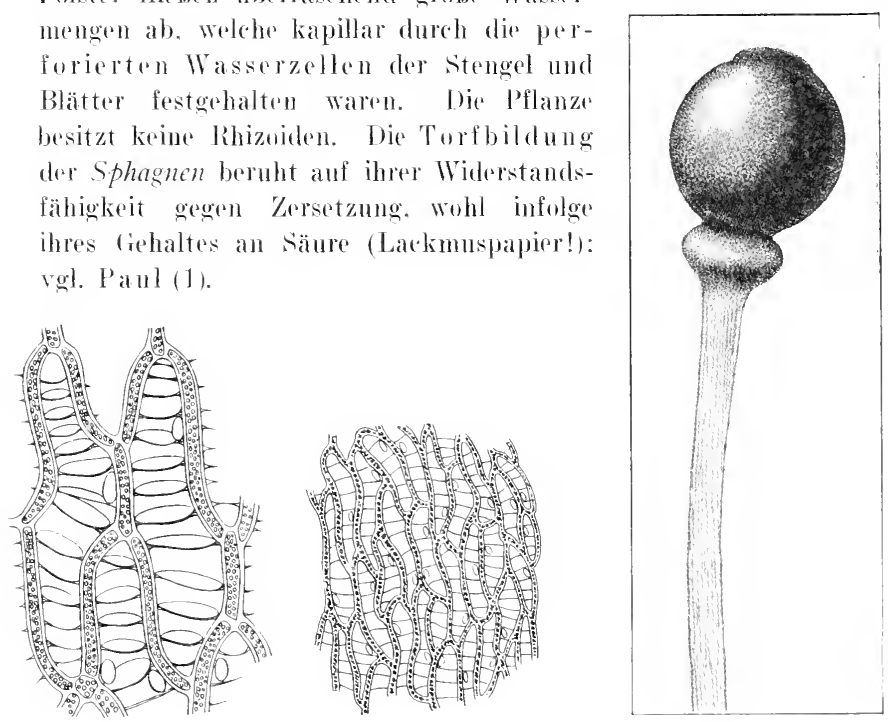

Abb. 95. Sphagnum cymbifolimm. Wasserzellen und chlorophyllführende Zellen bei 120 facher Vergr. nach II. Scchenck. Desgl, hei 30 facher (Lupen-tVergr. nach II. Bethge. (Nenzeichnungen.)

Abh. 96. Sphagnum cymbifolizm. Kapsel in doppelter Vergr. (Original.)

*) Die Moosbezeichnung sphagnos bei Plinius leitet sich wahrscheinlich von spongos (Schwamm) ah. 
Die meisten Torfmoose verlangen weiches Wasser. Ihre Polster sind meist reich an Desmidiaceen, wie iberhaupt Moosrasen vielfach von Kleinlebewesen bewohnt werden.

Bemerkenswert ist bei Sphagnum der Mechanismus beim Aufspringen der Sporenkapsel [vgl. Nawaschin (1)]. Wenn man Polster von Sphagnum mit gut entwickelten Sporangien (im Juli und August) aus dem Freien ins trockene Zimmer oder in die direkte Sonne bringt, wird man die Deckel von den Kapseln mit deutlichem, knipsenden Geräusch abfliegen hören und eine Sporenstaubwolke aus jeder Kapsel hervorpuffen sehen.

Nawaschin kommt mit Schimper zu der Ansicht, daB die infolge des Eintrocknens im Innern der Kapsel komprimierte Luft das Platzen bewirke, und die sporen wie aus einem Tesching hervorschieben. Er hat ermittelt, dab die eingeschlossene Luft bis anf mindestens 3 Atmosphären komprimiert wird. Das Abspringen des Deckels wird noch dadurch erleichtert, daß dieser durch verdickte Parenchymzellen starr ist und deshalb der Kontraktion der iibrigen Kapselteile nicht folgen kann.

\section{- Andreaea petrophila.}

(Nach dem Apotheker $\mathrm{N}$. Andreae in Hannover.)

Vgl. Taf. XII. Abbild. 8 (links) und K. Osterwald (1).

\section{Dicranum scoparium. Besenmoos.}

Name von dikranos = zweiköpfig, zweizinkig, wegen der meist in zwei Schenkel gespaltenen Peristomzähne. scopae $=$ Besen.

Die stattliche Pflanze wird 10-18 c $\mathrm{m}$ hoch; die Blätter sind meist sichelförmig nach einer Seite gebogen. Sie wächst in trockenen Kiefernund Laubwäldern am Boden, oft bestandbildend.

D. mains wächst fast ausschließlich in Laubwäldern.

\section{Ceratodon purpureus. Hornzahmmoos.}

Name von keras $=$ Horn und odus $=$ Zahn; wegen der widderhornartigen Peristomzähne.

Die Blätter sind in charakteristischer Weise gekielt (wie ein Schiff). Die Seta ist meist rot. die Kapsel rötlichbrann. Im Frïhling fallen die jungen, glänzend purpurroten Kapselstiele in den Rasen des Mooses oft besonders in die Augen. Die Pflanze ist variabel und dadurch im sterilen Zustand nicht immer leicht sicher zu erkemnen. Sie ist allenthalben gemein und weit verbreitet (kosmopolitisch) anf Sandboden, Strohdäehern, Mauern usw. und steigt bis hoch in die Gebirge anf. Sie findet ihr Gedeihen an ganz trockenen standorten, aber auch auf fenchten Brettern, Floßhölzern und in Sümpfen.

Die Sporen frisch entdeckelter Kapseln werden nach Steinbrinck durch die (sich in ihren Bewegungen hemmenden und dam zuriickschnellenden) Schenkel der Peristomzähne umhergeschleudert.

Die Abbildung stellt einen fruchtenden Rasen auf Erdboden und ein steriles Polster von einem Strohdach dar. 


\section{Leucobryum glaucum. Weißmoos.}

Name von leucos $=$ weiß und bryon $=$ Moos.

Die Pflanze wächst in dichten, mehr oder weniger halbkugelig gewölbten. bis $15 \mathrm{~cm}$ hohen Rasen, welche oben bläulich grïn, innen weißlich sind. Die sehr dicht gestellten Blätter haben Wasser- und Chlorophyllzellen, ähnlich Sphagnum, doch von etwas anderem Bau. Abbild. siehe bei Kerner, Bd. II, S. 208; vgl. anch C. Warnstorf (1).

Lencobryum lebt am Boden von Nadelwäldern, Erlenbrïchen, Heiden usw. Seine Lebensweise kann oft als hemixerophytisch bezeichnet werden. Es scheint Kalkboden zu meiden.

\section{- Barbula unguiculata. Bartmoos.}

Name von barba = Bart, wegen der langen fadenförmigen, gewundenen Peristomäste.

Die Rippe der Blätter tritt als kurze Stachelspitze am Blattende aus, die Rasen sind gelbgrïn.

Die Pflanze gedeiht besonders an Wegrändern und auf festgetretenen Gartenwegen (wie Bryum argenteum und Ceratodon purpureus), auch auf Tuffsteingrotten in Gärten.

Verwandt mit Barbula ist die Gattung Tortula. Von dieser wächst die sehr verbreitete $T$. muralis besonders auf alten Nanern, T. ruralis anf Sandfeldern und auf alten Strohdächern in Dörfern.

\section{Grimmia pulvinata.}

Name nach Dr. K. Grimm, Leibarzt in Gotha, $† 1821$.

Das Moos lebt echt xerophytisch weitverbreitet anf Steinen, Manem usw., meist mit Kapselfrüichten förmlich übersät. Die spezies von Grimmia finden sich anch auf erratischen Blöcken. Die Amnahme, daß sich auf solehen steinen bei uns Relikte ans der Eiszeit gehalten haben, erscheint unhaltbar. Es besitzt die Fähigkeit, stark anszutrocknen und beim Befenchten wieder anfzuleben. In diesem Punkte verhalten sich die Moose graduell verschieden.

Die Peristomzähne von Grimmia verschließen, wi bei den meisten Moosen, bei Fenchtigkeit die Kapsel, während sie bei Trockenheit spreizen: Ahb. s. bei Kerner, Bd. II, S. 568. Der Mechanismus steht im Dienste der sporenverbreitung. Die hygroskopischen Bewegungen der Zähne an den Mooskapseln sollen hier aber nicht näher besprochen werden, da sie gegenuiber den Bewegungen der Zähne an den Samenkapseln höherer Pflanzen (s. dort) nichts wesentlich Neues bieten.

\section{Rhacomitrium sudeticum.}

Name von rhacos= zerschlitzt und mitron = Mïtze.

Die Planze wächst mit Vorliebe an kalkfreien Felsen. Neben ihr ist ein Rasen von Andreaca angesiedelt. Das Material stammt ron der Sehncekoppe im Riesengebirge. 

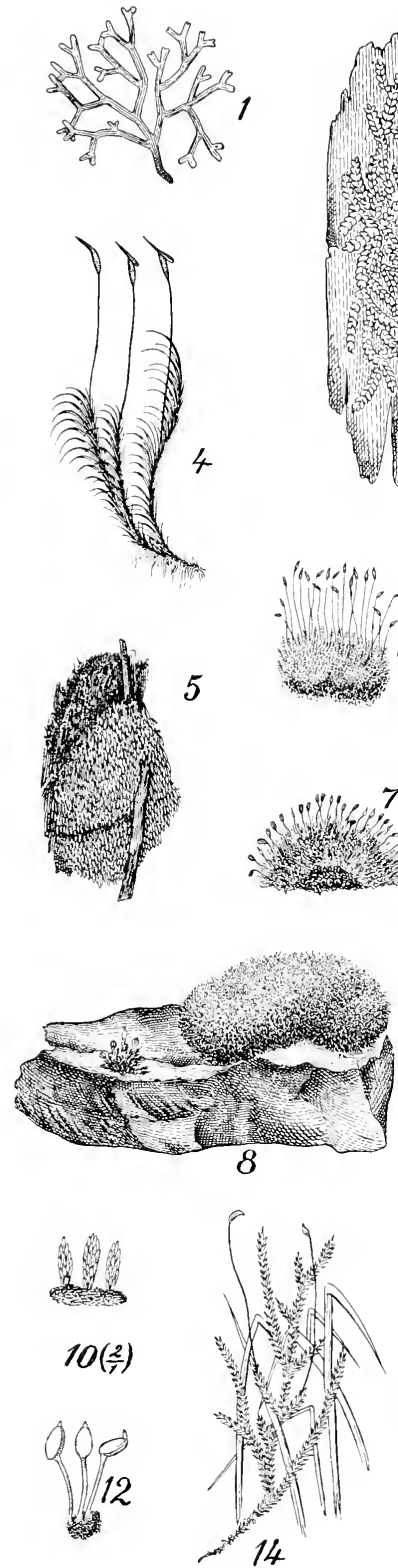
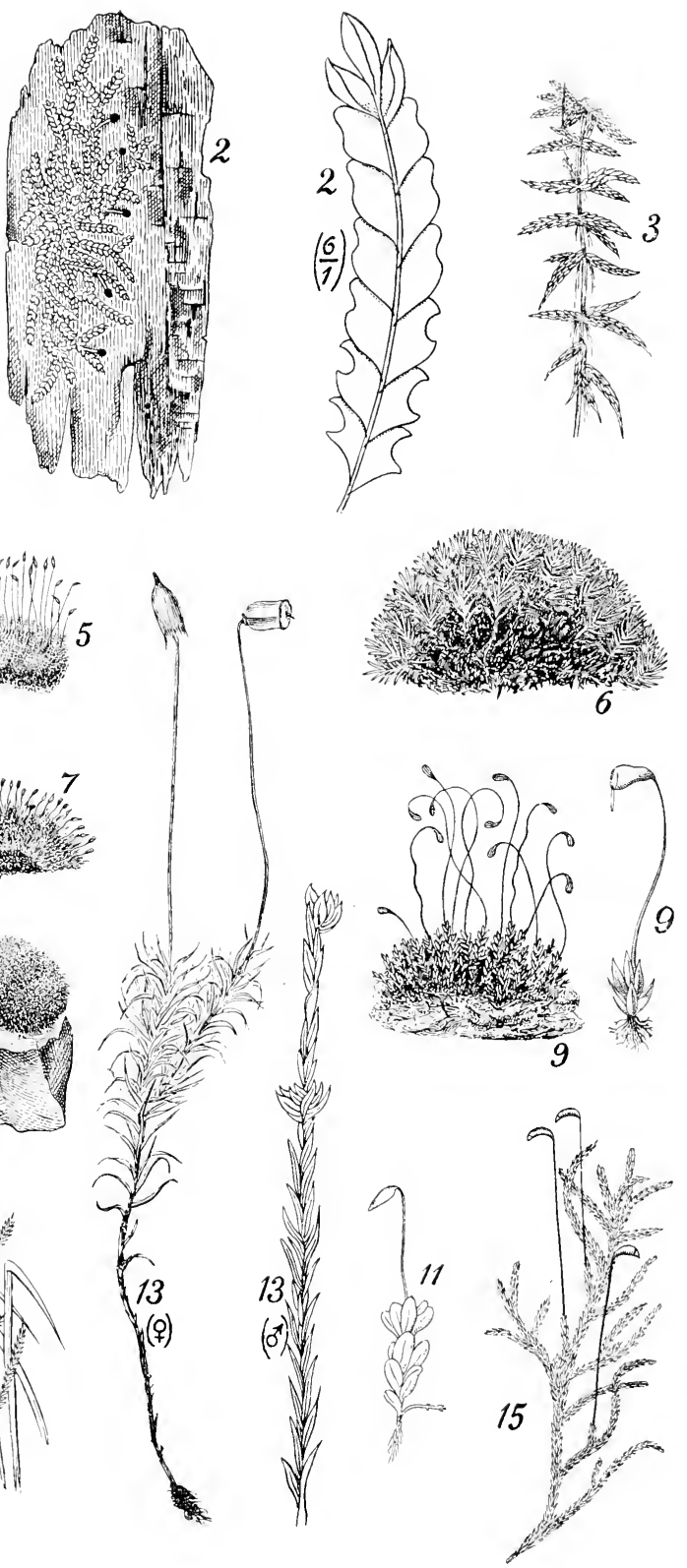

I o o s e.

Erläuterungen siehe S. 205 u. ff. 

9. Funaria hygrometrica. Drelmoos.

Name von funis = Seil, wegen der seilartig gedrehten Fruchtstiele (Seten).

Das Moos lebt meist truppweise auf feuchtem sand, an Waldplätzen (mit verasehtem Holz), auf porösem, steinigen Substrat usw. an belichteten Partien. Es fällt durch seine inn unreifen Zustand'saftgriinen, in der Reife rotbraunen sporogone mit hygroskopischer, gedrehter Seta auf; bei massenhaftem Vorkommen bildet es teppichartige Überziige von griiner bzw. rotbrauner Farbe. An trockeneren Standorten erreichen die Pflanzen (inklusive Sporogon) (a. 3 cm Höhe, an fenchteren bis 6 cm und mehr.

Die Blätter eignen sich zu Versuchen über den Einfluß des Lichtes auf die Lage der Chloropbyllkörner (vgl. auch Abb. 3) und zu Beobachtungen iiber die Teihung dieser Körner; vgl. strasburger u. Koernicke (1), Abschn. IV.

Über die Kultur von Funarias. P. Janzen (2).

\section{- Schistostega osmundacea. Leuchtmoos.}

Dieses bemerkenswerte Hoos wächst mit Vorliebe in engen Felshöhlen der Sandsteingebirge (Fichtelgebirge. Sächsische Schweiz usw.)

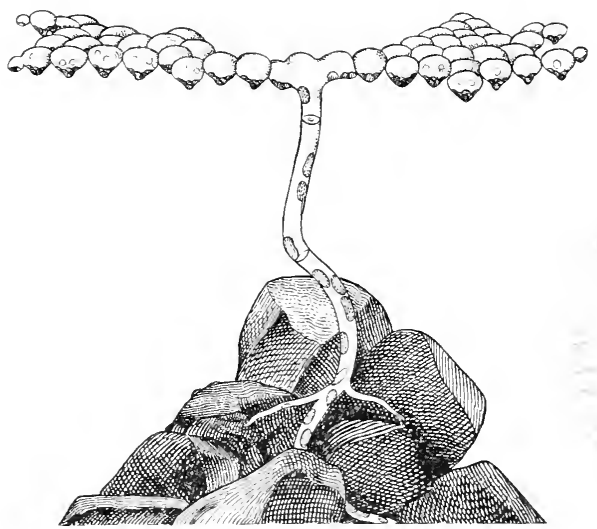

Vorkeim bei schwacher VergröGerung Abb. 97. Schistostega osmundacea. Vorkeim beim
(Neuzeichnmig nach F. Noll).

und zeichnet sich durch ein auch in seinem oberirdischen Teike bleibendes Protonema mit rundlichen Zellen aus, welche, ähnlich den Katzenaugen, das Licht auf die hintere Wand konzentrieren und von dort wieder reflektieren. Dadurch strahlen sie ein ïberraschend mildes, chlorophyllgriunes Licht, das natiurlich mit Phosphoreszenz nichts zu tun hat, zurïck; rgl. die Abb. und Chromulina. 
Eine farbige Abbildung von Leuchtmoos-Protonema in einer Felshöhle findet sich bei Kerner, Bd. I, S. 374. Zum Gedeihen der

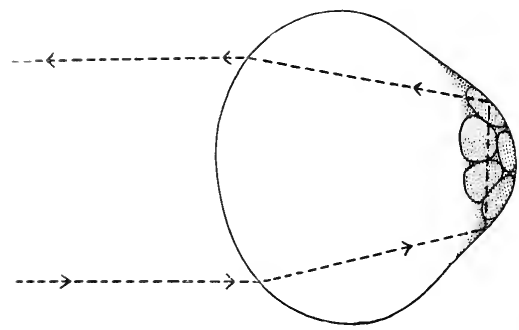

1hb. 98. Schistostega osmundacea. Gang eines Lichtstrahles durch eine Protonemazelle. Das austretende Licht erscheint durch das Passieren der Chlorophyllkömer grün. (Neuzeichnung nach F. Noll).

Vorkeime gehört aine richtige Abstimmung von Licht und Feuchtigkeit. Die Kultur des Protonemas auf Agarnährboden ist P. Janzen (1) bis jetzt nicht gelungen, doch haben Versuche im Botanischen Garten in München gezeigt, daß man es lange Zeit in Saatschalen im Gewächshaus ziehen kann, wenn man es mit Nutterboden aushebt.

10. Bryum argenteum. Silbermoos.

Name von bryon, hei Dioscorides Bezeichnung für Moos (auf Rinden).

Die niedrigen Rasen sind in trockenem Zustand silberweiß glänzend. Sie bestehen ans dicht anliegend beblätterten, kätzchenförmigen Sprossen. Die vegetative Vermehrung erfolgt reichlich durch Brutund Bruchknospen. Die hängenden Kapsehn haben ein kompliziertes Peristom, welches eine ganz allmähliche Ausstreumg der Sporen gewährleistet; man vergleiche dazu L. Loeske (2), S. 117.

Das Moos ist anf der ganzen Erde verbreitet: z. B. gemein auf festgetretenen Wegen, zwischen Pflastersteinen, auf Äckern usw. Es ist meist rrster Pionier in frischen feuchten Sandstichen, da es sehr genïgsam und zählebig ist, nach C. Narnstorf darin dem Polygonum aviculave vergleichbar. Auf Rieselfeldern verträgt es Beriesehung mit Abwasser. Es wächst oft in Gemeinsehaft mit Ccratodon purpurcus. Bryum capillare (Blätter mit aufgesetzter Stachelspitze) wär'hst ebenfalls häufig anf Gartenwegen.

Weitere Pioniere auf kahlen Sandflächen sind Bryum pondulum, Br. caespiticium und Ceratodon purpurcus. Die sporen und Brutorgane werden nach Ausstichen usw. auf weiten Strecken besonders durch Vögel, auf kiirzeren auch durch Wind verbreitet.

\section{Mnium punctatum.}

Name ron mnion, im Altertum Bezeichnung für Noos oder Alge.

I) Blätter sind rundlich und von ansehnlicher Größe, ihre Zellen groß und punktförmig erscheinend (daher punctatum. Planktoukammer!). I)ie Blätter oignen sich sehr gut und leicht zum Studium der Chlorophyllkörner. Man braucht nur oin Blatt unter Zugabe eines Wassertropfens unter das Mikroskop zu legen und kann damn die Chloroplasten 
ohne weiteres betrachten. Das Moos gedeiht an Waldbärhen, anf feuchtem Boden der Laubwälder usw. Vergl. die farbige Tafel in Kerner, Bd. Il bei s. 57.

Mn. cuspidatum ist synoecisch.

Mn. undulatum ist eines der stattliehsten und schönsten unserer heimischen Moose. Es hat eine gewisse Ahnlichkeit mit Catharinea undulata*), welche aber im regetativen Zustande durch die relativ stumpfe Blattspitze und durch das Fehlen der Assimilationslamellen auf den Blättern von ihm unterschieden werden kann.

Viele Hoose am Grunde sehattiger Laubwälder (Waldmoose) gedeihen am besten bei mäBiger Belichtumg.

Der Generationswechsel der Moose ist in einem Brendelschen Modell an Mnimm dargestellt.

\section{Buxbaumia aphylla.}

Nach Prof. J. C. Buxbaum in Petersburg $(\dagger 1730)$ benannt.

Dieses nur 1-2 cm hohe, aber mit ziemlich großer Kapsel ausgestattete Moos wächst xerophytisch. besonders an kahlen Wegabstithen in Kiefernwäldern. Die Blätter sind sehr vergänglich und daher selten zu finden; sie kömmen demnach zur Emährumg ter Pflanze, wie

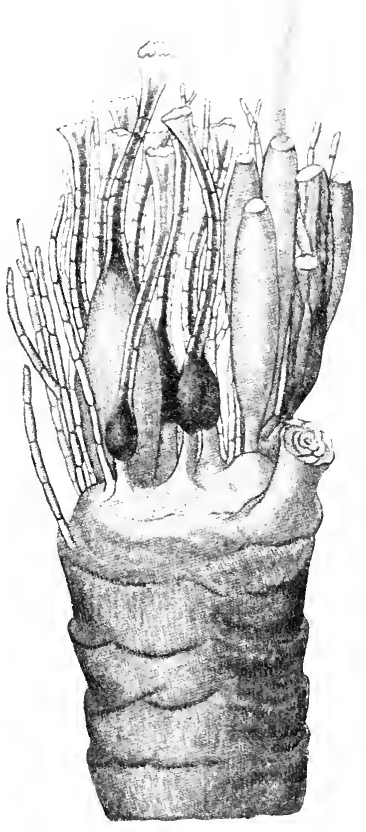

Abb. 99. Männliche und weibliche Geschlechtsorgane eines Lambmooses. Nach Hedwig, Gesammelte Abhandl., Leipzig. 1793. sonst bei Moosen, wenig beitragen. Vergl. dazu Haberlandt (2). Das Protonema kann auf Agarnährboden kultiviert werden.

13. Polytrichum commune ${ }^{* *}$ ) Widerton-Moos***).

Dieses stattliche, hoehorganisierte Moos (s. die Abb.) ist ein Hydrophyt (Polytrichum juniperimum dagegen ein Xerophyt); es vermag auf Moorboden und soustigen feuchten Stellen in schwellenden, dunkelgrïnen Rasen weite Strecken zn ïberziehen, auch an triefenden Felsen ausgedehnte Rasen zu bilden. Die Pflanze kann zur Torfbildung beitragen.

*) Benannt nach der Kaiserin Catharin a II von Rufland.

**) Wegen der langbehaarten Kalyptra als vielhaarig bezeichnet.

***) Bedeutet: Wider das Antun, Behexen. 
Beim Trocknen führen die Blätter mehr oder weniger ausgesprochene Verbiegungen und Drehungen aus, bei deren Zustandekommen Kohäsionsmechanismen im spiel zu sein scheinen.

Die Blätter zeigen auf der Oberfläche zahlreiche, längsverlanfende Lamellen, durch welehe die Assimilationsflächen vergrößert werden.

Die aufrechten Kapseln besitzen spaltöffnungen, welche sich in der Einschnurung zwischen Hals und L'rne befinden. Das Peristom ist einfach gestaltet, wie bei aufrechtstehenden Kapseln iiberhaupt (gleichsam Mohnkopftypus).

Die Pflanze besitzt eine Art inneren Leitgewebes fïr Wasser, scheint aber nach Oltmanns auch äuBerlich. wie viele andere Hoose, das Wrasser kapillar anfzusangen und für ihre Zellen zu verwerten.

Die sporemreife fällt auf Ende Mai und Juni, die Geschlechtsreife in den Hochsommer, doch findet man, wie bei vielen Moosen iiberhaupt, gut entwickelte Geschlechtsorgane sehon im Monat Mai.

$P$. juniperimum wächst xerophytisch auf Sandboden und an anderen Orten. Pogonatum (Polytrichmm) namum hat ein sehr üppig entwickeltes Protonema. clas ansgedehnte. smaragdgrime Rasen anf Erdabhängen bildet. Protonemen finden sich hänfig anch anf Blumentöpfen, namentlich in Gewächshäusern: man vergleiche Schistostega, Hypum cupressiforme und die Abb. ibber den Generationswechsel bei den Farnen.

- Fontinalis antipyretica. Quellmoos.

antipyreticus = gegen Fenersbrunst schützend, weil früher die Blockhäuser mit diesem Moos gefugt wurden.

Die Pflanze ist Taf. VII und im Abschnitt Ökologie abgebildet. Sie bildet meist kräftige, unter Wasser lebende Biischel von dunkelgrüner bis bräunlicher Farbe. Die Stämmchen können bis $50 \mathrm{em}$ und mehr lang werden, besonders in fließenden Gewässern. Das Moos wird hänfig in Aquarien gehalten.

Amblysteginm riparium wächst mehr in der Emersionszone, aueh in Brumnentrögen, an Wassermïhlen usw., auch wie Rhynchostegium. rusciforme gern auf hölzernen Miihlrädern.

\section{Brachythecium rutabulum.}

Name von brachys $=$ kurz und theke $=$ Büchse, wegen der melst dicken, kurzen Kapsel. rutabuhm = Ofenkrïcke, wegen der gekrümmten Äste.

Die breiteifürmigen. zugespitzten Blätter sind ziemlich locker gestellt, oft fast wagerecht abstehend. Das Moos wäehst in Gebiischen und Waldungen, häufig auch in wenig besomnten Gärten (z. B. in nach Norden gelegenen Hausgärtuhen), in denen es den Wuchs des Rasens unterdriickt.

Überhanpt gedeihen viele Laubmoose gut im Schatten, wodureh sie befähigt sind, an weniger beliehteten Stellen den Rasen, der meist lichtbedürftig ist, zu unterdriieken oder ihn mit Moos zu durehsetzen. 
Rhynchostegiella tenella, ein in West- und Süddeutschland hesonders an Kalk, Sandsteinmanern und trockenen Felsen verbreitetes Moos, findet sich nach Veröffentlichungen von Prof. Fr. ThomasOhrdruf in der var. cavernarum bei dem verhältnismäßig schwachen Schein einer elektrischen (ilühlampe in der Dechenhöhle bei Iserlohn in fruchtendem Zustand. Das elektrische Licht vermochte also das Sonnenlicht zu ersetzen.

Amblystegium juratzkanum, das im gleichen Rasen vorhanden war, fruchtete ebenfalls.

Bryum capillare gedeilht in der Hermannshöhle bei Rübeland im Harz (nach den Feststellungen von Prof. Lindau) ebenfalls im elektrischen Licht.

\section{- Hypnum cupressiforme. Astmoos.}

hypnos = Ioosname im Altertum.

Dieses nächst Ceratodon gemeinste Ioos bildet mit Vorliebe teppichartige, ausgedehnte Überzüge auf Baumstämmen, -stümpfen usw. Diese Überzüge haben im trockenen Zustand hellgrünes seidiges Aussehen.

Seine weite Verbreitung und die Fähigkeit, an trockenen Baumstämmen I. dgl. zu leben, verdankt das Moos als Xerophyt seiner Widerstandsfähigkeit gegen Austrocknen. Ähnliches gilt von den Moosen auf den Strohdächern der Banernhäuser, z. B. von Ceratodon purpureus.

Wie die Abbildung zeigt, kann man ans der Seta von $H$. cupressiforme*) das Protonema (stellen-

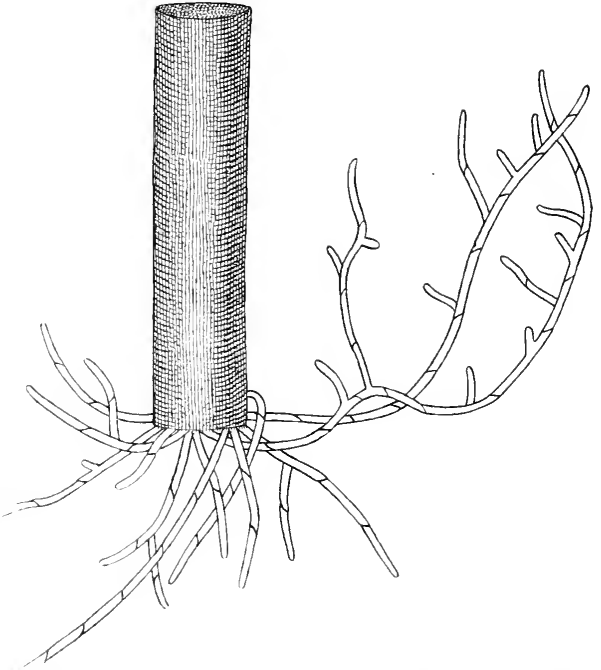

Abh. 100. Protonema von Hypnum cupressiforme, aus einem Stiick in fenchten Sand eingepflanzter brauner Seta hervorwachsend. In diesem Falle entsteht das Protonema ans der Sporengeneration unter Überspringen der Sporen. Vergr. ca. 30 fach. (Nach N. Pring sheim). weise schiefe Querwände) durch geeignete Kultur hervorbringen, also die beblätterte Moospflanze (Geschlechtsgeneration) unter Umgehung

*) Wegen der neneren Nomenklatur vergleiche man C. Warnstorf (1). 
der Sporen unmittelbar ans lem Gewebe der Sporogongeneration erzeugen: vgl. auch das Kapitel Farne und Marchal (1).

\section{- Hypnum schreberi.}

(Mit rotem Stengel).

Lebt xerophytisch and bildet. besonders in Kiefernwäldern. sehr ausgedehnte Bestände.

\section{Hypnum purum.}

(Mit gr ï nem Stengel).

Wächst ähnlich, ist aber ein weniger ausgesprochener Xeroplỵt. H.cuspidatum ist vorwiegend Hygroplyt. Hypmum molluscum ist ein für Kalkgebiete charakteristisches Waldmoos.

Kalkmoose, welche in ähnlicher Weise wie die Armleuchtergewächse Kalk in ihren Membranen ablagern. gibt es nicht, wohl aber können sich aus hartem Wasser Kalkinkrustationen anf Moosen niederschlagen.

\section{- Hylocomium squarrosum.}

Name von hyle $=$ Wald und kome $=$ Haar, Lanb.

Das Moos lebt in fenchten Gebüschen und Wäldern. oft in ausgedehuten Beständen. Die Pflanze ist als Kranzmoos bekannt.

- Hylocomium splendens. Etagenmoos.

Die Pflanze bildet neben Hypmum purum und $H$. schreberi häufig Massenbestände in trockenen Laub- und Nadelwäldern. Dadurch. daß es jährlich einen neuen aufstrebenden Ast bildet, entgeht es leicht der Eindeckung durch abfallendes Laub.

\section{Literatur und Sammlungen.}

E. Bauer (1), Europäisches Laubmoosherbar.

Joh. Hedwig (1), Prachtwerk mit farbigen Tafeln.

V. Schiffner (1), Europäisches Lebermoosherbar.

(Vol. auch Engler-Prantl).

W. Ph. Schimper (1), Prachtwerk mit schwarzen Tafeln.

Trocken gewordene Moose kann man meist mit bestem Erfolg wieder zu ihrer natürlichen Form anfweichen: Jungermanniaceen z. B. durchgehends, wenn auch manchmal erst nach längerer Zeit. Riccien lassen sich mit Wasser nicht aufweichen, Marchantien nur schlecht.

Brotherus u. a. (1).

Correns (1).

Goebel (1 und 2), hetr. Moose und Farne.

Haberlandt (2).

Limpricht (1).

Loeske (1), Anordnung nach standorten.

Lorch (1).

Migula (!).

Warnstorf (1).

IV ïnsche (1). Anordnumg nach Standorten. 


\section{Gruppe. Pteridophyta, Farne.}

\section{Die Sporengeneration der Farne.}

Die Einteilung der Farne geschieht nach der sporengeneration in folgende vier hier in Betracht kommende Klassen:

a) Filicales:

Hymenophyllaceae,

Cyatheaceae,

Polypodiaceae,

Osmmindaceae,

Marsiliaceae,

Ophioglossaceac,

Pecopterides (II. a. m.), fossil.

b) Sphenophyllales:

Salviniaceae,

Sphenophyllaceae, fossil.

Beistehend ist eine Sumpflandschaft fossiler Farne abgebildet, welche ein Bild von mächtig entwickelten Sporengenerationen vergangener Zeiten

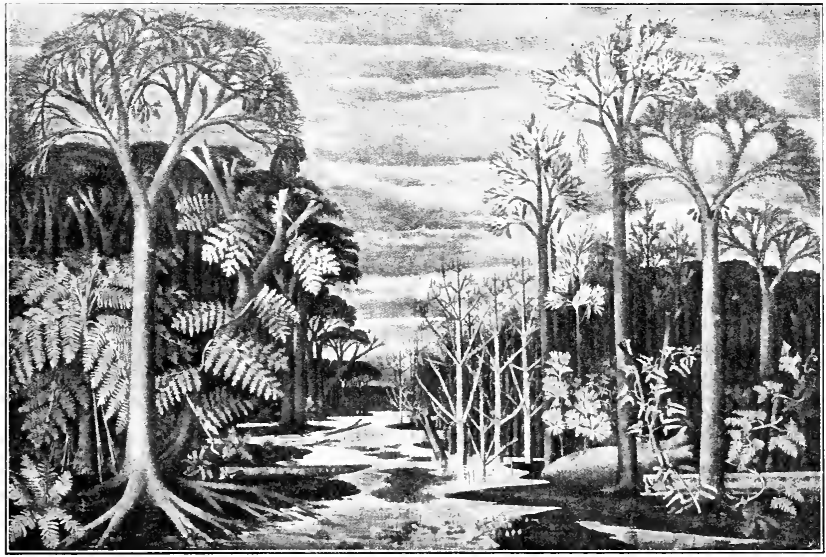

Abb. 101. Waldmoor der Steinkohlenzeit. Links: Vorn ein Lepidodendron, ein Farnbaum (Pecopteris) und eine kletternde Sphenopteris. Am Bodeu liegend ein Megapyton-Stamm. Mitte: Im Wasser Sphenophyllum cuneifolnum. Rechts: Vorn Sigillaria-Baum und kletternde Farne, dahinter große und kleine Cordaites (bandförmigblätterig und fächer-hlätterig). Zum Teil im Wasser Calamites ramosus.

[Nach Potonié (2), Wandtafel betr. eine Landschaft der Steinkohlenzeit].

gibt und an die physiologischen und chemischen Prozesse erinnern soll, welche durch Zersetzung von Pflanzensubstanz, Bildung von Faulschlamm 
usw. zur Entstelumg von steinkohle Anlaß gegeben haben*); vgl. Potonié(1).

Im Laufe der Entwicklung unserer Erde sind die Riesenfarne der Vorzeit, offenbar infolge Anderung der klimatischen Verhältnisse. mehr und mehr zurückgegangen. Besonders die Bärlappgewächse, auch die Schachtolhalme, stellen gegenwärtig nur noch kleine Formen einst bedentungsvoller Geschlechter dar. Nach H. Bruchmann scheinen bei den Lycopodiales in dem lockeren, humosen Boden in der Vorzeit, der durch verrottende Stämme bei der Üppigkeit der Vegetation immer von neurm anfgefuillt wurde, die Bedingungen für die Entwicklung der unterirdisch lebenden Geschlechtsgeneration ganz besonders giustig gewesen zu sein.

Gegenwärtig haben wir in den tropischen Baumfarnen (z. B. Cvathea und Alsophila) noch einigermaßen hochstämmige Formen. Von den in Europa wachsenden Gattungen vermag nur noch der Königsfarn (Osmunda regalis) dicke kurze Stämme zu bilden (im Kaukasus).

Die Wedel der Farne tragen die Sporangien mit den darin enthaltenen sporen an lokal begrenzten Stellen anf ihrer Unterseite oder am Rande, z. B. Aspidium filix mas, Scolopendrium vulgare. Pteris aquilina und Polypodium vulgare. Bei anderen dagegen fuihrt die Bildung der sporangien zum Verschwinden der griinen Blattspreite und damit zu wesentlichen Veränderungen in der Ernährung dieser Wedelteile.

Beispicle hierfür sind in der folgenden Zusammenstellung genannt:

\section{Umbildung sporangientragender Wedelteile.}

\begin{tabular}{|c|c|c|}
\hline Beispiele & Sterile, grüne Wedel & Fruchtbare Wedel \\
\hline Struthiopteris germanica & doppelt fiederspaltig & $\begin{array}{l}\text { ähnlich, aber zu einer Art brammer } \\
\text { StrauBenfeder mmgebildet }\end{array}$ \\
\hline Blechnum spicant & fiederteilig & $\begin{array}{l}\text { ähnlich, aber die Flächenteile fast } \\
\text { bis anf die Hauptnerven reduziert }\end{array}$ \\
\hline Osmunda regalis & doppelt gefiedert & $\begin{array}{c}\text { ählich, aber zu einer Art bramner } \\
\text { Rispe umgebildet }\end{array}$ \\
\hline Narsitia quadrifolia & mit vier Blättchen & $\begin{array}{l}\text { außerdem mit hohnenförmiger } \\
\text { „Sporenfrucht"***) }\end{array}$ \\
\hline Ophioglossum v'ulgatum & zungenförmig & außerdem mit ährenförmigem Teil \\
\hline Botrychizm lunaria & meist einfach gefiedert & $\begin{array}{l}\text { auBerdem mit meist doppeit ge- } \\
\text { fiedertem, spreitenlosen, sporen- } \\
\text { tragenden Teil }\end{array}$ \\
\hline Equisetum arzense & scheidenförmig & schildförmig \\
\hline Lycopodium clavatum & schmales Bläittchen & $\begin{array}{c}\text { breites, gelbliches Blättehen mit } \\
\text { einem Sporanginm ***) }\end{array}$ \\
\hline $\begin{array}{l}\text { *) Es sei daran er } \\
\text { und Sumpfyflanzen anch } \\
* * \text { ) Offnet man ein } \\
\text { Einlegen in Wasser ein } \\
* * *) \text { Die Sporen von }\end{array}$ & $\begin{array}{l}\text { nert, daß nach nenere } \\
\text { der Bildung von Pet } \\
\text { solche (ev, viele. Jahre }\end{array}$ & $\begin{array}{l}\text { Anschanmigen Reste von Wasser- } \\
\text { lenm heteiligt sind. } \\
\text { te) "Sporenfrucht", so quillt beim }\end{array}$ \\
\hline
\end{tabular}


Zum näheren Studium der zu sori rereinigten siporangien eignen sich Aspidium filix mas (s. die Abb.), Polypodium vulgare, Scolopendrium officinale u. a. m. Man halte sieh Herbarmaterial in geniugender Menge vorrätig. Um zunächst ein Z̈bersichtsbihd ïber die sporangienhäufeben zu gewimnen, verfahre man folgendermaben:

Man lege Teile des Blattes von Polypodium vulgare bei den die sporangien nicht durch ein Indusium bedeckt sind), trocken auf den (b)jektträger und betrachte sie bei schwacher (40-100facher) Vergröberung im

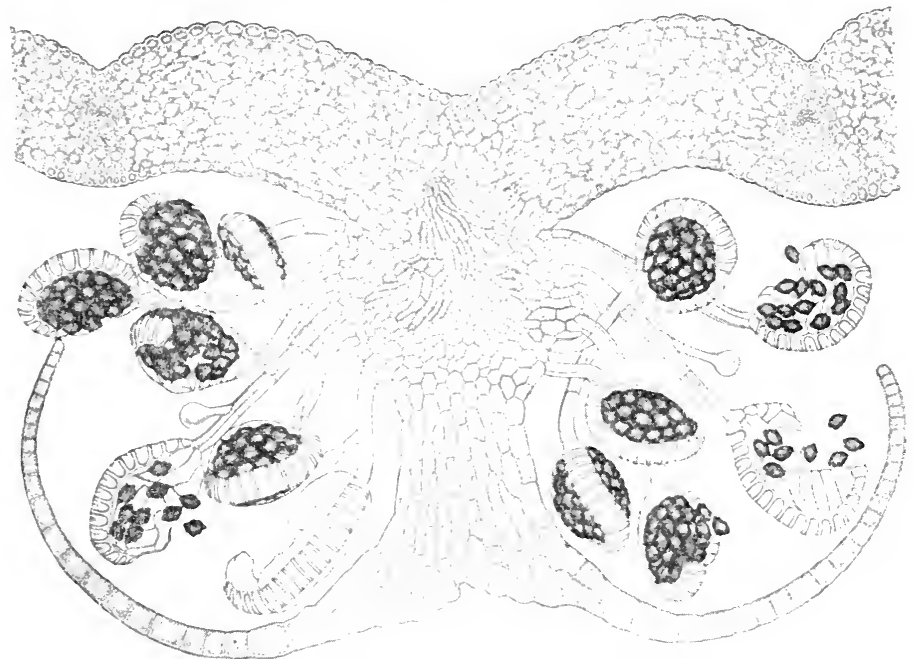

Abb. 102. Aspidizm filix mas. Querschnitt dureh einen Sorus, die Sporangien mnter den Indusinm zeigend. Nittelstark vergrößert. (Nach L. K n y).

auffallenden Licht, bei Beleuchtung mit einer hell teuchtenden elektrischen Taschenlampe. Man wird ansgezeichnet in situ die brannen sporangien, den brammoten, wie eine Raupe erscheinenden Annulus nud die umberliegenden gelblichen Sporen sehen, besonders wenn das Material nicht iiberreif war*).

Die sporangien zeigen rinen sehr bemerkenswerten Mechanismus zum Fortschleudern der Sporen, welcher nachstehend besprochen werden soll.

*) Stiicke solcher sporangientragenden Wedel können sehr gut zur Anfertigung von Trockenpräparaten anf schwarzem Ol,jektträger dienen. Nan kittet auf einen solchen Objektträger von undurchsichtigem schwarzen Glase einen zylindrischen Messingring von ca. $1.5 \mathrm{~mm}$ Höhe, 1,0 mm Wandstärke und $15 \mathrm{~mm}$ lichtem Durchmesser mit schwarzem Lack anf, der das Metall vollkommen eindeckt, so daß man eine ganz schwarze Kammer für das Präparat erhält. In diese wird ein Blattstïck mit Sporangien eingelegt und durch ein rundes Deckgläschen verschlossen, welches man ebenfalls unter Verwendung von schwarzem Lack mittels Ringmaschine (am hesten aus Metall, nicht aus Holz) festklebt. 


\section{Der Öffnungs- und Schleudermechanismus der Farnsporangien.}

Die reifen Sporangien von Aspidium filix mas, Polypodium vulgare, Scolopendrium officinale u. a. m. zeigen eine eigentümliche Einrichtung zum Fortschleudern der Sporen.

Um diese zu demonstrieren, verfährt man in folgender Weise:

Man schabt das Sporangienmaterial*) vom Wedel ab und weicht es auf einem Objektträger ein, ohne ein Deckgläschen aufzulegen. Es wird zunächst bei sthwacher (20 maliger oder noch schwächerer) mikroskopischer Vergrößerung betrachtet, weil man dann ein großes Gesichtsfeld hat. Infolge der Befeuchtung sind die Sporangien geschlossen; sobald das Wasser aber verdunstet, streckt sich der Annulus zusehends, krümmt sich, wie die Abbildung zeigt, zurïck und springt dann plötzlich in seine ursprüngliche Lage. Dabei werden Sporangien und Sporen fortgesehleudert (bei im Sorus festsitzenden Sporangien werden diese naturgemäß nur erschïttert, die Sporen aber auch hier umhergeschleudert). Das Springen auf dem Objektträger ist so lebhaft, daß manche Sporangien aus dem Gesichtsfeld rerschwinden, andere, die vorher nicht siehtbar waren, hineinspringen. Die sporen fliegen allenthalben umher.

Das Springen kann erst beginnen, wenn auf dem Objektträger kein blankes Wasser mehr zu sehen ist. Man saugt deshalb mittels Fließpapier das Wasser zweckmäßig von vornherein so weit ab, daß das Präparat stumpf erscheint. Wenn das Wasser in den Zwischenräumen der Sporangienmasse ruckweise verdunstet. ist der Moment des Springens ziemlich nahe. Man kann den Prozeß dadurch beschleunigen, daß man während des Beobachtens ein glimmendes Streichholz unter den Objektträger hält oder vorher iiber der Lampe, der Glasflamme oder einem brennenden Streichholz gelinde erwärmt.

Durch das Erwärmen pflegt das Springen auch verstärkt zu werden. Bei manchen Exemplaren streckt sich der Anmulus nur und schnellt nicht zuriitek.

Während man das springen beobachtet, hält man zweckmäßig den feuchten Atem durch die Hand oder einen Hauchschirm ab.

Der Versuch kann an demsetben Material durch erneutes Befenchten wiederhelt werden.

Der Mechanismus, welcher der vorliegenden Erscheinung zugrunde liegt, ist besonders durch Schrodt und Steinbrinck studiert worden. Das Wasser verdunstet durch die diinnen Membranstellen des Amnulus. Dadurch verringert sich das Volumen der Zellen. wobei dureh Adhäsion des Wassers an der Wand und dureh seine Kohäsion der Ring sich zurieckkrïmmt. Ist ein Maximum der Spannung iiberschritten, so reißt das Wasser auseinander und es entstehen luftverdünnte Räume, welche unter dem Mikro-

*) Die Sporangien eignen sich zu Dauerpräparaten in Glyzeringelatine. Modelle finden sich in der Brendelschen Sammlung. 
skop wie Luftblasen erscheinen (s. die Abb.). Das Auftreten soleher Räume erklärt sich dadurch, daß das Wasser dureh Verdunsten herans, die Luft durch die Wände der Annuluszellen aber nicht hinein kann. Sobald das
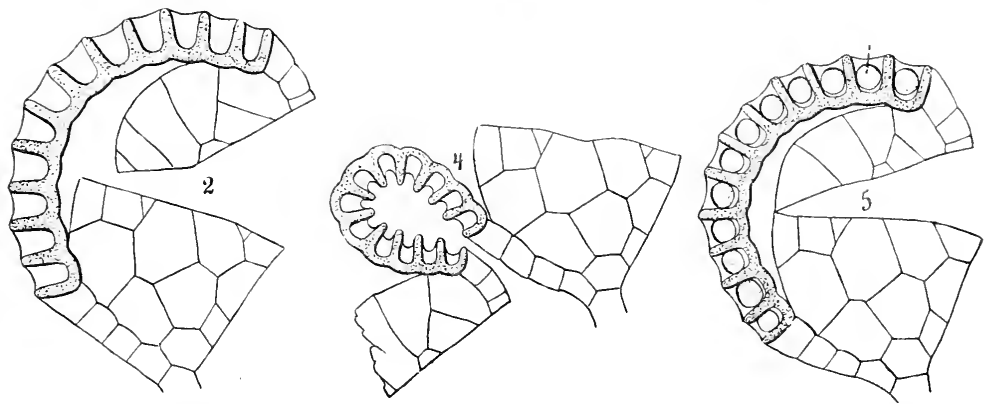

Abb. 103. Aspidiun: filix mas. Vergrößerte Sporangien. 2. Bei Beginn des Öffnens.

4. Vollständig geöffnet. 5. Nach dem Springen. (Nach Leclerc du Sablon).

Wasser reißt, schlägt der Ring zurück und bewirkt durch die plötzlich eingetretene Erschiitterung das Umherschlendern der Speren.

Ungestielte Sporangien, z. B. diejenigen von Botrychium, besitzen keinen Schleuder- wohl aber einen öffnungs- und Schließmechanismus. Bei feuchtem Wetter sind die Sporangien geschlossen; Abb. s. bei Kerner, Bd. II, S. 568 .

\section{Zusatz.}

Gleichfalls zu den Kohäsionsmechanismen rechnen die zum öffnen der Antheren vieler Bliiten dienenden Struktureigentiimlichkeiten in den Zellen der Faserschicht der Stanbblätter (vgl. Abb. 10).

Umrein hy groskopische Mechanismen, bei denen die ungleiche Quellbarkeit von Iembranenschichten infolge ungleicher Nicellarstruktur (nicht das Lumen der Zellen) eine Rolle spielt. handelt es sich bei den folgenden $\mathrm{Ob}$ jekten:
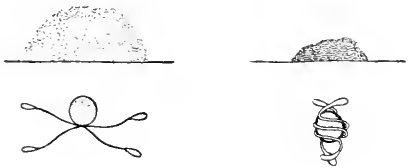

Abb. 104. Equisetum ariense. Sporenhaufen trocken (links) und feucht (Nat. Gr.). Einzelne Sporen trocken und feucht (schwach vergr.). Vergl. auch Kerner, Bd. II, S. 569. (Original).

Equisetum, Elateren der Sporen; s. die Abb.

Moose, Peristomzähne der Kapseln: vgl. S. 212 und 216.

Melandryum, Agrostemma, Kapseln, wenn sie gut reif sind. Die Zähne schließen die Kapseln in warmem Wasser sogleich, in kaltem nach ${ }_{4}{ }_{4}-1 / 2$ Stunde; $\mathrm{vgl}$. Abb. 9. Die an der AnBenseite liegenden dynamischen Zellen nehmen beim Befeuchten in der Längsrichtung der Kapsel mehr Wasser anf als die an der Innenseite befindlichen. Demrentsprechend sind die Poren der nach außen liegenden Zellen zur Kapselachse quergestellt. 
Erodium, Grannen der Früchte; vgl. P. Claussen (1), S. 20.

Näheres lese man bei G. Haberlandt (1) nach.

Bei der Bewegung der Blätter und Blättchen von Mimosa pudica handelt es sich, wie bereits im I. Teil gesagt ist, um einen Reizmecha$n$ is $\mathrm{mus}$.

\section{Die Prothalliengeneration der Farne.}

Die Prothallien der Farne bilden als Träger der Antheridien ( $\left.\delta^{\circ}\right)$ und Archegonien (o) die Geschlechtsgeneration.

Die Prothallien entwickeln sich:

a) oberirdisch bei Aspidium, Polypodium, Equisetum u. a. m. und haben dann Chlorophyll;

b) unterirdiseh bei Lycopodium. Ophioglossum und Botrychium und sind danm chlorophyllfrei;

c) in der Spore, wenigstens zum größeren Teil, z. B. bei Salvinia, Selaginella und Isoctes.

Näheres zeigen die Abbildungen.

Die Prothallien von Aspidium filix mas und verwandten Vertretern findet man im Freien am leichtesten an feuchten Felswänden farnreicher Täler, am Boden von Wäldern, auf Erlenstümpfen nsw., meist in Form kleiner, herzförmiger Blättchen von etwa Linsengröße. In Gewächshäusern erscheinen sie häufig auf der Oberfläche von Blumentöpfen in Farnhänsern.
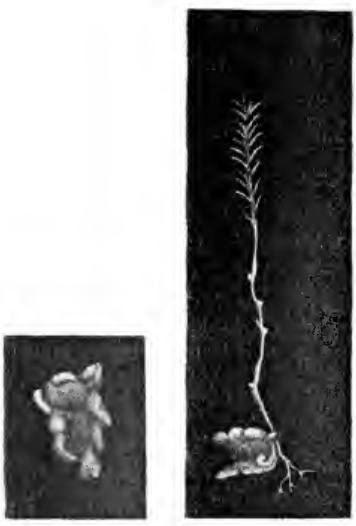

Abb. 105.
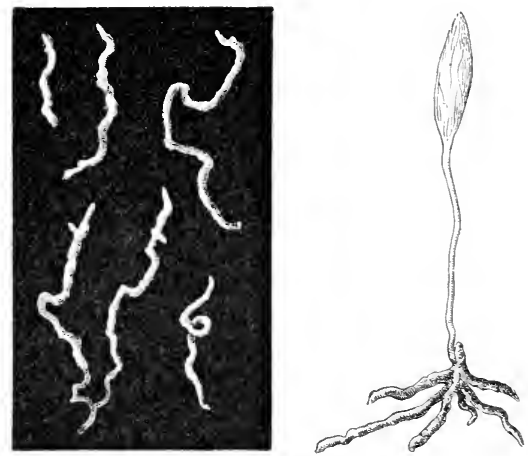

Abl). 106.

Ab). 105. Lycopodium clavatzm. Prothallien und junges Pflänzchen in nat. Größe. (Original.)

Ahb. 106. Ophioglossum vulgatum. Links: Größere Prothallien in nat. Größe, einfach. verzweigt und z. T. von der Basis her absterbend. Rechts: Keimpflanze mit entfaltetem, grünem Blatt in nat. Größe. (Neuzeichnungen nach H. Bruchmann). 
Die Prothallien des bärlapps (Lycopodimm finden sich nach H. Bruchmann (1) etwa in $1 / 2-10 \mathrm{~cm}$ Tiefe im Waldboden, bisweilen so häufig, daß in 11 Erde etwa 10 Exemplare zu finden sind, am besten an solchen Stellen, wo die Sporen durch Erdarbeiten im Walde eingerleckt sind. Die Ausbildung der Prothallien von L. clavatum erfordert im Freien schätzungsweise 7-12 Jahre. Sie sind, wie die Abbildung zeigt, unregelnüßig wulstig gestaltet und von gelhlich-weifer Farbe. Die Geschlechtsorgane sind mehr oder weniger tief in die Peripherie des rewebes eingesenkt.

Die Prothallien der Natternzunge (Ophioglossum vulgatum) fand H. Bruchmann (2) etwa 2-10 cm tief unter der Erdoberfläche, unter 1 qm Boden durchschnittich acht Exemplare. Sie stellen in der Regel wurmförmige Gebilde von bräunlicher Farbe dar, welche mehr oder weniger
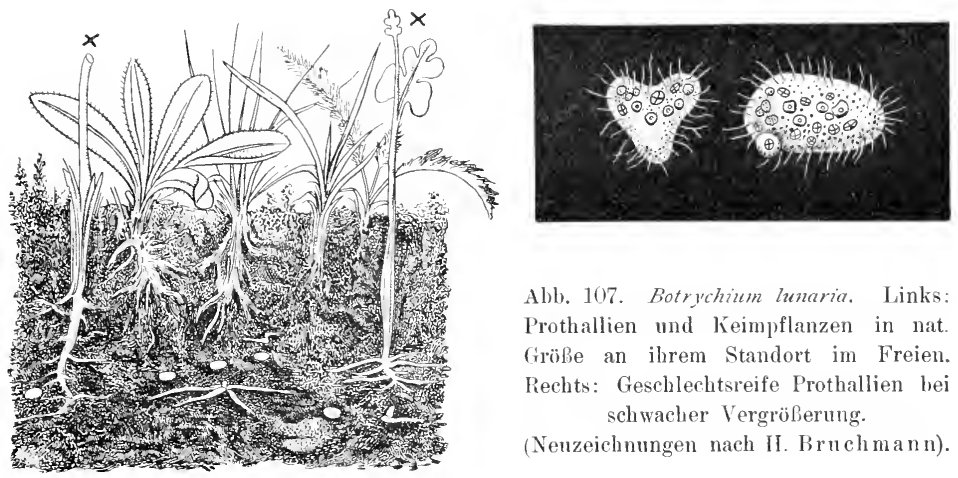

Abb. 107. Botrychium lunaria. Links: Prothallien und Keimpflanzen in nat. Größe an ihrem Standort im Freien. Rechts: Geschlechtsreife Prothallien bei schwacher Vergrößerung.

(Neuzeichnungen nach II. Bruchmann).

vertikal gerichtet sind. Die Dicke beträgt ca. $1 \mathrm{~mm}$, die Länge höchstens $6 \mathrm{~cm}$. Die Prothallien sind monöcisch, ihre Antheridien und Archegonien in großer Zahl in clas Gewebe eingesenkt. Ihr Alter beträgt schätzungsweise 3-20 Jahre; Symbiose mit Wurzelpilzen ist wahrscheinlich.

Botrychium lunaria (s. die Abh.) erzeugt Prothallien, welche $1-3 \mathrm{~cm}$ tief zwischen Wurzelgeflecht unter der Erdoberfläche wachsen. Sie finden sich bisweilen gleichsam nesterweise in Form kleiner eiförmiger, mitunter auch herzförniger Körper von etwa $1-2 \mathrm{~mm}$ Länge und 1/2 - $1 \mathrm{~mm}$ Breite, von weiblicher oder schwach hellbrauner Farbe, und sind allseitig mit Rhizoiden besetzt. Die Prothallien sind monöcisch und tragen die Geschlechtsorgane auf der der Erdoberfläche zugekehrten Seite.

Die Mikrosporen von Salvinia natans*) sind eigentlich nur die Behälter für die Spermatozoiden, während die Makrosporen dicht mit Proteinkörnern, Öl umı Stärke erfüllt sind; sie enthalten gleichsam die

*) Salvinia natans ist eine einjährige, wurzellose Wasserpflanze. Die diöcischen Sori sitzen an den wurzelälınlichen Wasserblättern. Fundort: z. B. Potsdam-Kietz. Kolkwitz, Pflanzenphysiologie. 
Dottermasse für den heranwachsenden Embryo. Die Befruchtung und nachfolgende Keimung kann schon im Februar beginnen, wenn die Pflanzen
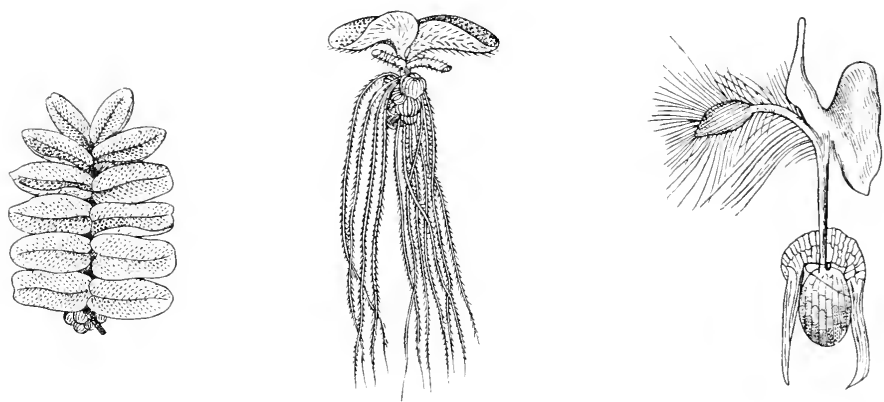

Ahb. 108. Salvinia natans. Pflanze von olen betrachtet und in der Seitenansicht (mit Sporangienbehältern). Nat. Gr. Rechts: Makrospore mil Prothallium und Keimpflanze, schwach vergrößert. (Links: Original, Mitte: nach Sachs, rechts: nach Pringsheim).

den Winter über im geheizten Zimmer gehalten werden. Die Keimpflanze schwimut auf dem Wasser; man vergleiche hierzu die Abbildungen.

Als Studienobjekt für physiologische Beobachtungen wählen wir die Prothallien von Aspidium filix mas (s. die Abb.).

Um gntes Sporenmaterial zur Anzucht von Prothallien zu erhalten, sammelt man gut entwickelte Farnwerlel im Freien (möglichst nıcht aus Gärten, weil man auf diese Weise am sichersten gut keimfähige Sporen erhält. Man legt die Wedel auf weibes Papier und läßt die Sporen bis zum nächsten Tag von selbst ausfallen. Das eingesanmelte Sporenmaterial wird dann in mit Datum versehenen Papierhülsen aufbewahrt oder sogleich ausgesät. Ein Nachreifen der Sporen findet nicht statt; sie sind ohne weiteres keimfähig. Die K'eimkraft der Sporen bleibt etwas über 1 Jahr erhalten.

Die Sporen werden zur Anzucht der Prothallien auf zerkleinertem. am besten durch ein Sieb von etwa 5 mm Maschenweite gesiebten Torfmul**) in Saatschalen von etwa $20 \mathrm{~cm}$ Durchmesser und ca. $8 \mathrm{~cm}$ Höhe ausgesät und durch Eingieben von Wasser in den Untersatz ständig feucht gehalten. Die Schale bleiht von Anfang bis zu Ende mit einer (ilasscheibe bedeckt. Resteht die Gefahr einer Infektion mit Vaucheria, wird das Substrat vorher durch Übergießen mit heißem Wasser sterilisiert.

*) Torfmult kann aus Samenhandlungen hezogen werden. 
Die Entwicklungsdauer bis zur Entstehung geschlechtsreifer Prothallien kann sich je nach der Zeit der Aussaat erstrecken vom August bis Oktober, Oktober bis Januar, Jannar bis März usw.

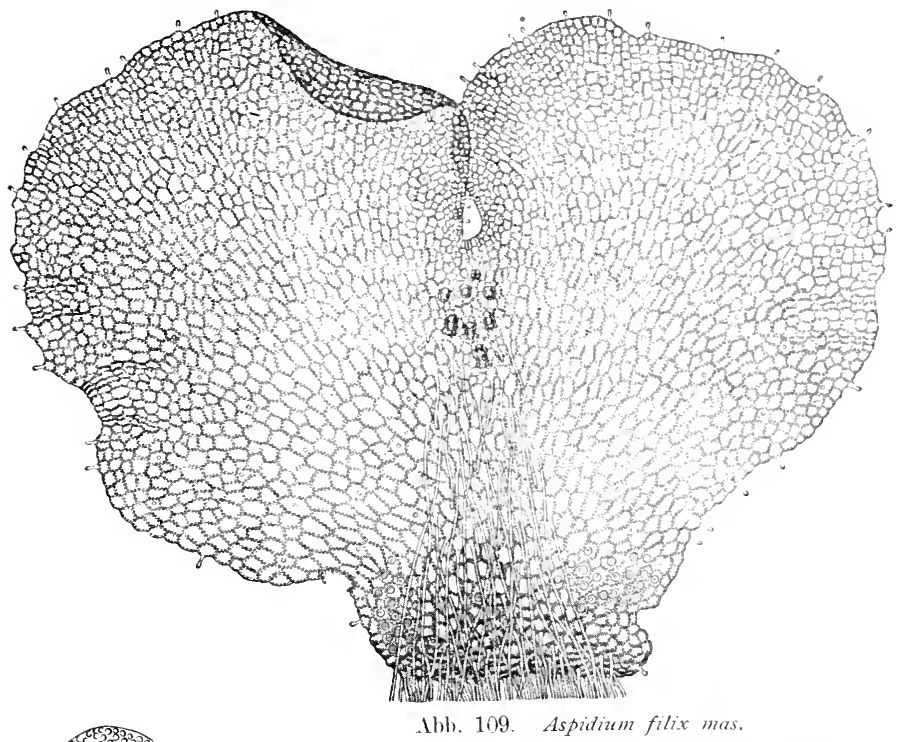

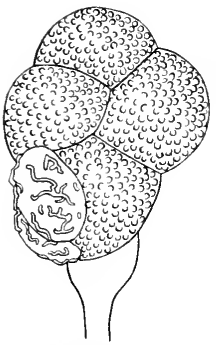

Abl. 109 .
Erstes Keimprodukt der Spore und entwickeltes, geschlechtsreif es Prothalli um bei mittelstarker Vergrößerung. (Nach L. K n y).

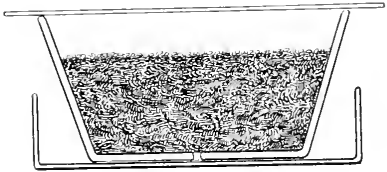

Abb. 110. Schale zur Kultur von Prothallien. Der Untersatz wird mit etwas Wasser gefïllt, die Saatschale mit einer Glasscheibe bedeckt; ca. $1 / 6$ nat. Größe. (Original).

Man kamn die Prothallien auch in Wasserkulturen ziehen und zwar in folgender Nährlösung (nach H. Fischer):

Wasser. . . . . . . $1-101$
Monokaliumphosphat . . . $1 \mathrm{~g}$
Ammonimmutrat . . . . . $1 \mathrm{~g}$
Chlorcalcium . . . . . . . $0,1 \mathrm{~g}$




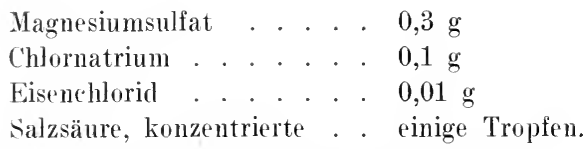

Die Gefäße und Lösungen werden zweckmäßig sterilisiert.

Haben die grïnen Prothallien eine gewisse Reife erlangt, so pflegen sie reichlich Antheridien (ઠ) und Archegonien (ㅇ) zu erzeugen, die bei Aspidium filix mas nicht immer auf demselben Prothallium vorhanden zu sein branchen. [Bei Equisetum*) ist die Zweihäusigkeit der Prothallien die Regel]. Die Ausbildung der Prothallien und ihrer Geschlechtsorgane ist abhängig von der Dichtigkeit der Sporenaussaat, von eventuellem Pikieren, von der Belichtung usw.; man vergleiche dazu O. Schlumberger (1).

Kurz vor der Untersuchung halte man die Kulturen nicht zu naß, weil sonst die Spermatozoiden aus den Antheridien vorzeitig ausschlüpfen können.

Zur Untersuchung nehme man ein Prothallium mit der Pinzette heraus und entferne (z. B. mittels einer Nadel) die zwischen den Rhizoiden haftenden Torfpartikelchen. Für die mikroskopische Beobachtung wird das Prothallium mit der Lnterseite nach oben unter Zusatz von Wasser auf den Objektträger gebracht. Jan sucht num bei mitt-
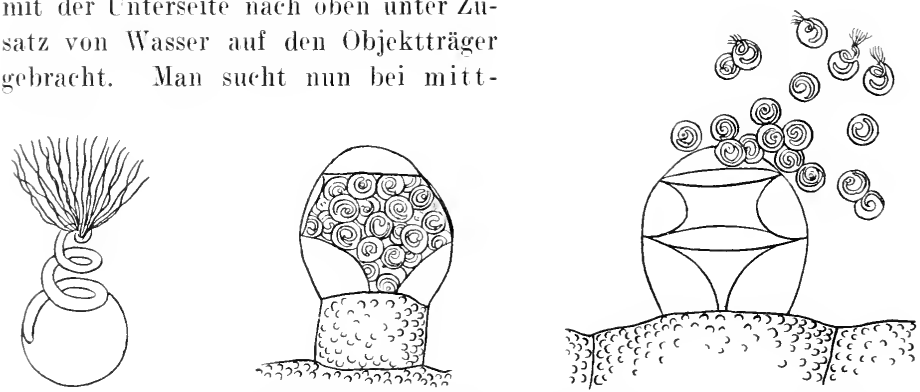

Abb. 111. Aspidium filix mas. Reifes Antheridium (ठ), geöffnetes Antheridium und freies Spermatozoid bei starker Vergrößerung. (Neuzeichnung nach L. Kny).

le rer Vergrößerung nach Geschlechtsorganen und führt dann die genauere Beobachtung bei stärkerer mikroskopischer Vergrößerung aus. Bisweilen muß man eine geringere Zahl von Prothallien durchmustern, bis man ein mit besonders gut entwickelten Antheridien und Archegonien ausgestattetes Exemplar findet.

Solehe Prothallien, welche durch Grünalgen, Kieselalgen (z. B. Navicula mesolepta) und Nematoden stark verunreinigt sind, verwerfe man nach Möglichkeit.

Die Geschlechtsorgane sind manchmal so häufig, daß fast eines das andere beriihrt: das ganze Gesichtsfeld kann bisweilen voll von Antheridien

*) Die I'rothallien von Equisetum entwickeln sich unter den üblichen Kulturbedingungen auf feuchtem, sterilisiertem Lehm, bieten aber physiologisch wenig Neues. 
oder Archegonien sein. Im Durchschnitt pflegen sich einige Dutzend $\delta$ und + Organe pro Prothallium zu finden; die männlichen Organe überwiegen aber in der Mehrzahl der Fälle die weiblichen.

Die männlichen Organe sind von kugeliger Gestalt. Kurz vor der Reife sieht man deutlich die Spermatozoidmutterzellen in ihnen; es liegen dann Kugeln in einer Kugel. Am deutlichsten erkennt man den Bau des Antheridiums, wemn dieses am Rand des Prothallinms steht und darüber hinausragt. Die schmalen, keulenförmigen Gebilde am Rande der Prothallien sind Harzdriisen, welche mit der Fortpflanzung nichts zu tun haben. Die erwachsenen Antheridien sind farblos. Nach 5-10 Minuten währender Berührung mit dem Präparatwasser pflegen die Spermatozoiden in Kugelform am Gegenende der Anhaftungsstelle des Antheridiums herauszutreten mnd dann sehr bald in Schrauben-(Sprungfeder-)form umherzuschwimmen. Diese Form erkennt man natırgemäß am besten damn, wenn die Spermatozoiden quer zur Beobachtungsrichtung schwimmen. Ein gelinder Druck auf das Deckgläschen kann bisweilen das Platzen der Antheridien etwas beschlemnigen. Sind zahlreiche Spermatozoiden ausgetreten, so erscheinen sie im Präparatwasser wie Miickenschwärme. Sehr schön lassen sieh die männlichen Befruchtungskörper beobachten, wenn sie vereinzelt im Antheridium zuriickgeblieben sind.

Alte Antheridien sind meist braun und erscheinen wie runde Boviste mit Scheitelöffnung.

Die weiblichen Organe haben eine gedrungene wulstige Form (nicht flaschenförmige wie bei Laubmoosen) und sind meist sehwach gekriimmt. Sie pflegen den mittleren mehrschichtigen Teil des Prothalliums, gleichsam die Rippe, einzunehmen. Im erwachsenen Zustande sind die Arehegonien ebenso wie die Antheridien farblos; der Hals besteht, wie die mikroskopische Betrachtung lehrt, aus vier Längsreihen von Zellen, in denen die Kerne oft sehr deutlich und klar erseheinen können. Blickt man direkt von oben auf ein Archegonium, so erkennt man diecharakteristischeKreuzteilung, welche zur Entstehung der Halszellen führt.
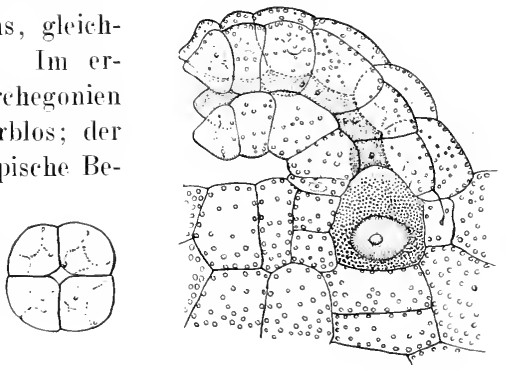

Abb. 112. Aspidium filix mas. Reifes geöffnetes Archegonium ( $Q$ ) in der Seitenansicht und Halzellen im optischen Querschnitt. Stark vergrößert. (Neuzeichnung nach L. Kny).

Im gleichen Gesichtsfeld sieht man bisweilen geschlossene und offene Archegonien nebeneinander, an letztgenannten die Mïndungszellen bisweilen gerade im Stadium des Klaffens. Im Halskanal beobachtet man häufig einen meist körnigen schleimpfropf. Das Ei im Bauchteil ist ohne Präparation nicht deutlich zu erkemmen. 
Abgestorbene (nicht befruchtete) Archegonien erscheinen innen braun.

Ist ein Ei durch Eindringen eines Spermatozoids in das Archegonium infolge der Anlockung durch Äpfelsäure (nach W. Pfeffer) befruchtet worden, so wäehst sehr bald eine junge Farnpflanze (die sporentragende Generation) heran.

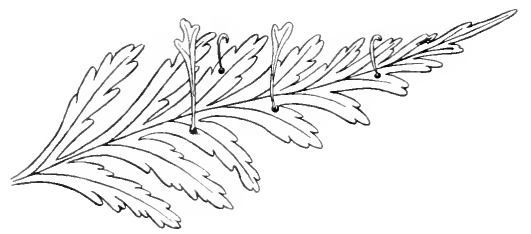

Albb. 113.

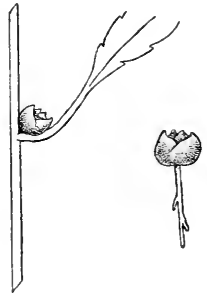

Abb. 114.

Abb. 113. Asplenium bulbiferum. Bei diesem paläotropischen Farn entwickeln sich auf den Wedeln Knospen, aus denen kleine Avdentiv-Pflänzchen hervorgebrochen sind. (Original nach Gewächshausmaterial).

Abb. 114. Dentaria bulbifera. Brutzwiebeln gesammelt im Mai. Rechts: Nach Einflanzen gekeimte Brutzwiebel mit Wïrzelchen. (Original).

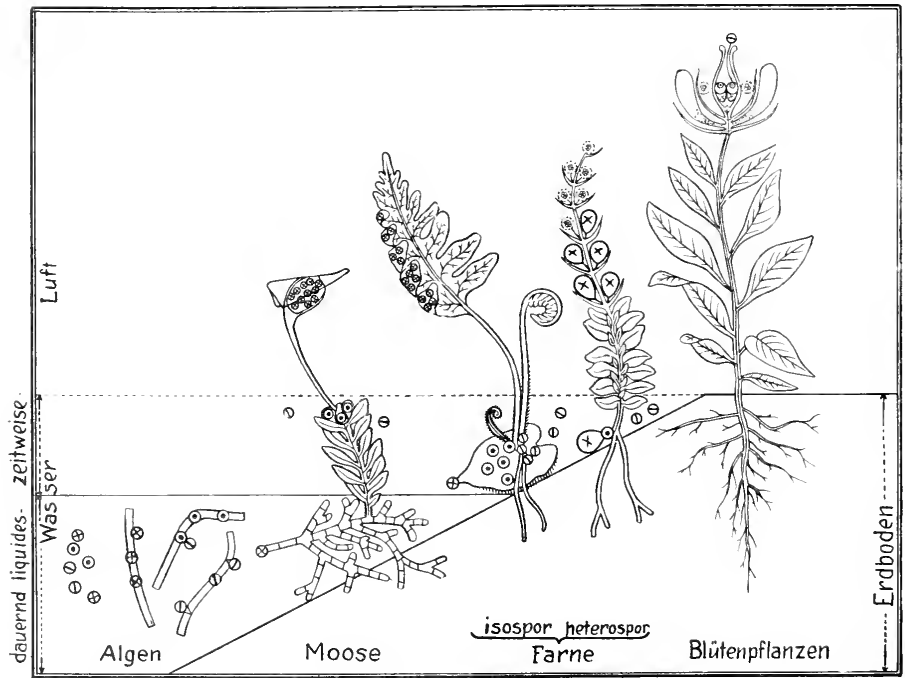

(8) ungeschlechtliche Sporen. (1) männliche-, Oweibliche Fortpflanzungsorgane.

Ahb 11.5. Entwicklung der Cormophyten und der IIomologienihrer Organe. Schematische Darstellung. Neuzeichnung nach R. v. Wettstein.

Vom vegetativen Teil des Prothalliums verdienen noch die als Ausstuilpungen von ziemlich betrïchtlichem Durehmesser erseheinenten Rhizoiden. welche die Bodemnahrung aufnehmen, Erwähnung, ebenso die in 
den Prothallienzellen reichlich vorhandenen Chlorophyllkörner mit ihren Teilungsstadien: rund, eiförmig, eingeschnürt, doppelscheibig.

Das Chlorophyll der Prothallien entsteht anch bei völligem Lichtabschluß, was als Anpassung an das Waldesdunkel gedentet werden kann.

Die Prothallien eignen sich zu Danerpräparaten in Glyzerin und Glyzeringelatine.

Der Generationswechsel zwischen Prothallium- und Sporenpflanze ist im allgemeinen obligatorisch, doch gibt es auch Ausnahmen. So entstehen z. B. bei Asplenium bulbiferum (s. die Abb.) und bei Cystopteris bulbifera (s. Kerner, Bd. II, s. 33 u. S. 572) anf den Wedeln unter Überspringen der Gesehlechtsgeneration neue Pflänzehen. Man vergleiche hierzu auch die Ausfiihrungen bei Hypum cupressiforme.

Ähnliche Erscheinungen treten anch bei höheren Pflanzen auf. Legt man z. B. ein Blatt der Crassulace Bryophyllum calycinum freisehwimmend auf Wasser. so wird nach einigen Wochen fast ans jedem Zahnwinkel ein Pflänzchen hervorwachsen. Eine Abbildung findet sich ebenfalls bei Kerner. Dentaria bulbifera (s. d. Abb.), Lilium bulbiferum n. a. m. bilden ähnlich den genannten Formen (aber in den Blattachseln) Brutzwiebelehen, welehe zu neuen Pflanzen austreiben. Man kann die reifen Gebilde trocken aufbewahren und später in Blumentöpfe eimpflanzen. Sie treiben auch während des Winters sehr bald Wurzehn, selbst wemn sie bereits stark geschrumpft waren.

An der Hand des beigefügten Bildes können wir ersehen, wie mit dem Übergang zum Luftleben die an Fenchtigkeit angepaßte Prothalliumgeneration mehr und mehr zurïckgegangen ist.

Bei den Cycadeen und einigen mehr sind bereits normale Pollenschlänche ausgebildet, aber in diesen entstehen noch typische Spermatozoiden, wie sie die Abbildung zeigt. Bei den Blütenpflanzen endlich ist auch diese
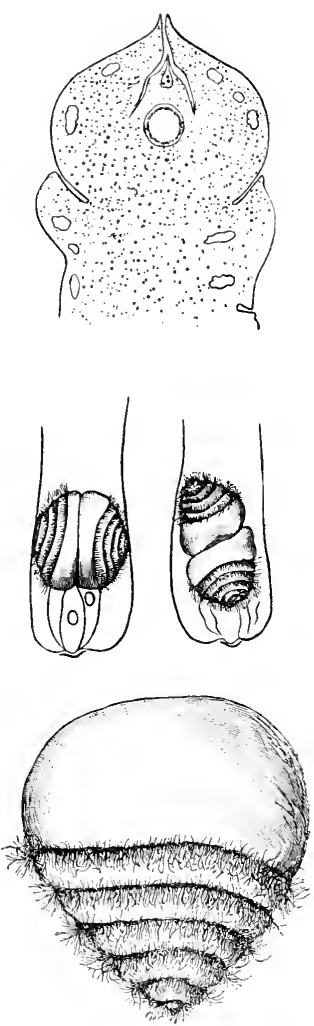

Abb. 116. Zamia floridana. Pollenschläuche mit Spermatozoiden (in Entwicklung) und frei schwimmendes, reifes Spermatozoid. Oben: Ginkgo biloba, Längsschnitt durch die Samenanlage (Makrosporangium).

(Nach Coulter und Chamberlain nnd H. J. Webber). Erseheinung zum Versehwinden gekommen.

Wir sind mit dieser Betrachtung wieder zu derjenigen Gruppe zurückgekehrt, welche den Ausgangspunkt fïr unsere Darstellungen im I. Teil des Buches bildete. 


\section{Literatur.}

Abderhalden, Emil (1), Biochemisches Handlexikon, Bel. VII. Berlin, J. Springer, 1912 .

- (2). Physiologisches Praktikum. Chemische und physikalische Vlethoden. Berlin, J. Springer, 1912.

Abel, Rud. (1), Bakteriologisches Taschenbuch. Die wichtigsten technischen Vorschriften zur bakteriologisehen Laboratoriumsarbeit. 17. Aufl., Würzburg 1913.

Abel, Rud. u. Buttenberg, Paul (1), Über die Einwirkung von Schimmelpilzen auf Arsen und seine Verbindungen. Der Nachweis von Arsen auf biologischem Wege. Zeitschr. f. Hyg.. Bel. 32, S. $449-490.1899$.

Appel, O. (1), Flugblatter der Kais. Biolog. Anst. f. Land- u. Forstwirtsehaft. 1905 bis 1907.

Nr. 15: Über das Einmieten der Kartoffeh.

Nr. 28: Die schwarzbeinigkeit und die nit ihr zusammenhängende Knollenfäule der Kartoffel.

Nr. 42: Die Blattrollkrankheit der Kartoffel. Verlag von Paul Parey, Berlin.

Appel, 0. (2), Beispiele zur mikroskopischen Untersuchung von Pflanzenkrankheiten. 2. Aufl, 54 seiten mit 63 Abb. Berlin, J. Springer, 1908.

Appel u. Westerdijk (1), Die Pilzkrankheiten der Kulturpflanzen und ihre Bekämpfung. Berlin, Gebr. Bornträger; erscheint 1914.

Appel u. Wollenweber (1), Grundlagen einer llonographie der Gattung Fusarium (Link). Arb. a. d. Kais. Biol. Anst. f. Land- u. Forstwirtschaft, Bd. VIII. 1910.

Babiy, J. (1), Über das angeblich konstante Vorkommen von Jod im Zellkern. Ber. d. Deutschen Bot. Ges., Bd. XXXI, S. 35. 1913.

Bade, E. (1), Die Praxis der Aquarienkunde (Sïßwasseraquarium, Seewasseraquarium). Mit 185 Textabbildungen, 9 schwarzen und 1 Farbentafel. 203 Seiten. Magdeburg, Creutzsche Verlagsbuchhandlung.

Bary, A. de (1). Vergleichende Morphologie und Biologie der Pilze, Mycetozoen und Bakterien. Leipzig 1884.

-, vergl. Absehnitt Flechten.

Bauer, Dr. Erust (1), Musci europaei exsiccati. Die Laubmoose Europas. Selbst. verlag, Prag-smichow, Palackygasse 43.

Behrens, W. (1), Tabellen zum Gebrauch bei mikroskopischen Arbeiten. 4. Aufl., von E. Küster. Leipzig, S. Hirzel, 1908.

Beijerinek (1), Über Spirillım desulfuricans als Ursache von Sulfatreduktionen. Cbl. f. Bakt.. Il. Abt. 1895 , Bd. 1, S. 1.

- (2), Schwefelwasserstoffbildung in den Stadtgräben und Aufstellung der Gattung

Aerobater. ('bl. Bakt., II. Abt. 1900, Bd. VI, S. 193.

Benecke, Wilh. (1), Ban und Leben der Bakterien. B. G. Teubner, 1912.

- (2), C̈ber Bacillus chitinovorus, einen Chitin zersetzenden Spaltpilz. Bot. Ztg. 1905.

Bethge, H. (1), Das IIavelplankton im Sommer 1911. Ber. d. Deutsehen Bot. Ges. 1911. Bi. XX1X. s. $4966-504$. 
- (2), Über die Verwendung der Planktonkammer im Unterricht. Monatshefte f. d. naturw. Unterricht 1912, Bd. V, S. 461-465.

Blakeslee, vgl. S. 106 11. 107.

Blochmann, Fr. (1), Die mikroskopische Tierwelt des Süßwassers. Hamburg 1895.

Borodin, J. (1), Über Chlorophyllkristalle. Bot. Ztg. 1882, Bd. XI, S. 608 u. S. 622. Botkin, vgl. S. 86 .

Brandt u. Apstein. Nordisches Plankton. Von 1901-1909. 12 Lieferungen.

Braner, A. (1), Die Sïßwasserfauna Deutsehlands. Eine Exkursionsfauna in ca. 20 Ileften, 1909 u. ff.

Brefeld, O. (1), Botanische Untersuchungen iber Schimmelpilze, Heft 1, 1872.

Brotherus, Müller, Ruhland u. Warnstorf, Musei (Laubmoose) in Engler-Prantl. Die natïrlichen Pflanzenfamilien, Teil I, 1909.

Bruchmann, H. (1), Über die Prothallien und die Keimpflanzen mehrerer europäischer Lycopodien. Gotha, Perthes, 1898.

- (2), Über das Prothallimm und die lieimpflanze von Ophioglossum vulgatum L. Bot. Ztg. 1904, Bd. LXII, S. 227-248. Nit 2 Taf.

- (3), C̈ber das Prothallinm und die Sporenpflanze von Botrychium lunaria. Flora 1906, Bd. 96, s. $203-230$. Mit 2. Taf.

Bruns, Kolkwitz, Schreiber (1), Talsperrenwasser als Trinkwisser. Mitt. a. d. Kgl. Landesanst. f. Wasserhygiene 1913. Heft 17, S. 151-268.

Burgeff, Hans (1), Die Wurzelpilze der Orchideen. Ihre Kultur und ihr Leben in der Pflanze. Jena 1909.

Burri, vgl. S. 77 .

Bütschli, O. (1), Protozoa in Bronns Klassen und Ordnungen d. Tierreichs. 1. Abt., $1880-1889$.

Chodat, R. (1), Algues vertes de la Suisse. 1899. Cultures pures 1913.

Claussen, P. (1), Pflanzenphysiologische Versuche und Demonstrationen für die Schule, 2. Aufl. Leipzig 1910.

Cooke, II. C. (1), Illustrations of british fungi. London 1881-1891.

Correns, C. (1), Untersuchungen ïber die Vermehrung der Laubmoose durch Brutorgane und Stecklinge. Jena, Gust. Fischer, 1899.

Courchet, I. Lucien, Recherches sur les chromoleucites. Ann. d. sc. nat. 1888, 7. sér., Bd. VII. Vgl. S. 22 .

Czapek, Fr. (1), Biochemie der Pflanzen. 2 Bände. Jena 1905.

- Ibidem, Bd. I, 2. Aufl., Jena 1913.

- (2), Zur Biologie der holzbewohnenden Pilze. Ber. d. Deutschen Bot. Ges. 1899, Bd. XVII, S. $166-170$.

Dengler, A. (1), Eine neue Methode zum Nachweis der Spaltöffnungsbewegungen bei den Koniferen. Nit 1 Tafel und 1 Textfig. Ber. d. Deutschen Bot. Ges. 1912, Bd. XXX, S. $452-462$.

Depp, N. von, (1), Mittel zur Vermehrung der Daphnien (Daphnia pulex) für die Er• nährung der Fischbrut. Blätter f. Aqu. u. Terr.Freunde 1893, Bd. IV, S. 181 bis 183 .

Detmer, W. (1), Das kleine pflanzenphysiologische Praktikum, 4. Aufl. Jena 1912.

Diakonow, N, W., vgl. S. I05.

Dodel, Arnold (1), Beitrag zur Morphologie und Entwicklungsgeschichte der Stärkekörner von Pellionia Daveanana. Flora 1892, Bd. LXXV, S. 267-280.

Dost, K. (1), Die Löslichkeit des Lnftsauerstoffes im Wasser. Mitt. a. d. Kigl. Prüfungsanstalt f. Wasservers. u. Abwässerbes. 1906, Heft 7.

Dunbar (1), Leitfaden für die Abwasserreinigungsfrage, 2. Aufl., 1913.

Ehrenberg, Chr. G. (1), Die Infusionstierchen als vollkommene Organisnen. Mit Atlas. 1838. 
Ehrlich, F. (1), C̈ber die Bedingungen der Fuselölbildung und über ihren Zusammenhang mit dem Eiweißaufbau der Hefe. Ber. d. Deutschen Chem. Ges. 1907, 40. Jahrg., S. $1027-1047$.

Eijkman. C. (1), Die Gärungsprobe bei $46^{\circ}$ als Hilfsmittel bei der Trinkwasseruntersuchung. (bbl. f. Bakt., Il. Abt., 1913, Bd. 39, S. 75-80.

Emmerling, O. (1), Die Enzyme. In Roscoe-Schorlemmer, Lehrbuch der Chemie, IX., Organ. Chem. 1901.

- (2), Die Zersetzung stickstoffreier organischer Substanzen durch Bakterien. Braunschweig 1912.

Engler, A. u. (iilg, E. (1), Syllabus der Pflanzenfamilien. Mit Abb. Berlin, Gebr, Bornträger, 1913.

Engler-Prantl (1), Die natürlichen Planzenfamilien. Leipzig, Wilh. Engelmann, $1889-1909$.

Eriksson, Jacob (1), Die Pilzkrankheiten der landwirtschaftlichen Kulturpflanzen Deutsch von Grevillius. Leipzig 1913.

Esser, Dr. P., Das Pflanzenmaterial für den botanischen Unterricht, 2. Aufl. Verlag u. Druck von J. P. Bachem, Köln 1903.

Euler, H. (1), Grundlagen und Ergebnisse der Pflanzenchemie, Teil 1 (1908), Teil 2 (1909) u. Teil 3, Die chemischen Vorgänge im Pflanzenkörper (1909), S. $128 \mathrm{ff.}$

Eyferth, Schoenichen, Kalberlah (1), Einfachste Lebensformen des Tier- und Pflanzenreiches. Naturgeschichte der mikroskopischen Süßwasserbewohner, 4. Aufl., Braunschweig 1909.

Falck, Rich. (1), Die Merulius-Fäule des Bauholzes. Aus A. Möller, Haussehwammforschungen 1912, Heft 6. Jena, Gust. Fischer.

Figdor, vgl. S. 55 .

Fischer, Alfred, Vorlesungen über Bakterien. 2. Anfl., 1903. Jena, Gustav Fischer.

Fischer, Emil (1), Organische Synthese und Biologie, 2. Anfl. Berlin, J. Springer, 1912.

Fischer, Hugo, vgl. Abschnitt Farne.

Fl ïgge, Carl (1), Die Mikroorganismen, 2. Aufl., 1896.

Forel, F. A. (1), Le Léman. Monographie limnologique, Bd. I (1892), Bd. II (1895), Bd. III (1902). Siehe auch: Handbuch der Seenkunde. Stuttgart 1901.

Francé, R. H. (1), Das Edaphon. Untersuchungen zur Ökologie der bodenbewohnenden Mikroorganismen. München 1913.

Friedenthal, vgl. s. 78 .

Froehlich, Herm., vgl. S. III.

Fünfstück u. Zahlbruckner, Lichenes (Flechten). Die natürlichen Pflanzenfamilien von A. Engler. I. Teil. Lejpzig, Wilh. Engelmann, 1907.

Gillet, C. C. (1), Les champignons qui croissent en France. Paris 1878-1896.

Goebel, K. (1), Archegoniatenstudien, I-X1V. Flora, 1892-1913.

(2), Organographie der Pflanzen. Jena, Gust. Fischer, 1898-1901.

- Ibidem, 2. Aufl., Bd. I, 1!13.

Goppelsroeder, Friedr. (1), Kapillaranalyse. Mit 59 Tafeln. Basel 1901.

Gramberg, E., Pilze der Heimat. Schmeils naturwissenschaftlicheAtlanten, 2 Bände.

Leipzig, Quelle u. Neyer, 1913.

Grosse-Boble, H. (1), Untersuchungen über den Satuerstoffgehalt des Rlteinwassers.

Mitt. a. d. Kgl. Prüfungsanst. f. Wasservers. u. Abwässerbes. 1906, Heft 7 .

Grüß, J. (1), Biologie und Kapillaranalyse der Enzyme. Berlin, Gebr. Bornträger, 1912. Gïnther, Carl (1), Einfülrnng in das Studium der Bakteriologie, 6. Aufl., 1906.

Haberlandt, G. (1), Physiologische Pflanzenanatomie, 4. Anfl., Leipzig 1909.

- (2), Beitrïge zur Anatomie und Physiologie der Laubmoose. Pringsheims Jahrb. 1886, Bd. XVII, S. $359-498$. 
Hartig, Rob.(1), Lehrbuch der Baumkrankleiten. Nit 11 Tafeln. Berlin 1882.

Hedwig, Johann(1), species muscorum frondosorum. 6 Bände mit 325 farbigen Tafeln. Supplemente von Prof. Fr. Schwägrichen. Leipzig 1801-1842.

Heering, W. (1), Die Süßwasseralgen Schleswig-Holsteins, ‥ Teil. ('hlorophyceae. Hamburg, L. Gräfe u. Sillem, 1907.

Heim, Ludwig (1), Lehrbuch der Bakteriologie, 4. Aufl. Stuttgart, Ferd. Enke, 1911. Vgl. S. 75 .

Hennings, P. (1), Hymenomycetineae. In Engler-Prantl, Natiirliche Pflanzenfamilien, I. Teil, Abt. $1^{* *}$. S. 105.1900.

Herpell, G. (1), Das Präparieren und Einlegen der Hutpilze für das Herbarium. Verh. d. naturhist. Vereins d. preuß. Rheinlande und Westfalens, 37. Jahrg., 4. Folge 7. Jahrg., Bonn 1880. Vgl. auth Lindau (4).

Herter, W. (1), Pilze. Kryptogamenflora d. Mark Brandenburg, Bel. VI. Berlin, Gebr. Bornträger, 1910 11. ff.

Herzfeld u. Paetow (1), Über die Anwentbarkeit der Fluorverbindungen zur Verhinderung ter Inveitzuckerbildung in Zuckersirmpen. Ztschr. f. Zuckerindustrie 1891. Bd. XLI, s. 678.

Heymons, Kolkwitz, Lindau, P. Magnus, Llbrich (1), Richtlinien zur Untersuchung der Pflanzen- und Tierwelt, besonders in Naturschutzgebieten. Conwentz, Naturdenkmäler, Heft 1. Berlin, Gebr. Bornträger, 1913.

Jaeger, H. (1), Die Bakteriologie des täglichen Lebens. In 18 gemeinverstäntlichen Vorträgen. Hamburg 1909.

Jahn, E. (1), Myxomycetenstudien. Die Keimung der Sporen. Ber. t. Deutschen Bot. Ges. 1905, Bd. XXIH, s. $489-497$.

Janzen, P. (1), Die Jugendformen der Laubmoose und ihre Kultur. 35. Ber. d. Westpr. Bot.-Zool. Vereins. Danzig 1912.

- (2), Funaria hygrometrica. Ein Moosleben in Wort und Bild. Schriften d. Naturf. Ges., Bd. XII. Danzig 1909.

Jellinek, Karl, Das Hydrosulfit. Sammlıng chemischer und chemisch-technischer Vorträge. Herausgegeben von Prof. Dr. W. Herz, Breslau. Stuttgart, Verlag von Ferdinand Enke, 1911.

Johnstone u. Croell (1), The Nature printed British Sea Weeds. London 1859-1860. Jost, L. (1), Vorlesungen über Pflanzenphysiologie, 3. Aufl. Jena 1913.

Junge, Fr. (1), Der Dorfteich als Lebensgemeinschaft. Kiel 1885.

Kähler, K., Staubmessungen in Potstlam, auf dem Brocken und auf der Schneekoppe. Veröff. d. Kgl. Preuß. Meteorol. Inst. 1912, s. 137-148.

Keil, Friedr. (1), Beiträge zur Physiologie der farblosen Schwefelbakterien. Beitr. z. Biol. d. Pflanzen, Bd. XI 1912, s. $335-372$.

Kerner v. Marilaun (1), Pflanzenleben, 2. Aufl., 1896-1898.

Kienitz-Gerloff, F. (1), Botanisch-mikroskopisches Praktikum. Leipzig 1910.

Kirchner, O. (1), Die mikroskopische Pflanzenwelt des Siißwassers, 2. Aufl., 1891.

Kirchner, Loew u. Schroeter, Lebensgeschichte der Blütenpflanzen Mitteleuropas, 1906 Bd. I u. ff.

Kisskalt u. Hartmann (1), Praktikum der Bakteriologie und Protozoologie, 2. Aufl., 1. Teil: Bakteriologie, $1909 ; 2$. Teil: Protozoologie, 1910.

Klebahn, H. (1), Grundzüge der allgemeinen Phytopathologie. Berlin, Gebr. Borrlträger, 1912.

- (2), Uredineae. Kryptogamenflora d. Mark Brandenburg, Bt. Va. 1913.

Klebs, G.(1), Über das Verhältnis der Außenwelt zur Entwicklung der Pflanzen. Sitzungsbericht d. Heidelberger Akad. d. Wiss., math.-naturw. Klasse, 1913.

- (2), Die Bedingungen der Fortpflanzung bei einigen Algen und Pilzen. Jena 1896.

Klein, Jos. (1), Organische Chemie, 3. Aufl. Sammlung Göschen, Leipzig 1905. 
Klut, Hartwig (1), Untersuchung des Wassers an Ort und Stelle. Mit 30 Textfiguren.

2. Aufl. Berlin, J. Springer, 1911.

- (2), Die Härte des Wassers. Pharmazent. Ztg. 1913, Nr. 79.

- (3), Die Bedentung der chemischen Wasseruntersuchung für Zentralversorgungen.

Das Wasser, Zeitschr. f. d. gesamte Wassertechnik u. Wasserwirtschaft. Leipzig 1913, 9. Jahrg., S. 842.

Knauer-Hollrung (1), Der Rübenban. Thaer-Bibliothek, 1906, 9. Aufl.

Knauthe, Larl (1), Das süßwasser, Chemische, biologische und bakteriologische Untersuchungsmethoden. Vom fischereilichen Standpunkt aus geschrieben. Neudamm 1907.

Kniep, H. und Minder, F., Über den Einfluß verschiedenfarbigen Lichtes auf die Kohlensänreassimilation. Zeitschr. f. Bot. 1909, Bd. I, S. $619-650$.

Knoll, F. (1), Über die Abscheidung von Flüssigkeit an mnd in den Fruchtkörpern verschiedener Hymenomyceten. Ber. d. Dentsch. Bot. Ges. 1912, Bd. XXX, S. $(36)-(44)$.

Kny, L. (1), Botanische Wandtafeln mit erläuterndem Text. Berlin 187t-1906. Enthält auch zahlreiche physiologische Angaben.

Kolkwitz, R. (1), Pflanzenphysiologische Versuche zu Übungen im Winter. Potoniés Naturwissenschaftl. Wochenschr. 1899, Bı. XIV. Nr. 5-8.

- (2). Über die Atmung der Gerstenkörner. Bl. f. Gersten-, Hopfen- u. Kartoffelbau, Nov. 1901. Vgl. auch Ber. d. Deutsch. Bot. Ges. 1901, Bd. XIX, S. 285.

- (3), Schizomycetes, Spaltpilze, Bacteria. Kryptogamenfl. d. Mark Brandenburg 1909, Bd. V, s. $1-186$.

- (4), Quantitative Studien über das Plankton des Rheinstroms, von seinen Quellen bis zur Mündung. Berlin, Hirschwald, 1912. Mitt. a. d. Kigl. Landesanst. f. Wasserhygiene. Heft 16 u. Ber. d. Deutsch. Bot. Ges. 1912, Bd. XXX, S. 205.

- (5), Die Farbe der Seen und Neere. Deutsche Vierteljahrsschr. f. öffentl. Gesundheitspflege 1910, Bd. XLII, s. 305-317.

Kolkwitz, Reichle, Schmidtmann, Spitta, Thumm (1), Wasser und Abwasser. Vit 111 Abb. u. 3 farlo. Tafeln. Leipzig, S. Hirzel, 1911. Vgl. auch Rubner, Handb.

Kolkwitz u. Thiesing, Chemische und biologische Untersuchungen über Talsperren. Mit 112 Abb. im Text u. 11 Tafeln. Berlin, Aug. Hirschwald, 1911.

Kolkwitz, R. u. Marsson, M. (1), Ökologie der pflanzlichen Saprobien. Ber. d. Deutsch. Bot. Ges. 1908 , Bd. 26 a, S. $505-519$.

- n. - (2), Ökologie der tierischen Saprobien. Internationale Revue der gesamten Hydrobiologie und Hydrographie 1909, Bd. II, S. 126-152.

König, J. n. Bömer, A. (1), Chemie der menschl. Nahrungs- u. Genußmittel. 4. Aufl., 乞 Bd. Jul. Springer, Berlin 1903-1904.

Krabbe, G. (1), Entwicklungsgeschichte und Morphologie der polymorphen Flechtengattung Cladonia. Leipzig 1891.

Kr ümmel, O. (1), Handb. d. Ozeanographie 1907-1911, 2 Bde., 2. Aufl.

Kruse, W. (1), Allgemeine Mikrobiologie. Leipzig 1910.

Kuckuck, P. (1), Der Strandwanderer. München, J. F. Lehmann, 1905.

Kïster, Ernst (1). Anleitung zur Kultur der Mikroorganismen. Verlag von B. G. Teubner, 1913, 2. Aufl.

- (2), Ihie Gallen der Pflanzen. Nit 158 Abb. Leipzig 1912.

Kylin, 11., vgl. Absehnitt Algen.

Lafar, Franz (1), Handbuch der Technischen Mykologie. 5 Bde., 1904 ff..

Lampert, liurt (1), Das Leben der Binnengewässer, 2. Aufl. Leipzig 1910.

Leclere du Sablon(1), Recherches sur la germination des graines oléagineuses. Revue gémérale de Botanique 1895 , p. 150 .

- (2), Recherches sur la dissémination des spores chez les eryptogames vaseulaires. Ann. d. se. nat. 1885 , V11. sér., Tome II. 
Lee, A. B. u. Mayer, Paul (1), Grundzüge der mikroskopischen Technik, 3. Aufl. Berlin, Friedländer u. Sohn, 1907.

Lehmann, K. B. n. Neumann, R. O., Atlas und Grundriß der Bakteriologie, 4. Aufl. Hïnchen, Verlag von J. F. Lehmann, 1907.

Leick, Erich (1), Untersuchungen über die Blütenwärme der Araceen. Greifswald, Bruncken u. Co., 1910.

- (2), Die Temperatursteigerung der Araceen als blütenbiologische Anpassung. Greifswald, Jul. Abel, 1911.

Lemmermann, E. (1), Algen. Kryptogamenflora der Mark Brandenburg. 1910 u. ff. Leunis, Joh. (1), Synopsis der Pflanzenkunde. 3. Aufl. von A. B. Frank, Hannover. 1886, Bd. III.

Lilienfeld, Maurice (1), Z̈ber den Chemotropismus der Wurzel. Beih. z. Bot. Zbl. 1905 , Bd. XIX, Abt. 1, Heft 1, Originalarbeiten.

Limpricht, K. G. (1), Die Laubmoose Deutschlands, Österreichs und der Schweiz. Leipzig $1885-1904$.

Linda u, G. (1), Hilfsbuch für das sammeln parasitischer Pilze. Berlin, Gebr. Bornträger, 1901.

- (2), Die mikroskopischen Pilze. Vit 558 Figuren im Text. Berlin, Jul. Springer, 1912. Aus der Sammlung: Kryptogamenflora f. Anfänger, Bd. II.

- (3), Fungi imperfecti in Engler-Prantl, Die natürlichen Pflanzenfamilien, I. Teil. 1900.

- (4), Die höheren Pilze (Basidiomyceten). Nit 607 Figuren im Text. Berlin, Jul. Springer, 1911. Ans der Sammlung: Kryptogamenflora f. Anfänger, Bd. I.

- (5), Die Flechten. Mit 306 Figuren im Text. Berlin, Jul. Springer, 1913. Aus der Sammlung: Kryptogamenflora f. Anfänger, Bd. III. Bezüglich der Moose vgl. Loreh.

Lindner, P. (1), Mikroskopische Betriebskontrolle in den Gärungsgewerben, 5. Aufl.. 1909. Dazu Atlas, 2. Aufl., 1910.

- (2), Atlas der mikroskopischen Grundlagen der Gärungskunde, 2. Aufl., 1910.

Lindroth, Lvar (1), Beiträge zur Kenntnis der Zersetzungserscheinungen des Birkenholzes. Naturw. Zeitsehr. f. Land- u. Forstwirtsch. von v. Tubeuf, 1904, Bd. II, S. $393-406$.

Linsbaner, L. u. K., Vorschule der Pflanzenphysiologie. Wien 1906.

Lippmann, E. v. (1), Die Chemie der Zuckerarten, 3. Aufl. Braunsehweig 1904.

Lister, A. u. G. (1), A monograph of the Aycetozoa, 2. Aufl. London 1911.

Loeske, Leop. (1), Zur Morphologie und Systematik der Laubmoose. Berlin, Verlag von Max Lande, 1910.

- (2), Die Moosvereine im Gebiete der Flora von Berlin. Abh. d. Bot. Ver. d. Prov. Brandenburg 1900, Bd. XLH, S. $75-164$.

Lohmann, K. (1), Über das Nannoplankton und die Zentrifugierung kleinsterWasserproben zur Gewinnung desselben in lebendem Zustande. Internat. Rev. d. ges. Hydrobiol. n. Hydrographie 1911, Bd. IV, Heft 1. Vgl. ferner: Untersuchungen zur Feststellung des vollständigen Gehaltes des Meeres an Plankton. Wissenschaftl. Meeresuntersuchungen, Abt. Kiel, 1908, Bd. X, s.. 131-370.

Lorch, Wilh. (1), Die Laubmoose. Hit 265 Figuren im Text. Berlin, Jul. Springer, 1913. Aus G. Lindau, Kryptogamenflora f. Anfänger, Bd. V.

Marchal, El. u. Em. (1), Aposporie et sexualité chez les mousses. Bull. Acad. Royal Belgique 1911.

Marsson, M. (1), Die Bedeutung der Flora und Fauna der natürlichen Gewässer für ihre Reinhaltung sowie ihre Beeinflussung durch Abgänge von Wohnstätten und Gewerben. Mitt. a. d. Prüfungsanstalt f. Wasservers. I. Abwïsserbes. 1910, Heft 14.

Mathuse, Otto (1), Bau und Lebenstätigkeit der Pflanzen. Wissenschaftl. Beil. z. IX. Jahresb. des Jahn-Realgymn. zu Boxhagen-Rummelsburg. Ostern 1912. 
Matzdorff, C. (1), Biologie. Mit 300 Abb. im Text, 18 ein- und mehrfarbigen Tafeln und 3 farbigen Karten. Breslan, F. Hirt, 1910.

Merz, Alfr. (1), Berliner Seenstudien und Meeresforschung. Zeitschr. d. Ges. f. Erdkunde 1912 .

- (2), Die schottisehe Seenforschung. Zeitschr. d. Ges. f. Erdkunde zu Berlin 1912, Nr. 8. Mesnard, M. Eugène (1), Recherches sur la formation des huiles grasses. Ann. I. sc. nat., 7 sér., I893, Tome XVIII.

Meyer, Arthur (1), Erstes mikroskopisehes Praktikum, 2. Aufl. Jena 1907.

- (2), Praktikum der botanischen Bakterienkunde. Jena 1903.

Mez, C. (1), Mikroskopisehe Wasseranalyse. 1898.

$-(2)$, vgl. S. 78 .

Michael, Edm. (1), Führer für Pilzfreunde. Zwickau 1902-1909.

Migula, W. (1), Kryptogamenflora. Tafelwerk. Verlag von Köhler, Gera, 1904 ı. ff. Mikrokosmos, Zeitschr. f. prakt. Arbeit auf d. Gebiet d. Naturwissenschaften. Stuttgart.

Minden, H. v. (1), Chytridiineae in Kryptogamenfl. der Mark Brandenburg 1911 u. ff., Bel. $\mathrm{V}$, s. $445-456$.

Il iyoshi, vgl. S. 94 .

Moliseh, H. (1), Die Kristallisation und der Nachweis des Xanthophylls (Karotins) im Blatte. Ber. d. Deutsch. Bot. Ges. 1896. Bd. XIV, S. 18.

- (2), Leuchtende Pflanzen. Eine physiolog. Studie. 2., verm. Aufl. Jena, G. Fiseher, 1912.

- (3), Die Eisenbakterien. Jena, G. Fischer, 1910.

- (4), Die Purpurbakterien. Jena 1907.

- (5), Das Warmbad als Mittel zum Treiben der Pflanzen. Jena, G. Fischer, 1949.

- (6), Mikrochemie der Pflanze. Jena, G. Fischer, 1913.

Möller, A., Hausschwammforschungen. Jena 1907-1912 u. ff.

llonteverde, N. A. (1). Das Absorptionsspektrum des ('hlorophylls. Acta Horti Petropolitani 1893, Bd. XIII, Nr. 9, S. 123.

Il ïller, Otto (1), Abh. über Kieselalgen in Englers Bot. Jahrb. 1903-1910 u. in Ber. (l. Deutsch. Bot. Ges., Bd. I-XIX.

II ïnch, Ernst (1), Untersuchungen ïber Immunität und Krankheitsempfänglichkeit der Holzptlanzen. Naturw. Zeitschr. f. Land- u. Forstwirtseh. von v. Tubeuf, 1909 , Bil. VII, S. $54 \mathrm{ff}$.

Natson, G. A., vgl. S. 5 .

Nargeli, C. v. (1), Untersuchungen über niedere Pilze, 188\%.

Nathansohn, A. Allgemeine Botanik, 1912.

Xia $u$ mann, Einar (1), Z̈ber die Ursachen einer braunen Färbung des Wassers in einem Teiche der Fischereiversuchsstation Aneboda in siidschweden. Internat. Rev. d. ges. Hydrobiol. 1913.

Nawaschin (1), C̈ber die Siporenaussehleuderung bei den Torfmoosen. Flora 1897. Bd. \&3, s. 151 .

Némee, B., Studien über die Regeneration. Berlin. Gebr. Bornträger, 1905.

- Das Problem der Befruehtungsvorgänge. Berlin, Gebr. Bornträger, 1910.

Nestler, A., vgl. S. 85 .

Nitardy, E. (1), Zur bildlichen Darstellung des Kammerplanktous. Mitt. a. d. Kgl. Landesanst. f. Wasserhyg. 1913, Heft 17.

NnBbaum. M., Karsten, (i., Weber, M., Lehrbuch der Biologie für Hochsehulen. Leipzig, W. Engelmanu, 1911.

().1s, I)r. Walter, Pflanzenphysiologische Versnehe, für die sehule znsammengestellt, 2. Anfl. Braunsehweig, Vieweg 11. Sohn, 1907.

()hlmïller, W. n. Spitta, O. (1), Die Lntersuehung und Beurteilung des Wassers und des Abwassers, 3). Aufl. Berlin 1910. 
Oltmanns, Fr., Morphologie und Biologie der Algen. Jena, G. Fischer, 1904, Bd. I; $1905, \mathrm{Bd}$ II.

Omelianski, vgl. s. 87 .

Oppenheimer, Carl (1), Die Fermente und ure Wirkungen. 3. Aufl. Leipzig, F. c. W. Vogel, 1909.

Ostenfeld, C. H. (1), Das Plankton der dänischen Meere. Mém. de l'Acad. Royale des se. et des lettres de Danemark. Kopenhagen 1913.

Osterwald, K. (1), Neue Beiträge zur Moosflora von Berlin. Zugleich ein Verzeichnis sämtlieher im Umkreis von 7 Heilen um Berlin bisher beobachteten Noose. Verh.

d. Bot. Ver. d. Prov. Brandenburg 1908, Bd. XL, S. $23-48$.

Palladin, W. (1), Pflanzeuphysiologie. Bearbeitet anf Grund der 6. russischen Auflage. Dentseh bei Jul. springer, Berlin, 1911.

- , vgl. S. $f^{6}$.

Pascher, A. (1), Die Süßwasserflora Deutsehlands, Österreichs und der Schweiz. Jena, G. Fiseher, 1913 u. ff.

Pasteur, L. (1), Die in der Atmosphäre vorhandenen organisierten Körperchen. Prüfung der Lehre von der Urzengung, 1862. Übersetzt in Ostwalds Klassikern, Nr. 39.

- (2), Etudes sur la bière. Paris 1876.

Paul, H. (1), Die Kalkfeindlichkeit der sphagna und ihre Lrsache, nebst einem Anhang über die Aufnahmefähigkeit der Torfmoose für Wasser. Mitt. Bayr. Moorkulturanst. 1908, Nr. 2.

Penck, Morphologie der Erdoberfläehe 1894.

Perrin, J. (1), Die Brownsche Bewegung und die wahre Existenz der Moleküle. Dresden 1910.

Pfeffer, W. (1), Pflanzenphysiologie. Leipzig 1897, 1904.

Pleißner, vgl. Abschnitt Plankton.

Plïmecke, O. (1), Zur Biologie mecklenburgischer Gewässer. Arch. f. Hydrobiologie ı. Planktonkunde, Bd. IX, $1913 f 14$.

Postels u. Ruprecht, vgl. Abschnitt Algen.

Potonie, H. (1), Die Entstehumg der Steinkohle und der Kanstobiolithe überhaupt wie des Torfs, der Bramkohle, des Petrolenms usw., 5. Aufl., 1910.

- (2), Eine Landsehaft der Steinkohlenzeit. Erläuterung zu der Wandtafel. Leipzig. Gebr. Bornträger, 1899.

Prantl-Pax (1), Lehrbuch der Botanik, 13. Aufl. Leipzig 1909.

Pringsheim, Ernst H. (1), Kulturversuehe mit chlorophyllführenden Mikroorganismen. Beitr. z. Biologie d. Pflanzen 1912, Bd. XI.

Pringsheim, Hans (1), Über die Vergärung der Zellulose durch thermophile Bakterien. (bl. f. Bakt., Il. Abt. 1913, Bd. 34, S. 513-516.

- (2), Die Variabilität der niederen Organismen. Eine deszendenztheoretische Studie. Berlin, J. springer, 1910.

Pringsheim, N.(1), Über Sprossung der Moosfrüchte und den Generationsweehsel der Thallophyten. Jahrb. f. wissensel. Bot., Bd. XI, 1877.

Prowazek, s. v., Einführung in die Physiologie der Einzelligen (Protozoen). B. G. Tenbner. 1910 .

Raulin (1), Etudes chimiques sur la végétation. Ann. d. se. nat., 5. sér., 1869, Tome XI, p. 201.

Regnard, P., Lal vie dans les eanx. Paris, G. Massen, 1891.

Reinke, J., vgl. S. I7.

Richter, O. (1), Die Emährung der Algen. Monographien u. Abhandlungen z. Int. Rev. 1911.

- (2), Reinkulturen der Diatomeen. Ber. d. Dentseh. Bot. Ges. 1903, Bd. XXI, s. 493 bis 506 .

Ricken, Adalbert(1), Die Blätterpilze (Agaricaceate). Leipzig, Osw. Weigel, 1910 u. ff. 
Rubner, v. Gruber u. Ficker (1), Handbuch der Hygiene, Leipzig, S. Hirzel, 1911, Bd. II, 2. Abt. Wasser u. Abwasser.

R ̈̈he, F. E. (1), Monographie der Daphniden Deutschlands und der benachbarten Giebiete,

I. Monographie des Genus Bosmina.

A. Bosmina coregoni im baltischen Seegebiet. $4^{\circ}$. Leipzig 1912. W. Klinkhardt. Ruhland, W. (1), Untersuchungen über die Kohlenhydratstoffwechsel von Beta vulgaris (Zuckerriibe). Jahrb. f. wiss. Bot. 1911, Bd. L, S. 200-257.

Sachs, Jul. (1), Handbuch der Experimentalphysiologie, 1865.

- (2), Vorlesungen über Pflanzenphysiologie, 2. Aufl., 1887.

- (3), Über das Auftreten der Stärke bei der Keimung ölhaltiger Samen. Bot. Ztg. 1859 , S. 178 mit Taf. VIII.

Scheffer, W. (1), Wirkungsweise und Gebrauch des Mikroskopes und seiner Hilfsapparate. B. G. Teubner, 1911.

Schiemenz, P. (1), Vergleichung der Fruchtbarkeit von Seen und Flüssen. Aus deutscher Fischerei, Thles-Heft, S. 75-82. Neudamm 1911.

Schiffner, Victor, Prof. (1), Hepaticae europaeae exsiccatae. Selbstverlag, 1901 u. ff. - (2), Hepaticae (Lebermoose) in Engler-Prantl, Die natürlichen Pflanzenfamilien, 1909. Schimper, F. (1), Pflanzengeographie auf physiologischer Grundlage. ‥ Aufl. Jena 1908. Schimper, W. Ph. (1), in Gemeinschaft mit Bruch u. (i ïmpel, Bryologia europaea Stuttgart 1836-1855. Suppl. 1864-1866. Mit 680 Tafeln.

- (2), Mémoire pour servir à l'histoire naturelle des sphaignes (Sphagnum L.). Paris 1857. Mit 24 Tafeln.

Sehindler, B. (1), C̈ber den Farbenwechsel der Oscillarien. Zeitschr. f. Bot. 1913, Bd. V. S. 497 .

Śchlechtendal, R. v.. Die Gallbildungen (Zoocecidien) der deutschen GefäBpflanzen. Zwickau 1891. Aus d. Jahresber. d. Ver. f. Naturk. zu Zwickan f. d. Jahr 1890, besonders abgedruckt. Enthält leicht benutzbare Bestimmungstabellen.

Schleichert, F., Anleitung zu botanischen Beobachtungen und pflanzenphysiologischen Experimenten. Unter Zugrundelegung von Detmers Pflanzenphysiol. Praktikum, 7. Aufl., 1909. Langensalza, H. Beyer u. Söhne.

Schlumberger, Otto (1), Familienmerkmale der ('yatheaceen und Polypodiaceen und die Beziehungen der Gattung Woodsia und verwandter Arten zu beiden Familien. Flora 1911, Bd. CII, S. $383-414$.

S'chmeil, O. (1), Leitfaden der Botanik, 51. Aufl. Leipzig, Quelle u. Meyer, 1913.

- (2), Naturwissenschaftliche Atlanten. Eugen Gramberg, Pilze der Heimat. Quelle n. Meyer, Leipzig, 1913, 2 Bände.

Schmid, B., Biologisches Praktikum für höhere Schulen 1909. Vit 75 Abb. u. 9 Tafeln, Schmidt, R. H. (1), Über Aufnahme und Verarbeitung von fetten Ölen durch Ptlanzen. Flora 1891, s. 360 .

Schoenichen, W. (1), Das biologische Schullaboratorium. Vorschläge und Nitteilungen aus der Praxis. Mit 31 Abb., 67 Seiten. Leipzig, Quelle u. Meyer, 1910.

- (2), Einführung in die Biologie. Ein Hilfsbuch für höhere Lehranstalten und für den Selbstunterricht. Mlit 6 farbigen Tafeln und zahlreichen Abbildungen im Text. Leipzig, Quelle u. Heyer, 1910.

Schrodt, J., Neue Beiträge zur Nlechanik der Farnsporangien. Flora 1887, S. 177. Vgl. auch Ber. d. Deutsch. Bot. Ges. 1897.

Schroeter, ('. (1), Das Pflanzenleben der Alpen. Eine Schilderung der Hochgebirgsflora. Zürich, Verlag von Alb. Raustein, 1908.

Schroeter, J., Pilze in F. Cohns Kryptogamenflora von schlesien, Bd. III. Breslau $188 \%$.

Schulz, Georg E. F., Natururkunden. Biologisch erläuteste photographisehe Aufnathmen frei lebender Tiere und Pflanzen. Berlin, Verlag von Paul Parey, 1908 u. ff. 
Schulze, Paul (1), Studien über tierische Körper ter Karotingruppe. Sitzungsber. d. Ges. naturf. Frde. 1913, S. 1-22. Mit ausführlichem Literaturverzeichnis. Schwalbe, Carl G. (1), Die Chemie der Zellulose unter besonderer Berücksichtigung der Textil- und Zellstoffindustrie. Berlin, Gebr. Bornträger, 1911.

Schwendener, S. (1), Vorlesungen iiber mechanische Probleme der Botanik, bearbeitet und herausgegeben von C. Holtermann. Leipzig 1909.

- (2), Untersuchungen über den Flechtenthallus. Nägelis Beitr. z. wissensch. Botanik, Heft 2-4. Leipzig 1860; München 1862.

- (3), Die Algentypen der Flechtengonidien. Basel 1869.

Seligo, A., Hydrobiologische Untersuchungen. Kommissionsverlag von L. Saunier in Danzig, 1890 u. ff.

Selk, H. (1), Beitr. z. Kenntnis d. Algenflora d. Elbe u. ihres Gebietes. Jahrb. d. Hamb. Wiss. Anst. 1907, Bd. XXV.

Servettaz, C. (1), Recherches expérimentales sur le développement et la nutrition des mousses en milieux stérilisés. Ann. d. sc. nat. Bot. 9. sér., 1913, t.17, p. $111-224$.

Smalian, Grundzüge der Pflanzenkunde. Leipzig, Verlag von G. Freytag.

Sorauer, P. (1), Handbuch der Pflanzenkrankheiten, 2 Bände, 3. Aufl., 1909.

Spitta, O. (1), Die Wasserversorgung. In Kolkwitz, Reichle, Schmidtmann, Spitta, Thumm, Wasser und Abwasser. Leipzig, S. Hirzel, 1911. Zngleich Bd. II, 2 von Rubner, Handbuch der Hygiene.

Stahl, Ernst (1), Zur Biologie des Chlorophylls. Laubfarhe und Himmelslicht, Vergilbung und Etiolement. Jena 1909.

- (2). Einige Versuche über Transpiration und Assimilation. Bot. Ztg. 1894, Bd. LII, S. $117-146$.

Steinbrinck, C. (1), Der Öffuungs- und Schleudermechanismus des Farnsporangiums. Ber. d. Deutsch. Bot Ges. 1897.

Steuer, Adolf (1), Planktonkunde. Leipzig und Berlin 1910.

Stoklasa, Julius, Biochemiseher Kreislauf des Phosphat-lons im Boden. Jena, G. Fischer, 1911.

Strasburger, Ed. u. Koernicke, Max (1), Das Botanische Praktikum, 5. Aufl. Jena 1913.

Strasburger, Noll, Schenck, Schimper, Lehrbuch der Botanik für Hochschulen. 12. Aufl. Bearb. von Fitting, Jost, Sehenck, Karsten. Jena, G. Fischer, 1913.

Tangl, Ed. (1), Z̈ber offene Kommunikationen zwischen den Zellen des Endosperms einiger Samen. Pringsheims Jahrb. $1879-81$, Bd. XII, S. 170-190, mit Taf. V und VI.

Ternetz, Charlotte, vgl. S. III.

Thumm, K. (1), Über Anstalts- und Hauskläranlagen. Ein Beitrag zur Abwasserbeseitigungsfrage. 2. Aufl. Berlin, Verlag von Aug. Hirschwald, 1913.

Tieghem, Ph. van (1), Recherches physiologiques sur la germination. Ann. d. se. nat. 1873.

Tobler, G. u. F. (1), Zur Bildung des Lycopins und über Beziehungen zwiselien Farbund Speicherstoffen bei Daucus. Ber. d. Dentsch. Bot. Ges. 1912.

- F. (2), Zur Ernährungsphysiologie der Flechten. Ber. d. Deutschen Bot. Ges. 1911, Bd. 29, S. 3.

Traube, Moritz (1), Gesammelte Abhandlungen. Berlin, Verlag von Mayer u. Müller, 1899.

Tswett, vgl. S. 12 .

Tubeuf, C. v. (1), Holzzerstörende Pilze unt Haltbarmachung des Holzes. Lafars Handb. d. Techn. Mykologie, Bd. 111, 190t-1906.

Vöchting, Herm. (1), Organbildung im Pflanzenreich, 1879.

Kolkwitz, Pflanzenphysiologie. 
Vogel, Müllenhoff, Röseler (1), Leitfaden für den Lnterricht in der Botanik, 21. Aufl., 1902.

Voigt, Max (1), Die Praxis der Naturkunde, 2 Bde. Leipzig, Dieterichs Verlag, 1913,

Volk. R. (1), Hamburgische Elbuntersuchung, 1901-1908. Mitt. a. d. Naturhist. Museum in Hamburg.

Vries, H. de (1), Eine Methode zur Analyse der Turgorkraft. Jahrb. f. wiss. Bot. 1884, Bd. XIV.

- (2), Wachstunsgeschichte der Zuckerrübe. Landwirtsch. Jahrb. 1579, Bd. VIII, s. 417.

Wagner. Maximilian, 100 physiologische schulversuche iiber das Leben der Gemasebohne. Leipzig, B. G. Tenbner, 1912.

Warming, Eng. (1), Oecology of plants. Oxford 1909.

Warnstort, C. (1), Moose, Kryptogamenflora der Mark Brandenburg. Berlin, Gebr. Borntrïger, 1903 11. 1906.

Wesenberg-Lund (1), Plankton investigations of the danish lakes. Spezieller Teil (1. Text, 2. Tafeln). Kopenhagen 1904. Allgemeiner Teil, 1908. Dieses Work ist nach den Angaben des Verfassers als planktologisches Pendant zu Forels limnologischer Monographie iiber den Genfer see zu betrachten.

West, W. u. West. (i. S. (1). A monograph of the British Desmidiaceae. The Raty Society, Vol. I-III. Londom $1904-1908$.

Wettstein, R. v. (1), Handbuch der systematisehen Botanik, 2. Aufl. Leipzig n. Wien, 1911.

Wrilhelmi, Jul. (1), Die makroskopische Fanna des Golfes von Neapel, vom Standpunkte der binlogischen Analyse des Meerwassers. Mitt. a. d. Kgl. Prüfungsanst. f. Wasservers. 11. Abwïsserbes. 1912. Heft 16, s. $47-166$. Mit 78 Textfiguren.

W'ill, H. (1), Beiträge zur Kenntnis rotgefärbter niederer Pilze. (bl. f. Bakt.. II. Abt.. 1912, B.t. XXXY, s. 81-118.

Wille, N. (1), Conjugatae und Chlorophyceate in Engler-Prantl, Die natürlichen Pflanzenfamilien, I. Teil. Leipzig 1897.

Willstätter, Rich. (1), Lntersuchungen ïber ('hlorophyll. Liebigs Annalen der ('hemie 1907, Bd. 35s, s. 267 11. folg. Bände.

Willstäter n. stoll (1), Lntersuchungen über ('hlormphyll. Methoden n. Ergebnisse. Berlin, Verlag von Jul. springer, 1913.

Winkler, L. W., rgl. Abschnitt Plankton.

Winogratsky (1), vgl. S. 03 .

- (22), Recherches sur les organismes de la nitrification. Ann. de l'Institut Pasteur 1890. Erste Abhandlung.

Woltereck, R. (1), Internationale Revue d. ges. Hydrobiologie u. Hydrographie, 1908 u. fif.

Hossidlo, Leitfaten der Botanik. Berlin, Weidmannscher Verlag.

Wïnsche, Otto (1). Die Kryptogamen Deutsthlands. Leipzig, B. G. Teubner, 1875 , Zacharias, O. (1), Archiy f. Hydrobiologie n. Planktonkunde.

- (2), Das Siibwasserplankton. Aus Natur und Gieisteswelt, 2. Aufl. B. G. Teubner, 1911

Zimmermann, A. (1), Wie botanische Mikrotechnik. Tübingen 1892.

Zopf, Wilh. (1), I)ie Pilze. In Schencks Handb. d. Bot.. Bd. IV.. 1890. 


\section{Register.}

Ibbe, liondensor 66 .

, Zeichenapparat 65.

Abendlichtnelke, hygroskopicehe Kapseln $20,22,223$.

-, Silfteitung in Bliiten 55 .

Abschlagaplarat 197.

Absitzbecken $\$ 3$.

Ibsoptionsspektrum des chlorophylls 10.

Abwasser. fieston 183.

Acacia lophanta, seliafstellnng der Blattor 21.

Acer platamoiless, Blattkrankheit 113. Taf. IV.

Aceton 9, 1113.

Achlya, fakult. Parasitismus 108.

Acilius suleatus 179, Taf. VIII.

Arineta gramdis, Nilurme 173, Taf. VIll.

definastrum hantzsehii, Plankton 15.5, Taf. YII.

Aetinophrys sol 170, Taf. VIJl.

Actinospharerium (ichhorni 170, Tate VIll.

Athäsionskultur nath Linduer 101.

Apcidiosperen, Farbe 12.

- Rostpilz 115.

Aecidium berberidis 112, 115. Tat. IV.

derotaxis bei spermatozoulen 162.

Aethalinm septicnm, Jebensweise 67.

Igar, Stichkultmen 74.

-, Strichkulturen 74 .

Agricus campestris 124 . mellews 126, Tat. V.

Agrion puella 178, Talf. VIII.

Agrostemma 223.

Ahorn, Battkrankheit 113, Taf IV.

Albugo candital 111, 11:, Taf. IVt.

Alburnus lueidus 179. Taf VIII.

Aldrovandia vesiculosit 47.

Algen, an biinmen 137.

-, auf Erile 137.

-, mixutrophe Enaburung 137.

- Ökologie 137.

-, Reinkulturen 137.

-, Sägespan-141, Taf. VII.

-, System 137.

Algenfresser 167.

Alenronkörner 39.

Alisma plantago 166 .

Alkoholgärung 103.

Allinm, Reservezellulose 37.

-, Zucker in der Zwiebel os, 38 .

Amanita mappa 127 , Taf. $\mathrm{T}$.

- muscaria 127.

- pustulata 127.

- rubescens 127.

- nmbrina-pantherina 127.

Amanrochaete atra 69.
Amatrosporear 124.

Amblystegium riparium 216.

Amicia zygomeris, Sehlafstellung der blatter 21 .

Aminosiuren $2(1)$.

- bei Rinssula 123.

, Giarung 103.

, in fiewaissern 200.

Ammoniakverb. d. Fettsituen 200.

Ammoniommolvbelat, Phosphornachweis 38.

Immoniumphosphat, Chemotropismus if.

Amoeba protens 169, Tatf. VIll.

Amöben. Funderte 70 .

- Kultur 70.

Amorpha fruticesa, sichlafstellung der blätter 21 .

Ampelopsis, Rauken 2.2.

Amphiplema pellueila 150, Taf. VII.

Amphora ovalis 150, Taf. V11.

Amyloid 37.

Anabaena species 141, Tat. VII.

Anariobe Atmong $46,103$.

- Bakterien sis.

- Wiirmer 17:3.

Anastigmatlupen 6:, Tal. X.

Anerlistineen 11:3.

Andreaea petrophila 211, Tat. XII.

Ammulata 124, 126, Taf. V.

Ammulus der sporangien 221.

Anodonta mutabilis 175 .

Anpassung, llalophyten 57.

Wasirepflamzen 5\%.

Niistempflamzen 5:2.

Xerophyten 57.

Antheridien, Aspidinm 208.

Inthocvan 12, 17, 23.

Anthophysa, Lebensweise 170, Taf. VIII.

Anturaea aculeata 175, Taf. VIIl. eochlearts 175, Taf. V'lll.

Apfel, Znekernatehweis 25.

Aptelsame, ('hemotaxis 230). Zuckerribe 25.

Aptelsine, Zuckernachweis 28.

Aphanizomenon flos aquae 141, Taf. IIl.

Aphanomyers 108 .

Aplanatlupen 63 .

Apochromatobjektive 66.

Apodya lacteal 108, 16.5, Taf. V'll.

Apothecien 134.

Apposition, Wachstum 32 .

Crabinose 27.

Areella vulgaris, Vorkommen 169, Taf. V111.

Archegonien der Farne 209.

Arion subfuscus, Pilzfresser 117.

Armillaria mellea 126, Taf. I. 
Armlenchtergewachse 166.

Arsennachweis durch Penicillium 110.

Arthospira 140, Taf. Vll.

Arum maculatum, Wärmebildung 4.5.

Ascomycetes 107, 117.

Asellus aquatiens 176 , Taf. VIII.

Askogene Hyphen 131.

Askus-Hymenien 131.

Asparagin in Lupinus 42.

_, Nahrung der Hefen 101.

- in Zuckerrübe 25 .

Aspergillus niger 107, 109.

Aspidium filix mas 221.

Asplanchna, Nahrung 174, Taf. VIII.

Asplenium bulbiferum 230 .

Assimilation 3.

- Gewebe 6 .

-, Stärke 31.

-, Wirkung der spektralfarben 8 .

Assimilationslamellen 215 .

Asterionella, Assimilation 149, Taf. VII.

Astmoos 217.

Atemmot dureh sauerstoffmangel 44, 201.

Atemwurzeh, Funktion 58.

Atmosphärendruck osmotisch wirksamer Losungen 24.

Atmung $43 \mathrm{ff}$.

- Nachweis 44.

intramolekulare 45.

W:irmebildung 45.

- ana

Atriplex litorale 58.

Atrosporeae 121.

Augenfleck der Flagellaten und Schwärmer 12,145 .

Anstrocknen der Moose 217.

Auszichstock 195, Taf. X.

Autonome Bewegungen 21.

Autotrophe Ernahrung 47, 82, 94.

Azeton, siehe Aceton.

Azotobacter 86, 142, Taf. VII.

Bacillaria paradoxa, Bewegung 151.

Bacillariales 146.

liacillus anvlobacter 85 .

ralfactor 86 .

- cellulosae methanicus 86 .

- subtilis s., 142, Taf. VII.

Bacteriopurpurin 12.

Bacterium aceti 80 .

('hitinovorum 121 .

roli 77,81 .

flenitrificans 82 .

fluoreseens 6, s7, Taf. VII.

gelatienm 74 .

lactis aciali 81 .

nitrobacter 5, s2.

phytophthorum s1, 111, 112.

prodigiosum \&2.

rallicicola 84.

termo ses.

tuberenlasis 77, 84.

- typhi 81 .

violacenm 87 .

vulgare s.). T'aft. VII.

xylinm+1 sil.
Bateyers Hypothese 4 .

liakterien, Begeißelung 78.

-, Färbung 77.

-, Filter 73 .

-, Fundorte 71, 72.

-, Kultur $74 \mathrm{ft}$.

-, sauerstoffempfindliche 6 .

-, System 78.

Bakterienfresser 167.

Bakteroiden 84.

Balanophora dioica 49 .

Bandflechte 133, Taf. VI.

Barbula unguiculata 212 .

Bärklaue 11.

Bartflechte 133, Taf. VI.

Bärtierchell 178, Taf. VIII.

Bartmoos 212.

Barytlauge, Kohlensäurenachweis 44 .

Basidien bei Russula 122.

Basidiomycetes 112, $117 \mathrm{ff}$.

Batrachium, IIvdrophyt 58.

Batrachospermum moniliforme, Farbe 162.

Bammfarne 220 .

Banmwollfaser 202 .

Banmzerstörende Pilze 114, 120.

Berherflechte 132, Taf. VI.

lineherpilz, Peziza 118.

Becherrost 115.

Brogiatoa alloa 71, 94, Taf. VII.

- mirabilis 95.

Begonia, Gewebespannung 20.

Beijerincksche Methode, Diastasewirkung 35.

Bellis perenuis, Öfnen und Sehließen ter Bliitenkijpfe 22.

linuthos 180.

Burberitze, Aecielien des Rostpilzes 115.

Berkefeldfilter 73.

bisenmogs 211, Taf. XII.

Beta volgaris 25 .

Betain, Zuckerrïbe 25.

Betula, Blutungsdruck 55 .

-, Saft 30,55 .

Bengungsbilder 66 .

Bewegung, autonome 21 .

- der Chlorophyllkörner 9.

- durch mechanische Reize $\mathbf{2 0}, 21,224$.

- heliotaktische 9.

-, Iyktitropische 20.

Bierwiirzegelatine 74 .

Billbergia horrida 53.

Bio-Oxyelation 200.

Bio-Roiluktion 200.

Biologisehe selbstreinigung 199.

Biologische Tropfkörper 83.

Birke, Blutungsiruck 55.

, Saft 30,55 .

Binc, Zuckernachweis 28 .

Biuretreaktion, Eiweißnachweis 39.

Blischenmethode, Assimilationsnachweis 7 .

Blasentang 161.

Blattflechten 132 .

Blattschimmel 113.

Blattstruktır, mikroskopische 6 .

Bleischut $z$, biologiseher 92.

Blïten, Farbstoffe 12 . 
Bliiten, Öffnen und schließen 20, 22.

Blutkörperchen, Osmose 24.

Bodensee, Plankton 187.

Bodo ovatus in Aufgüssen 170, Taf. VIII.

Boletus bulbosus (=edulis) 120, Taf. V.

- castaneus 120 .

Borodinsehe Nethode für Chlorophyllkristalle 11

Bosmina, Plankton 177, Taf. VIII.

Botryehium lunaria 225.

Botryocoecus braunii, a. d. Oberfl. schwimmend 154 .

Botrytis cinerea $107,110$.

Bouillonkulturen 74 .

Bovist, Bauchpilz 128.

-, Schleimpilz 68 .

Brachionus urceolaris 174, Taf. VIII.

Brachsenkraut 166, Taf. VII.

Brachythecium, unterdrückt Gras 216, Taf. XII.

Brandpilz 115.

Brassica, Atmung 43.

Braunalgen 158.

Brettwurzeln 59.

Brownsche Molekularbewegung 30, 151.

Brunnenfaden 88, 89.

Bryonia alba, Ranken 22.

Bryophyllum calyeinum 231.

Bryophyta 205.

Bryum argenteum 214, Taf. XII.

- capillare 217.

Burhnerscher Apparat fïr Anaërobenkultur 86

Buchweizen, Eiweißsynthese 42.

Burmannia, Saprophyt 47.

Burri, Bakterienfärbung 77.

Buttersäure, Bazillus 85 .

-, Gärung 86.

Buxbaumia, Lebensweise 215, Taf. XII.

Bythinia tentaculata 175 , Taf. VIII.

Calanus, Plankton 176.

Callidina elegans 174, Taf. VIII.

Callitriche vernalis 167 .

Calophyllum 59.

Calothrix 135.

Caltha, Hydrophyt 58.

Calystegia dahurica, autonome sprobbewegung 21 .

Canarium 59.

Cantharellus cibarius 121.

Canthocamptus. Lebensweise 176.

Capsella bursa pastoris. Wirtspflanze des weißen Rostes 112 , Taf. IV.

Carchesium lachmanni $\alpha \mathrm{m}$ 172, Taf. VIII.

Carex vulgaris 167, 193.

Catharinea undulata 215.

Cattleya, Keimling 48.

Caulerpa 158.

Cellulose, siehe Zellulose.

Ceramium rubrum, Farbe 164.

Ceratium hirundinella, Schwalbenschwanzalge 146 , Taf. VII.

Ceratium tripos $79, \mathbf{1 4 6}$, Taf. VII.

Ceratodon purpureus, Lebensweise 211, Taf. XII.
C'eratophyllum demersum 167, Taf. VII. Ceratopogon communis 179, Taf. VIII.

Cetraria islandica 133.

Chaetoceras whighamii, Gallerthaut 148 .

Champignon 124.

-, Brut 126.

-, Fliege 126.

-, Haus 125.

Chantransia chalybaea 163, Taf. VII.

Chara foetida, Kalk 166.

— fragilis 193.

Chara, Plasmaströmung 8 .

Chemotaxis bei Chromatium 96.

- bei Farnen 230.

- bei Fuligo 67.

('hemotropismus bei Wurzeln 53.

Chenopodium enthïlt Nitrate 27.

Chilodon cucullulus 171, Taf. VIII.

Chinesische Tusche, Bakterienfärbung 77.

-, Nolekularbewegung 31.

-, Oscillatoria-Bewegung 140.

Chironomus 179, Taf. VIII.

('hisocheton (Neliaceae) 59.

('hitinrest 202 .

Chlamydomonas species, pro 1 cem 154, Taf. VII.

('hlamydosporen bei Hefen 98.

Chlamydothrix 89, 90.

-, Fundort 71.

Chloralhydrat, Stärkenachweis $31,163$.

Chlorella, Menge 186.

- , Spezies 155 .

Chloride, Bestimmung 190.

-, im Wasser 190.

Chlorobium limicola 5.

Chlorophyll $3 \mathrm{ff}$.

- als Sensibilisator 5.

-, Extraktion 9.

-, Fluoreszenz 9.

-, inaktives 5 .

-, Kapillaranalyse 10.

- kolloidales 11.

- Komponenten 11.

- Kömer 8, 214, 231.

-. Kristalle 10.

- Lösung 9.

-, Spektrum 10.

-, Zerlegung 10.

- Zersetzung 9, 10.

Chlorophyllase 11 .

Chlorophyllid 11.

Chloroplasten 11, 214.

Chlorzahlen 190.

Chromatium okenii 71,95 , Taf. VII.

-, Farbstoff 12, 13.

- weissii 95 .

Chromatophoren 7.

Chromulina rosanoffii 144 .

('hroococcus limneticus 139, Taf. VII.

('hrysomonadales 143.

Chrysophansäure 133.

('hydorus sphaericus 177 , Taf. VIII.

Chytridiaceae 70.

Chytridineen 113.

Chytridium olla 113, 157.

Cirkulationsbewegung bei Tradescantia 8 . 
Clatomia mateilenta 132, Taf. VI

- pyxidata 13\%, Taf. II.

- rangiferina 131 .

- squamosa 131.

- stellata 130.

Cladophora, Assimilation 4.

- Vorkommen und Kintur 157, Taf. V'll.

C]adosporim herbarum 76, 104, 110.

('ladothrix dichotoma 93, Taf. VII.

('latlirocystis 139.

('latvaria botrytis 119 .

- pistillaris 11!. Tat. $Y$.

('alviceps purpurea 112, 115, Tat. IV.

('lematis vitalba, Ranken 2.2.

('livia nobilis, Karotin 13.

C'lö̈ diptera 17s. Tat. PIII.

('lonothrix s!).

- Findort 71 .

C'bosterinm aterosum 186.

('losterimm, spezies 151, Tat. VII.

—, Tauzstiibehen 31.

Cubarat scamtens. Kanllemanken 22.

recoolithen 144

('oceolithophoridate 1s!).

foceoneis pediculus, schildlaus-lieselatge 149, Tat. VII.

Cocos nucifra, Zuckernathweis 28.

('oelastrum microporum 186.

foffera, Resirvezellulose 37.

Coleps hirtas. Lebensweise 171 Tat. VIll.

Collema pulposum 135.

('ollybia tuberosa 123 .

(a)pidinm enlpoda, Lehensweise 171. Tat'. VIII.

Colurus species 174, Taf. VIII.

('ompositen, Inulin 31 .

Conferva bombyeina 156, Tat. VII.

Coniosybe ehlorina 136.

Convolvulus sepium. alutonome sprobbewegung 21 .

Coprinus atramentarius 121.

(ampanulatus 121.

comatus 121 .

stercorarius 121

('orallina officinalis, Kalk 164.

(oralliorrhiza innatil 47.

Cordycens militais 110, 114. Taf. IV.

(orethra plumieornis 17!), Taf. Vl]I.

Corixastriata 17- Tat. VIII.

coromillat varia. Sehlafistelung der Blatter 21.

Cortinarius, solleim 124.

fosmarium botrytis, reingriin 151, Tat. V'lJ.

('renotlarix, 85, 89, 90 ). Fundort 71 .

('rucus, (j)finen und sehlie ben der Blüten 22.

Crucifuren, Naberplatuzen der Plasmodiophorat 69.

- Nïhpflanzen des weiben Rostes 112. Crucigenial reetangularis 186.

ciastaceal 176 .

l'ryptomonatales 144

Cryptomonas, Lebensweise 144, Taf. VII.

('uenmis sativus, Rauken 22.

('ueurbital pepo, Ranken 22.

, (j) in tiantul 38. (alex pipiens 179, Taf. VIII.

('uscuta europaea 49, 50).

('vanophyceae 140.

('vanophyll 10.

(veaderen, Nostor 140.

-, Spermatozoiden 231 .

('velanthera explodens, Ranken 2.2.

Cyclas 175, Taf. VIII.

('yelops leuckarti 176, Taf. VIII.

Crelotella kuetzingiana 186.

('vmatopleara solea 151 , Taf. VII.

crmbella lanceolata, Crallertstiele 150 , Tat. VIJ.

cvphoderia, schale 169, Taf. VIII.

(Ypris fusea 177, Taf. VIII.

('vitiden bei Russula 12.2.

(vistucoceus in Flechten 130.

C'vistokarpien 163.

Grstopus candidus 111, 112, Taf. IV.

frtase, Wirliung 120.

l) ampetopl 74 .

Datplnia pulex. Nalurung 17T, Tat. VIII.

1)arlingtonia ralifornica 47 .

barmalge 15 is.

Hancus carota, (i]ukosenachweis $2 y$.

, Karotin 12.

- ()smose 14 .

- Pilzkrankheit 116.

-. Zutkernachweis '29.

bolesseria sanguinea, stärenmsatz 164.

l)utaria bulbifera, Brutzwiebeln 230.

berminus hypmi 123, Taf. I.

Desinfektion 73 .

besmifliaceen, zwischen Tortmoos 211.

Desmodium grrans. Blattbewegung 21.

Detritusfresser 167 .

Dextrate bei Cetraria 133.

1)xtrangarung 78 .

l)iageotropismus 21 .

Dialyse d. Eiweib 42.

Diaphanoskop 10.

Diaptomus graciloides, Plankton 176, Taf. VIII.

Diastase 35.

Jiatoma elongatum 149, Taf. VII.

Diatomesn. Assimilation 7.

- Farbstolif 13.

-, Tebensogehichte $146 \mathrm{ft}$.

- Reinkultur 147.

- Trpenplatte 65.

Hicranam seoparium 211, Tat. XII.

bietyosphaterium 188.

])ifflugia, Fundorte 7() . pyriformis 169 , Taf. VIII.

I)igitalis purpurea, Antberen 23.

I inobryon species 144. Taf. VII.

Dionaea muscipula 47.

Diphenylamin, Reaktion auf Nitrate 27, 84.

Iiplophrys, a m 170, Taf. VIII.

loplosiga, passiv planktonisch 170, Taf. VIII.

liptera 179.

Jisaccharide 30 .

Dischidia rafflesiana 53.

[istephanus speculum 14t, Taf. VII. 
Drainröhren 83 .

Drainwässer 201.

Trehmoos 213, Taf. XII.

Dreissensia polymorpha 176 , Tat. VIII.

I) retsche 198 .

I)rosera, Halbsaprophyt 47.

-, Kultur 48, 49.

- Pepsinabsonderung 40.

Drosophyllum lusitanicum 47, 49.

Jumbarsches Enteisenungstab 9.2.

1)unkelfeldbelenchtung 66 .

-, Bakterienbeobarhtung 72 .

Iyticus marginalis 179 , Taf. VIII.

Edaphon 180.

Erlinger Zeichenapparat 65.

Eisenbakterien $881 \mathrm{f}$.

Eisenoxydhyelrat $20^{\circ}$.

Eiweil. $41 \mathrm{ff}$.

- bei Hefen 99.

-, Dialyse 42 .

-, Kristalle $33,34, \mathbf{3 5}$.

-, Nachweis 39, 41.

-, Reaktion 41 .

-, Synthese 42ff., $100 \mathrm{ff}, 105$.

Elastizität der Zellmembran 18. 19.

Elateren, hygroskopisch 223.

Elle (Synedra) 14s, Taf. VII.

Elodea, Assimilation 3.

-, Atmung 43.

-, Hydrophyt 5s.

- Karotin 13.

Empusa museate 111, 112, Tat. IV.

Emulsion, Fett 40 .

endolithiseh 135.

Endomyers magnusii 107, 109.

Endomycetes 98, 109.

Endosmose 15, 19.

Endosperm bei Ricinus 38 .

Engelmanns bakt. Nethode 6 .

Enteisenung 88, 91.

Enteisenumgsia 192.

Enteromorpha intestinalis 156 .

Enzymwirkungen bei Schimmelpilzen 106.

Eosinlösung, Narhweis der Saftleitung 55 .

Ephebe 135.

Epipogon gmelini, Saprophyt 47.

Epistylis a uf Gehiusen v. Schnecken 172, Taf. VIII.

Epithemia turgida anf Wasserpflanzen 150 , Taf. VII.

Eririeren der Pflanzen 18, 152.

Eristalis tenax 179 , Taf. VIII.

Ergotinin 114.

Erodium, Grannen 2.24.

Erythrodextrin 35, 163.

Essigmutter 80.

Essigpilz 80.

Essigsäure, Bakterien 71.

_. Gärung 80.

Etagenmous 218.

Etiolement 5.

Etiolin 12.

Eucampia-Zellen 188.

Euchlanis dilatata 174, Taf. Y'III.

Eudorina alegans 154, Taf. VII.
Engenia (Myrtaceate) 50.

Euglenat acus var. rigida $1 \mathrm{~N} 6$.

viridis 144, Taf. VII.

Euglena, Heliotaxis 9, 14.5.

Euglypha alveolata 16i. Tat. VIII.

Eumverestes 96 iff.

Euphorbiat cyparissias, Rostkranklowit 116.

Euplotes charon 172.

Emplerasia offecinalis 50.

Evelatale 123.

Evernia prmastri 133, Taf. I'l.

Evernsinte 133.

Exkursiousbesteck 198.

Exkursionsmikroskop, 194.

Exoasens pruni 112, 113, Taf. IV.

Exobasidium vaceinii 112 , 116, Tat. IV.

Experimentalökologie 199.

Extraktion des chlorophylls 9.

Fadeuwiomer 174.

Farbe, Wasser 184.

Farne 219 .

Fatulsehlamm 219.

Farmsporangien, Mechanismus $23, \mathbf{2 0 2}$.

Falkammer 87 .

Fänlnisbakterim se, Taf. VII.

Fegatella conica 209 .

Fohlingsche Lösung, Zuckernachweis 2s.

Fermente, fettspaltemde 40.

-, wxydiereude 120 .

-, stailielösende 36.

Firroc vankupfermembran 16.

Fett, bei Iiatomern 146.

- bei Hefen 9!?.

- in Ricinussamen 37.

-, Petroleumbildung 2006.

Ficus rastica 6 .

Filze, Algen 140. organische 193 .

Fingerhut, Antheren 23.3 .

Fingertang 159.

Fischbrut fribt Plankton 179, Tat. V111.

Fischnahrung 201.

Flechten 130.

Band- 13:3, Taf. VI.

Balt-133, Taf. Vl.

-, Becher-132, Tat. VI.

, Blatt-132, Tat. VJ.

- Viallert- 135.

- Gonidien 140.

-, Krätze-135, Tat. VI.

-, Kreisblatt-134, Tat. VI.

- Krusten-132.

-, Lackmus- 133.

-, Landkatten-135, Tat. VJ.

-, Manna- 135.

_, Sänlehen- 132, Tat. Yl.

-, Säuren- 130.

-, Seheiben- 135.

-, Schild- 134, Taf. VI.

-, Schrift- 136 .

-, sehuissel-134, Taf. I1.

-, Standorte 131.

- Stein-135.

-, Strauch-132.

- Synthese 186. 
Flechten, Teller- 135.

-, Verwitterung v. Gestein 132.

-, Wand-, gelbe 133, Taf. VI.

Fleischmuskelfaser 202.

Flieder, Zuekernachweis 2.

Fliegenpilz 127.

Flohkrebs 176, Taf. Vifl.

Florideae 162.

Fluglorand d. Hlafers 115. Taf. II.

Fhoresze'uz d. Chlorophylis y.

Fluoreszierender spaltpilz si.

Flubplinkton 188, 205.

Fontinalis antipyretica $4, \mathbf{1 6 6}, 193,216$ Taf. VII.

Formaldehyd, Assimilationsprodukt $t$.

Fragilaria eapucina, Bänder 148, Tat. VIl.

- crotonensis 148, Tilf. VII.

Froschbiß 167, Taf. VII.

Froschlatichalge 162.

Frosehlitichpilz 78 .

Froschlöffel 166.

Fruktose in Zuckerriibe 25.5 .

Frullania dilatata 210.

Fuchsia, Wurzeldruck 55.

Fueus serratus, Spermatozoiden 162.

-, vesiculosus, Befruehtung 161.

Fuligo varians 67.

Funaria hygrometrica 9, 213, Taf. Xll.

Fungi 96.

Fusarium aqnateductmm 142, 16t, Talf. VII,

Fusicladiun dendritienm 116.

- pirinum 116.

Galaktane bei Cetraria 133.

Galeopsis tetrahit, Chloroplivll 11.

Galera hypni 123, Taf. V.

Giallenbildumgen 70 .

Gallestflechte 135.

Gallionella 89.

-, Fundort 71.

Gammarus pulex 176, Taf. VIII.

Giirflasche 101.

Garmethode, Zuekernachweis -9.9.

Gärung, Alkohol- 10. fft.

-, Buttersäure- 86.

-, Dextralu- 78.

- dureh Bakterien soff.

-. durch flefen 10.eff.

-, Essigsinure- sio.

-, Methan- 87.

-, Milchsäure- 81.

- Salpeter- 82.

schwefelwasserstoff- 94

Crobirgswaisser. Plankton $153,1 \times 7$.

(ievibeln, Balkterien 72,47 , Tal. VIl. Firbung $77,145$.

(indatine, Plattenkulturen Taf. H.

-, Rollkulturen 74 .

Stichkulturen it.

Strichkulturen 7 t.

Cielbrimel 179. Tilf. Pull

(ielenkpolstr, Merhanismus 20 .

(inmerationswechsed 2:30. 2:31.

Gieotropismus bei Wurzelu ie.

(ierbsaiure in Kuckerrialene 25.5
Gerstenkörner, Atmung 43.

-, transitorische stärke 32.

-, Wärmeentwicklung bei Atmung 45.

Getreiderost 115, Taf. IV.

Gewebespannung 20.

Gipszerstörer, bakterielle si.

Glaskrebs 177, Taf. VIII.

Glaucoma, Kultur 171, Tat. VIII.

Globigerinen 204.

Glockentierchen 172, Taf. VIII.

Globoide bei Ricinus 38.

Gloeotrichia, planktonisch 141, Taf. VIl.

Glukosazon 29.

Glukose, in Znckerriiben 25.

-, Nachweis 29.

Glutamin in Zuckerrïbe 25.

Glyceria aquatica $167,193$.

Glycerin, zum Einbetten 34.

Glyceringelatime zum Einbetten 33.

(ilycogen, Hefen 99.

-, Myxomyceten 68.

-, Phallus 127.

Goldglanz bei Algen 144.

(iolfkraut 162.

Gomphonema acuminatum 150, Taf. VII.

(ioppelsroeders Kapillaranalyse 10 .

Graphis scripta 136, Taf. VI.

(irenzzellen bei spaltalgen $1+1$.

Grimmia pulvinata 212, Taf. XII.

Größenbestimmung. mikrosk. Objekte 65 .

Girundregion 194.

Grïndlingung durch Lıpinen 84.

Grünling (Tricholoma) 123.

Gulnaria 175, Taf. VIll.

Gummibatum 6.

Gymnodinium palustre 146 .

Gyvophora cylindrica 134, Taf. VI.

Habichtspilz 119.

Hafer, Flugbrand 115, Tiaf. IV.

Haffblüte $1+1$.

Hallimasch 126, Taf. V.

Halophyten, Osmose 24.

- Anpassung 57, 5\%.

Halteria grandinellal. Plankton 171, Taf. VIII.

Ilanffaser 202 .

Hantzsehia amphioxys. Ernährumg 151 . Taf. Yll.

Haplotaxis gordioides 173.

llartbovist 129.

Hiiste des Wassers 191.

Ilärtebestimmung 191.

IIärteskala 191.

Harzergiisse, durch Pilze hervorgerufen 126.

lalusschwamm 1o. Taf. V.

llanstorien 49.

Heten !riff.

, System 97.

- nitergärige 97.

Ileizungsbazillus 86 .

Helianthus annuus, Wurzeldruek 5.5.

Helichrysum, Xerophyt 57.

Heliotaxis, bei ('hromatium 45.).

-, bei linglena 9, 145.

, bei Fuligo 67. 
Heliotropismus, bei Pilobolus 10\%.

- bei stengeln 52.

- bei Wurzeln 54.

Heliozoen, Fundorte 70.

- Lebensweise 170 .

Ilelvella esculenta 119.

Helvellasaure 119 .

Hemizellulose 36 .

Hepaticae (Lebermoose) 205.

Heraclem sphondylium 11.

Herbarium fïr l'ilze 129.

Herbstblätter, Fïrbung 12. 13.

Herkuleskenle 119, Taf. V.

Hernie, Kobl 69, Taf. IV.

Heterocysterl 141.

Heterotrophe Ernährung 47.

Heu, Selbsterwärmung 86.

Ileubazillus 85, 142, Taf. III.

Hexenringe bei Penicillium 110.

Hirsehpilz (Clayaria) 119.

Hirtentiuschelkraut, Wirtspflanze d. weilien Rostes 112, Taf. IV.

Hochwasser, Einwirkmog 2014.

Hohlzalm, Chlorophyll 11.

llolunder, Chkorophyllkörner 9.

Ilolzfaseris, zersetzt 202.

Holzkörper, sattleitung 56.

Holzpilz (Xylaria) 119.

Honckenya peploides, Ilalophyt 58.

Honigtau der Gräser 114.

Hopfen, Winden 21, 22.

Hordelum, Atmung d. Samen 43.

-, Warmebildung lyi Atmmng 45.

Hornkrant 167, Tal. V'Il.

Hornzahnmoos 211, Taf. XII.

Höschen d. Wurzelhaare 51.

Hostienpilz 82.

Humulus lupulus, autonome Sprobbeweguing 21.

Hiipferling 176, Tat. VIII.

Hutwerfer (Pilobolus) 107.

Hyacinthus. Spaltöfnungen 59.

Hyalodaplunia,euplanktoniseh 177.Taf.VIII.

Hyalodiseus limax 169, Taf. VIII.

Ifydathoden 1:21.

Hydnum auriscalpimm 119, Taf. I.

- imbricatum 119.

Hydra, fribt Daphnien 173. Taf. VIII.

Hydrachna globosa 177, Tat. VIH.

Hydrocharis morsus ranae, Frosehbib 167 . Taf. VII

Hydrolyse der Stärke 34.

Hydrometra lacustris 178.

Hodrophyten 57, 58, 137.

Hydrotropismus bei Wurzeln 52.

Hydropsvehe 178, Taf. VHI.

Hygroskopische Mechanismen 22, 223.

Hylocomium sequarosum 218.

- splendens 218.

Hypholoma faseiculare 124.

Hyphomycetes 107, 110.

Hypunn cupressiforme 217.

cuspidatum 218.

molluscum 218.

purum 218.

- schreberi 218.
Inpatiens, Nachweis d. Leitungsbahnen 55.

Impfstrichkulturen bei Hefen 100.

Indigomethode :3.

Indusium 221.

Interzellularräume 58.

bei d. Zuekerrïbe 26 .

Intramolekulare Atmung 45.

Inulin bei Kompositen 31 .

Inversion des Rohrzuckers 30 .

luvertase 10;3.

Jot, Stärkenathweis 159 .

Joul-Jolkalium, Stäkenachweis $32,23:$.

Jodoform, Nichweis v. Alkohol 102.

Iris, spaltöfinmongen 5 :).

- starkehileher :33.

s]ändisches Moos 133.

Isoötes lateustris 166, 204, Taf. VIl.

lsosmotise he Lösungen 24, 26 .

Isotonischer lioeffizient 24 .

lsotenische Lösungen 15, 2:3 if.

Jungermannia 209 , Tat. Xll.

Justicia carnea, Vertuustung a. Blatter ăb.

Lahmhaut beim Heubazillus 85 .

bei Hefen 97.

Kalimethode fiir Karotin 13.

lialkalgen 164.

lialkmoose 218.

Kammalge 148, Taf. VII.

liammerplankton 186.

-, Bilder von 187.

Kampfenzyme 137.

Lamenpflanze, Pepsinabsonderung 40.

liapillaranalyse d. Chlorophylls 10 .

Kapillitim 68, 128.

Karotin 11-13.

bei Ilefen 98.

- Kalimethode 13.

-, Kristalle 13.

líarotinoide $10, \mathbf{1 2}$.

- bei Schimmelpilzen 110.

liarpogone 163 .

liartoffel, liorkgawobe 56 .

- Kulturmedinm für Bakterien 74, 75.

-, Sehwarzbeinigkeit 112.

-, Stärke 33.84.

- Substrat für Schimmelpilze 101.

-, Wundperiderm 57.

Katharobien 20:

Liaulquappe 180, Taf. V111.

Kéfir 81.

Keimung, Nloossporen 206.

-, Myxomveetensporen 68.

-, Pollenkörner 47.

Kieselalgen $146 \mathrm{ff}$.

Lirchmeriella lumatat $1 \mathrm{hb}$.

Kirschen, Krankleit 115.

-, Osmose 15, 1s.

- Zuckennachwois 24.

Klatsehpräparate 8.5

Klee, Atmung t. Samen 4.).

-, antomone Blattbewegungen 21.

-, Schlafstellung d. Blitter 21.

Kleingarmethode 103.

linöllchenbakterium 84 .

Kinollenblätterpilz 127. Taf. V. 
Knopsche Nählösung 42.

Kobaltprobe, Nachweis der Transpiration $56,57$.

köcherfliege 17s, Tat. VIll.

kochsalz, ('hemotropismus 54.

Hirkung auf Plankton 25.

Kohäsion 1. Wassters $56,2.2 .2$.

lohäsionsmechanismen 23,222 .

Kohl, Hernie bis. Tate IV.

lohlehvalate in Zuckerribisen 25. als Nährstoffe 100.

loblenbildung 204.

kohlensäure, Assimilation 4.

- Anssaheidung 43.

-, bej Girme 102.

-, Nachweis 44 .

Kohlenst offassimilation $3,146$.

Kiohlepartikel 202.

liokosmub, Zuckernachweis :2s. 30.

liolbenschimmel 109.

liolloilales Ferrocyankupter 16.

kompensationsokulare 66.

Konidien bei Penicillimm 10s

Komidientrager bei Pezizal 11 s.

limiferen, heimlinge 13.

kïnigsfarn 200.

Kontraktion dareh Plasmolyse 19, 206.

liorallenalge 164.

lierallempilz (cla varia) 119.

lorkgewebe, Verdumstumgshemmung 56 .

liotkwarzen $58 \mathrm{ff}$.

Kotyledonen d. Erbse, Starkegehalt 36.

horrosion der stäkekörner 36.

- von llarmorplatten d. Wurzeln 5.s.

Kranklheiten der Kulturpflanzen 111.

Kratzeflechte 135, Tat. VI.

liraushatralge 156 , Taf. VII.

lirebschenlarve 176 , Taf. Vill.

Krelspanzer, Farbstoff 12.

lireisblattflechte 134. Tat. V1.

Kreislanf der Materie 205.

liruzbliitler, Nähpefinzen der Plasmodiophora 69 .

liriebelmäcke 179. Tat. T111.

Krustenflechten 132.

Kiryohydratpunkt 18 .

kiichenzwiebel, Zuckermarchweis es. is.

Kingelalge 154. Taf. VII.

Kugelmuschel 175, Taf. Vill.

Kugelkristalle von Inulin 31.

kialtur. Amöben 70.

bakterien $74 \mathrm{ff}$.

höherer Pilze 12+ff.

[)iatomenen 147 .

Farmprothallien $2.2-$.

Tonstralle 5t, 202

knlturgefaibe für hobimmelpilze n. Ilefen 104fif.

Kinlturhefen 97.

kinlturmedion fiir Bakterien 3 .

lïr IIefont $99 \mathrm{ff}$.

fïr Aleren 146iff.

Jimules 81 .

linptorsieblisten 195, Tal. X.

Kiarbis, Ranken -20.

-, (j) in tidmen 38.

liutikuaise Transpiration 56.
Latcease 120.

Lackmustlechte 133.

Lackmus-Molke-Kulturen it.

Lactaria deliciosa 122 , Taf. $V$. piperata 122.

Laichkraut 166, 193.

Laminaria, Abbili. 159, 160.

-, Jodnachweis 159.

- saccharina, llannit 158.

-, Quellung 161.

Lamprocystis roseo-persicina 96, Taf. VII.

-, Farbstoff 13. 14:.

-, Stamelort 71 .

Lampropeclia $79,139,142$, Taf. VII.

-, Fundort 72 .

Landkartenflechte 135, Taf. VI.

Lathraea squamaria 49.

Latubmoose 205 .

Lehermoose 205.

Lecanora esculenta 135.

- subfusca 135. Taf. VI.

Lecanorsäure 13.).

Leridea 135.

Lederbeeren bej Trauben 113.

leguminosen. Knöllchen 84.

- Schlafitellumg 21.

Leitungsbahnen d. Saftes 5.

Lamanea fluviatilis in Kaskaden 162. Tat. VII.

Lemma arrhiza. Anpassung 52, 167. trisulca 9, 167, 198.

Lenticellen 5xif.

Lepielium sativum 51.

Lepidoziat reptans 209.

Lepiota procera 126 .

Lepocinelis ovum 188.

Lepra, Flechten 134.

Leptodora, räuberiseh 177, Tat. VIII.

Leptomitus lacteus 106, 10., 165. Tat. VII.

, in Abwitssern 25.

Lenchtbakterien 7s, 142, Tat. VII.

leuchtmous 213 .

Leucobrym glaucum 212, Taf. XII.

Leukoplasten 33.

Lichenes 130 ).

Lichina 135 .

Lichtlage der blatter 21.

Lilium bulbifermm, Brutzwiebelchen 2:31.

limnaea aluricularia 175 , Taf. VIIl.

- stagnalis 175, Taf. VIII.

Limonatenbiere 85.

Limhersche Flaschen $9 y$. Pilzgläser 106.

Tröpfeluenkultur 97, 101.

Linum, Öffnen u. sichließen d. Blïten 22. Lionotus 171, Taf. VIII.

Literbecher aus Aluminium 195, Tat. X.

Löeherpilz (Polyporus) 120.

lohnsteins saccharometer 29.

bohpilz 67.

Lophocolea ont), Tat. XlI.

Loranthus ruropatess 50 .

Loxophyllum fasciola 171, Titf. VIII.

Luftströnar in der Pflanze 5s.

Laftwurzeln 58 .

l.upx $63 \mathrm{ff}$., 'Taf. X.

lavougala epidendron 69. 
Lycoperdon bovista 128.

- , gemmatum 128 .

Lycopodium 225.

- clavatum 225.

Lupinus albus, Asparaginnachweis 42.

- - Atmung d. Krimlinge 43.

- Chemotropismus 54 .

- -, Gewebespanmung 20.

-, Plitsmolvere 19.

Hacrobiotus macronyx 178, Taf. VIJ].

Miterocystis pyrifera 161 .

Magnesinmehlorid, Meerwasser 164 .

Mais, Eiweibsynthese 42.

Maischwamm (Tricholomia) 122.

Makrosporen 225.

Mallomonas acaroides 143 , Taf. VII.

Maltase 35.

Maltose 35.

Valz, -Agar 99.

-, -Körner, Diastasewirkung 35.

-, -Peptone 74.

-, -Zncker 35.

Mannaflechte 135.

Mannit bei Pilzen 12:.

-, bei Tangen 158.

Mannose 27.

Mambrium 141.

Marasmius alliaceus 121 .

- alliatus 121.

- rotulir 122.

- scorodonius 121.

Marchantia polymorpha 207.

-, Kultur $20 \%$.

- Assimilationszellen 208.

Mark, lebendes 20.

Marsilia quadrifolia 200.

Mechanismus der Farnsporangien 2.2.).

Meeresdiatomeen 148.

Merespflanzen, Osmose 24.

Mrer, Sedimente 204.

Merersalat 156 .

Mehltan d. Stachelbeere 114.

- d. Teins 113.

Melampyrum nemorosum 50.

Melandryum, hygroskopische kapseln $\mathbf{2}$, 223.

_. Saftleitung in Bliiten 55 .

Mricitose 27.

Melosira species 147 , Tat. VII.

Merismopedial glaucal 79, 139), Taf. VII.

Merulius laerymans 120 , Taf. $\mathrm{V}$.

Mesembrianthemm. Xerophyt 57.

Mesosaprobien 200.

Metzgeria, xprophytisch 210 .

llierococeus phosphoreus 78,142 , Taf. VIl. ureate 82.

Microspira desulfuricans 87.

Mikrokosmos, Seen 205 .

Mikrophotographie 66 .

Mikroskope $63 \mathrm{ff}, 198$.

Mikrosporen 225 .

Milehsaft bei Pilzen 122.

- in höheren Pflanzen 33.

Milchsäure 81.
Milchsäurebakterium 81 .

, Fundort 71

Millons Reagenz, Eiweibnachweis 39.41 , 100.

Mimosal pudica 20, 224. -, Schlafstellumg d. Blatter 21.

Nincralisation 199, 201.

Misehplankton 186 .

Mittelmeer, liammerplanktoit 189.

Mixotrophe Ernährung 47, 137.

Mnium, Chlorophyllkörner 214, Tat. Xll.

Mohrribe, Glukosenachweis 29.

- Kirotin 12 .

-, Osmose 14.

- Pilzkrankheit 116.

- Zuckernachweis 28

Holekulatrgewicht, bestimmbar aluch isotonische Lüsungen 24, 26.

Nobllers Diatomeen-Typenplatte 65.

Nonaden, goldgelbe 143.

Honls vivipara 170 , Taf. VIIl.

Nomilia cinerea 112, 115, 116. sitophila $107,110$.

Monosiceharide 30 .

Momotropa, Saprophyt 47 .

Mouse 205.

- Ast- 217.

- Anstrocknen 217.

- Bart- 212.

--, Besen- 211, Talf. Xll.

-, Dreh- 213, Taf. XIJ.

- Etagen- 218.

- anf Gartenwegen 212.

- tieschlechtsorgane 215.

-, llornzahn- 211, Taf. XII.

- in Höhlen 217 .

-, isländisches 133.

-, Kalk- 218.

- Keimung a. Sporen 206.

- Kultur 206.

- Lebensbedingungen 205 .

- Lencht- 213 .

als Pioniere 214 .

-, Quell- 216.

- Saprophyten 206.

-, Torf- 210, Taf. XIJ.

- -, Wasserzellen 210.

- Tropen- 206.

-, Wald- 215.

- Wasserleitung der 216.

-, Weiß- 212, Taf. XII.

Monstier 175. Taf. VIII.

Moosvegetation, Arktis 206.

- Tropen 206.

Morehella conica 118, Taf. $Y$.

- esculenta 118.

Mongeotia genuflexa, (hromatophorenstellung 151, Taf. ViJ.

Mucor, Luftschimmel 104, 106, 107.

-, Wasserschimmel 107, 165, Taf. VII.

Mïndlungsgebiete 1. Fliisse 25, 205.

Musearin 127.

Muschelkrebschen 177. Tat. VIII.

Musei 205.

Muscineae 205.

Musseron 121, 12:. 
Mutterkornpilz 114. Tat. IV.

Mycel 117.

Mycelleiter 126 .

Mycena Species 123, Tat. Y.

Mycetophila 11 i

Mycoderma 98.

Mvcorrhiza 107, 111.

- bei Saprophyten 47.

-, ektotrophe 111.

-, endotrophe 111.

Myriophyllum spicatum 58, 167, Taf. VII.

Myristiea 59, 163.

Myxamöbe 68 .

Myxomycetes $23, \mathbf{6 7}$.

-, Ölaufnahme 41.

Nabelpilz 123, Taf. Y.

Nacktschnecken als Pilzfresser 117.

Nähragar 74.

Nährböden für bakterien 73 ff.

- für Hefen $99 \mathrm{ff}$.

- für Diatomeen 147.

Nährbouillon 73.

Nährgelatiue 74 .

Nährlösung für Hefen 100, 101.

- für Schimmelpilze $105 \mathrm{ff}$.

- nach Beijerinek 100.

- nach Diakonow 105.

- nach Hansen 101.

- nach Havduck 101

- nach Pastenr 100.

- nach Raulin 105.

Nannoplankton 143. 144, Taf. VII.

Narcissus, Diageotropismus 21.

- Keimung, d. Pollenkömer 47.

Naturselbstiluck 129.

Nauplius 176 , Tat. VIII.

Navicula Species, Standorte 150. Taf. VII.

Nectria cinnabarina 112,114 , Taf. I.

- ditissima 115.

Nekridien 19.

Nektarorganismen 96, 103.

Nekton 185.

Nematoden 174.

Neottia nidus avis 47.

Nepa cinerea 178.

Nepenthes als Ilalbsajophyt 47.

-, Pepsinabsonderung 40.

Nephelis, Nahrung 173, Taf. VIII.

NeBlersches Reagenz, Ammoniaknachweis 84.

Nitella, Plasmaströmung 8, 165.

-, Ökologie 165, Taf. III.

Nitratbildner 8.).

Nitrate in Chenopodium 27.

Nitritbildner 87.

Nitrosomonas enropatea $8 \bar{i}$.

Nitzschia aeiculatis 151, Taf. VII. sigmoidea 151, Taf. VII.

Noctiluca miliaris 79 .

Nodularia spumigena, Ostsep 141.

Nordsee, Plankton 188.

Nostoc in Flechten 134, 135.

- punctiforme 140 .

- verrucosum 140, Taf. VIl.

Notonecta glanca 178 , 'taf. VIII.
Nutation, revolutive $20,21$.

Nyctalis parasitica 122, Taf. V.

Nyktitropisehe Bewegungen 20 .

Objektträger, schwarze 60, 135, 221.

Odontoglossum mit Wurzelpilz 48 .

Oedogoninm rivulare 157 , Taf. VII.

Oekologie 181.

der Gewässer 192.

Oenothera, Öffnen u. SehlieBen d. Blüten 2..

Öfnungsmechanismus der Farmsporangien 222.

Ohrlöffelpilz 119, Taf. V.

Ohrschneeke 175, Taf. VIII.

Oidien bei Hefen 98.

Oidium lactis 107, 110.

- tuckeri 113.

Öl, in Rizinussamen 37.

-, Nachweis 41.

-, Transport 40 .

-, Umwandlung in Zucker 3S.

- Zerspaltung 40.

Oligosaprobien 201.

Olpidium luxurians 113.

Omphalia fibula 123, Taf. $\mathrm{V}$.

Ophioglossum vulgatum 225.

Ophrydium versatile, gelatinös $140,17.2$.

Orchestia littorea 176.

Orchidaceen, Symbiose 48.

()rganischer Detritus: 202 . Filz 193.

Urobanehe speciosa 49.

() cillatoria agardhii 140. Taf. VII.

- limosa 140, Taf. VII.

Oscillatorien, Assimilation 7.

- Turgor 19.

-, Ökologie 140 .

Osmiumsïure, Nachweis von Fett 41.

Osmose $14 \mathrm{ff}$.

Oxalsäure in Zuckerrïbe 25 .

Oxydasen 120.

1)xydationsreinigung 84 .

Ozean, Plankton 189.

Ozon zum Sterilisieren 73.

Paketkokken 80, 142.

$\rightarrow$, Fundort 72 .

Palisadenzellen 5, 16.

Palmentang 159.

Paludina vivipara 175 , Taf. VIII.

Panaeolus campanulatus 121.

Pandorina mornm 154, Taf. VII.

Pantoffel-Diatomee 151, Taf. VIl.

Pantoffeltierchen 171, Taf. VIII.

Paraboloidkondensor, Bakterienbeobachtung 72 .

Paraffin 134 .

Paramaeeium caukatum $\alpha$ m 171. Taf. VIII.

Paraphysen bei Russula 122.

Parasiten, höhere Pflanzen $47 \mathrm{ff}$.

-, Pilze 111.

Parasolpilz 126.

Parenehym im Schwammgewebe 16 .

- in der Zuckerrïbe 26.

Parmélgelb 133. 
Parmelia furfuracea 133. physodes 134, Taf. VI.

Parthenocissus, Ranken 22.

Parthenogenesis 166.

Pasteurisieren 73.

Pediastrum species 155, Taf. VII.

Pellionia daveauana, Stärkebildner $3 *$.

Peltigera canina 134, Taf. VI.

Pelzmonate 143 , Taf. VII.

Penicillium brevicaule, Arsenprobe 110.

- glaucum 104, $107,109$.

- - in KokosuuB 30.

- - Keime in Luft 76.

Pepsin 39, 40.

Peridinim divergens 146 , Taf. VII.

- tabulatum 146, Taf. VII.

Perigordtriiffel 119.

Perindisch planktoniseh 141.

Peristom 216 .

Peristomzälnne 211, 212, 213.

Perla bicaudata 178, Taf. VIII.

Permeabilität des Plasmaschlauches 17.

Peronospora viticola 111, 113, Taf. IV.

Pertusaria commun is 136 .

Petrischalen $76 \mathrm{ff}$., Taf. II.

Petroleumbildung 220.

Peziza a urantia 118 , Taf. V.

Pfahlkratzer 197, Taf. X.

Pfefferling 121.

Pferdemist für Kultur von Mucor 104, 107. - - - - Pilobolus 107.

Pflanzenzerstörendes Bakterium 81, Taf. IV. Pflaume, Zuckernachweis 28.

Ptlaumendekokt $104 \mathrm{ff}$.

Phacotus lenticularis 188.

Phacus longicanda 145 , Taf. VII.

Phaeophyceae 158.

Phacosporeae 124.

Phajus grandifolius, Stärkebildner 33 .

Phallus impudicus 127, 128.

Phascum eurvieollum 206.

Phaseolus multiflorus, autonome Bewegung 21.

$-\quad-$, Schlafstellung d. BJätter 21 .

Phenylhydrazin, Zuckernachweis 29.

Philadelphus, Verdunstung d. Blätter 56.

Philodina aculeata 174, Taf. V1I1.

Phoenix, Reservezellulose 37.

Phoma rostrupii 112, 116.

Phormidium uncinatum 140, Taf. VII.

Phosphorbronze 195.

Phosphor in Rizinnssamen 37.

-, Nachweis 38 .

Phragmidium rosarum 116.

Phragmites communis 167 .

Phreoryetes menkeanus 173.

Phryganea, Gehäuse 178, Taf. VIII.

Phyeocyan 140, 163.

Phycoerythrin, Bedeutung 163.

Phycomyces nitens 106, 107.

Phycomyeetes 106.

Physciol 133.

Physodin 134.

Phytelephas, Reservezellulose 37.

Phytol, in Chlorophyll 11.

Phytophthora infestans 113.
Picea excelsa, Papierfabrikation 27.

Pilobolus crystallinus 106, 107.

Pilostyles hauslineehtii 49 .

Pilze, höhcre $116 \mathrm{ff}$.

-, parasitisehe $111 \mathrm{ff}$.

-, Schimmel- $104 \mathrm{ff}$.

-, Sehleim- $67 \mathrm{ff}$.

-, Spalt- $71 \mathrm{ff}$.

Pinguicula vulgaris $4 \overline{7}$.

Pinnularia 150, Taf. V11.

Pinselsehimmel 109.

- in liokosnub 30 .

Planaria, amimalische Nahrung 173. Tat. VIII.

Planktou, Definition 180.

-, Fangmethoden 180.

-, Gliiser 195.

-, Hauptbestantiteile 180.

-, Kammer $64,186,187,195$, Taf. 1. X.

-: Konservierung 181.

- - Kunde 1. Bakteriologie 181.

- -mengen 183.

- -nahrung 15.5 .

- -netz 194.

-, Osmose 25.

-, Ökologie 180.

-pumpe 197.

-region 192.

-, Röhrchen 18\%.

-, Sautstoffproduktion 189.

-, Schwebefähigkeit 182.

-sieb 66, 194, Taf. X.

_-zusammensetzung 185.

iil $1 \mathrm{ccm} 18 \%$.

-, Misch- 186.

-, Seen- 183.

- Tiefen- 185.

-, Winter- 184.

1. Wasserbeschaffenheit 184 .

- Truahrung 181.

- Bodensee 187.

-, Mittelmeer 189.

-, Nordsee 188.

, Ozean 189.

-, Rhein 188.

-, Gebirgsseen 187.

, Gebirgsbäche 183.

Planorbis cornens 175 , Taf. VIII.

Plasma, extramembranos 140.

-, Strömung 8, 166.

Pleurosigma, Testobjekt 65, 150. acuminatum 150, Taf. V1l.

Plasmodiophora brassicae 69, 111, 112, Taf. IV.

Plasmodium 67.

Plasmolyse 15, 23, 26.

Plasmopara viticola 113.

Plasmorhyse 23.

Plattengießen 75.

Plumatella repens 175, T'af. VIII.

Pneumatophoren 58.

Podetien 132.

Podura aquatica 178, Taf. VIII.

Polarisation, Mikroskop 34, 66.

-, Zuekernachweis 29.

Polaritait d. Zweige 52. 
Pollen, bej Cycas 231

-, lieimung 47.

Polyarthra platyptera 174. Taf. VIIl,

Polyeystis aeruginosa 139, Taf. VII.

Polygonum fagopyrum, Eiweils ynthese 42.

Polyp (Hydra) 173. Taf. VIll.

Polypodium valgare 221 .

Polyporus versicolor 120), Taf. $\mathrm{V}$.

Polysaprobien 199.

Polytomat Iuvella, farblos 154, Taf. Vill.

Polytrichum, Bau 1t. Leben 215, Taf. Xll.

Pontosphaera huxleyi 144, Taf. VII.

Posthornschnecke 175, Taf. VIII.

Potamogeton perfoliatus 8, 166, 198.

Präparieren, höhere Pilze 129.

PreiBelbeeren, Pilzkrankheit 116, Taf. IV.

Preissia commutata 209.

Preßhefe 97.

Primordialschlauch 19, 26 .

Produktionskraft der Gewisser 184.

Proteus 82.

Prothallien, Anzucht 226.

- von Aspidium 9, $\mathbf{2 9 6 .}$

- von Botrychium 225.

- des Bärlapps 2.55.

- -generation 224.

- der Nitternzunge 2.25.

Prothallium, geschlechtsreif 2.27.

Protococcus in Flechten 130.

Protonema 213, 215.

- aus Seten 217.

bei Pogonatum 216.

Protoplasma 8.

- Schlauth 16. 17, 26.

Psalliota ampestris 124 .

Psemdorlichotomie 93, 141.

Pseudomonas europaea $8.2,57$.

- fluorescens 6, $\mathbf{5}$. Tat. VI]. violacea 57 .

Psora ostreata 135. Taf. VI.

Pteridophyta 219.

Pteromonas alata 186.

Puccinia graminis 112, 11.; Taf. JV.

Purpurbakterien 96, Tat. VI\}.

Purpurspirillum 143.

Putrescin 120.

Pykniden anf llohrriibe 116.

Pyrenoite 152.

Quellmogs 166, 216. Taf. V11.

Guellung der Stäkekirnor :34.

(Mellungsilrnck 34 .

Riidertiere 174.

Radiolarien 204.

Ratfinose in Znckertibe 25.

Ratiflesia 49.

Ranal esculenta 18n. Tal. VuII.

Rankin $21,2 \cdot 2$.

Raltenhatar gov.

Rattenschwamzlate 17!), Tat. VHIt.

Rirlepilz (IIyd num) 119.

Reinkulturen. Bakterien 7 ttl.

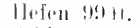

Sholimmelpilze $10+4$ fif.

- Miatomenesir 147.
Reizbewegung bei Mlimosa …

- bei Ranken 21.

Reizker (Lactaria) 122.

Reizmechanismus bei Nimosa 2.24.

Renntierflechte 131.

Reservestärke 32, 163.

Reservezellulost 36 .

Reticularia lycoperton 68 .

Revolutive Nutation 20 .

Rhacomitrium sudeticum 212, Taf. XIl.

Rhaphidium polymorphum 155, Taf. IIJ.

Rhein: Plankton 188.

Rhein, Seston des 203.

Rheotaxis bei Fuligo 67.

Rhinanthus 50.

Rhipsalis (Xerophyt) 57.

Rhizocarpon geographicum 135, Taf. II.

Rhizoiden 230 .

Rhizomorpha subterranea 126.

Rhizophora mangle 58 .

Rhizoporlen, Fundorte 70.

Rlizoselemia semispina 147, 188.

Rhodospirillum 143.

Rhoicosphenia curvata, Emährung 149 , Taf. V'll.

Rhynchestegimm rusciforme 216 .

Rlytisma acerinum 112, 113, Taf. 小.

Ribes, Verdunstung der Blïtter 56.

Riccia fluitans 209, Taf. Xll.

Richteriella botrvoides. Ernährung 155. Taf. VII.

Ricin 41.

Ririnus communis, fiewebespannung 20 .

- Globoide 38 .

- , Keimung 37.

-. Ögehalt des samens 37.

Riesenfarme der Vorzeit 2026.

Rindenspannmig 20.

Ringelungsversnche, an Zweigen 56.

livilaria, Lebensweise 141, Taf. VIl.

Rececella tinctoria 133.

leohrzucker, in Znckerrübe 25. Kristalle 26 .

Rollkulturen nach Esmareh 7t. 106.

Romijns Planktomnetz 194.

Rost des Getreides 115.

-, weiber an cruciferen 112.

Rotalgen 162.

Rotationsbewegmng des Plasmas it.

Rotatoria, Nahrme 174.

Rotifer actimurus 17t, Taf. V1lI.

Rotkohl, Anthocyan 17.

Rotpustelkrankheit der Biame 114, Tat. $1{ }^{-}$.

Rottanne, Papierfabrikation 27.

Rozites gongylophoral 127.

Riibensehnitzel, liffnsion 2 .

Riibsen. Atmmeng tis.

Riickensehwimmer 17s, Tat. Vill.

Runkelrïbe, Osmose 25.

-. Zuckrrnathwejs 28.

Rïsselkrebschen 17\%, Tat. VIII.

linssulat atlusta 120.2, Taf. V.

- nigricans 120. rubra 12.2.

Russulina 122. 
saccharometer 29.

saccharomyces $97,98$.

Saceharose 27.

saft. Leitungsbahnen ós.

Sägespan-Alge 141, Taf. VII.

salicornia herbacea 58 .

salpeterbakterien $8:$.

-, Eiweißsynthese 43.

- Rohkultur 84.

salpeterfresser 82.

salpeterplantagen 84 .

Salvinia natans 166 , 925.

sambucus nigra, Chlorophyllkörner y.

- Crewebsspannung 20 .

- Lentizellen 59.

- Verdunstung der Blitter 56.

Sanchezia nobilis, Wurzeldruck 5.5.

Saprobien, Ökologie 139.

-, marine 139.

sitprolegnia monoica $106,10 \mathrm{~s}, 165$, Taf. I'II.

saprophyten, höhere 47.

Hoose 206.

sarcina 80, 142. Taf. VII.

- Fundort 72 .

sarcodes, Saprophyt 47.

Sargassum baceiferum 162.

Sarracenia purpmea 47.

satuerstoff, Ausseheithng $3,7$.

- Bestimmung 189.

- Produktion dureh Plankton 189.

- Sättigungsmenge 190.

- L'berträger 12.

- Verbrauch bei Atmung 44, 45.

Sallginfusor 173 , Taf. VIII.

Saulchenflechte 13:, Taf. VI.

scenedesmus species 15.5, 186, Taf. VII.

sebarmetz 198 , Taf. X.

sichattenblatt 5 .

richanmstruktur des Zollgewebes 27.

scheibenflechte 135 .

schildflechte 134, Taf. V1.

Schilf $167,193$.

Schilfmesser 197, Taf. X.

sehimmel der stubenfliege 112 .

schimmelpilze $104 \mathrm{t}$.

Sehistostega osmmudacea 213 .

Schizolobium excelsum, Wurzeldruck 5.5.

schizomycetes, Fürbmng 77.

- Fundort 71, 72.

- Geibeln 78.

-, Kultur $74 \mathrm{ff}$.

-, System 78.

schizophyceate 139.

schizosaccharomycetes 97 .

sehlammegel 173 , Tat. V1I1.

sehłammheber 198, Taf. X.

Schlammschnecke 175, Taf. VIII.

sichlammsieb 198, Taf. X.

schlammwurm 173, Taf. VIII.

schlanchalge 157, Taf. TII.

Schlauchfasergewebe 130 .

Sehleier, bei Beggiatoa 94

- bei Pilzen 123, 124.

SchleimfluB, Organismen 109.

Schleimpilze $41,67$.

Schleudermechanismus der Sporangien 222.
Sichlingpflauzen 201, 22.

Sehmarotzer, höhere Pflanzen 49, 50 .

- Pilze 111 tit.

sehneckenlaich 140.

seluraubenalge 152 , Taf. VII.

sehraubenbakterien 88 .

- Fundort 72.

Schriftflechte 136 , Taf. VI.

s.hüsselflechte 134, Taf. VI.

schützenbergersches Reagenz 4.

schwadengras $167,193$.

sehwammgewebe 5, 16.

sehwamminalet 173.

Schwarzbeinigkeit der liartotfel s1, 112, Taf. ] V.

shaluevakuolen 140.

siohwefolbakterien 78, $94 \mathrm{if}$.

_. Eiweibsyuthese 43 .

Fundorte 71.

Rohkulturen 95.

schwefoliopt (llypholoma) 124.

sehweinsblase, Osmose 18 .

Sehwimmsehieht 83.

siclerolerma vulgare 129, Taf. V.

sirerotinia cinerea 115 , Taf. IV.

sekundare Vermureinigung 203.

sielum atre, Xerophyt 57.

Seegras 166.

Seenplankton 183.

rienstudien 201.

Selaginella 224 .

sialektives Verhalten der Wirzeln 55.

helbstverunreinigung 204.

Selenastrum bibraianum 186.

semipermeable Nembranen 16.

- bui Znckrriube 27.

sensibilisator 5 .

septic-tank 87 .

sicston 183, 205.

- Abb. 89,202 .

les Rheins 203 .

Sialis lutaria 178 , Taf. TIII.

sichtscheibe 197, Taf. X.

sichttiefe 197.

Sicyos angulatus, Ranken 22.

siderocapsa treubii \$9, 91, 158.

silbermoss 214 , Taf. XII.

silene mutans, ijfnen und schlieben der Bliitun

vilicoflagellata 144 .

silikatzollen 17 .

Simulium ornatum 179, Taf. VIII.

Sinkstoffe 83.

Sklerotimm des Mutterkorus 114. bei sehimmelpilzen 110.

skorpion- Wasserwanze 178.

Solanwm tuberosim, s. Kartoffel.

Soldanella, Wämebildnng 45.

Somnenblatt 5.

connenblume, Wurzeldruck 55.

Sommentau, Kinltur 49.

- Pepsinabsonderung 40.

sommentierchen 170, Taf. VIII.

Soredien 131.

Sori der Farne 221.

spaltalgen 139. 
Spalthefen 97, 109.

Spaltöffnungen, bei Tradescantia $58,59$.

-, eingesenkte 58.

Funktion 59.

spaltpilze, Begeißelumg 78.

-. Färbung 77.

- Fundorte 71, 72.

- Kultur $74 \mathrm{ff}$.

-, System 78.

Sparassis crispa 119.

Speichel, Wirkung auf Stärke 34.

Spermatozoiden bei Cycadeen 231. bei Farnen 228.

Sphaerium corneum 175, Taf. VIII.

Sphaerotheca mors uvae $112, \mathbf{1 1 4}$, Taf. IV. sphaerotilus 92. Taf. VII.

-, Fundort 71.

- roseus 142 .

Sphagnum eymbifolium 210, Taf. XII.

Sphagnum, Säure 210.

-, Sporangienmechanismus 211.

Spindelalge 151, Taf. VII.

Spiralfaser 202.

Spirillum undula 88,142 , Taf. VJI.

, Fundort 72 .

Spirochaete plicatilis 170 , Taf. VIII.

Spirogyra nitida 153.

- porticalis 152, Taf. VII.

Spirogyra, Assimilation 6 .

- Kopulation 152.

- Stäkebildung 31, 152.

-., Turgor 19.

Spirostomum ambigunm 171, Taf. VIII.

Spirulina, Lebensweise 140, Taf. VII.

Spitzmorchel 118, Taf. V.

Spongilla lacustris 173 , Taf. VIII.

Sporangien, Springen 222.

- Schlendermechanismus 222.

Sporen, bei Bakterien 85, Taf. VIl.

-, bei Hefen 97.

-, Keimmmg bei Myxomyceten 68 .

- Priparate 85.

- bei Farnen 221 fif.

Sporenfarbe der höheren Pilze 129.

Sporenfrucht 220.

Sporengeneration 219.

Sporenkapsel, Mechanismus 211.

Springsehwanz 178. Taf. VIII.

Sprobhefen 109.

Sputumschleim, Tuberkelbakterien 84.

Stachelbeere, Mehltau 114, Taf. IV.

Stahlsehe liobaltprobe, Nachweis der

Transpiration 56, 57 .

Stirkt, in Erbsen 36.

- in Florideen 163.

-, in Getreitlkömern 36.

- iil Zuckerriibe 25.

-, in Zwicheln 36.

-, Korrosion 36.

-, Nachweis 32.

-, Polatisation 33. 34.

- Quellung 34.

- transitorische $32,39$.

Umwandlung in Dextrin und Zurkel $34,35$.

starkubildurer 32, 33.
Stiirkeherd 152.

Stärkereaktionen 163.

Stärkescheide 39.

Statoblasten 175.

Statolithentheorie 52.

Staurastrum gracile, planktonisch 151 . Taf. VII.

Stauroneis phoenicenteron 150, Taf. VII.

Stechmiicke 179.

Steinfleehte 135, Taf. VI.

Steinheillupen 63.

Steinkohle, Entstehung 220.

Steinkohlenzeit, Waldmoore 219.

Steinpilz 120, Taf. V.

Stentor cocruleus, $\alpha \mathrm{m} 172$.

Stentor roeseli, Ernährung 172, Taf. VIII.

Stephanodisens hantzsehianus 147 , Taf. VII.

Sterigmen bei Russula 122.

sterilisation 73 .

- Versuche 73 .

Sternalge 148, Taf. VII.

Stickstoff, Assimilation 142 .

Stigeoclonium tenue, Schwärmsporen 156 , Taf. VII.

Stigonema 135.

stinkbrand des Weizens 115.

Stinkpilz 127.

Stomata 58, 59.

Stomatäre Transpiration 56 .

Strandfloh 176, Taf. VIII.

Stratiomys chamacteon 179 , Taf. VIII.

Strauchflechten 132.

Streptococens mesenterioides 78,142 , Taf. VII.

Strömungen und Plankton 184.

Strudelwurm 173, 'Taf. VIII.

Stryehnos nux vomica, Plasmaverbindungen 154.

Stylonychia mytilus 172 , Taf. VIII.

Sumpfgasbiliner 86 .

Silimpf-Segge 167.

Sumpfschnecke 175, Taf. VIII.

Surirella biseriata, Schlamm-Kieselalge 151, Taf. VII.

symbiose bej Flechten 130.

- bei Orehideen 48.

Synchaeta tremula 174, Taf. VIII.

Symedra acus, Plankton 148, Taf. VIII.

Synedra uhna, brame Überzïge 148, Taf. VII.

Synthese, des Eiweiß 42ff., $100 \mathrm{ff} ., 105$.

- der Flechten 136.

Synmra uvelka, Gurkengeruch 144, Taf. VII.

Syringa vulgaris, Lentizellen 59.

-. Zuckernachweis 28 .

Tabellaria fenestrata. Planktonisch 149 , Taf. VII.

flocculosa 149.

Tafelkokken $\mathbf{7 9}, \mathbf{1 4 2}$, Taf. VIJ.

-, Fundort 72 .

Tafelsternalge 155, Taf. VII.

Tanzstübchen bei Closterium 31, 151.

Taraxacum, Gewebespannung 20.

- , Öffnen mnd Schließen der Blütenköpfe 
Taschenkrankheit der Pflaume 113, Taf. IV.

Täubling (Russula) 122.

Tausendblatt 167, Taf. VII.

Teerfleckenkrankheit des Ahorns 113, Taf. IV.

Teichmuseliel 175.

Telentosporen, Farbe 12.

-, vom Rostpilz 115, Taf. IV.

Tellerflechte 135, Taf. VI.

Tentipes 179.

Testobjekt für Mikroskope 65.

Tetrasporen 163.

Thallusareole 136 .

Thallus horizontalis 131 .

- verticalis 131 .

Thermotaxis bei Fuligo 67 .

Thesium intermedium 50.

Thiopedia rosea 79 .

Thiospirillum sanguineum 186.

Thiothrix nivea 143 , Taf. VII.

Tiefenplankton 185 .

Tillandsia usneoides 53.

Tilletia caries 115 .

Tintinnopsis 188 .

Thiopolycocens 71.

Thiothrix 71, Taf. VII.

Tintenpilz 121, Taf. V.

Tolypothrix lanata 141, Taf. VII.

Tönncheninfusor 171, Taf. VIII.

Torfbildung 210.

Torfmoos 210, Taf. XII.

Torula 98 .

Trachelomonas, Bau 145, Taf. VII.

-. Hänfigkeit 145, Taf. VII.

Tradescantia, Spaltöffnumgen 58,59 .

-, Zellsaft $17, \mathbf{2 3}$.

-, Zirkulationsbewegung des Plasmas 8.

Tragopogon, Öffnen und SchlieBen der Blütenköpfe 22.

Transpiration, Naehweis 56,57 .

-, kutikuläre 56.

- stomatäre 56 .

Transversalgeotropismus der Seitenwurzeln 52.

Traubes künstliche Zelle 15.

Traubenzucker 4,35 .

-. Abbau durch Cymase 103.

Tratumatropismus 54 .

Trehalose 27.

Trentepohlia iolithus 12, 136.

- in Flechten 133, 136.

Triceratium favus 148 , Taf. VII.

Tricholoma equestre 123.

- graveolens 122.

Trifolium pratense, Atmung der Samen 43.

-, antonome Bewegungen 21.

-, schlafstellung der Blätter 21.

Trinema enchelys, Vorkommen 169, Taf. VIII.

Trinkwisser, Seston 183.

Triuris, Saprophyt 47.

Triton taeniatus 180, Taf. VIII.

Trompetentierchen 172, Taf. VIII.

Tropaeolum majus, Zellulose 37.

Tropenmoose 206 .

Tröpfchenkultur wach Lindner 97, 101.
Tropfenkammer 196.

Trüffel 119.

-, falsche 129, Talf. I.

Trypsin 39, 40.

Tuber brumale 119.

melanos porum 119.

Tuberkelbakterien 84.

Tubifex rivulorum, Lebensweise 173 .

Taf. VIII.

Tulipa, Öffnen und Schlie Ben der Blüten 22.

-. Reservestärke 32.

Turgor $14 \mathrm{ff}$.

-. kïnstlicher 18.

Tyrosin 122.

Trrosinase in Rinssula 123.

Cekelei 179, Tat. VIII.

Eterregion 19:3.

Ilothrix zonata, schwärmsporen 156 , Taf. VII.

Ultramikrobien 72.

Ultramikroskop 31, 66.

I'Iva lactuca, Ernährung 156.

Uncimula spiralis 113.

Untergärige Hefen 97.

Uredosporen, Farbe 12.

-, vom Rostpilz 115, Taf. IV.

Uroglena volvox, Geruch 144, Taf. VII.

Uromyces pisi 116.

Urtica macrophylla, Wurzeldruck 55.

Usnea barbata 133, Taf. VI.

Usninsäure 133, 136.

Ustilago avenae 112,115 , Taf. IV.

Utricularia vulgaris 47 .

Vaccinium, Pilzkrankheit 116, Taf. IV.

Vallisneria 58.

Valvata piscinalis 175, Taf. VIII.

Variolarien 136.

Vaucheria, Ernährung 157, Taf. VII.

- ungeri, Schwärmsporen 158.

Veilchenblaner Spaltpilz 87.

Veilchenmoos, Farbstoff 12.

-, Standort im Freien 136.

Velatae 123, 124.

Verlandungsprozesse 204.

Verletzungsreiz 8, 54, 57.

Viscum album 50 .

Vitis vinifera, Ranken 22.

Vogelfeflerstrahlen 202.

Voitia nivalis, anf Mlist 206.

Volvatae 127.

Volvox aureus, Plasmaverbindungen 154' Taf. VII.

Vorticella, Ernährung 172, Taf. VIII.

Voyria (Gentianaceae) 47 .

Waldmoose 215.

Wandermuschel 176, Taf. VIII.

Wandflechte, gelbe 133, Taf. VI.

Wärmebildung bei Atmung 45.

Wasser als Nälnrstoff $50 \mathrm{ff}$.

Wasserassel 176, Taf. VIII.

Wasserbärchen 178, Taf. VIII.

Wasserbeschaffenheit und Plankton 184.

Wasserblüte 141, 185, Taf. IX. 
Masser, Eigenfarbe 184.

Wasserentziehmng durch Osmose 14, 19.

Wasserfloh 176, 177. Taf. VIII.

Wasserłäufer 178.

Wasserlinse 9, 167, 193.

Wassermilbe 17\%. Taf. VIII.

Wasser-Mukor 165, Taf. VII.

Wasserpest 167. Taf. 1.

Wasserschimmel 116.

Wasserschëpfer mach Richard 197.

Wasserstern (('allitriche) 167.

Wasserzellen bei T'orfmoos 210. bei Lencobrvom 212.

Wedel der Farne 220.

Weiden. Nachwris der Polatrität der Zweige 52.

Weißmors 212, Tat. XIl.

Wrin, Ranken 2).2.

Weimberere. Zackernachweis 24.

Meinsiure in Kurktrübe 25.

Weizen, stinkbrand 115.

Mämebilatung bei Atmung 45.

Willia anomala 97.

Winter-Plankton $18 t$.

Wollfaser 202 .

Wundermonade 82.

Wundperiderm der Kartoftel 5\%.

Würzeagar 99.

Würzegelatine 99.

Wurzel, Atem- 5R.

-, Brutt- 59.

- Chemotropismus 53.

-loruck 51, 5.5.

- Cieotropismus 52.

-. llatare 51

-. Heliotropismus 52.

- Hydrotropismus 52.

-. Luft- 58 .

- selektives Verhalten 55.

- ispitzenwalehstum 51 .
Wurzelpilz s. Nyeorrhiza.

Wüstenpflanzen, Wasserversorgung 52.

Xanthophyll 10, 11.

Xanthoproteinreaktion zum Eiweißnachweis $39,41$.

Xanthoria pariétina 133. Taf. VI.

Xerophyten 57.

Xylaria hypoxylon 119, Taf. V.

Xylose 2\%.

Yoghurt 81.

Za mays, Eiweilis vnthese 42.

Zeichenappitrat $65^{\circ}$.

Zelle, Demonstration 8, 25, 153, 214

-., künstliehe 15.

Zellkern 8, 17 .

-, Torkommen in Zwiebel 28. boi spirogyra 152 .

Zellulose, Zersetzung durch Bakterien s6.

Zelhulosehaut der Zellen 26 .

Zellsaft, Osmose $15, \mathbf{Q} \mathbf{6}$.

Ziegenbart 119.

Zitronensäure in Zuckerrübe 25.

Zome der Reduktionen 199.

Zone des Reinwassers 201.

Zoogloea ramigera 94. Taf. VII. uva 143, Taf. VII.

Zoogloeatest für Wasserprïfung 71 .

Zostera marina 166.

Zncker, liildung aus Stärke 34 ff.

-, osmotische Wirkung 14 .

-, Vergärung 102.

Zuckerrïbe, (Ismose 25.

-, Zuekernachweis 28 .

Zuckertang 158.

Zygnema stellinum 153, Taf. VII.

Cygusaceharomyces 97.

Tymase 108.

\section{Druckfehler-Berichtigung.}

$\therefore \quad 10$, Zeile 20, hesser Azeton statt Alkohol.

S. 52, letzter Absatz, lies Hy drophyten statt Hyglophyten.

s. 11s, unter l'eziza, lies Askussporen statt Askusporen.

s. 136, mnter Pertusaria, lies commu $u$ is statt commune.

s. 17:3, unter Planaria, lies an imaliseh statt mineraliscl.

S. 215, miter Polytrichmm, lies Hy grophyt statt Hydrophyt.

s. 222, tritter Alisatz, lies G asf lam $\mathrm{m}$ e statt Glasflamme. 





